UNIVERSIDADE DE SÃO PAULO

INSTITUTO DE GEOCIÊNCIAS

\title{
EVOLUÇÃO PALEOPROTEROZOICA DO CINTURÃO MINEIRO: GEOCRONOLOGIA U-Pb, ISÓTOPOS DE Nd-Hf-Sr E GEOQUÍMICA DE ROCHAS PLUTÔNICAS
}

Natali da Silva Barbosa

Orientador: Prof. Dr. Wilson Teixeira

\section{TESE DE DOUTORADO}

Programa de Pós-Graduação em Geoquímica e Geotectônica

São Paulo

2015 
UNIVERSIDADE DE SÃO PAULO

INSTITUTO DE GEOCIÊNCIAS

\section{EVOLUÇÃO PALEOPROTEROZOICA DO CINTURÃO MINEIRO:}

GEOCRONOLOGIA U-Pb, ISÓTOPOS DE Nd-Hf-Sr E GEOQUÍMICA DE ROCHAS PLUTÔNICAS

Natali da Silva Barbosa

Orientador: Prof. Dr. Wilson Teixeira

TESE DE DOUTORADO

COMISSÃO EXAMINADORA

São Paulo

2015 
Barbosa, Natali da Silva

Evolução paleoproterozoica do Cinturão Mineiro: geocronologia U-Pb, isótopos de $\mathrm{Nd}-\mathrm{Hf}-\mathrm{Sr} \mathrm{E}$ geoquímica de rochas plutônicas. / Natali da Silva Barbosa. -- São Paulo, 2015.

229 p. : il.

Tese (Doutorado): IGc/USP

Orient.: Teixeira, Wilson

1. Paleoproterozoico 2. Cráton do São Francisco 3. Geocronologia I. Título 


\section{AGRADECIMENTOS}

Agradeço inicialmente a quem compartilho a vida desde que nasci, meu irmão gêmeo Natanael, por me ajudar em todos os momentos da vida pessoal e principalmente acadêmica, das mais diversas formas possíveis e imagináveis (principalmente no design das figuras desta Tese e discussões geológicas), devo tanto que só o tempo geológico para repor. Em sequência a minha irmã Elisabete por todo apoio e incentivo, ajuda quando possível na escrita da Tese e discussões geológicas. A meu namorado Robenilson a quem compartilho meus dias e me ajuda e incentivo sempre, também a meu pai Natalino, e irmãs Silvânia e Jaqueline por sempre torcerem mesmo não entendendo nada do tema.

De fundamental importância foi o Professor Teixeira, que acompanhou meu desenvolvimento acadêmico nestes 4 anos, mostrou caminhos, incentivou a produção acadêmica e me permitiu entender o mundo da evolução crustal.

Ao professor Patrício, por quase um ano de co-orientação não oficial e grande ajuda na interpretação dos dados.

Os trabalhos de campo não seriam possíveis sem a ajuda dos Professores Ciro Ávila e Everton Bongiolo, aos quais agradeço imensamente por toda ajuda durante as campanhas de campo e já no escritório com as interpretações dos resultados analíticos.

Aos colegas e amigos Alessandra, Andréa, Ângela, Carlos Mário, Carlos Eduardo, Cláudia, Daniel, Donald, Edilce, Ezequiel, Fátima, Geane, Gustavo, Laura, Mariana, Mariângela, Nívea, Soraia, Thaís, e Vicente agradeço pelas conversas, ajuda, companheirismo, discussões geológicas e uma vida inteira pela frente de amizade.

Aos outros amigos distantes, Ana Carla, Néa, Fabiane, Rose, Andréa, Radamés que torcem fortemente pelo sucesso da minha jornada.

Aos professores sempre prontos para ensinar, inicialmente a Basei pelas discussões a respeito da geocronologia, Ginaldo, Maria Helena, Gergly, Silvio, Blay, Cordani, Oswaldinho, Mario Campos, Paulo Roberto, Fábio e Caetano.

Agradeço a equipe do CPGeo pela amizade conquistada nestes anos, Liliane, Roberto, Vasco, Elen, Ivone, Silvânia, Roberta, Walter, Artur, Isabel, Solange, Márcio, Rodrigo, Sato, Nayara e Fernanda.

Também aos funcionários do Instituto de Geociências Samuel, Leonardo, Katarine, Henrique, Stella, Bruno pela grande ajuda sempre que necessário.

Mais importante, eu gostaria de agradecer, de alguma forma, minha mãe quem sempre me encorajou a seguir meus sonhos e a nunca desistir. Sem o incentivo dela, esta Tese não seria possível. Dedico esta Tese para ela. 


\section{RESUMO}

O cinturão Mineiro corresponde a um extenso terreno juvenil composto por metagranitoides e sequências supracrustais que compõem a orogenia acrescionária Minas na porção meridional do cráton do São Francisco. A produção da crosta continental ocorreu a partir de 3 arcos magmáticos desde $2,47 \mathrm{Ga}$, com duração de ca. $380 \mathrm{Ma}$. Sendo que o arco mais jovem $(2,17-2,10 \mathrm{Ga})$ causou a remobilização de boa parte do antepaís arqueano, conforme dados da literatura. Esta Tese apresenta e interpreta novos dados obtidos em rochas plutônicas (idades U/Pb em zircão - SHRIMP e LA-ICPMS, isótopos de Nd-Sr-Hf e dados geoquímicos) com intuito de melhor caracterizar o ambiente tectônico e as fontes dessas rochas no contexto da evolução crustal. O principal mecanismo atuante foi a fusão da crosta oceânica em subducção com variável contribuição da crosta continental. O ortognaisse Cassiterita, mais antigo identificado no cinturão Mineiro, possui idades U/Pb em zircão entre 2472-2414 Ma com o superimposição metamórfica datada em 2,16-2,04 Ma. Os elementos maiores e menores indicam que o ortognaisse possui afinidade TTG de alto $\mathrm{Al}_{2} \mathrm{O}_{3}$, enquanto que os elementos traços sugerem que o principal mecanismo da diferenciação magmática é a fusão parcial. Como tal, este conjunto de rochas seria produto do desenvolvimento de um arco oceânico. Parâmetros petrológicos (e.g., $\varepsilon_{\mathrm{Nd}(\mathrm{t})}$ : $+5,2 \mathrm{e}+1,3$ e ${ }^{87} \mathrm{Sr}^{86} \mathrm{Sr}_{\mathrm{i}}$ : 0,7000,702) destas rochas são consistentes com uma derivação a partir da fusão de metabasaltos toleíticos (MORB). Significantes variações nos valores de $\varepsilon_{\mathrm{Hft}}$ (em zircão) bem como a assinatura geoquímica (e.g., ausência de anomalias de Eu e $\mathrm{Sr}$, altos valores de $\mathrm{Sr}$ e $\mathrm{Sr} / \mathrm{Y}_{\mathrm{N}}$ e baixo conteúdo de $\mathrm{Y}$ ) sugerem que o magma gerador do plúton Cassiterita foi produto de uma fonte máfica com granada, com possível envolvimento de material derivado da crosta continental. Um magmatismo mais jovem, mas ainda associado ao evento tectônico gerador do ortognaisse Cassiterita é representado pelo ortognaisse Resende Costa e a suíte Lagoa Dourada (2356-2317 Ma). Os dados geoquímicos (TTG, metaluminoso, alto $\left.\mathrm{Al}_{2} \mathrm{O}_{3}\right)$ e isotópicos $\left(\varepsilon_{\mathrm{Hft}}\right.$ negativos e $\varepsilon_{\mathrm{Ndt}}$ positivos) indicam gênese similar entre estes corpos, compatível com ambiente intraoceânico. O segundo evento tectono-magmático gerou as rochas das suítes Serrinha (2227-2211 Ma) e Tiradentes (2217-2204) e do ortognaisse Nazareno (2161 Ma). Os valores de $\varepsilon_{\mathrm{Nd}(\mathrm{t})}$ : $-0,5 \mathrm{a}+1,8$ e ${ }^{87} \mathrm{Sr}^{86} \mathrm{Sr}_{\mathrm{i}}$ : 0,701-0,706 e os dados geoquímicos (cálcioalcalino, metaluminosa a peraluminosa, tipo I) são amplamente correlacionáveis e apontam uma fonte máfica heterogênea ou com contaminação crustal. O terceiro evento tectono-magmático é representado por um largo pico de idades, que variam entre 21742109 Ma representando a cristalização de diferentes batólitos. Os dados geológicos e relações de campo indicam que os batólitos Macuco de Minas (2174-2106 Ma), o Represa de Camargos (2173-2114 Ma) e o Ritápolis (2149-2121 Ma) apresentam idades variantes que ilustram a geração por intrusões múltiplas. As características químicas e isotópicas são consistentes com a derivação destes corpos a partir da fusão da crosta oceânica envolvendo crosta continental e inferior e manto litosférico subcontinental, em ambiente de arco continental. A distribuição de elementos incompatíveis e as características geoquímicas (cálcio-alcalina, tipo I, metaluminosa a levemente peraluminosa) favorecem uma origem através da fusão de uma fonte máfica de modo a gerar uma variação composicional entre dioritos e granitos. Isto pode ser explicado pelo fracionamento da hornblenda, epidoto e apatita. Em termos paleotectônicos os novos dados indicam que o regime acrescionário que construiu o cinturão Mineiro envolveu proeminente encurtamento crustal e da litosfera oceânica. O desenvolvimento progressivo de arcos continentais e oceânicos com posterior colagem ao antepaís arqueano resultou na formação do paleocontinente São Francisco-Oeste Congo. 
Correlações geológicas e tectônicas entre os arcos Mantiqueira, Juiz de Fora e Mineiro, além dos Cinturões Itabuna-Salvador-Curaçá, Eburnian (Oeste da África) indicam uma escala intercontinental para este processo. O cenário paleotectônico é consistente com o crescimento global das placas litosféricas durante o Paleoproterozoico, quando o núcleo do supercontinente Columbia foi formado, corroborado por unidades orogênicas identificadas em outros continentes. 


\begin{abstract}
The Mineiro belt is a large juvenile terrane composed of plutonic rocks and supracrustal sequences, making up the Minas accretionary orogeny in the south of São Francisco craton. The juvenile continental crust of this Belt was produced during 3 successive magmatic arcs initiating at ca. $2.47 \mathrm{Ga}$ and lasting about $380 \mathrm{Ma}$. Wherein the younger arc (2.17-2.10 Ga) caused remobilization of the Archean foreland as supported by published information. This Thesis presents and interprets new data performed in plutonic rocks by means of U-Pb analyses in zircon (SHRIMP and LA-ICPMS), Nd-SrHf isotopes, and geochemical data. The objective of our work is to achieve the better characterization of the tectonic environment, as well as the sources of the rocks in the context of the crustal evolution. This set of data shows that many granitoids derive from the melt of heterogeneous sources. The main active mechanism of crustal growth was the melt of the subducted oceanic crust with variable contribution of the continental crust. The Cassiterita pluton, highlighted by the Orthogneiss, is the oldest identified so far in the Mineiro belt. It has U/Pb ages in zircon of 2472-2414 Ma, with its metamorphism dated at 2.16-2.04 Ma. The major and minor elements indicate that the orthogneiss has high $\mathrm{Al}_{2} \mathrm{O}_{3}$ TTG affinity, while the trace elements suggest the main mechanism of magmatic differentiation is the partial melting. As such, these rocks would be the product of an oceanic arc. Petrologic parameters $\left(e . g ., \varepsilon_{\mathrm{Nd}(\mathrm{t})}:+5.2\right.$ and +1.3 and $\left.{ }^{87} \mathrm{Sr} /{ }^{86} \mathrm{Sr}_{\mathrm{i}}: 0.700-0.702\right)$ of these rocks are consistent with partial melting of MORBlike metabasaltic rocks. Significant variations in zircon $\varepsilon_{\mathrm{Hf}(\mathrm{t})}$ values, as geochemical signatutes (e.g., absence of Eu-Sr anomalies, high $\mathrm{Sr}$ and $\mathrm{Sr} / \mathrm{Y}_{\mathrm{N}}$ and low $\mathrm{Y}$ contents) suggest that the magma Cassiterita pluton were the product of a mafic source with garnet. However minor contribution of older continental material was involved in the magma genesis. A younger magmatism, but yet associated to the tectonic event of the Cassiterita orthogenesis is represented by the Resende Costa orthogneiss and Lagoa Dourada suite (2356-2317 Ma). Geochemical (TTG, metaluminous, high $\mathrm{Al}_{2} \mathrm{O}_{3}$ ) and isotopic (negative $\varepsilon_{\mathrm{Hft}}$ and positive $\varepsilon_{\mathrm{Ndt}}$ ) data indicate that the genesis and the tectonic environment of these bodies are similar, and akin to an oceanic arc setting. The second tectonic-magmatic event produced the Serrinha (2227-2211 Ma) and Tiradentes (2217$2204 \mathrm{Ma})$ suites, and of Nazareno orthogneiss (2161 Ma), according to our data. The values of $\varepsilon_{\mathrm{Nd}(\mathrm{t})}$ : -0.5 to +1.8 and ${ }^{87} \mathrm{Sr}^{86} \mathrm{Sr}_{\mathrm{i}}$ : $0.701-0.706$, and the geochemical data (calcium-alkaline, metaluminous to peraluminous, I type) are broadly correlative among the three bodies, and indicate that they derived from a mafic source with some sort of crustal contamination. The third tectonic-magmatic event defines a granitoid age peaks and varies between 2174-2106 Ma, given by the crystallization in different batholiths. Our data and field relations indicate that the Macuco de Minas (2174-2109 Ma), Represa de Camargos (2173-2114 Ma) and Ritápolis (2149-2121 Ma) batholiths present varying ages, which illustrate a generation by multiple intrusions. The isotopic and chemical characteristics are consistent with melting of oceanic crust, involving continental crustal, lower crust and sublithospheric continental mantle in a continental arc setting. Immobile trace and REE distributions and some geochemical characteristics (calc-alkaline, I-type, metaluminous to slightly peraluminous) favor an origin of the rocks through melting of a mafic source with compositional variation from diorite to granite, what can be explained by increasing fractionation of hornblende, epidote and apatite. In paleotectonic terms, the new data and regional geologic-correlations indicate that the accretionary regime that set up the Mineiro belt involved prominent crustal shortening of the oceanic lithosphere. The progressive development of the continental and oceanic arcs and eventual docking with Archean foreland resulted in the São
\end{abstract}


Francisco-West Congo paleocontinent. Geologic and tectonic correlations among the Mantiqueira, Juiz de Fora and Mineiro arcs, the Itabuna-Salvador-Curaçá, Eburnian (West Africa) belts, highlight an intercontinental scale for this process. The paleotectonic scenery is consistent with the global growing of the lithospheric plate during early Paleoproterozoic times, when the core Columbia was formed, what is corroborated by the tectonic units with rougly similar $\mathrm{U}-\mathrm{Pb}$ ages in other continents. 


\section{SUMÁRIO}

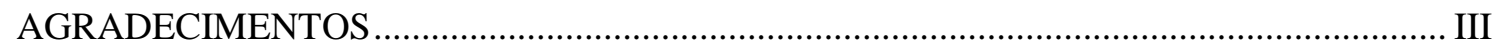

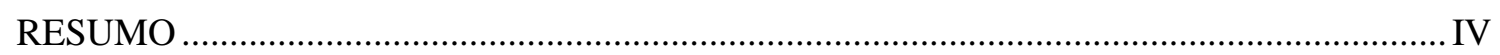

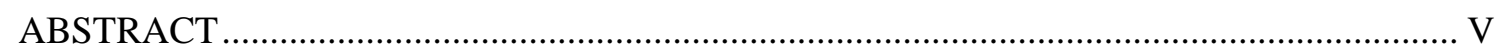

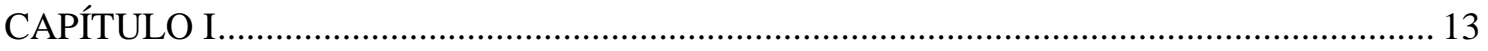

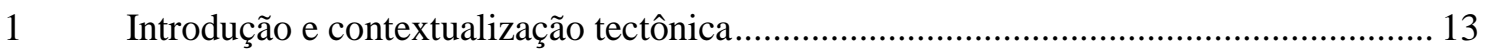

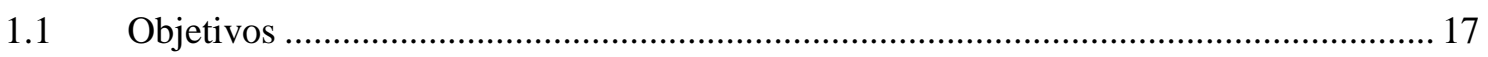

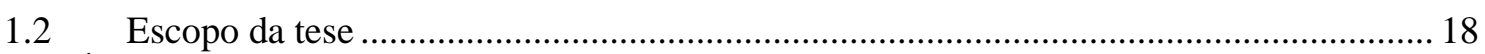

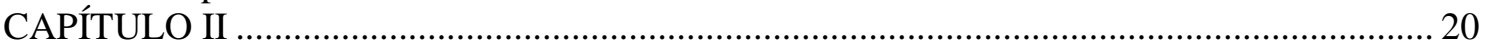

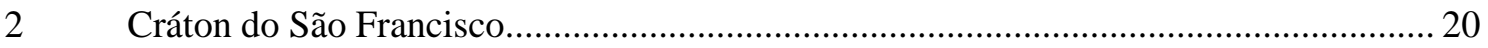

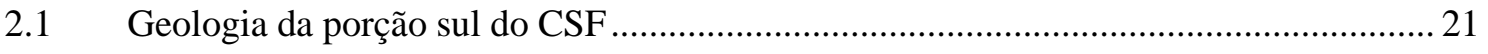

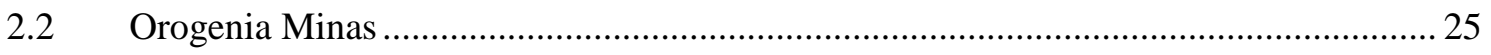

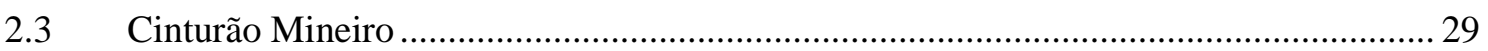

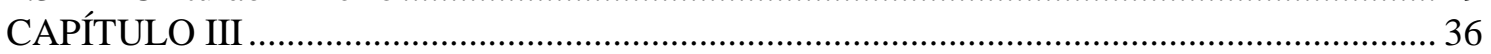

3 Estratégia de estudo e métodos de trabalho..................................................................... 36

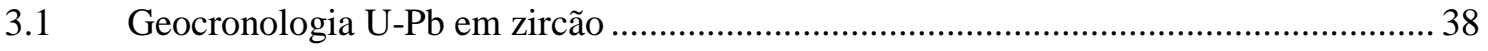

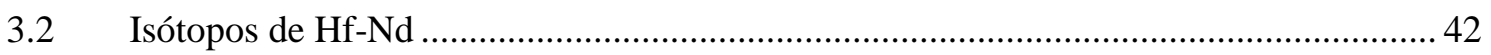

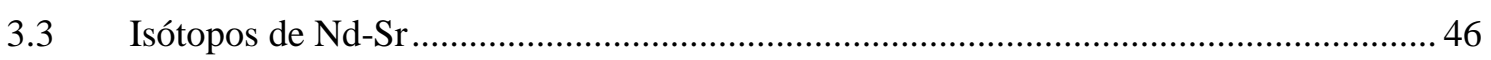

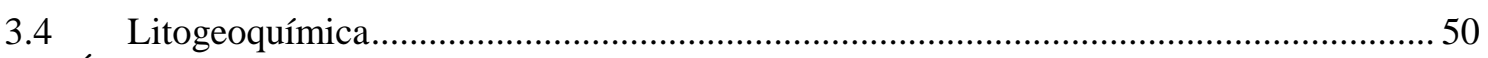

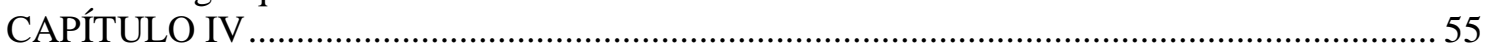

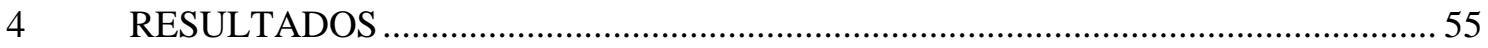

4.1 Corpos plutônicos da porção sudoeste do cinturão Mineiro............................................... 55

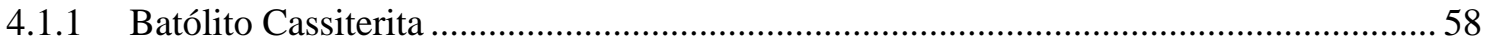

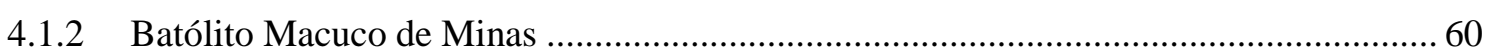

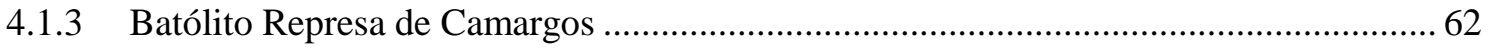

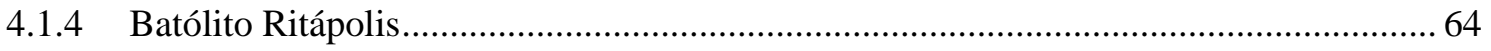

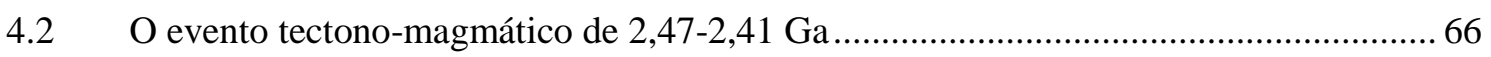

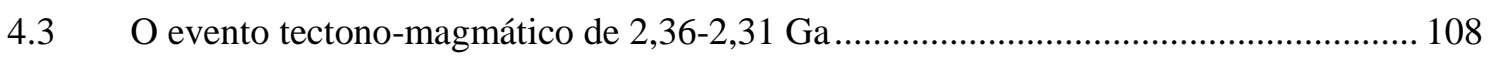

4.4 O evento tectono-magmático de 2,26-2,22 Ga ............................................................. 109

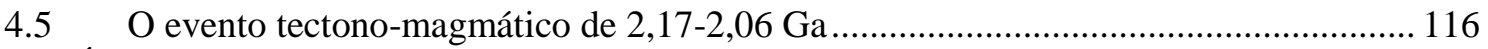

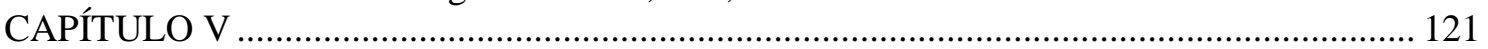

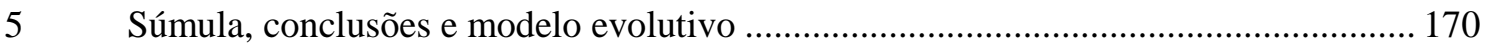

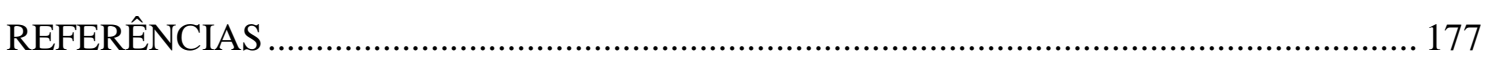

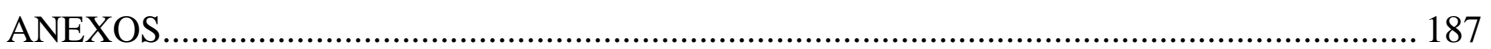

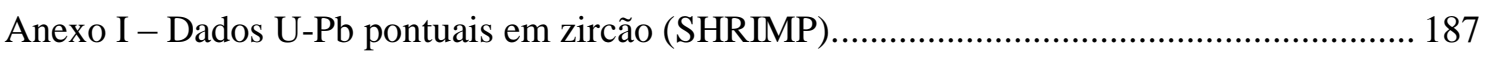

Anexo II - Dados U-Pb pontuais em zircão (LA-ICPMS). ..................................................... 198

Anexo III - Imagens de catodoluminescência. Referente aos dados da seção 4.5 . .................... 204

Anexo IV - Evento tectono-termal de 2,36-2,31 Ga............................................................ 208 


\section{Lista de Figuras}

Figura 1. Mapa geológico do Cráton do São Francisco (CSF) mostrando o embasamento Arqueano/Paleoproterozoico; Sequências do Paleo- Mesoproterozoico e Coberturas Neoproterozoicas. (Alkmim e Martins-Neto, 2012).

Figura 2. Mapa geológico do embasamento arqueano (Quadrilátero Ferrífero e granitoides) na porção sul do Cráton do São Francisco (Romano et al., 2013).

Figura 3. Coluna estratigráfica do Supergrupo Minas e Rio das Velhas na região do Quadrilátero Ferrífero (Alkmim e Noce, 2006 in: Ávila et al., 2014).

Figura 4. (a) Localização dos Cráton São Francisco e Oeste Congo e o Orógeno Araçuaí-Oeste Congo (Alkmim et al., 2006; Noce et al., 2007); (b) Mapa tectônico mostrando a distribuição do embasamento Paleoproterozoico e no Cráton do São Francisco e suas imediações (Heilbron et al., 2008; Valeriano et al., 2004; Noce et al., 2007). Legenda: (1) Sedimentos fanerozoicos; (2) Faixa Brasília, Ribeira e Araçuaí; (3) Sequências neoproterozoicas de margem passiva; (4) Grupo Bambuí; (5) Terreno Apiaí; (6) Terrenos Embú e Paraíba do Sul; (7) Terreno Cabo Frio; (8) Sequências Mesoproterozoica do Espinhaço; (9) Complexo Mantiqueira e rochas relacionadas; (10) Complexo Juiz de Fora e sequências Neoproterozoicas; (11) Cinturão Mineiro; (12) Supergrupo Minas e o Supergrupo Rio das Velhas; (13) Complexos Arqueanos; (14) Terreno Guanhães.

Figura 5. Esboço geológico-tectônico do paleocontinente São Francisco, mostrando rochas arqueanas do Cráton e os cinturões Mineiro, Mantiqueira e Juiz de Fora. LSZ: Zona de cisalhamento Lenheiros; RV: Supergrupo Rio das Velhas; QF = Quadrilátero Ferrífero; RC: Ortognaisse Resende Costa e rochas coevas; (1): Suíte Lagoa Dourada; (2) Batólito Ritápolis; (3) Batólito Alto do Maranhão. Cidades: ST (São Tiago), LD (Lagoa Dourada), SJ (São João del Rei), BA (Barbacena), CO (Congonhas), OP (Ouro Preto), BH (Belo Horizonte), RI (Ritápolis), LV (Lavras), AC (Acaiaca), IT (Itabira) (Teixeira et al., 2015).

Figura 6. Quadro geológico da região meridional do Cráton do São Francisco (adaptado de Ávila et al., 2003 in: Ávila et al., 2010) mostrando os complexos basais (Campo Belo, Bonfim e Passa Tempo), em contraposição ao cinturão Mineiro (CM) exposto na parte meridional. I Crosta Arqueana parcialmente retrabalhada durante o Paleoproterozoico. II - Greenstone Belt e sequências metavulcanossedimentares Paleoproterozoico: (A) Rio das Mortes, (B) Nazareno e (C) Dores de Campos. III- Granitoides Arqueanos. IV - Supergrupo Minas (Arqueano/Paleoproterozoico). V - Corpos plutônicos félsicos e máficos paleoproterozoicos. VI - Sequências supracrustais (Paleoproterozoico - Neoproterozoico). VII - Estrutura tectônica. VIII - limite tentativo do CM. Corpos plutônicos paleoproterozoicos (CM): 1 - Quartzomonzodiorito Glória; 2 - Diorito Brumado; 3 - Diorito Rio Grande; 4 - Gabro Rio Grande; 5 Gabro São Sebastião da Vitória/ Granodiorito do Lajedo; 6 - Quartzo-diorito Brito; 7 - Gabro Vitoriano Veloso; 8 - Diorito Ibitutinga; 9 - Tonalito/trondhjemito Cassiterita; 10 Trondhjemito Tabuões; 11 - Granitoide Ritápolis; 12 - Granodiorito Brumado de Baixo; 13 Granodiorito e corpos granofíricos Brumado de Cima; 14 - Granitoide Tiradentes; 15 - Granito Nazareno; 16 - Ortognaisse e granito Itumirim; 17 - Tonalito Congonhas; 18 - Granito-gnáisse Fé; 19 - Tonalito Alto Maranhão. QF - Quadrilátero Ferrífero. BSJL Lineamento - Bom Sucesso - Jeceaba. LSZ - Zona de cisalhamento Lenheiro.

Figura 7. ( $a, b)$ Modelo evolutivo simplificado (Arqueano-Paleoproterozoico) para o arco Serrinha-Tiradentes (Ávila et al., 2010; 2014). 
Figura 8. Ilustração comparativa entre as cavidades geradas pelas técnicas SHRIMP e LAICPMS (modificado de Patchett e Samson, 2005). SHRIMP: Tamanho do spot depois de 15 minutos. LA-ICPMS: Tamanho do spot depois de um único pulso.

Figura 9. Diagrama da concórdia mostrando a evolução das razões ${ }^{206} \mathrm{~Pb} /{ }^{238} \mathrm{U}$ versus ${ }^{207} \mathrm{~Pb} /{ }^{235} \mathrm{U}$ no decorrer do tempo (Wetherill, 1956).

Figura 10. Seção esquemática da crosta e do manto mostrando a transição entre mineralógica entre as camadas da Terra. A variação do coeficiente de distribuição para Lu e Hf é apresentada para cada fase do manto (Nowell et al., 2004).

Figura 11. $\varepsilon_{\mathrm{Hf}} v s . \varepsilon_{\mathrm{Nd}}$ inicial para todas as rochas terrestre em relação ao bulk silicate earth (Vervoot et al., 1999). Terrestrial array, (amostras crustais: sedimentos, basaltos continentais, granitoides, rochas juvenis etc) de diversas idades; (amostras mantélicas: representantes de todos os basaltos oceânicos).

Figura 12. Evolução isotópica do CHUR em função do tempo geológico CHUR (a partir de 4,55 Ga). Maior evento de diferenciação em 2,7 Ga (empobrecimento a crosta na razão $\mathrm{Sm} / \mathrm{Nd}$ e enriquecendo o manto) (Faure, 1986).

Figura 13. (A) Evolução $\mathrm{Nd}$ versus tempo; (B) $\varepsilon_{\text {Ndt }}$ versus ${ }^{87} \mathrm{Sr} /{ }^{86} \mathrm{Sr}$ inicial mostrando a composição complementar do manto empobrecido e da crosta continental relativa ao manto primitivo (Rollinson, 2007).

Figura 14. Diagramas ETR (A) $\mathrm{Dy} / \mathrm{Dy}$ * versus $\mathrm{Dy} / \mathrm{Yb}_{\mathrm{N}}(\mathrm{B}) \mathrm{Eu} / \mathrm{Eu}^{*}$ versus $\mathrm{SiO}_{2}$ (Davidson et al., 2013).

Figura 15. Diagrama de Variação - Harker - para rochas cogenéticas relacionadas a processos de cristalização fracionada (Wilson, 1989).

Figura 16. Diagrama $\mathrm{Nb} / \mathrm{La}$ vs. $\mathrm{Nd} / \mathrm{Sr}$ mostrando a curva de mistura para formar rochas da crosta continental (Rudnick e Gao, 2003).

Figura 17. Carga catiônica versus raio iônico para os elementos menores. Campo MRFE (Mantle Rock Forming Elements); LILE (large ion lithophile elements); HFSE (high field strength elements).

Figura 18. Mapa de localização e amostragem das rochas estudadas. Os números são as abreviações das amostras segundo a Tabela 4 (Coluna 1).

Figura 19. Mapa geológico da porção sul do Cráton do São Francisco, mostrando as unidades do Cinturão Mineiro (adaptado de Duarte et al., 2003; Quéméneur et al., 2003; Ávila et al., 2010; Corrêa Neto et al., 2012; Seixas et al., 2012).

Figura 20. Aspectos de campo do ortognaisse Cassiterita: (A) NAT-36: mostrando a foliação definida pelos grãos de biotita; (B) dique granitoide cortando o ortognaisse; (C) NAT-5: xenólito do batólito Cassiterita no batólito Macuco de Minas; (D) similar a Fig. (A), a foliação é definida pelos grãos de biotita. Aspectos petrográficos do ortognaisse Cassiterita: (E) NAT-36: aspecto geral mostrado a textura lépido-granoblástica; (F) NAT-8: mostrando a textura geral e agregados de quartzo poligonizados em forma de sigmoide; (G) NAT-8: Allanita envolvida por epidoto euedral e biotita; (H) NAT-5: aspecto geral mostrando a textura lépido-granoblástica.

Figura 21. (A) Amostra NAT-17 mostrando o envolvimento do ortognaisse e metatonalito; (B) Ortognaisse Morro do Resende (NAT-16) mostrando os cristais de magnetita; (C) Zona de 
cisalhamento (NAT-9 e 23) mostrando as rochas paralelizadas (E-W); (D) Amostra NAT-4 mostrando a textura porfirítica.

Figura 22. (A) Amostra NAT-17 mostrando incipiente foliação e textura equigranular; (B) Ortognaisse Morro do Resende (NAT-16) mostrando o bandamento gnáissico, cristais de quartzo agregados e a biotita foliada; (C) Amostra NAT-23 mostrando a orientação dos grãos de biotita; (D) Amostra NAT-4 com agregado de quartzo envolto por cristais de biotita e plagioclásio.

Figura 23. Aspectos de campo do batólito Represa de Camargos (A) Amostra FG-42 mostrando a textura equigranular do metatonalito; (B) Ortognaisse Itumirim (NAT-26) mostrando injeções granitoides no ortognaisse; (C) Ortognaisse granítico (NAT-25) com injeções pegmatíticas; (D) Metatonalito NAT-32 com rafts de anfibolito.

Figura 24. Aspectos petrográficos do batólito Represa de Camargos (A) Amostra FG-42 mostrando incipiente foliação e textura equigranular; (B) Ortognaisse Itumirim (NAT-16) mostrando a textura inequigranular; (C) Amostra NAT-25 mostrando grãos de quartzo agregados e a biotita definindo a foliação; (D) Amostra NAT-32 mostrando o plagioclásio sericitizado.

Figura 25. Aspecto de campo das rochas do batólito Ritápolis (A) Amostra NAT-34: mostrando a textura equigranular fina do granito; (B) afloramento mostrando textura média e inequigranular. Aspectos petrográficos das rochas do batólito Ritápolis; (C) textura inequigranular mostrando grãos de biotita discretamente orientados; (D) paragênese metamórfica típica das rochas do $\mathrm{CM}$ (Ep, aln, bt), mostrando o plagioclásio sericitizado.

Figura 26. Características petrográficas e de campo do ortognaisse Nazareno. (A e B) Porções do afloramento mais homogenea e porções mais foliada e com injeções quartzo-feldspáticas, (C) Aspecto geral da textura grano-lepidoblástica; (D) Fotografia mostrando sericitização do plagioclásio.

Figura 27. Imagem de catodoluminescência dos zircões do ortognaisse Nazareno.

Figura 28. Diagrama da Concórdia para o ortognaisse Nazareno.

Figura 29. Diagrama de Harker para as rochas da suíte Tiradentes, símbolo de losango representa a amostra NAT-13 (Ávila et al., 2014).

Figura 30. Diagrama discriminante para a rocha do ortognaisse Nazareno e da suíte Tiradentes (a) Diagrama $\left[\mathrm{Al}_{2} \mathrm{O}_{3} /\left(\mathrm{CaO}+\mathrm{Na}_{2} \mathrm{O}+\mathrm{K}_{2} \mathrm{O}\right)_{\mathrm{mol}} \times\left[\mathrm{Al}_{2} \mathrm{O}_{3} /\left(\mathrm{Na}_{2} \mathrm{O}+\mathrm{K}_{2} \mathrm{O}\right)_{\text {mol }}\right.\right.$ (Maniar e Picolli,1989); (b) Diagrama $\mathrm{MgO}-\mathrm{FeO}^{*}-\mathrm{Na}_{2} \mathrm{O}+\mathrm{K}_{2} \mathrm{O}$ (Irvine e Baragar, 1971); (c) Diagrama $\mathrm{Ab}-\mathrm{An}-\mathrm{Or}$ (O’Connor, 1965); (d) Diagrama Ca-Na-K (Barker eArth, 1976). Dados de Ávila et al. (2014). O losango representa a amostra NAT-13.

Figura 31. Diagrama $\varepsilon_{\mathrm{Nd}(\mathrm{T})}$ versus ${ }^{87} \mathrm{Sr}^{86}{ }^{86} \mathrm{Sr}_{(\mathrm{t})}$ para rochas da suíte Serrinha, Tiradentes e uma amostra do ortognaisse Nazareno (Ávila et al., 2014). A estrela representa a amostra NAT-13.

Figura 32. Diagrama da Concórdia para as rochas do tonalito Brejo Alegre e do granito Gentio.

Figura 33. Diagramas (A) $\mathrm{SiO}_{2}$ vs. $\mathrm{Na}_{2} \mathrm{O}+\mathrm{K}_{2} \mathrm{O}-\mathrm{CaO}$ (Frost et al., 2001), (B) A/NK vs. A/CNK (Frost et al., 2001), (C) $\mathrm{FeO}_{\mathrm{t}} /\left(\mathrm{FeO}_{\mathrm{t}}+\mathrm{MgO}\right.$ ) vs. $\mathrm{SiO}_{2}$ (Frost et al., 2001); (D) $\mathrm{Rb}$ vs. $\mathrm{Y}+\mathrm{Nb}$ e (E) Nd vs. Y (Pearce et al., 1984). Os círculos preenchidos indicam as amostras estudadas. Os quadrados cinza são dados de Silva (2013). 
Figura 34. Modelo genético para os arcos do CM.

Figura 35. Modelo tectônico esquemático para rochas do CM, durante o paleoproterozoico. Estágio 1: 2,4-2,3 Ga geração do arco 1, que compreende o batólito Cassiterita, o ortognaisse Resende Costa e a suíte Lagoa Dourada em ambiente oceânico, simultâneo a deposição dos carbonatos na margem passiva Minas; 2,2 Ga geração do arco Serrinha. Estágio 2: 2,1 Ga subducção contínua do oceano paleoproterozoico e geração do arco continental. Estágio 3: 2,12,0 Ga fechamento do oceano paleoproterozoico e deformação das rochas de arco e do paleo cráton do São Francisco. 


\section{Lista de Tabelas}

Tabela 1. Características geológicas e tectônicas do CM (1. Teixeira et al., 2015; 2. Ávila et al., 2014; 3. 2010; 4.Seixas et al., 2012; 5. Seixas et al., 2013; 6. Noce et al., 2000; 7. Barbosa et al., submetido).

Tabela 2. Localização e métodos utilizados das rochas estudadas no CM.

Tabela 3. Propriedades morfológicas do zircão, suas feições correspondentes e interpretações (Silva, 2006).

Tabela 4. Localização, litologia e unidade geológica das rochas estudadas no CM.

Tabela 5. Petrografia das amostras estudadas do batólito Cassiterita. Abreviações para os minerais: Pl: Plagioclásio; Kfs: K-feldspato; Qtz: Quartzo; Olg: Oligoclásio; Ep: Epidote; Zrn: Zircão; Aln: Allanite; Chl: Clorita; Ttn: Titanita; Cal: Calcita; Ser: Sercita; Grt: Granada; Ap: Apatita; Di: Diopsidio; Hbl: Hornblenda; Bt: Biotita; e Opq: minerais opacos. Abreviações de acordo com Whitney e Evans (2010).

Tabela 6. Petrografia dos afloramentos estudados do batólito Macuco de Minas.

Tabela 7. Petrografia dos afloramentos estudados do batólito Represa de Camargos.

Tabela 8. Petrografia dos afloramentos estudados no batólito Represa de Camargos.

Tabela 9. Dados U-Pb SHRIMP para o ortognaisse Nazareno (NAT-13).

Tabela 10. Relação das amostras não publicadas nos artigos científicos. 


\section{CAPÍTULO I}

\section{Introdução e contextualização tectônica}

O Paleoproterozoico (2,5-1,6 Ga; IUGS, 2013) marca importantes transformações no regime geodinâmico terrestre em relação ao do Arqueano, em termos de processos tectônicos e características da litosfera (e.g., Condie, 2005; Windley, 1995). Nesta era, os principais mecanismos atuantes no manto conduziram ao retrabalhamento da crosta arqueana e ao desenvolvimento e propagação dos orógenos acrescionários. Além desses processos, verifica-se a formação de extensas plataformas continentais, bacias sedimentares cratônicas, magmatismo anorogênico com intrusões máfico-ultramáficas estratificadas e deposição de formações ferríferas bandadas (BIF’s) em bacias marginais (e.g., tipo Lake-Superior). O surgimento dos primeiros depósitos glaciais ocorreu em função do decréscimo dos níveis de $\mathrm{CO}_{2}$ atmosféricos e do gradiente geotérmico (Condie, 2005; Hou et al., 2008, Hofman, 1988).

O Sideriano (2,5-2,3 Ga) é marcado por uma provável "estabilização" das massas continentais. Estaria, portanto, relacionado a uma atenuação das atividades tectono-termais, com produção reduzida de rochas magmáticas juvenis entre 2,45-2,20 $\mathrm{Ga}$, conforme sugerem os registros de idades U-Pb em zircões ígneos e detríticos em nível mundial (e.g., Condie et al., 2009; Erikson e Condie, 2014). De acordo com Condie et al. (2009) e Erikson e Condie (2014) o magmatismo anorogênico, o crescimento episódico da crosta continental, o acúmulo de oxigênio na atmosfera, a diminuição de fluxo de gases vulcânicos e a diminuição de ocorrência de greenstone belts, BIF's, TTGs e LIPs poderiam refletir a estagnação da tectônica de placas no início do Paleoproterozoico. Modelos alternativos (e.g., Hawkesworth et al., 2009; Partin et al., 2014) propõem que a presença de rochas de arco depende do potencial de preservação da crosta admitindo um crescimento crustal contínuo a partir do neoarqueano com base em evidências geocronológicas, em oposição às interpretações que postulam a significante diminuição na produção de crosta neste período.

Nas últimas décadas, o avanço no mapeamento geocronológico de terrenos paleoproterozoicos, principalmente fazendo uso dos métodos $\mathrm{U}-\mathrm{Pb}$ e $\mathrm{Lu}-\mathrm{Hf}$, tem identificado com maior frequência rochas de idade sideriana em escala global. Nesse contexto, idades entre 2,45 e 2,22 Ga tem sido encontradas no Canadá (Partin et al., 2014), no Brasil (Seixas et al., 2012; Teixeira et al., 2015), no Oeste da África (Gasquet 
et al., 2003) e no norte da China (Zhao et al., 2008). A partir desses dados, Partin et al. (2014) defendem um regime geodinâmico global atuante nesse período, marcado por um registro emergente de rochas félsicas e máficas com idades entre 2,45 e 2,20 Ga, as quais foram geradas em ambientes extensionais e colisionais. Estas conclusões sugerem que as interpretações sobre um período de shutdown da evolução geológica da Terra estejam equivocadas.

No Riaciano (2,3-2,05 Ga) e no Orosiriano (2,05-1,8 Ga) elementos indicadores de uma tectônica horizontal já são visualizados com a identificação dos "primeiros" ofiolitos e eclogitos (Dilek, 2003; Horodyskyj et al., 2009). Nestes períodos, são registrados globalmente sucessivos eventos de crescimento continental por orogenias acrescionárias e colisionais, este último associado ao processo de convergência de massas continentais arqueanas (Barley et al., 2005; Condie e Kröner, 2013). Os orógenos envolvem ambientes intra-oceânicos e continentais, arcos magmáticos com volumosas injeções de granitoides (com contribuição ou não de crosta pré-existente), e colisões continentais. Representando o principal agente crescimento crustal (Windley, 2003; Condie, 2005).

Os orógenos acrescionários envolvem vários ciclos de sedimentação, subducção, atividade ígnea e metamorfismo, gerenciados por eventos tectonotermais que resultam em espessamento e, consequentemente, na estabilização da litosfera (e.g., Cawood et al., 2009; Condie, 2007). Rochas granitoides, sequências supracrustais (e.g., greenstone belts), rochas metassedimentares e ofiolitos são associações típicas dos orógenos acrescionários (Zhao et al., 2002a; Condie et al., 2009; Cawood et al., 2009; Isozaki et al., 2010). Estes configuram, em termos evolutivos, o crescimento crustal pós-arqueano no tempo e no espaço (Condie, 1994; Condie e Kröner, 2013).

Entre 2,1 e 1,8 Ga (i.e. Riaciano-Orosiriano), processos orogênicos quase universais levaram à excepcional produção de granitoides juvenis acrescionados aos embriões arqueanos e/ou segmentos crustais já formados (Condie, 2007; Dewey, 2007; Cawood et al., 2009; Condie e Kröner, 2013). Esse processo global, presente em quase todos os continentes, tem sido compreendido como a construção progressiva do supercontinente Colúmbia/Nuna que agregou parte da América do Sul (e.g., Cráton do São Francisco e Rio de La Plata, segmentos da Amazônia e do Cráton São Luís), África central e oeste (e.g., Congo, Kasai) e América do Norte (e.g.,Wyoming; Zhao et al., 2002, 2004; Rogers e Santosh, 2009; Cordani et al., 2009; Evans et al., 2011; Meert, 2012; Zhang et al., 2012). Por outro lado, evidências paleomagnéticas crescentes 
apontam que este supercontinente teria sobrevivido até cerca 1,4 Ga (e.g., D’AgrellaFilho et al., 2012; Araujo et al., 2012).

Na plataforma Sul-Americana, em particular no Cráton do São Francisco, rochas dessa idade (ca. 2,1 Ga) estão bem caracterizadas por estudos geocronológicos e isotópicos (e.g., Cordani e Sato, 1999; Sato e Siga Jr., 2002). Associações de rochas granitoides intrusivas em sequências metavulcanossedimentares ocorrem desde o Arqueano até o Proterozoico. Em particular estão onipresentes nos orógenos acrescionários e colisionais progenitores de grandes porções de crosta no Cráton do São Francisco, devido à convergência entre massas continentais previamente formadas e representantes da construção do supercontinente Columbia.

Em termos paleogeográficos, o cinturão Itabuna Salvador Curaçá e cinturão Mineiro (e.g., Barbosa e Sabaté, 2002; Teixeira e Figueiredo, 1991) representam dois dos mais extensos e completos segmentos crustais preservados no continente Sul Americano. O primeiro, localizado na porção norte do Cráton do São Francisco é constituído por arcos magmáticos contínuos que amalgamaram diferentes tipos de rochas (embasamento arqueano e metavulcanossedimentares), em um orógeno de caráter colisional (Barbosa e Sabaté, 2004). A colisão ocorreu em condições de fácies granulito entre 2,08-2,07 Ga, indicada pela litologia e paragênese mineral (e.g., kinzigitos, quartzitos e quartzitos com granada e ortopiroxênio; Barbosa e Sabaté, 2004). Cabe também notar que a oeste do chamado bloco Gavião foi identificado outro segmento orogênico paleoproterozoico. O Cinturão Urandi-Paratinga apresenta idade de 2,05 Ga e está associado a um ambiente orogênico do tipo pós-colisional. A assinatura isotópica e os dados químicos apontam como fonte progenitora dos magmas um manto metassomatizado (Rosa, 1999).

O Cinturão Mineiro (CM) - objeto de estudo da presente tese de Doutorado situa-se na porção meridional do Cráton do São Francisco (CSF) e suas rochas dispõemse alongadas na direção SW-NE. Possui aproximadamente $170 \mathrm{~km}$ de exposição de rochas, uma vez que sua porção oriental foi obliterada/retrabalhada durante a aglutinação do Gondwana (e.g., Noce et al., 2007). As características essencialmente juvenis e cálcio-alcalinas das rochas ígneas do $\mathrm{CM}$ e a existência de sequências vulcano-sedimentares evidenciam o fechamento de um oceano neoarqueano/paleoproterozoico marginal ao embrião arqueano do proto-CSF (Noce et al.,2000; Teixeira et al., 2000; Ávila et al., 2010). 
Em uma perspectiva tectonoestratigráfica, o $\mathrm{CM}$ e as unidades paleoproterozoicas adjacentes (i.e., complexo Mantiqueira e Juiz de Fora) preservam um ciclo de Wilson completo de 380 Ma (i.e. entre 2,4-2,1 Ga) com subducção da litosfera oceânica, geração de rochas juvenis e posteriormente espessamento da crosta arqueana através dos processos acrescionários (Alkmim e Marskak, 1998; Noce et al., 2007; Heilbron et al., 2010; Teixeira et al., 2015). O resultado final foi uma estruturação tectônica complexa de rochas metavulcanossedimentares e granitoides de idades distintas, cujos ambientes de formação têm sido elucidados a partir de estudos geológicos sistemáticos, apoiados por geocronologia e geoquímica (e.g., Seixas et al., 2013).

Em termos históricos, a definição do CM (Teixeira 1985), com base nos primeiros estudos geocronológicos regionais ( $\mathrm{Rb}-\mathrm{Sr}$ e $\mathrm{K}-\mathrm{Ar}$ ) em rochas plutônicas, possibilitou delinear um extenso domínio paleoproterozoico a sudoeste do chamado Quadrilátero Ferrífero, em contraposição ao domínio setentrional, composto por rochas arqueanas características do embrião cratônico. Posteriormente, Noce et al. (2000) demonstraram a abrangência de rochas plutônicas de naturezas distintas (juvenis e crustais) associadas ao cinturão, com base na interpretação integrada de dados geoquímicos, isotópicos ( $\mathrm{Nd}$ e $\mathrm{Sr}$ ) e geocronológicos (U-Pb). Mais recentemente, Alkmim (2004) propôs uma definição alternativa "lato sensu" para o CM, de modo a abranger um extenso domínio onde está registrada a deformação paleoproterozoica superimposta às rochas arqueanas, onipresentes na região do Quadrilátero Ferrífero e para o noroeste cratônico (e.g., Marshak et al., 1997).

O emprego de técnicas geocronológicas de grande potencial interpretativo (e.g., $\mathrm{U}-\mathrm{Pb}, \mathrm{Sm}-\mathrm{Nd}$, Lu-Hf) tem proporcionado uma visão mais aprofundada sobre a evolução tectono-magmática do CM (e.g., Ávila et al., 2010, 2014; Seixas et al., 2012, 2013; Teixeira et al., 2015). Em outras palavras, a aplicação das ferramentas combinadas (e.g., petrografia, geocronologia, geoquímica isotópica e litoquímica) aliadas a uma base geológica confiável tem permitido a interpretação da evolução tectônica de diversos segmentos do CM. A aplicação destas técnicas em rochas granitoides permite alcançar um significado petrogenético e tectônico dos diferentes corpos, uma vez que suas composições químicas e isotópicas identificam possíveis fontes e decodificam a história da crosta continental no Paleoproterozoico.

O presente estudo é justificado em função da complexidade geológica inerente ao $\mathrm{CM}$ e pelo fato de que estudos regionais anteriores (i.e., geológicos, isotópicos e 
geoquímicos) apontaram a existência de diferentes pulsos magmáticos com participação ou não de componentes crustais (Noce et al., 2000; Cherman, 2004; Ávila et al., 2010, 2014; Teixeira et al., 2008, 2015).

De uma perspectiva geodinâmica, a região selecionada é de particular interesse, pois apresenta compartimentos tectônicos distintos através dos quais é possível caracterizar a transição entre o CM - uma entidade do Paleoproterozoico - em contraposição aos complexos metamórficos arqueanos primitivos do Cráton do São Francisco e a bacia marginal (Supergrupo Minas) que ocorrem ao norte. Vale também notar que, nos últimos anos, rochas ortoderivadas com idades peculiares (i.e. 2,4 - 2,3 Ga) vêm sendo identificadas no interior do CM (Seixas et al., 2012; Teixeira et al., 2015) corroborado com idades determinadas em outros trabalhos a nível mundial (e.g., Partin et al., 2014 e referências internas).

Atualmente as informações sobre a gênese das rochas plutônicas do CM a partir da aplicação dos métodos isotópicos e geoquímicos ainda são, em grande parte, incompletas. Desta forma, com o objetivo de elucidar a evolução crustal do orógeno, torna-se necessário a utilização de ferramentas mais precisas (e.g., isótopos de $\mathrm{Nd}-\mathrm{Sr}$ Hf) para desvendar a natureza das rochas, calcada em informações geoquímicas (e.g., elementos traços).

Finalmente, a singularidade intrínseca às rochas siderianas do $\mathrm{CM}$ e de outros terrenos paleoproterozoicos no continente Sul Americano e em outros continentes demonstra a importância científica do foco de estudos desta Tese de Doutorado quanto ao registro geocronológico que desperta um interesse cada vez maior da comunidade geológica internacional. Portanto, a obtenção de dados complementares (geocronológicos, geoquímicos e isotópicos) a essas informações são fundamentais para uma melhor compreensão da petrogênese destes plútons, dos ambientes tectônicos associados e dos processos geodinâmicos que nortearam as sucessivas aglutinações que constituíram o CM.

\subsection{Objetivos}

O objetivo central desta Tese é a avaliação conjunta dos processos geológicos, por meio de estudos geocronológicos $\mathrm{U}-\mathrm{Pb}$, isotópicos (i.e., $\mathrm{Nd}, \mathrm{Sr}, \mathrm{Hf}$ ) e geoquímicos do CM. Mais especificamente, volta-se para o estudo dos corpos intrusivos selecionados 
que ocorrem na região de Lavras, Itumirim, Itutinga, Nazareno, Cassiterita e Ritápolis. Para tanto, fora utilizado como base os trabalhos de mapeamento geológico sistemático nesta região, na escala 1:50.000, que vêm sendo realizados pelo Professor Dr. Ciro Ávila e colaboradores, como parte do curso de geologia do Instituto de Geociências da Universidade Federal do Rio de Janeiro. A doutoranda, a medida do possível, participou de quatro etapas de campo para o reconhecimento das unidades e coleta de amostras para as análises desta Tese.

Os novos dados obtidos tem ênfase nas idades $\mathrm{U}-\mathrm{Pb}$ de rochas granitoides na porção sudoeste do $\mathrm{CM}$, nas respectivas idades modelo (i.e., $\mathrm{Nd}$ e $\mathrm{Hf}$ ), acompanhados de análises geoquímicas. Consequentemente, foram analisados parâmetros de campo e utilizados dados petrográficos (e.g. assembleia mineral, textura e estrutura), isotópicos (e.g., $\mathrm{Nd}, \mathrm{Hf}$ e $\mathrm{Sr}$ ) e geoquímicos (e.g., elementos maiores, menores) para distinguir/agrupar espacialmente os diferentes corpos plutônicos. Durante a interpretação, essas informações foram comparadas com o acervo de dados já publicados sobre plútons paleoproterozoicos do $\mathrm{CM}$ para determinar a história magmática e a contribuição relativa de magmas derivados do manto versus retrabalhamento crustal.

Apesar do avanço recente nas técnicas analíticas (e.g., SHRIMP, Lu-Hf em zircão) e do acesso mais franco a laboratórios no Brasil e exterior, o conhecimento geológico do CM vem se aprimorando, mas várias e importantes perguntas-chave ainda continuavam em aberto, tais como: (i) Quais as fontes específicas das diversas gerações de rochas plutônicas na porção sudoeste do CM? Estas podem ser integradas, em termos tectônicos às rochas plutônicas identificadas na porção nordeste? Qual o limite ocidental do Cinturão? (ii) Qual(ais) o(s) período(s) de diferenciação manto/crosta representativos da evolução paleoproterozoica? (iii) Qual o ambiente tectônico para as rochas estudadas? (iv) Qual o significado do CM perante a evolução crustal do Cráton do São Francisco e sua importância em termos globais (Columbia)?

\subsection{Escopo da tese}

Esta Tese está organizada em cinco capítulos. Estes informam sobre o contexto da tese, sua principal finalidade, objetivos e descrição dos métodos utilizados para o alcance dos objetivos sumarizados no item anterior. A organização dos resultados 
(Capítulo 4) inicia com a contextualização geológica dos batólitos estudados, em sequência cronológica de cada conjunto de rocha ou suíte estudada (do mais antigo ao mais jovem), em termos da interpretação e discussão dos dados $\mathrm{U}-\mathrm{Pb}$, dados geoquímicos, isótopos de $\mathrm{Nd}$ e $\mathrm{Sr}$ e variavelmente de Hf. Os resultados estão apresentados na forma de três artigos completos (publicados, submetidos e em elaboração) que representam subitens deste Capítulo. Um dos artigos intitula-se "TTG plutonism (2.4 Ga) unravelled in the Mineiro belt, southern São Francisco craton: zircon $\mathrm{U}-\mathrm{Pb}-\mathrm{Hf}, \mathrm{Nd}-\mathrm{Sr}$ and geochemical fingerprints and tectonic significance (geodynamics) (Barbosa et al., em preparação), o qual está em fase de finalização para submissão a um periódico internacional. O segundo artigo (em coautoria) trata de um evento acrescionário precoce no CM: "A juvenile accretion episode $(2.35-2.32 \mathrm{Ga})$ in the Mineiro belt and its role to the Minas accretionary orogeny: zircon $\mathrm{U}-\mathrm{Pb}-\mathrm{Hf}$ and geochemical evidences" (Teixeira et al., 2015), apresentado em anexo.

Adicionalmente será apresentado um sub-capítulo a respeito do evento plutônico relacionado à idade de 2,2 Ga. Este fará inferências a um dado produzido nesta Tese em conjunto com os dados publicados referentes às suítes Serrinha e Tiradentes (Ávila et al., 2010, 2014), pois a posição geográfica/tectônica e a idade destas rochas são semelhantes.

O terceiro artigo intitulado "2.17-2.09 Ga crust forming episodes in the Mineiro belt, São Francisco craton, Brazil: U-Pb ages and geochemical constraints" foi submetido ao periódico Precambrian Research (Barbosa et al., submetido). Este artigo trata do maior conjunto de dados obtidos nesta Tese e interpretação do significado tectônico do evento plutônico de ca. 2,1 Ga. A apresentação dos quatro trabalhos é precedida de considerações para ressaltar a estratégia de estudo e sua importância em termos da evolução tectono-magmática do CM. O capítulo 5 apresenta um sumário da contribuição científica da tese, respostas às questões propostas e um quadro evolutivo para o CM à luz da interpretação dos novos dados comparada à literatura pertinente. 


\section{CAPÍTULO II}

\section{Cráton do São Francisco}

O Cráton do São Francisco - CSF (Almeida, 1977), localizado na porção centro leste da Plataforma Sul-Americana, consiste essencialmente de blocos siálicos arqueanos separados e/ou limitados por orógenos paleoproterozoicos (e.g.: Almeida e Hasui, 1984; Teixeira e Figueiredo, 1991; Brito Neves et al., 1996; Barbosa e Sabaté, 2002, 2004; Alkmim e Noce, 2006). O desenvolvimento do Cráton do São FranciscoOeste Congo registra dois grandes períodos importantes: um Arqueano com geração de grande volume de crosta continental e outro Paleoproterozoico marcado pela aglutinação das massas continentais arqueanas, por conta da propagação de arcos juvenis coevos à subducção da litosfera oceânica (e.g., Alkmim e Noce, 2006; Noce et al., 2007).

Em termos continentais os orógenos paleoproterozoicos (Cinturão Mineiro 2,32,1 Ga, Itabuna Salvador Curaçá 2,4-2,1 Ga, Guanambi-Correntina 2,1 Ga) registram a principal época de construção crustal da chamada plataforma Sul-Americana (Mascarenhas, 1979; Barbosa e Dominguez, 1996; Barbosa e Sabaté, 2002; Noce et al., 2007; Brito Neves, 2011), a exemplo da orogenia Minas (Teixeira et al., 2015) no extremo meridional do Cráton do São Francisco.

As principais unidades litoestratigráficas do Cráton do São Francisco (Figura 1) compreendem o embasamento arqueano e paleoproterozoico e coberturas de idade Paleoproterozoicas do Supergrupo Espinhaço (1,75-0,9 Ga) à Neoproterozoicas do Supergrupo São Francisco (850-580 Ma; Teixeira et al., 2000; Alkmim e Martins-Neto, 2012; Barbosa et al., 2012). Acrescimentos juvenis e retrabalhamento crustal ocorreram em razão da evolução policíclica, caracterizando a formação do proto-Cráton durante o Neoarqueano e o Paleoproterozoico (e.g., Teixeira et al., 2000; Barbosa et al., 2012), à semelhança de outras áreas cratônicas do mundo.

O substrato cratônico é constituído por um complexo arranjo de terrenos metamórficos de alto a médio grau (gnaisses, metagranitoides e granulitos) geralmente de composição TTG de idade arqueana, associações do tipo granito-greenstone, complexos máfico-ultramáficos e granitoides sin- e pós-tectônicos (Teixeira et al., 2000; Barbosa et al., 2012). Cinturões de rochas paleoproterozoicas, onde predominam rochas plutônicas com grande variedade composicional, estão expostos na porção norte 
(Cinturão Itabuna Salvador Curaçá) e no extremo sul do Cráton (Cinturão Mineiro, Complexo Mantiqueira e Complexo Juiz de Fora) (Teixeira et al. 2000; Barbosa e Sabaté, 2002; Barbosa et al., 2012; Oliveira et al., 2010; Rios et al., 2009).

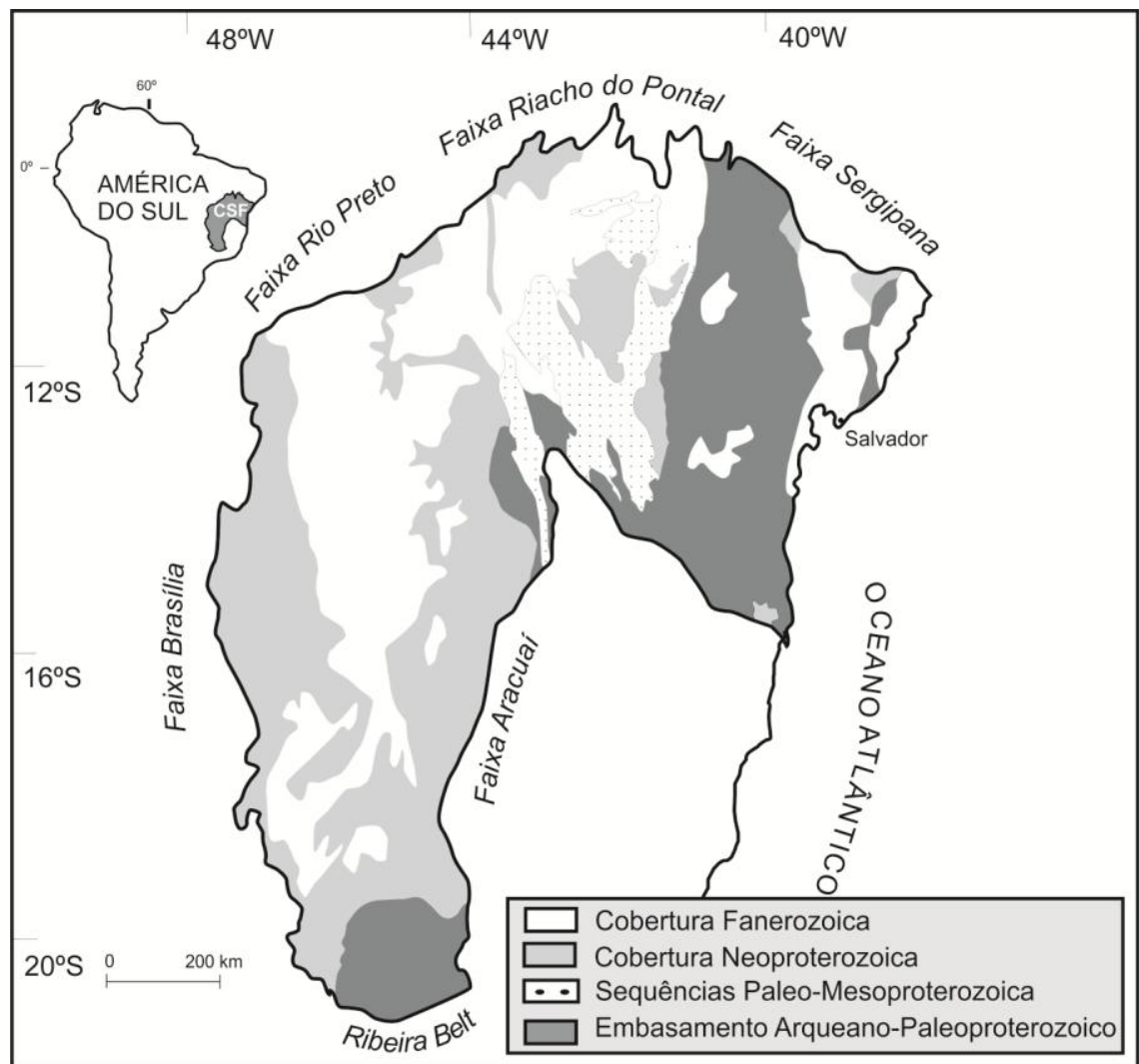

Figura 1. Mapa geológico do Cráton do São Francisco (CSF) mostrando o embasamento Arqueano/Paleoproterozoico; Sequências do Paleo- Mesoproterozoico e Coberturas Neoproterozoicas. (Alkmim e Martins-Neto, 2012).

\subsection{Geologia da porção sul do CSF}

A porção sul do CSF compreende uma crosta arqueana constituída por complexos metamórficos distintos marcados por suítes TTG, migmatitos, granulitos e rochas metagranitoides (Campo Belo, Passa Tempo, Bonfim, Belo Horizonte, Bação, Santa Bárbara e Caeté; Figura 2). Ocorrem, também, intrusões acamadadas máficoultramáficas e os greenstones belts Piumhi e Rio das Velhas (e.g., Teixeira et al., 1996, 2000; Campos et al., 2003; Campos e Carneiro, 2008; Alkmim e Noce, 2006; Lana et al., 2013; Romano et al., 2013). 


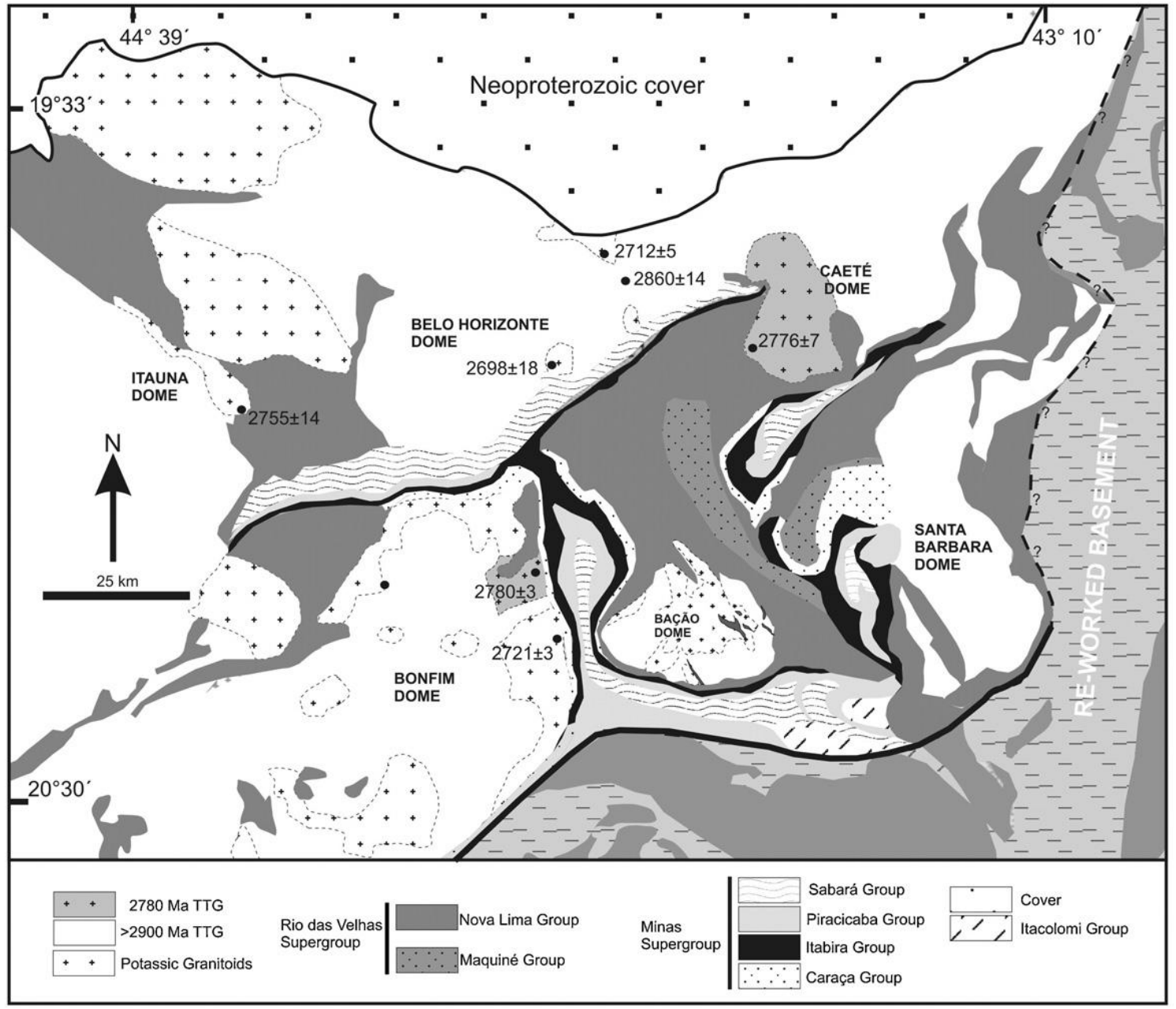

Figura 2. Mapa geológico do embasamento arqueano (Quadrilátero Ferrífero e granitoides) na porção sul do Cráton do São Francisco (Romano et al., 2013).

Associado à evolução dos complexos metamórficos ocorre a deposição da sequência vulcanossedimentar (greenstone belt) Rio das Velhas. O Supergrupo Rio das Velhas é dividido nos grupos Nova Lima constituído por rochas máfica-ultramáfica, félsicas, Bif's e pelitos; e no grupo Maquiné composto por arenitos, conglomerados, pelitos representantes de sedimentos plataformais (Dorr, 1969), sequência que obteve condições de metamorfismo fácies anfibolito (Romano et al., 2013). A cristalização das rochas vulcânicas félsicas ocorreu entre 2792-2751 Ma (Noce et al., 2005).

Esse segmento foi formado em três episódios de acreção distintos (3,21-3,10 Ga, 2,93-2,90 e 2,80-2,77 Ga; Lana et al., 2013). O evento mais antigo (3,21-3,10 Ga) originou o estágio embrionário juvenil definido como orogenia Campo Belo (Teixeira e Oliveira, em preparação). Este estágio compreende rochas do complexo Santa Bárbara $(3210 \pm 8$ Ma e $3212 \pm 9$ Ma) e do complexo Campo Belo (3205 \pm 25 Ma e $3047 \pm 25$ Ma) (Figura 2; Lana et al., 2013). O segundo estágio está relacionado à orogenia Rio das Velhas (2,93-2,90 Ga) e a migmatização dos complexos com o leucossoma datado 
em $2840 \pm 17$ Ma (Teixeira et al., 1996; Lana et al., 2013). Em seguida a crosta arqueana TTG foi intrudida por granitos potássicos (Figura 2) com idade de 2750-2700 Ma (Lana et al., 2013; Romano et al., 2013).

Estes dados permitem individualizar dois segmentos crustais arqueanos formados em períodos distintos, um mais antigo formado pelos complexos Campo Belo e Santa Bárbara e outro mais jovem formado por rochas dos complexos Belo Horizonte, Bonfim e Passa Tempo. Alguns autores (e.g., Lana et al., 2013; Romano et al., 2013) advogam que os eventos granitoides tardios marcaram a estabilização de um núcleo cratônico arqueano (Machado e Carneiro, 1992; Romano et al., 2013). Evidências geológicas, estruturais e tectônicas sugerem que este extensivo domínio atuou como uma plataforma durante a colagem de arcos paleoproterozoicos construindo a chamada placa São Franciscana - Oeste Congo (e.g., Alkmim, 2004; Noce et al., 2007).

Na transição Arqueano/Paleoproterozoico ocorreu extensão crustal e acumulação na margem passiva de sedimentos derivados da erosão da crosta arqueana (e.g., Alkmim e Noce, 2006; Romano et al., 2013). Este pacote sedimentar é representado pelo Supergrupo Minas (Dorr, 1969). Atualmente a bacia Minas situa-se nas imediações do Quadrilátero Ferrífero, superposto às rochas do embasamento arqueano.

O Supergrupo Minas representa um espesso pacote de rochas metassedimentares clásticas-químicas de ambiente plataformal a sin-orogênico, depositadas sobre discordância angular sobre o embasamento neoarqueano (Renger et al., 1994; Alkmim e Noce, 2006; Noce et al., 2007). Quatro grupos constituem a estratigrafia da base para o topo: (i) Caraça - formado por depósitos aluviais, eólicos e marinhos representado por rochas metassedimentares clásticas. Está dividido na Formação Tamanduá (metarenitos), Formação Moeda (metarenitos e mataconglomerados) e Formação Batatal (metapelitos) (e.g., Alkmim e Noce, 2006); (ii) Itabira - esse grupo registra a transgressão marinha e subsidência termal da margem passiva Minas. Está dividido na Formação Cauê (BIF's tipo lake superior, itabiritos, anfibólio-itabirito) e Gandarela (dolomitos e carbonatos) (Babinski et al., 1995); (iii) Piracicaba - constituído da Formação Cercadinho (metarenitos), Fecho do Funil (metapelitos), Tabuões (metarenitos) e Barreiro (pelitos carbonáticos); e (iv) Sabará - constituído por grauvacas e tufos (Reis et al., 2001; Alkmim e Noce, 2006). A coluna cronoestratigráfica da Figura 3 sumariza a edificação do Supergrupo Minas (Alkmim e Noce, 2006). 


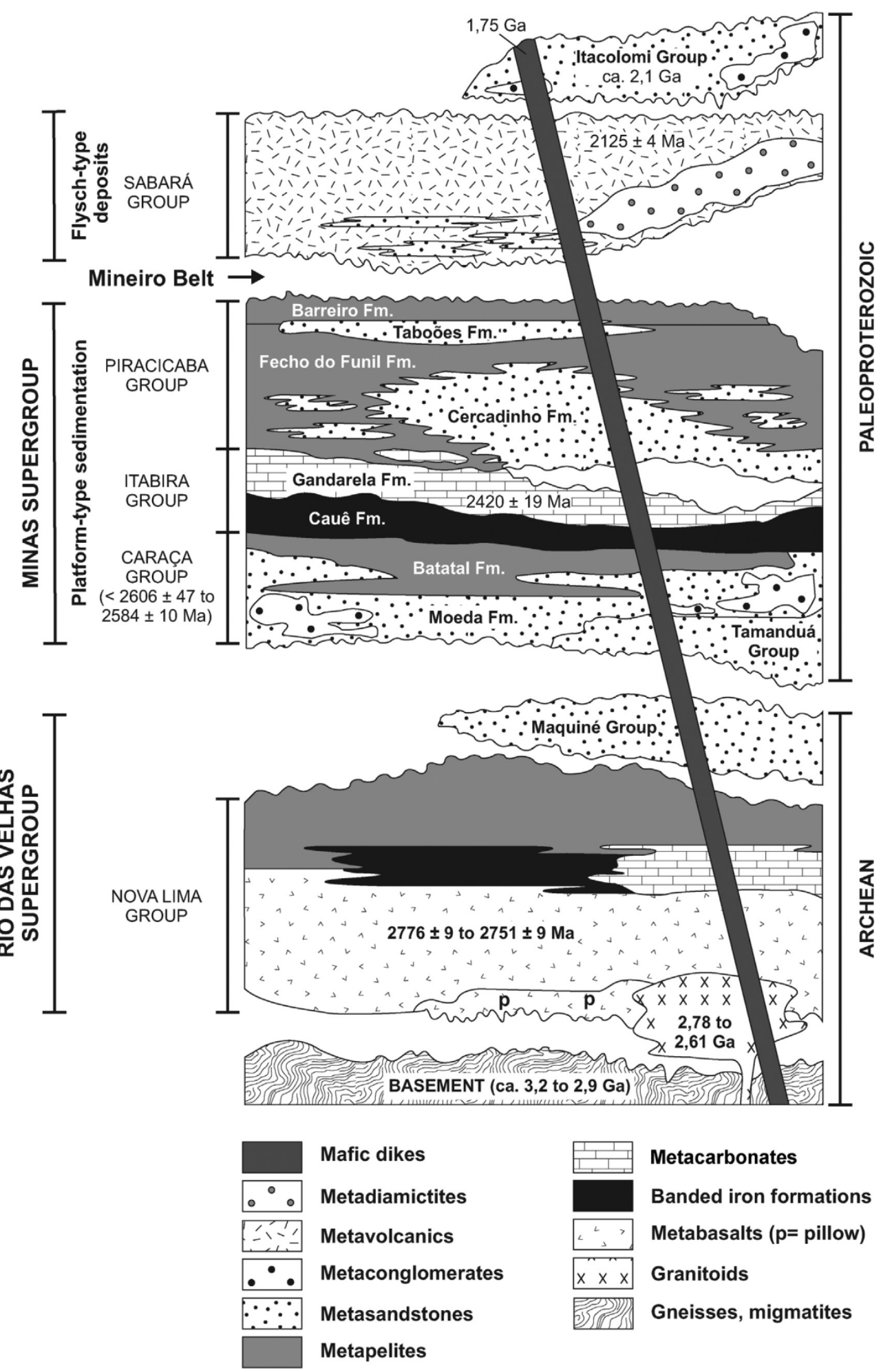

Figura 3. Coluna estratigráfica do Supergrupo Minas e Rio das Velhas na região do Quadrilátero Ferrífero (Alkmim e Noce, 2006 in: Ávila et al., 2014).

O Supergrupo Minas apresenta idade máxima de deposição em estudos de proveniência U-Pb em zircão de $2580 \pm 7$ Ma (Grupo Caraça) (Machado et al., 1996; Hartmann et al., 2006), enquanto que a idade dos grãos mais jovens é de $2125 \pm 4 \mathrm{Ma}$ obtida em grauvacas do Grupo Sabará (Machado et al., 1992). Por outro lado, recente 
datação em rochas metassedimentares nas imediações de Bom Sucesso, correlacionáveis ao Supergrupo Minas (Neri et al., 2013) forneceu uma idade U-Pb em zircões detríticos de $2603 \pm 7 \mathrm{Ma}$, através do qual se pode inferir a idade máxima de deposição para a sequência local. Por outro lado, Babinski et al. (1995) reportou idade ${ }^{207} \mathrm{~Pb} /{ }^{206} \mathrm{~Pb}$ em um dolomito da Formação Gandarela de $2420 \pm 19$ Ma, indicando a idade de deposição

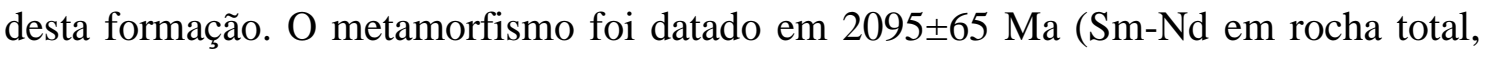
granadas e feldspatos) através de auréolas de metamorfismo desenvolvidas em metapelitos do grupo Sabará. As unidades desse Supergrupo são intrudidas por diques máficos datados em 1,75 Ga, a exemplo do gabro de Ibirité datado pelo método U/Pb em badeleíta (Silva et al., 1995).

Grandes descontinuidades tectônicas (Lineamento Jeceaba-Bom Sucesso e Congonhas-Itaverava) separam o CM (Paleoproterozoico) do embasamento arqueano ao norte. Em uma perspectiva tecto-estratigráfica o Supergrupo Minas se encaixa no lineamento Jaceaba-Bom Sucesso, o qual separa as duas unidades geocronológicas, contudo observações de campo indicam que em muitas áreas o lineamento não representa a divisão geográfica das unidades (Noce et al., 2007). O lineamento JeceabaBom Sucesso (Campos, 2004; Campos e Carneiro, 2008) estende-se desde a extremidade sul da Serra da Moeda (Quadrilátero Ferrífero) até a cidade de Lavras, marcado por exposições descontínuas e deformadas do Supergrupo Minas. Possui direção NE-SW concordante com as principais estruturas das rochas no CM. Outro lineamento regional, Congonhas-Itaverava, (Correa Neto et al., 2012) apresenta direção geral NW-SE e baliza as rochas da porção nordeste do CM (e.g., Batólito Alto Maranhão e a sequência supracrustal Congonhas Itaverava) e as rochas arqueanas (e.g., Seixas et al., 2012; Teixeira et al., 2015). Esses lineamentos regionais podem representar a sutura resultante da evolução tectono-magmática do CM que, com características de regime acrescionário, foi denominada de orogenia Minas (Teixeira et al., 2015).

\subsection{Orogenia Minas}

Os arcos acrescionários, originados através de subducções sucessivas da litosfera oceânica em margens continentais e oceânicas, geram espessamento do antepaís adjacente (e.g., Brito Neves, 2011). Os modelos tectônicos mais recentes, na borda sul 
do CSF, admitem que vários arcos magmáticos acrescionários desenvolveram-se durante o Paleoproterozoico (Noce et al., 2007; Heilbron et al., 2010; Ávila et al., 2010, 2014; Seixas et at., 2012, 2013; Teixeira et al., 2015). Neste período foram formados os complexos Mantiqueira, Juiz de Fora e Mineiro (Figura 4) (idades U/Pb entre 2,36 e $1,97 \mathrm{Ga})$. O desenvolvimento de arcos oceânicos e continentais culminou com a colagem no antepaís e posterior espessamento. Tais processos coletivos representam a orogenia acrescionária Minas (2,36-2,00 Ga) (Teixeira et al., 2015). A figura 4 ilustra o domínio acrescionário a crosta arqueana, envolvendo os arcos Juiz de Fora, Mantiqueira e Mineiro, respectivamente, de sudeste em direção ao noroeste.

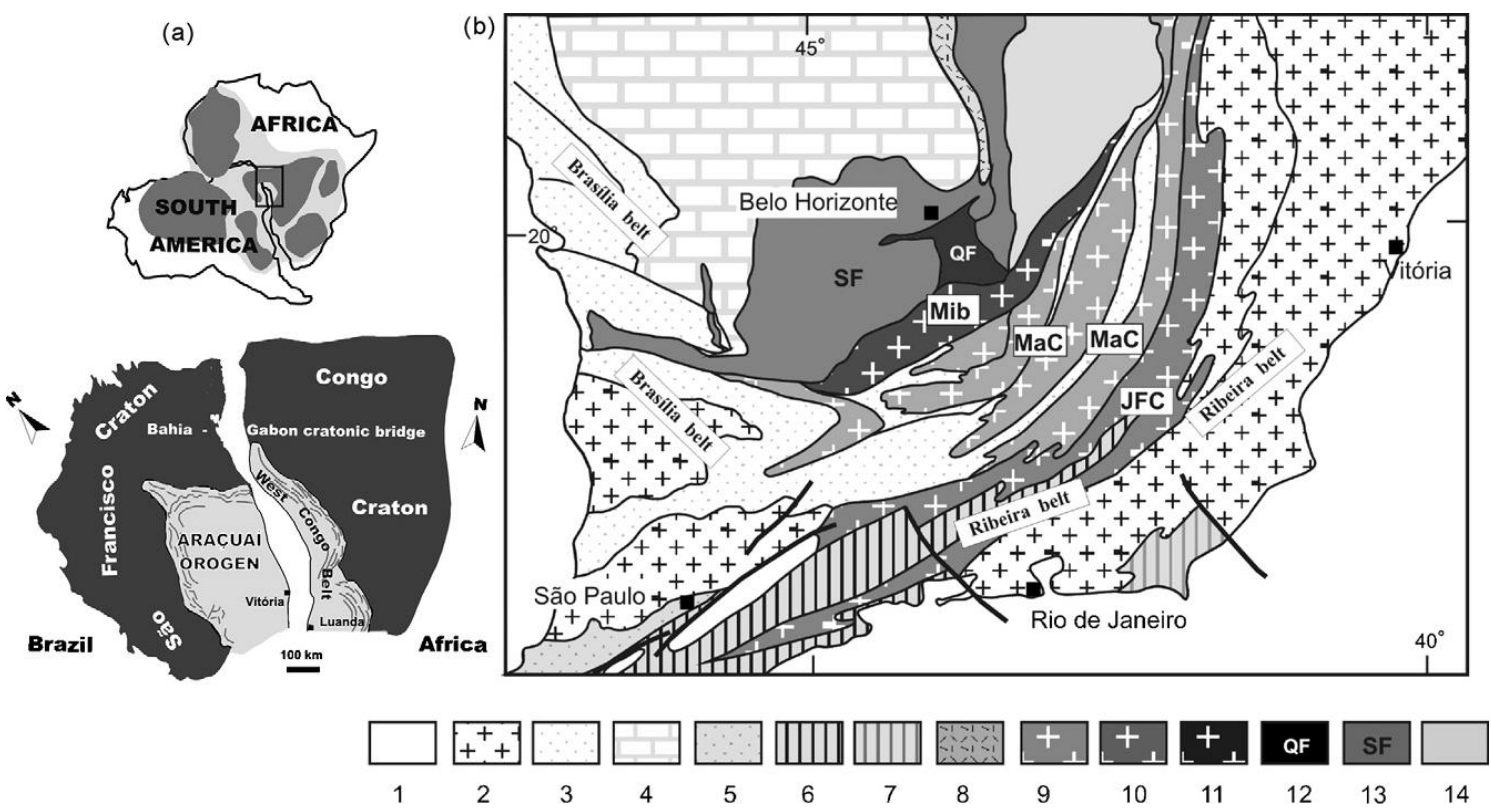

Figura 4. (a) Localização dos Cráton São Francisco e Oeste Congo e o Orógeno Araçuaí-Oeste Congo (Alkmim et al., 2006; Noce et al., 2007); (b) Mapa tectônico mostrando a distribuição do embasamento Paleoproterozoico e no Cráton do São Francisco e suas imediações (Heilbron et al., 2008; Valeriano et al., 2004; Noce et al., 2007). Legenda: (1) Sedimentos fanerozoicos; (2) Faixa Brasília, Ribeira e Araçuaí; (3) Sequências neoproterozoicas de margem passiva; (4) Grupo Bambuí; (5) Terreno Apiaí; (6) Terrenos Embú e Paraíba do Sul; (7) Terreno Cabo Frio; (8) Sequências Mesoproterozoica do Espinhaço; (9) Complexo Mantiqueira e rochas relacionadas; (10) Complexo Juiz de Fora e sequências Neoproterozoicas; (11) Cinturão Mineiro; (12) Supergrupo Minas e o Supergrupo Rio das Velhas; (13) Complexos Arqueanos; (14) Terreno Guanhães.

Segundo Noce et al. (2007), o complexo Mantiqueira possui origem crustal relacionado à margem continental ativa e sin-colisional, enquanto que o complexo Juiz de Fora evoluiu em um ambiente de arco oceânico. Baseado em correlações geológicas e tectônicas os autores apontaram que o complexo Mantiqueira e o Supergrupo Kimezinan (Oeste Congo) estariam relacionados às orogenias ao longo da margem continental ativa do Proto-Cráton do São Francisco Oeste Congo, como resultado de uma convergência continua de massas continentais arqueanas (Figura 4). Segundo 
Heilbron et al. (2010) o complexo Mantiqueira representa um arco continental que afetou significativamente o paleo-Cráton do São Francisco, em oposição ao Juiz de Fora (arco intra-oceânico) que durante sua acreção ao continente deformou e metamorfisou o complexo Mantiqueira. Tais arcos colidiram contra a margem do protocontinente São Francisco, entre 2,10 e 1,97 Ga.

O Cinturão Mantiqueira, situado a leste do CM, é representado predominantemente por rochas gnáissicas. Trata-se de tonalitos, granodioritos, granitos, orto- e paragnaisses, granulitos e kinzigitos que coletivamente são chamados de Complexo Mantiqueira (Teixeira e Figueiredo, 1991). Rochas intrusivas de natureza alcalina também são características deste domínio, a exemplo do sienito Matola $(2,15$ Ga). Geoquimicamente os gnaisses bandados são cálcio-alcalinos com afinidade de ambiente de arco continental. As idades $\mathrm{U} / \mathrm{Pb}$ em zircão variam de 2,18 a 2,05 Ga e $\mathrm{T}_{\mathrm{DMs}}(\mathrm{Nd})$ variam de 2,9 a 3,2 Ga, denotando protólitos arqueanos em escala regional. Com efeito, os valores de $\varepsilon_{\mathrm{Nd}(2,0 \mathrm{Ga})}(-9$ a -13$)$ evidenciam uma evolução policíclica e seus protólitos são gerados por fusão parcial de crosta pretérita e retrabalhamento crustal (Noce et al., 2007). De fato, vários dos diagramas concórdia possuem dados que apontam um retrabalhamento no Neoproterozoico, compatível com a evolução das faixas marginais.

O Cinturão Juiz de Fora, distal ao CM (Figura 4), é contituído por ortognaisses de composição enderbítica, charno-enderbítica e básicas de afinidade cálcio-alcalina (Heilbron et al., 2010 e referências internas). Representa rochas de natureza juvenil provavelmente desenvolvido em um ambiente oceânico metamorfisadas na fácies granulito por conta de seu envolvimento no ciclo Brasiliano (aglutinação gondwânica), que também gerou imbricações e zonas de cisalhamento regionais tanto neste complexo como no Mantiqueira. As idades U/Pb variam de 2,20 a 1,97 Ga, enquanto as idades $\mathrm{T}_{\mathrm{DMs}}(\mathrm{Nd})$ são de 2,3 a 2,6 Ga. Os valores de $\varepsilon_{\mathrm{Nd}(\mathrm{t})}$ variam de 0 a -3,5. Este último valor aliado à idade modelo de 2,6 Ga indica mistura de fontes juvenis e contribuição de componente arqueano (Heilbron et al., 2010). A Figura 5 ilustra o domínio originalmente envolvido na orogenia acrescionária Minas, mostrando a interação entre o CM, Mantiqueira e Juiz de Fora. Ao norte do CM estão expostos os complexos basais arqueanos e rochas da supraestrutura (Supergrupo Rio das Velhas e Minas). 


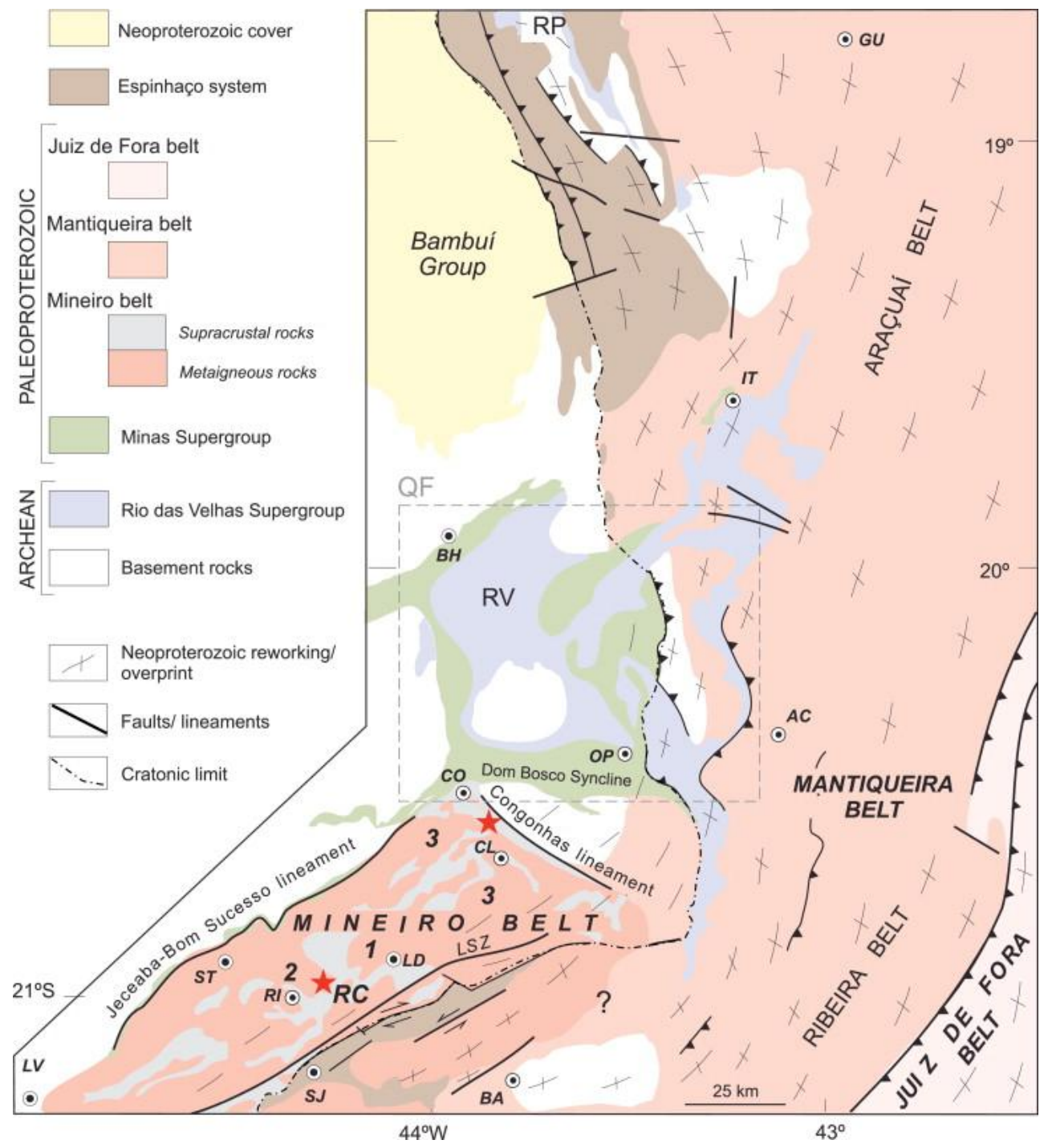

Figura 5. Esboço geológico-tectônico do paleocontinente São Francisco, mostrando rochas arqueanas do Cráton e os cinturões Mineiro, Mantiqueira e Juiz de Fora. LSZ: Zona de cisalhamento Lenheiros; RV: Supergrupo Rio das Velhas; QF = Quadrilátero Ferrífero; RC: Ortognaisse Resende Costa e rochas coevas; (1): Suíte Lagoa Dourada; (2) Batólito Ritápolis; (3) Batólito Alto do Maranhão. Cidades: ST (São Tiago), LD (Lagoa Dourada), SJ (São João del Rei), BA (Barbacena),CO (Congonhas), OP (Ouro Preto), BH (Belo Horizonte), RI (Ritápolis), LV (Lavras), AC (Acaiaca), IT (Itabira) (Teixeira et al., 2015).

O CM envolve rochas granitoides e sequências supracrustais intercaladas por duas unidades cronológicas distintas (rochas do embasamento arqueano e da faixa neoproterozoica Ribeira). É importante destacar que durante o desenvolvimento das faixas Neoproterozoicas adjacentes (Ribeira e Araçuaí) ao Cráton do São Francisco, os complexos Juiz de Fora e Mantiqueira foram fortemente retrabalhados, levando ao encurtamento crustal e ao metamorfismo que atingiu, em setores, a fácie granulito (Noce et al., 2007; Campos Neto et al., 2011). Enquanto que o CM registra esta 
deformação de forma sutil em idades de intercepto inferior em diagramas Concórdia. O CM será apresentado na seção seguinte em função do escopo desta Tese.

\subsection{Cinturão Mineiro}

O CM é um excelente laboratório para o estudo de terrenos paleoproterozoicos, uma vez que suas rochas (infra e supraestrutura) registram ampla abrangência temporal $(2,46-2,09 \mathrm{Ga})$. Estas rochas são representadas predominantemente por ortognaisses e sequências metavulcanossedimentares, intrudidos por granitoides conforme ilustrado na figura 6 (Ávila et al., 2010). O metamorfismo regional das diferentes unidades litoestratigráficas do cinturão é compatível com as fácies anfibolito à xisto verde (Toledo, 2002; Cherman, 2004; Ávila et al., 2010).

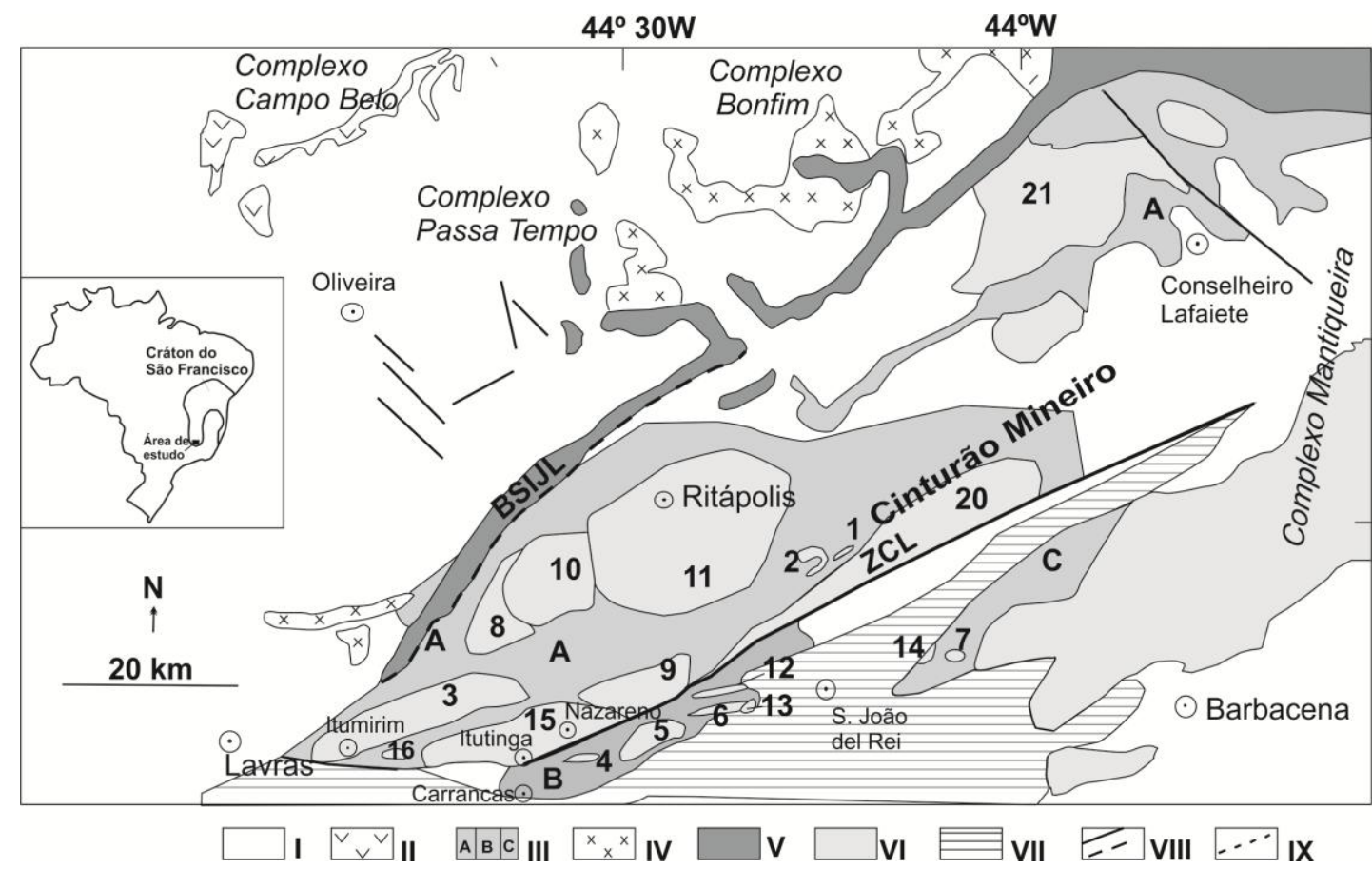

Figura 6. Quadro geológico da região meridional do Cráton do São Francisco (adaptado de Ávila et al., 2003 in: Ávila et al., 2010) mostrando os complexos basais (Campo Belo, Bonfim e Passa Tempo), em contraposição ao cinturão Mineiro (CM) exposto na parte meridional. I - Crosta Arqueana parcialmente retrabalhada durante o Paleoproterozoico. II - Greenstone Belt e sequências metavulcanossedimentares Paleoproterozoico: (A) Rio das Mortes, (B) Nazareno e (C) Dores de Campos. III- Granitoides Arqueanos. IV - Supergrupo Minas (Arqueano/Paleoproterozoico). V - Corpos plutônicos félsicos e máficos paleoproterozoicos. VI - Sequências supracrustais (Paleoproterozoico - Neoproterozoico). VII Estrutura tectônica. VIII - limite tentativo do CM. Corpos plutônicos paleoproterozoicos (CM): 1 Quartzo-monzodiorito Glória; 2 - Diorito Brumado; 3 - Diorito Rio Grande; 4 - Gabro Rio Grande; 5 Gabro São Sebastião da Vitória/ Granodiorito do Lajedo; 6 - Quartzo-diorito Brito; 7 - Gabro Vitoriano Veloso; 8 - Diorito Ibitutinga; 9 - Tonalito/trondhjemito Cassiterita; 10 - Trondhjemito Tabuões; 11 Granitoide Ritápolis; 12 - Granodiorito Brumado de Baixo; 13 - Granodiorito e corpos granofíricos 
Brumado de Cima; 14 - Granitoide Tiradentes; 15 - Granito Nazareno; 16 - Ortognaisse e granito Itumirim; 17 - Tonalito Congonhas; 18 - Granito-gnáisse Fé; 19 - Tonalito Alto Maranhão. QF Quadrilátero Ferrífero. BSJL Lineamento - Bom Sucesso - Jeceaba. LSZ - Zona de cisalhamento Lenheiro.

Três eventos metamórficos são registrados no $\mathrm{CM}$ (Tabela 1). $\mathrm{O}$ primeiro metamorfismo de idade U/Pb em zircão $2192 \pm 6$ Ma datado em anfibolitos ocorre entre Lavras e São João Del Rei e alcançou o metamorfismo fácies anfibolito (Cherman, 1999; Toledo, 2002; Ávila et al., 2010). O segundo afetou os greenstone belts, os metapiroxenitos e os granitoides com idade entre $2160-2100\left({ }^{207} \mathrm{~Pb} /{ }^{206} \mathrm{~Pb}\right.$ evaporação em zircão), também entre a região de Lavras e São João Del Rei nas fácies anfibolito baixo a xisto verde (Ávila et al., 2008). O terceiro episódio metamórfico é registrado próximo a cidade de São Tiago com idades U/Pb de $2050 \pm 12$ Ma (Silva et al., 2002) e em titanita (anfibolito; $2059 \pm 6$ Ma; Machado et al., 1992) este episódio alcançou a fácie anfibolito.

Cherman (1999) identificou dois eventos metamórficos: um progressivo e outro retrogrado (em metaultramafitos e metakomatiito: com as seguintes transformações mineralógicas: lizardita/crisotila $<200^{\circ} \mathrm{C}$, passando para antigorita $\sim 300^{\circ} \mathrm{C}$, chegando a talco magnesita $\sim 500^{\circ} \mathrm{C}$ ). Essas condições de metamorfismo podem ter alcançado pressões da ordem de $5 \mathrm{Kbar}$, e é nas rochas máficas que se encontra o registro do estágio mais avançado desse metamorfismo. O metamorfismo progressivo segundo a mineralogia pode ter alcançado temperaturas aproximadas de $500^{\circ} \mathrm{C}$ (transição das fácies xisto verde e anfibolito a fácies anfibolito de grau muito baixo), e pressão semelhante à anterior 5 Kbar. O metamorfismo retrógrado estabilizou-se em temperaturas de $\leq 500^{\circ} \mathrm{C}$ e $450-400^{\circ} \mathrm{C}$ e pressões máximas semelhantes àquelas assumidas durante o primeiro metamorfismo (Cherman, 1999).

As deformações no CM apresentam três fases principais: a primeira fase (D1) é observada em xenólitos de rochas máficas em que há xistosidade (Toledo, 2002; Cherman, 2004); a fase seguinte (D2) é caracterizada por zonas de cisalhamento e dobras verticais a reclinadas. D2 é a foliação principal NE-SW que representa a estruturação regional e a foliação do conjunto de rochas e zonas de cisalhamento principais, apresenta mergulho subvertical. A última (D3) é constituída por zonas de cisalhamentos e falhas associadas com orientação NW-SE (Ribeiro et al., 1998). 
A Tabela 1 sintetiza as características litológicas, isotópicas e tectônicas das unidades regionais do $\mathrm{CM}$, que foram interpretadas como representantes de arcos magmáticos que construíram o $\mathrm{CM}$.

Tabela 1. Características geológicas e tectônicas do CM (1. Teixeira et al., 2015; 2. Ávila et al., 2014; 3. 2010; 4.Seixas et al., 2012; 5. Seixas et al., 2013; 6. Noce et al., 2000; 7. Barbosa et al., submetido).

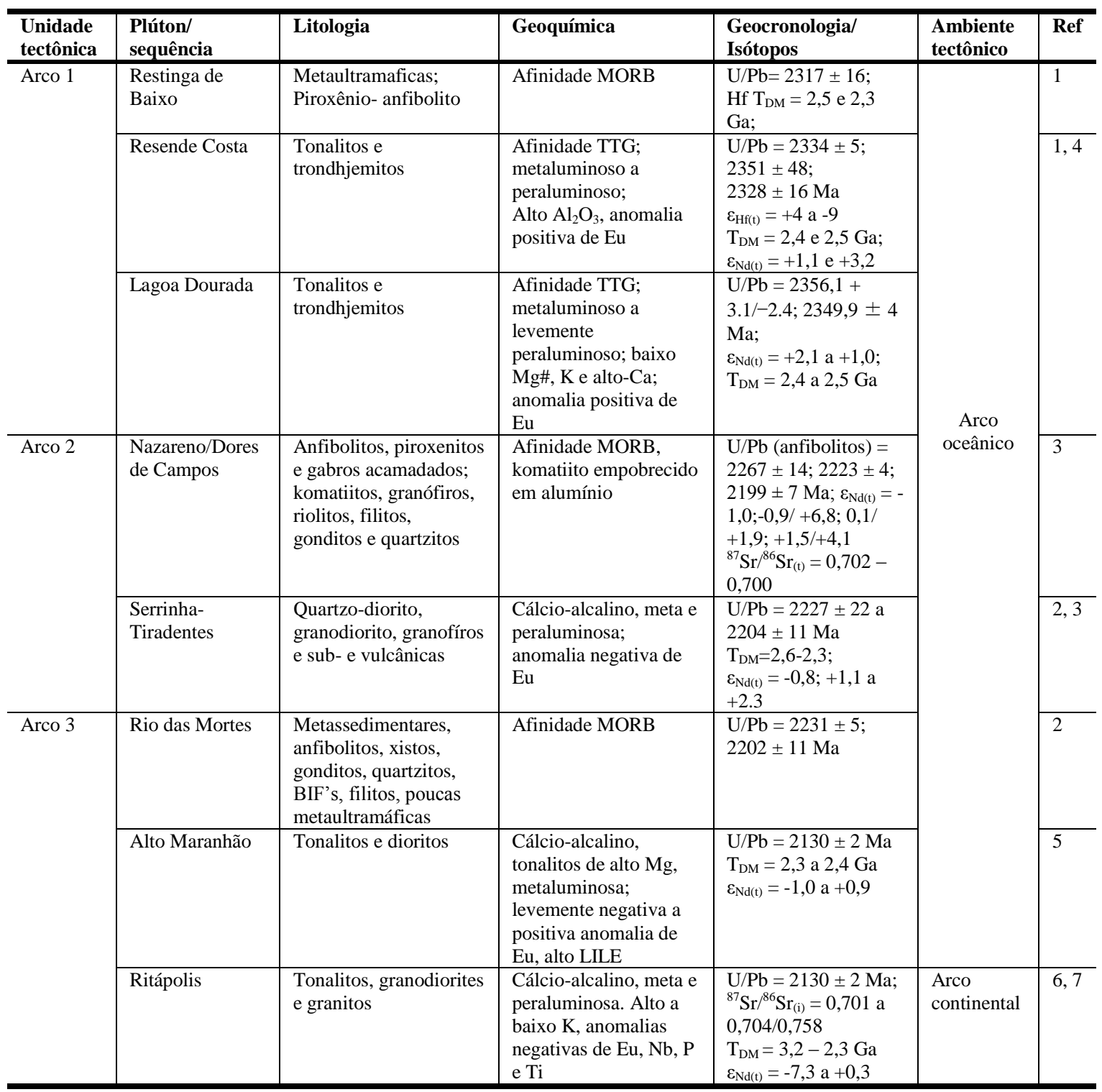

As colagens dos diferentes arcos magmáticos acrescionários paleoproterozoicos, representadas por zonas de cisalhamento regionais (e.g., Lenheiro: 2,1 - 2,0 Ga), compartimentam as unidades geológicas do CM, como por exemplo, as associações metavulcanossedimentares paleoproterozoicas (Rio das Mortes; Nazareno; Dores de Campos; ca. 2,2 Ga; Ávila et al., 2010). Essas sequências, que mostram peculiaridades 
distintas, se alongam na direção NE-SW (trend do CM) e podem ser cortadas ou domeadas por plútons que ocorrem em uma ampla região entre as cidades de Lavras, Ritápolis e Conselheiro Lafaiete. Os resultados isotópicos publicados apontam que estes corpos plutônicos (e.g., Glória, Ritápolis, Brumado, Fé, Lagedo, entre outros; Figura 6) guardam características isotópicas mistas (juvenis e crustais), em função da localização ao norte ou ao sul da zona de cisalhamento Lenheiro (e.g., Teixeira et al., 2008, 2015; Ávila et al., 2010, 2014), muito embora representem eventos particulares de crescimento crustal entre 2,3 e 2,1 Ga - como produto da evolução de arcos distintos no tempo e no espaço (e.g., Teixeira et al., 2015). Contudo, vale notar que o embasamento paleoproterozoico ocorre localmente no interior das unidades supracrustais a exemplo dos ortognaisses Resende Costa e Lagoa Dourada (Seixas et al., 2013; Teixeira et al., 2015; Figura 6).

No compartimento norte da zona de cisalhamento Lenheiro, a faixa metavulcanossedimentar Rio das Mortes contem essencialmente rochas de origem sedimentar e magmatismo máfico subordinado, em contraste com a faixa Nazareno no compartimento sul, onde o magmatismo máfico-ultramáfico (inclusive komatítico) é exuberante.

A sequência metavulcanossedimentar Rio das Mortes está localizada entre a zona de cisalhamento Lenheiro (a sul), e a norte o limite tectônico Bom Sucesso Jaceaba. Trata-se de rochas anfibolíticas e metassedimentares (filitos, gonditos e quartzito), e em menor quantidade rochas metaultramáficas (Ávila, 2000; Toledo, 2002). A assinatura isotópica dos anfibolitos $\varepsilon_{\mathrm{Nd}(2,2 \mathrm{Ga})}$ denota afinidade juvenil $(+0,1 \mathrm{e}-$ 1,5 ), enquanto as respectivas idades U/Pb estão entre $2231 \pm 5$ e $2202 \pm 11 \mathrm{Ma}$ (Ávila et al., 2012). Vários corpos metagranitoides em escala regional são intrusivos na sequência Rio das Mortes a exemplo do batólito Ritápolis $\left({ }^{207} \mathrm{~Pb} /{ }^{206} \mathrm{~Pb}=2121 \pm 7 \mathrm{Ma}\right.$; U/Pb $=$ $2149 \pm 10 \mathrm{Ma})$ e o plúton Fé $(\mathrm{U} / \mathrm{Pb}=2191 \pm 9 \mathrm{Ma})$ (Teixeira et al., 2008, 2014; Ávila et al., 2010). Estas idades definem um limite temporal mínimo para a unidade supracrustal.

A sequência metavulcanossedimentar (Nazareno) localizada a sul da zona de cisalhamento do Lenheiro é considerada do tipo greenstone belt por possuir principalmente rochas máficas e ultramáficas, além de metakomatiitos com textura spnifex na base da sequência. Esta unidade compreende também serpentinito, talcoclorita xistos, anfibolitos, filitos subordinados, quartzitos e gonditos (Toledo, 2002; Ávila et al., 2004, 2010). A assinatura isotópica dos anfibolitos $\varepsilon_{\mathrm{Nd}(2,2 \mathrm{Ga})}=+6,8$; 
${ }^{87} \mathrm{Sr} /{ }^{86} \mathrm{Sr}_{\mathrm{i}}=0,702$ e idade de cristalização U/Pb é de $2267 \pm 14$ a $2223 \pm 4$ Ma (Ávila et al., 2010, 2012). As informações geológicas e acervo geocronológico (U-Pb) disponível indicam que o greentone belt Nazareno é cortado pelo Granitoide Lajedo (2208 \pm 26 Ma) e pelas Suítes Tiradentes $(2217 \pm 23 \mathrm{Ma}, 2213 \pm 9$ Ma e $2204 \pm 11 \mathrm{Ma}-$ Ávila et al., 2014) e Serrinha (2227 \pm 22 Ma e $2211 \pm 22$ Ma - Ávila et al., 2010).

A sequência metavulcanossedimentar Dores de Campos, localizada na porção nordeste do CM, também ao sul da zona de cisalhamento do Lenheiro, é constituída principalmente por rochas toleíticas, composta por anfibolitos, e em menor quantidade rochas metaultramáficas, filitos, gonditos e quartzitos. Um anfibolito desta unidade apresentou idade de cristalização de $2255 \pm 51 \mathrm{Ma}$ (Ávila et al., 2014). As idades U-Pb em zircão do diorito intrusivo Dores de Campos é de $2199 \pm 7$ Ma (Ávila et al., 2006) e do granito intrusivo Gentio $2124 \pm 37 \mathrm{Ma}$ (Silva, 2013).

\section{Rochas plutônicas do CM}

De modo similar às sequências supracrustais, as rochas plutônicas representam o desenvolvimento dos sucessivos arcos continentais e oceânicos, como evidenciado por idades U-Pb em zircão, $\mathrm{Pb}-\mathrm{Pb}$ evaporação em zircão e isótopos de $\mathrm{Nd}-\mathrm{Sr}$. A seguir será destacado os plútons considerados mais representativos para a edificação do CM, sendo que os plúton da porção sudoeste será apresentado no Capítulo IV.

A suíte Lagoa Dourada situada a norte da falha do Lenheiros e sudoeste da sequência Rio das Mortes, compreende o primeiro registro de idade sideriana (2349 \pm 4 Ma - Seixas et al., 2012) no CM. A suíte compreende metatonalitos, de caráter cálcioalcalino, são metaluminosas a levemente peraluminosas de baixo $\mathrm{K}$, interpretadas como derivadas da fusão de uma crosta máfica, em ambiente intra-oceânico (Seixas et al., 2012). De modo similar à suíte Lagoa Dourada, idades entre $2351 \pm 48$ e $2317 \pm 16 \mathrm{Ma}$ foram identificadas na região de Resende Costa, pouco a oeste desta, em ortognaisses tonalíticos e anfibolitos coevos da chamada sequência metavulcânica Restinga de Baixo (Teixeira et al., 2015). Os dados isotópicos $\left(\varepsilon_{\mathrm{Nd}(\mathrm{t})},{ }^{87} \mathrm{Sr}^{86}{ }^{86} \mathrm{Sr}_{(\mathrm{t})}\right)$ e geoquímicos (elementos maiores e menores) (Tabela 1) reportados permitem uma comparação petrogenética com a suíte Lagoa Dourada. Em termos tectônicos esta associação de rochas foi denominada de arco magmático Resende Costa, estando geneticamente associado à parte superior (siliciclástica) da sequência metavulcanossedimentar Congonhas-Itaverava localizada a leste, cuja idade máxima de deposiçao é de 2349 Ma. Nesse sentido, Teixeira et al. 
(2015) interpretaram esta sequência como gerada no ambiente foreland associado à evolução do arco sideriano do CM. Por outro lado, os metabasaltos desta unidade possuem assinatura geoquímica de MORB e corresponderiam ao assoalho oceânico do arco Resende Costa.

As suítes Serrinha e Tiradentes (2,23-2,21 Ga) estão localizadas a sul da zona de cisalhamento Lenheiros. Estas são compostas por rochas tonalíticas a graníticas, metaluminosas a peraluminosas e apresentam assinatura de arco magmático. A Suíte Serrinha possui idade modelo $\mathrm{Sm} / \mathrm{Nd}$ entre 2,6 e $2,3 \mathrm{Ga}$, valores de $\varepsilon_{\mathrm{Nd}(2,2 \mathrm{Ga})}$ de $(-0,8$ a $+1,8)$ e ${ }^{87} \mathrm{Sr}^{86} \mathrm{Sr}_{\mathrm{i}}$ de 0,703 (Ávila et al., 2010). Quanto a Suíte Tiradentes, os valores de $\varepsilon_{\mathrm{Nd}(2,2 \mathrm{Ga})}(+1,1 \mathrm{a}+2,3)$; as razões iniciais ${ }^{87} \mathrm{Sr} /{ }^{86} \mathrm{Sr}(0,702$ a 0,703$)$ associados à idade $\mathrm{T}_{\mathrm{DM}}(2,4$ a 2,3 Ga) (Tabela 1) indicam que as duas suítes são provenientes de fontes juvenis com curta vivência crustal (Ávila et al., 2014). Pela semelhança dos dados geológicos referentes às Suítes Serrinha e Tiradentes, podemos considerar que fazem parte do mesmo arco magmático. Ávila et al. (2014) interpreta a evolução das sequências metavulcanossedimentares iniciando em um largo oceano Paleoproterozoico, desenvolvido na margem do antepaís arqueano (Figura 7). Entre 2,23-2,21 Ga um arco intra-oceânico gera as rochas plutônicas e vulcânicas da suíte Serrinha-Tiradentes (Figuras 7a,b). Em sequência rochas mais jovens são formadas (i.e., batólito Ritápolis) e a colisão continental ocorreu entre 2137 e 2041 Ma (Figura 7a).

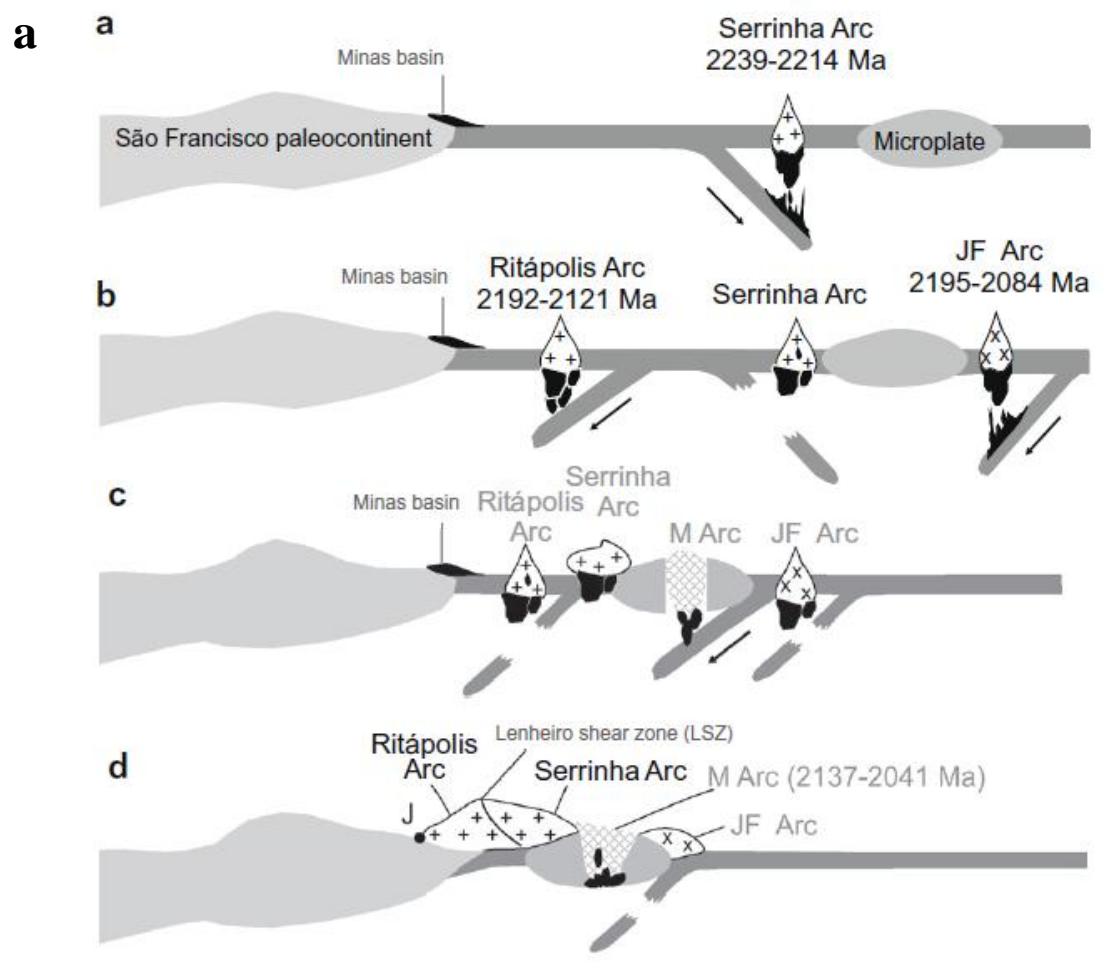



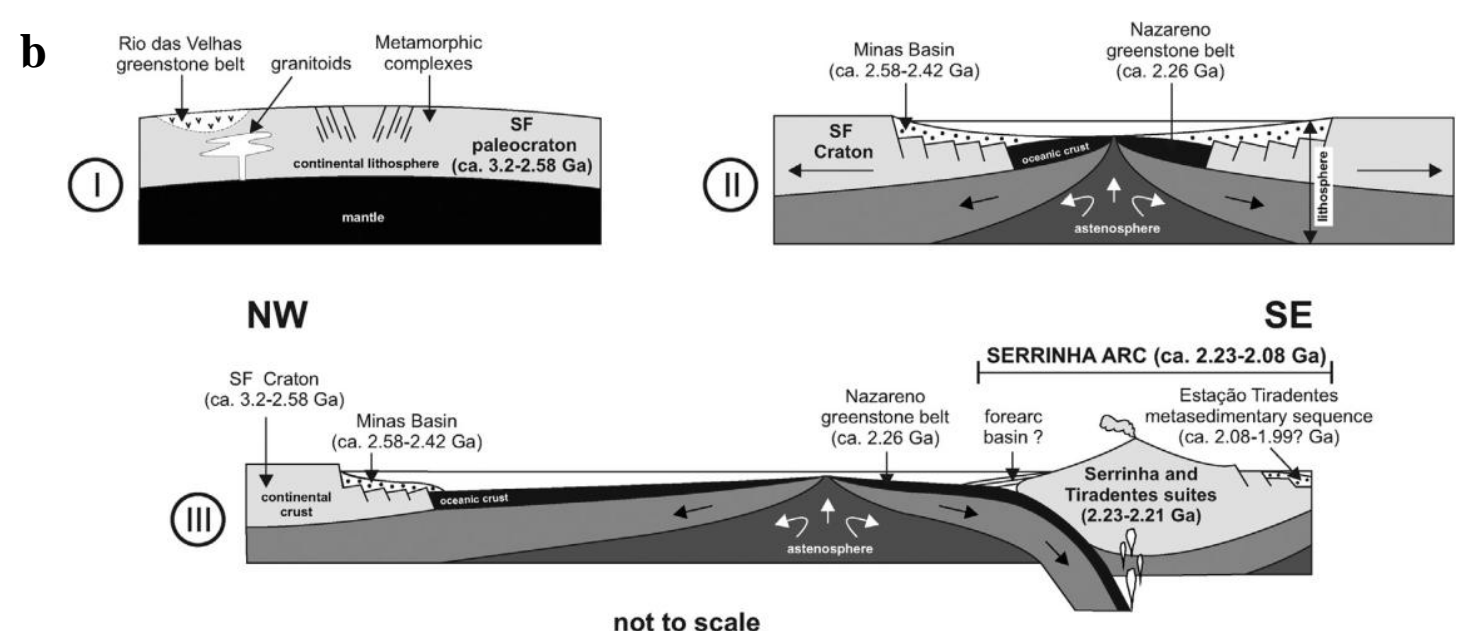

Figura 7. (a, b) Modelo evolutivo simplificado (Arqueano-Paleoproterozoico) para o arco SerrinhaTiradentes (Ávila et al., 2010; 2014).

O batólito Ritápolis aflora a norte da zona de cisalhamento Lenheiros, contém vários tipos de xenólitos (anfibolitos, dioritos e gabros). A idade ${ }^{207} \mathrm{~Pb} /{ }^{206} \mathrm{~Pb}$ é de $2121 \pm$ 7 Ma (Ávila, 2000), é mínima para a cristalização do corpo, uma vez que pelo método $\mathrm{U}-\mathrm{Pb}$ (LA-ICPMS) em zircão forneceu idade U/Pb de $2149 \pm 10$ Ma. As idades $\mathrm{Sm}-\mathrm{Nd}$ $\mathrm{T}_{\mathrm{DM}}$ variam entre 3,6 e 3,1 Ga e os valores de $\varepsilon_{\mathrm{Nd}(\mathrm{t})}$ entre -4,9 e -7,7 (Noce et al., 2000; Teixeira et al., 2014). Estes dados sugerem que os protólitos arqueanos participaram na gênese deste batólito (Noce et al., 2000; Teixeira et al., 2014). Os dados geoquímicos revelam que as rochas são cálcio-alcalinas, peraluminosas a levemente metaluminosas e de alto a baixo potássio. Este conjunto de dados foi interpretado como derivação de pelo menos dois magmas fontes (Teixeira et al., 2014).

O batólito Alto do Maranhão, localizado a norte da zona de cisalhamento Lenheiro e a nordeste do batólito Ritápolis (2,12 Ga) e da suíte Lagoa Dourada (2,35 $\mathrm{Ga}$ ), é contituído principalmente por metatonalitos com autólitos dioríticos, injetados por granitoides e pegmatitos. Os metatonalitos têm idade de cristalização U/Pb variando entre de $2124 \pm 2 \mathrm{Ma}$ (titanita), $2130 \pm 2$ e $2128 \pm 10 \mathrm{Ma}$ (zircão). Portanto representam o magmatismo mais jovem atualmente reconhecido no CM (Noce, 1995; Seixas et al., 2013). As idades $\mathrm{Sm}-\mathrm{Nd} \mathrm{T}_{\mathrm{DMs}}$ são 2,3 e $2,4 \mathrm{Ga}$ e valor de $\varepsilon_{\mathrm{Nd}(2,1 \mathrm{Ga})}$ variam de $-0,9$ a $+1,3$ (Seixas et al., 2013) e indicam uma origem a partir de uma fonte juvenil de curta vivência crustal. 


\section{CAPÍTULO III}

\section{Estratégia de estudo e métodos de trabalho}

Devido às dimensões da área de estudo (aprox. $1.600 \mathrm{~km}^{2}$ ), esta pesquisa tem enfoque regional subsidiado por um mapeamento geológico (escalas 1:25.000 e 1:50.000), coordenado por docentes da Universidade Federal do Rio de Janeiro, com participação de alunos de graduação e pós-graduação. A oportunidade de estudo decorre da cooperação científica entre o orientador desta tese e os professores Drs. Ciro A Ávila e Everton Bongiolo daquela instituição, sob os auspícios da FAPESP e CNPq. Para alcançar os objetivos propostos anunciados no capítulo $\mathrm{I}$, foi necessário $\mathrm{o}$ desenvolvimento de uma abordagem que envolvesse o tratamento e a integração de diferentes dados (e.g., cartográficos, petrográficos, litogeoquímicos, isotópicos e geocronológicos).

Geólogos que estudam rochas deformadas são confrontados com o produto final de uma complexa história evolutiva, pois comumente as evidências que indiciem a sequência de processos ocorridos durante a evolução de um segmento crustal são de difíceis interpretações. Por esta razão, a integração da geocronologia com outras linhas de pesquisa ilustra a aplicabilidade dessas ferramentas para a descoberta de fontes e processos.

A estratégia desta Tese é apresentar e discutir de modo integrado os dados litogeoquímicos (elementos maiores e menores), geocronológicos U-Pb (SHRIMP Sensitive High Resolution Ion Microprobe e LA-ICPMS Laser Ablation Inductively Coupled Plasma Mass Spectrometry) e isotópicos (Nd, Sr e Hf) dos corpos plutônicos (félsicos) no sudoeste do CM com ênfase na interpretação da evolução crustal do CM. Estas interpretações serão suportadas pelo mapeamento em curso na região e dados prévios relacionados às rochas estudadas. A base de dados gerada nesta pesquisa está apresentada na Tabela 2, com menção na referência geográfica, ao método utilizado e à unidade geológica. As undidades geológicas estão separadas por batólitos e sequências metavulcanossedimentares que ocupam principalmente a porção sudoeste do CM. São eles, a saber: batólito Macuco de Minas, batólito Represa de Camargos, batólito Cassiterita, batólito Ritápolis, granito Poço da Pedra e Dores de Campos, greenstone belt Nazareno e a sequência metavulcanossedimentar Rio das Mortes. 
Tabela 2. Localização e métodos utilizados das rochas estudadas no CM.

\begin{tabular}{|c|c|c|c|}
\hline Amostra & UTM & Unidade Geológica & Análises \\
\hline NAT-01 & $0526717 / 7654047$ & Macuco de Minas & Nd-Sr-Hf \\
\hline NAT-02 & $0527121 / 7655032$ & Macuco de Minas & U-Pb, Nd-Sr-Hf, geoquímica \\
\hline NAT-04 & $0526970 / 7652156$ & Macuco de Minas & U-Pb, Nd-Sr-Hf, geoquímica \\
\hline NAT-05 & $0526970 / 7652156$ & Macuco de Minas & U-Pb, Nd-Sr-Hf, geoquímica \\
\hline NAT-07 & $0538555 / 7655085$ & Macuco de Minas & U-Pb, Nd-Sr-Hf, geoquímica \\
\hline NAT-09 & $0544754 / 7663247$ & Macuco de Minas & U-Pb, Nd-Sr, geoquímica \\
\hline NAT-12 & $0536040 / 7641954$ & Nazareno & Nd-Sr, geoquímica \\
\hline NAT-13 & $0544655 / 7648001$ & Represa de Camargos & U-Pb, Nd-Sr Hf, geoquímica \\
\hline NAT-14 & $0549156 / 7650826$ & Represa de Camargos & U-Pb, Nd-Sr, geoquímica \\
\hline NAT-15 & $0537654 / 7650850$ & Nazareno & Nd-Sr-Hf, geoquímica \\
\hline NAT-16 & $0545508 / 7664711$ & Macuco de Minas & U-Pb, Nd-Sr-Hf, geoquímica \\
\hline NAT-17 & $0529035 / 7652896$ & Macuco de Minas & U-Pb, Nd-Sr-Hf, geoquímica \\
\hline NAT-18 & $0497565 / 7644617$ & Poço da Pedra & U-Pb, Nd-Sr-Hf, geoquímica \\
\hline NAT-22A & $0543238 / 7668323$ & Rio das Mortes & Nd-Sr-Hf, geoquímica \\
\hline NAT-22B & $0543238 / 7668323$ & Rio das Mortes & Nd-Nd, Sr-Sr, geoquímica \\
\hline NAT-23 & $0544754 / 7663247$ & Macuco de Minas & U-Pb, Nd-Sr-Hf, geoquímica \\
\hline NAT-24 & $0525899 / 7653108$ & Macuco de Minas & U-Pb, Nd-Sr-Hf, geoquímica \\
\hline NAT-25A & $0515829 / 7641996$ & Represa de Camargos & U-Pb, Nd-Sr-Hf, geoquímica \\
\hline NAT-25B & $0515829 / 7641996$ & Represa de Camargos & U-Pb, Nd-Sr-Hf, geoquímica \\
\hline NAT-26 & $0513080 / 7643634$ & Represa de Camargos & U-Pb, Nd-Sr-Hf, geoquímica \\
\hline NAT-27 & $0513080 / 7643634$ & Represa de Camargos & U-Pb, Nd-Sr-Hf, geoquímica \\
\hline NAT-30 & $0512250 / 7647306$ & Rio das Mortes & U-Pb, Nd-Sr-Hf, geoquímica \\
\hline NAT-32 & $0513294 / 7642127$ & Represa de Camargos & U-Pb, Nd-Sr-Hf, geoquímica \\
\hline NAT 33 & $0570695 / 7668550$ & Ritápolis & Nd-Nd, Sr-Sr, geoquímica \\
\hline NAT-34 & $0570474 / 7671238$ & Ritápolis & U-Pb, Nd-Sr-Hf, geoquímica \\
\hline NAT-35 & $0567074 / 7684690$ & Ritápolis & U-Pb, Nd-Sr-Hf, geoquímica \\
\hline NAT-37 & $0601448 / 7660984$ & Dores de Campos & $\mathrm{U}-\mathrm{Pb}, \mathrm{Nd}-\mathrm{Sr}$, geoquímica \\
\hline NAT-38 & $0601668 / 7661148$ & Dores de Campos & $\mathrm{U}-\mathrm{Pb}, \mathrm{Nd}-\mathrm{Sr}$, geoquímica \\
\hline NAT-39 & $0602723 / 7665421$ & Dores de Campos & U-Pb, Nd-Sr, geoquímica \\
\hline FG-42 & $0542911 / 7644796$ & Ritápolis & U-Pb, Nd-Sr-Hf, geoquímica \\
\hline NAT-08 & $0540250 / 7655731$ & Cassiterita & U-Pb, Nd-Sr-Hf, geoquímica \\
\hline FG-35 & $0556806 / 7664969$ & Cassiterita & U-Pb, Nd-Sr-Hf, geoquímica \\
\hline $\mathrm{CS}-03$ & $554255 / 7662896$ & Cassiterita & U-Pb, Nd-Sr-Hf, geoquímica \\
\hline NAT-36 & $0570772 / 7666285$ & Cassiterita & U-Pb, Nd-Sr, geoquímica \\
\hline
\end{tabular}

Várias técnicas foram utilizadas nesta Tese para atender à sua proposta e responder as questões descritas nos objetivos. Para esclarecer a esses questionamentos, foi necessário entender os princípios das técnicas analíticas (isotópicas e geoquímicas), interpretar os dados obtidos, compará-los com os resultados apresentados na literatura e integrar as informações, de modo que fosse possível apresentar um panorama mais completo das características inerentes à área estudada.

A geocronologia determina o tempo decorrido entre a cristalização de um magma ou recristalização de um mineral relacionado a um evento geológico específico e o momento atual, através de métodos de datação. A cronologia de eventos geológicos é baseada numa constante taxa de decaimento de alguns elementos radioativos (e.g., ${ }^{87} \mathrm{Rb}-{ }^{86} \mathrm{Sr},{ }^{147} \mathrm{Sm}-{ }^{143} \mathrm{Nd},{ }^{40} \mathrm{Ar}-{ }^{39} \mathrm{Ar},{ }^{238} \mathrm{U}-{ }^{206} \mathrm{~Pb}$ ), cujas meia-vidas permitem a datação de rochas antigas (e.g., Allègre, 2008). Cada um destes isótopos se comporta de forma 
diferente nas amostras e requerem uma interpretação coerente dos resultados obtidos. Uma ampla variação de estudos/métodos geológicos é aplicada para a compreensão da evolução da crosta continental. Uma delas consiste em datar os eventos modificadores da crosta por métodos robustos, como por exemplo, U-Pb in situ. As análises U-Pb in situ são preponderantes na precisão e reconstrução de eventos geológicos e em estudos relacionados à evolução crustal (Cawood et al., 2009; Condie e Kröner, 2013). Nesta seção destacaremos o potencial interpretativo do método U-Pb combinado aos isótopos de Nd, Sr (rocha total) e Hf (zircão) e geoquímica em rocha total.

\subsection{Geocronologia U-Pb em zircão}

Os métodos geocronológicos são de grande importância para revelar a história temporal das rochas, em especial o método $\mathrm{U}-\mathrm{Pb}$ se torna a ferramenta mais precisa para investigar o registro dos eventos geológicos da Terra. A geocronologia U-Pb em zircão, badaleíta e monazita é usada para determinar a idade de cristalização de rochas ígneas de várias composições. Contudo, rochas de composições félsicas tendem a possuir altas concentrações de $\mathrm{U}, \mathrm{Zr}$, Th e $\mathrm{Pb}$ na crosta em relação ao manto, daí a facilidade de datar estas rochas através do zircão (e.g., Hanchar e Hoskin, 2003). As idades U-Pb em minerais metamórficos (zircão, titanita e monazita) são usados para determinar eventos termais e histórias termocronológicas. Idades $\mathrm{U}-\mathrm{Pb}$ em zircão para sedimentos detríticos indicam à proveniência dos sedimentos e possivelmente a crosta que cedeu sedimentos à bacia (e.g., Dickin, 2005).

A morfologia dos zircões pode indicar a composição do magma, temperatura e taxa de cristalização (e.g., Pupin, 1980). As imagens de catodoluminêscencia (CL) ou Back-scattered electrons (BSE) de seções polidas (Anexo III) registram eventos geológicos sucessivos através da observação das zonas de sobrecrescimento em zircão. Apresentam uma importância particular no estudo das texturas internas dos grãos. A CL possibilita a visualização e interpretação da estrutura interna do cristal e a seleção de sítios específicos de datação de acordo com a finalidade de estudo (e.g., determinação dos protólitos, idade de cristalização e ciclos de crescimento do cristal), ou seja, auxiliam previamente domínios pretendidos para os estudos geológicos.

Muitos granitoides possuem zircões herdados (e.g., em xenocristais), em geral, esses minerais apresentam idades mais antigas. Isso ocorre devido à assimilação de 
fragmentos da rocha hospedeira onde o zircão fica "preservado" da fusão, podendo ser reconhecido através da forma do grão (i.e. núcleos arredondados, sobrecrescimento euedral; Corfu et al., 2003) (Tabela 3). O zircão pode apresentar bordas de sobrecrescimento a partir da recristalização metamórfica da rocha (Hoskin e Schaltegger, 2003), análises nestas bordas indicam as idades mais jovens do grão de zircão, enquanto as idades do núcleo indicam as mais antigas. Zircões metamórficos são arredondados e irregulares (Tabela 3), possuindo estrutura interna homogênea devido à destruição da estrutura magmática pré-existente (e.g., Corfu et al., 2003).

Tabela 3. Propriedades morfológicas do zircão, suas feições correspondentes e interpretações (Silva, 2006).

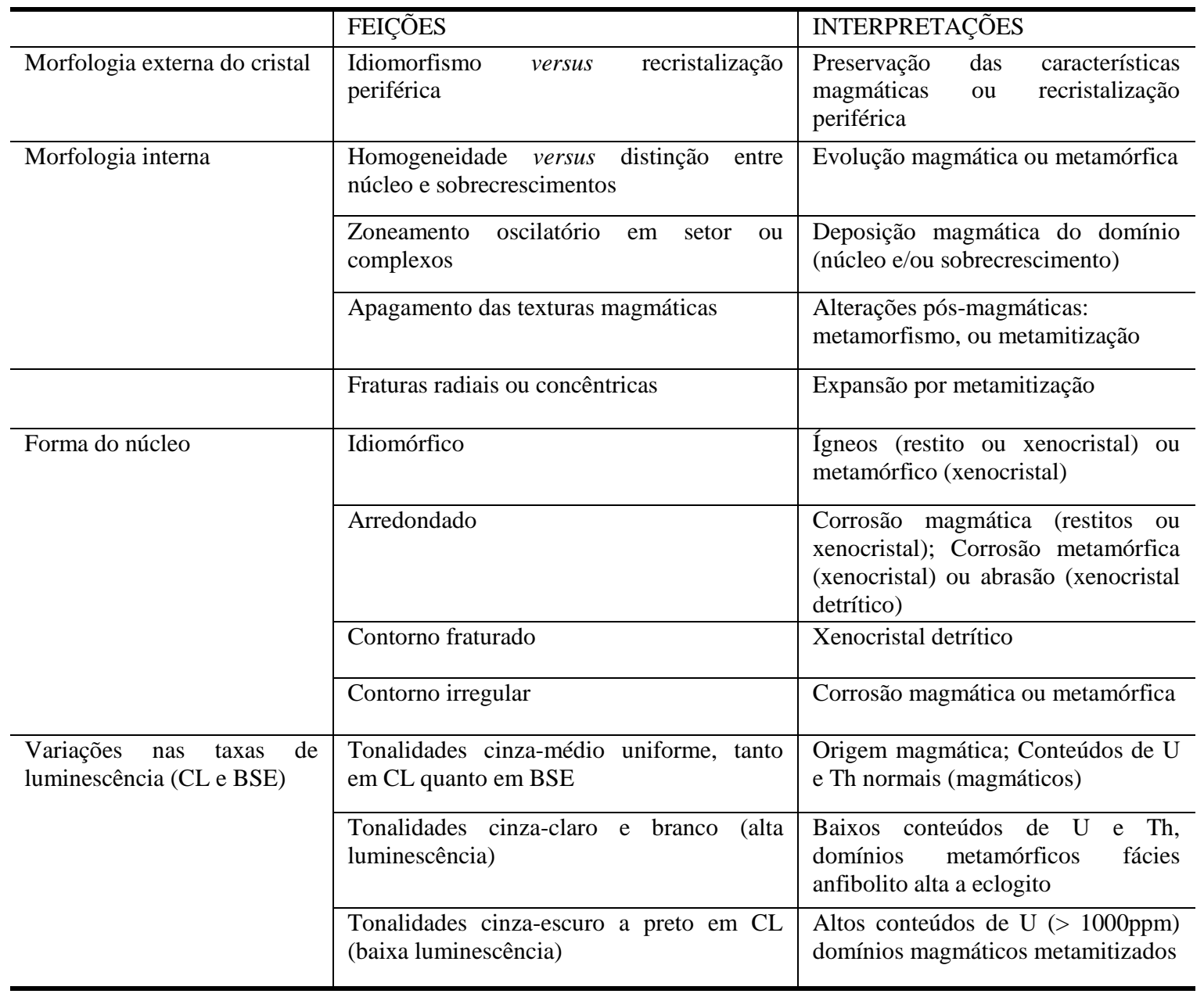

Nas últimas décadas a tendência de se usar análises in situ (LA-ICPMS e SHRIMP) em monocristais de zircão vem ganhando espaço em relação às técnicas de diluição isotópica (ID-TIMS). Análises in situ em porções do zircão revelam informações sobre a cristalização e eventos superpostos na rocha. De tal modo, crescimentos metamórficos ao redor de um núcleo indicam mais de uma fase de 
cristalização associados a diferentes eventos geológicos. As características metamórficas ou ígneas em um cristal de zircão são possíveis de ser reconhecidas através de imagens de catodoluminescência. Outro parâmetro é o valor da razão Th/U. As razões que variam entre 0,2 e 0,8 indicam cristais ígneos (e.g. Gebauer et al., 1997), enquanto que valores inferiores a 0,1 indicam a abertura do sistema isotópico em evento tectônico.

$\mathrm{O}$ advento das análises pontuais tem mostrado grande resolução espacial em escala $\mu \mathrm{m}$, o que possibilita a posição do spot em porções definidas para a datação de rochas produzindo idades mais precisas que as técnicas anteriores. Assim, a cavidade gerada pelo método SHRIMP (Figura 8) geralmente permite que se alcance uma idade mais precisa devido ao volume de amostra extraída pelo bombardeamento de ânions $\mathrm{O}_{2}$. Por outro lado, algumas análises LA-ICPMS gera uma cavidade maior (Figura 8), extraindo diferentes frações do zircão, o que indica maior erro analítico (Patchett e Samson, 2005).

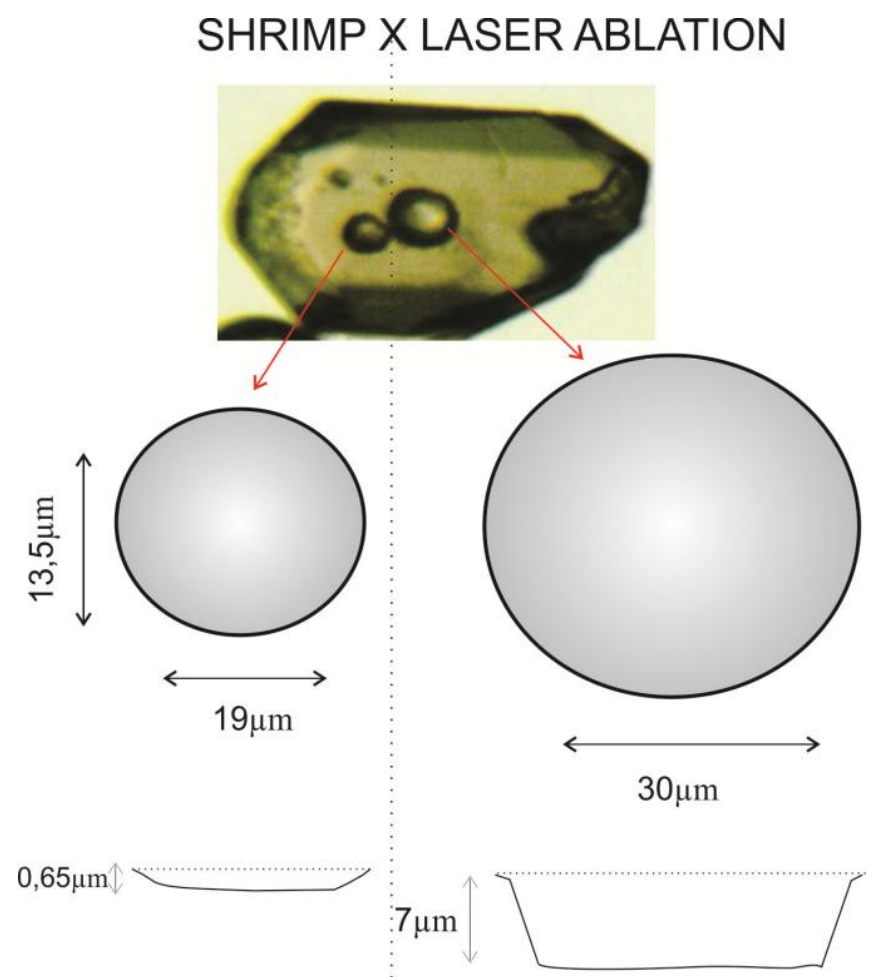

Figura 8. Ilustração comparativa entre as cavidades geradas pelas técnicas SHRIMP e LA-ICPMS (modificado de Patchett e Samson, 2005). SHRIMP: Tamanho do spot depois de 15 minutos. LA-ICPMS: Tamanho do spot depois de um único pulso. 
No zircão, além do estudo da idade de cristalização e metamorfismo, é possível obter a proveniência e idade modelo do magma gerador da rocha através dos isótopos de Hf (descrito na próxima seção). A combinação da idade e proveniência faz do zircão o mineral ideal para o estudo da evolução da crosta continental. Portanto para as análises Lu-Hf, previstas nesta pesquisa, serão selecionados zircões datados pelo SHRIMP face à pequena dimensão dos spots gerados por esta técnica.

O método U-Pb ocorre através do decaimento dos isótopos radioativos ${ }^{235} \mathrm{U}$ e ${ }^{238} \mathrm{U}$ para os respectivos isótopos radiogênicos ${ }^{207} \mathrm{~Pb}$ e ${ }^{206} \mathrm{~Pb}\left({ }^{238} \mathrm{U} \rightarrow{ }^{206} \mathrm{~Pb}=4,47 \mathrm{Ga}\right.$; ${ }^{235} \mathrm{U} \rightarrow{ }^{207} \mathrm{~Pb}=704 \mathrm{Ma}$ ) (Faure, 1986). Em função dos diferentes valores de meia-vida, o decaimento de ${ }^{235} \mathrm{U}$ e ${ }^{238} \mathrm{U}$ para os isótopos radiogênicos ${ }^{207} \mathrm{~Pb}$ e ${ }^{206} \mathrm{~Pb}$ ocorre em diferentes taxas. A idade do geocronômetro (i.e., qualquer mineral utilizado para medir o tempo geológico por decaimento radioativo) pode ser descrita com a aplicação da fórmula do decaimento constante através das Equações 1 e 2 (e.g., Faure, 1986; Harley e Kelly, 2007; Dickin, 2005):

$$
\begin{aligned}
& \left(\frac{{ }^{206} p b}{{ }^{204} p b}\right)=\left(\frac{{ }^{106} p b}{{ }^{204} p b}\right)_{0}+\left(\frac{{ }^{288} U}{{ }^{204} p b}\right)\left(e^{\lambda_{28 g} t}-1\right) \text { (Equação 1) } \\
& \left(\frac{{ }^{207} p b}{{ }^{204} p b}\right)=\left(\frac{{ }^{107} p b}{{ }^{104} p b}\right)_{0}+\left(\frac{{ }^{285} U}{{ }^{204} p b}\right)\left(e^{\lambda_{285} t}-1\right) \text { (Equação 2) }
\end{aligned}
$$

Onde: ${ }^{204} \mathrm{~Pb}$ é o isótopo de referência; $t$ é o tempo decorrido; $\lambda$ é a constante de decaimento; $O$ designa a razão isotópica atual da amostra.

A vantagem de dois cronômetros independentes se deve à possibilidade de detectar a perda de $\mathrm{Pb}$ ou de material herdado. O diagrama da concórdia $\left({ }^{206} \mathrm{~Pb} /{ }^{238} \mathrm{U}\right.$ versus ${ }^{207} \mathrm{~Pb} /{ }^{235} \mathrm{U}$ ) mostra que para um mineral no início da cristalização a curva é traçada na origem, com o decorrer do tempo o decaimento radioativo aumenta rapidamente a razão ${ }^{207} \mathrm{~Pb} /{ }^{235} \mathrm{U}$, enquanto o ${ }^{206} \mathrm{~Pb} /{ }^{238} \mathrm{U}$ aumenta lentamente, gerando a curva concórdia. A interseção superior da linha da discórdia com a curva da concórdia representa a idade do mineral ou rocha (Figura 9). O intercepto inferior pode indicar perda episódica de chumbo, vinculada a um episódio tectônico ou perda contínua por difusão (Harley e Kelly, 2007; Sato et al.,1995). 


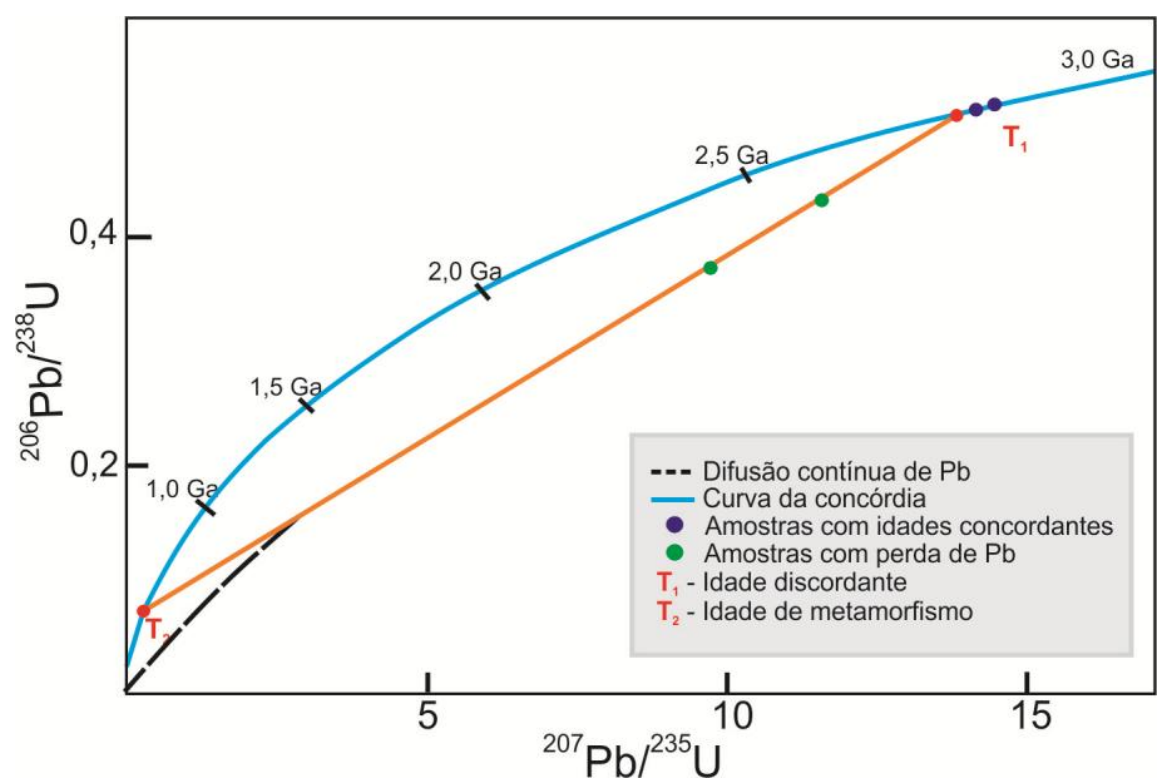

Figura 9. Diagrama da concórdia mostrando a evolução das razões ${ }^{206} \mathrm{~Pb} /{ }^{238} \mathrm{U}$ versus ${ }^{207} \mathrm{~Pb} /{ }^{235} \mathrm{U}$ no decorrer do tempo (Wetherill, 1956).

\subsection{Isótopos de Hf-Nd}

A diferença de comportamento químico do Lu e do Hf durante a cristalização do magma possibilita a obtenção da idade de cristalização (isócronas RT), idades modelo e proveniência (crosta e manto) (Kinny e Maas, 2003; Dickin, 2005). O uso combinado dos sistemas isotópicos quer seja U-Pb e Lu-Hf ou Lu-Hf e Sm-Nd permite inferências para desvendar a trajetória de eventos geológicos. O Hf é um elemento químico importante no zircão, o qual ajuda a controlar sua distribuição e abundância durante a evolução do magma. A análise de Hf in situ integrado à análise da morfologia do zircão e à imagens de CL - quando comparado a outros métodos isotópicos (e.g., $\mathrm{Nd}$-Sr em rocha total) - mostra que o $\mathrm{Hf}\left({ }^{176} \mathrm{Hf} /{ }^{177} \mathrm{Hf}\right)$ possui um maior potencial interpretativo (Belousova et al., 2006).

O zircão, por ser bastante sensível a processos crustais e mantélicos, preserva a razão inicial de Hf promovendo um registro permanente de sua fonte no momento de sua cristalização (Hoskin e Schaltegger, 2003). Esta razão pode ser utilizada para calcular a idade modelo (i.e. tempo em que a composição isotópica do magma gerado era a mesma de sua fonte) (Faure, 1986). Se a idade de cristalização é conhecida, tornase possível, também, estimar a idade modelo a partir do cálculo da curva de crescimento isotópico do manto empobrecido (Equação 6) (Griffin et al., 2002). 


$$
\begin{gathered}
\text { Hf } \mathrm{T}_{\mathrm{DM}}=1 / \lambda \times \ln \\
\times\left\{\frac{\left({ }^{176} \mathrm{Hf} /{ }^{177} \mathrm{Hf}\right)_{\text {sample }}-\left({ }^{176} \mathrm{Hf} /{ }^{177} \mathrm{Hf}\right)_{\mathrm{DM}}}{\left({ }^{176} \mathrm{Lu} /{ }^{177} \mathrm{Hf}\right)_{\text {sample }}-\left({ }^{176} \mathrm{Lu} /{ }^{177} \mathrm{Hf}\right)_{\mathrm{DM}}}+1\right\} \quad \text { (Equação 6) }
\end{gathered}
$$

Onde: ${ }^{177} H f$ é o isótopo de referência; $T_{D M}$ é o tempo decorrido desde a extração da fonte; $\lambda$ é a constante de decaimento; 0 designa a razão isotópica atual da amostra.

Uma idade $\mathrm{T}_{\mathrm{DM}}$ será confiável se o magma parental não for contaminado com outros componentes (Belousova et al., 2006).

A identificação do comportamento do Lu e do Hf em diferentes situações de pressão e temperatura na litosfera continental, no manto superior e no inferior determina o seu potencial nas interpretações petrogenéticas (Figura 10). Estudos realizados por Nowell et al. (2004; Figura 10) revelam que o Lu e o Hf bem como os ETR se comportam de maneira diversificada a depender das condições físico-químicas vigentes.

A Figura 10 mostra que não ocorre um aumento gradativo dos valores de $\mathrm{Lu} \mathrm{em}$ relação à profundidade, já que este elemento se estabelece nas fases residuais (i.e., com granada) do sistema em fusão. Em contrapartida, a concentração deste elemento é dependente da composição do manto. Em profundidades de até $75 \mathrm{Km}$ no manto (fase espinélio-peridotito) os valores de Lu são baixos e aproximadamente similar ao de Hf (Figura 10). A partir de $75 \mathrm{Km}$ (fase granada-peridotito) os valores de Lu aumentam significativamente (i.e., 100 vezes) em relação ao Hf. As modificações na composição mineralógica do manto, com o aumento da pressão e da temperatura (a partir de 400 $\mathrm{Km}$ ), resultam na diminuição gradativa nos valores de Lu em profundidade até valores incompatíveis em relação ao Hf (Figura 10).

Com a diferenciação contínua da Terra, o manto produz reservatórios com altos valores de ${ }^{176} \mathrm{Hf} /{ }^{177} \mathrm{Hf}$ (Lu/Hf > condrito). Já na crosta continental verifica-se baixa razão ${ }^{176} \mathrm{Hf} /{ }^{177} \mathrm{Hf}(\mathrm{Lu} / \mathrm{Hf}<$ condrito $)$. Essas relações ocorrem devido ao alto coeficiente de partição do Lu para a granada (Vervoot e Patchett, 1996). Dessa forma, magmas félsicos juvenis derivados da fase granada-peridotito podem produzir baixos valores de ${ }^{176} \mathrm{Hf} /{ }^{177} \mathrm{Hf}$. 


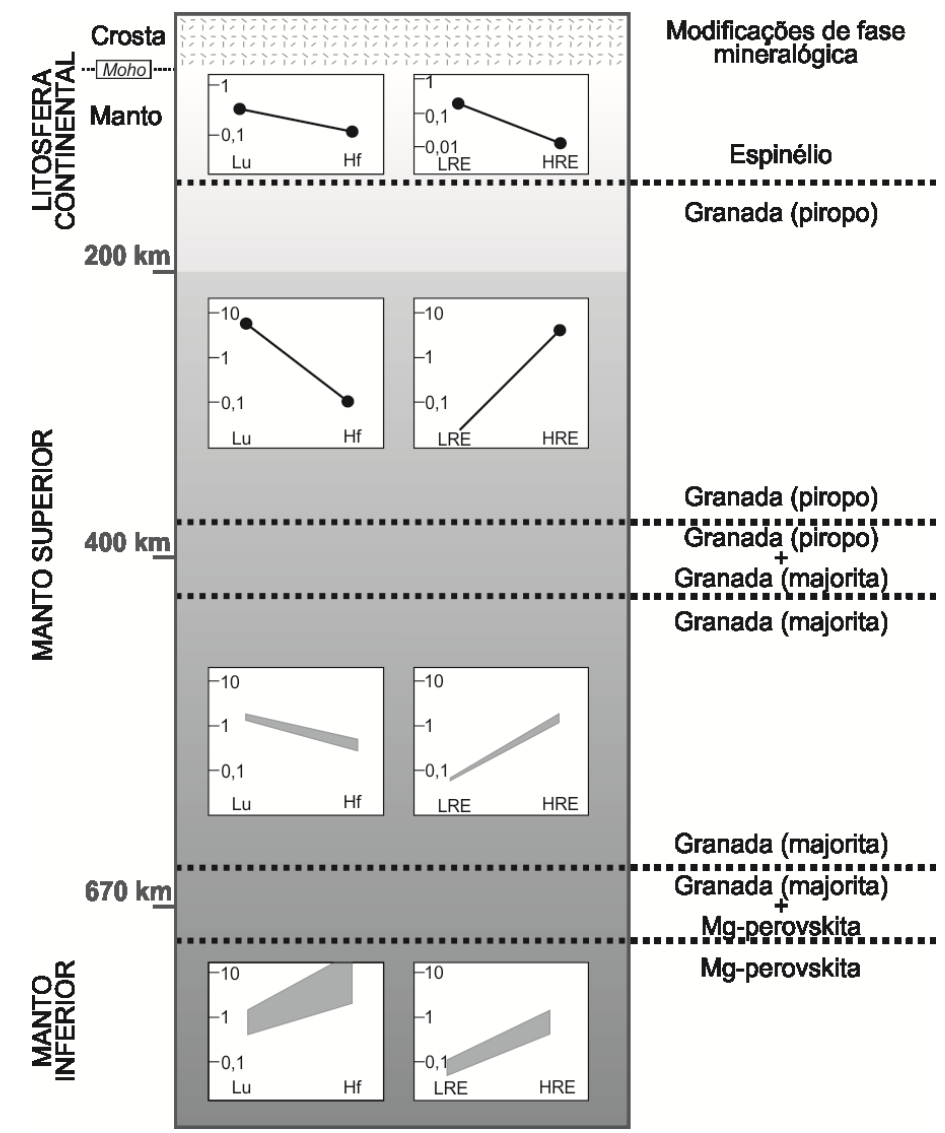

Figura 10. Seção esquemática da crosta e do manto mostrando a transição entre mineralógica entre as camadas da Terra. A variação do coeficiente de distribuição para Lu e Hf é apresentada para cada fase do manto (Nowell et al., 2004).

A razão isotópica de $\mathrm{Hf}$ pode ser expressa usando a notação Épsilon $\left(\varepsilon_{\mathrm{Hf}}\right)$ modelada para um tempo (T) calculado. Como em outros sistemas isotópicos a composição de Hf em relação ao condrito em um tempo T pode ser expressa seguindo a seguinte equação:

$$
\varepsilon_{H f}=\left[\left({ }^{176} H f /{ }^{177} H f\right)_{t} /\left({ }^{176} H f /{ }^{177} H f\right)_{\text {condrito }}-1\right] \times 10^{4} \text { (Equação 5) }
$$

Este parâmetro determina se a composição de ${ }^{176} \mathrm{Hf} /{ }^{177} \mathrm{Hf}$ inicial é maior ou menor que o condrito. Valores positivos $\varepsilon_{\mathrm{Hf}}$ apontam que a razão ${ }^{176} \mathrm{Hf} /{ }^{177} \mathrm{Hf}$ é maior que o condrito e que sua fonte é mantélica, enquanto que valores negativos indicam fontes crustais (Faure, 1986). Já a mistura de sedimentos e material continental na gênese dos magmas pode produzir valores de $\varepsilon_{\mathrm{Hf}}$ cabíveis de serem interpretados, com suporte de imagem de CL, da geoquímica e de outros isótopos (Vervoot et al., 1999).

Nas rochas granitoides, valores $\varepsilon_{\mathrm{Hf}(\mathrm{t})}$ positivos podem sugerir derivação juvenil (e.g., fusão de crosta oceânica em subducção, cristalização fracionada e formação de 
granitoides de arco oceânico). Por outro lado, $\varepsilon_{\mathrm{Hf}(\mathrm{t})}$ negativos evidenciam a fusão da crosta continental. A variação da composição isotópica de $\mathrm{Hf}\left(\varepsilon_{\mathrm{Hf}(\mathrm{t})}\right)$ em granitoides usualmente pode indicar uma fonte heterogênea e mistura de magmas (Griffin et al., 2002). De modo similar Kröner et al. (2014) apontam que valores positivos e negativos podem ser interpretados em arcos continentais como mistura da fusão de materiais juvenis e crustais, resultando na contaminação do magma. Já os valores variáveis em arco oceânico podem sugerir algum tipo de contaminação. Em ambos os casos, a retenção do $\mathrm{Hf}$ ou Lu por algum mineral (e.g., granada) também pode refletir esta variação (e.g., Kröner et al., 2014).

Os sistemas Lu-Hf e Sm-Nd possuem comportamentos análogos nos processos magmáticos (e.g., Hawkesworth e Kemp, 2006). Contudo, o Sm-Nd é mais sensível a distúrbios isotópicos em relação ao Lu-Hf, devido a maior mobilidade do $\mathrm{Nd}$ em relação ao Hf (e.g., Kröner et al., 2014). O comportamento similar dos sistemas Sm-Nd e Lu-Hf (Figura 11; Vervoot et al., 1999) resulta em uma regressão quase perfeita entre as diversas rochas do manto e crosta através do tempo (correlação positiva) (Vervoort e Blichert-Toft, 1999; Beard e Johnson, 1997).

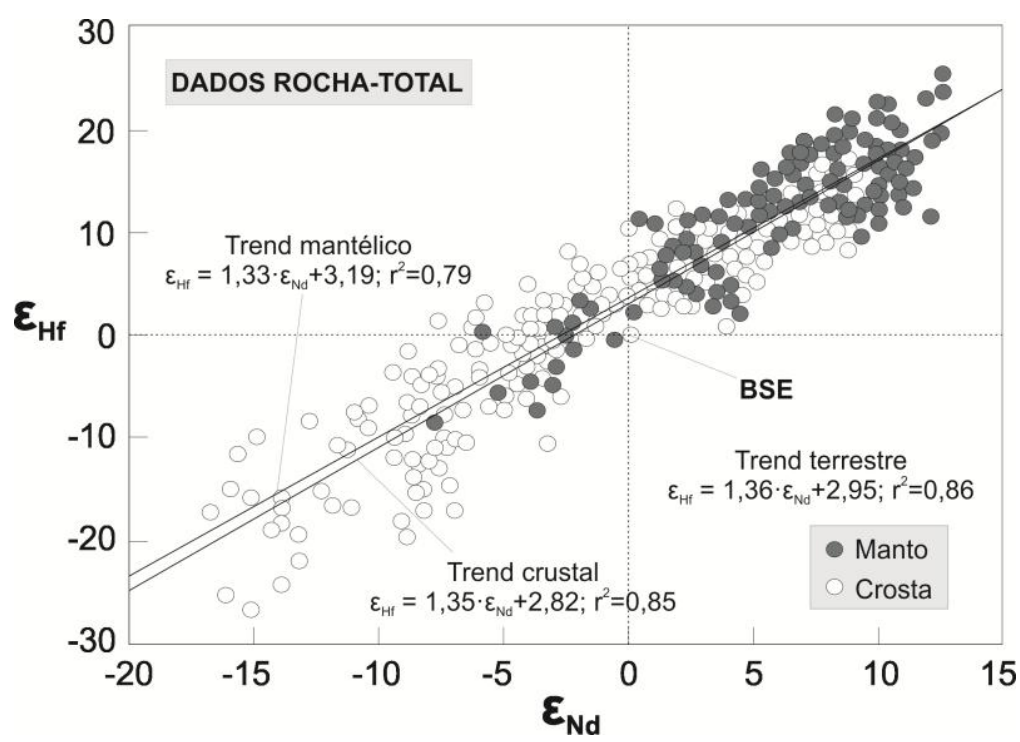

Figura 11. $\varepsilon_{\mathrm{Hf}} v s . \varepsilon_{\mathrm{Nd}}$ inicial para todas as rochas terrestre em relação ao bulk silicate earth (Vervoot et al., 1999). Terrestrial array, (amostras crustais: sedimentos, basaltos continentais, granitoides, rochas juvenis etc) de diversas idades; (amostras mantélicas: representantes de todos os basaltos oceânicos).

Em particular, no zircão, pode-se verificar baixas razões Lu/Hf e a preservação do conteúdo de ${ }^{176} \mathrm{Hf} /{ }^{177} \mathrm{Hf}_{\text {inicial }}$ em condições de metamorfismo (Kröner et al., 2014). Em geral, os valores de $\varepsilon_{\mathrm{Hft}}$ são sempre maiores que $\varepsilon_{\mathrm{Ndt}}$, em consequência da maior diferenciação do Lu e $\mathrm{Hf}$ em relação ao $\mathrm{Sm}$ e Nd durante a evolução manto/crosta 
(Kinny e Maas, 2003). Esta relação é de $\varepsilon_{\mathrm{Hf}}=1,3 \varepsilon_{\mathrm{Nd}}$, que pode ser observado nos três trends da figura 11.

\subsection{Isótopos de $\mathrm{Nd}-\mathrm{Sr}$}

O método Sm-Nd é importante na averiguação de fontes e processos, os quais são determinados mediante o cálculo das razões ${ }^{147} \mathrm{Sm} /{ }^{144} \mathrm{Nd}$ e ${ }^{143} \mathrm{Nd} /{ }^{144} \mathrm{Nd}$, da obtenção das idades modelo $\left(\mathrm{T}_{\mathrm{DM}}\right)$ e do parâmetro épsilon $\mathrm{Nd}\left(\varepsilon_{\mathrm{Nd}}\right)$. O princípio básico é que o principal evento modificador da razão Sm-Nd é o processo de diferenciação mantocrosta (Figura 12; DePaolo, 1988). Uma vez que, os raios atômicos dos elementos Sm e Nd são $1,04 \ddot{A}$ e $1,08 \ddot{A}$, respectivamente. Não obstante, esta pequena diferença nas propriedades químicas possibilita a identificação de processos formadores de magmas. $\mathrm{O}{ }^{147} \mathrm{Sm}$ decai para o ${ }^{144} \mathrm{Nd}$ em uma rocha ou mineral segundo a fórmula:

$$
\left(\frac{{ }^{14 \mathrm{~s}_{N d}}}{{ }^{144_{N d}}}\right)_{m}=\left[\left(\frac{{ }^{14 \mathrm{~s}_{N d}}}{{ }^{144_{N d}}}\right)_{t}+\left(\frac{{ }^{148} S_{m}}{{ }^{144_{N d}}}\right)_{m}\right] \times\left(e^{\lambda t}-1\right)(\text { Equação 6) }
$$

Onde: ${ }^{144} N d$ é o isótopo de referência; $t$ é o tempo decorrido; $\lambda$ é a constante de decaimento $\left(6,54 \cdot 10^{-12} \mathrm{a}^{-1}\right) ; m$ e $i$ designam a razão isotópica atual da amostra e a razão inicial, respectivamente.

A idade modelo $\left(\mathrm{T}_{\mathrm{DM}}\right)$ corresponde ao tempo decorrido desde que a rocha foi extraída de sua fonte. Essa difere das idades radiométricas absolutas (idade de cristalização da rocha), ou seja, representa o tempo T no qual a amostra tinha a mesma composição isotópica ${ }^{143} \mathrm{Nd} /{ }^{144} \mathrm{Nd}$ do magma de origem (e.g., Faure, 1986; Figura 12). A idade $\mathrm{T}_{\mathrm{DM}}$ requer a premissa que o $\mathrm{Sm}$ e $\mathrm{Nd}$ não estejam substancialmente fracionados na crosta, em conformidade com suas afinidades geoquímicas (e.g., Dickin, 2005).

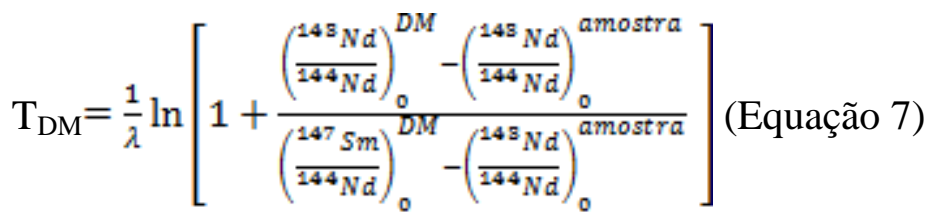

$$
\begin{aligned}
& \left({ }^{143} \mathrm{Nd} /{ }^{144} \mathrm{Nd}\right)_{i}^{\mathrm{CHUR}}=0,50677
\end{aligned}
$$




$$
\begin{aligned}
& \left({ }^{143} \mathrm{Nd} /{ }^{144} \mathrm{Nd}\right)_{0}^{\mathrm{CHUR}}=0,51264 \\
& \left({ }^{147} \mathrm{Sm} /{ }^{144} \mathrm{Nd}\right)_{0}^{\mathrm{CHUR}}=0,1967
\end{aligned}
$$

A figura 12 ilustra a evolução da razão ${ }^{147} \mathrm{Sm} /{ }^{144} \mathrm{Nd} \mathrm{e}{ }^{143} \mathrm{Nd} /{ }^{144} \mathrm{Nd}$ através do Tempo, em relação ao CHUR, manto empobrecido e a crosta continental, considerando que o principal evento de diferenciação crosta/manto ocorreu a partir de 2,7 Ga.

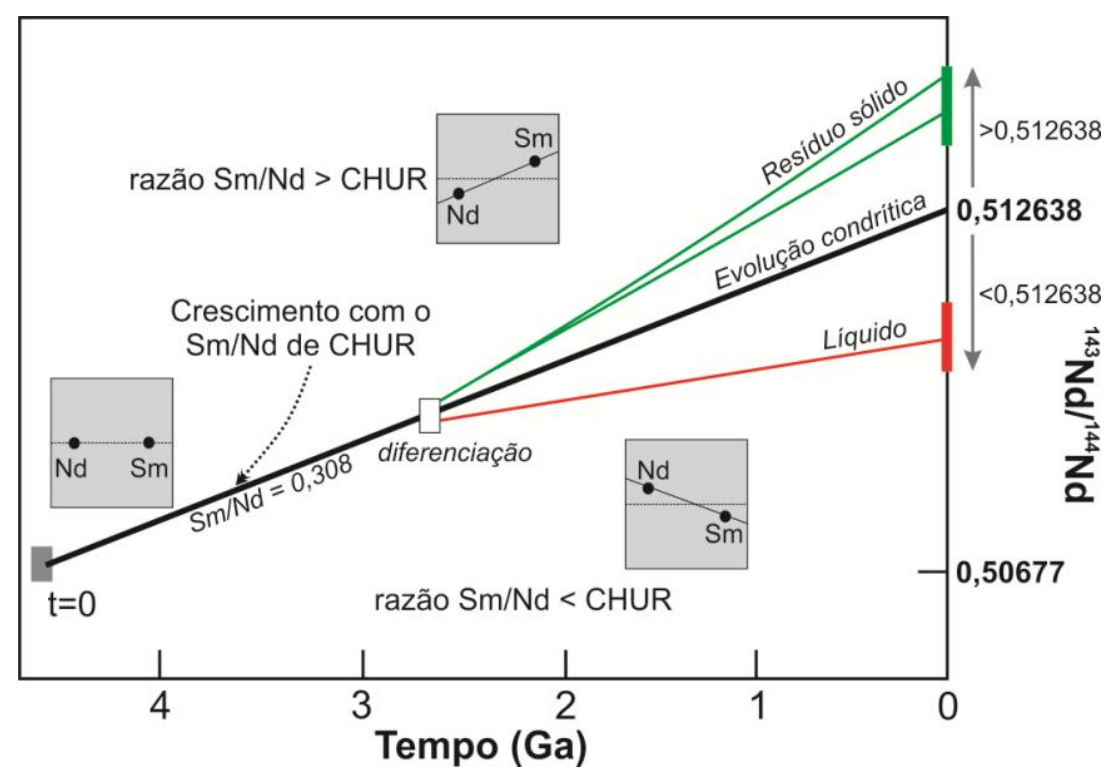

Figura 12. Evolução isotópica do CHUR em função do tempo geológico CHUR (a partir de 4,55 Ga). Maior evento de diferenciação em 2,7 Ga (empobrecimento a crosta na razão $\mathrm{Sm} / \mathrm{Nd}$ e enriquecendo o manto) (Faure, 1986).

$\mathrm{O}$ valor $\varepsilon_{\mathrm{Nd}}$ indica se a razão inicial da rocha ${ }^{143} \mathrm{Nd} /{ }^{144} \mathrm{Nd}$ é maior ou menor que o CHUR (i.e., 0,512638) (Albarède, 1995). Como resultado, maiores valores de ${ }^{143} \mathrm{Nd} /{ }^{144} \mathrm{Nd}$ que o CHUR ( $\varepsilon_{\mathrm{Nd}}$ positivo) representam rochas derivadas do manto. Em geral, quanto maior esse parâmetro mais empobrecido geoquimicamente é o manto. Já os valores negativos de $\varepsilon_{\mathrm{Nd}}$ representam rochas derivadas de uma fonte com razão ${ }^{147} \mathrm{Sm} /{ }^{144} \mathrm{Nd}$ inferior ao CHUR, o que significa que essas rochas foram derivadas da assimilação de material crustal, ou a partir de um manto enriquecido ou da fusão de rochas pré-existentes (Sato et al., 1995). Nas situações onde ocorre a participação das duas fontes (e.g., manto e crosta), os valores de $\varepsilon_{\mathrm{Nd}}$ variam em torno de zero, podendo ser ligeiramente negativo ou positivo, dependendo do grau de participação do material fonte. 


$$
\varepsilon_{C H U R}^{t=0}=\left[\frac{\left(\frac{{ }^{143} N d}{{ }^{144} N d}\right)_{0}}{\left(\frac{{ }^{143} N d}{{ }^{144} N d}\right)_{\substack{C H U R \\ t=0}}}-1\right] \cdot 10^{4}
$$

A concentração de Sm e Nd nos minerais silicáticos aumenta segundo sua ordem de cristalização. Nesta sequência, durante fusão ocorre uma tendência do Sm se concentrar nas fases residuais e o $\mathrm{Nd}$ nas fases líquidas (e.g. magma), resultando, neste último, em baixos valores ${ }^{143} \mathrm{Nd} /{ }^{144} \mathrm{Nd}$ (Albarède, 1995). O mesmo processo ocorre durante a cristalização fracionada. Comparativamente, as rochas máficas possuem altos valores $\mathrm{Sm} / \mathrm{Nd}$ enquanto que as rochas félsicas têm baixos valores (Figura 12).

Em rochas que sofreram um fracionamento isotópico significativo (i.e. grandes quantidades de minerais acessórios como allanita e epidoto, metamorfismo de médio a alto grau) pode ocorrer o fracionamento do sistema Sm/Nd (Pimentel e Charney, 1991; Sato, 1998). Por exemplo, allanita incorpora grande parte dos ETRL (e.g., La, Ce, Pr e Nd), excluindo o Sm (Pimentel e Charney, 1991). Em seguida, as razões $\mathrm{Sm} / \mathrm{Nd}$ e ${ }^{143} \mathrm{Nd} /{ }^{144} \mathrm{Nd}$ diminuem na rocha e os valores de $\varepsilon_{\mathrm{Nd}}$ são negativos. Portanto, a idade modelo e o parâmetro $\varepsilon_{\mathrm{Nd}}$ são fundamentais do ponto de vista petrogenético, pois possibilitam a identificação de protólitos mantélicos ( $\varepsilon_{\mathrm{Nd}}$ positivo), crustais $\left(\varepsilon_{\mathrm{Nd}}\right.$ negativo), a discriminação de ambientes tectônicos, além de avaliar o tempo de diferenciação crosta-manto.

O grau de fracionamento pode ser obtido através do parâmetro $f \mathrm{Sm} / \mathrm{Nd}$ com valores de até 0,55 para as rochas crustais e da razão ${ }^{147} \mathrm{Sm} /{ }^{144} \mathrm{Nd}$ da ordem de 0,085 a 0,125 (Bennet e DePaolo, 1987; Sato, 1998). Valores acima de -0,55 sugerem que um evento posterior ou a composição química dos minerais acessórios produziu um fracionamento no sistema Sm-Nd. Nessa situação, serão obtidos valores anômalos para a idade $\mathrm{T}_{\mathrm{DM}}$ calculada para um único estágio (Liew e Hofmann, 1988). O modelo de evolução de dois estágios compensa o possível efeito do segundo fracionamento em processos intra-crustais (Figura 13). Em casos de mistura de fontes, o sistema irá fornecer uma idade $\mathrm{T}_{\mathrm{DM}}$ média do tempo de residência do material na crosta. Neste caso, a idade $\mathrm{T}_{\mathrm{DM}}$ não representa a idade correta da segregação do magma, mas possibilita interpretações sobre as possíveis fontes envolvidas (Arndt e Goldstein, 1987). 

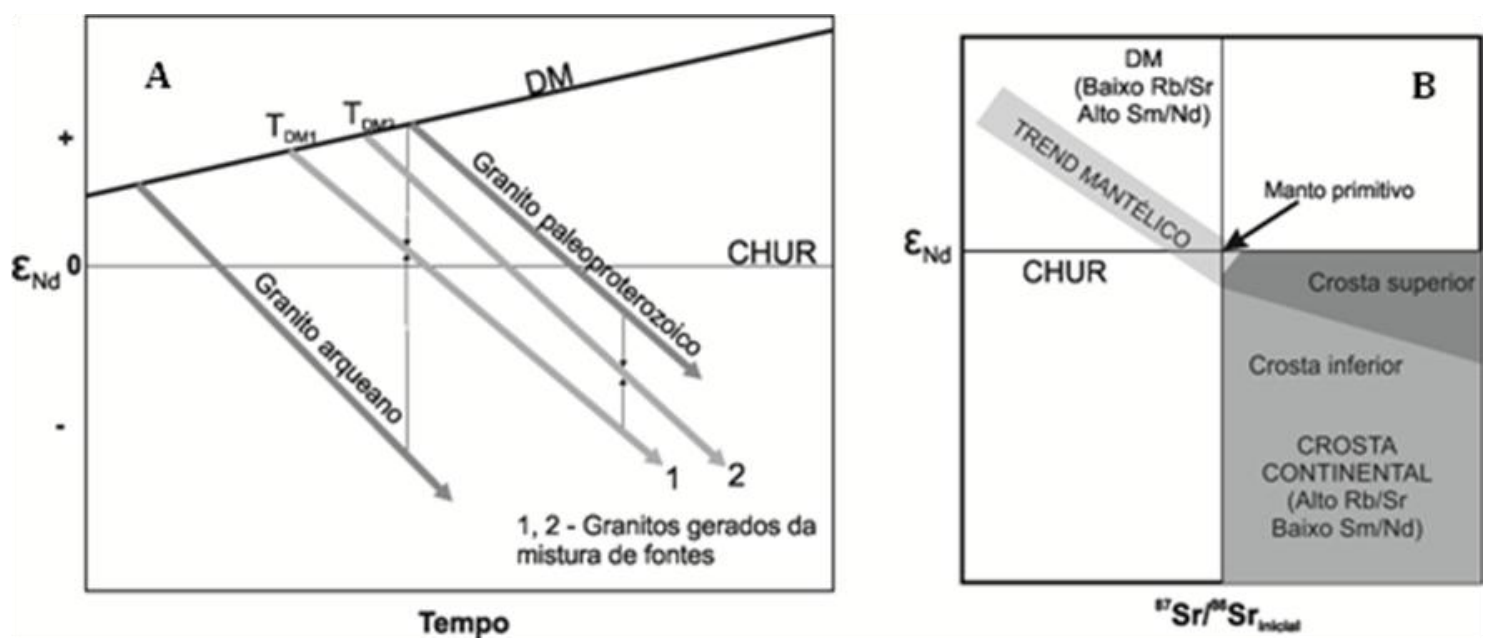

Figura 13. (A) Evolução Nd versus tempo; (B) $\varepsilon_{\mathrm{Ndt}}$ versus ${ }^{87} \mathrm{Sr} /{ }^{86} \mathrm{Sr}$ inicial mostrando a composição complementar do manto empobrecido e da crosta continental relativa ao manto primitivo (Rollinson, 2007).

Os diagramas $\varepsilon_{\mathrm{Nd}}$ versus Tempo e $\varepsilon_{\mathrm{Nd}}$ versus $\varepsilon_{\mathrm{Sr}}$ são úteis para indicar ambientes tectônicos e parâmetros petrogenéticos. A Figura 13A foi construída através da comparação da composição isotópica de uma amostra em relação ao DM, CHUR e possíveis fontes. Nela, os valores de $\varepsilon_{\mathrm{NdT}}$ mostram um trend evolutivo do manto em relação a crosta continental e apresentam os processos de mistura de fontes (Rollinson, 2007).

Os dados isotópicos de Sr-Nd são dependentes da idade de cristalização e da composição isotópica inicial da fonte. A interação entre reservatórios (e.g. crosta continental e manto) pode ser modelado pelo diagrama $\varepsilon_{\mathrm{NdT}}$ versus ${ }^{87} \mathrm{Sr} /{ }^{86} \mathrm{~S}_{\text {inicial. }}$. Na Figura 13, a correlação entre o $\mathrm{Nd}$ e $\mathrm{Sr}$ ilustra o domínio do manto (i.e., $\varepsilon_{\mathrm{Ndt}}>0$; ${ }^{87} \mathrm{Sr} /{ }^{86} \mathrm{Sr}_{\mathrm{i}}<0,704$ ) e da crosta continental (i.e., $\varepsilon_{\mathrm{Ndt}}<0 ;{ }^{87} \mathrm{Sr} /{ }^{86} \mathrm{Sr}_{\mathrm{i}}>0,704$ ) (Rollinson, 2007).

Muitas rochas continentais possuem composições que dificultam a identificação do magma fonte. Nestes casos, a modelagem isotópica permite desvendar estes processos que afetam a maioria das rochas durante sua geração. Um procedimento utilizado é descrito por DePaolo (1981), no qual utiliza a mistura entre dois componentes e, assim, demonstra o papel da contaminação de reservatórios mantélicos distintos ou da crosta em magmas juvenis. Essa técnica facilita a identificação de diferenças sutis entre o manto enriquecido, a contaminação crustal e o input de diferentes reservatórios. O cálculo da interação entre as fontes, resultam em hipérboles que dependem da concentração da razão $\mathrm{Nd} / \mathrm{Sr}\left(\mathrm{q}=(\mathrm{Sr} / \mathrm{Nd})_{1} /(\mathrm{Sr} / \mathrm{Nd})_{2}\right) ; \mathrm{q}=\left(\mathrm{C}_{1} / \mathrm{C}_{2}\right)$ 
$\beta /\left(\mathrm{C}_{1} / \mathrm{C}_{2}\right) \alpha(\beta, \alpha=$ fontes; 1,2 = concentração da mistura isotópica) (DePaolo, 1981; Albarède, 1995).

Identicamente ao $\mathrm{Nd}$, isótopos de $\mathrm{Sr}$ fornecem informações sobre a origem e processos geológicos que afetam as rochas (Geraldes, 2010). Devido à alta mobilidade química, o $\operatorname{Sr}(1,13$ Ä) tende a se concentrar no manto em relação ao Rb, enquanto que o $\mathrm{Rb}(1,48 \mathrm{~A})$ na crosta. No processo de fusão parcial, o Rb é fracionado do magma em maiores proporções que o Sr. Dessa maneira, com o decorrer do tempo, a crosta é enriquecida em ${ }^{87} \mathrm{Sr}$ radiogênico quando cotejado com o $\mathrm{Sr}$ do manto superior. Logo, as rochas da crosta continental possuirão maiores razões ${ }^{87} \mathrm{Sr} /{ }^{86} \mathrm{Sr}$ (i.e., $>0,705$ ) do que às relacionadas ao manto superior (i.e., <0,705) (Dickin, 2005). Em geral, a razão $\mathrm{Rb} / \mathrm{Sr}$ aumenta gradualmente no magma durante a cristalização (Faure, 1986). Deste modo, o parâmetro petrogenético ${ }^{87} \mathrm{Sr} /{ }^{86} \mathrm{Sr}$ inicial registra informações sobre o magma a partir do qual as rochas se cristalizaram, ou seja, indica se um magma foi originado no manto superior ou na crosta continental.

Durante a cristalização de um magma, os minerais apresentam a mesma razão ${ }^{87} \mathrm{Sr} /{ }^{86} \mathrm{Sr}$ inicial do magma parental. Contudo, o $\mathrm{Rb}$ e o $\mathrm{Sr}$, em função de similaridades de raio iônico, possuem afinidades geoquímicas com o $\mathrm{K}$ e $\mathrm{Ca}$, respectivamente (Faure, 1986). Dessa forma, diferentes razões $\mathrm{K} / \mathrm{Ca}$ nos minerais refletem distintas razões $\mathrm{Rb} / \mathrm{Sr}$. Comumente, esta razão aumenta em ordem do plagioclásio, hornblenda, Kfeldspato, biotita, moscovita. Assim, a relação entre as razões ${ }^{87} \mathrm{Rb} /{ }^{86} \mathrm{Sr}$ e ${ }^{87} \mathrm{Sr} /{ }^{86} \mathrm{Sr}$ nos minerais será diretamente proporcional, após um significativo tempo de decaimento do ${ }^{87} \mathrm{Sr}$ radiogênio (Albarède, 1995).

\subsection{Litogeoquímica}

Trocas físico-químicas entre a geodinâmica da crosta e do manto, no decorrer do tempo, geraram fortes contrastes nas características químicas das rochas (e.g., de gabros a granitos). Assim para obter a interpretação mais robusta entre fontes e processos, torna-se necessário analisar a rocha fonte (referência) para entender o processo de evolução de um material primitivo até se transformarem em rochas mais diferenciadas (Rollinson, 1997). A maneira mais eficiente para alcançar este objetivo é inicialmente datando a rocha gerada, assim como os seus possíveis geradores. Após a identificação 
dos possíveis protólitos, é recomendado modelar geoquimicamente estas rochas (nos mesmos diagramas) para comparações pertinentes.

Neste sentido as rochas granitoides são sempre estudadas para o entendimento da evolução da crosta continental e, também, para uma melhor compreensão acerca do modo como o magma félsico se comporta até a cristalização. Os granitoides juvenis por se formarem em vários ambientes tectônicos (e.g., arco oceânico, continental, intraplaca) no tempo guardam importantes informações sobre o registro desta evolução (Nédélec e Bouchez, 2015). Enquanto que as rochas máficas são geradas principalmente em ambiente extensional e são os principais protólitos das rochas félsicas. Informações geoquímicas, principalmente relacionadas a elementos menores, em granitoides promovem inferências sobre o ambiente tectônico, a fonte e os processos posteriores, tais como: fusão parcial e assimilação (e.g., cálcio-alcalino, tipo I ou S, magnesiano, conteúdo de ETRP, anomalias negativas de Nb-Ti-Ta; Rollinson, 2007). Neste contexto, os processos magmáticos podem ser identificados, pois geram uma variedade composicional entre as rochas. Nesse caso, tais efeitos podem ser rastreados através de diagramas com elementos maiores e valores de ERTL, LILE e HFSE.

Os elementos maiores e traços revelam inicialmente a derivação mantélica ou crustal das rochas, mas em especial os elementos Terra Raras (ETR) é o principal meio para identificar fontes e processos. Este grupo varia em relação ao número atômico 57 a 71 (La-Lu) e raio iônico 1,06-0,85 $\ddot{A}$ (La-Lu). Essas características controlam o particionamento dos ETR durante os processos magmáticos (Albarède, 1995). Em consequência, o comportamento dos ETR normalizados e plotados em diagrama/spidergrams indica ou reflete o grau de dissociação do elemento durante a fusão parcial e diferenciação magmática (Wilson, 1989). Quando existe uma grande interpolação entre os ETR (diagramas ETR ou spidergrams) é aconselhável analisar separadamente os elementos TR. Por exemplo, o parâmetro Dy/Dy* que é o resultado entre a interpolação dos ETRL (La) e os ETRP (Yb) (Figura 14; Davidson et al., 2013). Igualmente, o parâmetro Eu/Eu* que representa a interpolação entre o ETRL (Sm) e o ETRM (Gd), estes elementos possuem comportamento geoquímico similar (Figura 14A e B). 

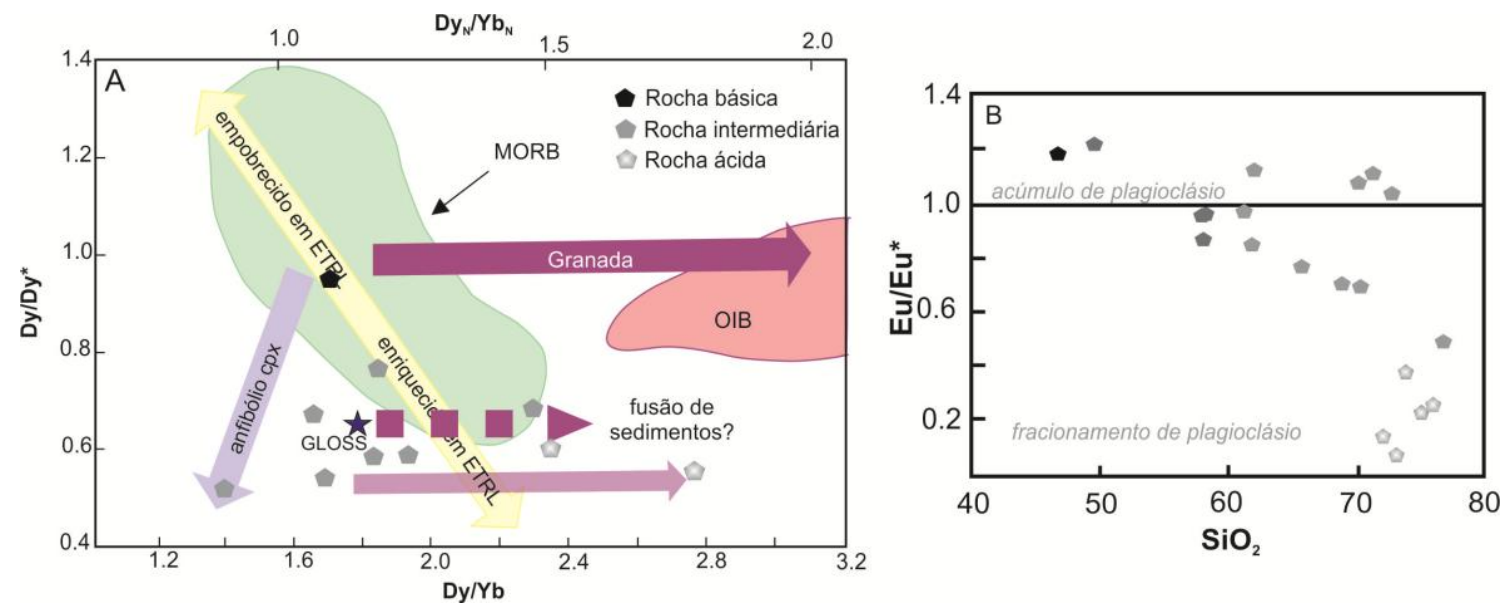

Figura 14. Diagramas ETR (A) Dy/Dy* versus $\mathrm{Dy} / \mathrm{Yb}_{\mathrm{N}}$ (B) Eu/Eu* versus $\mathrm{SiO}_{2}$ (Davidson et al., 2013).

Diagramas utilizados para avaliar os processos magmáticos são Harkeres, spidergrams, razão de elementos menores entre outros. Os diagramas de variação ou de Harkeres mostram os trends evolutivos da cristalização fracionada, verificados através da correlação positiva entre elementos maiores (Figura 15). O trend linear no diagrama de Harker pode ser continuo ou com inflexões, correspondendo a trocas na assembleia mineral (Figura 15). Isso quer dizer que a composição do cumulato sofreu alterações no curso da diferenciação (Wilson, 1989).
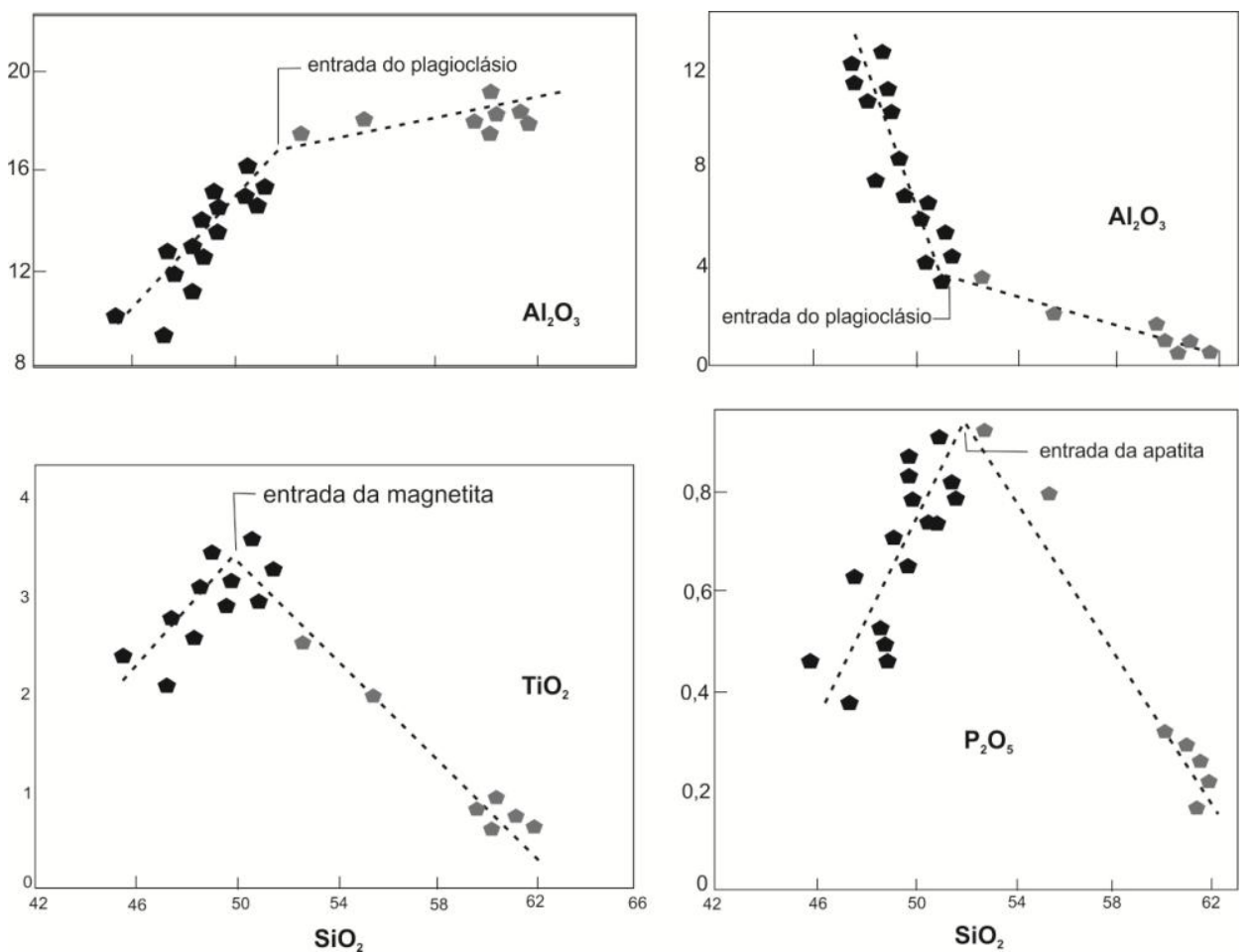

Figura 15. Diagrama de Variação - Harker - para rochas cogenéticas relacionadas a processos de cristalização fracionada (Wilson, 1989). 
$\mathrm{O}$ efeito de contaminação em magmas pode ser marcado por diagramas utilizando elementos traços e isótopos de $\mathrm{Nd}, \mathrm{Hf}, \mathrm{Sr}$ e $\mathrm{Pb}$. Contudo a diferença entre a contaminação na fonte e processos de assimilação durante a colocação do magma é de difícil controle. Um exemplo é a figura 16 que ilustra a variação $\mathrm{Nb} / \mathrm{La}$ versus $\mathrm{Sr} / \mathrm{Nd}$ para rochas crustais comparadas a OIB, MORB, arco oceânico e o manto primitivo. A figura 16 mostra a evolução a partir da fusão parcial de rochas máficas gerando rochas de composições crustais. As razões $\mathrm{Nb} / \mathrm{La}$ e $\mathrm{Sr} / \mathrm{Nd}$ são relativamente robustas em magmas félsicos (Rudnick e Gao, 2003), assim os processos de cristalização fracionada não afetam facilmente estas rochas.

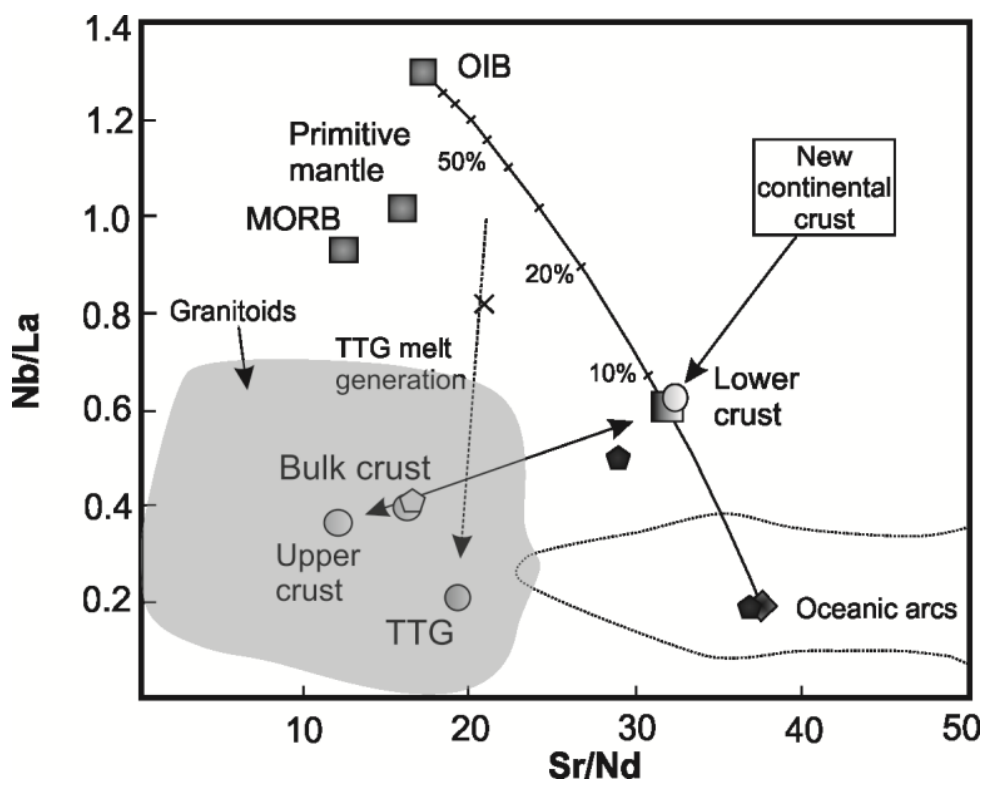

Figura 16. Diagrama $\mathrm{Nb} / \mathrm{La}$ vs. $\mathrm{Nd} / \mathrm{Sr}$ mostrando a curva de mistura para formar rochas da crosta continental (Rudnick e Gao, 2003).

Em resumo, vários diagramas podem ser utilizados para identificar processos magmáticos, ambiente tectônico e fontes. Comumente elementos traços como LILE (large ion lithophile elements) ocorrem em rochas félsicas em larga quantidade (incompatível), porém com algumas exceções ( $\mathrm{Rb}$ em biotita, $\mathrm{Sr}$ em plagioclásio). Cs, $\mathrm{Rb}, \mathrm{K}, \mathrm{Ba}, \mathrm{Sr}, \mathrm{Pb}$, por exemplo, possuem pequena carga e largo raio iônico (Figura 17), que permite a mobilidade no magma (também pode ser sujeito a intemperismo). Neste caso, o uso desses elementos requer cuidado, especialmente no que diz respeito à interpretação (Wilson, 1989). Os HFSE (high field strength elements) possuem comportamento variável, geralmente incompatível, com algumas exceções (Y em granada e Nb em hornblenda) (Figura 17). Os HFSE: Sc, Y, Th, U, Pb, Zr, Hf, Ti, Nb, 
Ta não são facilmente lixiviados no intemperismo e são relativamente imóveis, o que faz com que se tornem importantes indicadores petrogenéticos. A razão entre elementos traços pode ser usada desde que seus componentes apresentem o mesmo comportamento químico (e.g., $\mathrm{Nb}$ e Ta; $\mathrm{Zr}$ e Hf).

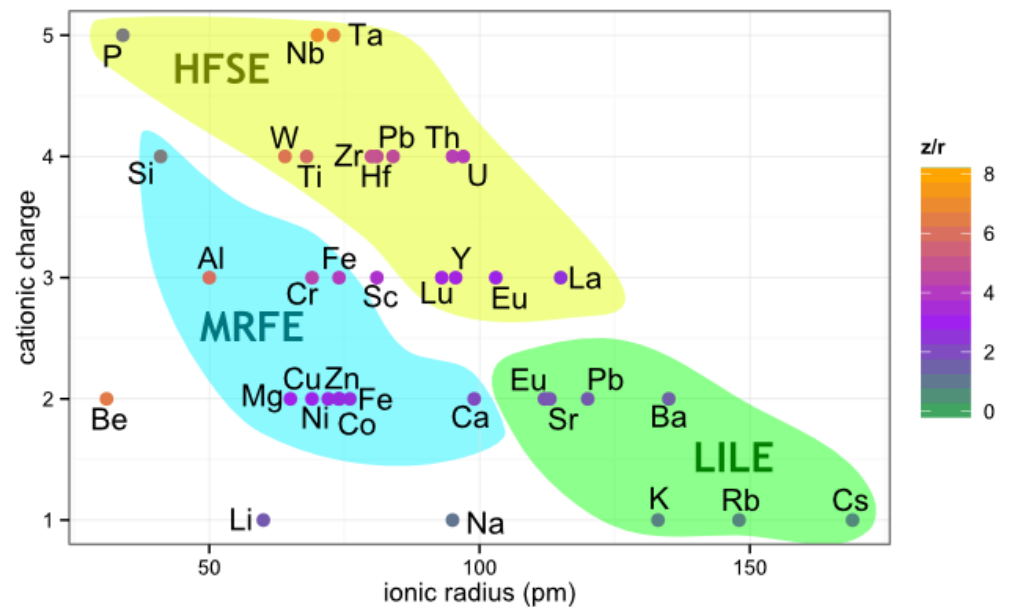

Figura 17. Carga catiônica versus raio iônico para os elementos menores. Campo MRFE (Mantle Rock Forming Elements); LILE (large ion lithophile elements); HFSE (high field strength elements). 


\section{CAPÍTULO IV}

\section{RESULTADOS}

Este capítulo está organizado em 4 seções. A primeira contextualiza a geologia de quatro batólitos do $\mathrm{CM}$, apresentados do mais antigo ao mais novo, a saber: Cassiterita, Represa de Camargos, Macuco de Minas e Ritápolis. Desse modo, a seção 4.2 se voltará para a apresentação do evento plutônico de 2,4 Ga, sobre o qual um artigo se encontra em preparação; a seção 4.3 tratará do evento plutônico de 2,2 Ga e apresentará informações referentes a um dado produzido nesta Tese, o qual está associado à interpretações encontradas na literatura, trata-se de rochas coevas que formam as suítes estudadas; o último subitem, o 4.4, trata do evento plutônico de 2,1 $\mathrm{Ga}$, o qual gerou um artigo já submetido à um periódico internacional.

\subsection{Corpos plutônicos da porção sudoeste do cinturão Mineiro}

Em escala regional, as rochas estudadas, correspondem principalmente a corpos meta-ígneos que afloram de forma descontínua em diferentes porções do CM entre as sequências metavulcanossedimentares. As rochas afloram geralmente em forma de batólitos e possuem relação intrusiva com as sequências metavulcanossedimentares. Em termos litológicos variam desde dioritos a granitos exibem diferentes estruturas e deformações. Expõem-se entre as cidades de Lavras e Ritápolis.

A seguir serão descritos os principais corpos granitoides presentes na área de estudo. A tabela 4 lista as amostras estudadas nesta Tese, a Figura 18 mostra a localização da área de estudo e a figura 19 o mapa geológico do CM. 
Tabela 4. Localização, litologia e unidade geológica das rochas estudadas no CM.

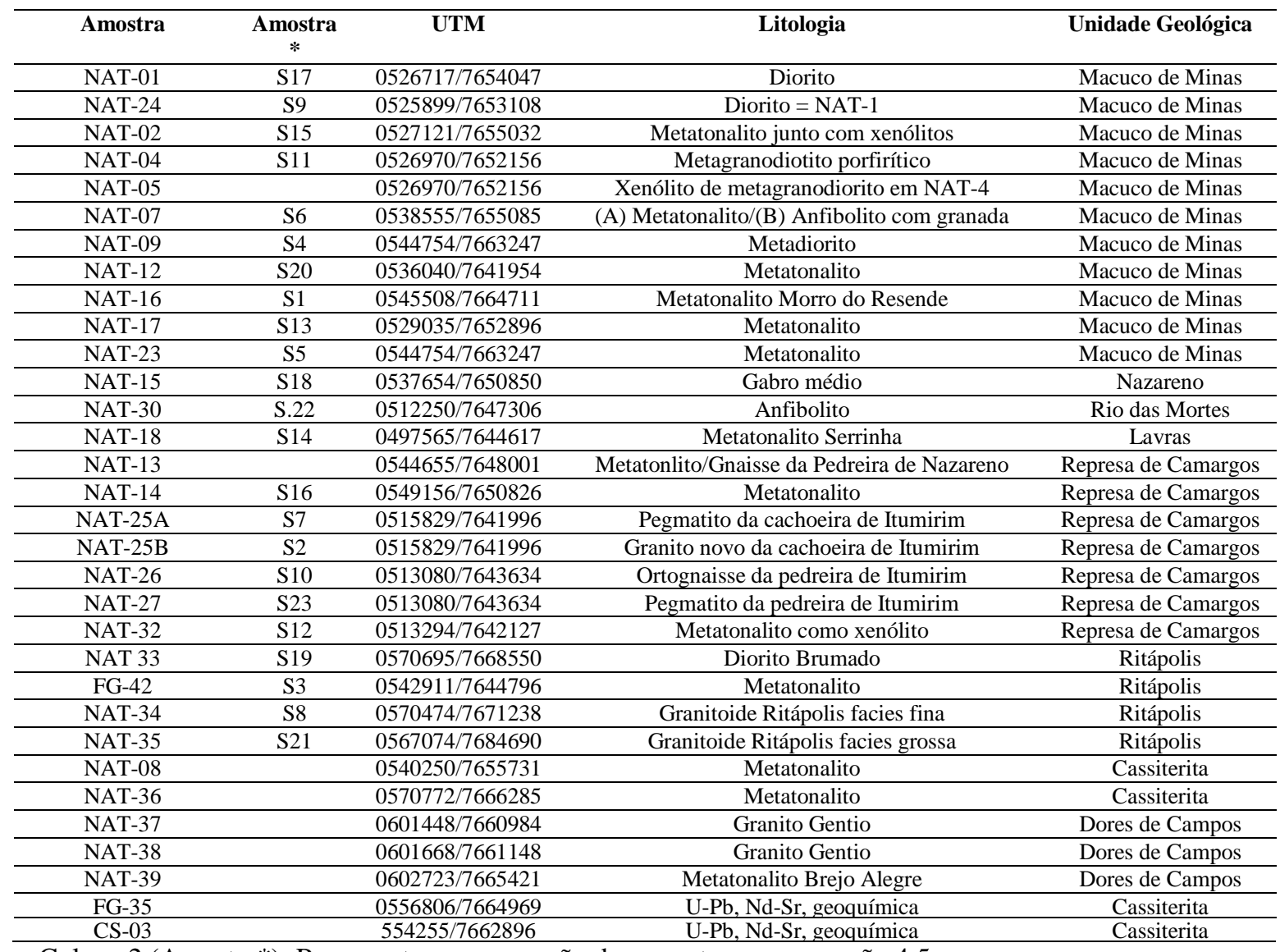

Coluna 2 (Amostra*): Representa a renomeação das amostras para a seção 4.5.

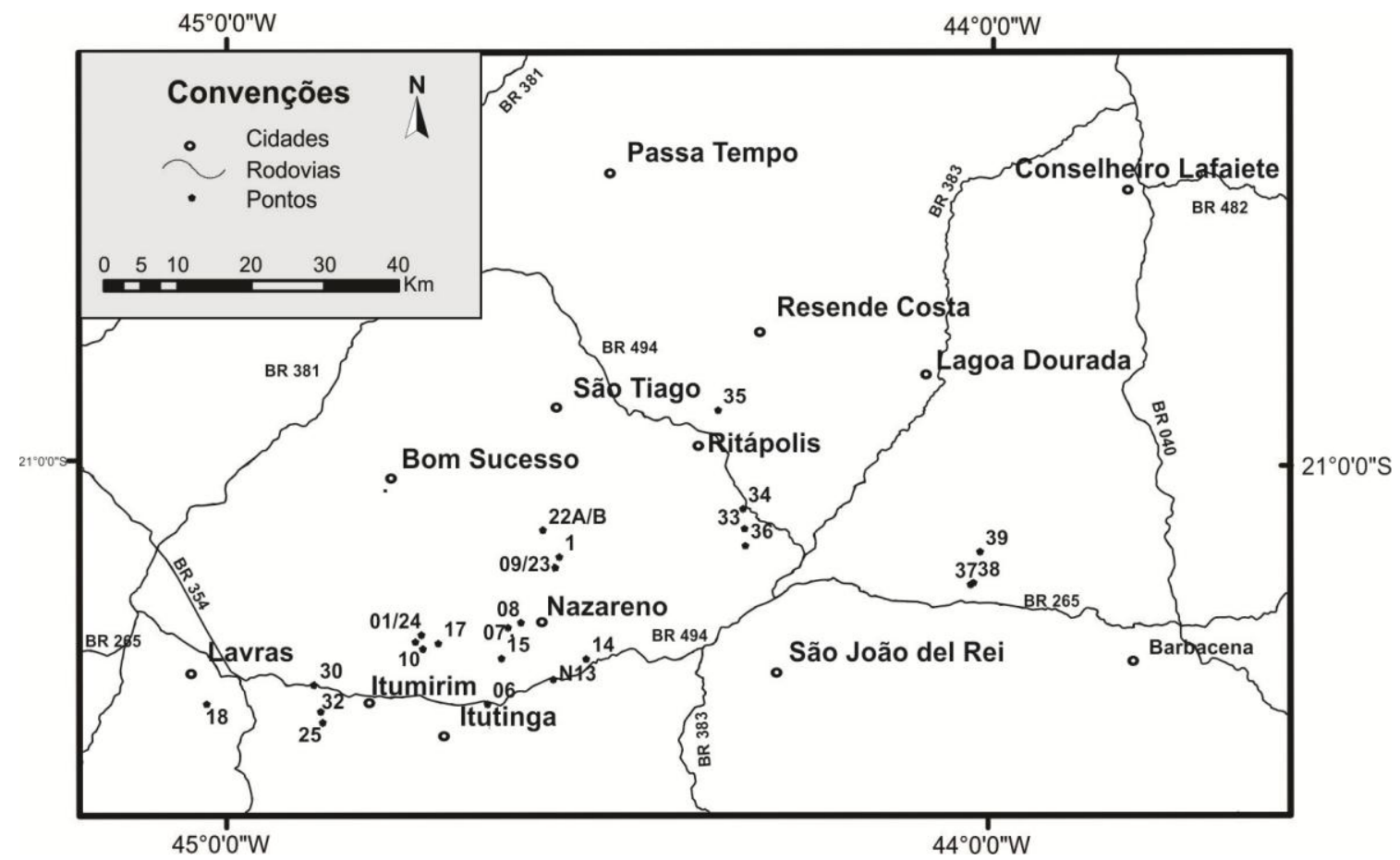

Figura 18. Mapa de localização e amostragem das rochas estudadas. Os números são as abreviações das amostras segundo a Tabela 4 (Coluna 1). 


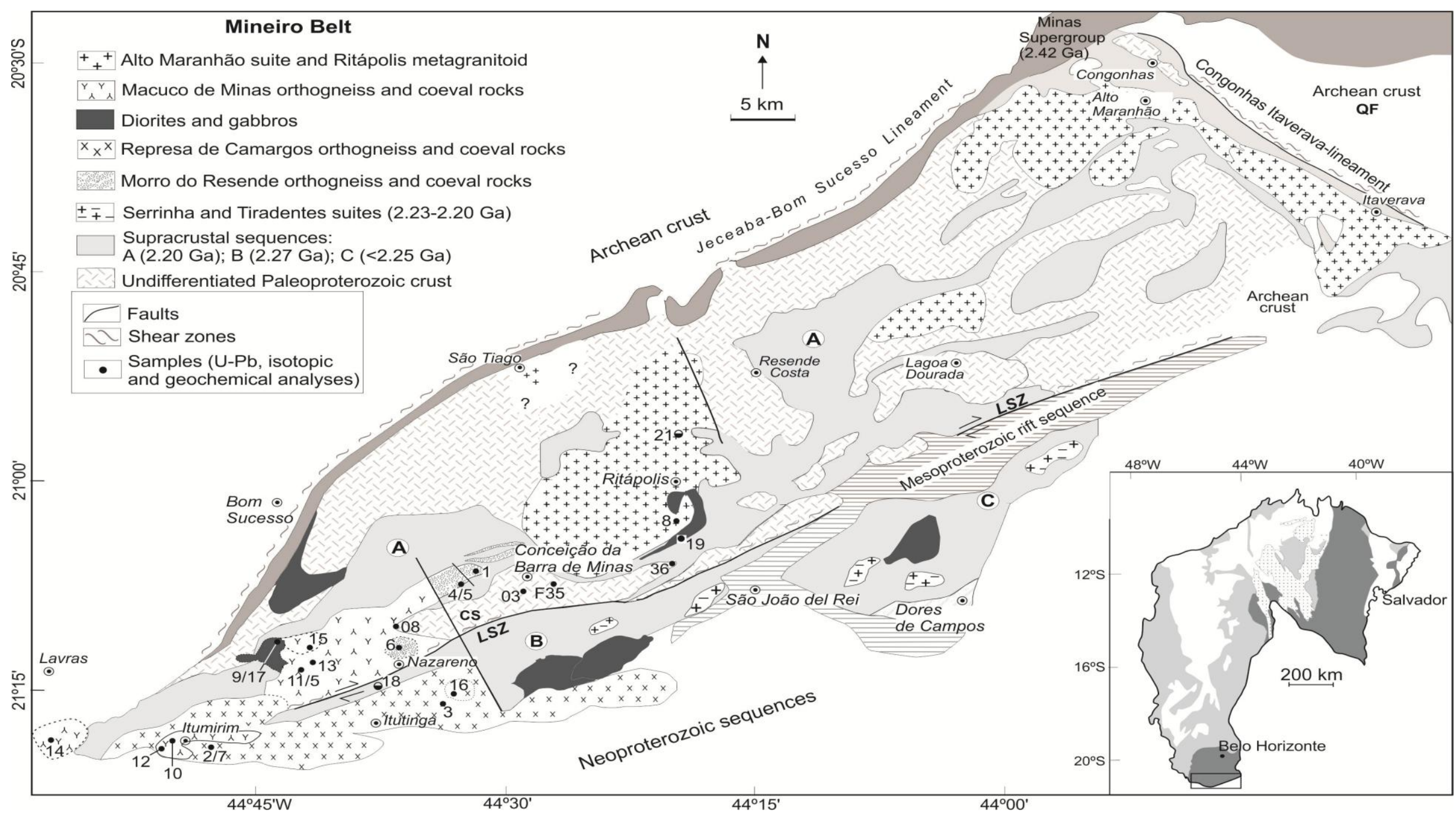

Figura 19. Mapa geológico da porção sul do Cráton do São Francisco, mostrando as unidades do Cinturão Mineiro (adaptado de Duarte et al., 2003; Quéméneur et al., 2003; Ávila et al., 2010; Corrêa Neto et al., 2012; Seixas et al., 2012). 


\subsubsection{Batólito Cassiterita}

O batólito Cassiterita, o mais antigo na região, ocorre na porção sudoeste do CM, nas imediações da cidade de Conceição da Barra de Minas, alongado na direção NE-SW, com dimensão de aproximadamente $150 \mathrm{Km}^{2}$. O corpo é constituído por rochas relativamente pouco diferenciadas de composições tonalítica e trondhjemítica (Ávila et al., 2003). É intrudido por granitoides e pegmatitos e contém xenólitos de rochas máficas e ultramáficas. É ainda cortado por zonas de cisalhamento e falhas. Em escala mesoscópica as rochas se apresentam em lajedos de tamanhos variados e cortes de estradas, que foram amostrados para os estudos desta Tese.

Os tonalitos e trondhjemitos (ou leucotonalitos; $\mathrm{M}=0-10 \%$ ) apresentam um fabric de origem metamórfica (Figura 20A e C). A orientação preferencial dos cristais de biotita gera a foliação tectônica de orientação NE-SW. A foliação é bem marcada com direções de 160/65; 150/45 e 155/58, apresentando porções miloníticas. O contato do batólito Cassiterita ao sul é brusco marcado por um sistema de falhas transcorrentes representada pela zona de cisalhamento regional Lenheiros (Figura 6 e 19). Na porção norte e leste este corpo encontra-se delimitado por ortognaisses e rochas máficas. $\mathrm{O}$ contato a norte/oeste com o corpo Manuel Inácio é irregular e intrusivo. A petrografia está descrita na Tabela 5 e o aspecto petrográfico na Figura 20.

Tabela 5. Petrografia das amostras estudadas do batólito Cassiterita. Abreviações para os minerais: Pl: Plagioclásio; Kfs: K-feldspato; Qtz: Quartzo; Olg: Oligoclásio; Ep: Epidote; Zrn: Zircão; Aln: Allanite; Chl: Clorita; Ttn: Titanita; Cal: Calcita; Ser: Sercita; Grt: Granada; Ap: Apatita; Di: Diopsidio; Hbl: Hornblenda; Bt: Biotita; e Opq: minerais opacos. Abreviações de acordo com Whitney e Evans (2010).

\begin{tabular}{lcccc}
\hline Amostra & Litologia & Aspecto de campo & $\begin{array}{c}\text { Minerais } \\
\text { principais }\end{array}$ & $\begin{array}{c}\text { Minerais } \\
\text { acessórios/secundários }\end{array}$ \\
\hline NAT-05 & Metagranodiorito & $\begin{array}{c}\text { Granul. fina, leucocrática, tex. } \\
\text { granolepidoblástica, equigranular }\end{array}$ & Qz, pl, mic e bt & ep, ttn, zrn, opq \\
\hline NAT-08 & Metatonalito & $\begin{array}{c}\text { Granul. Fina a média, leucocrática } \\
\text { granolepidoblástica, inequigranular }\end{array}$ & Qz, pl e bt & ep, ttn, zo, ap, zrn, all e opq \\
\hline NAT-36 & Metatonalito & $\begin{array}{c}\text { leucocrática, inequigranular, } \\
\text { granolepidoblástica }\end{array}$ & Qz, pl, bt & ep, ttn, zo, ap, zrn, aln, cla e \\
opq
\end{tabular}




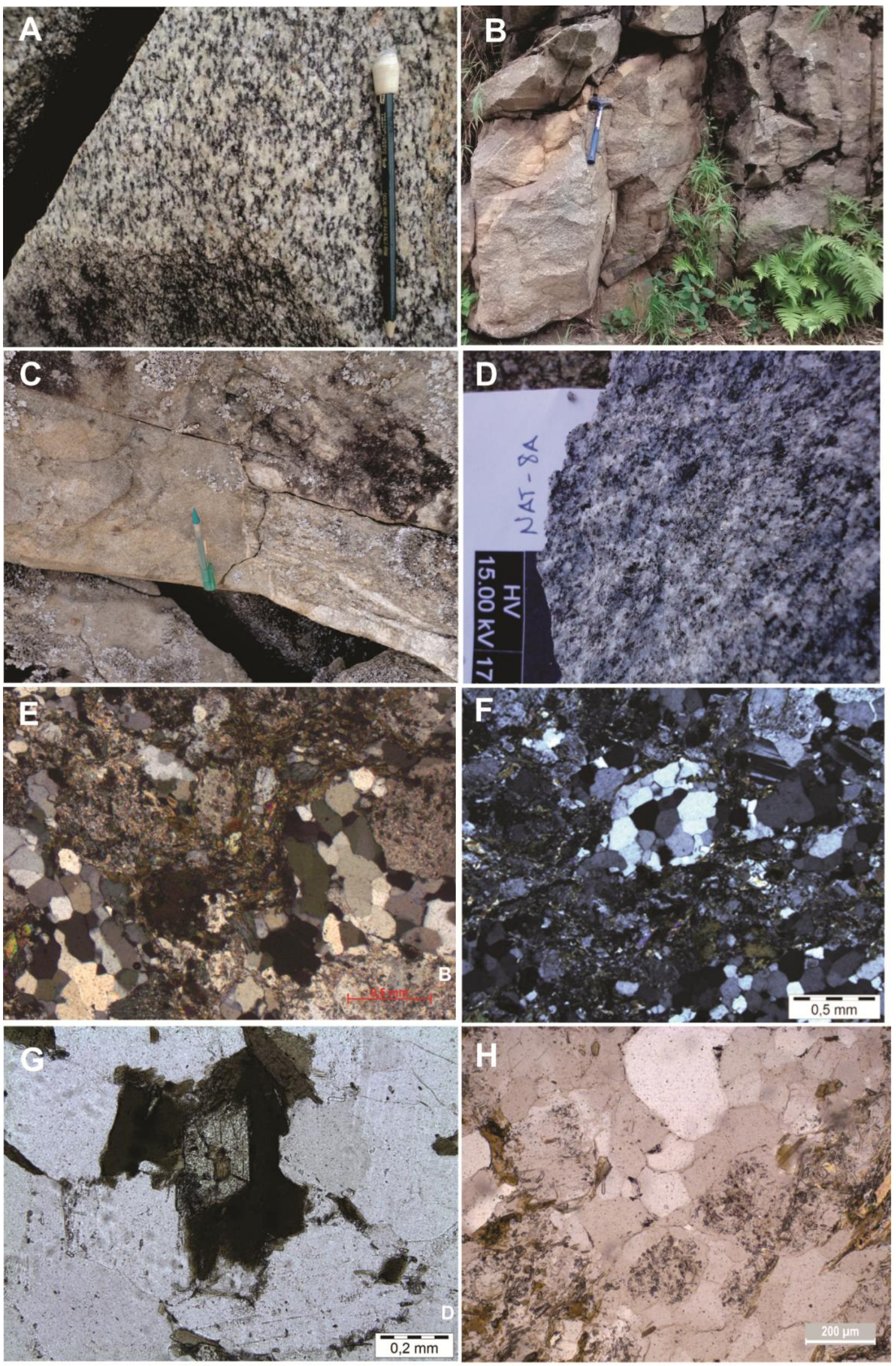

Figura 20. Aspectos de campo do ortognaisse Cassiterita: (A) NAT-36: mostrando a foliação definida pelos grãos de biotita; (B) dique granitoide cortando o ortognaisse; (C) NAT-5: xenólito do batólito 
Cassiterita no batólito Macuco de Minas; (D) similar a Fig. (A), a foliação é definida pelos grãos de biotita. Aspectos petrográficos do ortognaisse Cassiterita: (E) NAT-36: aspecto geral mostrado a textura lépido-granoblástica; (F) NAT-8: mostrando a textura geral e agregados de quartzo poligonizados em forma de sigmoide; (G) NAT-8: Allanita envolvida por epidoto euedral e biotita; (H) NAT-5: aspecto geral mostrando a textura lépido-granoblástica.

\subsubsection{Batólito Macuco de Minas}

O corpo ocupa a porção sudoeste do CM, com área de afloramento por cerca de $180 \mathrm{Km}^{2}$. O metagranitoide Macuco de Minas apresenta uma grande heterogeneidade geológica (tonalitos a granitos) em relação ao batólito adjacente Cassiterita, o que pode ser observado na Figura 21. Tal pluralidade composicional pode ser atribuída a múltiplos estágios magmáticos (ver seção 4.5). O batólito apresenta diversas litologias intercaladas por rochas ultramáficas e máficas da sequência Rio das Mortes. Apresentase, ainda, intrudido por granitoides e pegmatitos e, contém xenólitos de rochas félsicas, máficas e ultramáficas. Está geralmente cortado por zonas de cisalhamento e falhas com várias orientações. Os contatos dispõem-se ora bruscos, ora gradacionais em relação ao batólito Cassiterita e as sequências metavulcanossedimentares. Ao sul, possui contato tectônico com a zona de cisalhamento Lenheiro, a norte com rochas da sequência metavulcanossedimentar Rio das Mortes. Os contatos a leste e oeste ocorrem com os batólitos Cassiterita e Represa de Camargos respectivamente. Em escala mesoscópica os afloramentos são dispostos na forma de lajedos de tamanhos variados, boulders, leito de rios, pedreiras e cortes de estradas. As rochas são levemente foliadas a gnáissicas, a granulometria varia de média a grossa. A petrografia (Figura 22) dos afloramentos estudados está apresentada na tabela 6 .

Tabela 6. Petrografia dos afloramentos estudados do batólito Macuco de Minas.

\begin{tabular}{|c|c|c|c|c|c|c|c|c|}
\hline \multirow[t]{2}{*}{ Amostra } & \multirow[t]{2}{*}{ Litologia } & \multirow[t]{2}{*}{ Aspectos de campo e textura } & \multicolumn{5}{|c|}{ Minerais (\%) } & \multirow[b]{2}{*}{$\begin{array}{l}\text { Minerais } \\
\text { acessórios/secundários }\end{array}$} \\
\hline & & & $\mathrm{Qz}$ & $\mathrm{Pl}$ & $\mathrm{Bt}$ & $\mathrm{Hbl}$ & $\mathrm{Mc}$ & \\
\hline NAT-16 & $\begin{array}{l}\text { Ortognaisse } \\
\text { granodiorítico }\end{array}$ & $\begin{array}{l}\text { Granul. média a fina; textura } \\
\text { lepidogranoblástica;intrusivo nos } \\
\text { anfibolitos (Rio das Mortes) }\end{array}$ & 36 & 36 & 9 & & 20 & $\begin{array}{l}\text { Mgt, aln, zrn, ttn, chl, } \\
\text { opq, grt, ap, ep, zo }\end{array}$ \\
\hline \multirow[t]{2}{*}{$\begin{array}{l}\text { NAT- } \\
9 / 23\end{array}$} & $\begin{array}{l}\text { Metaquartzo- } \\
\text { diorito }\end{array}$ & $\begin{array}{l}\text { Granul. média a fina; textura } \\
\text { granolepidoblástica; estrutura } \\
\text { foliada;variedade litológica } \\
\text { paralelizada (NE-SW) }\end{array}$ & 15 & 47 & 23 & 10 & & Opq, Ep, Zrn, ttn, hbl \\
\hline & Metatonalito & $\begin{array}{l}\text { Granul. fina; estrutura } \\
\text { maciça/levemente foliada; textura } \\
\text { granolepidoblástica }\end{array}$ & 50 & 45 & 5 & & & $\begin{array}{l}\text { Ep, zo, opq, ap, zrn, } \\
\text { aln, chl, ttn, hbl }\end{array}$ \\
\hline NAT-7 & Metatonalito & $\begin{array}{l}\text { Granul. média; levemente foliada; } \\
\text { textura granoblástica; xenólitos de } \\
\text { anfibolito }\end{array}$ & 25 & 63 & 12 & & & $\begin{array}{l}\text { Ep, zo, ap, zrn, aln, ttn, } \\
\text { hem }\end{array}$ \\
\hline NAT- & Diorito & Granul. grossa; levemente foliada; & 10 & 60 & 4 & 25 & & Chl, opq, ep/zo, mc, \\
\hline
\end{tabular}




\begin{tabular}{|c|c|c|c|c|c|}
\hline $1 / 23$ & & $\begin{array}{l}\text { texturas ofítica, porfirítica, } \\
\text { inequigranular e granonematoblástica }\end{array}$ & & & cal, ser, ttn, zrn \\
\hline NAT-4 & $\begin{array}{l}\text { Meta } \\
\text { granodiorito }\end{array}$ & $\begin{array}{l}\text { Granul. média a grossa; texturas } \\
\text { porfirítica e inequigranular; xenólitos } \\
\text { de granitoides e diques pegmatíticos }\end{array}$ & $\begin{array}{ll}40 \quad 60\end{array}$ & 10 & $\begin{array}{l}\text { Ep, opq, ttn, ap, zrn, } \\
\text { aln, zo }\end{array}$ \\
\hline NAT-17 & Metatonalito & $\begin{array}{l}\text { Granul. média; levemente foliada; } \\
\text { texturas porfirítica, equigranular, } \\
\text { granolepidoblástica; com xenólitos de } \\
\text { gnaisses e anfibolitos, diques } \\
\text { pegmatíticos e graníticos }\end{array}$ & $13 \quad 54$ & 28 & $\begin{array}{l}\text { Ep, opq , ttn, ap, zrn, } \\
\text { aln, zo, amp }\end{array}$ \\
\hline NAT-18 & Metatonalito & $\begin{array}{l}\text { Granul. grossa; levemente foliada; } \\
\text { textura mega porfirítica; xenólito de } \\
\text { gnaisse e anfibolitos }\end{array}$ & $39 \quad 40$ & 10 & Ep, ap, zrn, ttn, opq, \\
\hline NAT-2 & Metatonalito & $\begin{array}{l}\text { Granul. média; levemente foliada; } \\
\text { textura granolepidoblástica; xenólitos } \\
\text { de anfibolitos e gnaisses }\end{array}$ & $30 \quad 55$ & 14 & $\begin{array}{l}\text { Hbl, ep, opq, ttn ap, } \\
\text { zrn, aln, zo }\end{array}$ \\
\hline
\end{tabular}
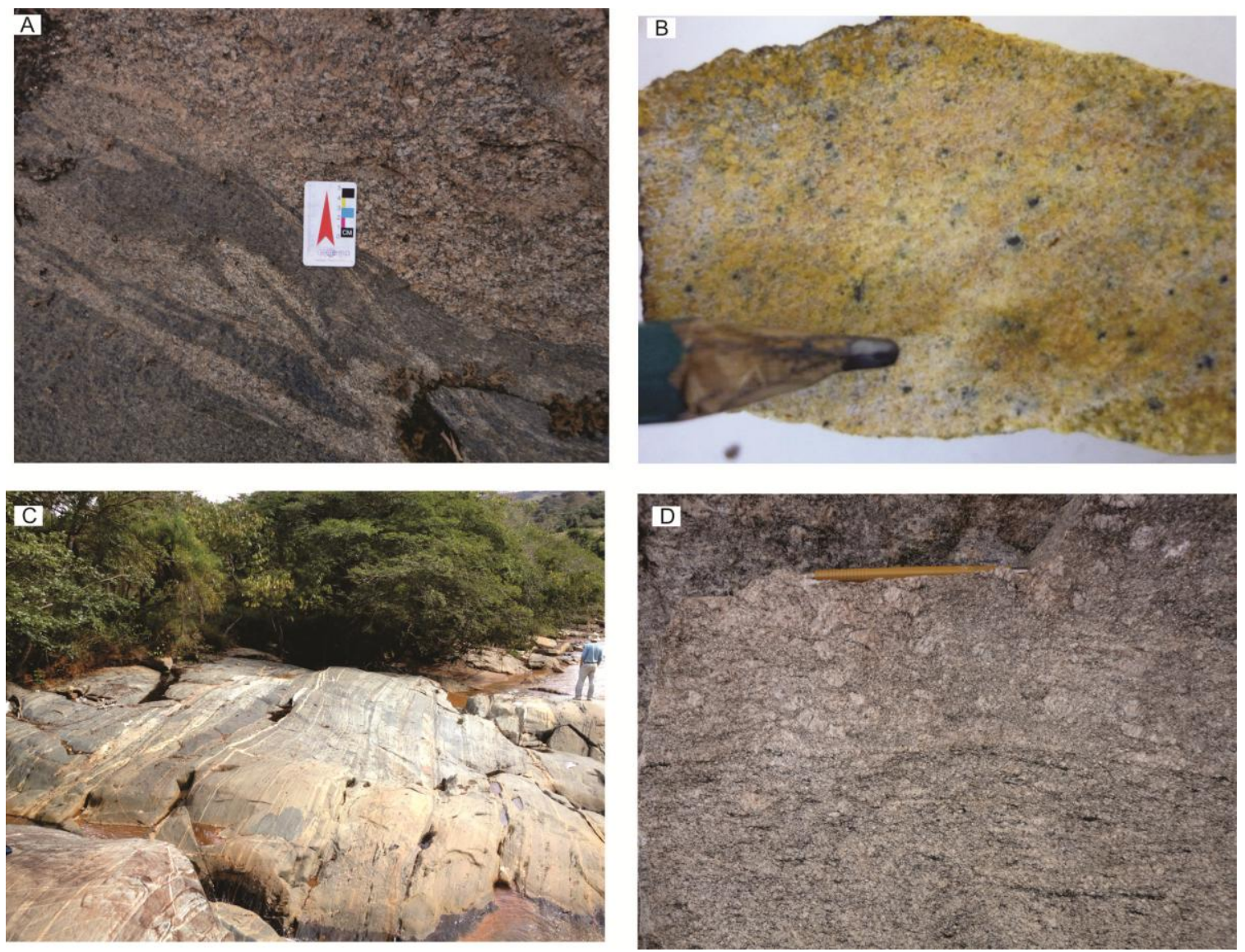

Figura 21. (A) Amostra NAT-17 mostrando o envolvimento do ortognaisse e metatonalito; (B) Ortognaisse Morro do Resende (NAT-16) mostrando os cristais de magnetita; (C) Zona de cisalhamento (NAT-9 e 23) mostrando as rochas paralelizadas (E-W); (D) Amostra NAT-4 mostrando a textura porfirítica. 

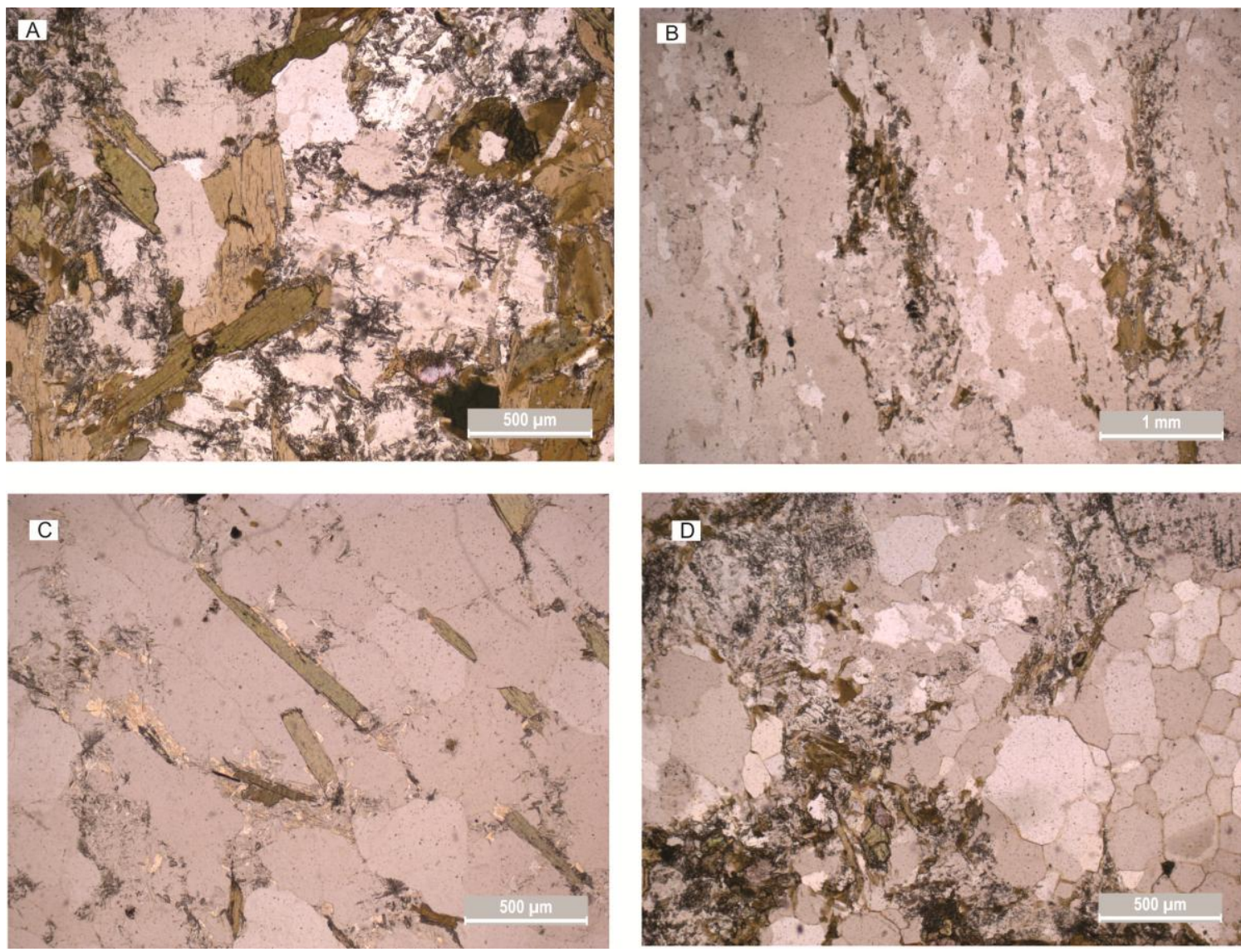

Figura 22. (A) Amostra NAT-17 mostrando incipiente foliação e textura equigranular; (B) Ortognaisse Morro do Resende (NAT-16) mostrando o bandamento gnáissico, cristais de quartzo agregados e a biotita foliada; (C) Amostra NAT-23 mostrando a orientação dos grãos de biotita; (D) Amostra NAT-4 com agregado de quartzo envolto por cristais de biotita e plagioclásio.

\subsubsection{Batólito Represa de Camargos}

O batólito Represa de Camargos ocupa a porção mais extrema sudoeste do CM, incluindo as cidades de Itumirim e Itutinga. A maior parte do batólito está localizada a sul da zona de cisalhamento Lenheiros, com dimensões de $\sim 350 \mathrm{Km}^{2}$. Este corpo faz contato com o greenstone belt Rio das Mortes e o batólito Macuco de Minas. Predominam rochas de composições granodioríticas a graníticas. As rochas também se apresentam como lajedos de tamanhos variados, com xenólitos de sequências metavulcanossedimentares e ortognaisses (alguns estirados e dobrados com os granitos). Macroscopicamente as rochas apresentam foliação ora bem marcada ora incipiente, sempre direcionada por grãos de biotita que gera a foliação tectônica na direção NESW. O batólito é heterogêneo desde sua composição (Figura 23) (e.g., granito foliado; ortognaisse granodiorítico, metatonalitos) até sua estrutura, textura e deformação. Possui estrutura que varia de levemente foliada até gnáissica, a granulometria varia de 
fina a média. Apresenta veios e injeções de aplitos, granitos e pegmatitos concordantes ou não com a foliação. A textura varia entre granoblástica, granolepidoblástica, equigranular e inequigranular. A petrografia (Figura 24) das rochas estudadas está apresentada na tabela 7 .

Tabela 7. Petrografia dos afloramentos estudados do batólito Represa de Camargos.

\begin{tabular}{|c|c|c|c|c|c|c|c|c|}
\hline \multirow[t]{2}{*}{ Amostra } & \multirow[t]{2}{*}{ Litologia } & \multirow[t]{2}{*}{ Aspectos de campo e textura } & \multicolumn{4}{|c|}{$\begin{array}{c}\text { Minerais } \\
(\%)\end{array}$} & \multirow[b]{2}{*}{$\begin{array}{l}\mathrm{M} \\
\mathrm{c}\end{array}$} & \multirow[b]{2}{*}{$\begin{array}{l}\text { Minerais acessórios/ } \\
\text { secundários }\end{array}$} \\
\hline & & & Qz & $\mathrm{Pl}$ & $\mathrm{Bt}$ & $\begin{array}{l}\mathrm{Hb} \\
1\end{array}$ & & \\
\hline NAT-25 & $\begin{array}{l}\text { Ortognaisse } \\
\text { granítico }\end{array}$ & $\begin{array}{l}\text { Granul. média; tex. lepidogranoblática; } \\
\text { xenólito de gnaisse máfico, rafts de } \\
\text { anfibolito e diques pegmatíticos }\end{array}$ & 34 & 30 & & 5 & 30 & $\begin{array}{l}\text { Zrn, bt, opq, grt, ap, } \\
\text { ep, zo }\end{array}$ \\
\hline NAT-26 & $\begin{array}{l}\text { Ortognaisse } \\
\text { granodioríti } \\
\text { co }\end{array}$ & $\begin{array}{l}\text { Granul. média a grossa; texturas } \\
\text { granolepidoblástica e inequigranular; } \\
\text { diques pegmatíticos, xenólitos e injeções } \\
\text { de granitoides }\end{array}$ & 40 & 24 & 7 & & 25 & Zrn, ap, aln, chl \\
\hline NAT-32 & $\begin{array}{l}\text { Meta- } \\
\text { tonalito }\end{array}$ & $\begin{array}{l}\text { Granul. fina; levemente foliada; textura } \\
\text { equigranular; rafts de anfibolito e diques } \\
\text { de pegmatitos }\end{array}$ & 45 & 35 & 12 & 7 & & $\begin{array}{l}\text { Ep, opq, ttn, ap, zrn, } \\
\text { aln, zo, hbl }\end{array}$ \\
\hline
\end{tabular}
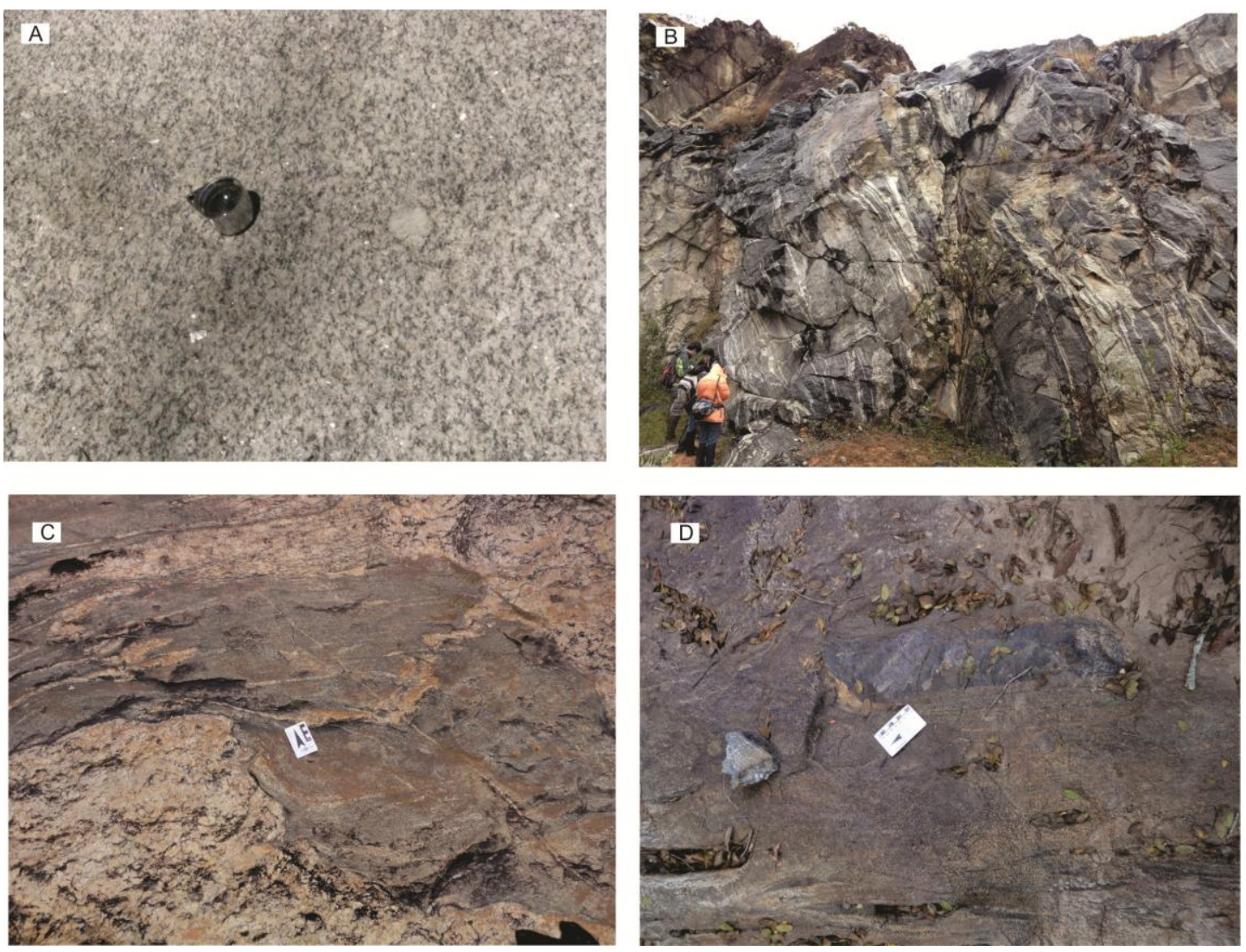

Figura 23. Aspectos de campo do batólito Represa de Camargos (A) Amostra FG-42 mostrando a textura equigranular do metatonalito; (B) Ortognaisse Itumirim (NAT-26) mostrando injeções granitoides no 
ortognaisse; (C) Ortognaisse granítico (NAT-25) com injeções pegmatíticas; (D) Metatonalito NAT-32 com rafts de anfibolito.
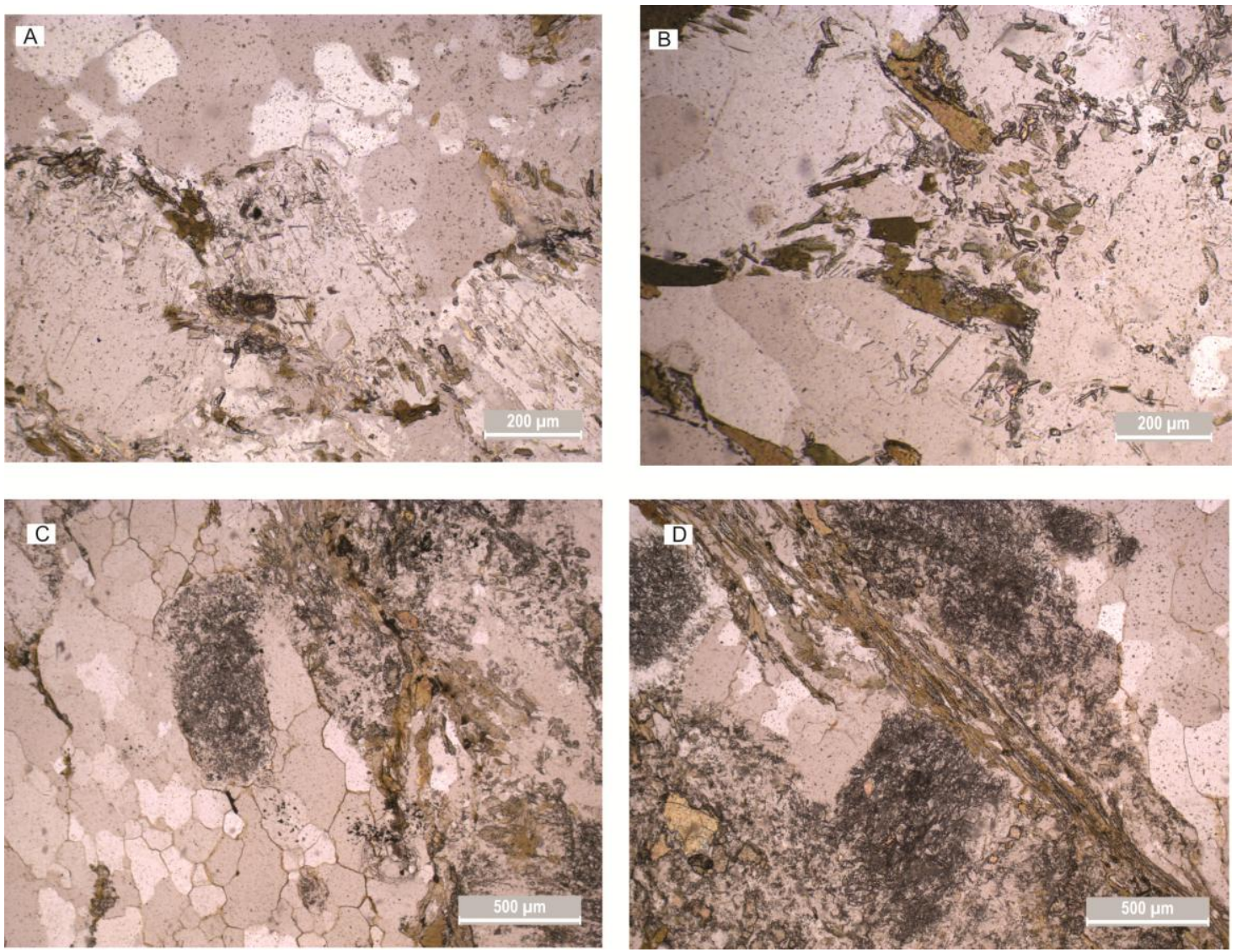

Figura 24. Aspectos petrográficos do batólito Represa de Camargos (A) Amostra FG-42 mostrando incipiente foliação e textura equigranular; (B) Ortognaisse Itumirim (NAT-16) mostrando a textura inequigranular; (C) Amostra NAT-25 mostrando grãos de quartzo agregados e a biotita definindo a foliação; (D) Amostra NAT-32 mostrando o plagioclásio sericitizado.

\subsubsection{Batólito Ritápolis}

O batólito Ritápolis tem sido estudado por diversos pesquisadores (e.g.: Noce et al., 2000; Quéméneur e Garcia, 1993; Teixeira et al.,2014), em termos composicionais químicos e isotópicos. É intrusivo na sequência Rio das Mortes, e está localizado ao norte da zona de Cisalhamento Lenheiros e a sudeste seus aplitos graníticos cortam o diorito Brumado. Faz contato tectônico com o ortognaisse Resende Costa, datado em 2,36 Ga (Teixeira et al., 2015). O batólito representa um corpo ovalado com dimensão de $\sim 400 \mathrm{Km}^{2}$, localizado na porção central do CM. Possui grande variedade petrográfica, composto por tonalitos a leucogranitos.

Em geral não possui foliação/xistosidade e quando ocorre, é incipiente. Faixas miloníticas podem ser observadas na borda sul do maciço. A granulometria varia de fina 
a grossa e localmente porfirítica. O batólito apresenta xenólitos de tonalitos e anfibolitos, cortado por diques pegmatitos. Dois afloramentos foram estudados, a petrografia está descrita na tabela 8 , enquanto que os aspectos de campo e petrográficos estão na Figura 25.

Tabela 8. Petrografia dos afloramentos estudados no batólito Represa de Camargos.

\begin{tabular}{|c|c|c|c|c|c|c|c|c|}
\hline \multirow[t]{2}{*}{$\overline{\text { Amostra }}$} & \multirow[t]{2}{*}{ Litologia } & \multirow[t]{2}{*}{ Aspectos de campo e textura } & \multicolumn{4}{|c|}{ Minerais (\%) } & \multirow[b]{2}{*}{$\mathrm{Mc}$} & \multirow[b]{2}{*}{$\begin{array}{l}\text { Minerais } \\
\text { acessórios/secundários }\end{array}$} \\
\hline & & & $\overline{\mathrm{Qz}}$ & $\mathrm{Pl}$ & $\mathrm{Bt}$ & $\mathrm{Hbl}$ & & \\
\hline NAT-34 & Granito & $\begin{array}{l}\text { Granul. fina; estrutura maciça/levemente } \\
\text { foliada; textura granoblástica e } \\
\text { equigranular; xenólitos de anfibolitos e } \\
\text { diques pegmatíticos }\end{array}$ & 35 & 25 & 5 & & 35 & $\begin{array}{l}\text { Ep, zo, ap, zrn, aln, chl, } \\
\text { ttn, ilm }\end{array}$ \\
\hline NAT-35 & Granodiorito & $\begin{array}{l}\text { Granul. média; estrutura levemente } \\
\text { foliada; textura granolepidoblástica e } \\
\text { equigranular; xenólitos de anfibolitos e } \\
\text { diques pegmatíticos }\end{array}$ & 40 & 30 & 10 & & 20 & $\begin{array}{l}\text { Ep, zo, ap, zrn, aln, chl, } \\
\text { ttn, ilm }\end{array}$ \\
\hline
\end{tabular}
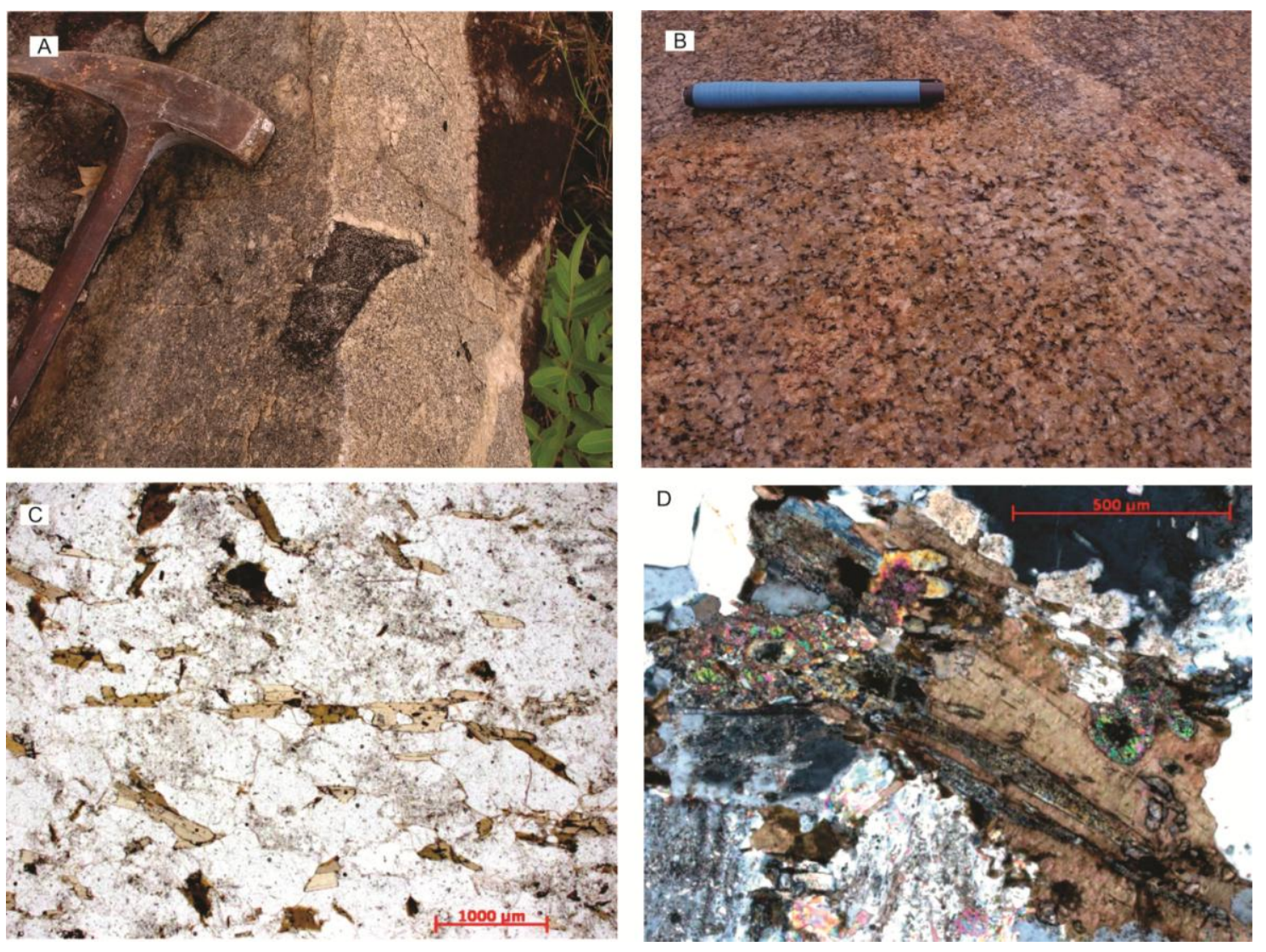

Figura 25. Aspecto de campo das rochas do batólito Ritápolis (A) Amostra NAT-34: mostrando a textura equigranular fina do granito; (B) afloramento mostrando textura média e inequigranular. Aspectos petrográficos das rochas do batólito Ritápolis; (C) textura inequigranular mostrando grãos de biotita discretamente orientados; (D) paragênese metamórfica típica das rochas do CM (Ep, aln, bt), mostrando o plagioclásio sericitizado. 


\subsection{O evento tectono-termal de $2,47-2,41 \mathrm{Ga}$}

TTG plutonism (2.4 Ga) unravelled in the Mineiro belt, southern São Francisco craton: zircon $\mathrm{U}-\mathrm{Pb}-\mathrm{H} f, \mathrm{Nd}-\mathrm{Sr}$ and geochemical fingerprints and tectonic significance

Este artigo trata da caracterização inédita, em preparação, do evento plutônico de 2,4 Ga que registra a fase inicial do plutonismo no CM. Idades desta ordem são de amplo interesse na comunidade científica internacional pela sua raridade, visto que a natureza episódica do magmatismo granítico é reconhecida nos períodos entre 2,7-2,5 e 2,1-1,9 Ga. Portanto, as idades eosiderianas aqui definidas para o batólito Cassiterita e sua gênese trazem uma nova perspectiva ao cenário do paleoproterozoico em termos globais. Como se sabe existe um debate atual acerca da geodinâmica do manto no intervalo Neoarqueano/Paleoproterozoico (e.g., Condie et al., 2009; Hawkesworth et al., 2009; Partin et al., 2014). A crescente descoberta de rochas com esta idade pode gerar uma possível reavaliação, do ponto de vista geotectônico, da interpretação para este período.

A área de estudo está localizada na porção sudoeste do CM, compreende essencialmente o batólito Cassiterita. Suas rochas possuem composição tonalítica e trondhjemítica, alinha-se na direção NE-SW consistente com o trend regional do CM. O objetivo deste trabalho foi detalhar a gênese e significado tectônico deste batólito. Para tanto, foram utilizados dados petrográficos, químicos, isotópicos e geocronológicos. Este plúton apresenta uma composição homogênea (observações de campo) ao longo de seu trend, característica esta não observada pelos batólitos mais jovens, estes dados permitiram, inicialmente, individualizar o batólito Cassiterita dos outros corpos do CM.

Estudos prévios (Ávila et al., 2003), no batólito Cassiterita, indicaram as primeiras inferências acerca de fontes, processos magmáticos e ambiente tectônico (i.e., fusão parcial, ambiente de arco continental). Contudo, os novos dados obtidos nesta Tese, apresentados com técnicas mais precisas, apontaram diferentes padrões geocronológicos e interpretações dos obtidos naquele trabalho.

Os resultados obtidos neste artigo foram 4 idades $\mathrm{U} / \mathrm{Pb}$ em zircão que variam de 2472 a 2414 Ma; 16 análises geoquímicas e 3 dados Nd-Sr e Hf. Os dados químicos e isotópicos corroboram os dados anteriores (Ávila et al., 2003) em se tratar de rochas TTGs geradas a partir de fusão de crosta máfica. Em relação ao ambiente tectônico estamos interpretando que se trata de rochas geradas em ambiente intra-oceânico com 
eventual contaminação de sedimentos derivados da margem do antepaís arqueano/Margem passiva Minas (Paleo-Cráton São Francisco). Esta interpretação é bem amarrada por dados químicos e isotópicos aliados ao conhecimento que durante a formação do batólito Cassiterita $(2,4 \mathrm{Ga})$, sedimentos carbonáticos de margem passiva estavam sendo depositados na bacia marginal. Este batólito está sendo interpretado como parte do primeiro arco $(2,4-2,3 \mathrm{Ga})$ gerado no $\mathrm{CM}$, adicionado às rochas do ortognaisse Resende Costa e da suíte Lagoa Dourada. 
TTG plutonism (2.4 Ga) unravelled in the Mineiro belt, southern São Francisco craton: zircon U-Pb-Hf, $\mathrm{Nd}-\mathrm{Sr}$ and geochemical fingerprints and tectonic significance

\author{
N. S. Barbosa ${ }^{a}$, W. Teixeira ${ }^{b *}$, C. A. Ávila ${ }^{c}$, P. M. Montecinos ${ }^{b}$, E. M. Bongiolo ${ }^{d}, F$. \\ F. Vasconcelos ${ }^{\mathrm{d}}$ \\ a Programa de Pós-Graduação em Geoquímica e Geotectônica, Instituto de Geociências, \\ Universidade de São Paulo, São Paulo, SP, Brazil (natali@usp.br) \\ ${ }^{\mathrm{b}}$ Instituto de Geociências, Universidade de São Paulo, São Paulo, SP, Brazil \\ (wteixeir@usp.br) \\ ${ }^{\mathrm{c}}$ Museu Nacional, Universidade Federal do Rio de Janeiro, Rio de Janeiro, RJ, Brazil \\ ${ }^{\mathrm{d}}$ Instituto de Geociências, Universidade Federal do Rio de Janeiro, Rio de Janeiro, RJ, \\ Brazil
}

\title{
Abstract
}

The $2.45 \mathrm{Ga}$ Cassiterita orthogneiss is one of the largest batholiths of the Mineiro belt, southern portion of the São Francisco Craton. We present and discuss new zircon ages, geochemical data, coupled with whole-rock $\mathrm{Sr}-\mathrm{Nd}$ and zircon $\mathrm{Hf}$ isotopic constraints for unravelling the nature and tectonic setting of the Cassiterita pluton, in the context of the Paleoproterozoic accretionary evolution of the main belt. Three U-Pb zircon crystallisation ages are between $2472 \pm 11 \mathrm{Ma}$ and $2414 \pm 29 \mathrm{Ma}$ whereas the metamorphic overgrowths yield ages between 2160-2020 Ma. One metatonalite yields $2156 \pm 17 \mathrm{Ma}$, whilst a single inherited nuclei at $2426 \pm 17 \mathrm{Ma}$ (concordant ${ }^{207} \mathrm{~Pb} /{ }^{206} \mathrm{~Pb}$ age). The Cassiterita rocks consist of tonalites, granodiorites and trondhjemites. The trace elements study point out that these rocks are probably product of partial melting with a subordinate role of fractional crystallization. Major and minor element contents suggest a TTG affinity, also mirrored in diagrams like $\mathrm{K}-\mathrm{Ca}-\mathrm{Na}$ and An-Ab-Or. The positive $\varepsilon_{\mathrm{Nd}(\mathrm{t})}(+5.2$ to +1.3$)$ and low ${ }^{87} \mathrm{Sr}^{86}{ }^{8 \mathrm{Sr}_{\mathrm{i}}}$ 0.700-0.702 isotopic signatures coupled with geochemical data (e.g., negative $\mathrm{Nb}$ and $\mathrm{Ti}$ anomalies) are consistent with an enriched LREE MORB magma source that was subjected to minor crustal assimilation of older felsic material. Additionally, the negative Hf signatures and the lack of significant $\mathrm{Eu}$ and $\mathrm{Sr}$ anomalies support a garnet amphibolite as residue during the petrogenesis. The Cassiterita batholith may be comparable in composition, geochemistry and isotopic terms with genesis of the nearby $2.35 \mathrm{Ga}$ Lagoa Dourada TTG suite and the coeval Resende Costa orthogneiss that similarly originated in oceanic arc setting ca. 100 m.y later. The geologic-tectonic correlations indicate that the Cassiterita arc-related I-type pluton marks the earliest orogenic phase of a long-lived accretionary process $(2.47-2.10 \mathrm{Ga})$ during which the Mineiro belt and two other adjoining belts (Mantiqueira, Juiz de Fora) were formed outboard the proto-Archean margin of the São Francisco Craton. 


\section{Keywords}

São Francisco Craton, early Paleoproterozoic, TTG rocks; Zircon U-Pb-Hf, Nd-Sr isotopes, Geochemistry.

\section{Introduction}

Coeval tonalites, trondhjemites and granodiorites comprise TTG suites that represent important constituents of continental crust (Jahn et al., 1981). They are chemically characterized by high $\mathrm{Na}$ contents, low $\mathrm{K}_{2} \mathrm{O} / \mathrm{Na}_{2} \mathrm{O}$, high $\mathrm{Al}_{2} \mathrm{O}_{3}$, high LREE and low HREE contents (Moyen and Martin, 2012 and references therein).

The genesis of TTG suites is a fundamental issue for better understanding the processes by which the Archean continental crust was developed. However they are also present in early Paleoproterozoic times, given that the primitive continental crust grew through oceanic accretionary arcs (e.g., Reimink et al., 2014; Condie and Kroner, 2013). Distinct magmatic processes have been envisaged for the origin of TTG suites such as direct melts of subducted oceanic crust (Condie, 1981), and further fractional crystallisation (e.g., Martin, 1987), fractional crystallisation of wet basaltic magma (Arth, 1979; Martin et al., 2005), partial melting of the mantle with metasomatised fluids (Moorbath, 1975), among other models. According to Foley et al. (2002) TTG melts have low $\mathrm{Nb} / \mathrm{Ta}$ and high $\mathrm{Zr} / \mathrm{Sm}$ ratios related to a garnet bearing amphibolite residue, which is HREE enriched. We note that this has important bearing for the Hf systematics given by the lower $\mathrm{Lu} / \mathrm{Hf}$ ratio in the melt compared to the residue because the Lu-Hf fractionation toward the continental crust is very high. In contrast the $\mathrm{Sm} / \mathrm{Nd}$ systematic does not show contrasting signatures between these members because the lower Sm-Nd fractionation within the crust, after the mantle derivation of a given rock (Hawkesworth and Kemp, 2006). As such the combination of the Hf-Nd constraints on granitoid rocks are a powerful tool to decipher the petrogenesis and differentiation of the magma source.

At global scale, Early Paleoproterozoic granitoids rocks (2.45-2.20 Ga) like TTG suites, are relatively scarce compared to the Archean ones. This peculiarity has been a matter of debate in terms of the geodynamic significance of the mantle given the expected cyclic production of continental crust through time. For instance several hypothesis have been proposed, such as minor mantle melting at that time interval (e.g., Condie et al., 2009) and/or weak crustal production, as suggested by the 
geochronological and isotopic constraints of arc-granitoids elsewhere (Eriksson and Condie., 2014). In particular U-Pb zircon age in granitoid rocks, in distinct continents indicated a shortage of ages between 2.45-2.20 Ga with a marked gap of the 250 m.y. immediately after the Archean time (O’Neill et al., 2007; Silver and Behn, 2008; Condie et al., 2009). Alternative views pointed out that this "global gap" could reflect different potential preservations of continental crust through time, and depending on the specific arc setting where the granitoid rocks are formed (e.g., Hawkesworth et al., 2009).

In this regard it is worth noting that recent compilation of $\mathrm{U}-\mathrm{Pb}$ data worldwide including TTG suites, granitoid rocks and mafic/felsic dykes revealed and a significant number of representative rocks (both arc and extensional settings) in the 2.4-2.3 Ga age interval (e.g., Partin et al., 2014) suggesting a continuous subduction regime during the Early Paleoproterozoic. In consequence this led to arc-magmatism and crustal reworking, such as reported in the Canadian Shield (siliciclatic and granitoid rocks $2.31 \mathrm{Ga}$ ), Côte d'Ivoire - West Africa (TTG rocks of the Dabakala area - 2.31 Ga) (Gasquet et al., 2003) and North China (TTG gneiss of the Lüliang complex - 2.38 Ga (Zhao et al., 2008), among other examples. Notably the 2.42 Ga Scourie dykes on the Baltic shield are related to intraplate setting (Heaman and Tarney., 1989). From the above Partin et al. (2014) argue that a crustal age gap between 2.4-2.3 Ga is probably an artifact, as previously suggested by Hawkesworth and coauthors (2009).

In a similar matter, the South American continent preserves scattered Early Paleoproterozoic arc-related rocks with ages between 2.4 and $2.3 \mathrm{Ga}$, as follow: (i) TTG rocks of Lagoa Dourada-Resende Costa suite, Mineiro belt - southern São Francisco craton, Brazil - 2360-2330 Ma (Seixas et al., 2012; Teixeira et al., 2015); (ii) Granulite rocks with tholeiitic chemical signatures in the Juiz de Fora complex - $2427 \mathrm{Ma}$ (Heilbron et al., 2010) to the east of the Mineiro belt, though strongly reworked in the Neoproterozoic. (iii) Charnockitic gneisses of the Jequié complex, northern São Francisco craton - $2473 \mathrm{Ma}$ (Silva et al., 2002). iv) TTG suite of the Granja complex Borborema Province - 2358-2288 Ma (Dos Santos et al., 2009); (v) Tonalites of the Bacajá domain, Amazonian craton - 2359-2314 Ma (Vasquez et al., 2008; Macambira et al., 2009). Nevertheless the major period of orogenic crustal growth occurred between 2.2 and $2.0 \mathrm{Ga}$ ago, as supported by radiometric and isotopic data on granitoid rocks and siliciclastic sequences (detrital zircon ages) over most continents. The Wopmay orogeny in NW Canadian shield (Hildebrand et al., 1987), Sleaford orogeny in south 
Australia (Goodwin, 1991), Svecofennian-Karelides in Baltic shield (Lahtinen and Huhma, 1997), Eburnean in Africa (Egal et al., 2002), Transamazonian in Amazonia (Brito Neves, 2011) are some of the examples. From a paleotectonic point of view these age records have been interpreted as a genetic fingerprint of a growing Columbia (also known as Nuna) - e.g., Zhao et al., 2004; Meert, 2012; Evans and Mitchell, 2011).

The Minas accretionary orogeny in southern SFC (Teixeira et al., 2015) provides an ideal laboratory for detailing the nature and evolution of the Paleoproterozoic crust, given the widespread exposure of different generations of granitoid rocks (e.g., Ávila et al., 2010; Seixas et al., 2012). This orogeny comprised a system of oceanic and continental arcs that produced significant continental growth between 2.36-2.12 Ga ago (outboard an Archean landmass - the proto SFC) such as in the Mineiro belt (Noce et al., 2000; Seixas et al., 2013; Ávila et al., 2014; Teixeira et al., 2015). In this regard, TTG suites have been described in the main belt, such as the 2.35 Ga Lagoa Dourada and the 2.12 Ga Alto Maranhão suites (Seixas et al., 2012; 2013; Teixeira et al., 2015).

This paper presents isotopic and geochemical data of the Cassiterita batholith, the oldest pluton identified in the Mineiro belt so far. We performed systematic age zircon and isotopic ( $\mathrm{Hf}, \mathrm{Nd}, \mathrm{Sr}$ ) studies and geochemistry in the attempt to interpret the petrogenesis and the tectonic significance of the Cassiterita rocks. The geodynamic significance of the new data is also addressed, considering the Mineiro belt and a global scale approach.

\section{Geologic framework}

Polycyclic terranes constitute the southern fringe of the São Francisco craton, given by Archean rocks (granulites and amphibolite facies migmatized gneisses), greenstone belts and supracrustal sequences (e.g., Rio das Velhas and Minas Supergroups), and a variety of metaigneous rocks (e.g., Machado and Carneiro, 1992; Teixeira et al., 1996; Hartmann et al., 2006; Campos and Carneiro, 2008). The Archean rocks (3.20-2.60 Ga) have been characterized as distinct gneissic complexes, and exhibit variable deformation and metamorphism (Teixeira et al., 1996; Alkmim and Marshak, 1998; Lana et al., 2013; Romano et al., 2013). They were formed in two major orogenies, the Campo Belo (3.2-3.0 Ga) and Rio das Velhas (2.78-2.70 Ga) - Teixeira et al. (submitted). The gneisses and migmatites are intruded by potassic granitoids (2.75- 
2.60 Ga; Noce et al., 1997; Romano et al., 2013) after which the Archean continental crust attained tectonic stability.

The deposition of the Minas Supergroup - an alluvial to marine foreland basin low- to medium grade metasedimentary strata - occurred after $2.6 \mathrm{Ga}$ ago from erosion of distinct sources, as suggested by $\mathrm{U}-\mathrm{Pb}$ zircon provenance studies and geologic relationships with the Archean country rocks (Table 1). The Minas Supergroup is a classical unit of the Quadrilatero Ferrífero $(\mathrm{QF})$ due to the huge deposits of Iron ores (Door, 1969). It is composed of clastic and chemical metasedimentary rocks, banded iron formations, dolomites and marbles that highlight the distinct evolutionary stages of the proto-basin (Renger et al., 1994; Alkmim and Noce, 2006). The Caraça Group, the lowermost unit, consists of alluvial and aeolian deposits evolving to marine ones. The $\mathrm{U}-\mathrm{Pb}$ detrital zircon ages range between 3250-2580 Ma, where the younger age mode $(2.58 \mathrm{Ga})$ infers the maximum age of deposition (e.g., Hartmann et al., 2006; Machado et al., 1996). The overlying Itabira Group comprises the Cauê formation (thick BIFs and amphibole-rich itabirites) and the upper Gandarela formation (dolomites, magnesian limestone and dolomitic itabitite) (Babinski et al., 1995). The dolomites were dated at $2420 \pm 19 \mathrm{Ma}\left({ }^{207} \mathrm{~Pb} /{ }^{206} \mathrm{~Pb}\right.$ whole isochron age; Babinski et al., 1995). The upper Piracicaba Group contains predominantly zircon derived from Archean crust, and yields ages range from 3353-2775 Ma (Machado and Carneiro, 1996).

The uppermost Sabará Group (rocks metapelites, diamictites, conglomerates, and lithic sandstones) represents a significant change of sediment sources compared to the lower strata of the Minas Supergroup, and its maximum deposition age is 2164-2125 $\mathrm{Ma}$ on the basis of U-Pb detrital zircon ages in grawackes and tuffs (Machado and Carneiro, 1992, 1996; Alkmim et al., 2014). The Itacolomi Group corresponds to a sucession of sandstones, conglomerates and minor pelites (Alkmim and Noce, 2006). There is a regional unconformity between Sabará and Itacolomi Groups, which the last is interpreted as a molasse deposit (Dorr, 1969). Alkmim and Marshak (1998) propose a small intermontane basin to deposit the sediments. From a paleotectonic perspective, the lower strata of the Minas Supergroup were eventually subjected to significant crustal shortening at the time of deposition of the Sabará and Itacolomi Group. According to Alkmim and Noce (2006) the Paleoproterozoic structural framework is consistent with a NNW-verging thrusting and associated folding, representing the development of the foreland fold/thrust belt of a collisional orogen at ca. $2.1 \mathrm{Ga}$ after which basement 
domes and associated keels of supracrustal rocks were formed (extensional collapse conditions ) - as observed in the Quadrilátero Ferrífero region.

Table 1. Chronostratigraphic-tectonic characteristics of the Minas Supergroup at the Quadrilátero Ferrífero.

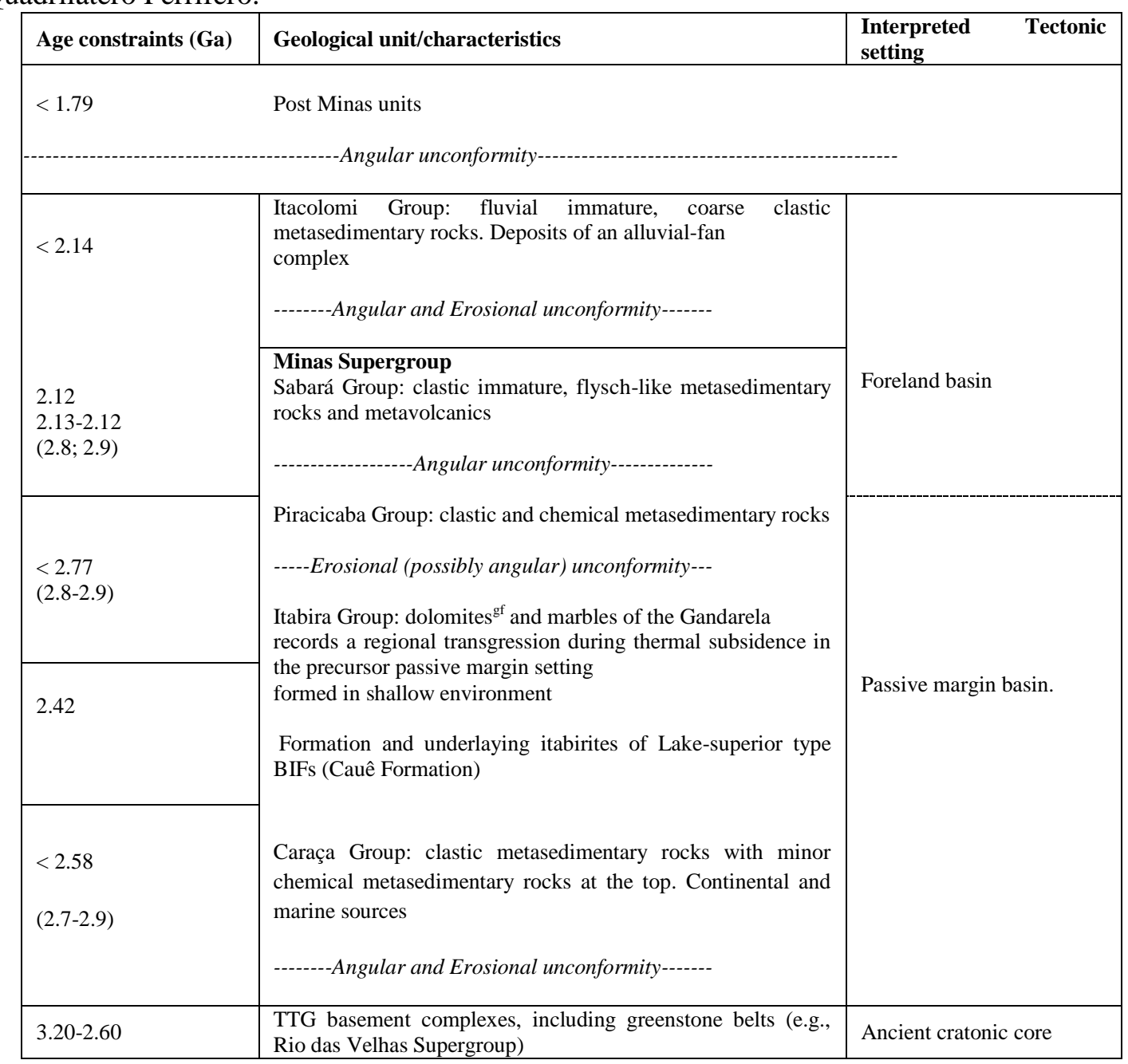

\subsection{Mineiro belt}

The Mineiro belt (MB) (e.g., Ávila et al., 2014 and references therein) crops out to the south of the Jeceaba-Bom Sucesso lineament where scattered exposures of the Minas Supergroup and older rocks are present (Fig. 1). The belt is bounded to the east along the Congonhas-Itaverava lineament (Campos and Carneiro, 2008; Teixeira et al., 2015). Geologic and geochronologic evidence suggest that the Archean basement (see above) acted as a tectonically stable foreland during outboard propagation of magmatic arcs of the MB. In such model, the Minas Supergroup represents the related passive- 
margin to syn- orogenic unit because the Minas strata were eventually deformed and metamorphosed at Paleoproterozoic times (Alkmim and Noce, 2006; Teixeira et al., 2015).

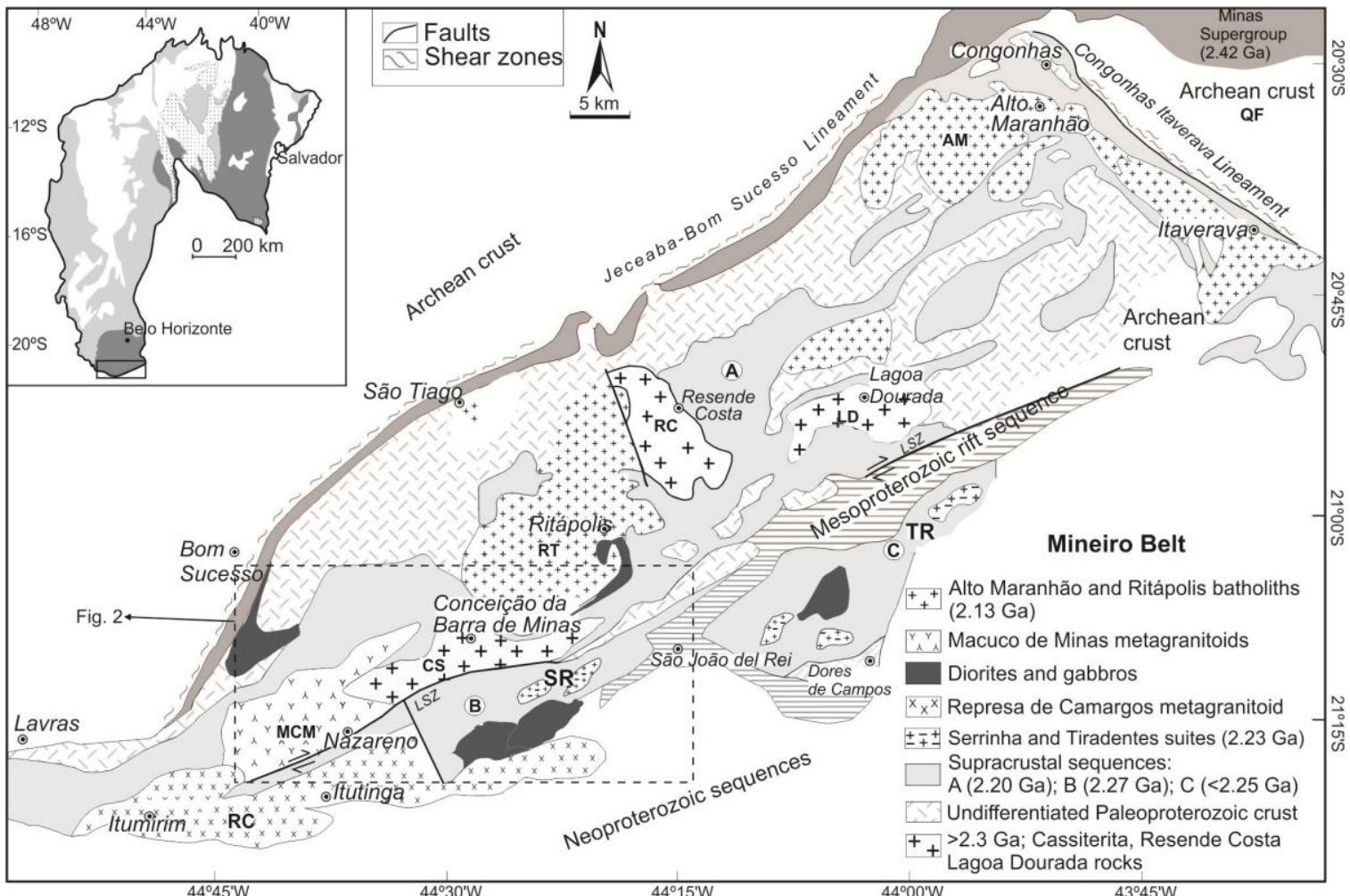

Figure 1. Geologic framework of the southernmost part of the São Francisco Craton - SFC, showing the main units of the Mineiro belt (adapted from Duarte et al., 2003; Quéméneur et al., 2003; Ávila et al., 2010; Corrêa Neto et al., 2012; Seixas et al., 2012, 2013; Teixeira et al., 2015). QF: Quadrilátero Ferrífero. LZC: Lenheiros shear zone. Inset shows the SFC: dark gray: basement rocks; light gray and white: covers. RC: Resende Costa suite; LD: Lagoa Dourada suite; CS: Cassiterita batholith; TR: Tiradentes orthogneiss; SR: Serrinha suite; MCM: Macuco de Minas batholith; RC: Represa de Camargos batholith; RT: Ritápolis batholith.

Much of the Mineiro belt (MB) is comprised by granitoid rock, orthogneisses and metavolcanosedimentary sequences of low- to medium metamorphic grade. They are locally termed Nazareno, Rio das Mortes and Dores de Campos (Ávila et al., 2014; Teixeira et al., 2015). These units collectively make up a Paleoproterozoic orogen (2.36$2.09 \mathrm{Ga}$ ) that can be distinguished in time and space in terms of distinct arc-plutonic units. For example the Lagoa Dourada suite and the Resende Costa orthogneiss (Table 2) represent the oldest (2.36-2.33 Ga) TTG association within the main belt. According to Teixeira et al (2015) these rocks disclose juvenile-like $\varepsilon_{\mathrm{Nd}(\mathrm{t})}$ and $\varepsilon_{\mathrm{Sr}(\mathrm{t})}$ values that suggest derivation from a short-lived, slightly depleted source akin to products of island arcs. The geochemical signature is consistent with high $\mathrm{Al}_{2} \mathrm{O}_{3}$ trondhjemites, derived from a tholeiitic source with minor crustal assimilation, as also suggested by the positive to negative zircon $\varepsilon_{\mathrm{Hf}(\mathrm{t})}$ zircon values. The other younger arcs formed the 
Serrinha-Tiradentes (2.23-2.22 Ga) suites which rocks show calc-alkaline affinity (Ávila et al., 2010; 2014). Eventually, the 2.13 Ga Alto Maranhão batholith which shows peculiar TTG affinity (Seixas et al., 2013) was formed in oceanic setting (see Table 2). It is intrusive into the Rio das Mortes supracrustal sequence (Teixeira et al., 2015). Notably the Ritápolis calc alkaline batholith yields a U-Pb ICPCM-LA zircon crystallisation age of $2149 \pm 10 \mathrm{Ma}$ (Teixeira et al., 2015), which is c. $28 \mathrm{~m}$.y older than the previous published ${ }^{207} \mathrm{~Pb} /{ }^{206} \mathrm{~Pb}$ zircon evaporation age $(2121 \pm 7 \mathrm{Ma}$; Ávila et al., 2003). In other words both batholiths are coeval and were formed during the youngest arc of the Mineiro belt (Teixeira et al., 2015). This plutonic arc probably triggered the Paleoproterozoic architecture of the Archean basement of the QF, as evidenced by previously published structural studies (Alkmim and Marshak, 1998).

Table 2 presents the geologic and chemical characteristics of the recognized arcs of the MB.

Table 2. Summary of geologic-tectonic characteristic of the MB. Data compiled from 1. Teixeira et al., 2015; 2. Ávila et al., 2010, 3. 2014; 4.Seixas et al., 2012; 5. 2013; 6. Noce et al., 2000; 7. Barbosa et al., submitted.

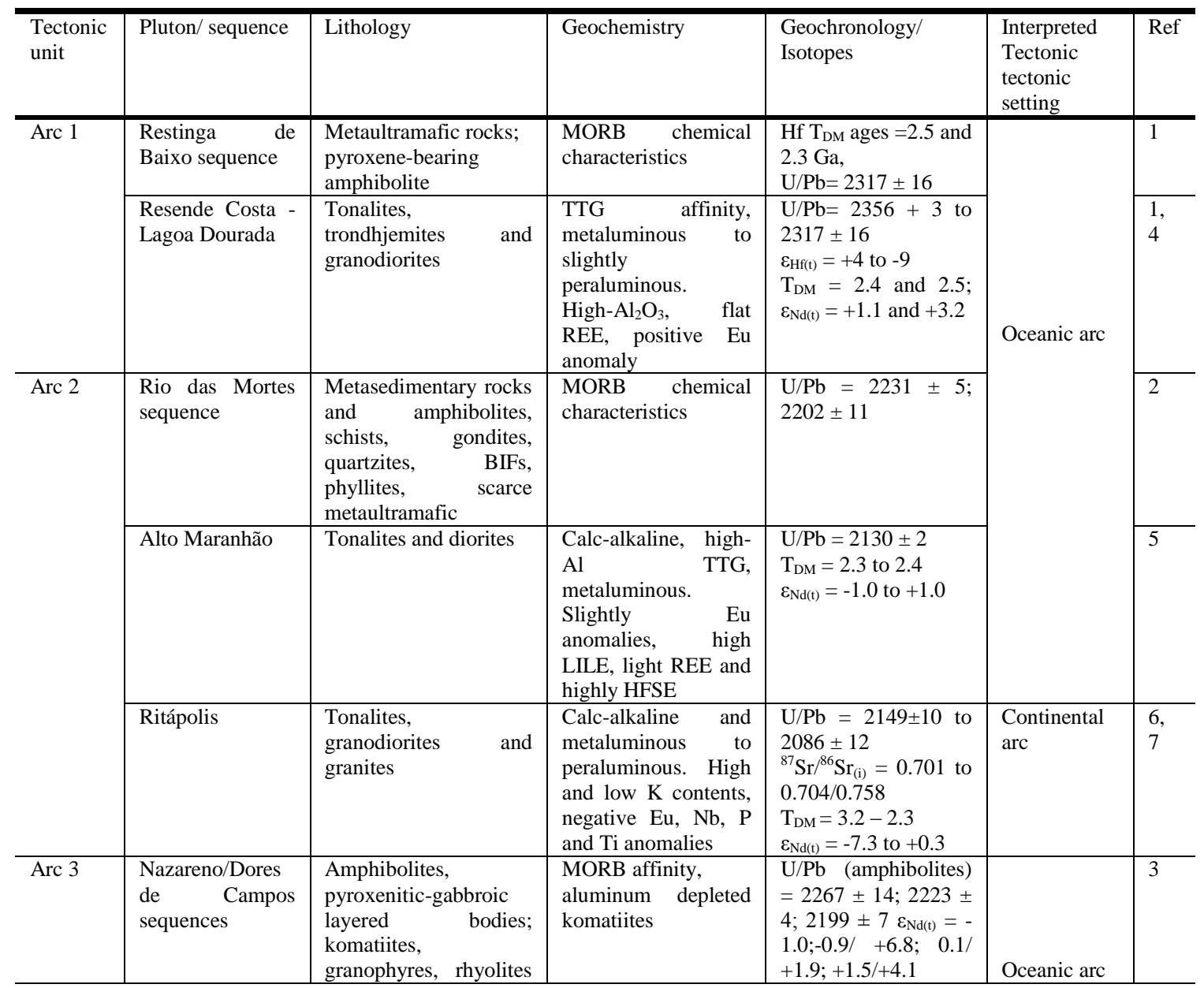




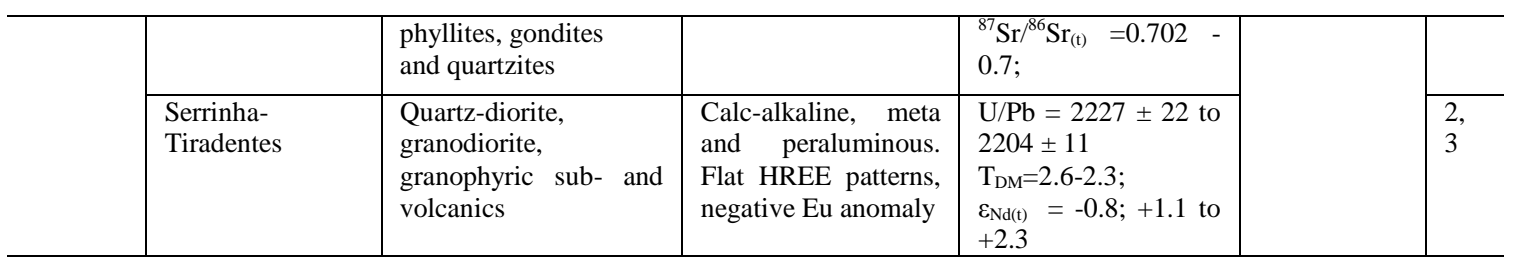

Geologic-tectonic correlations support the point of view that all these plutonic units among others are products from a long-lived subduction regime active in the Paleoproterozoic (Ávila et al., 2010, 2014; Seixas et al., 2012; 2013; Barbosa et al., submitted), named Minas accretionary orogeny by Teixeira et al., 2015. The adjoining Mantiqueira and Juiz de Fora plutonic complexes are also genetically related to the accretionary processes, though strongly reworked in Neoproterozoic times.

The Mineiro belt is compartmented into two blocks by the NE-trending Lenheiros shear zone. This structure separates the Nazareno sequence and Serrinha suite (southern block) from the Rio das Mortes sequence, Ritápolis batholith and the Resende Costa orthogneiss that occur in the northern block (Ávila et al., 2010). This regional structure have been considered to trace the collage of the accretionary arcs of the MB, because the observed juxtaposition side-by-side of distinct magmatic and supracrustal units (Ávila et al., 2010; Ávila et al., 2014). Final docking of the Mineiro belt onto the precursor continental margin occurred along the Jeceaba-Bom Sucesso lineament. The convergent stage also produced strong crustal shortening of the country rock in the QF (see above) - see Fig. 1 (Campos and Carneiro, 2008; Correa-Neto, 2012; Teixeira et al., 2015).

\subsubsection{Geology of the Cassiterita orthogneiss}

The Cassiterita Orthogneiss, focus of this study, occupies an area of ca. $300 \mathrm{~km}^{2}$, occurring predominantly in the vicinities of the towns of Conceição da Barra de Minas, Nazareno and Volta Grande - state of Minas Gerais, Brazil. This pluton is a NE-SW trending, elongated batholith that crops out close to amphibolites and metapelites of the 2.2 Ga Rio das Mortes metavolcanic-sedimentary sequence (Fig. 2). The pluton is tectonically controlled by transcurrent faults that might be related with the Lenheiros structure. A NW-trending fault crosscuts the batholith (Ávila, 2000; Toledo, 2002; Cherman, 2004; Ávila et al., 2003; Vasconcelos, 2015). The Macuco de Minas batholith 
(2.17-2.11 Ga) and the Rio das Mortes metasedimentary sequence encompasses the orthogneiss (Cherman, 2004; Ávila et al., 2010; Barbosa et al., submitted).

Local EW trending milimetric shear zones are mirrored by subparallel elongated biotite flakes. Pegmatites and tabular-like granitic intrusions are also present. The latter can be offset by the WE shear zones (Vasconcelos, 2015). These intrusions have been interpreted to be related to the $2.15 \mathrm{Ga}$ Ritápolis batholith that occurs to the northeast (see previous section). Notably a few scattered outcrops of NE-SW trending amphibole are observed within the Cassiterita batholith. However their geologic meaning is dubious due to lack of direct geologic relations; they could be either xenoliths (i.e., relicts of an unknown mafic unit enclosed in the orthogneiss) or dykes that were eventually deformed and sheared together with the Cassiterita batholith, as they are parallel to the regional foliation (Vasconcelos, 2015). Hence further geologic mapping is needed to solve this geologic complexity.

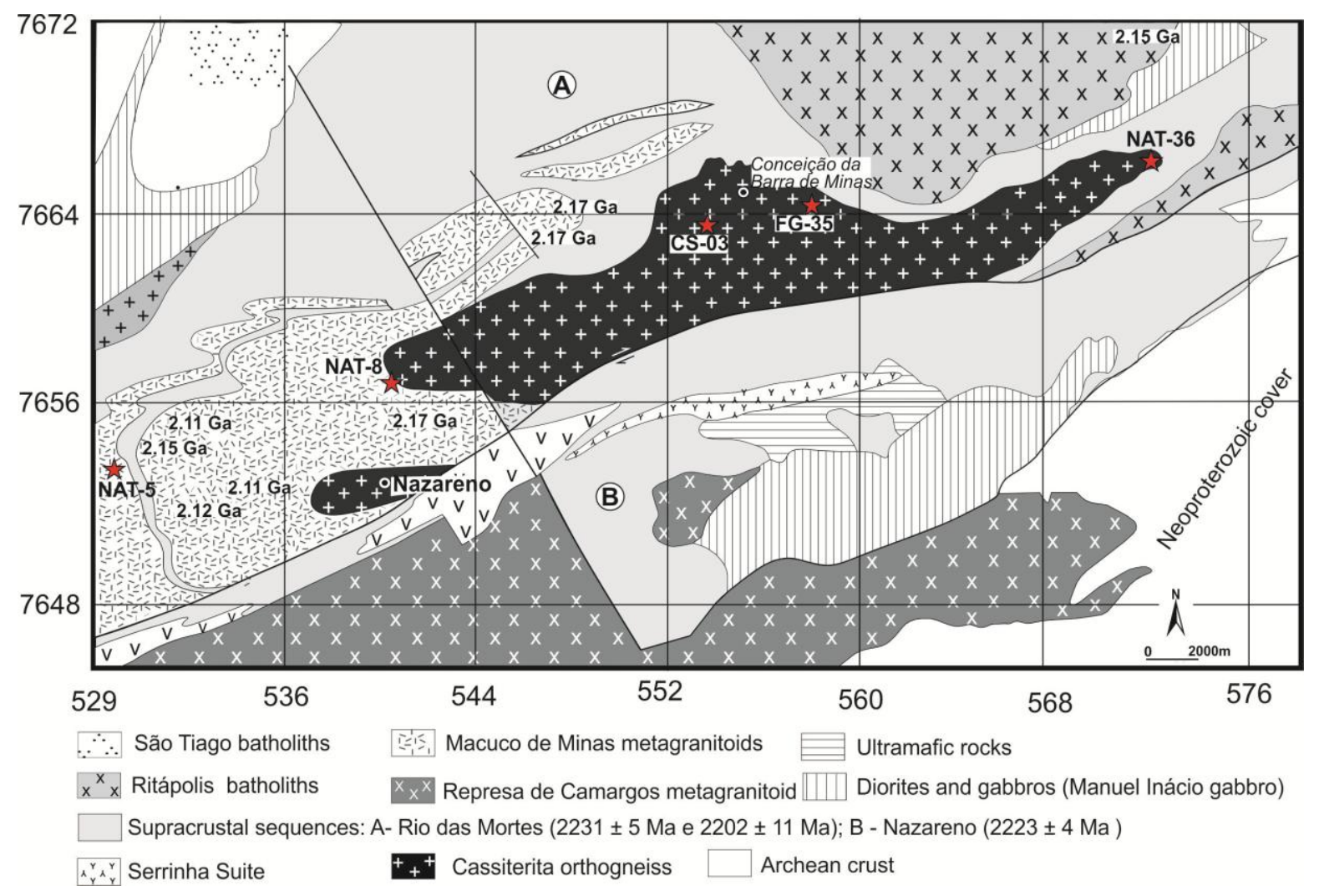

Figure 2. Geological map of the Cassiterita pluton and adjoining units (adapted from Duarte et al., 2003; Quéméneur et al., 2003). LZC: Lenheiros shear zone.

According to Ávila et al. (2003) the Cassiterita pluton consists of tonalitic and trondhjemitic rocks that have large areal distribution in the southwestern portion of the 
Mineiro belt. The main mineral constituents are biotite, plagioclase, quartz, microcline, hornblende where the biotite, feldspar and elongated quartz bands, highlighted by the inequigranular xenoblastic texture. These minerals define the anastomosing foliation that dips to south and southeast (Vasconcelos, 2015). However, a relict equigranular hipidiomorphic texture is locally reported (Ávila et al., 2003), given by subhedric grains of plagioclase (2.5 $\mathrm{mm}$ dimension).

The accessory and secondary minerals are: zircon, apatite, allanite, magnetite, ilmenite, molybdenite, pyrite, rutile, epidote, titanite, muscovite, carbonate and chlorite. Chemically, the rocks are peraluminous and calk-alkaline, and show affinity with the high $\mathrm{Al}_{2} \mathrm{O}_{3}$ trondhjemites. The previously published ${ }^{207} \mathrm{~Pb} /{ }^{206} \mathrm{~Pb}$ zircon evaporation age for a Cassiterita sample is $2162 \pm 10 \mathrm{Ma}$ whereas the $\mathrm{Sm}-\mathrm{Nd} \mathrm{T}_{\mathrm{DM}}$ age is $2.5 \mathrm{Ga}\left(\varepsilon_{\mathrm{Nd}(2.16}\right.$ Ga) of +2.47), implying to short crustal residence of the protholith (Ávila et al., 2003). In consequence, the Cassiterita pluton has been tentatively correlated with the Ritápolis batholiths, because the age match of the available ${ }^{207} \mathrm{~Pb} /{ }^{206} \mathrm{~Pb}$ zircon evaporation datings (see table 1). From a tectonic perspective the Cassiterita rocks were interpreted by Ávila et al (2003) as product of partial melting of subducted oceanic crust that led to a trondhjemitic-tonalitic magma emplaced into continental arc setting. In view of the need for more robust $\mathrm{U}-\mathrm{Pb}$ geochronology and isotopic geochemistry about this particular pluton, we present new data from representative outcrops of the main pluton and one intrusive stock, supported by geologic mapping.

\section{Analytical methods}

In situ U-Pb zircon isotopic analyses by SHRIMP and LA-ICMPS were obtained at the Geochronological Research Center (CPGeo) of IGc-USP in five samples of the Cassiterita orthogneiss, after preparation and concentration using the conventional heavy liquid and magnetic techniques and further handpicking under a binocular microscope.

Three analyses were performed using the SHRIMP II of the CPGeo. The samples were mounted on adhesive tapes, enclosed in epoxy resin and polished together with the TEMORA 1 zircon standard $\left({ }^{206} \mathrm{~Pb} /{ }^{238} \mathrm{U}\right.$ age $=416.78 \pm 0.33 \mathrm{Ma}$; Black et al., 2003). The internal domains of the grains were evaluated using cathodoluminescence (CL) image to select the spot for isotopic analyses. The SHRIMP isotopic data were collected in sets of five scans throughout the masses and the TEMORA standard was 
measured after four unknown analyses. The abundances of $\mathrm{U}, \mathrm{Th}$ and $\mathrm{Pb}$, and the $\mathrm{Pb}$ isotopic ratios, were normalized using the SL13 zircon standard ( $U=238 \mathrm{ppm}$; Sato et al., 2014). Analyses with common $\mathrm{Pb}$ lower than $10 \%$ were used after correction of the measured ${ }^{204} \mathrm{~Pb}$ and assuming the $\mathrm{Pb}$ composition of Stacey and Kramers (1975). The data reduction was performed using the SQUID 1.06 Excel macro (Ludwig, 2000), and the statistical assessments were calculated with the ISOPLOT software of Ludwig (2003). The uncertainties in the isotopic ratios and the ages are reported at the $1 \%$ level and the weighted mean ages are reported as 95\% confidence limits (Sato et al., 2014). Data were plotted on Concordia diagrams, using ISOPLOT/Ex® 3.00 software (Ludwig, 2003).

The LA-ICPMS technique was applied for two samples, using the ThermoFisher Neptune laser-ablation (LA) multi-collector inductively coupled plasma mass spectrometer (ICP-MS), with ArF-193 $\mu$ m Photon laser system (frequency of $6 \mathrm{~Hz}$; intensity of $6 \mathrm{~mJ}$; focused bean to $29 \mu \mathrm{m}$ spots) of the CPGeo. The correction of laser induced fractionation of ${ }^{206} \mathrm{~Pb} /{ }^{238} \mathrm{U}$ ratio follow the linear regression of the Kösler et al. (2002). The in situ zircon analyses were carried out according to the standard-sample bracketing method and referred to the zircon GJ-1 standard (U-Pb mean age of $601 \pm$ 3.5 Ma; Elholou et al., 2006). The analytical data were obtained in sets of 2-3 sheets including two blanks, three GJ-1 analyses, 13 unknown zircon spots, followed by analysis of two more blanks and two GJ-1 standards (after Sato et al., 2010). The ${ }^{202} \mathrm{Hg}$ contents of the analyses controlled the common $\mathrm{Pb}$ measurements. Raw data were processed on-line and reduced in an Excel worksheet (Sato et al., 2009; 2010) adapted from the software SQUID 1.02 (Ludwig, 2001). Data were plotted on Concordia diagrams, using ISOPLOT/Ex® 3.00 software (Ludwig, 2003).

Three zircon Hf isotopic analyses were performed in the same samples dated by SHRIMP, using a Neptune laser ablation multi-collector inductively coupled plasma mass spectrometer of the CPGeo. Laser spot diameter was $39 \mu \mathrm{m}$ focused on or adjacent to the spots dated by $\mathrm{U}-\mathrm{Pb}$. The ablation time was 60 seconds with a repetition rate of 7Hz. He was used as carrier gas (Sato et al., 2009, 2010). Reference zircon standards were considered for quality control during the Hf analytical session. A decay constant for ${ }^{176} \mathrm{Lu}$ of $1.867 \times 10^{-11} / \mathrm{yr}$ (Söderlund et al., 2004) was used for the calculation of initial ${ }^{176} \mathrm{Hf} /{ }^{177} \mathrm{Hf}$ ratios. ${ }^{176} \mathrm{Hf} /{ }^{177} \mathrm{Hf}$ ratios were normalized to ${ }^{176} \mathrm{Hf} /{ }^{177} \mathrm{Hf}=0.7325$. ${ }^{176} \mathrm{Lu} /{ }^{175} \mathrm{Lu}$ ratio of (0.02669) was used to calculate ${ }^{176} \mathrm{Lu} /{ }^{177} \mathrm{Hf}$. Mass bias corrections of Lu-Hf isotopic analyses were carried out applying the variations of GJ1 standard. 
The $\varepsilon_{\mathrm{Hf}}$ values were calculated assuming present-day chondritic ratios of ${ }^{176} \mathrm{Hf} /{ }^{177} \mathrm{Hf}=$ 0.282772 and ${ }^{176} \mathrm{Lu} /{ }^{177} \mathrm{Hf}=0.0332$ (Blichert-Toft and Albarede, 1997). On each sample the individual $\varepsilon_{\mathrm{Hf}}$ determinations were grouped following a $2 \sigma$ outlier test. With this intention, a $95 \%$ confidence interval was calculated for average $\varepsilon_{\mathrm{Hf}}$ initial values and $2 \sigma$ external reproducibility. $\varepsilon_{\mathrm{Hf}(\mathrm{t})}$ values are referred to the ${ }^{207} \mathrm{~Pb} /{ }^{206} \mathrm{~Pb}$ crystallisation age of the particular spot analyses.

Three samples were analyzed for $\mathrm{Sr}-\mathrm{Nd}$ isotopes at the CPGeo, according to procedures of Sato et al. (1995). Ion exchange resin was applied for primary separation of the rare earth elements (REE), followed by a second LN column for separation of Sm and Nd. The isotope ratios were measured on a Triton-Thermo Fisher Scientific mass spectrometer. The ${ }^{143} \mathrm{Nd} /{ }^{144} \mathrm{Nd}$ and ${ }^{147} \mathrm{Sm} /{ }^{144} \mathrm{Nd}$ ratios have quoted errors at $2 \sigma$ and $1 \sigma$ levels, respectively. The measured ${ }^{143} \mathrm{Nd} /{ }^{144} \mathrm{Nd}$ ratio obtained for the JNDi-1 standard gave a mean ${ }^{143} \mathrm{Nd} /{ }^{144} \mathrm{Nd}$ ratio $=0.512100 \pm 9(1 \sigma)$. The calculations of corrections were performed tracer content and for blanks of 40pg $(\mathrm{Nd})$ and 20pg $(\mathrm{Sm})$. Corrections were applied for instrumental bias, tracer content and for blank of 40pg (Nd) (Petronilho, 2009). Sm-Nd $\mathrm{T}_{\mathrm{DM}}$ ages were calculated using the depleted mantle model of De Paolo (1981), whereas the $\varepsilon_{\mathrm{Nd}(\mathrm{t})}$ values are referred to the U-Pb crystallisation age of $2.1 \mathrm{Ga}$ (see below). The $\mathrm{Rb}-\mathrm{Sr}$ isotope ratios were measured either on the Triton-Thermo Fisher mass spectrometer or on the Finnigan-MAT 262 of the CPGeo. ${ }^{87} \mathrm{Sr} /{ }^{86} \mathrm{Sr}$ ratios were normalized to ${ }^{86} \mathrm{Sr} /{ }^{88} \mathrm{Sr}=0.1194$. The final quoted errors are external values $(1 \sigma)$ based on replicate analyses of $\mathrm{NBS}-987 \mathrm{SrCO}_{3}$ standard, which yielded a mean ratio of $0.710251 \pm 0.000043(2 \sigma)$ during the period of the analyses. The mean blank for Sr was 200 pg during the period of the analyses. Decay constants are those recommended by Steiger and Jäger (1977).

The chemical compositions of 16 whole-rock samples were measured at the Acme Analytical Laboratories, Vancouver, Canada. Major element compositions were analyzed by X-ray fluorescence (XRF; Rikagu RIX 2100) using fused glass disks (lithium metaborate/tetraborate fusion to digest the samples). Trace element compositions were analyzed by ICP-MS (Agilent 7500a with a shield torch) after acid digestion of samples in Teflon bombs. Analyses of US Geological Survey mafic standards (BCR-2, BHVO-1, and AGV-1) indicate precision and accuracy better than $5 \%$ for major elements and $10 \%$ for trace elements (Rudnick et al., 2004). ICP-emission spectrometry determined the contents of major oxides and minor elements, whereas trace and REE elements were acquired by ICP mass spectrometry. 


\section{Results}

\subsection{Petrographic aspects}

Representative samples were selected in a roughly NE-SW transverse along the Cassiterita batholiths. Most rocks of the batholith are medium grained, with some dark and white portions that highlight the anastomosed gneissic structure (160/60 dip/dip direction), as similarly reported by Ávila et al. (2003) and Vasconcelos (2015). They can be classified as tonalites, trondhjemites and granodiorites according to our petrographic studies (Fig. 4). In general, the Cassiterita samples (FG-35, NAT-36, NAT-08), show a similar mineralogy, textures and deformation, and are moderately altered (sericitization of the plagioclase and chloritization of biotite), as summarized below. One granitic intrusion (CS-03) and one xenolith (NAT-5) of another pluton were also investigated.

The quartz grains are anhedral, often in ribbons or sigmoidal shapes. When recrystallized they form polygon edges, and show undulatory extinction. Plagioclase occurs as euhedral to subhedral prismatic grains, and may preserved relict prismatic habit. Biotite occurs as elongate subhedral crystals (Figure 4C) with tabular flakes that define the NE-SW trending foliation. The biotite surrounds the plagioclase and quartz, whereas the titanite is observed as inclusion in the biotite. Microcline is occasionally interstitial between quartz and plagioclase, and is probably recrystallized. Epidote is interstitial between biotite and plagioclase, and originated from alteration of the plagioclase. Euhedral short-prismatic crystals of allanite are commonly enclosed in biotite and epidote (Figure 4B). All samples are moderately altered, showing sericitization of the plagioclase and chloritization of biotite.

\subsubsection{FG-35 - Metatonalite}

This sample was taken from the central part of the Cassiterita Orthogneiss. The outcrop shows a gneissic rock highlighted by tabular flakes of biotite that defines the NE-SW trending foliation. Granitic dykes of the Ritápolis batholith is also present. The rocks is foliated, leucocratic, medium grained and inequigranular. The main mineralogy comprises plagioclase, quartz and biotite. Accessory minerals are zircon, epidote, 
zoisite, chlorite, allanite, titanite, opaque minerals and apatite. The grano-lepidoblastic texture is characteristic.
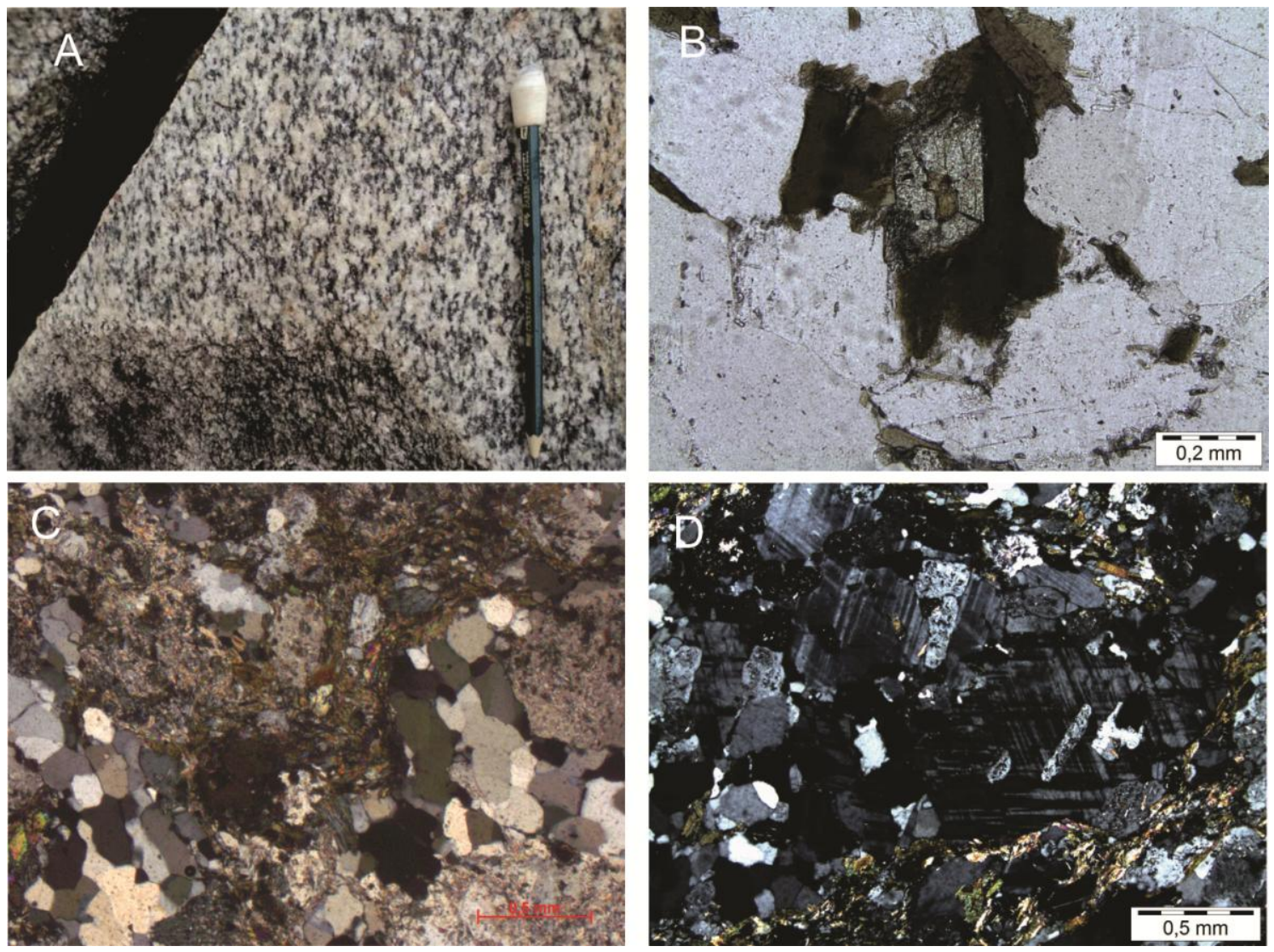

Figure 4. Microscopic view from tonalities and granodiorite. (A) Field aspects; (B) Allanite encircled by epidote and biotite; (C) Grano-lepidoblastic texture; (D) Apatite encircled by microcline.

\subsubsection{NAT 36 Metatonalite}

This sample crops out in the northeast portion of the pluton, ca. $14 \mathrm{~km}$ apart from FG-35 sample (Fig. 2). It is foliated, leucocratic, medium- to coarse-grained and inequigranular (Figure 4A). The main mineralogy comprises plagioclase, quartz, biotite and minor microcline. Accessory minerals are zircon, epidote, zoisite, chlorite, allanite, titanite, opaque minerals, garnet and apatite. The grano-lepidoblastic, hypdiomorphic texture is characteristic.

\subsubsection{NAT-8 Metatonalite}

This sample was taken from southwest portion of the pluton, nearby the town of Nazareno (Fig. 2). This particular occurrence is outside the main exposure of the Cassiterita batholith, and is encompassed by younger granitoids (Figure 1) and the Rio 
das Mortes supracrustal sequence. The studied rock is leucocratic, medium- to coarsegrained, and foliated like the NAT-36 sample. This metatonalite is composed of quartz, plagioclase, and biotite. Titanite, allanite, zircon, opaque minerals, apatite, epidote, zoisite, chlorite, calcite and muscovite are the accessory minerals. The characteristic texture is inequigranular, grano-lepidoblastic, given by biotite grains.

\subsubsection{CSO3 intrusive Metatonalite}

This rock crops out ca. 8km away from the town of Conceição da Barra de Minas (Fig. 2), and is intrusive into the Cassiterita Orthogneiss. The sample is leucocratic and consists of medium- to coarse-grained, inequigranular tonalite. The main mineralogy comprises plagioclase, quartz and biotite. Accessory minerals are zircon, epidote, zoisite, chlorite, allanite, titanite, opaque minerals and apatite. The grano-lepidoblastic texture is characteristic.

\subsubsection{NAT-5 xenolith in Metagranodiorite}

The studied outcrop is a porphyritic granodiorite (termed Macuco de Minas; 2.12 Ga; Fig. 2) in the southwest fringe of the Cassiterita pluton (Fig. 2). NAT-5 sample is a xenolith (metric scale) in the main outcrop, showing a sharp contact with the host rock. It is light gray to pink color, fine grained, showing massive structure with injections of fine quartz-feldspar veins. The main phases are quartz, plagioclase, biotite and microcline, consistent with a granodiorite composition. The accessory minerals are: epidote, titanite, apatite, zircon and opaque minerals. The texture of the xenolith is lepido-granoblastic.

\subsection{In situ U-Pb zircon ages}

\section{FG-35 - Metatonalite}

Zircon crystals are characterized by elongate, subhedral shape with a grain size of $79-142 \mu \mathrm{m}$. They vary from opaque to transparent and light to dark brown in color. Metamorphic overgrowth is present in most grains, given by relatively higher $\mathrm{U}$ contents compared to cores that are black and white. In addition several cores show resorption and inclusions. Forty in-situ analyses were performed by LA-ICPMS. Eight nearly concordant data of cores (between -1.4 to $1.4 \%$ discordant) yield $\mathrm{Th} / \mathrm{U}$ ratios 
between 0.29 and 0.89 (Table 3 supplementary material). These data regress to define an upper intercept of $2472 \pm 11$ Ma (Fig. 4A; MSWD =0.22). Seven additional analyses in the metamorphic rims $(\mathrm{Th} / \mathrm{U}=0.08-0.27)$ plot along a linear array with an upper intercept at $2024 \pm 54(\mathrm{MSWD}=2.1$; Fig. 4A $)$.

\section{NAT 36 -Metatonalite}

The zircon grains were dated by SHRIMP. The crystals are composed of translucent to opaque and vary from light brown to dark brown. They have subhedral prismatic habit or short prism and range in size from 55 to $255 \mu \mathrm{m}$. Most cores in CL images (Fig. 3) are light (with some sort of resorption) and show typical magmatic oscillatory zoning. Narrow darker metamorphic rims are also present (e.g., spots 6.1 and 10.1). Thirteen in-situ analyses (cores) show variable $\mathrm{Th} / \mathrm{U}$ ratios (0.27 and 1.39; Table 3 supplementary material). The data regress to yield an upper intercept age at $2418 \pm 67$ Ma (MSWD = 11.6). Two spot analyses cluster the Concordia at $2419 \pm 13$ Ma (MSWD $=0.082$ ), defined here as the crystallisation age for the rock (Fig. 4B). Two rim analyses

were performed. One of them (10.1) is concordant, yielding a ${ }^{207} \mathrm{~Pb} /{ }^{206} \mathrm{~Pb}$ age of $2066 \pm$ $15 \mathrm{Ma}(\mathrm{Th} / \mathrm{U}=0.27)$. This youngest age is match with the youngest upper intercept age of FG-35 (see above), and probably marks a metamorphic imprint. 
NAT-36

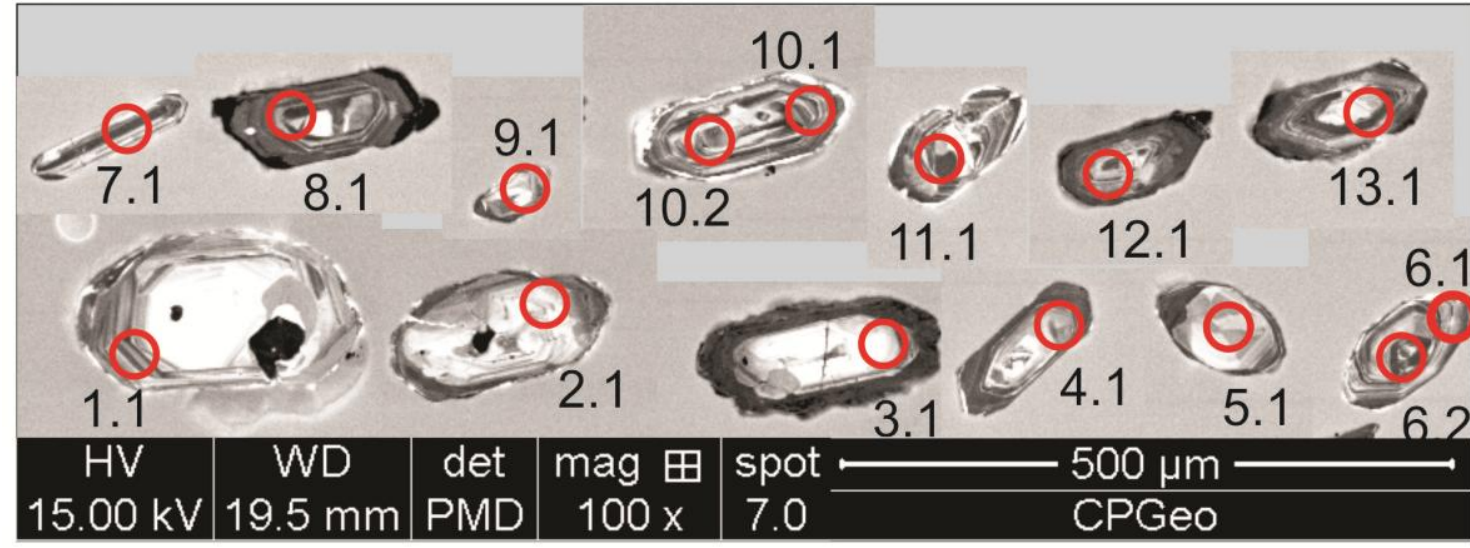

NAT-8

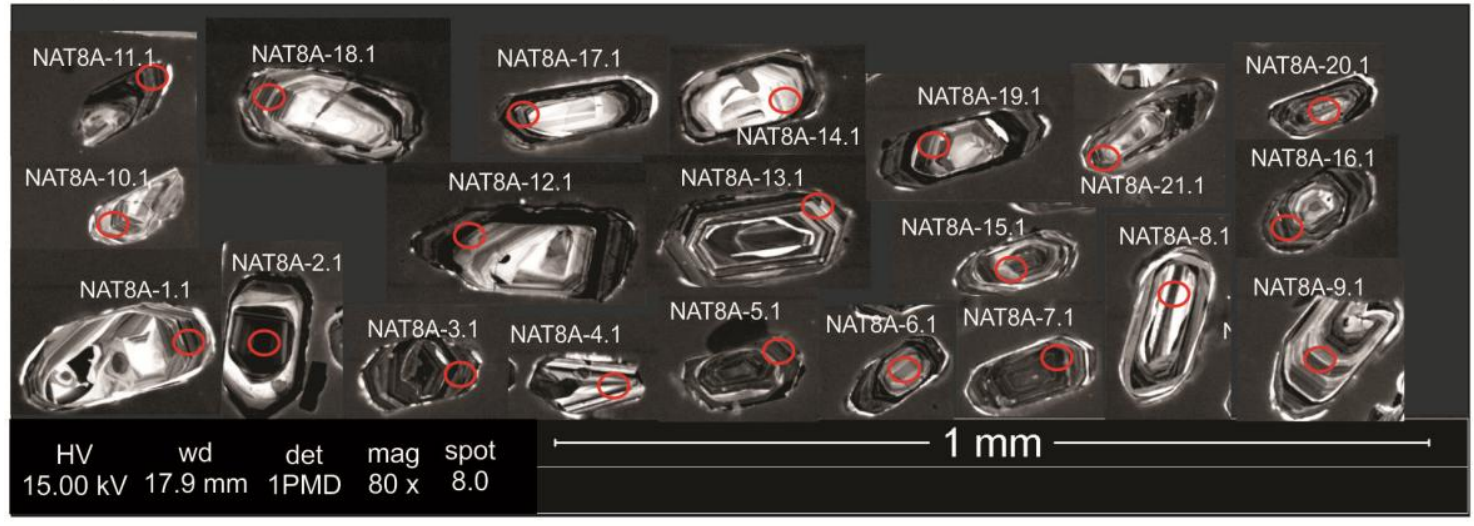

CS-03

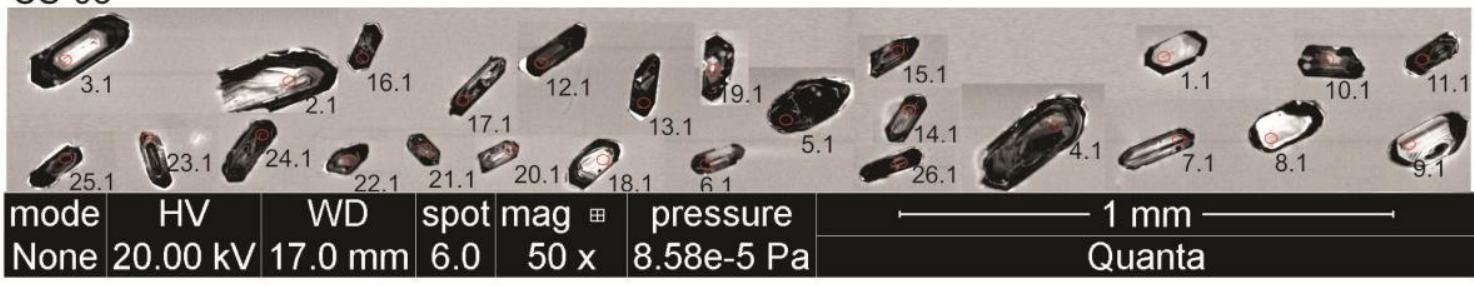

NAT-5

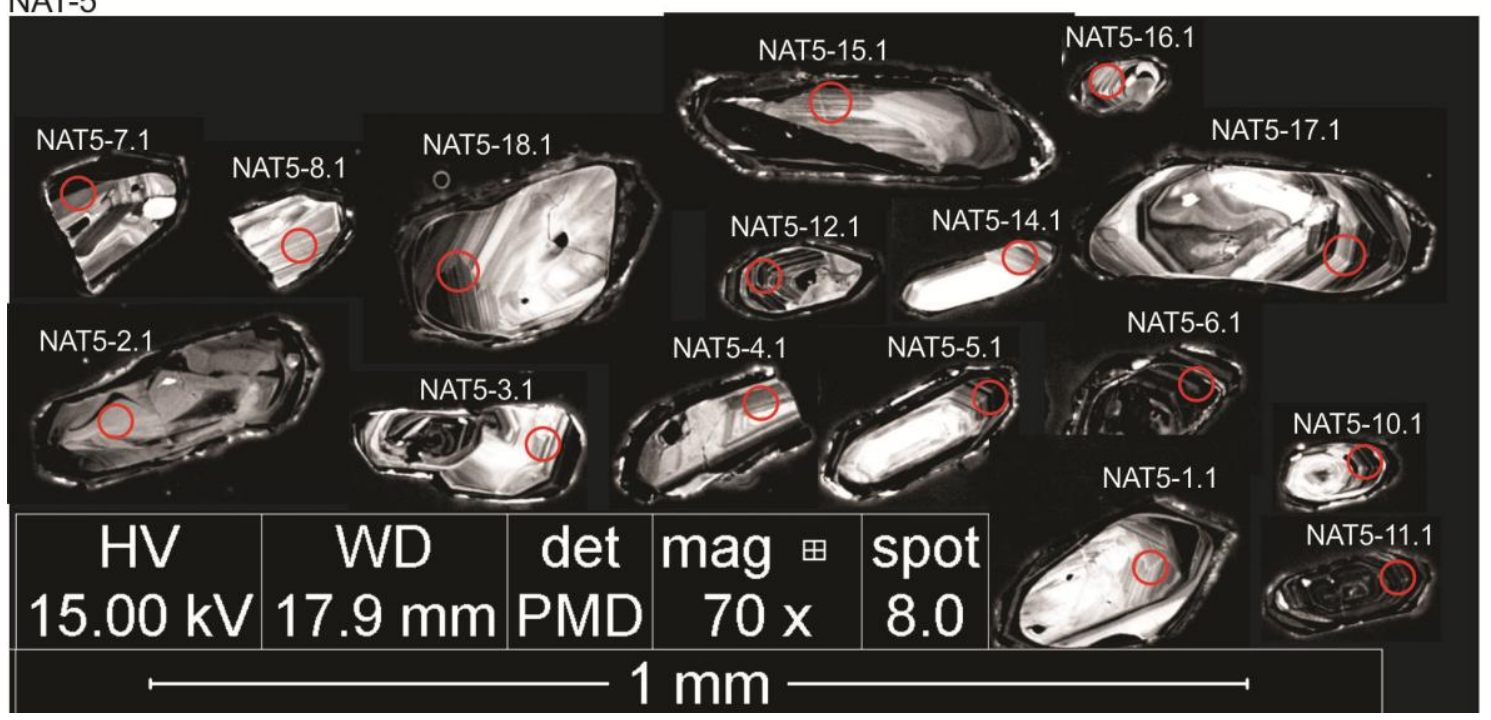

Figure 3. Cathodoluminescence imagery of zircons for the Cassiterita orthogneiss. 

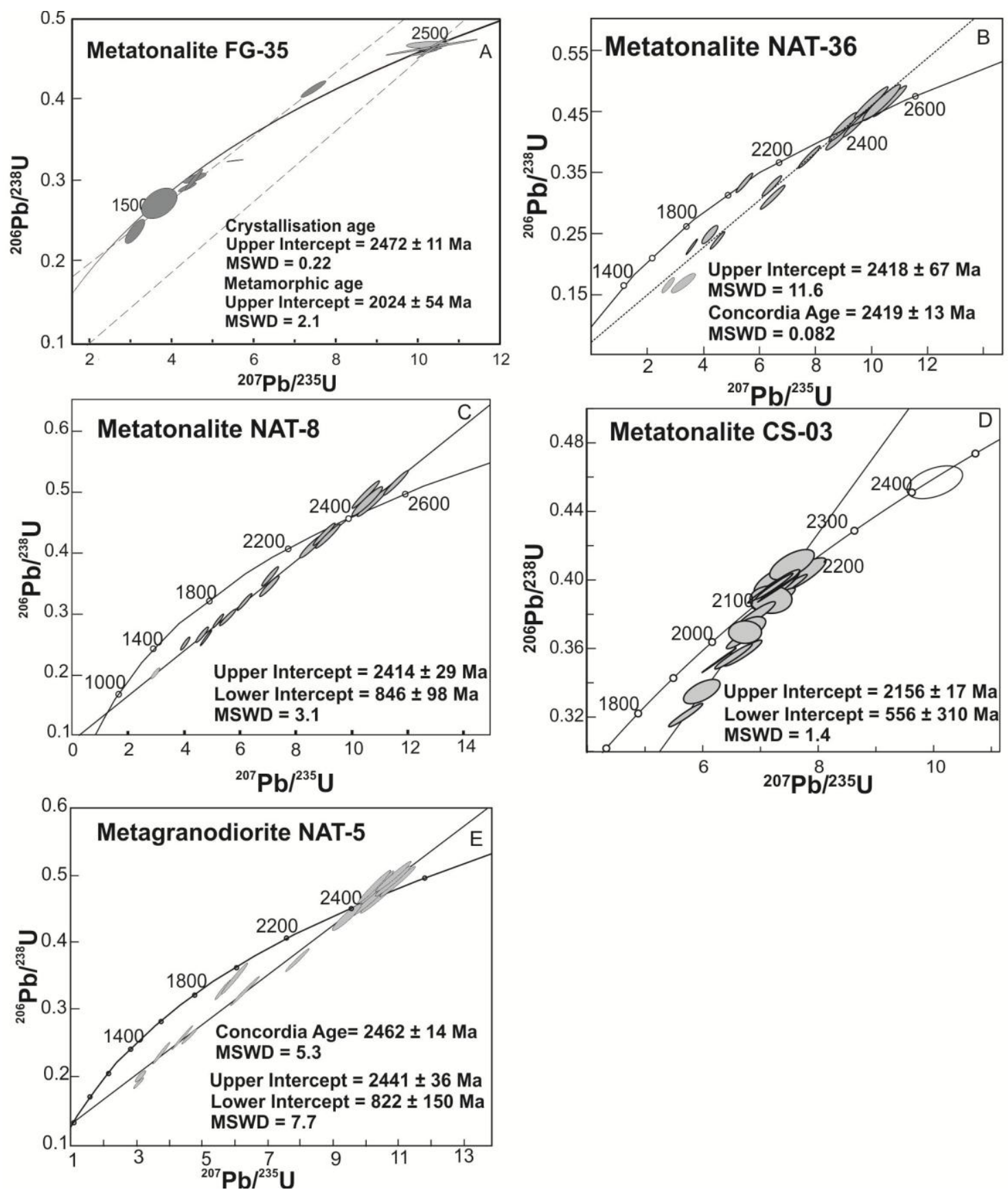

Figure 4. U-Pb Concordia diagrams for the Cassiterita pluton.

\section{NAT 8-Metatonalite}

The subhehdral zircons range in size from 97 to $277 \mu \mathrm{m}$ where the prismatic, subrounded crystals predominate. They are mostly translucent to opaque, and vary from yellow, light brown to dark brown. The crystals display concentric and linear oscillatory zoning. Recrystallisation and partly resorbed cores are also present, as well as thin metamorphic rims (Fig. 3). Twenty five spots (Fig. 4C) were analyzed through the SHRIMP. Th/U ratios vary from 0.19 to 0.96 (Table 3 supplementary material). The 
upper intercept age is $2414 \pm 29 \mathrm{Ma}(\mathrm{MSWD}=3.1)$, with a lower intercept with the Concordia at $846 \pm 98 \mathrm{Ma}$ (Fig. 4C). One almost concordant analysis (NAT8-9.1 metamorphic overgrowth) yields ${ }^{207} \mathrm{~Pb} /{ }^{206} \mathrm{~Pb}$ of $2160 \pm 13$ Ma whereas one inherited zircon (NAT8-8.1; Th/U =0.67) is reverse concordant, yielding a ${ }^{207} \mathrm{~Pb} /{ }^{206} \mathrm{~Pb}$ age of $2712 \pm 15$ Ma.

\section{CS-03 - intrusive Metatonalite}

Zircon population consists of translucent to opaque crystals, varying from yellow, light brown to dark brown. The grains are subhedral, prismatic and range in size from 63 to $296 \mu \mathrm{m}$. In $\mathrm{Cl}$ images (Fig. 3) some cores (light or dark) are resorbed and/or recrystallised. Magmatic oscillatory zoning (linear) is apparent only in thin grains. Some grains show thin dark metamorphic rims. Twenty six in-situ analyses (Table 3) were carried out by LA-ICPMS, mostly in cores. Twenty five of them regress to yield an upper intercept crystallisation age of $2156 \pm 17 \mathrm{Ma}(\mathrm{Th} / \mathrm{U}=0.22-0.67$; MSWD $=$ 1.4) with a lower intercept of $556 \pm 310 \mathrm{Ma}$ (Fig. 4D). Notably the only exception is 4.1 core which yields a concordant ${ }^{207} \mathrm{~Pb} /{ }^{206} \mathrm{~Pb}$ age of $2426 \pm 17$ Ma which is interpreted as an inherited age.

\section{NAT 5 - Metagranodiorite (xenolith)}

Zircon population is composed of translucent to opaque prismatic crystals (subhedral form), varying from light brown to dark brown, where several grains display inclusions. The zircon grains have dimensions between 76 and $353 \mu \mathrm{m}$. Some of them display complex structures in CL images (Fig. 3), such as resorption and recrystallisation, whilst cloudy oscillatory zoning is also observed. Thin metamorphic rims are also present, but they could not be analysed. Twenty one SHRIMP analyses were performed in cores and igneous overgrowths (e.g., 6.1). The analyses show Th/U ranging from 0.23 to $1.0-1.5$ (Table 3 ; supplementary material). The data are variable and regress to yield an upper intercept age of $2441 \pm 36$ Ma (Fig. 4; MSWD = 7.7). Twelve of the almost concordant analyses ( -6 to $1 \%$; $\mathrm{Th} / \mathrm{U}=1.02-0.41)$ define a crystallisation age of $2463 \pm 14 \mathrm{Ma}(\mathrm{MSWD}=5.3$; Fig. 4E). 


\section{3. $\mathrm{Nd}, \mathrm{Sr}$ and $\mathrm{Hf}$ isotopes}

Four Sm-Nd whole-rock analyses yielded $f \mathrm{Sm} / \mathrm{Nd}$ values between -0.43 and 0.63 (Table 4). Notably NAT-8 and NAT-8.1 samples yielded anomalous $f \mathrm{Sm} / \mathrm{Nd}$ compared to mean crustal values (Bennet and De Paolo, 1987). Therefore they will be not considered here after. NAT- 36 metatonalite (U-Pb age of $2420 \mathrm{Ma}$; see above) yielded "normal" crustal $f \mathrm{Sm} / \mathrm{Nd}$ value of -0.43 . The $\mathrm{Sm}-\mathrm{Nd} \mathrm{T}_{\mathrm{DM}}$ age is $2.5 \mathrm{Ga}$ and the $\varepsilon_{\mathrm{Nd}(\mathrm{t})}$ value is +1.5 . This indicates a short-lived history for the protholith. Tentatively, we consider that the positive $\varepsilon_{\mathrm{Nd}(\mathrm{t})}$ value $(+2.7)$ of NAT-5 xenolith (U-Pb zircon age of 2460 $\mathrm{Ma}$; see above) is geologically significant, given that its $\mathrm{T}_{\mathrm{DM}}$ age (ca. $2.4 \mathrm{Ga}$ ) is roughly in match with that of NAT-36. In consequence, both samples (i.e. Cassiterita orthogneiss) are juvenile derived. Considering the $\mathrm{Rb} / \mathrm{Sr}$ systematic, these two samples yielded significantly low ${ }^{87} \mathrm{Sr} /{ }^{86} \mathrm{Sr}(2.4 \mathrm{Ga})$ values of ca. 0.700 . In other words the above $\mathrm{Nd}-\mathrm{Sr}$ signatures are consistent with a predominant depleted mantle (DM) source for the Cassiterita orthogneiss, as suggested by the respective isotopic signature of DM calculated for $2.4 \mathrm{Ga}$ (see Table 4). Of note a previously published data for the Cassiterita orthogneiss yielded a $\mathrm{T}_{\mathrm{DM}}$ age of $2.5 \mathrm{Ga}$ (Ávila et al., 2003). Its $\varepsilon_{\mathrm{Nd}(\mathrm{t})} \mathrm{value}$ recalculated for $2.4 \mathrm{Ga}$ is +2.4 , in roughly agreement with the signature of our samples.

Table 4. Sm-Nd and $\mathrm{Rb}-\mathrm{Sr}$ whole rock data for selected rocks of the Cassiterita batholith Minerio belt.

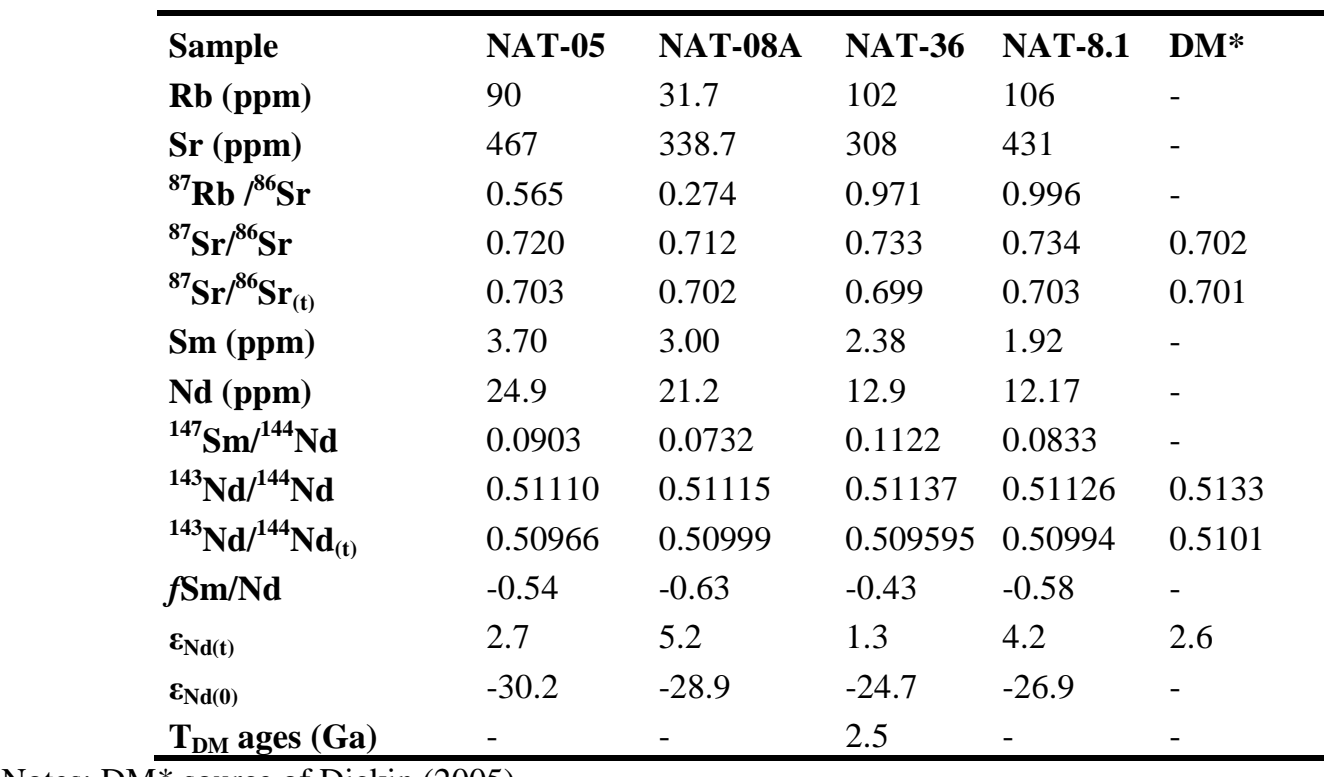

Notes: DM* source of Dickin (2005). 
In situ zircon Lu-Hf analyses were performed in three samples: two metatonalites (NAT-8 and NAT-36) and one metagranodiorite (NAT-5). The isotopic data are shown in Table 5 where only the concordant and nearly concordant analyses were considered for the interpretation.

NAT-36 metatonalite shows variable negative initial ${ }^{176} \mathrm{Hf} /{ }^{177} \mathrm{Hf}$ values (0.281066-0.281487) which correspond to $\varepsilon_{\mathrm{Hf}(2.4 \mathrm{Ga})}$ values from mostly negative (from 3.3 to -5.4$)$ to positive (+9.0) (only one value). The respective $\mathrm{Hf} \mathrm{T}_{\mathrm{DM}}$ ages range from 3.2 to $2.9 \mathrm{Ga}$, with one exception (core 9.1) that yields ca. $2.3 \mathrm{Ga}$ (Table 5). NAT-8 metatonalite has more homogeneous initial ${ }^{176} \mathrm{Hf} /{ }^{177} \mathrm{Hf}$ values $(0.281187-0.281106)$. The calculated $\varepsilon_{\mathrm{Hf}(2.4 \mathrm{Ga})}$ values fall mostly between -2.2 to -4.4 and the $\mathrm{Hf}_{\mathrm{DM}}$ ages are between 3.3-3.0 Ga. NAT-5 xenolith yields again homogeneous ${ }^{176} \mathrm{Hf} /{ }^{177} \mathrm{Hf}$ values from $0.281026-0.281152$ but the calculated $\varepsilon_{\mathrm{Hf}(2.4 \mathrm{Ga})}$ parameters show a variation between 6.2 and -1.8. The $\mathrm{Hf}_{\mathrm{DM}}$ ages range from 3.3-3.0 Ga. In consequence all data fall below CHUR, and indicating two distinct signatures (Fig. 5B), as follow: i) the negative values (>-5) suggest an enriched mantle source; ii) the variable and strongly negative values $(<-5)$ suggest some sort of partial melts (i.e., reworked zircons). This is also consistent with the $\mathrm{T}_{\mathrm{DM}}$ ages in the range 2.9 to $3.3 \mathrm{Ga}$.
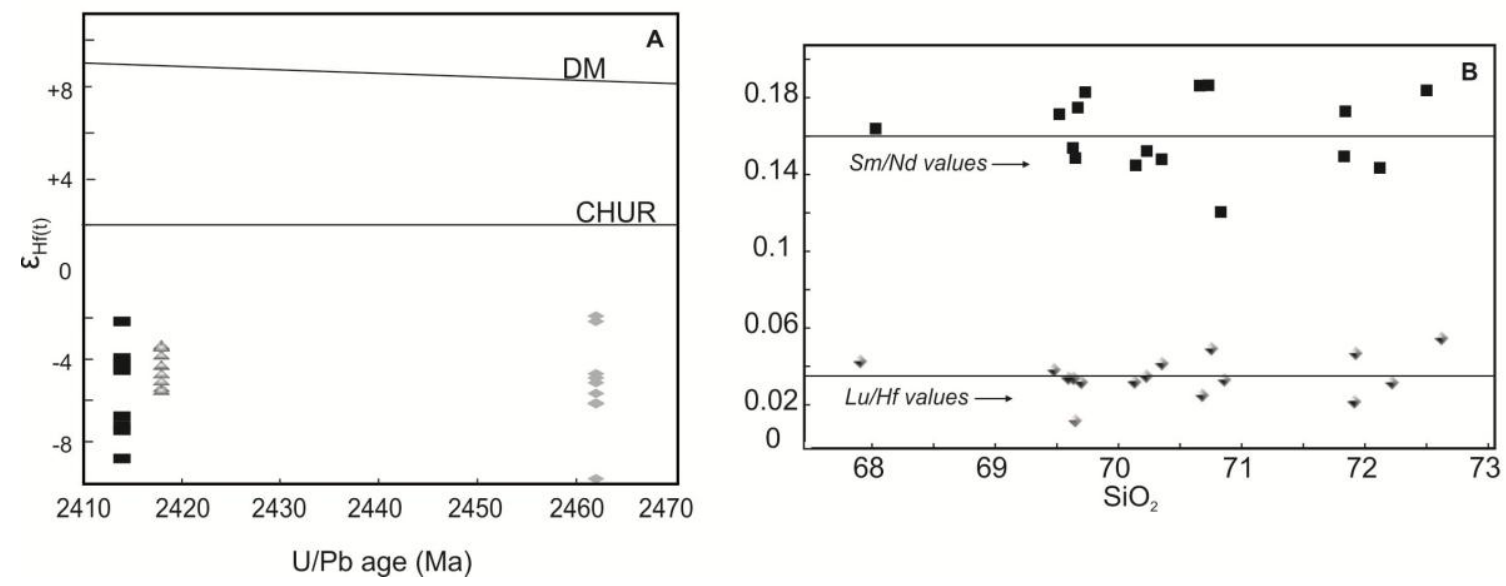

Figure 5. (A) $\varepsilon_{\mathrm{Hf}(\mathrm{t})}$ evolution vs. Time diagram; (B) Plot of Lu/Hf and $\mathrm{Sm} / \mathrm{Nd}$ versus silica for Cassiterita orthogneiss. The horizontal lines show the mean $\mathrm{Lu} / \mathrm{Hf}$ and $\mathrm{Sm} / \mathrm{Nd}$ whole rock values.

Fig. 5B correlates $\mathrm{Lu} / \mathrm{Hf}$ and $\mathrm{Sm} / \mathrm{Nd}$ versus silica for Cassiterita samples. The data indicate that the $\mathrm{Lu} / \mathrm{Hf}$ values are lower than the $\mathrm{Sm} / \mathrm{Nd}$ ones in the crust, in agreement with the higher Hf partition related to Lu for the crust, as similarly observed by the $\mathrm{Nd}$ in relation to $\mathrm{Sm}$. 
Table 5. In situ, individual Lu-Hf analyses of magmatic zircon from the select rocks of the Cassiterita pluton - Mineiro belt.

\begin{tabular}{|c|c|c|c|c|c|c|c|}
\hline Spot & $\begin{array}{l}{ }^{207} \mathrm{~Pb} /{ }^{206} \mathrm{~Pb} \\
\text { age }\end{array}$ & ${ }^{176} \mathrm{Lu} /{ }^{177} \mathrm{Hf}$ & ${ }^{176} \mathrm{HF} /{ }^{177} \mathrm{Hf}$ & ${ }^{176} \mathrm{HF} /{ }^{177} \mathrm{Hf}_{(\mathrm{t})}$ & $\varepsilon_{\mathrm{Hf} 0}$ & $\varepsilon_{\mathrm{Hf}(\mathrm{t})}$ & $\mathrm{T}_{\mathrm{DM}}$ \\
\hline \multicolumn{8}{|c|}{ NAT 5 - Metagranodiorite } \\
\hline 1.1 & 2465 & 0.000574 & 0.281098 & 0.281071 & -59 & -4.90 & 3239 \\
\hline 2.1 & 2432 & 0.000516 & 0.281095 & 0.281071 & -59 & -5.65 & 3262 \\
\hline 3.1 & 2487 & 0.000687 & 0.281166 & 0.281134 & -57 & -2.15 & 3081 \\
\hline 4.1 & 2469 & 0.000699 & 0.281185 & 0.281152 & -56 & -1.89 & 3051 \\
\hline 5.1 & 2463 & 0.000753 & 0.281113 & 0.281077 & -59 & -4.70 & 3225 \\
\hline 7.1 & 2065 & 0.000305 & 0.281056 & 0.281044 & -61 & -15.03 & 3570 \\
\hline 8.1 & 2426 & 0.000735 & 0.280992 & 0.280958 & -63 & -9.81 & 3519 \\
\hline 14.1 & 2480 & 0.000728 & 0.281060 & 0.281026 & -61 & -6.16 & 3330 \\
\hline 15.1 & 2437 & 0.000720 & 0.281088 & 0.281054 & -60 & -6.12 & 3295 \\
\hline 17.1 & 2498 & 0.000817 & 0.280706 & 0.280667 & -73 & -18.49 & 4120 \\
\hline 18.1 & 2479 & 0.000606 & 0.281084 & 0.281055 & -60 & -5.13 & 3264 \\
\hline 1.1 & 2465 & 0.000574 & 0.281098 & 0.281071 & -59 & -4.90 & 3239 \\
\hline \multicolumn{8}{|c|}{ NAT-8 - Metatonalite } \\
\hline 1.1 & 2491 & 0.000658 & 0.281107 & 0.281076 & -59 & -4.1 & 3209 \\
\hline 2.1 & 2491 & 0.001367 & 0.281146 & 0.281081 & -58 & -3.9 & 3197 \\
\hline 6.1 & 2404 & 0.000846 & 0.281226 & 0.281187 & -55 & -2.2 & 3018 \\
\hline 8.1 & 2712 & 0.001867 & 0.281189 & 0.281092 & -56 & 1.6 & 3015 \\
\hline 10.1 & 2386 & 0.000600 & 0.281077 & 0.281050 & -60 & -7.5 & 3340 \\
\hline 14.1 & 2433 & 0.000631 & 0.281136 & 0.281106 & -58 & -4.4 & 3181 \\
\hline 16.1 & 2253 & 0.000556 & 0.281243 & 0.281219 & -54 & -4.5 & 3053 \\
\hline 18.1 & 2470 & 0.000740 & 0.281050 & 0.281015 & -61 & -6.8 & 3361 \\
\hline 19.1 & 2160 & 0.001707 & 0.281519 & 0.281448 & -44 & 1.5 & 2598 \\
\hline 20.1 & 2363 & 0.000914 & 0.281067 & 0.281026 & -60 & -8.8 & 3409 \\
\hline 21.1 & 2371 & 0.000761 & 0.281101 & 0.281066 & -59 & -7.2 & 3315 \\
\hline 1.1 & 2491 & 0.000658 & 0.281107 & 0.281076 & -59 & -4.1 & 3209 \\
\hline \multicolumn{8}{|c|}{ NAT 36 - Metatonalite } \\
\hline 1.1 & 2508 & 0.000689 & 0.281107 & 0.281074 & -59 & -3.8 & 3201 \\
\hline 2.1 & 2416 & 0.000584 & 0.281116 & 0.281089 & -59 & -5.4 & 3231 \\
\hline 3.1 & 2450 & 0.000666 & 0.281130 & 0.281098 & -58 & -4.3 & 3187 \\
\hline 5.1 & 2481 & 0.001421 & 0.281134 & 0.281066 & -58 & -4.7 & 3237 \\
\hline 4.1 & 2286 & 0.000619 & 0.281197 & 0.281170 & -56 & -5.5 & 3140 \\
\hline 9.1 & 2428 & 0.000955 & 0.281531 & 0.281487 & -44 & 9.0 & 2319 \\
\hline 10.1 & 2066 & 0.000777 & 0.281355 & 0.281325 & -50 & -5.0 & 2942 \\
\hline 10.2 & 2403 & 0.000718 & 0.281187 & 0.281154 & -56 & -3.4 & 3094 \\
\hline 12.1 & 2109 & 0.000838 & 0.281555 & 0.281521 & -43 & 2.9 & 2468 \\
\hline 11.1 & 2365 & 0.000586 & 0.281207 & 0.281181 & -55 & -3.3 & 3060 \\
\hline 13.1 & 2358 & 0.000659 & 0.281212 & 0.281183 & -55 & -3.4 & 3061 \\
\hline 1.1 & 2508 & 0.000689 & 0.281107 & 0.281074 & -59 & -3.8 & 3201 \\
\hline
\end{tabular}




\subsection{Geochemistry}

The studied samples are similar in major element composition having high $\mathrm{SiO}_{2}$ contents between 68.0 and 72.5 wt.\% commonly higher than $65 \%$. The only metagranodiorite has $\mathrm{SiO}_{2}$ content of the 69.65.

Table 6 presents the major and trace elements analyses for our rocks. Chemically, the samples show $\mathrm{SiO}_{2}$ contents between 68.0 and 72.5 wt.\% and coupled total alkalis $\mathrm{Na}_{2} \mathrm{O}+\mathrm{K}_{2} \mathrm{O}$ from 6.06-7.39 wt.\%, and are weakly peraluminous with $\mathrm{A} / \mathrm{CNK}<1.15$ (Fig. 6A). The latter ratios are comparable with those of the $2.33 \mathrm{Ga}$ Resende Costa orthogneiss but are slightly higher than those of the Lagoa Dourada suite (Seixas et al., 2012). The ortogneiss of the Cassiterita pluton fall in the magnesian field in Frost's diagram $\left(\mathrm{FeO}_{\mathrm{t}} / \mathrm{FeO}_{\mathrm{t}}+\mathrm{MgO}\right)$, with variation from 0.7-0.8 (Fig. 6B). According to these chemical signatures, as well the presence of the biotite, hornblende and titanite, these samples can be classified as I-type rocks (Frost et al., 2001).

Table 6. Major and trace element data for whole rock samples (Cassiterita orthogneiss).

\begin{tabular}{|c|c|c|c|c|c|c|c|c|c|c|c|c|c|c|c|c|}
\hline & $\begin{array}{l}\text { CS- } \\
01\end{array}$ & $\begin{array}{l}\text { CS- } \\
02\end{array}$ & $\begin{array}{l}\text { CS- } \\
03\end{array}$ & $\begin{array}{l}\text { CS- } \\
04\end{array}$ & $\begin{array}{l}\text { CS- } \\
05\end{array}$ & $\begin{array}{l}\text { CS- } \\
06\end{array}$ & $\begin{array}{l}\text { CS- } \\
07\end{array}$ & $\begin{array}{l}\text { CS- } \\
08\end{array}$ & $\begin{array}{l}\text { CS- } \\
09\end{array}$ & $\begin{array}{l}\text { CS- } \\
10\end{array}$ & $\begin{array}{l}\text { CS- } \\
11\end{array}$ & $\begin{array}{l}\text { CS- } \\
12\end{array}$ & $\begin{array}{l}\text { CS- } \\
13\end{array}$ & $\begin{array}{l}\text { NAT- } \\
05\end{array}$ & $\begin{array}{l}\text { NAT- } \\
\text { 08A }\end{array}$ & $\begin{array}{l}\text { NAT } \\
36\end{array}$ \\
\hline $\mathrm{SiO}_{2}$ & 70.4 & 71.8 & 69.5 & 70.2 & 68.0 & 69.7 & 71.8 & 69.7 & 70.7 & 70.7 & 69.6 & 70.1 & 72.1 & 69.65 & 70.83 & 72.50 \\
\hline $\mathrm{TiO}_{2}$ & 0.29 & 0.30 & 0.27 & 0.29 & 0.35 & 0.33 & 0.20 & 0.28 & 0.31 & 0.26 & 0.27 & 0.29 & 0.29 & 0.44 & 0.30 & 0.196 \\
\hline $\mathbf{A l}_{2} \mathbf{O}_{3}$ & 15.4 & 14.4 & 15.7 & 15.3 & 16.2 & 15.6 & 14.6 & 15.8 & 15.1 & 15.1 & 15.6 & 15.7 & 14.5 & 15.2 & 15.2 & 14.2 \\
\hline $\mathrm{Fe}_{2} \mathrm{O}_{3}$ & 2.57 & 2.46 & 2.92 & 2.75 & 3.35 & 3.12 & 2.00 & 2.63 & 2.72 & 2.65 & 2.90 & 2.77 & 2.81 & 2.70 & 2.88 & 2.02 \\
\hline MnO & 0.04 & 0.05 & 0.05 & 0.05 & 0.05 & 0.05 & 0.04 & 0.04 & 0.04 & 0.05 & 0.05 & 0.05 & 0.05 & 0.03 & 0.05 & 0.002 \\
\hline MgO & 0.86 & 0.78 & 0.96 & 0.88 & 1.21 & 0.90 & 0.65 & 0.87 & 0.94 & 0.91 & 0.95 & 0.83 & 0.61 & 0.80 & 0.71 & 0.50 \\
\hline $\mathrm{CaO}$ & 3.11 & 2.92 & 3.51 & 3.43 & 3.89 & 3.11 & 2.58 & 3.14 & 3.56 & 3.09 & 3.49 & 3.25 & 2.80 & 2.21 & 3.53 & 2.27 \\
\hline $\mathrm{Na}_{2} \mathrm{O}$ & 4.45 & 3.84 & 4.64 & 4.53 & 4.53 & 4.54 & 4.35 & 4.57 & 4.39 & 4.34 & 4.66 & 4.54 & 4.26 & 4.77 & 4.50 & 4.24 \\
\hline $\mathbf{K}_{2} \mathbf{O}$ & 1.61 & 1.86 & 1.36 & 1.43 & 1.31 & 1.85 & 2.50 & 1.28 & 1.29 & 1.80 & 1.39 & 1.58 & 1.47 & 2.62 & 1.00 & 2.45 \\
\hline $\mathbf{P}_{2} \mathbf{O}_{5}$ & 0.07 & 0.07 & 0.08 & 0.08 & 0.09 & 0.11 & 0.06 & 0.06 & 0.09 & 0.07 & 0.08 & 0.08 & 0.10 & 0.13 & 0.10 & 0.058 \\
\hline LOI & 1.1 & 1.3 & 0.8 & 0.9 & 0.8 & 0.5 & 1.0 & 1.5 & 0.7 & 0.9 & 0.8 & 1.2 & 0.7 & 1.2 & 0.7 & 0.76 \\
\hline $\mathbf{B a}$ & 712 & 809 & 515 & 489 & 332 & 804 & 738 & 314 & 507 & 652 & 485 & 602 & 476 & 1046 & 402 & 829 \\
\hline Co & 4.9 & 4.6 & 5.4 & 5.4 & 6.9 & 5.5 & 3.7 & 5.2 & 6.4 & 4.9 & 5.3 & 4.1 & 106. & 5.0 & 4.8 & \\
\hline Cs & 2.0 & 1.3 & 2.9 & 3.3 & 1.2 & 1.7 & 2.7 & 5.6 & 3.4 & 4.2 & 3.2 & 1.0 & 1.2 & 2.0 & 0.4 & 5.42 \\
\hline $\mathbf{G a}$ & 15.7 & 14.3 & 17.2 & 16.6 & 16.2 & 15.1 & 14.2 & 16.0 & 15.5 & 14.5 & 17.3 & 14.4 & 16.0 & 22.4 & 15.3 & 15 \\
\hline Hf & 2.9 & 4.0 & 3.4 & 3.7 & 3.3 & 4.4 & 2.8 & 2.8 & 3.5 & 3.9 & 3.8 & 3.1 & 4.7 & 5.1 & 4.8 & 3.64 \\
\hline $\mathrm{Nb}$ & 5.7 & 6.4 & 7.0 & 6.2 & 4.8 & 6.7 & 6.3 & 5.5 & 5.9 & 6.1 & 7.5 & 5.2 & 10.3 & 5.5 & 4.8 & 10.4 \\
\hline $\mathbf{R b}$ & 67 & 72 & 53 & 74 & 52 & 64 & 87 & 84 & 62 & 98 & 55 & 72 & 57 & 90 & 31 & 102 \\
\hline Sn & 1 & 1 & 2 & 2 & 1 & 1 & 1 & 1 & 1 & 2 & 2 & 2 & $<1$ & 2 & $<1$ & \\
\hline $\mathrm{Sr}$ & 412 & 308 & 387 & 378 & 449 & 317 & 292 & 375 & 433 & 301 & 367 & 325 & 292 & 467 & 338 & 308 \\
\hline Ta & 1.4 & 1.0 & 2.0 & 1.0 & 0.8 & 0.6 & 0.9 & 1.0 & 1.0 & 1.4 & 1.4 & 0.6 & 1.8 & 0.3 & $<0.1$ & \\
\hline Th & 8.7 & 8.4 & 7.3 & 11.3 & 6.2 & 15.3 & 11.8 & 7.5 & 9.2 & 11.1 & 8.0 & 8.3 & 10.0 & 17.2 & 8.9 & 12.7 \\
\hline $\mathbf{U}$ & 1.8 & 1.2 & 2.2 & 1.3 & 0.7 & 1.7 & 6.1 & 5.0 & 1.9 & 2.5 & 4.3 & 1.9 & 1.3 & 1.9 & 0.9 & 5.35 \\
\hline $\mathbf{V}$ & 27 & 20 & 30 & 28 & 39 & 28 & 25 & 27 & 36 & 35 & 32 & 29 & 17 & 25 & 18 & 15 \\
\hline $\mathbf{W}$ & 0.5 & 0.5 & 0.5 & 0.5 & 0.5 & 0.5 & 0.5 & 0.5 & 0.5 & 0.5 & 0.5 & 0.5 & 916. & 0.5 & 0.5 & \\
\hline
\end{tabular}




\begin{tabular}{|c|c|c|c|c|c|c|c|c|c|c|c|c|c|c|c|c|}
\hline$Y$ & 6.9 & 6.8 & 8.6 & 10.3 & 8.4 & 9.7 & 8.6 & 6.1 & 5.8 & 9.6 & 9.8 & 7.1 & 7.1 & 6.2 & 7.5 & 12.7 \\
\hline $\mathrm{Zr}$ & 120 & 159 & 136 & 141 & 132 & 176 & 83 & 110 & 136 & 115 & 141 & 126 & 187 & 228 & 201 & 101 \\
\hline Cd & 0.1 & 0.1 & 0.1 & 0.1 & 0.1 & 0.1 & 0.1 & 0.1 & 0.1 & 0.1 & 0.1 & 0.1 & 0.1 & 0.1 & 0.1 & \\
\hline $\mathrm{Cu}$ & 1.8 & 1.0 & 1.3 & 9.2 & 40.6 & 2.7 & 2.0 & 9.2 & 8.3 & 5.4 & 3.2 & 5.9 & 1.1 & 7.5 & 3.0 & 5 \\
\hline Hg & 0.01 & 0.01 & 0.01 & 0.01 & 0.01 & 0.01 & 0.01 & 0.01 & 0.01 & 0.01 & 0.01 & 0.01 & 0.01 & 0.01 & 0.01 & \\
\hline Mo & 0.1 & 0.1 & 0.1 & 0.1 & 0.1 & 0.1 & 0.1 & 0.1 & 0.1 & 0.1 & 0.1 & 0.1 & 0.9 & 0.1 & 0.6 & \\
\hline $\mathbf{N i}$ & 20 & 20 & 20 & 20 & 20 & 20 & 20 & 20 & 20 & 20 & 20 & 20 & 20 & 20 & 22 & \\
\hline $\mathbf{P b}$ & 8.2 & 16.7 & 2.6 & 7.6 & 1.6 & 4.2 & 14.5 & 4.0 & 3.0 & 4.1 & 2.7 & 8.6 & 3.8 & 10.8 & 1.9 & 28.6 \\
\hline Tl & 0.3 & 0.3 & 0.3 & 0.4 & 0.3 & 0.3 & 0.4 & 0.6 & 0.4 & 0.6 & 0.3 & 0.3 & 0.3 & 0.5 & 0.2 & \\
\hline $\mathbf{Z n}$ & 45 & 45 & 53 & 45 & 49 & 60 & 36 & 49 & 47 & 43 & 55 & 44 & 55 & 69 & 58 & 36 \\
\hline Sc & 2 & 2 & 9 & 4 & 5 & 5 & 3 & 3 & 4 & 5 & 9 & 4 & 4 & 3 & 3 & $<14$ \\
\hline La & 29.1 & 37.6 & 23.1 & 35.7 & 20.9 & 27.8 & 21.2 & 16.7 & 10.9 & 15.0 & 25.5 & 23.6 & 40.5 & 37.6 & 47.4 & 21.1 \\
\hline $\mathrm{Ce}$ & 2.0 & 1.3 & 2.9 & 3.3 & 1.2 & 1.7 & 2.7 & 5.6 & 3.4 & 4.2 & 3.2 & 1.0 & 1.2 & 2.0 & 0.4 & 5.42 \\
\hline $\operatorname{Pr}$ & 4.54 & 5.80 & 3.65 & 5.38 & 3.38 & 5.22 & 3.73 & 2.75 & 1.99 & 2.47 & 3.87 & 3.87 & 6.88 & 6.77 & 6.91 & 3.90 \\
\hline Nd & 14.8 & 19.4 & 11.9 & 17.8 & 12.2 & 18.3 & 12.2 & 8.2 & 6.6 & 8.9 & 13.0 & 13.4 & 20.7 & 24.9 & 21.2 & 12.9 \\
\hline Sm & 2.19 & 2.90 & 2.04 & 2.71 & 2.00 & 3.20 & 2.11 & 1.50 & 1.23 & 1.66 & 2.00 & 1.94 & 2.97 & 3.70 & 3.00 & 2.38 \\
\hline $\mathbf{E u}$ & 0.69 & 0.79 & 0.65 & 0.75 & 0.67 & 0.77 & 0.57 & 0.52 & 0.61 & 0.52 & 0.67 & 0.64 & 0.75 & 0.94 & 0.89 & 0.62 \\
\hline Gd & 1.58 & 2.14 & 1.77 & 2.32 & 1.76 & 2.53 & 1.67 & 1.26 & 1.12 & 1.39 & 1.84 & 1.68 & 1.88 & 2.36 & 2.57 & 2.11 \\
\hline Tb & 0.20 & 0.28 & 0.27 & 0.32 & 0.26 & 0.33 & 0.25 & 0.20 & 0.19 & 0.25 & 0.30 & 0.24 & 0.28 & 0.28 & 0.25 & 0.32 \\
\hline Dy & 1.15 & 1.22 & 1.64 & 1.72 & 1.42 & 1.69 & 1.43 & 1.10 & 1.05 & 1.74 & 1.72 & 1.25 & 1.50 & 1.46 & 1.54 & 1.91 \\
\hline Ho & 0.21 & 0.23 & 0.31 & 0.33 & 0.30 & 0.32 & 0.28 & 0.23 & 0.20 & 0.33 & 0.33 & 0.25 & 0.26 & 0.19 & 0.16 & 0.40 \\
\hline $\mathbf{E r}$ & 0.62 & 0.65 & 0.84 & 0.87 & 0.79 & 0.87 & 0.89 & 0.64 & 0.61 & 1.04 & 0.95 & 0.71 & 0.79 & 0.63 & 0.83 & 1.15 \\
\hline $\mathbf{T m}$ & 0.10 & 0.10 & 0.13 & 0.13 & 0.13 & 0.14 & 0.14 & 0.10 & 0.09 & 0.17 & 0.15 & 0.10 & 0.12 & 0.07 & 0.11 & 0.18 \\
\hline $\mathbf{Y b}$ & 0.61 & 0.63 & 0.91 & 0.85 & 0.85 & 0.88 & 0.87 & 0.67 & 0.56 & 1.21 & 0.90 & 0.67 & 0.80 & 0.46 & 0.99 & 1.26 \\
\hline Lu & 0.12 & 0.09 & 0.13 & 0.13 & 0.14 & 0.15 & 0.13 & 0.09 & 0.09 & 0.19 & 0.13 & 0.10 & 0.15 & 0.06 & 0.16 & 0.20 \\
\hline $\begin{array}{l}\mathbf{L a} / \\
\mathbf{Y b}_{\mathbf{N}}\end{array}$ & $\begin{array}{l}32.1 \\
3\end{array}$ & $\begin{array}{l}40.1 \\
9\end{array}$ & $\begin{array}{l}17.1 \\
0\end{array}$ & $\begin{array}{l}28.2 \\
9\end{array}$ & $\begin{array}{l}16.5 \\
6\end{array}$ & $\begin{array}{l}21.2 \\
8\end{array}$ & $\begin{array}{l}16.4 \\
1\end{array}$ & $\begin{array}{l}16.7 \\
9\end{array}$ & $\begin{array}{l}13.1 \\
1\end{array}$ & 8.35 & $\begin{array}{l}19.0 \\
8\end{array}$ & $\begin{array}{l}23.7 \\
2\end{array}$ & $\begin{array}{l}34.0 \\
9\end{array}$ & 55.05 & 32.24 & 11.33 \\
\hline $\begin{array}{l}\text { Dy/ } \\
\text { Dy* }\end{array}$ & 0.42 & 0.40 & 0.49 & 0.47 & 0.46 & 0.49 & 0.45 & 0.45 & 0.55 & 0.49 & 0.50 & 0.46 & 0.41 & 0.60 & 0.35 & 0.47 \\
\hline $\begin{array}{l}\text { Dy/ } \\
\text { Yb } \mathbf{b}_{\mathbf{N}}\end{array}$ & 1.22 & 1.26 & 1.17 & 1.31 & 1.09 & 1.25 & 1.07 & 1.07 & 1.22 & 0.93 & 1.24 & 1.21 & 1.22 & 2.06 & 1.01 & 0.99 \\
\hline $\begin{array}{l}\text { Dy/ } \\
\text { Yb }\end{array}$ & 1.89 & 1.94 & 1.80 & 2.02 & 1.67 & 1.92 & 1.64 & 1.64 & 1.88 & 1.44 & 1.91 & 1.87 & 1.88 & 3.17 & 1.56 & 1.52 \\
\hline $\begin{array}{l}\mathbf{E u} / \\
\mathbf{E u} *\end{array}$ & 1.13 & 0.97 & 1.05 & 0.91 & 1.09 & 0.83 & 0.93 & 1.16 & 1.59 & 1.05 & 1.07 & 1.08 & 0.97 & 0.97 & 0.98 & 0.85 \\
\hline
\end{tabular}
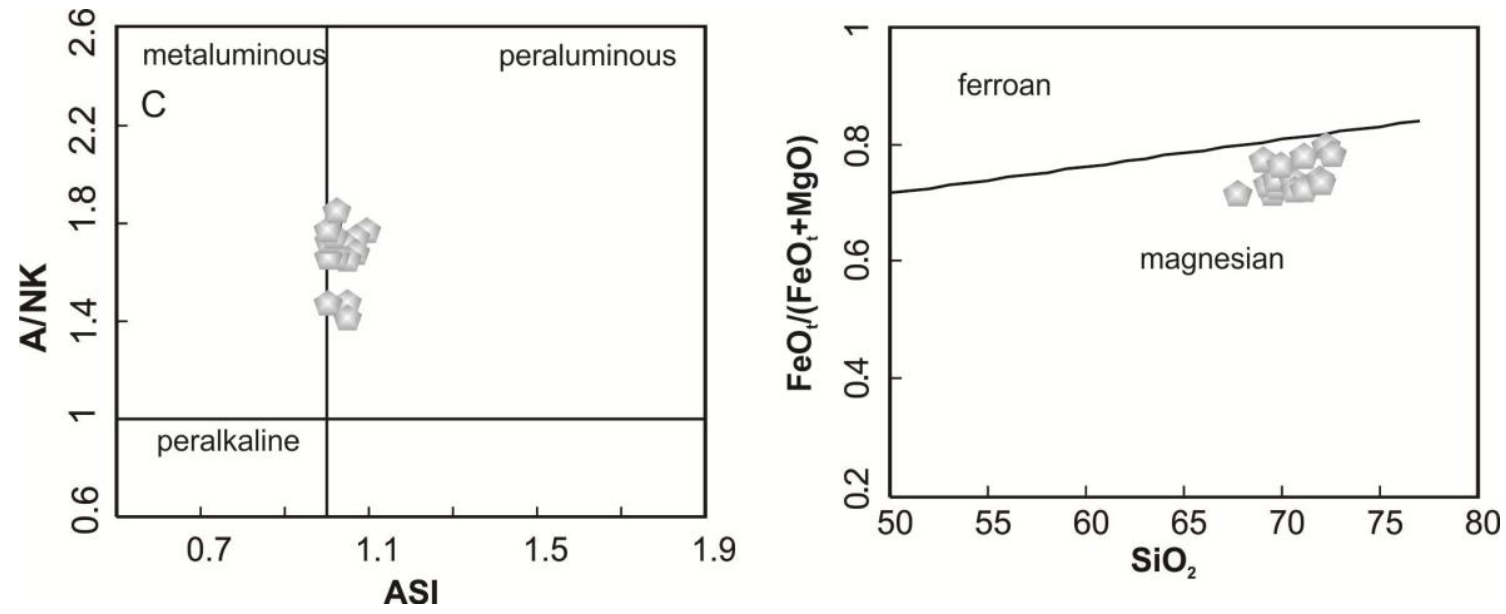

Figure 6. (A) A/NK vs. A/CNK (after Shand, 1943); (B) $\mathrm{FeO}_{t} /\left(\mathrm{FeO}_{\mathrm{t}}+\mathrm{MgO}\right.$ ) vs. $\mathrm{SiO}_{2}$ (Frost et al., 2001). 
The Harker diagrams show the correlation between $\mathrm{SiO}_{2}$ and major elements (Figs. 7A, B, C, D, E, F) among all samples. The $\mathrm{SiO}_{2}$ contents show narrow variation as well as the the major elements. The major elements abundances are as follow: $\mathrm{CaO}=$ 2.2-3.9; $\mathrm{TiO}_{2}=0.19-0.44 ; \mathrm{P}_{2} \mathrm{O}_{5}=0.06-0.13 ; \mathrm{MgO}=0.5-1.2 ; \mathrm{Fe}_{2} \mathrm{O}_{3}=2.0-3.4 ; \mathrm{Al}_{2} \mathrm{O}_{3}$ $=14.2-16.2$ wt. $\%$. The samples show slightly negative correlations between $\mathrm{CaO}, \mathrm{TiO}_{2}$, $\mathrm{P}_{2} \mathrm{O}_{5}, \mathrm{MgO}, \mathrm{Fe}_{2} \mathrm{O}_{3}$ and $\mathrm{Al}_{2} \mathrm{O}_{3}$ vs. $\mathrm{SiO}_{2}$. The marked negative trend between $\mathrm{Al}_{2} \mathrm{O}_{3}$ and $\mathrm{SiO}_{2}$ (Fig. 7) can be a reflex of the feldspar contents. According to Barker (1979) the samples that are enriched in $\mathrm{Al}_{2} \mathrm{O}_{3}$ belong to high $\mathrm{Al}$ group. Therefore, chemically our samples are broadly comparable with Resende Costa rocks $\left(\mathrm{Al}_{2} \mathrm{O}_{3}=16.4-13.2\right.$ wt. \%) that are interpreted as high $\mathrm{Al}_{2} \mathrm{O}_{3}$ trondhjemites (Teixeira et al., 2015).
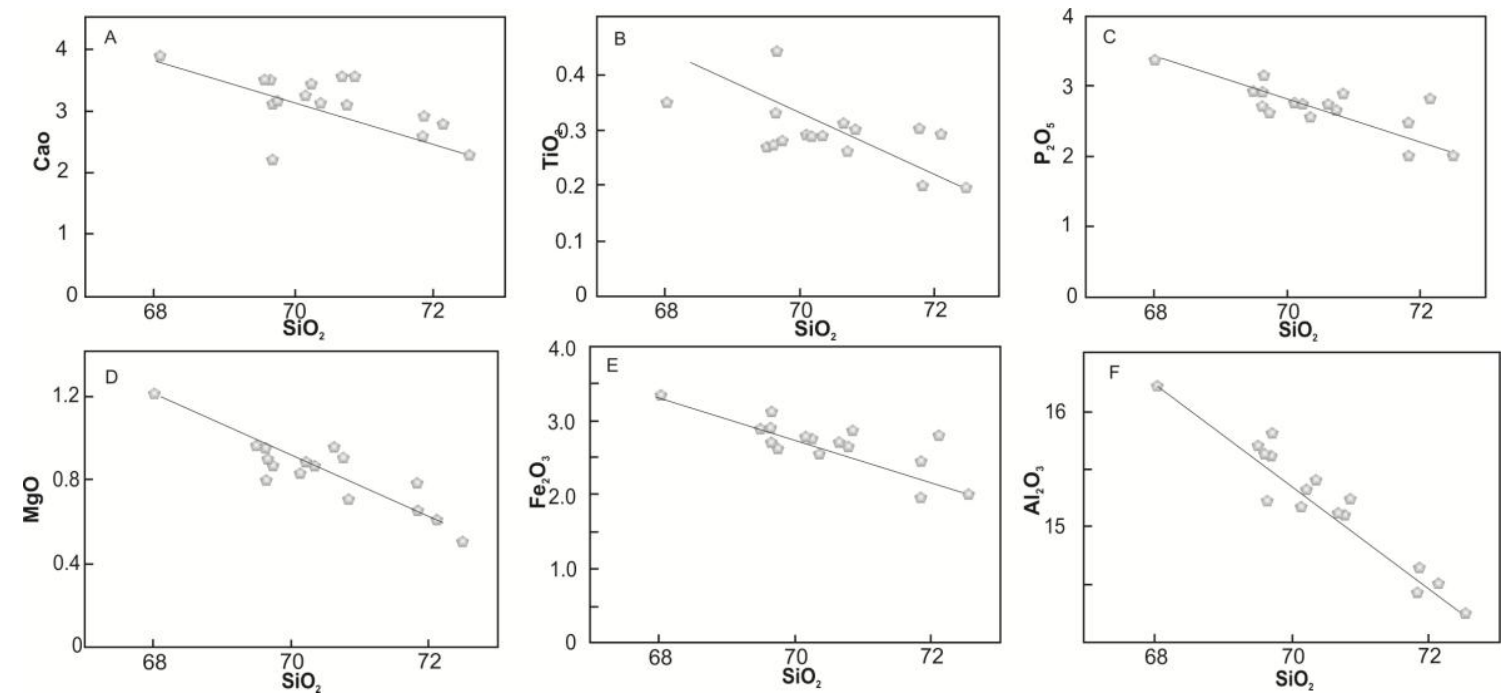

Figure 7. Harker correlation diagrams of selected major elements for the Cassiterita pluton.

The Figures 8A, B and $\mathrm{C}$ present the Harker diagrams for selected minor elements (LILE). Both $\mathrm{Rb}$ and $\mathrm{Ba}$ show positive correlation related to $\mathrm{SiO}_{2}$ increase while $\mathrm{Sr}$ decreases with silica increase (Figs. 8A, B and C). This is due to the depletion of Sr content in Ca plagioclase during fractional crystallization.

The REE elements indicate positive correlation with $\mathrm{SiO}_{2}$, as shown for example in La, Dy and $\mathrm{Yb}$ (Figs. 8D, E and F). Some trace elements exhibit similar trend to those of the major elements; for instance compatible elements as $\mathrm{Ni}, \mathrm{Co}, \mathrm{V}$ usually show a decrease with increasing $\mathrm{SiO}_{2}$ content (Figs. 8G, $\mathrm{H}$ and I). In contrast the incompatible and $\mathrm{REE}$ elements. Low $\mathrm{Cr}, \mathrm{Co}, \mathrm{Sc}, \mathrm{MgO}$ and $\mathrm{Ni}$ in metagranitoids suggest a basaltic source (Rollinson, 2007). Figures 8J, K and L show that the HSFE elements have positive correlation for $\mathrm{Zr}$ and $\mathrm{Th}$, while $\mathrm{U}$ content is scattered. The LILE 
and LREE increase such as $\mathrm{Rb}, \mathrm{Ba}, \mathrm{K}, \mathrm{La}, \mathrm{Ce}, \mathrm{Nd}$ has been related to some degree of arc maturity (Brown et al., 1984).
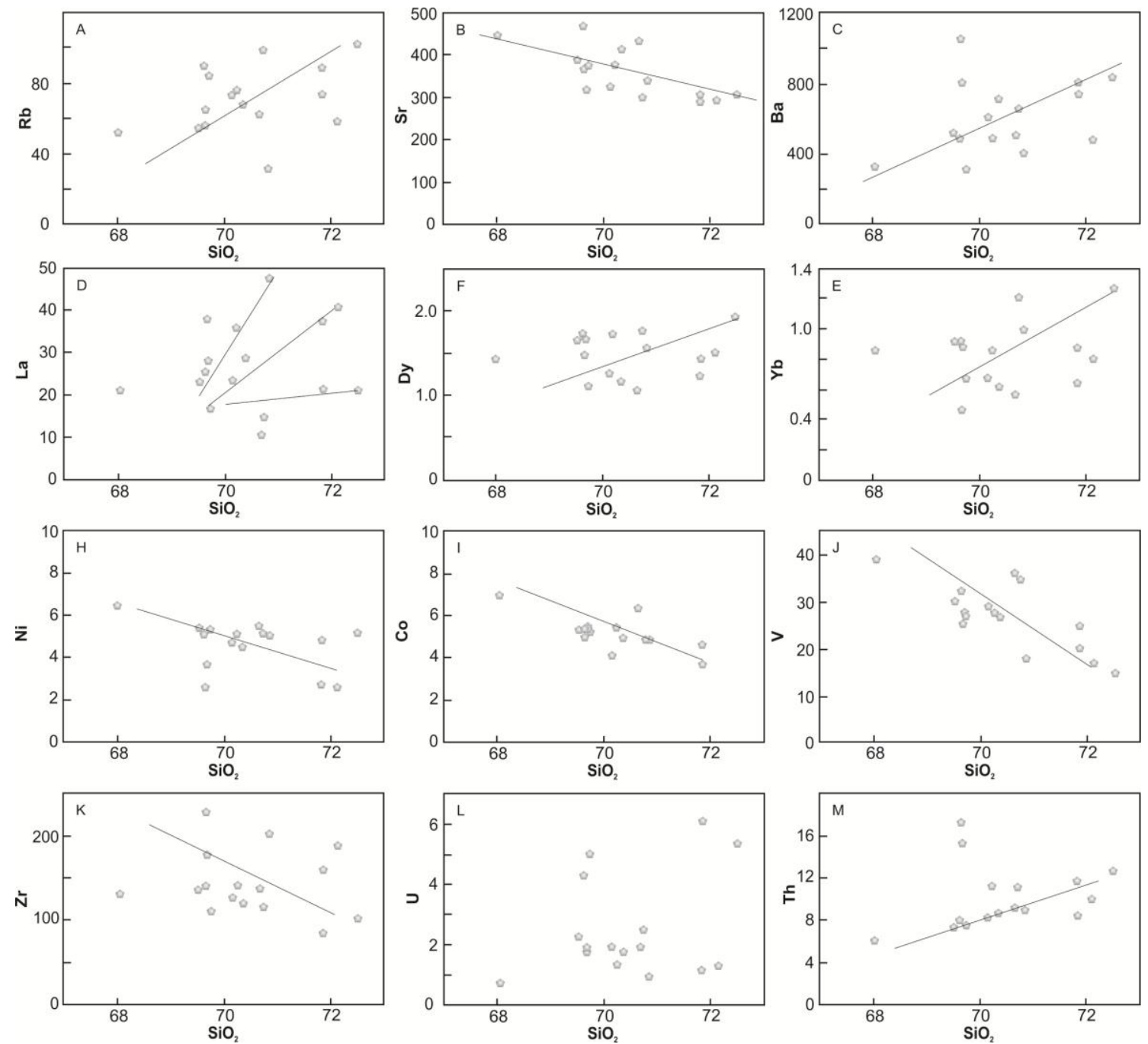

Figure 8. Harker diagram of selected minor elements for Cassiterita pluton.

The $\mathrm{Na}_{2} \mathrm{O}$ contents range from 3.84-4.77 (Table 6) and the ferromagnesian contents $\mathrm{Fe}_{2} \mathrm{O}_{3}+\mathrm{MgO}+\mathrm{MnO}+\mathrm{TiO}_{2}=2.7-4.9(<5)-$ not shown. This is consistent with the Moyen and Martin (2012) parameter to classify TTGs rocks. In a similar manner the $\mathrm{K}_{2} \mathrm{O} / \mathrm{Na}_{2} \mathrm{O}$ vs. $\mathrm{SiO}_{2}$ diagram (Fig $9 \mathrm{~A}$ ) the $\mathrm{K}_{2} \mathrm{O} / \mathrm{Na}_{2} \mathrm{O}$ values range from $0.22-0.57(<1)$. These values coupled with $\mathrm{SiO}_{2}$ contents (ca. 70\%wt) suggest a TTG affinity. In addition the K-N-Ca diagram, our samples plot below the boundary of the TTG field. The normative classification (An-Ab-Or triangle; Figs. 9B and C; O'Connor, 1965) confirms the Na-affinity of the samples that overlap the tonalite-granodiorite and trondhjemitc boundary, althought most plot in the granodiorite field. The $\mathrm{Al}_{2} \mathrm{O}_{3}$ contents range from 14.2-16.2 wt.\%, the most of the rocks belong to the high $\mathrm{Al}_{2} \mathrm{O}_{3}$ TTG group 
(Barker, 1979), indicating some sort of the continental contamination, like the Resende Costa rocks (Teixeira et al., 2015). In the $\mathrm{Nb} / \mathrm{Ta}$ vs. $\mathrm{Zr} / \mathrm{Sm}$ diagram (Fig. 9D) the samples fall into the amphibolite field (Foley et al., 2002), the high $\mathrm{Nb} / \mathrm{Ta}$ and $\mathrm{Zr} / \mathrm{Sm}$ in TTG rocks are consistent with a garnet bearing amphibolite restite (Foley et al., 2002 ). In other words our data are consistent with melts of mafic tholeiitic crust with garnet amphibolite as the residual phase. The $\mathrm{Rb} \times(\mathrm{Y}+\mathrm{Nb})$ tectonic discriminant diagram is also consistent with the hypothesis that the Cassiterita rocks are probably arc derived.

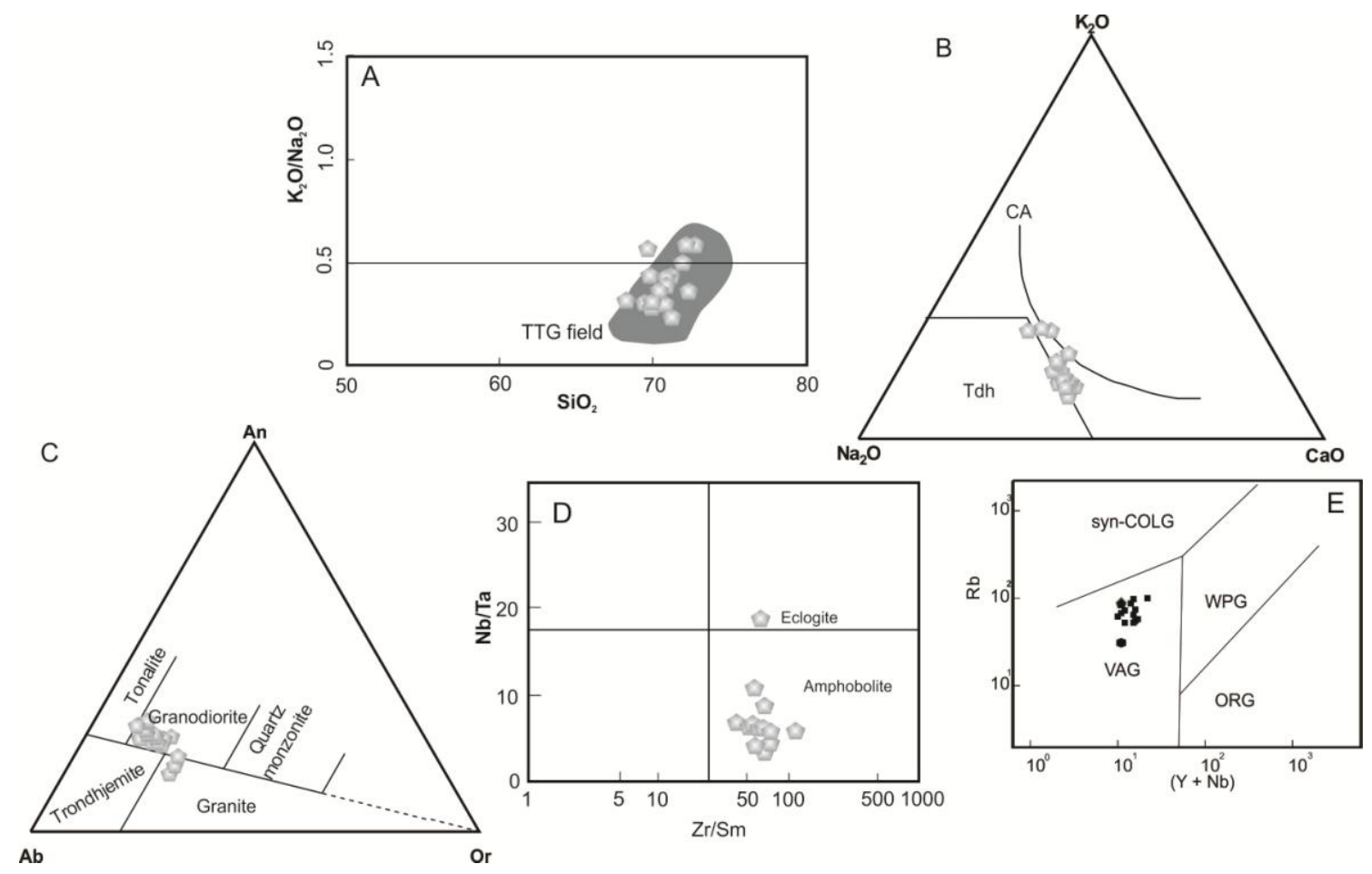

Figure 9. Geochemical characteristic for Cassiterita rocks. (A) $\mathrm{K}_{2} \mathrm{O} / \mathrm{Na}_{2} \mathrm{O}$ vs. $\mathrm{SiO}_{2}$ diagram; (B) Oxides $\mathrm{K}_{2} \mathrm{O}-\mathrm{Na}_{2} \mathrm{O}-\mathrm{CaO}$ diagram showing TTG field and calk-alkaline trend; (C) Normative An$\mathrm{Ab}$-Or triangle with trondhjemites, tonalities, granodiorites and granites fields (O'Connor, 1965); (D) Diagrams of $\mathrm{Nb} / \mathrm{Ta}$ versus $\mathrm{Zr} / \mathrm{Sm}$ ratios indicating the field of the TTG sources; (E) $\mathrm{Rb} \times(\mathrm{Y}+\mathrm{Nb})$ tectonic discriminant diagram (Pearce et al., 1984).

On chondrite-normalized rare element diagram (Fig. 10A), the TTGs rocks exhibit LREE enrichment and HREE depletion contents. Our samples exhibit high LREE, $\mathrm{La}_{\text {average }}=27.1 \mathrm{ppm}$ and low HREE $\mathrm{Yb}=0.82 \mathrm{ppm}$. These data result in high $\mathrm{La} / \mathrm{Yb}$ values (12.4-81.7) and $\mathrm{La} / \mathrm{Yb}_{\mathrm{N}}$ (8.3-55.0), $\left(\mathrm{La}_{\mathrm{N}}=44.5-193.5 ; \mathrm{Yb}_{\mathrm{N}}=2.8-7.6\right.$ ppm). The diagram 10 A show the absence of Eu anomaly, similar to the $\mathrm{Sr}$ (not shown) $\left(\mathrm{Eu} / \mathrm{Eu}^{*}=0.8-1.6\right)$. On primitive mantle-normalized diagram (Fig. 10B) the samples present enrichment in LILEs and HFSE, such as $\mathrm{Rb}, \mathrm{Ba}, \mathrm{Cs}$, Th, and depletion in some HFSE (e.g., Nb and Ti). 

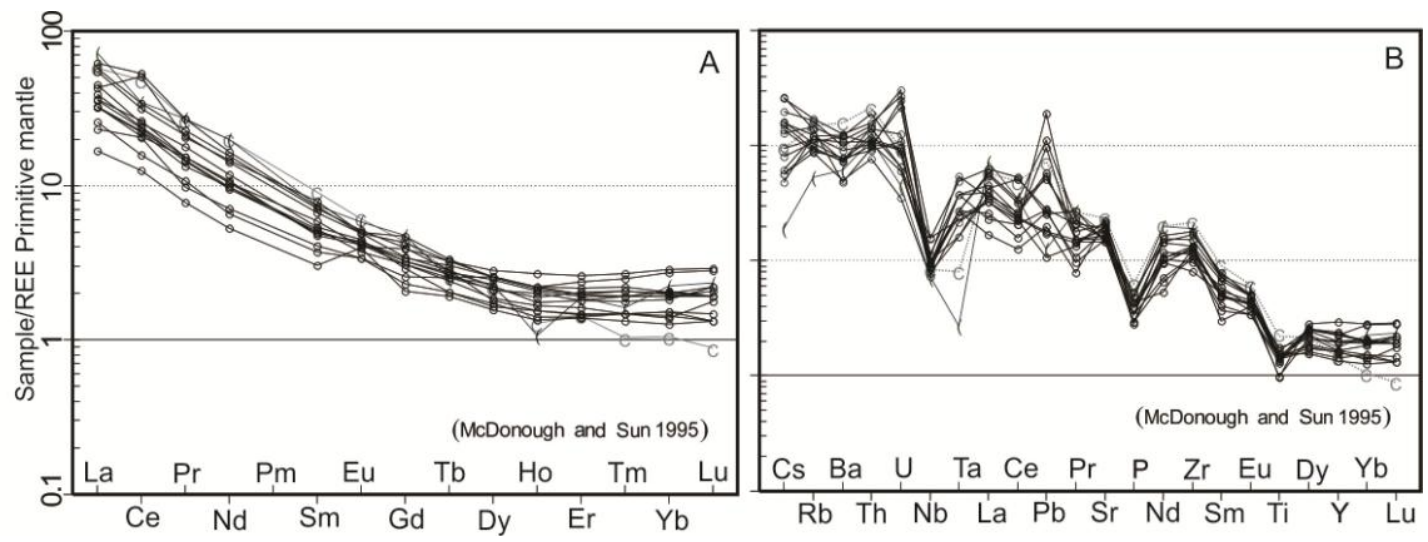

Figure 10. (A) Chondrite mantle normalized REE pattern; (B) Primitive mantle normalized spidergram for the Cassiterita rocks. Normalized values are from McDonough and Sun (1995).

\section{Petrogenesis and tectonic setting}

New data revealed first time 2.46-2.41 Ga plutonism (Cassiterita batholith) active in the evolution of the MB. From a tectonic point of view our data define that the Minas accretionary orogeny initiated ca. 100 m.y earlier than previously stated. The studied rocks share analogous major and minor elements compositions, this data coupled with the data ploted in triangle diagrams $\mathrm{N}_{2} \mathrm{O}-\mathrm{K}_{2} \mathrm{O}-\mathrm{CaO}$ and $\mathrm{Ab}-\mathrm{An}-\mathrm{Or}$ overall defining a TTG affinity (see section 5.4).

The main mechanism to generate the Cassiterita rocks is partial melt (Fig. 11). In general, magmatic processes to generate TTG rocks can be envisaged as fractional crystallisation and partial melt (see section 1). The fractional crystallisation depletes the melt in compatible elements, reduces the $\mathrm{Ni}, \mathrm{V}$ and $\mathrm{Cr}$ or other elements. On the other hand, the partial melt increase the incompatible elements. The behavior of the compatible and incompatible elements is presented in Fig. 11 (log diagrams). Two patterns are present. The horizontal line means that the increase of the incompatible elements refers to partial melt, while the vertical alignment characterizes the fractional crystallisation. In the Fig. 11 the studied samples follow along the horizontal trend. This suggests that partial melt is the mainly magmatic process in the Cassiterita pluton. 

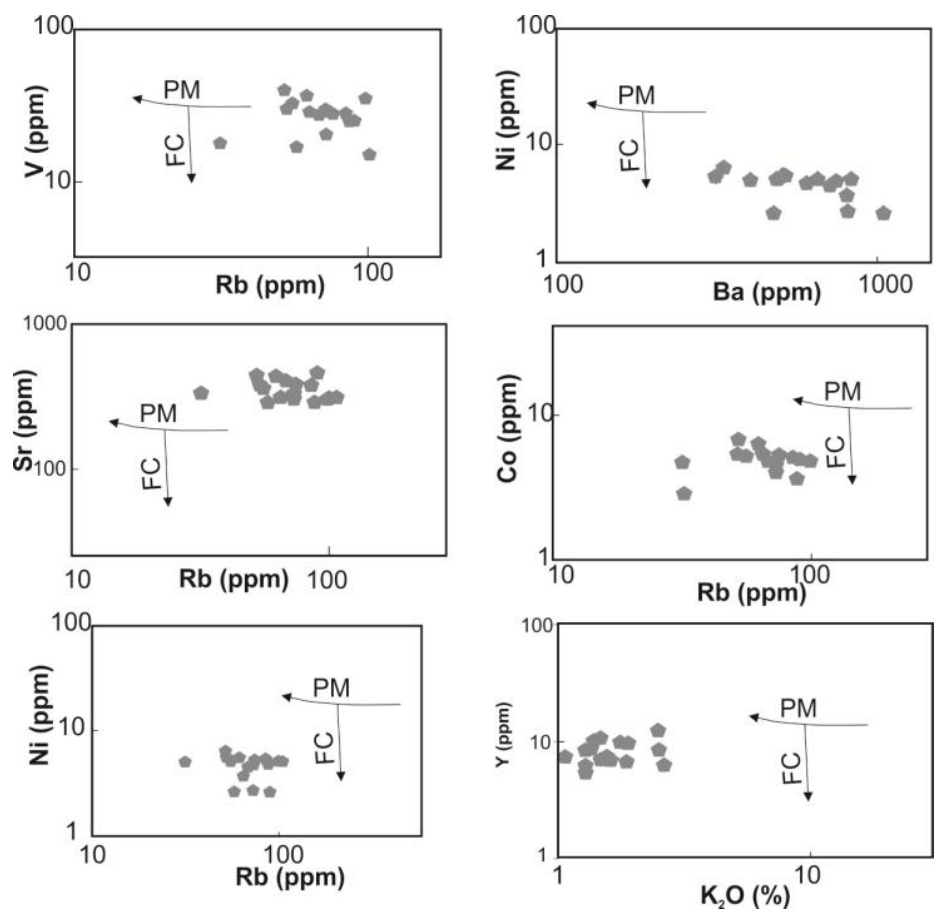

Figure 11. Compatible ( $\mathrm{Ni}, \mathrm{Co}, \mathrm{V}, \mathrm{Y}$ and $\mathrm{Sr}$ as compatible) vs. incompatible $\left(\mathrm{Rb}, \mathrm{Ba}, \mathrm{K}_{2} \mathrm{O}\right)$ showing partial melt process.

The La/Yb vs. La diagram (Fig. 12) confirms that the partial melt is the major process given the distribution of the samples that is subparallel to the reference line.

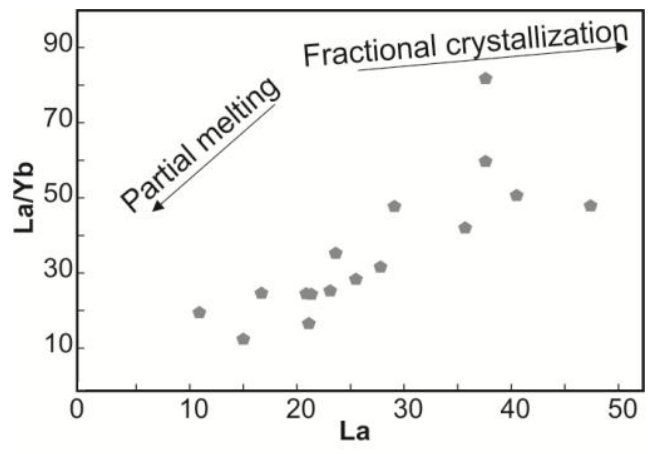

Figure 12. La/Yb vs. La showing partial melt process.

The bulk Sr-Nd signatures of the samples are consistent with an enriched MORB source in coherence with a subduction process. The depletion in $\mathrm{Nb}$ and $\mathrm{Ti}$, characterized by negative anomalies, helps to strengthen the interpretation that the rocks were formed in subduction process. However, the positive $\mathrm{Pb}$ anomalies (see Fig. 10), the increase of $\mathrm{Dy} / \mathrm{Yb}_{\mathrm{N}}$ ratios (Fig. 13) and high $\mathrm{Al}_{2} \mathrm{O}_{3}$ contents of our rocks indicate 
that mantle could be contaminated by sediments loaded in the slab subduction or crustal contamination.

An evidence of sediments contamination of oceanic crust influencing the magma generation is given by Dy/Dy* vs. Dy/Yb diagram (Fig. 13; Davidson et al., 2013). Our data show Dy/Dy* range from $0.38-0.55 / 0.60$ and $\mathrm{Dy} / \mathrm{Yb}$ from 1.44-2.02/3.17. Therefore the data plot to the right of fractional crystallisation of amphibole+cpx and below the LREE enriched source. The distribution of the samples is roughly compatible with sediment melts. The probable interpretation is that this enrichment occurred due to subducted sediments in oceanic crust enriching the mantle in incompatible elements.

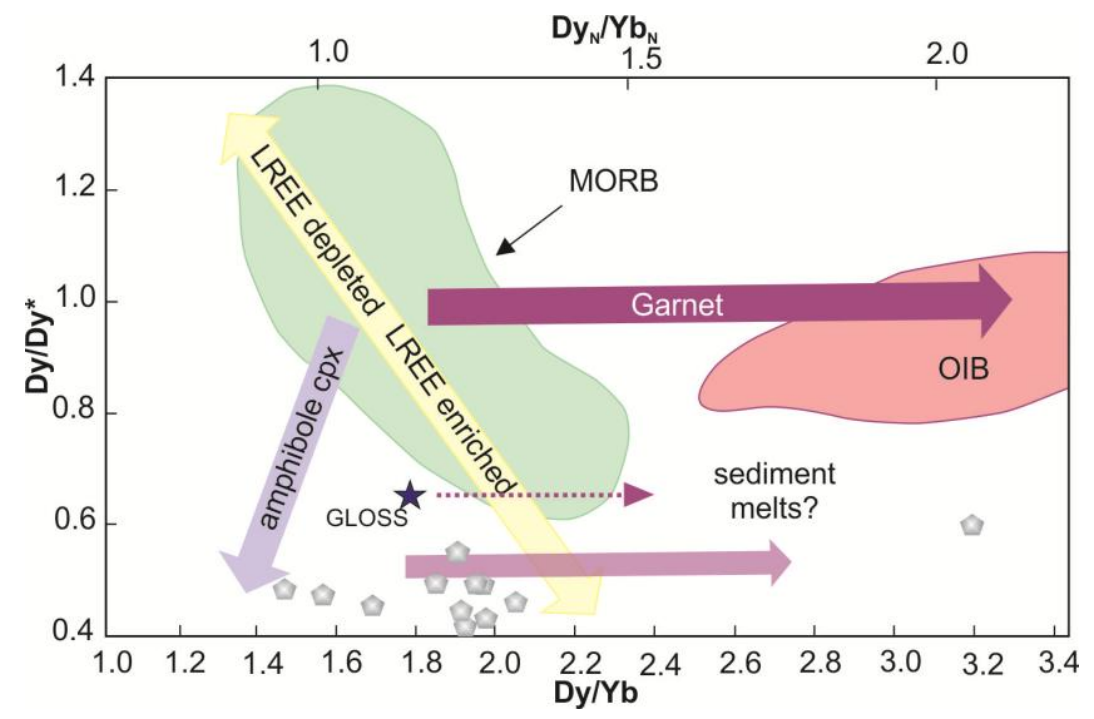

Figure 13. Plot of Dy/Dy* vs. Dy $\mathrm{N}_{\mathrm{N}} / \mathrm{Yb}_{\mathrm{N}}$ vs. Dy/Yb extended diagram (after Davidson et al., 2013). $\mathrm{Dy} / \mathrm{Dy} *=\mathrm{Dy}_{\mathrm{N}} /\left(\mathrm{La}_{\mathrm{N}}{ }^{4 / 13} \mathrm{x} \mathrm{Yb}_{\mathrm{N}}{ }^{9 / 13}\right)$.

TTGs rocks exhibit characteristic trace elements of the enrichment in LREE and impoverishment in HREE contents. Our samples exhibit high $\mathrm{LREE}, \mathrm{La}_{\text {average }}=27.1$ ppm and low HREE $\mathrm{Yb}=0.82 \mathrm{ppm}$, this data result in high $\mathrm{La} / \mathrm{Yb}$ values (12.4-81.7) and chondritic REE normalization values $\mathrm{La} / \mathrm{Yb}_{\mathrm{N}}$ (8.3-55.0). Additionally, the $\mathrm{Sr} / \mathrm{Y}$ $(<100)$, chondrite-normalised $\mathrm{La} / \mathrm{Yb}_{\mathrm{N}}(<50)$ ratios, low $\mathrm{Y}$ and $\mathrm{Yb}$ (Table 6) are consistent with TTG parameters (Moyen and Martin, 2012). On the other hand the Sr/Y vs. $\mathrm{Y}$ and $\mathrm{La} / \mathrm{Yb}_{\mathrm{N}}$ vs. $\mathrm{Yb}_{\mathrm{N}}$ diagrams are useful for modeling the composition of the restite. The high $\mathrm{Sr}$ and $\mathrm{Sr} / \mathrm{Y}_{\mathrm{N}}$ and low $\mathrm{Y}$ contents indicate the absence of plagioclase in the residue, this helps confirm the nature of the source.

The absence of Eu-Sr anomalies combined with low HREE contents imply to a possible presence of garnet and amphibole mainly in the residual phases (Champion and Smithies, 2003), as previously suggested in Figure 10 (see above). 
In the Fig. 14A $\left(\mathrm{La} / \mathrm{Yb}_{\mathrm{N}}\right.$ versus $\mathrm{Yb}_{\mathrm{N}}$ diagram) the Cassiterita samples plot again in the TTG field, following the modeled composition of the tholeiitic source with mainly garnet amphibolite residue (garnet amphibolite line). Notably few samples plot next the eclogitic trend. However eclogite residues requires high degree of partial melt (Foleu et al., 2002), thus the garnet amphibolite restite seems to be a more realistic situation due to dimensions of the rocks generated in Cassiterita batholith. For instance, the arrows in Sr/Y vs. Y diagram (Fig. 14B) suggest that the studied rocks produced the residue with 7-30\% garnet amphibolite composition (lines from Martin, 1986). All the data is broadly compatible with Lagoa Dourada suite studied by Seixas et al., (2012). However, due to lack of older $(2.4 \mathrm{Ga})$ metabasaltic rocks in the studied area, we cannot calculate a more robust geochemistry model for Cassiterita rocks.
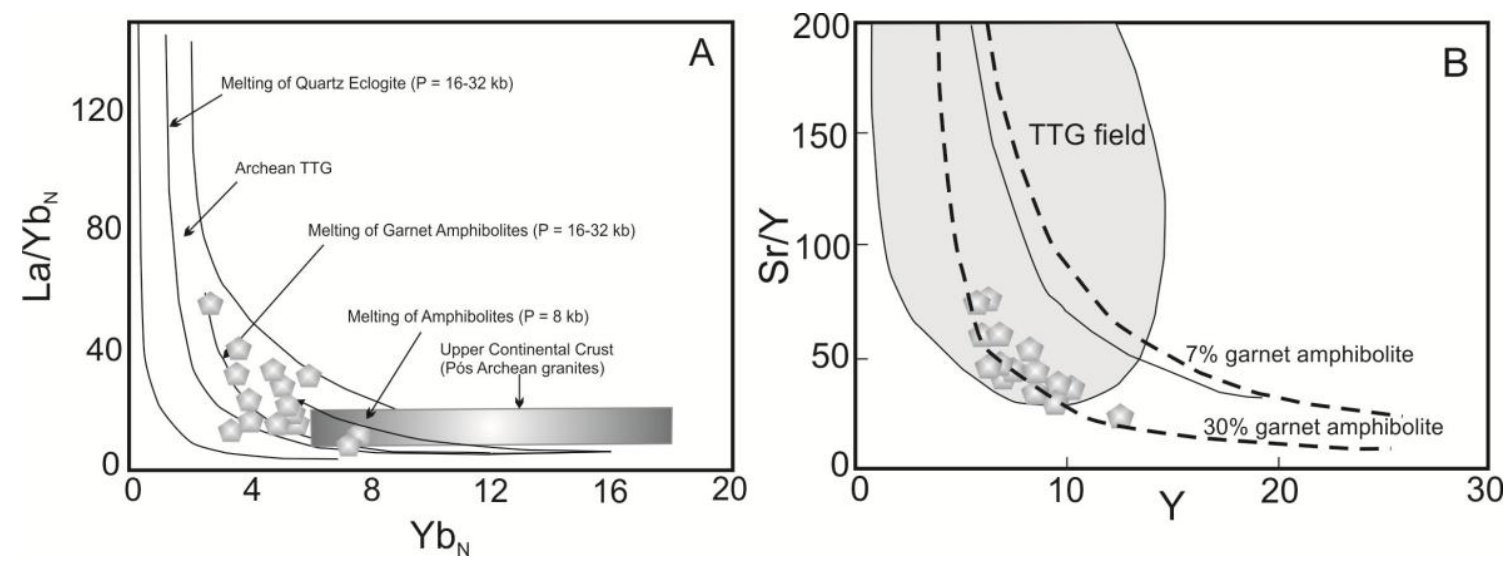

Figure 14. Calculated modeled composition of melts and residues derived from partial melting of the tholeiitic source. (A) La/Yb vs. Yb diagram; (B) Sr/Y vs. Y diagram.

Rock derivation in the subducted zones is usually constrained by isotopic and geochemical constraints (Rollinson, 2007; Albarède, 1995). The data are consistent with partial melt from tholeiitic source (Fig. 13) in the garnet stability field, i.e. garnet amphibolite as residue (Figs. 14A and B). In a similar manner the lack of Eu and $\mathrm{Sr}$ anomalies is interpreted as presence of garnet and amphibole, as well as the absence of plagioclase in residual phases. In consequence the partial melt will cause a decrease of the HREE values, because they are retained in garnet amphibolite residue, in particular $\mathrm{Lu}, \mathrm{Yb}$ and Y (HFSE). The opposite occurs with LREE and LILE, as shown in our data (Table 6).

The key isotopic features for the Cassiterita rocks include positive $\mathrm{Nd}$ and low Sr signatures. The whole rock $\varepsilon_{\mathrm{Nd}(\mathrm{t})}$ values are positive $(+2.7$ and +1.5$)$, the ${ }^{87} \mathrm{Sr}^{86} \mathrm{Sr}_{\mathrm{i}}$ $\leq 0.702$. The $\mathrm{Sm} / \mathrm{Nd} \mathrm{T}_{\mathrm{DM}}$ ages are ca. $2.5 \mathrm{Ga}$ indicating a short crustal residence for 
these samples. This suggests that TTG rocks were derived from juvenile source with depleted mantle $\mathrm{Nd}-\mathrm{Sr}$ signatures. In opposition, the zircon $\varepsilon_{\operatorname{Hf}(2.4)}$ values are all negative, ranging between -1.9 and $-6.8 /-9.8$. Usually, negative $\varepsilon_{\mathrm{Hf}(\mathrm{t})}$ values suggest reworked zircons derived from continental crust. However, during the melt of basaltic source occurs the enrichment of the magma in LREE and LILE, whereas the restite becomes enriched in HREE, as Lu. This process generates the negative $\varepsilon_{\mathrm{Hf}(\mathrm{t})}$ values and low $\mathrm{Lu} / \mathrm{Hf}$ ratios to melt, that increase the $\mathrm{T}_{\mathrm{DM}}$ age (Vervoort and Patchett, 1996). In this case the mineralogy and composition controls the decoupling of $\mathrm{Lu}$ in relation to the Hf (e.g., Schmitz et al., 2004). It should be noted that the interpretations of geochemical data indicates that these granitoids were generated in subducted zones by melting of oceanic crust, leaving a garnet amphibolite as residue. Due to Lu and $\mathrm{Hf}$ belong to different chemical group the fractionation of $\mathrm{Lu} / \mathrm{Hf}$ is almost twice of $\mathrm{Sm} / \mathrm{Nd}$ system, which will result in greater values of $\varepsilon_{\mathrm{Nd}(\mathrm{t})}$ related to the $\varepsilon_{\mathrm{Hf}(\mathrm{t})}$ ones and can identify different domains in mantle source (Patchett, 1983; Vervoort and Patchett 1996; Nowell et al., 2004).

In summary, the contrasting whole rock $\mathrm{Nd}$ and zircon $\mathrm{Hf}$ signatures can be interpreted as follow: the positive $\varepsilon_{\mathrm{Nd}(\mathrm{t})}$ values (up to +2.7 ) is roughly consistent with the low negative $\varepsilon_{\mathrm{Hf}(\mathrm{t})}$ ones (>-5). This may imply that these particular samples derived from melts with high Sm/Nd ratios (Beard and Johnson, 1993). Moreover one can consider that these sampled had an enriched HREE restite component in order to decouple the Lu-Hf system to produce the observed negative values. Alternatively the negative $\varepsilon_{\mathrm{Hf}(\mathrm{t})}$ values may indicate derivation from an enriched mantle (e.g., Montecinos et al., 2008). In other words, these isotopic differences suggest the decoupling of the two isotopic systems or disturbance in Lu or Sm systematics during magmatic process. Others interpretation for strongly negative $\varepsilon_{\mathrm{Hf}(\mathrm{t})}$ values $(>-5)$ are consistent with reworked zircons from sediments loaded through oceanic crust.

\section{Regional implications}

The zircon U-Pb data analyzed show ages from $2462 \pm 14 \mathrm{Ma} ; 2419 \pm 13 \mathrm{Ma}$; $2414 \pm 29 \mathrm{Ma}$ for Cassiterita rocks. The U-Pb data of our study do not support a high crust production during early Paleoproterozoic times.

Data from some areas show that Paleoproterozoic continental crust in Mineiro belt assumed a growth derived of the accretionary orogens. The accretionary orogen recently well characterized by several authors indicate that the granitoids of the Mineiro 
belt is predominatly I-type. This means that the granitoids identified so far were derived by partial melt of subducted oceanic crust, though subjected to variable contamination. The generation of extensive granitoids was dominated in successive oceanic arcs and a major continental arc, which collided against the Archean landmass at ca. 2.1-2.0 Ga.

From a paleotectonic perspective the Cassiterita pluton was formed away from the Archean paleocontinent. In our model at the time of formation of the Cassiterita arc, the Archean paleocontinent undergoes subsidence leading to deposition of the chemical sediments in the Minas passive margin basin (2.42 Ga; Babinski et al., 1995). Thus this is a robust evidence for the intraoceanic nature of the Cassiterita.

In the Mineiro belt, the oldest TTG rocks were produced during two distinct magmatic ages at 2.45 (Cassiterita pluton) and 2.36 Ga (Lagoa Dourada-Resende Costa suites). The $\varepsilon_{\mathrm{Nd}(\mathrm{t})}$ values from Resende Costa-Lagoa Dourada (+4 to -9$)$ fall in range with Cassiterita rocks, although these younger rocks show a little more continental contribution (represented by negative values of $\varepsilon_{\mathrm{Nd}(\mathrm{t})}$ ). Geochemical and isotopic evidence allow a possible genetic connection between these two magmatic episodes, which spatially can constitute the same magmatic arc.

Considering collectively the 2.4-2.3 Ga age rocks of the MB the scenario is consistent with a growing of lithospheric plate given by the Minas accretionary orogeny when the Columbia (Nuna) core was forming.

Noteworthy, scattered occurrences of rock assemblages with $2.4-2.3 \mathrm{Ga}$ ages are recorded in the South American continent (Amazonian craton, Borborema province, Amazonia) and other places in the world (see section 1). This particular Paleoproterozoic evolutionary stage with juvenile crustal growth contrasts, in part, with the idea (e.g., Condie et al., 2009) of minor crustal production in the early Paleoproterozoic time, based on the global age distribution of juvenile granitoid magmatism.

The propagation of the MB occurred from south to north by magmatic arcs during the whole Siderian-Rhyacian times (Ávila et al., 2010; Seixas et al., 2012, 2013; Teixeira et al., 2015). The younger ages $(2.17-2.09 \mathrm{Ga})$ in granitoid rocks scattered accross the MB establish the ultimate growth in continental arc setting. In other words this means that arc accrectionary regime played a major role in Paleoproterozoic evolution of the southern São Francisco craton. 


\section{References}

Albarède, F., 1995. Introduction to Geochemical Modeling. Cambridge University Press, Great Britain, 543 pp.

Alkmim, F.F., Lana, C., Duque, T.R.F., 2014. Zircões detríticos do Grupo Itacolomi e o registro do soerguimento do Cinturão Mineiro. In: $47^{\circ}$ Congresso Brasileiro Geologia, Boletim Resumos. Sociedade Brasileira de Geologia, CD-ROM.

Alkmim, F.F., Marshak, S., 1998. Transamazonian Orogeny in the Southern São Francisco Craton, Minas Gerais, Brazil: Evidence for Paleoproterozoic collision and collapse in the Quadrilátero Ferrífero. Precambrian Research 90, 29-58.

Alkmim, F.F., Noce, C.M., 2006. Outline of the geology of Quadrilátero Ferrífero. In: Alkmim, F.F., Noce, C.M. (Eds.). The Paleoproterozoic Record of São Francisco Craton. IGCP509 Field Workshop, Bahia and Minas Gerais. Field Guide and Abstracts, pp. 37-73.

Arth, J.G., 1979. Some trace elements in trondhjemites, their implication to magma genesis and paleotectonic setting. In: Barker, F. (Ed.), Trondhjemites, Dacites and Related Rocks. Elsevier, Amsterdam, pp. 123-132.

Ávila, C.A, Teixeira, W., Bongiolo, E.M., Dussin, I.A., Vieira, T.A.T, 2014. Rhyacian evolution of subvolcanic and metasedimentary rocks of the southern segment of the Mineiro belt, São Francisco craton, Brazil. Precambrian Research 243, 221-251

Ávila, C.A., Teixeira, W., Cordani, U.G., Moura, C.A.V., Pereira, R.M., 2010. Rhyacian (2.23 2.20 Ga) juvenile accretion in the southern São Francisco craton, Brazil: Geochemical and isotopic evidence from the Serrinha magmatic suite, Mineiro belt. Journal of South American Earth Sciences 29, 464-482.

Ávila, C.A., Valença, J.G., Moura, C.A.V., Klein, V.C., Pereira, R.M., 2003. Geoquímica e idade do Tonalito/trondhjemito Cassiterita, borda meridional do Cráton São Francisco, Minas Gerais. Arquivos do Museu Nacional 61, 267-284.

Babinski, M., Chemale, F., William, R., Van Schmus, W.R., 1995. The Pb/Pb age of the Minas Supergroup carbonate rocks, Quadrilátero Ferrífero, Brazil. Precambrian Research 72, 235-245.

Barbosa, N.S., Teixeira, W., Ávila, C.A., Montecinos, P.M., Bongiolo, E.M., 2.17-2.09 Ga crust forming episodes in the Mineiro belt, São Francisco craton, Brazil: U-Pb ages and geochemical constraints. Precambrian Research, submitted for publication.

Barker, F., 1979. Trondhjemite: Definition, environment and hypotheses of origin. In: Barker, F. (Ed.), Trondhjemites, dacites, and related rocks. Amsterdam, Elsevier, pp.1-12.

Beard, B.L., Johnson, C.M., 1997. Hafnium isotope evidence for the origin of Cenozoic basaltic lavas from the southwestern United States. Journal of Geophysical Research 102 (B9), 20, 149-20, 178.

Bennett, V. C., De Paolo, D. J., 1987. Proterozoic crustal history of the western United States as determined by neodymiom isotopic mapping. Geological Society of America Bulletin, 99(5), 674-685.

Bizzi, L.A., Smith, B.C., De Witt, M.J., Macdonald, I., Armstrong, R.A., 1994. Isotope characteristics of the lithospheric mantle underlying the SW São Francisco craton margin, Brazil. International symposium on the Physics and Chemistry of the Upper Mantle, Invited lectures, pp. 227-256.

Black, L.P., Kamo, S.L., Allen, C.M., Aleinikoff, J.N., Davis, D.W., Korsch, R.J., Foudoulis, C., 2003. TEMORA 1: a new zircon standard for Phanerozoic U-Pb geochronology. Chemical Geology 200, 155-170.

Blichert-Toft, J., Albarede, F., 1997. The Lu-Hf isotope geochemistry of chondrites and the evolution of the mantle-crust system. Earth and Planetary Sciences Letters 148, 243-258 Brown, G.C., Thorp R.S., Webb, P.C., 1984. The geochemical characteristic of granitoids in contrasting arcs and comments on magma source. Journal of the Geological Society of London 141, 41326.

Brito Neves, B.B., 2011. The Paleoproterozoic in the South American Continent: Diversity in the Geological time. Journal of South American Earth Sciences 32, 1-20, 
Brown, G.C., Thorp R.S., Webb, P.C., 1984. The geochemical characteristic of granitoids in contrasting arcs and comments on magma source. Journal of the Geological Society of London 141, 413-26.

Campos, J.C.S, Carneiro, M.A., 2008. Neoarchean and Paleoproterozoic granitoids marginal to the Jeceaba-BomSucesso lineament (SE border of the southern São Francisco craton): Genesis and tectonic evolution. Journal of South American Earth Sciences 26, 463484.

Champion, D.C., Smithies, R.H., 2003. Archaean granites. In: Blevin, P., Jones, M., Chappell, B. (Eds.), Magmas to Mineralisation: The Ishihara Symposium. Geoscience Australia, pp. 19-24.

Cherman, A.F., 2004. Geologia, petrografia e geocronologia de ortognaisses paleoproterozóicos da borda meridional do Cráton do São Francisco, na região entre Itumirim e Nazareno, Minas Gerais. PhD Thesis, DG-UFRJ, Rio de Janeiro, 259p.

Condie, K.C., 1981. Archean Greenstone Belts. Elsevier, Amsterdam, 435p.

Condie, K.C., Kröner, A., 2013. The building blocks of continental crust: Evidence for a major change in the tectonic setting of continental growth at the end of the Archean. Gondwana Research 23, 394-402.

Condie, K.C., O’Neill, C., Aster, R.C., 2009. Evidence and implications for a widespread magmatic shutdown for 250 My on Earth. Earth and Planetary Science Letters 282, 294-298.

Corrêa Neto, A.V., Modesto, A.M. de, Caputo Neto, V., Guerrero, J.C., 2012. Alteração hidrotermal em zona de cisalhamento associada ao Lineamento Congonhas, sul do Quadrilátero Ferrífero, Minas Gerais. Anuário do Instituto de Geociências - UFRJ - 35 (2), 55-64.

Davidson, J., Turner, S., Plank, T., 2013. Dy/Dy* variations arising from mantle sources and petrogenetic processes. Journal of Petrology 54 (3), 525-537.

De Paolo, D.J., 1981. Nd isotopic studies; some new perspectives on Earth structure and evolution. Transactions of American Geophysics Union 62, 137-140.

De Wit, M.J., Roering, C., Hart, R.J., Armstrong, R.A., de Ronde, C.E.J., Green, R.W.E., Tredoux, M., Peberdy, E., Hart, R.A., 1992. Formation of an Archaean continent. Nature 357, $553-562$

Dickin, A.P., 2005. Radiogenic isotope geology. 2ns edition. Cambridge University, 492p.

Dos Santos, T.J.S., Fetter, A.H., Van Schmus, W.R., Hackspacher, P.C., 2009. Evidence for 2.35 to $2.30 \mathrm{Ga}$ juvenile crustal growth in the northwest Borborema Province, NE Brazil. Geological Society, London, Special Publications 323, 271-281.

Druppel, K., McCready, A.J., Stumpf, E.F., 2009. High-K granites of the Rum Jungle Complex N-Australia: insights into the Late Archean crustal evolution of the North Australian craton. Lithos 111, 203-219.

Duarte, B.P., Heilbron, M., Nogueira, J.R., Tupinambá, M., Silva, L.G.E., Almeida, J.C.H., Guia, C., Prado, J., Succena, M., Soares, A.C.P., Noce, C.M., 2003. Mapa geológico das Folhas Juiz de Fora: In: Pedrosa Soares, A.C., Noce, C.M., Trouw, R., Heilbron, M. (coordenadores) Projeto Sul de Minas: map (1:100.000) and reports. Comig-Secretaria de Estado de Desenvolvimento Econômico de Minas Gerais. 822p.

Egal, E., Thie’blemont, D., Lahonde`re, D., Guerrot, C., Adi Costea, C., Iliescu, D., Delor, C., Goujou, JC., Lafon, J. M., Tegyey, M., Diaby, S., Kolie'e, P. 2002. Late Eburnean granitization and tectonics along the western and northwestern margin of the Archean Ke'ne'ma-Man domain (Guinea, West African Craton). Precambrian Research 117, 57-84.

Elholou, S., Belousova, E., Griffin, W.L., Peasom, N.J., O’Reilly, S.Y., 2006. Trace element and isotopic composition of GJ red zircon standard by laser ablation. Geochemical Cosmochemical Acta 70, i18, p. A158.

Eriksson, P.G., Condie, K.C., 2014. Cratonic sedimentation regimes in the ca. 2450-2000 Ma period: Relationship to a possible widespread magmatic slowdownon Earth? Gondwana Research 25, 30-47.

Evans, D. A. D., Mitchell, R. N., 2011. Assembly and breakup of the core of Paleoproterozoic-Mesoproterozoic supercontinent Nuna. Geology 39, 443-446. 1554 http://dx.doi.org/10.1130/G31654.1. 
Foley, S.F., Tiepolo, M., Vannucci, R., 2002. Growth of early continental crust controlled by melting of amphibolite in subduction zones. Nature 417, 637-640.

Frost, B.R., Barnes, C.G., Collins, W.J., Arculus, R.J., Ellis, D.J., Frost, C.D., 2001. A geochemical classification for granitic rocks. Journal of Petrology 42, 2033-2048.

Gasquet, D., Barbey, P., Adou, M., Paquette, J., 2003. Structure, Sr-Nd isotope geochemistry and zircon $\mathrm{U}-\mathrm{Pb}$ geochronology of the granitoids of the Dabakala area (Côte d'Ivoire): evidence for a 2.3 Ga crustal growth event in the Palaeoproterozoic of West Africa? Precambrian Research 127, 329-354.

Gibson, S.A., Thomson, R.N., Leonardos, O.H., Dickin, A.P., Mitchell, J.G., 1995. The late Cretaceous impact of the Trindade mantle plume: evidence of large-volume, mafic, potassic magmatism in SE Brazil. Journal of Petrology 36(1), 189-229. Precambrian Geology: The Dynamic Evolution of the Continental Crust Por Alan M. Goodwin 1991 livro Goodwin, 1991

Goodwin, A. M. (1991). Precambrian Geology. The Dynamic Evolution of the Continental Crust. Academic Press.

Goulart, L.M.A., Carneiro, M.A., 2013. New evidence of Neoarchean crustal growth in southern São Francisco Craton: the Carmópolis de Minas Layered Suite, Minas Gerais, Brazil. Brazilian Journal 66(4), 447-454.

Hartmann, L.A., Endo, I., Suita, M.T.F., Santos, J.O.S., Frantz, J.A., Carneiro, M.A., MacNaughton, N.J., Barley, M.E., 2006. Provenience and age delimitation of Quadrilátero Ferrífero sandstone based on zircon U-Pb isotopes. Journal of South American Earth Sciences 20, 273-285.

Hawkesworth, C., Cawood, P., Kemp, T., Storey, C., Dhuime, B., 2009. A Matter of Preservation Science 323 (5910), 49-50, http://dx.doi.org/10.1126/science.1168549.

Hawkesworth, C.J., Kemp, A.I.S. 2006. Using hafnium and oxygen isotopes in zircons to unravel the record of crustal evolution. Chemical Geology 226 144- 162

Heaman, L.M., Tarney, J., 1989. U-Pb baddeleyite ages for the Scourie dyke swarm, Scotland: evidence for two distinct intrusion events. Nature 340, 705-708.

Heilbron, M., Duarte, B.P., Valeriano, C.M., Simonetti, A., Machado, N., Nogueira, J.R., 2010. Evolution of reworked Paleoproterozoic basement rocks withinthe Ribeira belt (Neoproterozoic), SE-Brazil, based on U-Pb geochronology:implications for paleogeographic reconstructions of the São Francisco-Congopaleocontinent. Precambrian Researh 178, 136-148.

Hildebrand, R.S., Hoffman, P.F., Bowring, S.A., 1987. Tectonomagmatic evolution of the $1.9 \mathrm{Ga}$ Great Bear magmatic zone, Wopmay orogen, northwestern Canada. Journal of Volcanology and Geothermal Research 32, 99-118.

Jahn, B., Glikson, A.Y., Peucat, J.-J., Hickman, A.H., 1981. REE geochemistry and isotopic data of Archaean silicic volcanics and granitoids from the Pilbara block, western Australia: implications for early crustal evolution. Geochimica et Cosmochimica Acta 45, $1633-1652$.

Kösler, J., Fonneland, H., Sylvester, P., Tubrett, M., Pedersen, R.B., 2002. U-Pb dating of detrital zircons for sediment provenance studies, a comparison of laser ablation ICP14 MS and SIMS techniques. Chemical Geology 182, 605-618.

Lahtinen, R., Huhma, H., 1997. Isotopic and geochemical constraints on the evolution of the 1.93-1.79 Ga Svecofennian crust and mantle in Finland. Precambrian Research 82, 13-34

Lana, C., Alkmim. F.F., Armstrong, R., Scholz, R., Romano, R., Nalini, H.A., 2013. The ancestry and magmatic evolution of Archaean TTG rocks of the Quadrilátero Ferrífero province, southeast Brazil. Precambrian Research 230, 1-30.

Ludwig, K.R., 2000. Using Isoplot/Ex, version 3.00, a geochronological toolkit for Microsoft Excel. Berkeley Geochronology Center Special Publication 4, 74 pp.

Ludwig, K.R., 2001. Squid 1.02: A User Manual. Berkeley Geochronological Center Special Publication 4, 119p.

Ludwig, K.R., 2003. User's manual for ISOPLOT 3.00. A geochronological toolkit for Microsoft Excel. Berkeley Geochronological Center Special Publication 4, 70 p.

Macambira, M.J.B., Vasquez, M.L., da Silva, D.C.C., Galarza, M.A., Barros, C.E. de M., Camelo, J. de F., 2009. Crustal growth of the central-eastern Paleoproterozoic domain, SW 
Amazonian craton: Juvenile accretion vs. reworking. Journal of South American Earth Sciences 27, 235-246.

Machado, N., Carneiro, M.A., 1992. U-Pb evidence of late Archaean tectono-thermal activity in southern São Francisco shield, Brazil. Canadian Journal of Earth Sciences 29, 23412346

Machado, N., Schrank, A., Noce, C.M., Gauthier, G., 1996. Ages of detrital zircon from Archean-Paleproterozoic sequences: Implications for greenstone belt setting and evolution of a Transamazonian foreland basin in Quadrilátero Ferrífero, southeast Brazil: evidence from zircon ages by laser ablation ICP-1895 MS. Earth and Planetary Science Letters, 141, 259-276. Geological Society of America Bulletin 104, 1221-1227.

Martin, H., 1986. Effect of steeper Archean geothermal gradient on geochemistry of subduction-zone magmas. Geology 14, 753-756.

Martin, H., 1987. Petrogenesis of Archaean trondhjemites, tonalites and granodiorites from eastern Finland; major and trace element geochemistry. Journal of Petrology 28, 921-953.

Martin, H., Smithies, R.H., Rapp, R.P., Moyen, J.-F., Champion, D.C., 2005. An overview of adakite, tonalite-trondhjemite-granodiorite (TTG) and sanukitoid: relationships and some implications for crustal evolution. Lithos 79, 1-24.

McDonough W. F. and Sun S.-s. (1995) The composition of the Earth. Chemical Geology 120, 223-253.

Meert, J.G., 2012. What's in a name? The Columbia (Paleopangaea/Nuna) 1916 supercontinent. Gondwana Research 21, 987-993.

Montecinos, P., Schärer, U., Vergara, M., Aguirre, L., 2008. Lithospheric origin of Oligocene-Miocene magmatism in Central Chile: $\mathrm{U}-\mathrm{Pb}$ ages and $\mathrm{Sr}-\mathrm{Pb}-\mathrm{Hf}$ isotope composition of minerals. Journal of Petrology 49, 555-580.

Moorbath, S., 1975. Evolution of Precambrian crust from strontium isotopic evidence. Nature 254, 395-398

Moyen, J-F., Martin, H. 2012. Forty years of TTG research. Lithos 148, 312-336.

Nowell, G. M., Pearson, D. G., Bell, D. R., Carlson, R.W., Smith, C., B., Kempton, P. D. \& Noble, S. R., 2004. Hf isotope systematics of kimberlites and their megacrysts: new constraints on their source regions. Journal of Petrology 45, 1583-1612.

Noce C.M., Teixeira, W., Machado, N., 1997. Geoquímica dos gnaisses TTG e granitóides neoarqueanos do Complexo Belo Horizonte, Quadrilátero Ferrífero, Minas Gerais. Revista Brasileira de Geociências 27, 25-32.

Noce, C.M., Teixeira, W., Quéméneur, J.J.G., Martins, V.T.S., Bolzachini, E., 2000. Isotopic signatures of Paleoproterozoic granitoids from southern São Francisco Craton, NE Brazil, and implications for the evolution of the Transamazonian Orogeny. Journal of South American Earth Sciences 13, 225-239.

O'Connor, J.T., 1965. A classification of quartz-rich igneous rocks based on feldspar ratios. United States Geological Survey, Professional Paper 525-B, 79-84.

O'Neill, C., Lenardic, A., Moresi, L., Torsvik, T.H., Lee, C.-T.A., 2007. Episodic Precambrian subduction. Earth and Planetary Science Letters 262, 552-562.

Partin, C.A., Bekker, A., Sylvester, P.J., Wodicka, N., Stern., R.A., Chacko, T., Heaman, L.M., 2014. Filling in the juvenile magmatic gap: Evidence for uninterrupted Paleoproterozoic plate tectonics. Earth and Planetary Science Letters 388, 123-133.

Patchett, P. J., 1983. Importance of the $\mathrm{Lu}^{\wedge} \mathrm{Hf}$ isotopic studies of planetary chronology and chemical evolution. Geochimica et Cosmochimica Acta 47, 81-91.

Petronilho, L.A., 2009. O método Sm-Nd no CPGeo-IGc-USP: procedimentos analíticos atualmente em rotina. Simpósio 45 anos de Geocronologia no Brasil, Instituto de Geociências, USP. Boletim de Resumos Expandidos, pp. 116-118.

Pinese, J.P.P., 1997. Geoquímica, Geologia Isotópica e Aspectos petrológicos dos Diques Máficos Pré-Cambrianos da Região de Lavras (MG), Porção Sul do Cráton do São Francisco. $\mathrm{PhD}$ Thesis, Instituto de Geociências da Universidade de São Paulo. 178p.

Quéméneur, J.J.G, Ribeiro, A., Paciullo, F., Heilbron, M., Trouw, R., Valença, J., Noce, C.M. 2003. Mapa geológico da Folha Lavras. In: Pedrosa Soares, A.C., Noce, C.M., Trouw, R., 
Heilbron, M. (Eds.) Projeto Sul de Minas: map (1:100.000) and reports. Comig-Secretaria de Estado de Desenvolvimento Econômico de Minas Gerais. 822p.

Reimink J.R., Chacko, T., Stern, R.A., Heaman, L.M., 2014. Earth's earliest evolved crust generated in an Iceland-like setting. Nature Geoscience 7, 529-533.

Renger, F.E., Noce, C.M., Romano, A.W., Machado, N., 1994. Evolução sedimentar do 1997 Supergrupo Minas: 500 Ma de registro geológico no Quadrilátero Ferrífero, Minas Gerais, 1998 Brasil. Geonomos 2, 1-11.

Rollinson H. 2007. Early Earth Systems - A geochemical approach. blackwell publishing.

Romano, R., Lana, C., Alkmim, F.F., Stevens, G., Armstrong, R., 2013. Stabilization of the Southern São Francisco Craton, SE Brazil, through a long-lived and episodic period of potassic magmatism. Precambrian Research 224, 1-20.

Rudnick, R.L., Gao, S., Ling, W.L., Liu, Y.S., McDonough, W.F., 2004. Petrology and geochemistry of spinel peridotite xenoliths from Hannuoba and Qixia, North China Craton. Lithos 77, 609-637.

Sato, K., Basei, M.A.S., Siga Junior, O., Onoi, A.T., 2010. In situ U-Th-Pb isotopic analyses by excimer laser ablation/ICP-MS on Brazilian megacrystal xenotime: First results on $\mathrm{U}-\mathrm{Pb}$ isoptes at CPGeo-IGC-USP. VII SSAGI-South American Simposium on Isotope Geology, Brasília, Abstracts, pp. 349-352.

Sato, K., Siga Jr., O., Silva, J.A., McReath, I., Liu, D., Iizuka, T., Rino, S., Hirata, T., Sproesser, W.M., Basei, M.A.S., 2009. In Situ Isotopic Analyses of U and $\mathrm{Pb}$ in Zircon by Remotely Operated SHRIMP II, and Hf by LA-ICP-MS: an Example of Dating and Genetic Evolution of Zircon by $176 \mathrm{Hf} / 177 \mathrm{Hf}$ from the Ita Quarry in the Atuba Complex, SE Brazil. Geologia USP, Série Cientifica 9 (3), 61-69.

Sato, K., Tassinari, C.C.G., Basei, M.A.S., Siga Júnior, O., Onoe, A.T., Souza, M.D., 2014. Sensitive High Resolution Ion Microprobe (SHRIMP IIe/MC) of the Institute of Geosciences of the University of São Paulo, Brazil: analytical method and first results. Geologia USP, Série Científica 14 (3), 3-18.

Sato, K., Tassinari, C.C.G., Kawashita, K., Petronilho, L., 1995. O Método Geocronológico Sm-Nd no IG/USP e suas aplicações. Anais da Academia Brasileira de Ciências 67, 313-336.

Schmitz, M. K., , Vervoort, J. D., Bowring, S.A., Patchett, P.J. 2004. Geology Decoupling of the Lu-Hf and Sm-Nd isotope systems during the evolution of granulitic lower crust beneath southern Africa. Geology 32, 405-408.

Seixas, L.A.R, David, J., Stevenson, R., 2012. Geochemistry, Nd isotopes and U-Pb geochronology of a 2350 Ma TTG suite, Minas Gerais, Brazil: Implications for the crustal evolution of the southern São Francisco craton. Precambrian Research 196-197, 61-80.

Seixas, L.A.R., Bardintzeff J-M., Stevenson, R., Bonin, B., 2013. Petrology of the high-Mg tonalites and dioritic enclaves of the ca. $2130 \mathrm{Ma}$ Alto Maranhão suite: Evidence for a major juvenile crustaladdition event during the Rhyacian orogenesis, Mineiro Belt, southeast Brazil. Precambrian Research 238, 18- 41.

Silva, L.C.D., Armstrong, R., Noce, C.M., Carneiro, M.A., Pimentel, M., PedrosaSoares,A.C., Leite, C.A., Vieira, V.S., Silva, M.A., Paes, V.J.C., Cardoso Filho, J.M., 2002.Reavaliac, ão da evoluc, ão geológica em terrenos pré-cambrianos brasileiros combase em novos dados U-Pb Shrimp, Parte II: Orógeno Arac, uaí, Cinturão Mineiroe Craton São Francisco meridional. Revista Brasileira Geociências 32, 513-528.

Silver, P.G., Behn, M.D., 2008. Intermittent plate tectonics. Science 319, 85-88.

Söderlund, U., Patchett, J.P., Vervoort, J.D., Isachsen, C.E., 2004. The 176Lu decay constant determined by Lu-Hf and U-Pb isotope systematics of Precambrian mafic intrusions. Earth and Planetary Science Letters 219, 311-324.

Stacey, J.S., Kramers, J.D., 1975. Approximation of terrestrial lead isotope 202 evolutionby a two-stage model. Earth and Planetary Science Letters 26 (203), 207-221.

Steiger, R.H., Jäger, E., 1977. Subcommision on Geochronology convention on the use of decay constants in geo- and cosmochronology. Earth Planetary Science Letters 36, 359-362.

Teixeira, W., Ávila, C.A., Dussin I.A., Correa Neto, A.V., Bongiolo, E.M., Santos, J.O., Barbosa, N., 2015. A juvenile accretion episode (2.35-2.32Ga) in the Mineiro belt and its role to 
the Minas accretionary orogeny: Zircon U-Pb-Hf and geochemical evidences. Precambrian Research 256, 148-169.

Teixeira, W., Carneiro, M.A., Noce, C.A., Machado, N., Sato, K., Taylor, P.N., 1996. Pb, $\mathrm{Sr}$ and $\mathrm{Nd}$ isotope constraints on the Archean evolution of gneissic granitoid complexes in the southern Sao Francisco Craton, Brazil. Precambrian Research 78, 151-164.

Toledo, C.L.B., 2002. Evolução geológica das rochas máficas e ultramáficas no

Greenstone Belt Barbacena, na região de Nazareno, MG. PhD Thesis, IG-UNICAMP, Campinas, $307 \mathrm{p}$.

Vasquez, M.L., Macambira, M.J.B., Armstrong, R.A., 2008. Zircon geochronology of granitoids from the western Bacajá domain, southeastern Amazonian craton, Brazil: Neoarchean to Orosirian evolution. Precambrian Research 161, 279-302.

Vervoort, J. D., Patchett, P. J., Gehrels, G. E. \& Nutman, A. P., 1996. Constraints on early Earth differentiation from hafnium and neodymium isotopes. Nature 379, 624-62.

Whitney, D.L., Evans, B.W., 2010. Abbreviations for names of rock-forming minerals. American Mineralogist 95, 185-187.

Zhao, G., Sun, M., Wilde, S.A., Li, S., Zhang, J., 2006. Some key issues in reconstructions of Proterozoic supercontinents. Journal of Asian Earth Science 28, 3-19.

Zhao, G., Wilde, S.A., Sun, M., Li, S., Li, X., Zhang, J., 2008. SHRIMP U-Pb zircon ages of granitoid rocks in the Lüliang Complex: Implications for the accretion and evolution of the Trans-North China Orogen. Precambrian Research 160, 213-226. 


\subsection{O evento tectono-termal de 2,36-2,31 Ga}

A juvenile accretion episode $(2.35-2.32 \mathrm{Ga})$ in the Mineiro belt andits role to the Minas accretionary orogeny: Zircon $\mathrm{U}-\mathrm{Pb}-\mathrm{H} f$ andgeochemical evidences

Este artigo foi submetido à revista Precambrian Research (Teixeira et al., 2015), em anexo. Os novos dados obtidos trazem uma nova perspectiva à luz de um cenário geodinâmico de orógenos acrescionários que envolve um período de pelo menos 350 Ma. Os autores sugerem o termo "Orogenia acrescionária Minas" que define a orogenia que culminou na formação dos cinturões Mineiro, Mantiqueira e Juiz de Fora.

O conjunto de rochas investigadas representa tectonicamente, a partir de dados novos e compilação da literatura regional, parte de um regime acrescionário prolongado que envolveu sucessivas subducções da litosfera oceânica com intervenções das massas arqueanas e desenvolvimentos de arcos magmáticos que colidiram contra o PaleoCráton do São Francisco. Consequentemente estabeleceu-se a crosta continental paleoproterozoica, os quais representam parte da aglutinação do supercontinente Columbia.

Os novos dados apresentam as características de um conjunto de rochas denominado ortognaisse Resende Costa e comparações com rochas vizinhas de idade e composições semelhantes (suíte Lagoa Dourada). Também é apresentado o crescimento destes arcos considerando o cenário paleoproterozoico que construiu o CM.

Assim como no batólito Cassiterita (seção 4.2) as rochas do ortognaisse Resende Costa são de afinidade TTG geradas em ambiente de arco oceânico. O ortognaisse Resende Costa e a suíte Lagoa Dourada fazem parte de um segmento juvenil cogenético de idade 2,3 Ga. As assinaturas isotópicas são condizentes com rochas derivadas de uma fonte mantélica levemente enriquecida, devido à contribuição de sedimentos carreados no assoalho oceânico. Estudos em metabasaltos da unidade Congonhas-Itaverava (localizado próxima a suíte Resende Costa) indicam foram tentativamente interpretados como possível fonte desse ortognaisses.

Em sumário, este registro associado ao dado do batólito Cassiterita sugere que durante o início do paleoproterozoico a tectônica de placas operou distal ao embrião arqueano do CSF. 


\subsection{O evento tectono-termal de 2,26-2,22 Ga}

As rochas deste período ocorrem pontualmente no CM, sempre a sul da zona de cisalhamento Lenheiros. Este evento é representado por pequenos plútons denominados de suíte Serrinha e suíte Tiradentes, que foi definido por Ávila et al. (2010, 2014). Um resultado obtido nesta Tese (ortognaisse Nazareno - NAT-13) e não adicionado ao escopo dos artigos será descrito nesta seção. Esta rocha aflora segundo um alinhamento de direção NE-SW com as rochas das suítes Serrinha e Tiradentes, apresenta idade correlacionável às suítes permitindo ampliar a extensão geográfica deste evento, já que o posicionamento tanto das suítes como do ortognaisse é a sul da zona de cisalhamento Lenheiros. Adicionalmente, interpretações e correlações com os dados geológicos regionais serão apresentados. Todos os dados (exceto NAT-13) aqui apresentados são de Ávila et al. (2010; 2014).

\section{Ortognaisse Nazareno NAT-13 (0544655/7648001)}

A amostra estudada é um ortognaisse granodiorítico que pertence ao batólito Represa de Camargos. Localiza-se a sul da cidade de Nazareno. De acordo com os aspectos de campo o afloramento possui porções mais foliadas e intrusões quartzo feldspáticas e pegmatoides (Figura 26) e também contêm xenólitos de granitoides. Em escala mesoscópica possui granulometria média e a foliação é definida pela biotita. Petrograficamente a rocha é composta por quartzo, biotita, plagioclásio, anfibólio e microclina. Os minerais acessórios e secundários são: epidoto, muscovita, sericita, clorita, zircão, apatita, allanita e titanita. A textura é grano-lepidoblástica. A Figura 26 mostra o aspecto de campo, com porções menos foliadas (Figura 26 A) em relação a outras porções do afloramento (Figura 26 B). O aspecto petrográfico pode ser observado nas Figuras 26C e D. 

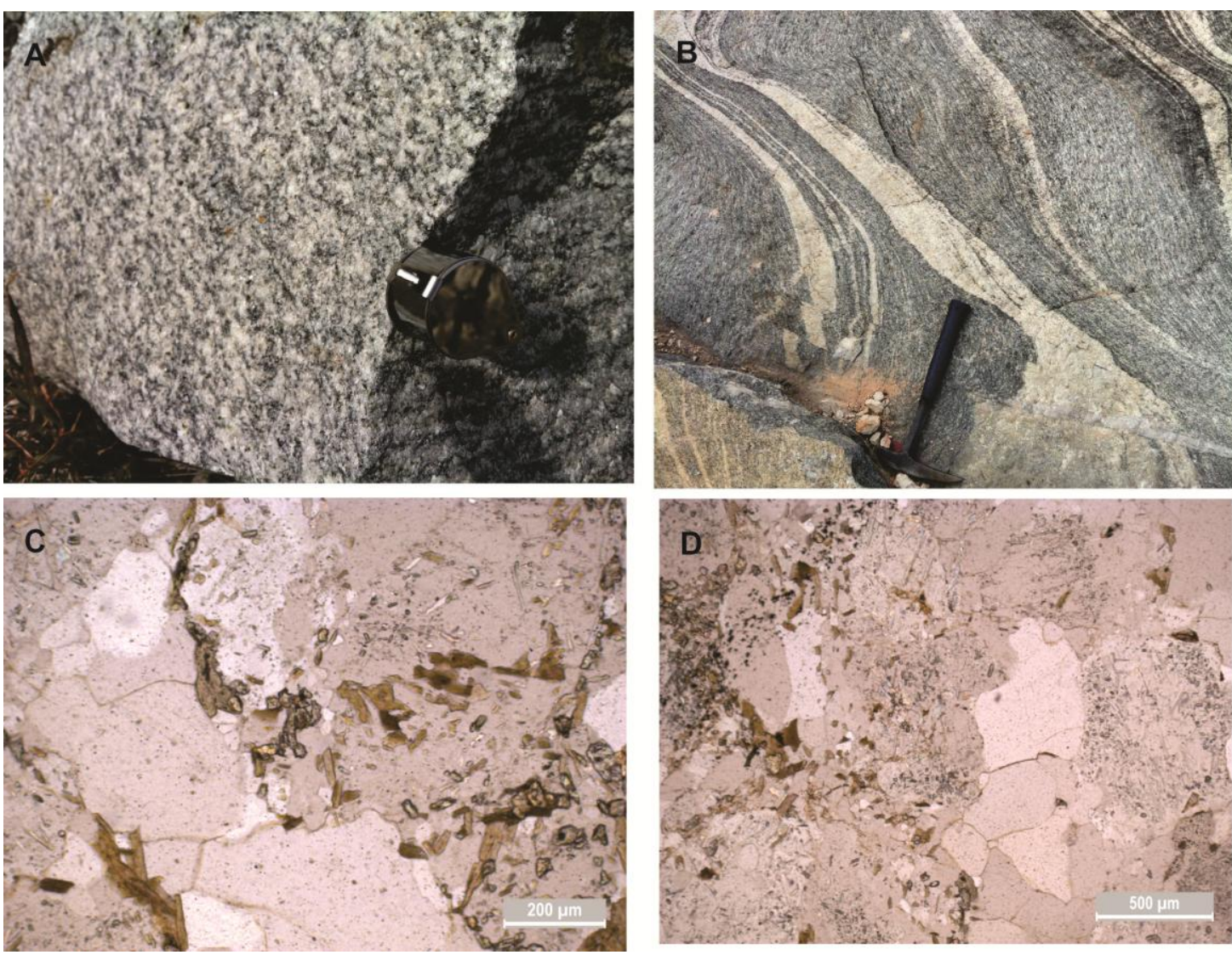

Figura 26. Características petrográficas e de campo do ortognaisse Nazareno. (A e B) Porções do afloramento mais homogenea e porções mais foliada e com injeções quartzo-feldspáticas, (C) Aspecto geral da textura grano-lepidoblástica; (D) Fotografia mostrando sericitização do plagioclásio.

\section{Geocronologia U-Pb}

A idade U-Pb do ortognaisse Nazareno (NAT-13) foi determinada pela técnica SHRIMP (Tabela 9). Os zircões são claros, prismáticos, com poucos núcleos herdados, com zoneamento oscilatório linear e concêntrico e tamanho variável entre 367 e $73 \mu \mathrm{m}$ (Figura 27). Poucos grãos são metamíticos e alguns apresentam recristalização e resorption. Foram analisados 18 pontos, com razão Th/U variando entre 0,10-1,26. Estes pontos definem um intercepto superior em $2261 \pm 21 \mathrm{Ma}(\mathrm{n}=18 ; \mathrm{MSWD}=4,2$; Figura 28), o qual é considerado como a idade de cristalização desta rocha. Considerando a única idade ${ }^{207} \mathrm{~Pb} /{ }^{206} \mathrm{~Pb} 100 \%$ concordante (NAT13-13.1) de $2234 \pm 14$ Ma, pode-se afirmar que esta rocha é coeva a Suíte Serrinha com idades de $2227 \pm 22$ Ma e $2211 \pm 22$ Ma (Ávila et al., 2010) e a suíte Tiradentes com idades de $2217 \pm 23$ Ma; $2204 \pm 11 \mathrm{Ma} ; 2213 \pm 9$ Ma (Ávila et al., 2014). 
Tabela 9. Dados U-Pb SHRIMP para o ortognaisse Nazareno (NAT-13).

\begin{tabular}{|c|c|c|c|c|c|c|c|c|c|c|}
\hline $\begin{array}{r}\text { Grain. } \\
\text { spot }\end{array}$ & $\overline{\mathrm{Th} / \mathrm{U}}$ & $\begin{array}{l}{ }^{207} \mathrm{~Pb} \\
{ }^{235} \mathrm{U}\end{array}$ & error & $\begin{array}{l}{ }^{206} \mathrm{~Pb} \\
{ }^{238} \mathrm{U}\end{array}$ & error & error & $\begin{array}{l}{ }^{207} \mathrm{~Pb} \\
{ }^{206} \mathrm{~Pb}\end{array}$ & error & ${ }^{207} \mathrm{~Pb} /{ }^{206} \mathrm{~Pb}$ & Disc.\% \\
\hline 1.1 & 0.22 & 6.6487 & 2.4650 & 0.3516 & 2.1669 & 0.8791 & 0.1371 & 1.0901 & 2192 & 13 \\
\hline 2.1 & 0.26 & 7.7532 & 2.3430 & 0.3975 & 2.2062 & 0.9416 & 0.1414 & 0.7873 & 2245 & 4 \\
\hline 3.1 & 0.21 & 8.5141 & 2.3287 & 0.4277 & 2.2454 & 0.9642 & 0.1444 & 0.6172 & 2280 & -1 \\
\hline 5.1 & 0.38 & 6.1916 & 2.3897 & 0.3320 & 2.1769 & 0.9109 & 0.1352 & 0.9426 & 2167 & 17 \\
\hline 6.1 & 0.85 & 8.6733 & 2.2970 & 0.4408 & 2.1885 & 0.9528 & 0.1427 & 0.6852 & 2260 & -4 \\
\hline 7.1 & 1.26 & 8.1904 & 2.4010 & 0.4224 & 2.2518 & 0.9379 & 0.1406 & 0.8245 & 2235 & -2 \\
\hline 8.1 & 0.37 & 7.6530 & 2.3807 & 0.3881 & 2.1752 & 0.9137 & 0.1430 & 0.9118 & 2264 & 7 \\
\hline 9.1 & 0.17 & 5.9357 & 2.6429 & 0.3149 & 2.1685 & 0.8205 & 0.1366 & 1.4048 & 2186 & 24 \\
\hline 10.1 & 0.21 & 5.1410 & 2.3558 & 0.2700 & 2.1743 & 0.9230 & 0.1381 & 0.8895 & 2203 & 43 \\
\hline 11.1 & 0.40 & 8.2528 & 2.4546 & 0.4089 & 2.2562 & 0.9192 & 0.1464 & 0.9667 & 2304 & 4 \\
\hline 12.1 & 0.17 & 7.4592 & 2.2552 & 0.3828 & 2.1761 & 0.9649 & 0.1413 & 0.5878 & 2243 & 7 \\
\hline 13.1 & 0.36 & 8.0543 & 2.3616 & 0.4156 & 2.2257 & 0.9425 & 0.1406 & 0.7856 & 2234 & 0 \\
\hline 14.1 & 0.19 & 7.2705 & 2.3953 & 0.3881 & 2.1804 & 0.9103 & 0.1359 & 0.9858 & 2175 & 3 \\
\hline 14.2 & 0.10 & 1.6678 & 2.9691 & 0.1291 & 2.1522 & 0.7249 & 0.0937 & 1.9766 & 1502 & 92 \\
\hline 15.1 & 0.20 & 6.9565 & 2.4636 & 0.3697 & 2.1739 & 0.8824 & 0.1365 & 1.1062 & 2183 & 8 \\
\hline 16.1 & 0.99 & 8.4906 & 2.3183 & 0.4311 & 2.1943 & 0.9465 & 0.1428 & 0.7429 & 2262 & -2 \\
\hline
\end{tabular}

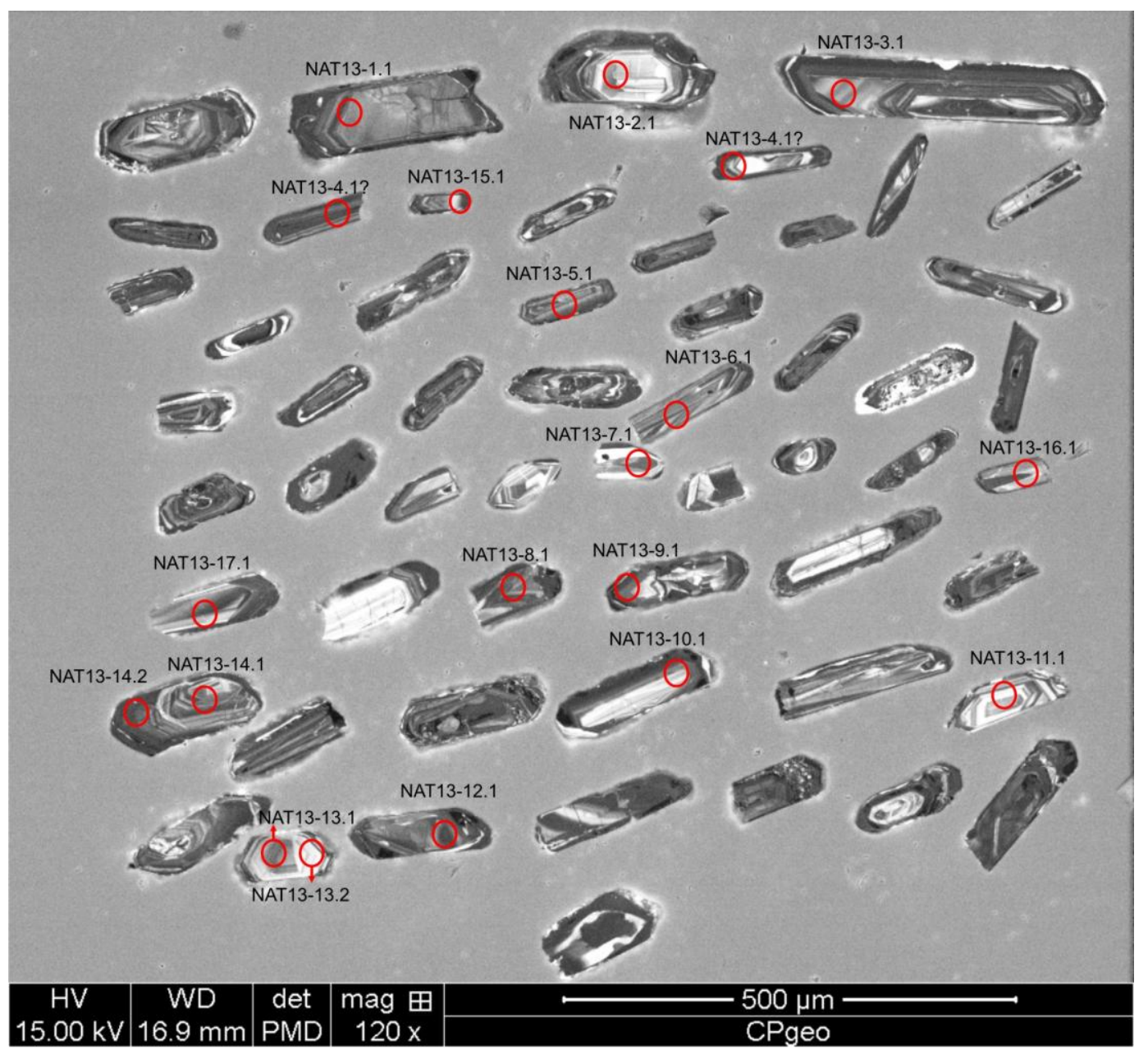

Figura 27. Imagem de catodoluminescência dos zircões do ortognaisse Nazareno. 


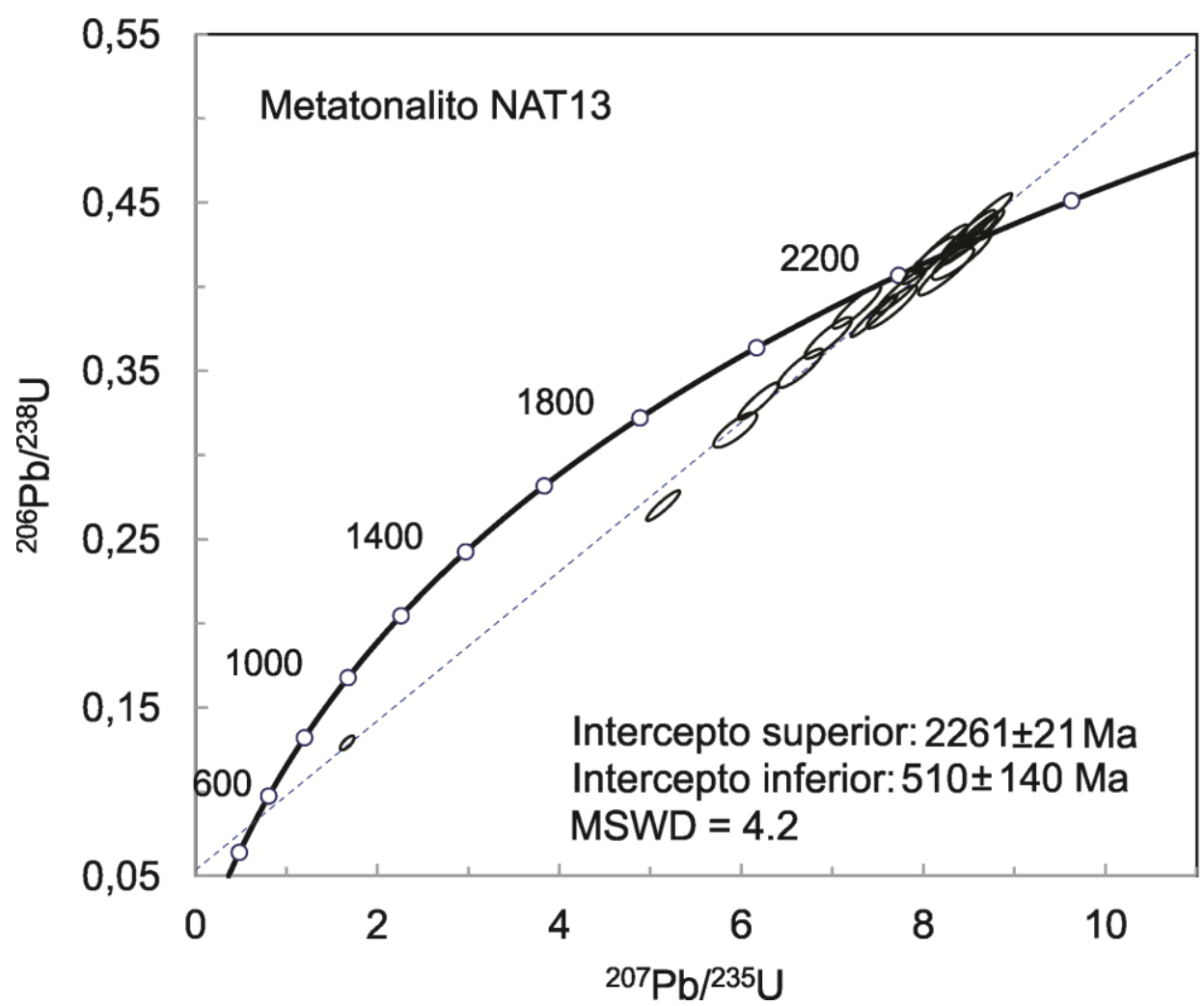

Figura 28. Diagrama da Concórdia para o ortognaisse Nazareno.

\section{Geoquímica}

Os dados geoquímicos apresentados para o ortognaisse Nazareno (NAT-13) serão interpretados em conjunto com as rochas das suítes Serrinha e Tiradentes.

Os dados para elementos maiores da amostra NAT-13 são: $\mathrm{SiO}_{2}(70,18-76,96$ wt.\%), $\mathrm{TiO}_{2}\left(0,14-0,54\right.$ wt.\%), $\mathrm{MgO}\left(0,03-0,99\right.$ wt.\%), $\mathrm{K}_{2} \mathrm{O}\left(0,18-1,57\right.$ wt.\%) e $\mathrm{P}_{2} \mathrm{O}_{5}$ $\left(0,01-0,10\right.$ wt.\%) e $\mathrm{Al}_{2} \mathrm{O}_{3}(12,7-15,01)$. Os valores estão dentro da variação dos elementos maiores da suíte Tiradentes (exceto $\mathrm{Al}_{2} \mathrm{O}_{3}$; Figura 29) e da suíte Serrinha (exceto $\mathrm{TiO}_{2}$ ). No geral, a correlação entre sílica e elementos maiores apresenta um trend coerente entre as rochas das suítes Tiradentes e Serrinha e o ortognaisse Nazareno. $\mathrm{Na}$ Figura 29 a maioria dos elementos mostra correlação negativa em relação a $\mathrm{SiO}_{2}$ $\left(\mathrm{TiO}_{2}, \mathrm{MgO}, \mathrm{CaO}\right.$ e $\left.\mathrm{P}_{2} \mathrm{O}_{5}\right)$, indicando o fracionamento do plagioclásio apatita, zircão e minerais máficos. A amostra NAT-13 é levemente peraluminosa, empobrecida em $\mathrm{MgO}$ (Figura 30B). Quanto aos diagramas triangulares Na-Ab-Or e K-Na-Ca a amostra NAT13 plota afastado do campo da suíte Tiradentes, sendo semelhante à suíte Serrinha e segue o trend trondhjemítico. 

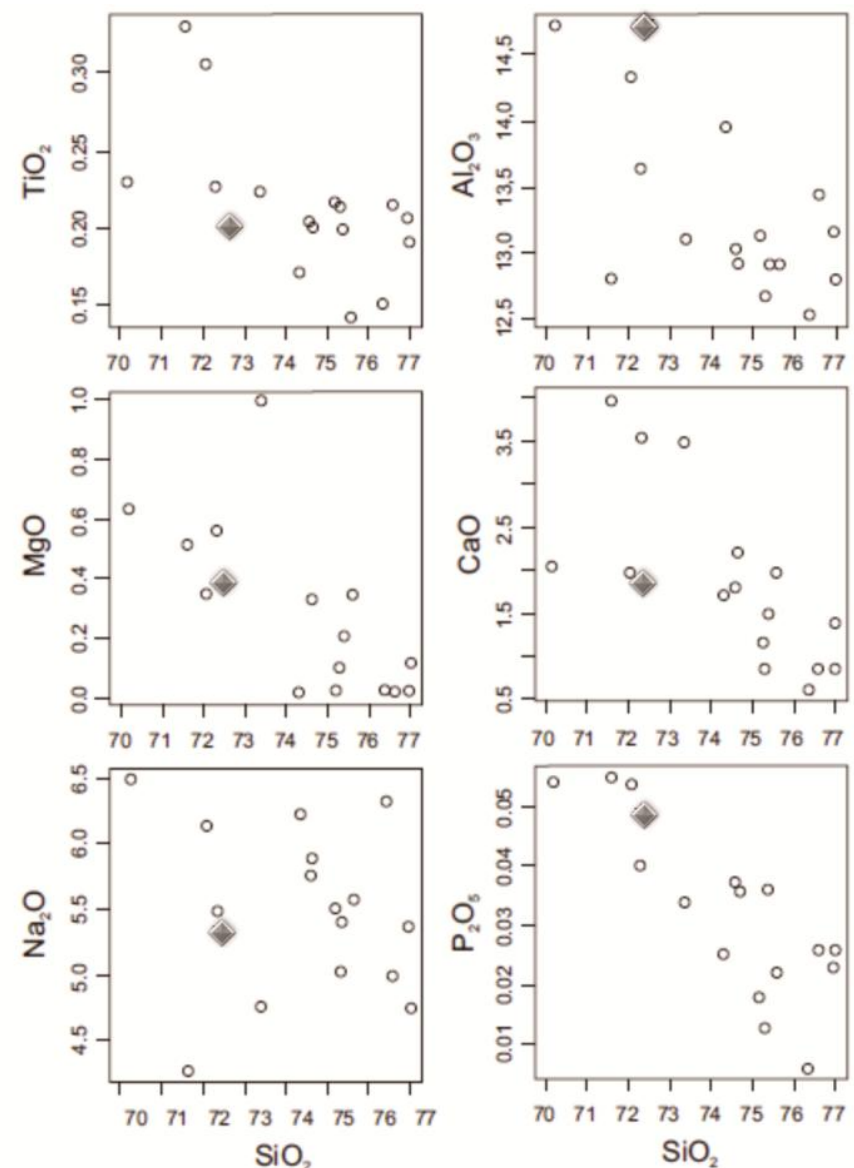

Figura 29. Diagrama de Harker para as rochas da suíte Tiradentes, símbolo de losango representa a amostra NAT-13 (Ávila et al., 2014).
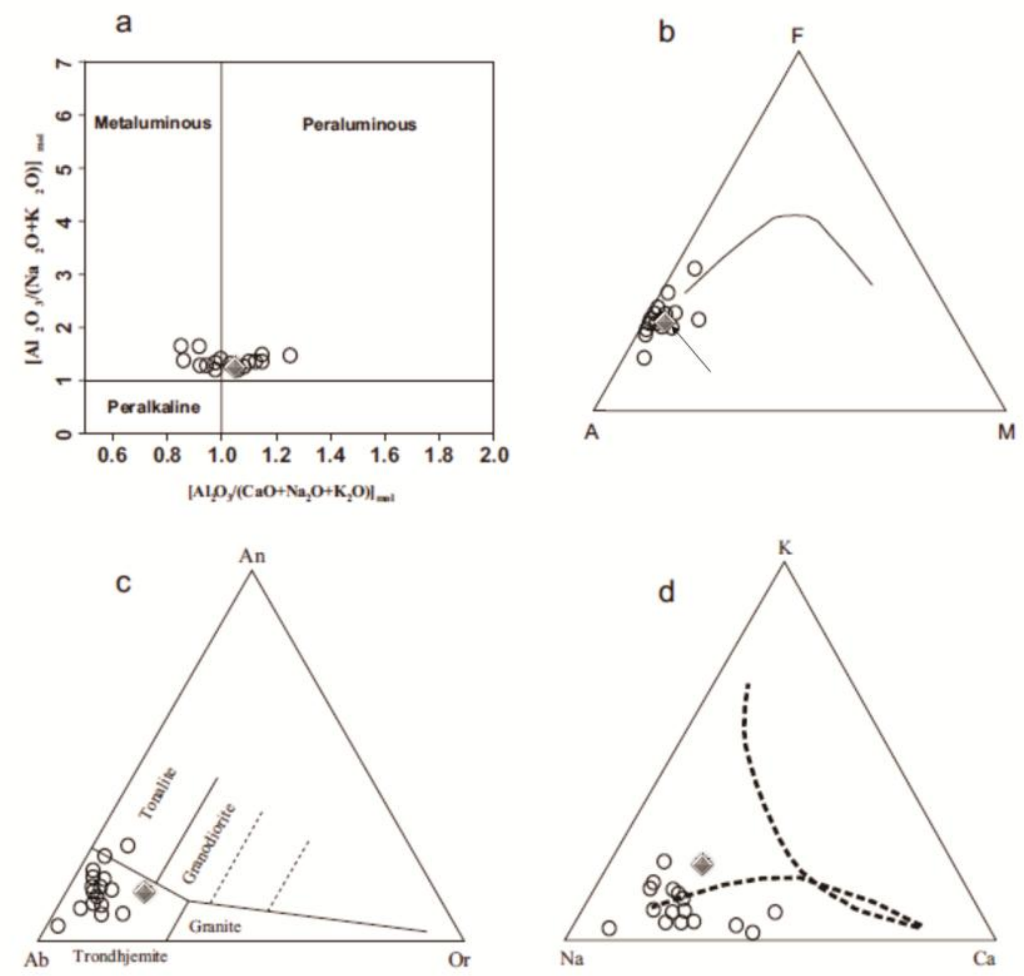

Figura 30. Diagrama discriminante para a rocha do ortognaisse Nazareno e da suíte Tiradentes (a) Diagrama $\left[\mathrm{Al}_{2} \mathrm{O}_{3} /\left(\mathrm{CaO}+\mathrm{Na}_{2} \mathrm{O}+\mathrm{K}_{2} \mathrm{O}\right)_{\mathrm{mol}} \times\left[\mathrm{Al}_{2} \mathrm{O}_{3} /\left(\mathrm{Na}_{2} \mathrm{O}+\mathrm{K}_{2} \mathrm{O}\right)_{\text {mol }}\right.\right.$ (Maniar e Picolli, 1989); (b) 
Diagrama $\mathrm{MgO}-\mathrm{FeO} *-\mathrm{Na}_{2} \mathrm{O}+\mathrm{K}_{2} \mathrm{O}$ (Irvine e Baragar, 1971); (c) Diagrama $\mathrm{Ab}-\mathrm{An}-\mathrm{Or}$ (O'Connor, 1965); (d) Diagrama Ca-Na-K (Barker eArth, 1976). Dados de Ávila et al. (2014). O losango representa a amostra NAT-13.

\section{Isótopos de Nd-Sr}

$\mathrm{O}$ ortognaisse Nazareno apresenta valores de $f \mathrm{Sm} / \mathrm{Nd}$ de $-0,54, \varepsilon_{\mathrm{Nd}(t)}$ de $+0,9$ e valores de ${ }^{87} \mathrm{Sr} /{ }^{86} \mathrm{Sr}$ de 0,703 . A Figura 31 revela que o dado plota no campo de variação das amostras da suíte Serrinha $\left(\varepsilon_{\mathrm{Nd}(t)}+1,8\right.$ e $-0,5 \mathrm{e}{ }^{87} \mathrm{Sr} /{ }^{86} \mathrm{Sr} 0,704$ e 0,706$)$ e próximo ao campo da suíte Tiradentes $\left(\varepsilon_{\mathrm{Nd}(\mathrm{t})}+2,3 \mathrm{e}-1,2 \mathrm{e}{ }^{87} \mathrm{Sr} /{ }^{86} \mathrm{Sr} 0,701\right.$ e 0,703; Figura 31) (Ávila et al., 2010; 2014). A idade modelo Sm-Nd $\mathrm{T}_{\mathrm{DM}}$ é de $2,4 \mathrm{Ga}$. Os valores positivos de $\varepsilon_{\mathrm{Nd}(\mathrm{t})}$ demonstram que o ortognaisse é juvenil, enquanto que os valores inciais de $\mathrm{Sr} / \mathrm{SR}$ acima de 0,7012 indicam um certo grau de contaminação crustal.

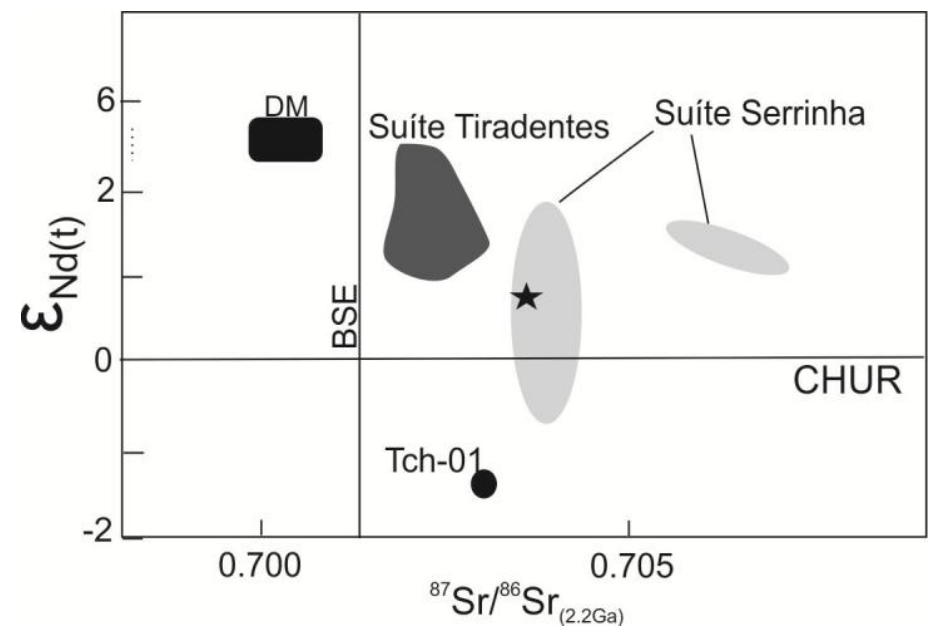

Figura 31. Diagrama $\varepsilon_{\mathrm{Nd}(\mathrm{T})}$ versus ${ }^{87} \mathrm{Sr} /{ }^{86} \mathrm{Sr}_{(\mathrm{t})}$ para rochas da suíte Serrinha, Tiradentes e uma amostra do ortognaisse Nazareno (modificado de Ávila et al., 2014). A estrela representa a amostra NAT-13.

\section{Implicações integradas}

Em resumo, as idades U-Pb no intervalo de 2200 e 2300 são escassas no CM. Atualmente são encontradas apenas a sul da zona de cisalhamento Lenheiros. O ortognaisse Nazareno (NAT-13) mostra evidências químicas, isotópicas e cronológicas similares às suítes Serrinha e Tiradentes. As rochas em conjunto apresentam assinatura de arco magmático. Os isótopos indicam a derivação de uma fonte máfica com possível mistura na fonte ou contaminação crustal. As idades $\mathrm{T}_{\mathrm{DM}}$ das suítes e da rocha estudada são próximas $(2,3-2,4 \mathrm{Ga})$ demonstrando que foram produzidas a partir de um protólito de curta residência crustal. Em síntese, este novo dado corrobora a interpretação de 
Ávila et al. (2010; 2014), a qual indica que as rochas estudadas estão associadas a uma ambiente de arco oceânico. 


\subsection{O evento tectono-termal de 2,17-2,09 Ga}

Esta seção apresenta os principais resultados desta Tese. Consiste de estudos associados à evolução crustal de rochas metaígneas utilizando das ferramentas: geocronologia, geoquímica e isótopos, com o objetivo de determinar o significado tectônico e a petrogênese destas rochas que estão amplamente distribuídas no CM. Será apresentado inicialmente resultados referentes a rochas da unidade Dores de Campos (nordeste do $\mathrm{CM}$ ) e em seguida será apresentado um artigo submetido referente a porção sudoeste do CM.

Três amostras estudadas (NATs 37, 38, 39) são contemporâneas ao evento plutônico mais jovem (2,17-2,09 Ga; ver abaixo). Possivelmente estas rochas em conjunto representam o magmatismo generalizado que atingiu desde a porção sudoeste até a porção nordeste do CM. Estas amostras não foram adicionadas ao escopo do artigo apresentado abaixo, pois estão associadas à sequência metavulcanossedimentar Dores de Campos. A Tabela 10 apresenta a sequência das amostras selecionadas.

Tabela 10. Relação das amostras não publicadas nos artigos científicos.

\begin{tabular}{cccc}
\hline Amostra & UTM & Litologia & Unidade Geológica \\
\hline NAT-37 & $0601448 / 7660984$ & Granito Gentio & Dores de Campos \\
\hline NAT-38 & $0601668 / 7661148$ & Granito Gentio & Dores de Campos \\
\hline NAT-39 & $0602723 / 7665421$ & Metatonalito Brejo Alegre & Dores de Campos \\
\hline
\end{tabular}

A seguir serão apresentados dados petrográficos, geoquímicos e geocronológicos destas amostras, seguidos de algumas interpretações.

\section{Metatonalito Brejo Alegre- NAT-39 (0602723/7665421)}

O metatonalito Brejo Alegre próximo à cidade de Dores de Campos, na sequência supracrustal Dores de Campos, sul da zona de cisalhamento Lenheiros. O afloramento contém xenólitos de rochas metaultramáficas e está cortado por diques graníticos. A foliação é definida pela orientação da biotita. A rocha possui granulometria fina e os minerais principais são: plagioclásio (45\%), quartzo (30\%), e biotita (15\%). Os minerais acessórios são apatita, zircão, allanita, ilmenita, carbonato e zoizita. 


\section{Granito Gentio NAT-38 e 37(0497565/7644617)}

O granito Gentio aflora a sul da zona de cisalhamento Lenheiros próximo a cidade de Dores de Campos. A rocha (NAT-38) é equigranular média, possui uma variedade composicional desde granodiorito a granito. A mineralogia principal é quartzo $(25 \%)$, plagioclásio (40\%), microclina (25\%) e biotita (8\%). Titanita, allanita, zircão, minerais opacos, epidoto, zoizita, clorita, calcita e muscovita são minerais acessórios. A amostra NAT-37 é um metagranodiorito, constituído por plagioclásio, quartzo, biotita, microclina, epidoto, zircão, clorita, apatita.

\section{Geocronologia U-Pb}

\section{Brejo Alegre tonalite (NAT 39)}

Os zircões são subedrais, prismáticos com bordas levemente arredondadas. A cor varia de castanho a castanho claro e são translúcidos a opacos. O tamanho varia de 400 a $190 \mu \mathrm{m}$. Em imagens de CL os zircões apresentam fraco zoneamento oscilatório, alguns com sobrecrescimento metamórfico. Cinco análises SHRIMP no núcleo (Th/U entre 0,11-0,28) definem um intercepto superior de $2166 \pm 14$ Ma $(\mathrm{MSWD}=0,46$; Figura 32) interpretada como a idade de cristalização desta rocha.
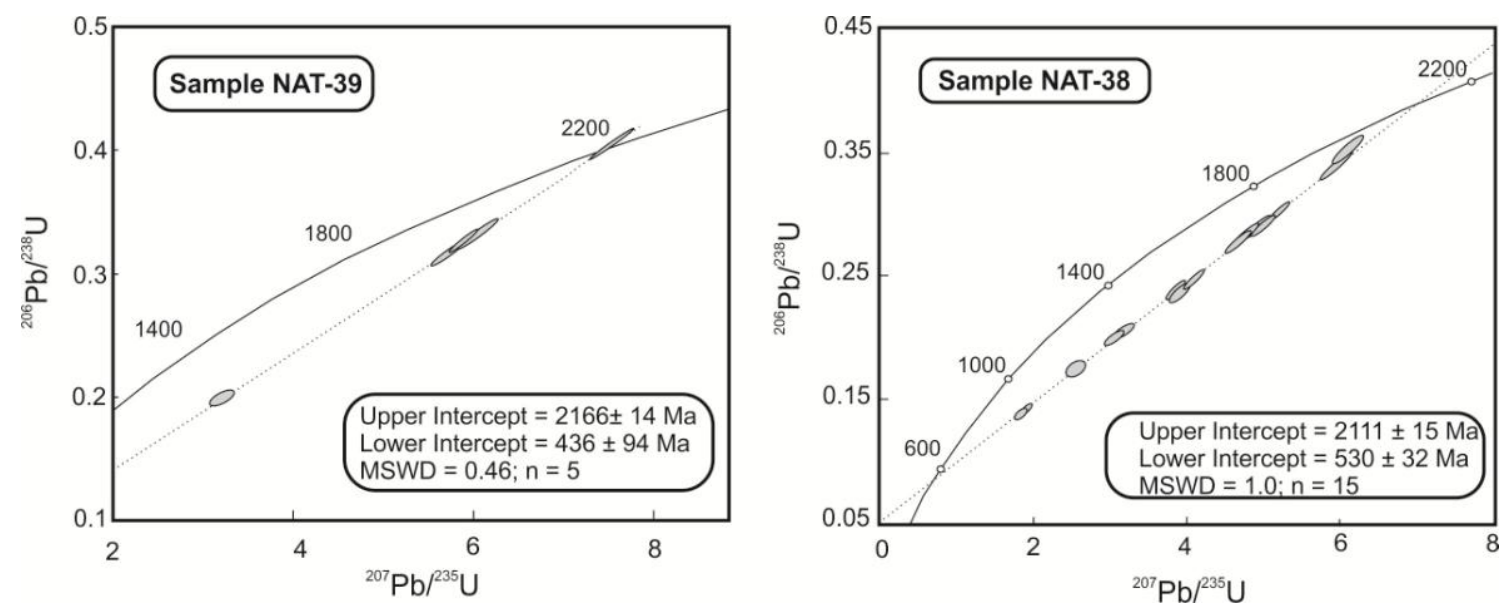

Figura 32. Diagrama da Concórdia para as rochas do tonalito Brejo Alegre e do granito Gentio. 


\section{Granito Gentio (NAT 38 e 37)}

A amostra NAT-38 apresenta zircões subedral, prismáticos e com bordas levemente arredondadas. A cor varia de castanho a castanho claro e são translúcidos a opacos. Os grãos apresentam tamanhos que variam entre 125 e $321 \mu \mathrm{m}$. Nas imagens de CL pode-se observar um leve zoneamento oscilatório (Anexo III). O sobrecrescimento metamórfico pode ser observado em alguns grãos. Quinze análises SHRIMP foram realizadas $(\mathrm{Th} / \mathrm{U}$ entre $0,12-1,0)$ e são variavelmente discordantes (6 a 81\%). A linha da discórdia definem intercepto superior em 2111 \$15 Ma (MSWD = 1,0; Figura 31), o que indica a idade de cristalização desta rocha.

A amostra NAT-37 pertence ao corpo Gentio apresenta zircões metamíticos e, portanto não foi possível obter uma idade de cristalização precisa. A idade gerada foi de $1776 \pm 240$ Ma, com discordância entre 39 a $92 \%$.

\section{Geoquímica e isótopos}

Os dados geoquímicos de três amostras do pluton Gentio (NAT 37, 38 e 39) são similares ao obtidos por Silva (2013). Conforme a Figura 33 as rochas são cálcioalcalinas, levemente peraluminosas, plotam predominantemente no campo magnesiano. Quanto ao diagrama de classificação tectônica (Pearce et al., 1984) observa-se que são granitoides de arco vulcânico.

Os valores isotópicos de $\varepsilon_{\mathrm{Nd}(\mathrm{t})}$ são de $-7,54,-1,86,+0,36$ (NAT-37, 38 e 39, respectivamente), a idade $\mathrm{T}_{\mathrm{DM}}$ é de 3,0 a $2,4 \mathrm{Ga}$. Os valores de ${ }^{87} \mathrm{Sr}^{86} \mathrm{Sr}_{(\mathrm{i})}$ variam de 0,705, 0,703, 0,702 (NAT-37, 38 e 39, respectivamente). Os resultados apontam uma gênese a partir de uma fonte máfica com a participação de fontes crustais. Tais resultados são similares aos dados apresentado no artigo a seguir. 

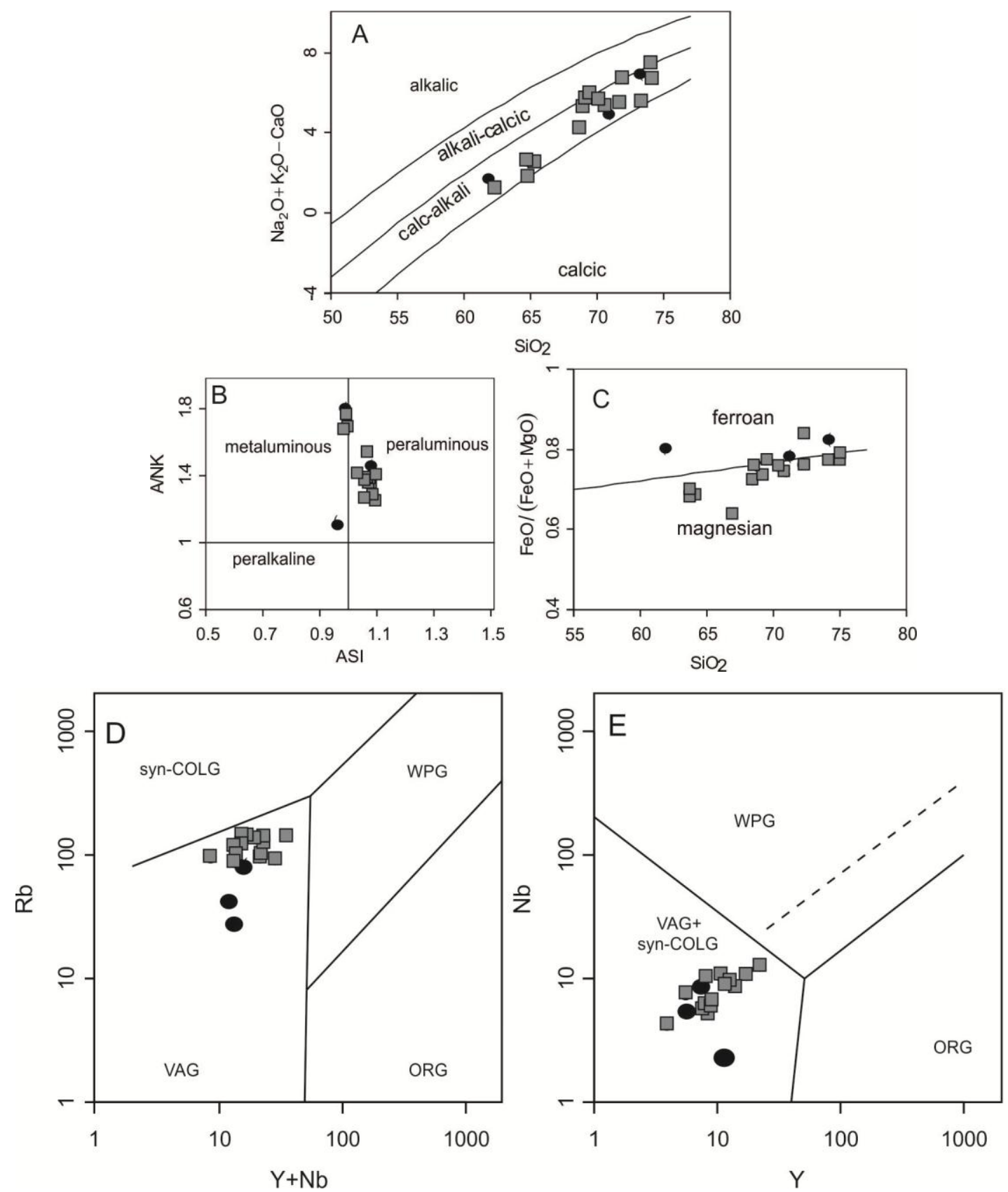

Figura 33. Diagramas (A) $\mathrm{SiO}_{2}$ vs. $\mathrm{Na}_{2} \mathrm{O}+\mathrm{K}_{2} \mathrm{O}-\mathrm{CaO}$ (Frost et al., 2001), (B) A/NK vs. A/CNK (Frost et al., 2001), (C) $\mathrm{FeO}_{\mathrm{t}} /\left(\mathrm{FeO}_{\mathrm{t}}+\mathrm{MgO}\right.$ ) vs. $\mathrm{SiO}_{2}$ (Frost et al., 2001); (D) $\mathrm{Rb}$ vs. Y+Nb e (E) Nd vs. Y (Pearce et al., 1984). Os círculos preenchidos indicam as amostras estudadas. Os quadrados cinza são dados de Silva (2013). 
2.17-2.09 Ga crust forming episodes in the Mineiro belt, São Francisco craton, Brazil: $\mathrm{U}-\mathrm{Pb}$ ages and geochemical constraints

O artigo aborda a geologia da porção sudoeste do CM. Este segmento siálico é representado por quatro batólitos em meio às faixas metavulcanossedimentares Rio das Mortes e Nazareno, três dos quais já foram estudados (Toledo, 2002; Cherman, 2004; Ávila et al., 2003). Estes batólitos possuem uma composição variada (tonalitos a granitos), e apresentam xenólitos félsicos e máficos.

Os batólitos estudados (Represa de Camargos, Ritápolis e Macuco de Minas) apresentam idades e litologias diversas e variável deformação, o que sugere tratar-se de intrusões múltiplas associadas evolução de arco magmático. O conjunto de dados obtidos logrou revelar a natureza da fonte das rochas, associadas à processos de fusão parcial e posterior cristalização fracionada. Outra conclusão importante advinda principalmente dos dados isotópicos e químicos é que estas rochas foram geradas em ambiente de arco continental, com variável contaminação/assimilação crustal da crosta arqueana. Cabe ressaltar, como exemplo, que o batólito Ritápolis apresenta padrões de contaminação bastante diversos. Os dados isotópicos e químicos obtidos corroboram a ideia de que a proximidade do batólito em relação à crosta arqueana (em direção ao norte) tem correlação direta com a maior contaminação de suas rochas. 
2.17-2.09 Ga crust forming episodes in the Mineiro belt, São Francisco craton, Brazil: U-Pb ages and geochemical constraints

\author{
N. S. Barbosa ${ }^{a}$, W. Teixeira ${ }^{\text {b* }}$, C. A. Ávila ${ }^{\text {c }}$, P. M. Montecinos ${ }^{b}$, E. M. Bongiolo ${ }^{d}$ \\ ${ }^{a}$ Programa de Pós-Graduação em Geoquímica e Geotectônica, Instituto de Geociências, \\ Universidade de São Paulo, São Paulo, SP, Brazil (natali@usp.br) \\ bInstituto de Geociências, Universidade de São Paulo, São Paulo, SP, Brazil \\ (wteixeir@usp.br) \\ ${ }^{c}$ Museu Nacional, Universidade Federal do Rio de Janeiro, Rio de Janeiro, RJ, Brazil \\ ${ }^{\mathrm{d}}$ Instituto de Geociências, Universidade Federal do Rio de Janeiro, Rio de Janeiro, RJ, \\ Brazil
}

\title{
Keywords
}

São Francisco Craton, Paleoproterozoic, Zircon U-Pb-Hf, Nd-Sr isotopes, geochemistry.

\begin{abstract}
Geologic information supported by new $\mathrm{U}-\mathrm{Pb}$ zircon dating coupled with zircon $\mathrm{Hf}$ and $\mathrm{Nd}-\mathrm{Sr}$ isotopic constraints, and geochemistry on granitoids, metagranitoids, orthogneisses and diorites unravel the nature of a magmatic arc in the Mineiro belt - São Francisco craton. The studied rocks show $\mathrm{SiO}_{2}$ contents from 54.8 -77.1 wt.\%, disclose calc-alkaline to high-K calc-alkaline affinities, are metaluminous to peraluminous and mostly magnesian. They are variable enriched in LREE, given by $\mathrm{La} / \mathrm{Yb}_{\mathrm{N}}=9.3-13.8$ (diorites) and $\mathrm{La} / \mathrm{Yb}_{\mathrm{N}}=2.24-91.2$ (granitoids, metagranitoids and orthogneisses). All samples show $\mathrm{Nb}$ and $\mathrm{Ti}$ negative anomalies, some with marked $\mathrm{P}$ negative ones. A set of samples yields Dy/Dy* and coupled $\mathrm{Dy}_{\mathrm{N}} / \mathrm{Yb}_{\mathrm{N}}$ values between 0.4 to 0.9 and 0.9 to 1.9, respectively. Thus they probably derived from a LREE enriched, MORB source. A group of samples with $\mathrm{Dy} / \mathrm{Yb}$ values up to 3.0 is probably related to crustal assimilation/contamination. Zircon U-Pb crystallization ages define two plutonic episodes from 2174-2158 Ma and 2149-2109 Ma. Few samples contain inherited zircons with concordant ${ }^{207} \mathrm{~Pb} /{ }^{206} \mathrm{~Pb}$ ages as old as $2785 \pm 6 \mathrm{Ma}$. This suggests the involvement of pre-existent crust in the origin. The new $\varepsilon_{\mathrm{Nd}(\mathrm{t})}$ (from -7.3 to +0.3 ) and ${ }^{87} \mathrm{Sr} /{ }^{86} \mathrm{Sr}_{(\mathrm{t})}$ (from 0.700 to 0.704 ) values indicate that two sources (MORB and sublithospheric continental mantle) were important in the magma genesis of the studied rocks, further subjected to Paleoproterozoic and Archean contaminants. This is also consistent with the $\varepsilon_{\mathrm{Hf}(\mathrm{t})}$ values (from +2.5 to -6.6 ), the $\mathrm{Sm}-\mathrm{Nd} \mathrm{T}_{\mathrm{DM}}$ and Lu-Hf $\mathrm{T}_{\mathrm{DM}}$ ages as old as $3.2 \mathrm{Ga}$. From a tectonic point of view the studied rocks are interpreted as originally I-type rocks, derived in continental arc setting, akin to a long-lived accretionary arc system (2.35-2.00 Ga). This system evolved outboard the Archean continental mass known as the proto-São Francisco craton.
\end{abstract}




\section{Introduction}

Granitoid plutons (2.2-2.1 Ga) are widespread in the Mineiro belt and make up the bulk tectonic architecture of the southern portion of the São Francisco Craton-SFC (Noce et al., 2000; Ávila et al., 2010, 2014; Teixeira et al., 2008, 2015; Seixas et al., 2012, 2013). This belt was formed by various magmatic arcs, and is a product of a Paleoproterozoic orogenic system - the so-called Minas accretionary orogeny - 2.35$2.00 \mathrm{Ga}$ (Teixeira et al., 2015). From a tectonic perspective, the Mineiro belt crops out to the southeast of the Jeceaba-Bom Sucesso lineament (Fig. 1) which is regarded as the northern boundary with the Neoarchean foreland of the proto- São Francisco Craton (Campos and Carneiro, 2008). The Mineiro belt and the adjoining Mantiqueira and Juiz de Fora belts have been attributed to the Minas accretionary orogeny (Teixeira et al., 2015). Moreover, according to Noce et al. (2007), the Mantiqueira (2.14-2.04 Ga) and Juiz de Fora (2.12-2.08 Ga) belts are correlative to the Kimezian basement of the West Congo. These tectonic units were formed by several magmatic arcs that eventually welded to the Archean continental mass to create the so-called São Francisco paleocontinent. The Mantiqueira and the Juiz de Fora belts show strong Neoproterozoic overprint (Noce et al., 2007; Heilbron et al., 2010), while the Mineiro belt is only locally affected, as suggested by published K-Ar ages (Teixeira, 1985; Noce et al., 2000; Ribeiro et al.; 2013).

Several geodynamic models have been proposed to explain the magmatic evolution of the Mineiro belt, assuming oceanic and/or continental environments on the basis of geologic correlations supported by geochronological and geochemical data (e.g., Noce et al., 2000; Ávila et al., 2010, 2014; Seixas et al., 2012, 2013; Teixeira et al., 2015). In this sense, the range in the isotopic and geochemical data for the recognized plutons suggests that the magma genesis involved different processes, such as mixing among mantle and continental sources. However, there is a limited knowledge about the potential magma sources for these rocks due to the lack of detailed petrological data (i.e., incompatible element ratios) and zircon Hf isotopic constraints coupled with the $\mathrm{Nd}-\mathrm{Sr}$ signatures to address a petrogenetic interpretation.

This paper aims to characterize the tectonic and magmatic evolution of some plutonic bodies in the southwestern portion of the Mineiro belt, occurring between the towns of Lavras, Itumirim, Itutinga, Nazareno and Ritápolis, based on field mapping in the 1:250.000 scale. For this purpose we carried out SHRIMP U-Pb (Sensitive High Resolution Ion Microprobe) and LA-ICP-MS (Laser Ablation Inductively Coupled 
Plasma Mass Spectrometry) zircon age determinations on selected rocks from these plutons, in the attempt to better understand their origin, and taking into account previously published geochronologic and geochemical interpretations. Additionally, new zircon Hf, whole rock $\mathrm{Nd}-\mathrm{Sr}$ isotopic analyses and lithogeochemical data were used to place spatial-temporal petrogenetic inferences on the nature and tectonic significance of such rocks in the context of the main belt. The involvement of different mantle and crustal components from which the metaigneous rocks derived are also addressed, to support the petrogenetic and tectonic model suggested here.

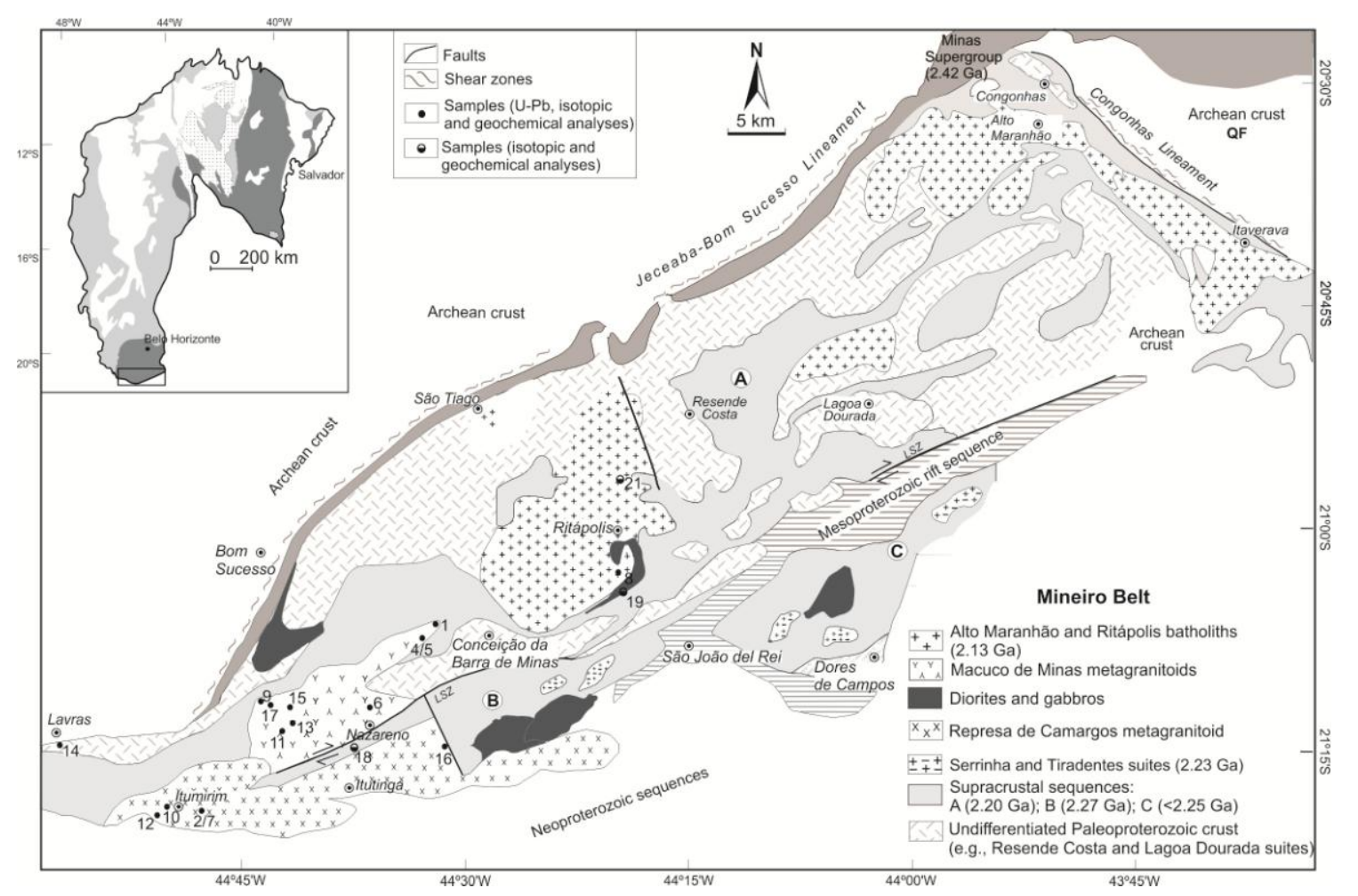

Fig. 1. Geologic framework of the southernmost part of the São Francisco Craton - SFC, showing the main units of the Mineiro belt (adapted from Duarte et al., 2003; Quéméneur et al., 2003; Ávila et al., 2010; Corrêa Neto et al., 2012; Seixas et al., 2012). QF: Quadrilátero Ferrífero. LZC: Lenheiros shear zone. The numbers represent the studied samples. See text for details. Inset shows the SFC: dark gray: basement rocks; light gray and white: covers (data from Alkmim and Martins-Neto, 2012).

\section{Geologic-tectonic framework}

The polycyclic basement in southern portion of the SFC encompasses two major compartments that show Archean and Paleoproterozoic ages, as reported by several efforts during the last 20 years (Teixeira et al., 1996; Noce et al., 2000; Alkmim and 
Noce, 2006; Ávila et al., 2006, 2010, 2014; Campos and Carneiro, 2008; Teixeira et al., 2008, 2015; Seixas et al., 2012, 2013; Lana et al., 2013; Romano et al., 2013). Several generation of TTG rocks dominated the Archean continental growth of the paleocontinental mass (proto-São Francisco craton), dated between 3.20 and $2.70 \mathrm{Ga}$ (e.g., Campo Belo, Belo Horizonte, Passa Tempo and Bonfim complexes - not shown). It includes the Neoarchean Rio das Velhas granite-greenstone terrane at the so-called Quadrilátero Ferrífero - QF. The country rocks are intruded in many places by latetectonic, potassic granitoids dated at 2.75-2.55 Ga (Teixeira et al., 1996; Romano et al., 2013 and references therein). The Neoarchean tectonic-magmatic stage has been collectively named the Rio das Velhas orogeny (2.78-2.70 Ga; e.g., Machado and Carneiro, 1992), although alternative views consider several local tectonic-magmatic episodes during this time frame (e.g., Lana et al., 2013). After Neoarchean tectonic stability the deposition of the Minas Supergroup ( $<2.58 \mathrm{Ga}$; Hartmann et al., 2006 and references therein) occurred in a passive margin basin setting, thought it was later deformed and thrusted at Paleoproterozoic times (Marshak et al., 1992; Alkmim and Noce, 2006). Typical exposures of the Minas Supergroup occur in the QF and along the Jeceaba-Bom Sucesso lineament (e.g., Campos et al., 2003; Campos and Carneiro, 2008; Neri et al., 2013; Fig. 1).

From a tectonic perspective, the Neoarchean landmass acted as foreland for the multiple Paleoproterozoic arcs (i.e., Minas accretionary orogeny) that produced widespread granitoid rocks, quartz-diorites, diorites, and gabbros such as in the Mineiro belt - see Fig. 1 (Teixeira et al., 2015). Final docking of the Mineiro belt onto the Archean foreland took place by 2.1-2.0 Ga ago by means of a NW-trending fold-thrust belt. The latter is characterized by dome-and-keel structures and related metamorphism that overprinted the polycyclic basement and supracrustal sequences in the QF area and to the west (Marshak et al., 1992; Alkmim and Noce, 2006). In contrast NE-SW transcurrent tectonics akin to the soft accretion collision between the magmatic arcs of the Mineiro belt, such as the Lenheiro fault zone (Fig. 1), controlled the geologic framework (e.g. Teixeira et al., 2008). According to Ávila et al. (2010) at least three distinct metamorphic-deformational episodes overprinted both the variable deformed plutonic rocks and supracrustal sequences of the Mineiro belt. Much of the Mineiro rocks were metamorphosed under amphibolite facies conditions at Paleoproterozoic times retrogressed to greenschist facies (Ávila et al., 2010 and references therein), such as nearby the towns of Nazareno, Itumirim and Ritápolis where the studied rocks crop 
out. However, a much younger metamorphism at regional scale is envisaged on the basis of published K-Ar ages in the 600-590 Ma time interval (e.g., Noce et al., 2000). This particular episode is probably a result of the outboard Ribeira/Araçuaí belt that developed along the southern fringe of the Craton (Ribeiro et al., 2013).

First geochronological studies by means of $\mathrm{Rb}-\mathrm{Sr}$ whole rock isochrones and ${ }^{207} \mathrm{~Pb} /{ }^{206} \mathrm{~Pb}$ zircon evaporation ages have distinguished felsic and mafic plutonic rocks formed in 2.25-1.90 Ga time interval in the Mineiro belt, such as between the towns of Lavras-Nazareno-Itumirim-Ritápolis-São João del Rei (Teixeira et al., 1985; Heilbron et al., 1989; Ávila, 2000; Noce et al., 2000; Quéméneur and Noce, 2000; Cherman, 2004; Cherman and Valença, 2005). As a whole these rocks show calc-alkaline affinities. At first glance, the $\mathrm{Nd}$ and $\mathrm{Sr}$ isotopic constraints for these plutons suggest some interaction between mantle-derived magmas and continental crust. This has been tentatively interpreted to be related to oceanic crust subduction and/or mafic magma underplating at Paleoproterozoic times to form these plutons (Noce et al., 2000). For instance some plutons contain xenoliths of amphibolites and tonalitic, granodioritic and granitic gneisses (e.g., Cherman, 2004; Teixeira et al., 2008), suggesting some sort of assimilation of pre-existent crust in the magma genesis.

Recent detailed geological mapping with emphasis in the cartography of the felsic and mafic plutonic intrusions, supported by precise U-Pb age determinations, $\mathrm{Nd}-$ Sr isotopic constraints and geochemistry, have provided a better understanding of the magmatic evolution through time, as well as the related tectonic settings. Current knowledge indicates that the Mineiro belt is comprised by successively younger plutonic arcs that originated the Resende Costa and Lagoa Dourada (2350-2320 Ma), Serrinha and Tiradentes (2230-2200 Ma) suites, Ritápolis and Alto Maranhão batholiths (2120 Ma), among other rocks (Ávila et al., 2010, 2014; Seixas et al., 2012, 2013; Teixeira et al., 2015) - Table 1. In particular these two batholiths (Fig. 1) have different origins, according to the isotopic and geochemical constraints. The Ritápolis batholith is a low to high $\mathrm{K}_{2} \mathrm{O}$ calc-alkaline granitoid, shows peraluminous to slightly metaluminous signatures and strong negative Eu anomalies (Noce et al., 2000). These rocks exhibit various textures. Previous radiometric data for the Ritápolis rocks disclosed different results: ${ }^{207} \mathrm{~Pb} /{ }^{206} \mathrm{~Pb}$ age (zircon evaporation) of $2121 \pm 7 \mathrm{Ma}$ (Ávila, 2000) and $\mathrm{Rb}-\mathrm{Sr}$ whole rock isochron of $1863 \pm 44 \mathrm{Ma}$ (Noce et al., 2000). Granitic dykes that are also ascribed to the Ritápolis granitoid crosscut the so-called Brumado diorite ( $\mathrm{U}-\mathrm{Pb}$ age of $2128 \pm 2 \mathrm{Ma}$; unpublished data). Field relationships suggest that the southern part of the 
Ritápolis batholith could be correlated to the Brumado diorite (Ávila et al., 2008). The variable negative $\varepsilon_{\mathrm{Nd}(\mathrm{t})}$ values (from -7.3 to -1.0 ), $\mathrm{Sm}-\mathrm{Nd} \mathrm{T}_{\mathrm{DM}}$ ages $=3.1-2.4 \mathrm{Ga}$ and the significantly high ${ }^{87} \mathrm{Sr}^{86} \mathrm{Sr}_{(\mathrm{t})}=0.758$ clearly indicate that the Ritápolis granitoid developed in continental arc setting (Noce et al., 2000) - see Table 1. In contrast the Alto Maranhão batholith can be classified as high-Al TTG suite with commingled dioritic enclaves, showing a distinct metaluminous character due the presence of hornblende, and present slightly negative to positive Eu anomalies (Seixas et al., 2013). The Alto Maranhão rocks yield $\varepsilon_{\mathrm{Nd}(\mathrm{t})}$ values of -1.0 and $+0.9, \mathrm{Sm}-\mathrm{Nd} \mathrm{T}_{\mathrm{DM}}=2.4-2.3 \mathrm{Ga}$, suggesting they probably formed in an oceanic arc setting through derivation from a tholeiitic source (Seixas et al., 2013).

Table 1 highlights the geologic-tectonic characteristics of recognized suites and batholiths in the Mineiro belt, based on previously published information. Notably rocks of these plutons intrude or are encompassed by metavolcano-sedimentary sequences (2.27 to 2.20 Ga old), namely Rio das Mortes, Nazareno and Dores de Campos (e.g., Ávila et al., 2010, 2014; Teixeira et al., 2015). These sequences are roughly compartmented by the Lenheiro shear zone - see Fig. 1.

Table 1. Summary of the published geologic-tectonic information of plutonic rocks of the Mineiro belt. Noce et al., 2000 (1); Quéméneur and Noce 2000 (2); Seixas et al., 2012 (3), 2013 (4); Ávila et al., 2010 (5), 2014 (6); Teixeira et al., 2015 (7). Abbreviation for minerals: Pl: Plagioclase; Kfs: K-feldspar; Qtz: Quartz; Olg: Oligoclase; Ep: Epidote; Zrn: Zircon; Aln: Allanite; Chl: Chlorite; Ttn: Titanite; Cal: Calcite; Ser: Sercite; Grt: Garnet; Ap: Apatite; Di: Diopside; Hbl: Hornblende; Bt: Biotite; and Opq: opaque mineral. (a) Primary minerals and (b) Acessory minerals. Abbreviations according to Whitney and Evans (2010).

\begin{tabular}{|c|c|c|c|c|c|c|}
\hline $\begin{array}{l}\text { Plutonic } \\
\text { bodies }\end{array}$ & Lithology & Petrography & Geochemistry & $\begin{array}{l}\text { SHRIMP U-Pb } \\
(\mathrm{Ma}) ; \mathrm{Pb}-\mathrm{Pb} \text { zircon } \\
(\mathrm{Ma}) ; \mathrm{Rb} / \mathrm{Sr} \text { ages } \\
(\mathrm{Ma}) ; \mathrm{Sm}-\mathrm{Nd} \mathrm{T}_{\mathrm{DM}} \\
\text { ages }(\mathrm{Ga})\end{array}$ & $\begin{array}{l}\text { Interpreted } \\
\text { Tectonic } \\
\text { setting }\end{array}$ & Ref. \\
\hline $\begin{array}{l}\text { Alto } \\
\text { Maranhão }\end{array}$ & $\begin{array}{l}\text { Tonalites and } \\
\text { diorites }\end{array}$ & $\begin{array}{l}\text { a) Pl, bt, hbl } \\
\text { b) Aln, ap, } \\
\text { zrn }\end{array}$ & $\begin{array}{l}\text { Calc-alkaline and high-Al } \\
\text { TTG affinity, } \\
\text { metaluminous. Slightly } \\
\text { neg. to posit. Eu } \\
\text { anomalies, high LILE, } \\
\text { light REE and highly } \\
\text { HFSE }\end{array}$ & $\begin{array}{l}\mathrm{U} / \mathrm{Pb}=2130 \pm 2 \\
\mathrm{~T}_{\mathrm{DM}}=2.3 \text { to } 2.4 \\
\varepsilon_{\mathrm{Nd}(\mathrm{t})}=-1.0 \text { to }+1.0\end{array}$ & Oceanic arc & 4 \\
\hline Ritápolis & $\begin{array}{l}\text { Granodiorites } \\
\text { and granites }\end{array}$ & $\begin{array}{l}\text { a) Kfs, qtz, } \\
\text { pl, bt } \\
\text { b) Ap, ep, } \\
\text { aln, ttn, ilm, } \\
\text { zrn }\end{array}$ & $\begin{array}{l}\text { Calc-alkaline and } \\
\text { peraluminous. High and } \\
\text { low } \mathrm{K} \text { contents, negative } \\
\mathrm{Eu}, \mathrm{Nb}, \mathrm{P} \text { and } \mathrm{Ti} \\
\text { anomalies }\end{array}$ & $\begin{array}{l}\mathrm{Pb} / \mathrm{Pb}=2121 \pm 7 \\
\mathrm{Rb} / \mathrm{Sr}=1863 \pm 44 ; \\
{ }^{87} \mathrm{Sr}^{86}{ }^{86} \mathrm{Sr}_{(\mathrm{t})}=0.758 \\
\mathrm{~T}_{\mathrm{DM}}=2.4-3.1 \\
\varepsilon_{\mathrm{Nd}(\mathrm{t})}=-7.3 ;-5.9 ;- \\
5.1 ;-3.3 \text { to }-1.0\end{array}$ & $\begin{array}{l}\text { Continental } \\
\text { arc }\end{array}$ & $\begin{array}{l}1, \\
2,5\end{array}$ \\
\hline $\begin{array}{l}\text { Serrinha - } \\
\text { Tiradentes }\end{array}$ & $\begin{array}{l}\text { Quartz- } \\
\text { diorite, } \\
\text { granodiorite, } \\
\text { granophyric } \\
\text { sub- and } \\
\text { volcanics }\end{array}$ & $\begin{array}{l}\text { a) Pl, qtz, } \\
\text { bt, amp; } \\
\text { b) Zrn, ap, } \\
\text { aln., kfs }\end{array}$ & $\begin{array}{l}\text { Calc-alkaline, } \\
\text { metaluminous and } \\
\text { peraluminous. Flat HREE } \\
\text { patterns, negative Eu } \\
\text { anomaly }\end{array}$ & $\begin{array}{l}\mathrm{U} / \mathrm{Pb}=2227 \pm 22 \text { to } \\
2204 \pm 11 \\
\mathrm{~T}_{\mathrm{DM}}=2.6-2.3 ; \\
\varepsilon_{\mathrm{Nd}(\mathrm{t})}=-0.8 ;+1.1 \text { to } \\
+2.3\end{array}$ & Oceanic arc & $\begin{array}{l}1, \\
5,6\end{array}$ \\
\hline
\end{tabular}




\begin{tabular}{l|l|l|l|l|l|l}
\hline Resende & Tonalites and & a) Pl, qtz, & TTG affinity, & $\mathrm{U} / \mathrm{Pb}=2356+3$ to & Oceanic arc & 3,7 \\
Costa - & granodiorites & bt, di, hbl; & metaluminous to slightly & $2317 \pm 16$ & \\
Lagoa & & b) Zrn, ap, & peraluminous. & $\varepsilon_{\mathrm{Hf}(\mathrm{t})}=+4$ to -9 & \\
Dourada & & aln. & $\begin{array}{l}\text { High- } \mathrm{Al}_{2} \mathrm{O}_{3} \text { rocks, flat } \\
\text { REE, positive Eu anomaly }\end{array}$ & $\begin{array}{l}\mathrm{T}_{\mathrm{DM}}=2.4-2.5 ; \\
\varepsilon_{\mathrm{Nd}(\mathrm{t})}=+1.1 \text { and } \\
+3.2\end{array}$ & & \\
& & & & & \\
& & & & & \\
\hline
\end{tabular}

\section{Analytical methods}

In the attempt to better constrain the crystallization age and nature of plutonic rocks nearby the towns of Ritápolis, Nazareno, Itumirim, Itutinga and Lavras we carried out U-Pb analyses (SHRIMP and LA-ICPMS). Additional geochemical data and Hf-Nd$\mathrm{Sr}$ isotopic inferences were performed for a more confident petrogenetic interpretation.

In situ U-Pb zircon datings were recovered from sixteen selected samples, using the conventional heavy liquid and magnetic techniques and purified by handpicking under a binocular microscope.

Twelve SHRIMP analyses were performed using the SHRIMP II at the Geochronology Research Center (CPGeo) of the Institute of Geosciences of the University of São Paulo. The samples were mounted on adhesive tapes, enclosed in epoxy resin and polished together with the TEMORA 1 zircon standard $\left({ }^{206} \mathrm{~Pb} /{ }^{238} \mathrm{U}\right.$ age $=416.78 \pm 0.33 \mathrm{Ma}$; Black et al., 2003). The internal domains of the grains were evaluated using cathodoluminescence (CL) image prior to the isotopic analyses. The SHRIMP isotopic data were collected in sets of five scans throughout the masses and the TEMORA standard was measured after four unknown analyses. The abundances of $\mathrm{U}$, Th and $\mathrm{Pb}$, and the $\mathrm{Pb}$ isotopic ratios, were normalized using the SL13 zircon standard ( $\mathrm{U}=238$ ppm; Sato et al., 2014). Analyses with common $\mathrm{Pb}$ lower than $10 \%$ were used after correction of the measured ${ }^{204} \mathrm{~Pb}$ and assuming the $\mathrm{Pb}$ composition of Stacey and Kramers (1975). The data reduction was performed using the SQUID 1.06 Excel macro (Ludwig, 2000), and the statistical assessments were calculated with the ISOPLOT software of Ludwig (2003). The uncertainties in the isotopic ratios and the ages are reported at the $1 \%$ level and the weighted mean ages are reported as $95 \%$ confidence limits (Sato et al., 2014).

The LA-ICPMS technique was applied to 4 samples, using the Thermo-Fisher Neptune laser-ablation (LA) multi-collector inductively coupled plasma mass spectrometer (ICP-MS), with ArF-193 $\mu \mathrm{m}$ Photon laser system (frequency of $6 \mathrm{~Hz}$; intensity of $6 \mathrm{~mJ}$; focused bean to $32 \mu \mathrm{m}$ spots) of the CPGeo. The correction of laser 
induced fractionation of ${ }^{206} \mathrm{~Pb} /{ }^{238} \mathrm{U}$ ratio follow the linear regression of the Kösler et al. (2002). In situ zircon analyses were carried out according to the standard-sample bracketing method and referred to the zircon GJ-1 standard (U-Pb mean age of $601 \pm$ 3.5 Ma; Elholou et al., 2006). The analytical data were obtained in sets of 2-3 sheets including two blanks, three GJ-1 analyses, 13 unknown zircon spots, followed by analysis of two more blanks and two GJ-1 standards (after Sato et al., 2010). The ${ }^{202} \mathrm{Hg}$ contents of the analyses controlled the common $\mathrm{Pb}$ measurements. Raw data were processed on-line and reduced in an Excel worksheet (Sato et al., 2009; 2010) adapted from the software SQUID 1.02 (Ludwig, 2001). Data selected were plotted on Concordia diagrams, using ISOPLOT/Ex® 3.00 software (Ludwig, 2003).

Thirteen zircon Hf isotopic analyses were performed in the same samples dated by SHRIMP and LA-ICPMS using a Neptune laser ablation multi-collector inductively coupled plasma mass spectrometer of the CPGeo. Laser spot diameter was $39 \mu \mathrm{m}$ on or adjacent to the $\mathrm{U}-\mathrm{Pb}$ dating, with an ablation time of 60 seconds, repetition rate of $7 \mathrm{~Hz}$, and He was used as carrier gas (Sato et al., 2009, 2010). Reference zircon standards were considered for quality control during the Hf analytical session. A decay constant for ${ }^{176} \mathrm{Lu}$ of $1.867 \times 10^{-11} / \mathrm{yr}$ (Söderlund et al., 2004) was used for the calculation of initial ${ }^{176} \mathrm{Hf} /{ }^{177} \mathrm{Hf}$ ratios. ${ }^{176} \mathrm{Hf} /{ }^{177} \mathrm{Hf}$ ratios were normalized to ${ }^{176} \mathrm{Hf} /{ }^{177} \mathrm{Hf}=0.7325$. ${ }^{176} \mathrm{Lu} /{ }^{175} \mathrm{Lu}$ ratio of $(0.02669)$ was used to calculate ${ }^{176} \mathrm{Lu} /{ }^{177} \mathrm{Hf}$. Mass bias corrections of Lu-Hf isotopic analyses were carried out applying the variations of GJ1 standard. The $\varepsilon_{\mathrm{Hf}}$ values were calculated assuming present-day chondritic ratios of ${ }^{176} \mathrm{Hf} /{ }^{177} \mathrm{Hf}=$ 0.282772 and ${ }^{176} \mathrm{Lu} /{ }^{177} \mathrm{Hf}=0.0332$ (Blichert-Toft and Albarede, 1997). A two-stage continental model ( $\mathrm{T}_{\mathrm{DM}}$ ages) was calculated assuming the initial ${ }^{176} \mathrm{Hf} /{ }^{177} \mathrm{Hf}$ of zircons and ${ }^{176} \mathrm{Lu} /{ }^{177} \mathrm{Hf}=0.022$ ratio for the lower continental crust (Griffin et al., 2004). On each sample the individual $\varepsilon_{\mathrm{Hf}}$ determinations were grouped following a $2 \sigma$ outlier test. With this intention, a $95 \%$ confidence interval was calculated for average $\varepsilon_{\mathrm{Hf}}$ initial values and $2 \sigma$ external reproducibility. $\varepsilon_{\mathrm{Hf}(\mathrm{t})}$ values are referred to the ${ }^{207} \mathrm{~Pb} /{ }^{206} \mathrm{~Pb}$ crystallization age of the particular spot analyses.

Selected samples were analyzed for Sr-Nd isotopes and for major, trace and REE elements. The $16 \mathrm{Nd}$ and $\mathrm{Sr}$ whole-rock analyses were carried out at the CPGeo, according to procedures of Sato et al. (1995). Ion exchange resin was applied for primary separation of the rare earth elements (REE), followed by a second LN column for separation of Sm and $\mathrm{Nd}$. The isotope ratios were measured on a Triton-Thermo Fisher Scientific mass spectrometer. The ${ }^{143} \mathrm{Nd} /{ }^{144} \mathrm{Nd}$ and ${ }^{147} \mathrm{Sm} /{ }^{144} \mathrm{Nd}$ ratios have 
quoted errors at $2 \sigma$ and $1 \sigma$ levels, respectively. The measured ${ }^{143} \mathrm{Nd} /{ }^{144} \mathrm{Nd}$ ratio obtained for the JNDi-1 standard gave a mean ${ }^{143} \mathrm{Nd} /{ }^{144} \mathrm{Nd}$ ratio $=0.512100 \pm 9(1 \sigma)$. The calculations of corrections were performed tracer content and for blanks of 40pg $(\mathrm{Nd})$ and 20pg $(\mathrm{Sm})$. Corrections were applied for instrumental bias, tracer content and for blank of 40pg $(\mathrm{Nd})$ (Petronilho, 2009). Sm-Nd $\mathrm{T}_{\mathrm{DM}}$ ages were calculated using the depleted mantle model of DePaolo (1981), whereas the $\varepsilon_{\mathrm{Nd}(\mathrm{t})}$ values are referred to the $\mathrm{U}-\mathrm{Pb}$ crystallization age of $2.1 \mathrm{Ga}$ (see below). The $\mathrm{Rb}-\mathrm{Sr}$ isotope ratios were measured either on the Triton-Thermo Fisher mass spectrometer or on the Finnigan-MAT 262 of the CPGeo. ${ }^{87} \mathrm{Sr} /{ }^{86} \mathrm{Sr}$ ratios were normalized to ${ }^{86} \mathrm{Sr} /{ }^{88} \mathrm{Sr}=0.1194$. The final quoted errors are external values $(1 \sigma)$ based on replicate analyses of $\mathrm{NBS}-987 \mathrm{SrCO}_{3}$ standard, which yielded a mean ratio of $0.710251 \pm 0.000043(2 \sigma)$ during the period of the analyses. The mean blank for Sr was 200 pg during the period of the analyses. Decay constants are those recommended by Steiger and Jäger (1977).

The chemical compositions of 16 whole-rock samples were measured at the Acme Analytical Laboratories, Vancouver, Canada. Major element compositions were analyzed by X-ray fluorescence (XRF; Rikagu RIX 2100) using fused glass disks (lithium metaborate/tetraborate fusion to digest the samples). Trace element compositions were analyzed by ICP-MS (Agilent 7500a with a shield torch) after acid digestion of samples in Teflon bombs. Analyses of US Geological Survey mafic standards (BCR-2, BHVO-1, and AGV-1) indicate precision and accuracy better than $5 \%$ for major elements and $10 \%$ for trace elements (Rudnick et al., 2004). ICP-emission spectrometry determined the contents of major oxides and minor elements, whereas trace and REE elements were acquired by ICP mass spectrometry.

\section{Results}

\subsection{Geology, sampling and petrography}

This section presents the petrographic aspects of studied samples to address issues related with the metamorphism and the magmatic aspects in the context of the Mineiro belt, supported by the published information (Fig. 1). Fig. 2 shows the macroscopic aspects of some of the selected outcrops. The orthogneisses may exhibit melt patches originating pegmatites such as shown in Fig. 2A. The strong sheared rocks are marked by E-W mylonitic foliation with elongated bodies of a variety of rock types (Fig. 2B). In some outcrops the mylonitic foliation is parallel to adjoining shear zones. 
Most of the outcrops present xenoliths of amphibolite and/or gneiss (Fig. 2C), whereas partial assimilation of felsic material may be also present (Fig. 2D).
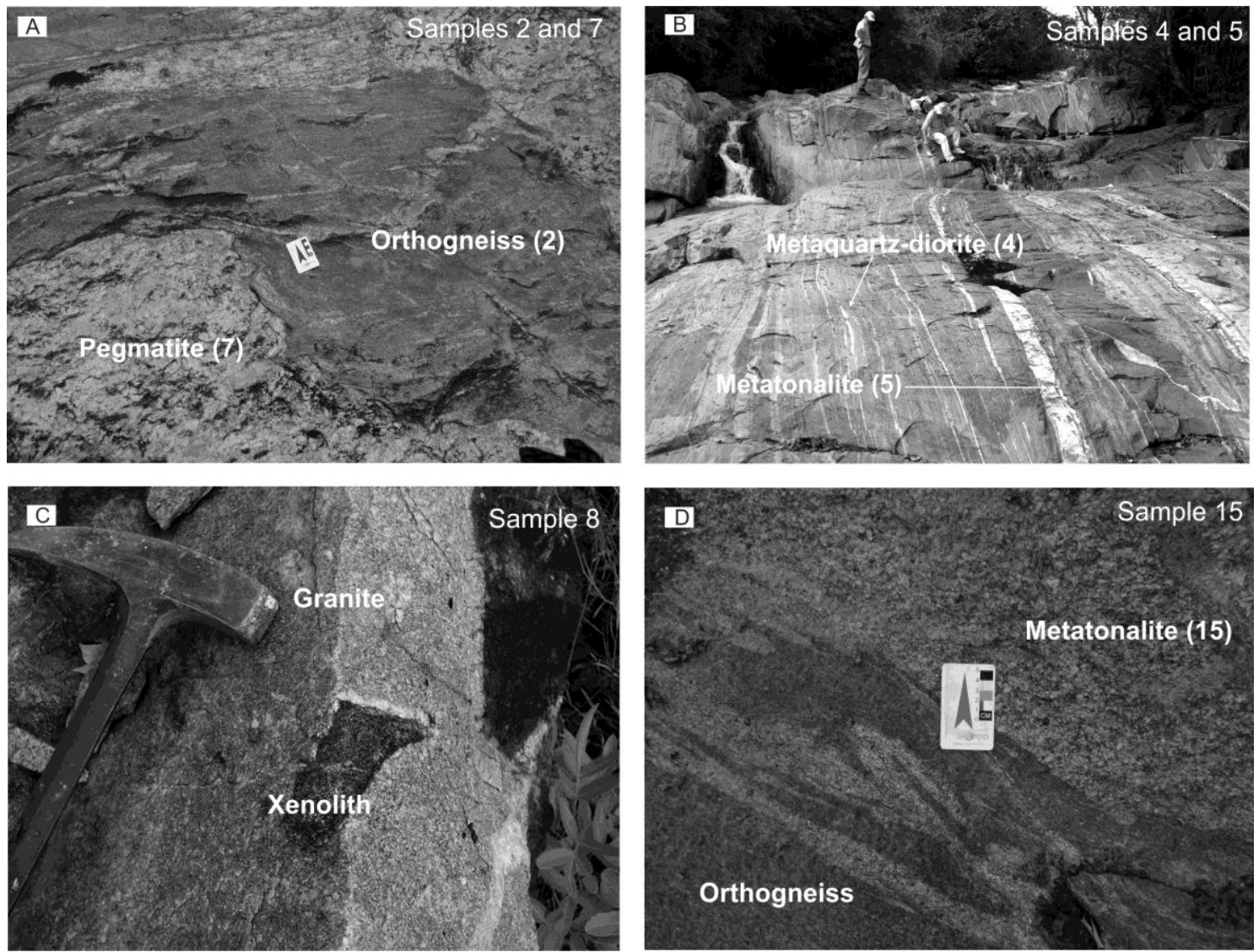

Fig. 2. Field aspects of some studied outcrops of the Mineiro belt. (A) Pegmatite injections into the Represa do Camargos orthogneiss. (B) NE-SW shear zone overprinting the Ribeirão do Amaral metaquartz-diorite and associated rocks. (C) Fine-grained facies of the Ritápolis granite with xenoliths (amphibolites). (D) Metatonalite injection into the Rio Grande orthogneiss, characterized by partial assimilation of the host rock. These rocks show the NE-trending regional deformation. See text for details. The numbers represent the studied samples.

Table 2 outlines the geologic and petrographic aspects of the studied samples, as follow: two diorites, one metaquartz-diorite and thirteen metagranitoid rocks (tonalites, granodiorites and granites). All data are organized in progressive numbers (samples 1 to 17) according to the $\mathrm{U}-\mathrm{Pb}$ ages, from the older to the younger rocks. Some of the plutonic rocks are intrusive into the Rio das Mortes supracrustal sequence. 
Table 2. Geologic-petrographic characteristics of the studied samples. Numbers in the first column indicate the order of the samples along the text, according to new $\mathrm{U}-\mathrm{Pb}$ crystallization ages from the older to the younger plutons.

\begin{tabular}{|c|c|c|c|c|c|c|c|c|c|c|}
\hline \multirow[t]{2}{*}{ Sample } & \multirow[t]{2}{*}{ Location } & \multirow[t]{2}{*}{ Pluton } & \multirow[t]{2}{*}{ Lithology } & \multirow[t]{2}{*}{ Field aspects/Texture } & \multicolumn{4}{|c|}{ Minerals (\%) } & \multirow[b]{2}{*}{$\mathrm{Mc}$} & \multirow[b]{2}{*}{$\begin{array}{l}\text { Accessory/secondary } \\
\text { mineral }\end{array}$} \\
\hline & & & & & $\mathrm{Qz}$ & $\mathrm{Pl}$ & $\mathrm{Bt}$ & $\mathrm{Hbl}$ & & \\
\hline S.1 & $0545508 / 7664711$ & $\begin{array}{l}\text { Morro do } \\
\text { Resende } \\
\end{array}$ & $\begin{array}{l}\text { Granodioritic } \\
\text { orthogneiss }\end{array}$ & $\begin{array}{l}\text { Medium- to fine-grained; granolepidoblastic texture; intrusive } \\
\text { into amphibolite (Rio das Mortes unit }\end{array}$ & 34 & 36 & 9 & & 20 & $\begin{array}{l}\text { Mgt, aln, zrn, ttn, chl, } \\
\text { opq, grt, ap, ep, zo }\end{array}$ \\
\hline S.2 & $0515829 / 7641996$ & $\begin{array}{l}\text { Represa } \\
\text { de } \\
\text { Camargos }\end{array}$ & $\begin{array}{l}\text { Granitic } \\
\text { orthogneiss }\end{array}$ & $\begin{array}{l}\text { Medium-grained; granolepidoblastic texture; xenolith of mafic } \\
\text { gneiss, amphibolitic rafts, pegmatite dykes }\end{array}$ & 34 & 30 & & 5 & 30 & $\begin{array}{l}\text { Zrn, bt, opq, grt, ap, } \\
\text { ep, zo }\end{array}$ \\
\hline S.3 & $0542911 / 7644796$ & $\begin{array}{l}\text { Represa } \\
\text { de } \\
\text { Camargos }\end{array}$ & Metatonalite & $\begin{array}{l}\text { Medium- to coarse-grained; slightly foliated/massive structure; } \\
\text { porphyritic texture mafic enclaves }\end{array}$ & 15 & 54 & 30 & & & $\begin{array}{l}\text { Ep, opq, ttn, ap, zrn, } \\
\text { aln, zo }\end{array}$ \\
\hline \multirow[t]{2}{*}{$\begin{array}{l}\text { S.4/ } \\
\text { S.5 }\end{array}$} & $0544754 / 7663247$ & $\begin{array}{l}\text { Ribeirão } \\
\text { do } \\
\text { Amaral }\end{array}$ & $\begin{array}{l}\text { Metaquartz- } \\
\text { diorite }\end{array}$ & $\begin{array}{l}\text { Medium- to fine-grained; granolepidoblastic texture; foliated } \\
\text { structure; strongly sheared (NE-SW), variety of rock parallel to } \\
\text { the shearing, local mylonites cross cut the main body }\end{array}$ & 15 & 49 & 25 & 10 & & Opq, Ep, Zrn, ttn, hbl \\
\hline & & & Metatonalite & $\begin{array}{l}\text { Fine-grained; massive/slightly foliated structure; granoblastic } \\
\text { texture }\end{array}$ & 50 & 44 & 5 & & & $\begin{array}{l}\text { Ep, zo, opq, ap, zrn, } \\
\text { aln, chl, ttn, hbl }\end{array}$ \\
\hline S.6 & $0538555 / 7655085$ & $\begin{array}{l}\text { Macuco } \\
\text { de Minas }\end{array}$ & Metatonalite & $\begin{array}{l}\text { Medium- grained; slightly foliated; granoblastic texture; xenolith } \\
\text { of amphibolites }\end{array}$ & 25 & 62 & 12 & & & $\begin{array}{l}\text { Ep, zo, ap, zrn, aln, } \\
\text { ttn, hem }\end{array}$ \\
\hline S.8 & $0570474 / 7671238$ & Ritápolis & Granite & $\begin{array}{l}\text { Fine-grained; massive/slightly foliated structure; equigranular/ } \\
\text { granolepidoblastic textures; xenoliths of amphibolites and } \\
\text { pegmatite dykes, }\end{array}$ & 35 & 25 & 6 & & 33 & $\begin{array}{l}\text { Ep, zo, ap, zrn, aln, } \\
\text { chl, ttn, ilm }\end{array}$ \\
\hline $\begin{array}{l}\text { S.9/ } \\
\text { S.17 }\end{array}$ & $0525899 / 7653108$ & $\begin{array}{l}\text { Rio } \\
\text { Grande }\end{array}$ & Diorite & $\begin{array}{l}\text { Medium to coarse-grained, slightly foliated; ophitic, porphyritic, } \\
\text { inequigranular and nematoblastic textures }\end{array}$ & 10 & 60 & 4 & 25 & & $\begin{array}{l}\text { Chl, opq, ep/zo, mc, } \\
\text { cal, ser, ttn, zrn }\end{array}$ \\
\hline S.10 & $0513080 / 7643634$ & $\begin{array}{l}\text { Represa } \\
\text { de } \\
\text { Camargos }\end{array}$ & $\begin{array}{l}\text { Granodioritic } \\
\text { orthogneiss }\end{array}$ & $\begin{array}{l}\text { Medium to coarse-grained; granolepidoblastic and } \\
\text { inequigranular textures; pegmatite dykes, granitic injections and } \\
\text { xenoliths of granitoid rocks }\end{array}$ & 40 & 24 & 10 & & 25 & Zrn, ap, aln, chl \\
\hline S.11 & $0526970 / 7652156$ & $\begin{array}{l}\text { Macuco } \\
\text { de Minas }\end{array}$ & Metagranodiorite & $\begin{array}{l}\text { Medium/coarse-grained; porphyritic and inequigranular textures; } \\
\text { xenoliths of granitoid rocks and pegmatite dykes }\end{array}$ & 40 & 47 & 12 & & & $\begin{array}{l}\text { Ep, opq, ttn, ap, zrn, } \\
\text { aln, zo }\end{array}$ \\
\hline S.12 & $0513294 / 7642127$ & Itumirim & Metatonalite & $\begin{array}{l}\text { Fine-grained; slightly foliated; equigranular texture; pegmatite } \\
\text { dykes }\end{array}$ & 45 & 35 & 12 & 7 & & $\begin{array}{l}\text { Ep, opaque, ttn, ap, } \\
\text { zrn, aln, zo, hbl }\end{array}$ \\
\hline S.13 & $0529035 / 7652896$ & $\begin{array}{l}\text { Macuco } \\
\text { de Minas }\end{array}$ & Metatonalite & $\begin{array}{l}\text { Medium-grained; foliated structure; equigranular and porphyritic } \\
\text { textures; xenolith of gneiss and amphibolite, pegmatite dykes } \\
\text { and granitic injections }\end{array}$ & 17 & 54 & 28 & & & $\begin{array}{l}\text { Ep, opq, ttn, ap, zrn, } \\
\text { aln, zo, amp }\end{array}$ \\
\hline S.14 & $0497565 / 7644617$ & $\begin{array}{l}\text { Serrinha } \\
\text { Granitoid }\end{array}$ & Metatonalite & $\begin{array}{l}\text { coarse-grained; slightly foliated; mega porphyritic texture; } \\
\text { xenolith of gneiss and amphibolitic rocks }\end{array}$ & 40 & 40 & 8 & 11 & & Ep, ap, zrn, ttn, opq, \\
\hline S.15 & $0527121 / 7655032$ & $\begin{array}{l}\text { Rio } \\
\text { Grande }\end{array}$ & Metatonalite & $\begin{array}{l}\text { Medium-grained; slightly foliated structure; granolepidoblastic } \\
\text { texture amphibolite and gneiss xenoliths }\end{array}$ & 30 & 55 & 14 & & & $\begin{array}{l}\text { Hbl, ep, opq, ttn ap, } \\
\text { zrn, aln, zo }\end{array}$ \\
\hline S.16 & $0549156 / 7650826$ & $\begin{array}{l}\text { Represa } \\
\text { de } \\
\text { camargos }\end{array}$ & Metatonalite & $\begin{array}{l}\text { Medium-grained; weakly foliated; granolepidoblastic texture; } \\
\text { amphibolitic rafts }\end{array}$ & 40 & 40 & 8 & 11 & & Zrn, mgt, ttn, opq, zo \\
\hline
\end{tabular}


According to the field relations they can be distinguished as mainly nondeformed (e.g., Ritápolis granitoid and Rio Grande diorite), slightly foliated (e.g., Serrinha and Represa de Camargos bodies) and orthogneisses rocks (e.g., Morro do Resende body) - thought the deformation is not dependent on a particular time interval as will be presented hereafter. Grain sizes in most felsic rocks vary from medium- to coarse-grained. They show distinct metamorphic textures (granolepidoblastic and granoblastic), but some preserve primary textures (ophitic and porphyritic), as summarized in Table 2. The metagranitoids have quartz, plagioclase and alkali-feldspar as main mineral phases, whereas biotite is the main primary Fe-silicate one (Table 2). Accessory and secondary minerals are: hornblende, opaque minerals, titanite, zircon, epidote, chlorite, apatite, allanite, zoisite, calcite and muscovite. The main constituents of the diorites are plagioclase, hornblende and biotite. Titanite, opaque minerals, chlorite, magnetite, zircon, epidote are secondary and accessory minerals. In the orthogneisses elongated biotite flakes define the anastomosed/lens-shaped structure, along with epidote, titanite, allanite and opaque minerals intercalated with quartz aggregates (Table 2).

The quartz aggregates occur as polygonal crystals, usually with subgrains and undulatory extinction. The aggregate crystals have sigmoid forms and sometimes are ribbons. The plagioclase, in most samples, underwent hydrothermal alteration/low grade metamorphism, where the Ca-component of plagioclase is altered to epidote, sericite and zoisite. Biotite may show alteration to chlorite. The K-feldspars (microcline) are relict grains. Titanite occurs either as igneous grains or as alteration of ilmenite and biotite. These grains crosscut the foliation - see Table 2 .

\subsection{Zircon $\mathrm{U}-\mathrm{Pb}$ geochronology}

Twelve rocks were performed by SHRIMP and 4 by LA-ICPMS techniques. The analytical data are presented in Tables 3.1 and 3.2 as supplementary material. Fig. 3 displays the CL images (as supplementary material). The organization of the data are presented in the text from the oldest to the youngest, but considering the nearby samples altogether in the attempt to characterize a magmatic history of more complex outcrops.

The Morro do Resende granodioritic orthogneiss (S.1) yielded the oldest age among the samples. The zircon crystals (50 to $290 \mu \mathrm{m}$ ) have euhedral to subhedral morphology and are transparent and colorless to brownish. Few well-developed prisms 
are also present, generally short in the CL images (see Fig. 3). Most zircons show oscillatory zoning with variable $\mathrm{U}$ contents according to their variable luminescence, whereas a few grains present outer recrystallized zones and/or fractures (Fig. 3). Sixteen SHRIMP analyses on both zircon cores and oscillatory outgrowths show a relatively tight range in Th (37-86 ppm) and U (94-199 ppm) concentrations with Th/U ratios between 0.39 and 0.56 (Table 3.1). Fifteen selected analyses yielded a Concordia age of $2174 \pm 4 \mathrm{Ma}(\mathrm{MSWD}=0.22 ;$ Fig. 4A), interpreted as the time of crystallization.

The Represa de Camargos granitic orthogneiss (S.2) is intruded by a pegmatite (S.7) - see Fig. 2A. The zircons from the S.2 sample are translucent to opaque, ranging in color from brown to dark brown. The grains are dominantly long prismatic and the range in size from 110 to $260 \mu \mathrm{m}$. CL images (see Fig. 3) show zircons with inherited nuclei. Resorpted and metamict grains are also present, as well as homogeneous dark ones, some of them with sector or weak oscillatory zoning. Ten SHRIMP analyses (cores and overgrowths) are near concordant to variably discordant (up to $73 \%$ discordance) but collinear. $\mathrm{Th} / \mathrm{U}$ ratios (Table 3.1) range from 0.07 (in the rim) to 0.64 (in the core). They regress to yield an upper intercept crystallization age of $2173 \pm 33$ Ma (MSWD = 2.1) with a lower intercept of $525 \pm 89$ Ma (Fig. 4B).

Zircon crystals of pegmatite (S.7) that is intrusive into the Represa de Camargos granitic orthogneiss (S.2) are light to medium brown, translucent to transparent and predominantly prismatic, with slightly rounded and subrounded terminations. Few grains are euhedral, with average length of $119 \mu \mathrm{m}(96-144 \mu \mathrm{m})$. In CL images the crystals are generally metamict (though not dated) and some show oscillatory concentric zoning (Fig. 3). Eight (Th/U ratios between 0.32-0.79) out of 12 spot analyses from the pegmatite are collinear but variably discordant in the Concordia diagram. They regress to yield an upper intercept crystallization age of $2158 \pm 27 \mathrm{Ma}(\mathrm{MSWD}=0.75)$ and a lower one of $659 \pm 100 \mathrm{Ma}$ (Fig. 4C). One single exception (core analysis) yields a ${ }^{207} \mathrm{~Pb} /{ }^{206} \mathrm{~Pb}$ concordant age of $2506 \pm 17 \mathrm{Ma}$, suggesting this grain could be a xenocryst.

The Represa de Camargos metagranite (S.3) was dated by LA-ICPMS, and field relations indicate that it is intrusive into S.2 sample (outcrop not shown) although both rocks yield identical crystallization ages within the errors. Most zircons are subhedral, light brown to brown in color, and translucent to opaque. They have prismatic habit and range in size from $90-181 \mu \mathrm{m}$ and some crystals have subrounded terminations. In CL images (see Fig. 3), the cores display oscillatory zoning; some are resorbed and some light zones yield low U contents. Three out of 12 spot analyses cluster the Concordia at 
$2172 \pm 32 \mathrm{Ma}(\mathrm{MSWD}=0.41)$, defining the crystallization age (Fig. 4D). The Th/U ratios of the concordant analyses range from 0.29-0.65 (Table 3.2). One inherited zircon (core) has $\mathrm{Th} / \mathrm{U}$ ratio of 0.52 , and yield a concordant ${ }^{207} \mathrm{~Pb} /{ }^{206} \mathrm{~Pb}$ age of $2462 \pm 14 \mathrm{Ma}$. This suggests that a crustal component participated in the magma genesis or this body have xenocrystals of significantly older material, as reported for nearby rocks dated at $2463 \pm 14 \mathrm{Ga}$ (Barbosa et al., 2013).

Two samples from the Ribeirão do Amaral outcrop (S.5 - metatonalite and S.4 metaquartz-diorite) were studied by SHRIMP. S.4 metaquartz-diorite shows a zircon population with subhedral to euhedral, elongated, brownish to yellow crystals, some with melt inclusions. The sizes range from $66 \mu \mathrm{m}$ and $500 \mu \mathrm{m}$. In CL images the zircon shows well-developed prisms with peculiar alteration, bright rims indicating their low $\mathrm{U}$ contents (Fig. 3). The cores show fractures along the high $U$ domains, and sometimes show oscillatory concentric zoning, and/or resorption and recrystallization. All analyses were performed in zircon cores, and the Th/ $\mathrm{U}$ ratios fall between $0.33-0.72$ (Table 3.1). Eleven analyses yield an upper intercept age of $2158 \pm 17 \mathrm{Ma}(\mathrm{MSWD}=1.30)$, whereas three spots define a Concordia age of $2172 \pm 13 \mathrm{Ma}(\mathrm{MSWD}=0.57)$. This is the preferred crystallization age of the S.4 metaquartz-diorite. The regression through these analyses similarly delineates a Neoproterozoic Pb-loss, indicated by the lower intercept age of $623 \pm 150 \mathrm{Ma}(\mathrm{MSWD}=1.3)($ Fig. 4E).

The zircons of the metatonalite are mostly euhedral to subhedral, light yellow to brown in color, and translucent. They occur predominantly as short prisms and range in size from 88 to $222 \mu \mathrm{m}$. Some crystals have rounded terminations. In CL images, they display oscillatory zoning with thin white rims that indicate low $U$ contents (Fig. 3). Fourteen zircon analyses cluster the Concordia at $2172 \pm 4$ Ma $(\mathrm{MSWD}=4.8$; not shown), some of them showing reverse discordance. A selection of seven data shows the high $\mathrm{Th} / \mathrm{U}$ ratios $(0.59-0.79)$ and regress to yield a Concordia age (Fig. 4F) of 2164 $\pm 5 \mathrm{Ma}(\mathrm{MSWD}=0.005)$.

The Nazareno metatonalite (S.6) was analyzed by SHRIMP. The zircon grains are subrounded, light brown to brown in color and translucent. Prismatic crystals predominate in the zircon population, and disclose subhedral forms. The zircon ranges in size from 38 to $192 \mu \mathrm{m}$. In CL images, they show oscillatory zoning, many of which consisting of large dark cores surrounded by light to pale gray, thin metamorphic overgrowths that could not be dated. Most zircons show recrystallization. Weak resorbed margins are also observed in few grains (Fig. 3). The zircons analyses were 
performed in core and internal portions that yield $\mathrm{Th} / \mathrm{U}$ ratios between 0.29 and 0.87 (Table 3.1). In the Concordia diagram most analyses show reverse concordance $(<11 \%)$, two are almost concordant and the other ones are discordant (from -10 to $21 \%$ ). However, all the data are collinear, and regress to yield an upper intercept age of $2142 \pm$ $15 \mathrm{Ma}(\mathrm{MSWD}=1.2)$. Six spots show a Concordia age of $2165 \pm 7 \mathrm{Ma}(\mathrm{MSWD}=4.2)$, which we interpret as the crystallization age for the metatonalite (Fig. 4G).

A granitic sample (S.8) from the Ritápolis batholith was analyzed by LA-ICPMS technique. The zircon grains are clear, yellow to light brown, with well-developed subhedral prisms $(77-200 \mu \mathrm{m})$. The CL images show most of grains with variable dark, concentric oscillatory zoning, and some have rounded light cores. Thin, darker overgrowths are also present. A few grains are homogeneous or have homogeneous portions, whereas other ones are recrystallized or resorbed (Fig. 3). Four analyses with variable $\mathrm{Th} / \mathrm{U}$ ratios between $0.15-0.71$ (Table 3.2) cluster the Concordia at $2149 \pm 10$ Ma (MSWD $=0.063)$. A chord, considering all the analyses with variable $\mathrm{Pb}$ loss, defines a lower intercept age of $662 \pm 65 \mathrm{Ma}$ (Fig. 4H). Likewise samples 4 and 5, this youngest age is interpreted as a metamorphic overprint, as suggested by the CL images of metamorphic overgrowths (e.g., grain S.8-16.1).

SHRIMP analyses of the Rio Grande diorite (S.9) were performed in core and rims that disclosed coherent results. The zircon grains are clear and transparent, ranging in color from brownish to colorless. Most grains are short-prismatic (140-270 $\mu \mathrm{m})$ with predominant round terminations and resorbed margins. CL images exposed oscillatory zoning, but the medium gray zones are predominant (Fig. 3). Fifteen analyses are concordant to slightly discordant (-5 to $-1 \%$ discordant; see Table 3.1; supplementary material), and the five most concordant ones define the crystallization age at $2145 \pm 7$ Ma (MSWD = 1.0; Fig. 4I). The selected grains show variable U contents (57-150 ppm) and $\mathrm{Th} / \mathrm{U}$ ratios between 0.55-1.06 (Table 3.1).

LA-ICPMS analyses were performed for the metagranodiorite (S.10) nearby Itumirim (i.e., Represa de Camargos batholith). It shows mostly euhedral to subhedral zircon grains that are light brown to brown in color, and transparent to translucent. They have prismatic habit with variable short to long prisms, and range in size from 83-208 $\mu \mathrm{m}$. Some crystals have rounded rims and subrounded terminations. In CL images, the cores display oscillatory zoning, some showing resorption and low U contents (Fig. 3). Five out of 21 spot analyses cluster the Concordia at $2131 \pm 5 \mathrm{Ma}(\mathrm{MSWD}=0.1)$. This is the crystallization age for this rock (Fig. 4J). The Th/U ratios of the concordant 
analyses range from $0.18-0.50$ (Table 3.2). Three inherited zircon cores (Th/U ratios between 1.28-0.39), yield concordant ${ }^{207} \mathrm{~Pb} /{ }^{206} \mathrm{~Pb}$ ages of $2698 \pm 6,2713 \pm 6$ and $2294 \pm$ $12 \mathrm{Ma}$. This implies to crustal contamination from distinct sources. Other sample (S.12) of the same batholith was analyzed by LA-ICPMS. Thirteen analyses were performed on a metagranodiorite from the Itumirim body. The zircons are subeudral, and generally thin prismatic with slightly rounded rims. The colors are brown and dark brown, but translucent to opaque crystals are also present. Their sizes range from 125 and $321 \mu \mathrm{m}$. In CL images a weak oscillatory zoning pattern is apparent; many zircons do not show metamorphic overgrowth or resorbed rims (see Fig. 3). They are variably discordant, and have $\mathrm{Th} / \mathrm{U}$ ratios between 0.08 (rim analysis) to $0.38-1.03$ (core analysis) (Table 3.2). The discordia line (12 spots) regress to yield an upper intercept age of $2130 \pm 50$ Ma $(M S W D=2.4)$, and a lower intercept at $519 \pm 240 \mathrm{Ma}$ (Fig. 4K). Three selected spot analyses show a Concordia age of $2124 \pm 13 \mathrm{Ma}(\mathrm{MSWD}=0.1)$.

SHRIMP analyses were carried out on the Macuco de Minas porphyritic metagranodiorite (S.11) and metatonalite (S.13) which is $5 \mathrm{~km}$ away from S.11 outcrop. In S.11 sample zircon grains are clear and translucent to transparent, ranging in color from pale brown to pale yellow. Most grains are prismatic (71-143 $\mu \mathrm{m})$ with predominant round and subrounded terminations. CL images show oscillatory zoning, but the medium gray zones predominate (Fig. 3). Spot analyses of core and rims yield $\mathrm{Th} / \mathrm{U}$ ratios between $0.27-1.92$ (see Table 3.1). Twenty analyses having variable $\mathrm{Pb}$ loss (up to $96 \%$ discordant) regress to yield an upper intercept (crystallization) age of $2125 \pm$ $21 \mathrm{Ma}(\mathrm{MSWD}=0.46)$ and a lower intercept age of $615 \pm 60 \mathrm{Ma}($ Fig. 4L). The zircon grains for the Macuco de Minas metatonalite (S.13) are clear, yellow to light brown, and form thin subhedral prisms $(113-177 \mu \mathrm{m})$. CL images show grains with oscillatory zoning, some with rounded terminations. A few grains are unzoned or have homogeneous portions (Fig. 3). Six zircon spots yield a Concordia age of $2114 \pm 6 \mathrm{Ma}$ $(\mathrm{MSWD}=3.1$; Fig. $4 \mathrm{M})$, which show $\mathrm{Th} / \mathrm{U}$ ratios from 0.06 (in the rim), 0.17 to 0.77 (in the core). The lower intercept of the Discordia using 13 analyses yield $513 \pm 80 \mathrm{Ma}$ (MSWD=1.4). A single exception (S.13-20.1) yields a $-6 \%$ discordant ${ }^{207} \mathrm{~Pb} /{ }^{206} \mathrm{~Pb}$ age of $2701 \pm 7$ Ma which suggests an Archean inheritance.

SHRIMP analyses were carried out in the Serrinha metatonalite (S.14). The zircons have euhedral to subhedral zircons, are transparent and colorless to light brown in color. Prismatic crystals predominate in the zircon population, and the size ranges from 121 to $182 \mu \mathrm{m}$. In CL images, they show concentric oscillatory zoning, many of 
which consisting of light cores surrounded by dark gray thin overgrowths (Fig. 3). Th/U ratios range between 0.18 and 0.68 (Table 3.1). Sixteen analyses of core and outgrowth spots yield a Concordia age at $2111 \pm 4 \mathrm{Ma}(\mathrm{MSWD}=1.8)$, which we interpret as the crystallization age (Fig. 4N).

The Rio Grande metatonalite (S.15) shows mostly euhedral to subhedral, light brown to brown, transparent to translucent zircon crystals. They have prismatic habit with variable short to long prisms, and range in size from 59 to $294 \mu \mathrm{m}$ (Table 3.1). Some crystals have rounded rims and subrounded terminations. In CL images, the cores display oscillatory zoning, resorbed features and low $U$ contents (Fig. 3). Nineteen zircons SHRIMP analyses of cores and rims, and the data are variably discordant. The upper intercept age is $2111 \pm 15 \mathrm{Ma}(\mathrm{MSWD}=1.0)$, where seven concordant analyses $(\mathrm{Th} / \mathrm{U}=0.30-1.0)$ yield $2109 \pm 5 \mathrm{Ma}(\mathrm{MSWD}=0.006$; Fig. 4O). This is considered the age of this rock. In addition, four inherited zircons (cores) yield significantly older concordant ${ }^{207} \mathrm{~Pb} /{ }^{206} \mathrm{~Pb}$ ages of $2785 \pm 6,2355 \pm 15,2329 \pm 16$ and $2316 \pm 25$ Ma with $(\mathrm{Th} / \mathrm{U}=0.38-0.52$; up to $-4 \%$ discordance). These data provide additional evidence for the distinct aged protholiths. Notably the lower intercept yields $512 \pm 57 \mathrm{Ma}$. This is compatible with other youngest ages (lower intercepts) for S.2, S.3, S.4, S.7, S.8, S.11, S.12, S.13 and S.15 (see below and Fig. 4). As a whole these results, though largely imprecise (670 to $510 \mathrm{Ma}$ ), suggest a late, low grade thermal overprint in the area, which may be time related with recognized escape tectonics to the south (e.g., Campos Neto et al., 2011).

Finally a metatonalite (S.16) nearby Itutinga (Represa de Camargos pluton) has predominantly subhedral zircon grains $(110-380 \mu \mathrm{m})$, generally thin prismatic with slightly rounded rims. Their colors are brown and dark brown, but translucent to opaque crystals are also present. In CL images the grains show weak oscillatory zoning patterns, and many of them have thin metamorphic overgrowth or resorbed rims (Fig. 3). Seventeen SHRIMP analyses were performed on the oscillatory zones including the inner ones. The selected spots $(\mathrm{Th} / \mathrm{U}$ ratios between $0.36-1.07)$ are variably discordant (Table 3.1), and regress to yield an upper intercept of $2086 \pm 12 \mathrm{Ma}(\mathrm{MSWD}=2.2$; Fig. 4P). This is interpreted as the crystallization age. 

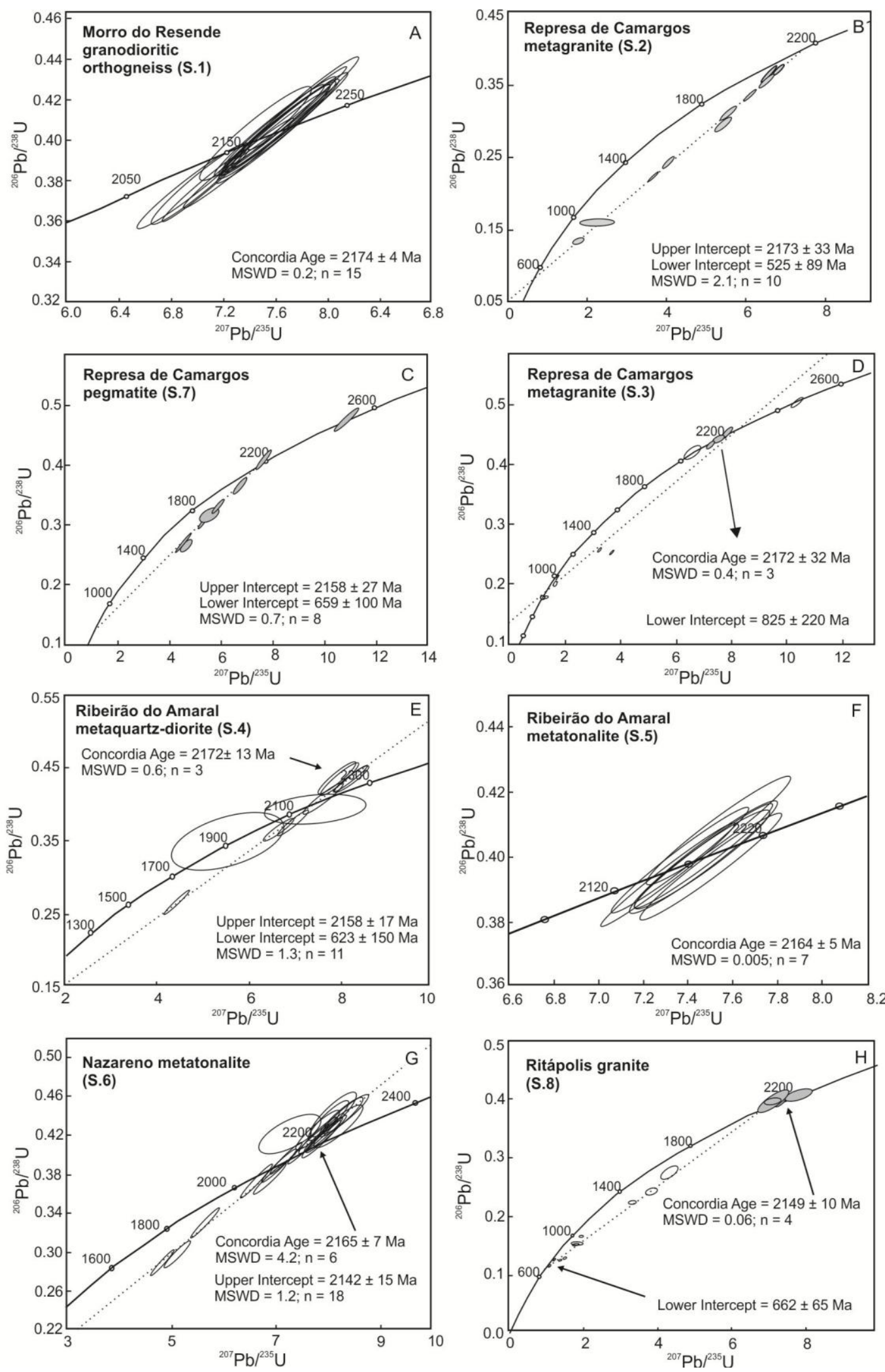

Fig. 4. U-Pb zircon Concordia diagrams for diorites, orthogneisses, granitoid and metagranitoid rocks. 

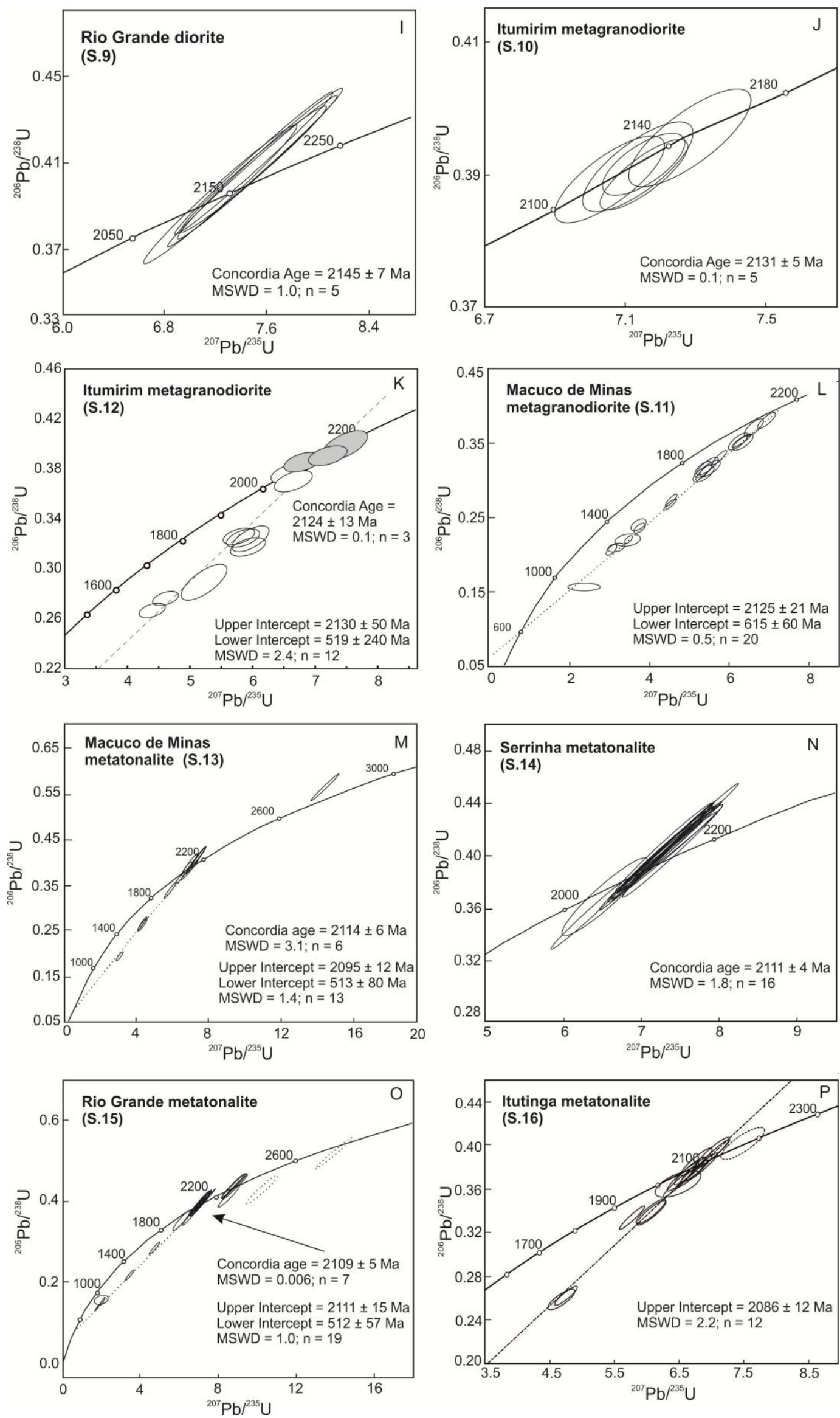

Fig. 4. U-Pb diagrams (continued). 


\subsection{Whole rock $\mathrm{Nd}-\mathrm{Sr}$ isotope signature}

The $\mathrm{Nd}$ and $\mathrm{Sr}$ isotopic data were performed in granitoid and metagranitoid rocks, orthogneisses and diorites (Table 4). The combined constraints are consistent with derivation from hybrid sources among primary melts and continental crust, as discussed below. The $\varepsilon_{\mathrm{Nd} 0}$ versus ages diagram (Fig. 5A) provides preliminary inferences regarding the petrogenetic process for our samples, compared to the isotopic trends of the Resende Costa rocks (2.35 Ga) and the Archean continental crust of the SFC (Teixeira et al., 2015 and references therein). The samples have variable $\mathrm{T}_{\mathrm{DM}}$ ages between 3.2 and $2.3 \mathrm{Ga}$ (Table 4), indicating the important role of crustal contribution in the magma genesis. The exceptions are: S.18 (diorite) that yields an anomalous youngest $\mathrm{T}_{\mathrm{DM}}$ age $(1.7 \mathrm{Ga})$ that does not allow calculation of the $\varepsilon_{\mathrm{Nd}(\mathrm{t})}$ value for $\mathrm{T}=2.1$ $\mathrm{Ga}$; and S.16 (Itutinga metatonalite) that gives an anomalous ${ }^{147} \mathrm{Sm} /{ }^{144} \mathrm{Nd}$ ratio $(0.1783)$. Hence these data will be not considered herein. 
Table 4. Rb-Sr and Sm-Nd isotopic data of diorites, orthogneisses, granitoid and metagranitoid rocks. Note: --* (assumed values as 0.700)

\begin{tabular}{|c|c|c|c|c|c|c|c|c|c|c|c|c|c|c|}
\hline Sample & Pluton & $\mathrm{Rb}$ & $\mathrm{Sr}$ & ${ }^{7} \mathrm{Rb}$ & ${ }_{0}^{37} \mathrm{Sr}$ & ${ }^{87} \mathrm{Sr}$ & $\mathrm{Sm}$ & $\mathrm{Nd}$ & ${ }^{477} \mathrm{Sm}$ & ${ }^{144} \mathrm{Nd}$ & ${ }^{144} \mathrm{Nd}$ & $\varepsilon_{\mathrm{Nd}(\mathrm{t})}$ & $\varepsilon_{\mathrm{Nd}(0)}$ & $\mathrm{T}_{\mathrm{DM}}$ \\
\hline S.2 & Represa de Camargos & 226.0 & 68.3 & 9.7036 & 0.975 & $--* * *$ & 5.77 & 25.40 & 0.1381 & 0.51146 & 0.5095 & -7.3 & -23 & 3.23 \\
\hline S.4 & Ribeirão do Amaral & 60.8 & 202.9 & 0.8788 & 0.725 & $--* * *$ & 5.41 & 23.20 & 0.1418 & 0.51187 & 0.5099 & -0.1 & -15 & 2.47 \\
\hline S.3 & Represa de Camargos & 304.7 & 57.8 & 15.454 & 1.1249 & $--* * *$ & 5.944 & 25.82 & 0.1399 & 0.51163 & 0.5097 & -4.3 & -32 & 2.96 \\
\hline S.8 & Ritápolis & 209.0 & 368 & 1.6655 & 0.752 & 0.7014 & 3.22 & 20.10 & 0.0974 & 0.51110 & 0.5098 & -3.2 & -30 & 2.55 \\
\hline S.9 & Rio Grande & 26.6 & 801.3 & 0.0973 & 0.706 & 0.7032 & 3.98 & 21.90 & 0.1105 & 0.51138 & 0.5098 & -1.4 & 25 & 2.46 \\
\hline S.17 & Rio Grande & 40.9 & 586.9 & 0.2044 & 0.709 & 0.7023 & 5.13 & 29.50 & 0.1057 & 0.51139 & 0.5099 & +0.3 & -24 & 2.32 \\
\hline S.10 & Represa de Camargos & 110.0 & 346 & 0.9323 & 0.730 & 0.7018 & 2.30 & 16.40 & 0.0853 & 0.51094 & 0.5098 & -3.1 & -33 & 2.50 \\
\hline S.11 & Macuco de Minas & 103.9 & 448 & 0.6801 & 0.722 & 0.7017 & 5.81 & 33.80 & 0.1045 & 0.51102 & 0.5096 & -6.7 & -31 & 2.84 \\
\hline S.12 & Itumirim & 255.0 & 377 & 1.9836 & 0.752 & $--* * *$ & 4.26 & 22.50 & 0.1151 & 0.51130 & 0.5097 & -4.1 & -26 & 2.70 \\
\hline S.13 & Macuco de Minas & 68.2 & 526.5 & 0.3799 & 0.716 & 0.70431 & 8.25 & 44.30 & 0.1132 & 0.51131 & 0.5097 & -3.4 & -26 & 2.63 \\
\hline S.14 & Serrinha & 99.8 & 566.2 & 0.5169 & 0.719 & 0.7036 & 5.19 & 41.40 & 0.0762 & 0.51097 & 0.5099 & -0.1 & -33 & 2.30 \\
\hline S.16* & Represa de Camargos & 172.0 & 88.6 & 5.6930 & 0.887 & 0.7147 & 2.89 & 9.80 & 0.1793 & 0.51160 & 0.5091 & -15.7 & - & - \\
\hline S. $18 *$ & Nazareno & 1.4 & 109.7 & 0.0374 & 0.702 & 0.7014 & 1.32 & 5.80 & 0.1384 & 0.51215 & 0.5102 & +6.4 & - & 1.78 \\
\hline S.19 & Brumado & 149.0 & 376 & 1.1621 & 0.738 & 0.7026 & 4.26 & 22.80 & 0.1136 & 0.51136 & 0.5098 & -2.4 & -25 & 2.56 \\
\hline S.21 & Ritápolis & 284.5 & 44.3 & 19.664 & 1.298 & 0.7032 & 5.24 & 24.50 & 0.1293 & 0.5114 & 0.5096 & -4.6 & -23 & 2.85 \\
\hline $\mathrm{AD}-22 * *$ & Itumirim & 112 & 164 & 2.0027 & 0.761 & $--* * *$ & 1.33 & 6.38 & 0.1257 & 0.51161 & 0.5099 & -0.9 & - & 2.50 \\
\hline $\mathrm{AD}-82 * *$ & Macuco de Minas & 154 & 293 & 1.5413 & 0.739 & $--* * *$ & 6.24 & 36.83 & 0.1025 & 0.51086 & 0.5094 & -9.3 & - & 3.03 \\
\hline ITM $1 * *$ & Itumirim & 148 & 312 & 1.3911 & 0.745 & 0.7030 & 3.07 & 20.59 & 0.0902 & 0.51093 & 0.5097 & -4.6 & - & 2.62 \\
\hline ITM $2 * *$ & Itumirim & 129 & 428 & 0.8839 & 0.729 & 0.7019 & 2.81 & 18.14 & 0.0938 & 0.51106 & 0.5098 & -3.0 & - & 2.54 \\
\hline $\operatorname{ITM} 3 * *$ & Itumirim & 133 & 400 & 0.9751 & 0.732 & 0.7024 & 5.62 & 39.01 & 0.0870 & 0.51103 & 0.5098 & -1.8 & - & 2.43 \\
\hline $\mathrm{AD}-79 * *$ & Itumirim & 263 & 127 & 6.0729 & 0.874 & --* & 4.05 & 23.30 & 0.1050 & 0.51102 & 0.5096 & -6.9 & - & 2.87 \\
\hline $\mathrm{AD}-83^{* *}$ & Itumirim & 119 & 424 & 0.8231 & 0.727 & 0.7018 & 3.47 & 22.97 & 0.0913 & 0.51086 & 0.5096 & -6.3 & - & 2.74 \\
\hline
\end{tabular}



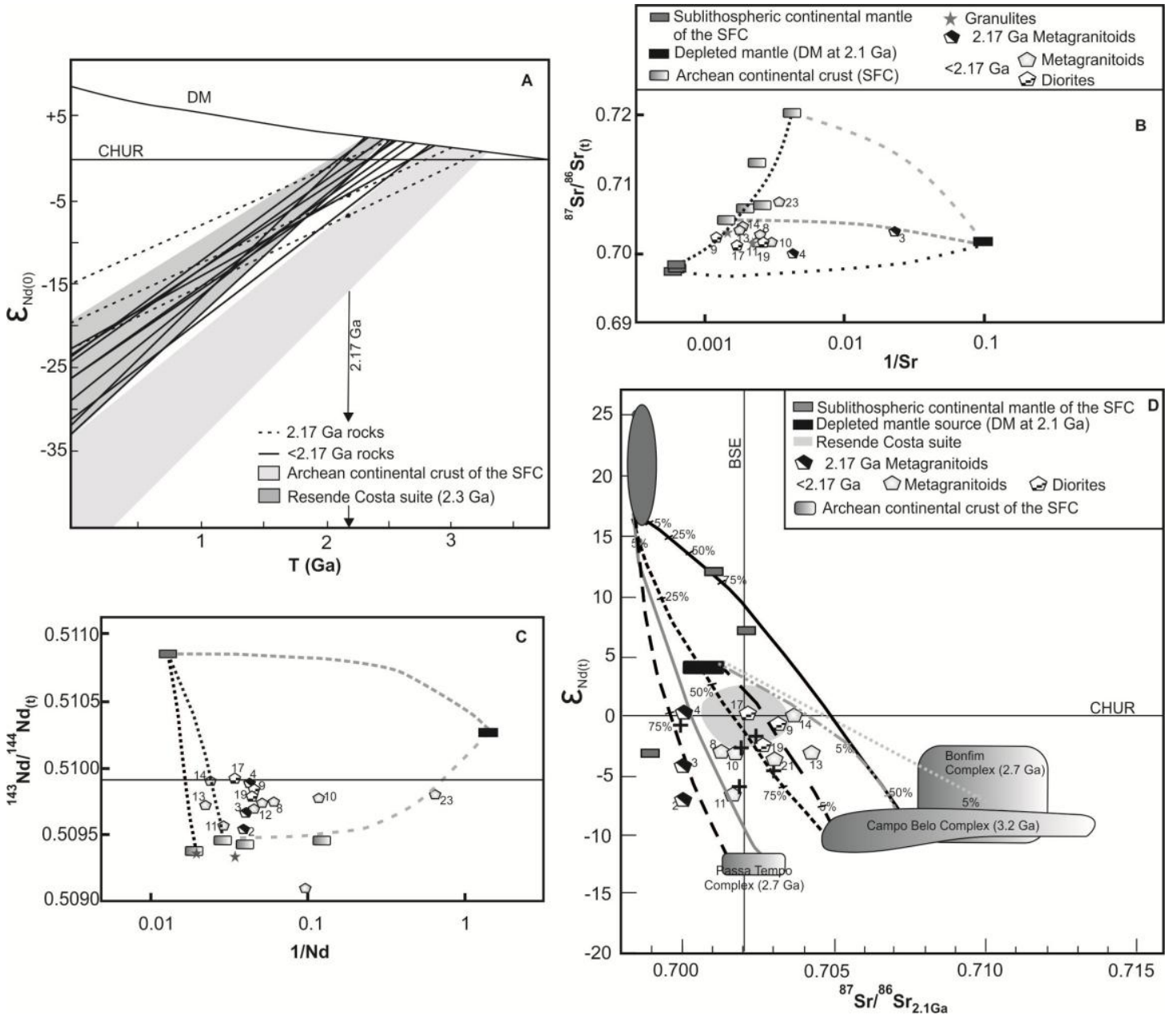

Fig. 5. (A) $\varepsilon_{\mathrm{Nd}(0)}$ vs. Time (Ga) diagram for studied granitoids, metagranitoids, orthogneisses and diorites; (B) ${ }^{87} \mathrm{Sr}^{86} \mathrm{Sr}_{(\mathrm{t})}$ vs. $1 / \mathrm{Sr}$; (C) ${ }^{144} \mathrm{Nd} /{ }^{143} \mathrm{Nd}_{(\mathrm{t})}$ vs. $1 / \mathrm{Nd}$ (Legend as in Fig. 5B); (D) $\varepsilon_{\mathrm{Nd}(\mathrm{t})}$ vs. ${ }^{87} \mathrm{Sr}^{86} \mathrm{Sr}_{(\mathrm{t})}$ diagram; Mixing lines are those calculated by Albarède (1995). Curves: $q=$ $\left(\mathrm{C}_{1} / \mathrm{C}_{2}\right)_{\beta} /\left(\mathrm{C}_{1} / \mathrm{C}_{2}\right)_{\alpha}$ (where $\beta$ and $\alpha$ are the end members, according to the legend; $\mathrm{C}_{1}$ and $\mathrm{C}_{2}=$ concentrations in mixture of isotope $\left({ }^{87} \mathrm{Sr}^{86} \mathrm{Sr}_{(\mathrm{t})}\right.$ and ${ }^{143} \mathrm{Nd} /{ }^{144} \mathrm{Nd}_{(\mathrm{t})} /$ elements $\left.(\mathrm{Sr}, \mathrm{Nd})\right)$. The numbers represent the studied samples. Crosses: selected data from Cherman (2004).

The crustal assimilation envisaged from the $\mathrm{Nd}-\mathrm{Sr}$ constraints is consistent with Archean ages obtained for few inherited zircons such as S.3, 10, 13 and S.15 samples (see section 4.2). In a similar manner the oldest $2.17 \mathrm{Ga}$ rocks (S.2, $\mathrm{T}_{\mathrm{DM}}=3.2 \mathrm{Ga}$; S.3, $\left.\mathrm{T}_{\mathrm{DM}}=3.0 \mathrm{Ga}\right)$ yield the most negative $\varepsilon_{\mathrm{Nd}(\mathrm{t})}$ values $(-7.3$ and -4.3$)$ in Fig. 5A that ratify contamination from Archean crust. Participation of Archean protholiths is also apparent for samples with $\mathrm{T}_{\mathrm{DM}}$ ages older than $2.4 \mathrm{Ga}$ (e.g., S11, 12, 13). In contrast the isotopic characteristics of $2.17 \mathrm{Ga} \mathrm{S.4}\left(\varepsilon_{\mathrm{Nd}(\mathrm{t})}=-0.1\right)$ and its distinct trend $\left(\varepsilon_{\mathrm{Nd}(0)}=-15\right)$ is compatible with a mafic composition (i.e., diorite) and/or slightly crustal contamination from Paleoproterozoic material such as from Resende Costa-like material. For instance 
the samples younger than $2.17 \mathrm{Ga}$ indicate a crustal signature akin to contamination from the Resende Costa crust (e.g., S.14, 17).

In the attempt to detail the nature of the crustal contaminants and juvenile sources we plotted our data in diagrams that correlate the ${ }^{87} \mathrm{Sr}^{86} \mathrm{Sr}_{(\mathrm{t})}$ ratios versus $1 / \mathrm{Sr}$ and ${ }^{143} \mathrm{Nd} /{ }^{144} \mathrm{Nd}_{(\mathrm{t})}$ ratios with $1 / \mathrm{Nd}$ respectively, assuming $\mathrm{T}=2.1 \mathrm{Ga}$. The isotopic mixing can be envisaged in Figs. 5B and C, where we consider various sources for the studied samples, as follow: (i) SLCM-Sublithospheric continental mantle (Peridotites of the SFC; Bizzi et al., 1994; Gibson et al., 1995; Goulart and Carneiro, 2013; (ii) Archean continental crust of the SFC (Bonfim and Campo Belo complexes; Teixeira et al., 1996; 1998); (iii) the Passa Tempo granulites - assumed here as the Archean lower crust of the SFC (data from Pinese, 1997) and (iv) DM - Depleted mantle (after Dickin, 2005). Both diagrams show that at least three end-members probably participated in the formation of those rocks because the data do not fall along the calculated mixing lines (dashed lines) between two given components, but instead they are scattered between these lines. This confirms the important role of multiple end-members in the magma genesis. In other words, this implies that partial melting was influenced by more than two end-members, including element concentrations. In the Fig. 5B the lowest ${ }^{87} \mathrm{Sr} /{ }^{86} \mathrm{Sr}_{(\mathrm{t})}$ values (< ca. 0.702) are consistent with derivation from DM component, whereas the other data suggest a larger contribution from continental crust. Fig. 5C displays the calculated end-members for the $\mathrm{Sm} / \mathrm{Nd}$ systematic where most samples are scattered close to the continental crust end-member. However our data also show variable $1 / \mathrm{Nd}$ values between $\mathrm{DM}$ and Archean continental crust of the SFC, implying that these end-components were involved in the generation of the rocks.

The $\varepsilon_{\mathrm{Nd}(\mathrm{t})}$ versus ${ }^{87} \mathrm{Sr} /{ }^{86} \mathrm{Sr}_{(\mathrm{t})}$ diagram (Fig. 5D) provides a more detailed view about the petrogenetic process, as shown by calculation of different percentage of contribution between four potential end-members including the Passa Tempo granulitic complex. This diagram illustrates the different percentage of assimilation and how each end-member could contribute to the formation of the studied rocks. All signatures were calculated for $2.1 \mathrm{Ga}$ including the values for DM, SLCM, Archean continental crust (SFC basement complexes and the Passa Tempo granulites). In this sense Vollmer (1976) reported the role of crustal contamination in magmatic rocks, via mixing between distinct compositional reservoirs (end-members), using the $\mathrm{Nd}-\mathrm{Sr}$ initial variations. Indeed it has been realized that plutonic rocks in continental settings show enriched chemical and isotopic signatures that could be the result from various 
processes underwent during crystallization (e.g., assimilation, crustal contamination, magma mixing). In other words, the degree of contamination during magma genesis would be related to a variable interaction of the reservoirs mentioned above (Vollmer, 1976; DePaolo, 1981; Albarède, 1995). In mixing diagrams, like Fig. 5D, the resulting hyperbolas are dependent on the $\mathrm{Nd} / \mathrm{Sr}$ concentrations for a given sample.

In Fig. 5D, our data plot in II, III and IV quadrangles, envisaging the complexity of the mixing processes involved in the origin of the studied rocks. The $\varepsilon_{\mathrm{Nd}(2.1 \mathrm{Ga})}$ values range from (-7.3 to +0.3$)$ and ${ }^{87} \mathrm{Sr}^{86} \mathrm{Sr}_{(\mathrm{t})}(0.700$ to 0.704$)$. In a similar manner published data from Cherman (2004; plutonic rocks in Itutinga and Nazareno regions) show $\varepsilon_{\mathrm{Nd} 2.1 \mathrm{Ga}}$ values from -6.3 to -0.9 and ${ }^{87} \mathrm{Sr}^{86}{ }^{8} \mathrm{Sr}_{(\mathrm{t})}(0.700$ to 0.703$)$. Most samples (S.9, 17, $19,14,21,13)$ show $\varepsilon_{\mathrm{Nd}(\mathrm{t})}$ from +0.3 to -4.5 and ${ }^{87} \mathrm{Sr}^{86} \mathrm{Sr}_{(\mathrm{t})}$ from 0.701 to 0.704 in coherence with a derivation from DM and minor contribution from Archean continental crust of SFC. In this case the crustal contamination does not exceed $10 \%$ according to the calculated mixing curves.

Other samples (S.2, 4, 3 - Represa de Camargos and Ribeirão do Amaral plutons; see Table 4) show slightly positive to negative $\varepsilon_{\mathrm{Nd}(\mathrm{t})}$ values coupled with similar low radiogenic Sr signatures $\left({ }^{87} \mathrm{Sr} /{ }^{86} \mathrm{Sr}_{(\mathrm{t})}=\right.$ ca. $0.700 ; \varepsilon_{\mathrm{Nd}(\mathrm{t})}=-0.1$ to -7.3 ; Fig. 5B). This could be explained by mixing of Archean lower crust (e.g., Passa Tempo granulites) with a SCLM (SFC peridotites) component, which would be capable to generate magmas of low ${ }^{87} \mathrm{Sr} /{ }^{86} \mathrm{Sr}$ such as envisaged for these particular samples. Particularly, S.3 and S.2 samples could be originated from dioritic magmas (like S.4 quartz-diorite), considering their ages and errors, as well as that they follow the same hyperbole in Fig. 5D. Three samples (S.8, 10, 11 Ritápolis, Itumirim and Macuco de Minas plutons) show intermediate isotopic composition between the $2.17 \mathrm{Ga}$ age-group and the remained younger one. This implies those distinct sources were involved in the crystallization of these rocks.

\subsection{Correlations between Zircon $\mathrm{Hf}$ and whole-rock $\mathrm{Nd}$ isotopes}

We determined the Hf zircon isotope compositions for selected samples (2.17$2.11 \mathrm{Ga}$; Table 5.1) that are plotted in Figs. $6 \mathrm{~A}, \mathrm{~B}$ and C. Figs. 6A and 6B show the $\varepsilon_{\mathrm{Hf}(\mathrm{t})}$ mean values against the U-Pb crystallization age for each sample, whereas Fig. 6C presents the individual $\varepsilon_{\mathrm{Hf}(\mathrm{t})}$ values versus time. Tables 5.1 and 5.2 present the mean ratios for each sample and the individual values for the spots, respectively. 
Table 5.1. Mean in situ Lu-Hf analyses of magmatic zircon from diorites, orthogneisses granitoid and metagranitoid rocks.

\begin{tabular}{ccccccccc}
\hline Spot & $\mathrm{U}-\mathrm{Pb}$ age & ${ }^{176} \mathrm{Lu} /{ }^{177} \mathrm{Hf}$ & ${ }^{176} \mathrm{HF} /{ }^{177} \mathrm{Hf}$ & ${ }^{176} \mathrm{HF}^{177} \mathrm{Hf}_{(\mathrm{t})}$ & $\varepsilon_{\mathrm{HfO}}$ & $\varepsilon_{\mathrm{Hf}(\mathrm{t})}$ & $\Delta_{\varepsilon \mathrm{eff}}$ & $\mathrm{T}_{\mathrm{DM}}$ age $(\mathrm{Ga})$ \\
S.1 & $2174 \pm 4 \mathrm{Ma}$ & 0.0023 & 0.281551 & 0.281457 & -43.2 & +2.1 & +3.2 & 2.57 \\
S.2 & $2173 \pm 33 \mathrm{Ma}$ & 0.0018 & 0.281531 & 0.2811455 & -43.9 & +0.5 & +8.4 & 2.62 \\
S.3 & $2169 \pm 18 \mathrm{Ma}$ & 0.0020 & 0.281441 & 0.281386 & -47.1 & +0.55 & +2.7 & 3.07 \\
S.5 & $2164 \pm 5 \mathrm{Ma}$ & 0.0022 & 0.281502 & 0.281413 & -44.93 & 0.4 & +1.5 & 2.67 \\
S.6 & $2165 \pm 7 \mathrm{Ma}$ & 0.0025 & 0.281539 & 0.281437 & -43.6 & +0.9 & +2.7 & 2.63 \\
S.8 & $2149 \pm 10 \mathrm{Ma}$ & 0.0011 & 0.281421 & 0.281394 & -47.8 & -0.05 & +2.6 & 3.19 \\
S.9 & $2145 \pm 6 \mathrm{Ma}$ & 0.0004 & 0.281510 & 0.281492 & -44.6 & +2.5 & +2.7 & 2.51 \\
S.10 & $2131 \pm 5 \mathrm{Ma}$ & 0.0008 & 0.281385 & 0.281354 & -49.0 & -3.0 & -0.3 & 2.84 \\
S.11 & $2125 \pm 21 \mathrm{Ma}$ & 0.0011 & 0.281351 & 0.281308 & -50.3 & -5.6 & +1.9 & 2.98 \\
S.12 & $2124 \pm 13 \mathrm{Ma}$ & 0.0017 & 0.281324 & 0.281256 & -51.2 & -5.8 & -1.8 & 3.05 \\
S.13 & $2114 \pm 6 \mathrm{Ma}$ & 0.0006 & 0.281304 & 0.281279 & -51.9 & -6.6 & -3.6 & 3.04 \\
S.14 & $2111 \pm 4 \mathrm{Ma}$ & 0.0006 & 0.281398 & 0.281377 & -48.6 & -2.1 & -3.7 & 2.79 \\
S.15 & $2109 \pm 5 \mathrm{Ma}$ & 0.0007 & 0.281426 & 0.281400 & -47.6 & -1.9 & +1.5 & 2.76 \\
\hline
\end{tabular}

The average of ${ }^{176} \mathrm{Lu} /{ }^{177} \mathrm{Hf}$ ratios ranges from 0.0004-0.0023, suggesting a strong partitioning between the $\mathrm{Lu}$ and $\mathrm{Hf}$ isotopes $(<0.08)$ which is usually acquired during partial melt (e.g., Beard and Johnson, 1997). The observed large variation combined with the low isotopic ratios $(<0.0023)$ suggests that multi-crustal components participated in the magma generation (e.g., Chappel, 1984). This inference is consistent with the Nd-Sr characteristics of our samples (Fig. 5D). According to Vervoort and Blichert-Toft (1999) the behavior of Lu-Hf and Sm-Nd systems is similar in magmatic processes, and results in a positive correlation of $\mathrm{Hf}$ and $\mathrm{Nd}$ isotopic compositions in mantle-derived rocks, as indicated in Fig. 6A. The studied samples yield a large range in composition ${ }^{147} \mathrm{Sm} /{ }^{144} \mathrm{Nd}$ (0.0076-0.1417; Table 4), in agreement with variably contribution of pre-existent material during magma genesis. In other words the large spread in the ${ }^{147} \mathrm{Sm} /{ }^{144} \mathrm{Nd}$ and ${ }^{176} \mathrm{Lu} /{ }^{177} \mathrm{Hf}$ ratios is consistent again with the idea of a heterogeneous mantle sources (see previous section) that were subjected to crustal assimilation and/or partial melt of continental crust. The analyses exhibit variable Hf $\mathrm{T}_{\mathrm{DM}}$ average ages (3.1 to $2.5 \mathrm{Ga}$; Table 5.1), in agreement with this hypothesis. For instance the zircon $\mathrm{Hf} \mathrm{T}_{\mathrm{DM}}$ model ages are broadly comparable with the Sm-Nd whole rock $\mathrm{T}_{\mathrm{DM}}$ ages (see Table 4), and then demonstrate the important bearing of some kind of assimilation from distinct crustal sources. 

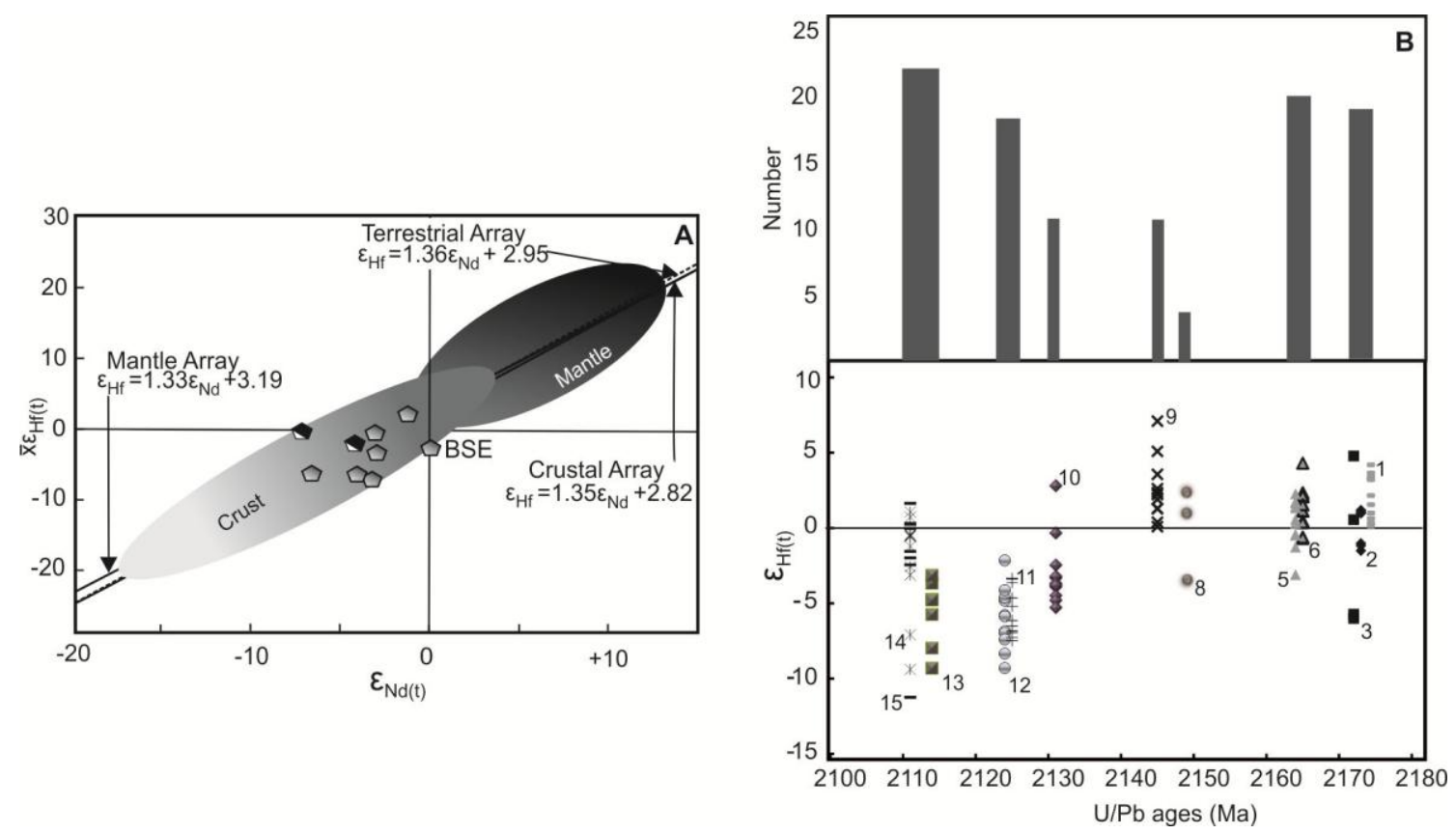

Fig. 6. (A) $\varepsilon_{\mathrm{Nd}(\mathrm{t})}$ vs. $\bar{x} \varepsilon_{\mathrm{Hf}(\mathrm{t})}$ diagram for the studied samples. Terrestrial, mantle and crust array were calculated after Vervoort et al. (1999); (B) $\varepsilon_{\mathrm{Hf}(\mathrm{t})}$ evolution vs. Time diagram and respective age histogram (upper part of the figure) based on concordant/slight concordant ${ }^{207} \mathrm{~Pb} /{ }^{206} \mathrm{~Pb}$ ages (for the given spot analyses). The numbers represent the studied samples.

Fig. 6A correlates the mantle and crust isotopic fields based on whole rock $\varepsilon_{\mathrm{Nd}(\mathrm{t})}$ values versus zircon $\varepsilon_{\mathrm{Hf}(\mathrm{t})}$ mean values, referred to the mantle and crustal arrays (adapted from Vervoort et al. 1999). According to these authors, the crustal array represents felsic granitoids, volcanic and mafic rocks of distinct ages (Precambrian to Phanerozoic), whereas the mantle array includes data from modern oceanic basalts (OIB and MORB). This is delineated by their compiled data that fall in the medium- and dark gray fields, respectively. On the other hand, the terrestrial array assumes an efficient mantle/crust mixing, and therefore would represent the isotopic composition of the Earth materials. The calculated $\varepsilon_{\mathrm{Hf}(\mathrm{t})}$ values for 9 samples range from +2.5 to -6.6 (Table 5.1), whereas the respective $\varepsilon_{\mathrm{Nd}(\mathrm{t})}$ values vary from -7.3 a -0.1 . Consequently these data fall mostly in the crustal field. In particular the data scatter of the 2.15-2.11 Ga metagranitoids (gray polygons) might be related to more differentiate magmatic processes plus contamination, as also suggested by the model of Vervoort et al. (1999). In any case the bulk feature of our samples suggests a broad juvenile episode that was subjected to some kind of crustal contribution. Alternatively one can use the $\Delta \varepsilon_{\mathrm{Hf}}\left(\varepsilon_{\mathrm{Hf}(\mathrm{t})}\right.$ $1.36 \times \varepsilon_{\mathrm{Nd}(\mathrm{t})}+1.63$; after Beard and Johnson, 1997) parameter for evaluating the petrogenesis of a given rock. This parameter uses the vertical deviations of the initial Hf isotopic compositions compared to the respective value of the terrestrial array in order 
to infer the nature of a given sample based on the differences in the $\mathrm{Nd}-\mathrm{Hf}$ isotope variation. The $2.17-2.16 \mathrm{Ga}$ samples yield $\Delta \varepsilon_{\mathrm{Hf}}$ values from +8.4 to +2.7 , whereas the younger rocks range from +2.7 to -3.7 (Table 5.1). In this sense felsic crust has usually negative $\Delta \varepsilon_{\mathrm{Hf}}$ values (Johnson et al., 1996), and then this requires a contribution from a component that has experienced long-term decoupling of Lu in relation to Hf (Vervoort et al., 1999, Nowell et al., 2004). Notably the data show slightly negative $\Delta \varepsilon_{\mathrm{Hf}}$ values and mostly positive ones. This suggests that our samples were subjected to minor contribution of continental source, as already shown by the Nd-Sr constraints.

Fig. $6 \mathrm{~B}$ presents the individual zircon $\varepsilon_{\mathrm{Hf}(\mathrm{t})}$ analyses (13 samples). We selected only the concordant and almost ${ }^{207} \mathrm{~Pb}-{ }^{206} \mathrm{~Pb}$ concordant analyses that were plotted against the $\mathrm{U}-\mathrm{Pb}$ ages for each sample. The bars of the upper part of the figure represent the total number of individual ${ }^{207} \mathrm{~Pb}^{206} \mathrm{~Pb}$ ages for a given spot where the $\mathrm{Hf}$ measurements were acquired for a group of samples (e.g., S.13, 14, 15). The lower part of the figure shows the respective $\varepsilon_{\mathrm{Hf}(\mathrm{t})}$ values for these samples. Given the age patterns (upper part of the diagram), two igneous episodes are apparent: 2.17-2.16 Ga (e.g., Represa de Camargos and Macuco de Minas plutons) and 2.15-2.11 Ga (e.g., Ritápolis, Macuco de Minas and Represa de Camargos plutons). Altogether the isotopic data show a depletion of ${ }^{176} \mathrm{Hf} /{ }^{177} \mathrm{Hf}_{(\mathrm{t})}$ composition with time (given by the concordant ${ }^{207} \mathrm{~Pb} /{ }^{206} \mathrm{~Pb}$ ages) which might be related to crustal recycling and/or variable $\mathrm{Pb}$ loss. The oldest sample $(\mathrm{S} .1=2.17 \mathrm{Ga})$ yields mostly juvenile zircons $\left(\varepsilon_{\mathrm{Hf}(\mathrm{t})}=+0.1\right.$ to +4.2 ; Table 5.2$)$ whereas other samples (2.17-2.16 Ga age-group) combine positive and negative $\varepsilon_{\mathrm{Hf}(\mathrm{t})}$ values (e.g., S.3 = -6.0 to +4.8$)$. The younger samples $(2.15-2.11 \mathrm{Ga})$ show mainly negative $\varepsilon_{\mathrm{Hf}(\mathrm{t})}$ values but one exception (S.9; diorite) has mostly juvenile zircons. From the above, we suggest that juvenile accretion occurred during both episodes that were defined by the new $\mathrm{U}-\mathrm{Pb}$ ages (see section 4.2). In conclusion, the large variation of $\varepsilon_{\mathrm{Hf}(\mathrm{t})}$ values unravels a complex isotopic history for the metaigneous rocks, with juvenile accretion (e.g., fractional crystallization) combined with variable crustal contamination/assimilation of the mantle sources, particularly for the younger samples, as already indicated in Fig. 5D.

Table 5.2. In situ, individual Lu-Hf analyses of magmatic zircon from diorites, orthogneisses, granitoid and metagranitoid rocks.

\begin{tabular}{cccccccc}
\hline Spot & $\begin{array}{c}{ }^{207} \mathrm{~Pb} /{ }^{206} \mathrm{~Pb} \\
\text { age }\end{array}$ & ${ }^{176} \mathrm{Lu} /{ }^{177} \mathrm{Hf}$ & ${ }^{176} \mathrm{HF} /{ }^{177} \mathrm{Hf}$ & ${ }^{176} \mathrm{HF} /{ }^{177} \mathrm{Hf}_{(\mathrm{t})}$ & $\varepsilon_{\mathrm{Hf} 0}$ & $\varepsilon_{\mathrm{Hf}(\mathrm{t})}$ & $\begin{array}{c}\mathrm{T}_{\mathrm{DM}} \text { age } \\
(\mathrm{Ga})\end{array}$ \\
& & & & $\mathrm{S} .1(2174 \pm 4 \mathrm{Ma})$ & & & \\
12.1 & 2143 & 0.001658 & 0.281502 & 0.28143461 & -44.9 & 0.6 & 2.64 \\
10.1 & 2150 & 0.002566 & 0.281613 & 0.28150769 & -41.0 & 3.4 & 2.47
\end{tabular}




\begin{tabular}{|c|c|c|c|c|c|c|c|}
\hline 2.1 & 2166 & 0.001173 & 0.281454 & 0.28140562 & -46.6 & 0.1 & 2.69 \\
\hline 6.1 & 2174 & 0.002038 & 0.281509 & 0.2814247 & -44.7 & 1.0 & 2.64 \\
\hline 15.1 & 2177 & 0.003150 & 0.281643 & 0.28151273 & -39.9 & 4.2 & 2.44 \\
\hline 1.1 & 2179 & 0.002036 & 0.281581 & 0.28149616 & -42.1 & 3.6 & 2.47 \\
\hline 11.1 & 2179 & 0.002349 & 0.281581 & 0.28148375 & -42.1 & 3.2 & 2.50 \\
\hline 13.1 & 2181 & 0.004068 & 0.281622 & 0.28145292 & -40.7 & 2.2 & 2.57 \\
\hline 3.1 & 2182 & 0.001590 & 0.281550 & 0.28148404 & -43.2 & 3.3 & 2.50 \\
\hline 14.1 & 2183 & 0.002100 & 0.281522 & 0.28143454 & -44.2 & 1.5 & 2.61 \\
\hline 4.1 & 2190 & 0.002142 & 0.281485 & 0.2813956 & -45.5 & 0.3 & 2.70 \\
\hline \multicolumn{8}{|c|}{ S.2 $(2173 \pm 33 \mathrm{Ma})$} \\
\hline 1.1 & 2147 & 0.004105 & 0.281602 & 0.281432 & -41.4 & 1.1 & 2.63 \\
\hline $2.1 *$ & 2109 & 0.001037 & 0.281551 & 0.281511 & -43.2 & 1.0 & 2.54 \\
\hline $3.1^{*}$ & 1968 & 0.000983 & 0.281526 & 0.281489 & -44.1 & -1.0 & 2.62 \\
\hline 4.1 & 2138 & 0.001109 & 0.281495 & 0.281450 & -45.2 & 1.0 & 2.61 \\
\hline 5.1 & 2122 & 0.001274 & 0.281484 & 0.281434 & -45.5 & -1.2 & 2.69 \\
\hline $6.1^{*}$ & 1534 & 0.001118 & 0.281485 & 0.281457 & -45.5 & -16.7 & 3.12 \\
\hline $7.1^{*}$ & 1946 & 0.002074 & 0.281517 & 0.281439 & -44.4 & -3.2 & 2.75 \\
\hline $8.1^{*}$ & 2095 & 0.001332 & 0.281466 & 0.281413 & -46.4 & -1.5 & 2.73 \\
\hline 9.1 & 2142 & 0.000919 & 0.281541 & 0.281505 & -43.5 & 1.2 & 2.54 \\
\hline \multicolumn{8}{|c|}{$\mathrm{S} .3(2169 \pm 18 \mathrm{Ma})$} \\
\hline 1.1 & $2231 *$ & 0.002080 & 0.281279 & 0.281191 & -53.0 & -6.0 & 3.130 \\
\hline $2.1^{*}$ & 2462 & 0.000747 & 0.281308 & 0.281272 & -51.8 & 2.2 & 2.78 \\
\hline $7.1^{*}$ & 1776 & 0.002726 & 0.281767 & 0.281676 & -35.5 & 0.8 & 2.35 \\
\hline $3.1^{*}$ & 987 & 0.001940 & 0.281373 & 0.281337 & -49.5 & -29.0 & 3.60 \\
\hline $11.1^{*}$ & 1030 & 0.002817 & 0.281510 & 0.281455 & -44.6 & -23.8 & 3.32 \\
\hline $5.1^{*}$ & 1015 & 0.001906 & 0.281311 & 0.281275 & -51.7 & -30.6 & 3.72 \\
\hline $6.1^{*}$ & 1456 & 0.002026 & 0.281341 & 0.281286 & -50.6 & -20.3 & 3.43 \\
\hline 10.1 & 2007 & 0.000464 & 0.281361 & 0.281343 & -49.9 & -5.7 & 2.94 \\
\hline 10.2 & 2137 & 0.001075 & 0.281480 & 0.281436 & -45.7 & 0.6 & 2.64 \\
\hline 9.1 & 2219 & 0.002090 & 0.281591 & 0.281502 & -41.8 & 4.8 & 2.43 \\
\hline $12.1 *$ & 798 & 0.003836 & 0.281529 & 0.281472 & -43.9 & -28.4 & 3.42 \\
\hline
\end{tabular}

$\begin{array}{cc}1.1 & 2172 \\ 2.1 & 2169 \\ 3.1 & 2150 \\ 4.1 & 2170 \\ 5.1 & 2139 \\ 6.1 & 2191 \\ 7.1 & 2169 \\ 8.1 & 2172 \\ 9.1 & 2150 \\ 11.1 & 2155 \\ 12.1 & 2187\end{array}$

0.002320
0.002076
0.002292
0.002936
0.002371
0.002541
0.002242
0.002329
0.001438
0.001998
0.001311

S.5 $(2164 \pm 5 \mathrm{Ma})$

0.281482

0.281524

0.281386

0.281555

0.281434

0.281532

0.281539

0.281479

0.281438

0.281461

0.281312

0.281435

0.281433

0.281504

0.281387

0.281435

0.281407

0.281555

0.281376

0.281484

0.281473

$-45.8$

$-0.4$

2.73

$\begin{array}{lll}-44.1 & 1.3 & 2.62\end{array}$

$\begin{array}{lll}-43.0 & 1.7 & 2.57\end{array}$

$\begin{array}{lll}-47.3 & -3.1 & 2.90\end{array}$

$\begin{array}{lll}-43.8 & 0.6 & 2.64\end{array}$

$\begin{array}{lll}-43.6 & 1.7 & 2.6\end{array}$

$-45.7 \quad-0.5 \quad 2.73$

$\begin{array}{lll}-44.9 & 0.3 & 2.68\end{array}$

$\begin{array}{lll}-47.3 & -1.3 & 2.77\end{array}$

$\begin{array}{lll}-43.0 & 2.3 & 2.55\end{array}$

S.6 $(2165 \pm 7 \mathrm{Ma})$

$\begin{array}{cccccccc}11.1 & 2040 & 0.001958 & 0.281457 & 0.281381 & -46.52 & -3.64 & 2.83 \\ 6.1 & 2086 & 0.000874 & 0.281547 & 0.281512 & -43.33 & 2.08 & 2.50 \\ 13.1 & 2126 & 0.001542 & 0.281556 & 0.281493 & -43.02 & 2.32 & 2.52 \\ 14.1 & 2141 & 0.002786 & 0.281512 & 0.281399 & -44.55 & -0.69 & 2.72 \\ 8.1 & 2147 & 0.002221 & 0.281565 & 0.281475 & -42.67 & 2.14 & 2.55 \\ 10.1 & 2159 & 0.003801 & 0.281575 & 0.281419 & -42.31 & 0.45 & 2.66 \\ 17.1 & 2170 & 0.004538 & 0.281597 & 0.281409 & -41.55 & 0.36 & 2.68 \\ 16.1 & 2184 & 0.001803 & 0.281497 & 0.281422 & -45.08 & 1.13 & 2.64 \\ 9.1 & 2191 & 0.003432 & 0.281573 & 0.281429 & -42.42 & 1.54 & 2.62 \\ 15.1 & 2191 & 0.002009 & 0.281591 & 0.281507 & -41.78 & 4.30 & 2.44 \\ 12.1 & 2201 & 0.002221 & 0.281455 & 0.281362 & -46.58 & -0.62 & 2.76\end{array}$




\begin{tabular}{|c|c|c|c|c|c|c|c|}
\hline \multicolumn{8}{|c|}{$\mathrm{S} .8(2149 \pm 10 \mathrm{Ma})$} \\
\hline $4.1 *$ & 1445 & 0.001418 & 0.281335 & 0.281296 & -51.0 & -20.2 & 3.41 \\
\hline 6.1 & 2143 & 0.000600 & 0.281508 & 0.281483 & -44.7 & 2.4 & 2.53 \\
\hline 7.1 & 2142 & 0.000866 & 0.281480 & 0.281445 & -45.7 & 1.0 & 2.62 \\
\hline $13.1 *$ & 1041 & 0.002698 & 0.281567 & 0.281514 & -42.6 & -21.5 & 3.18 \\
\hline 1.1 & 2108 & 0.000517 & 0.281362 & 0.281341 & -49.9 & -3.5 & 2.87 \\
\hline $15.1^{*}$ & 1900 & 0.000984 & 0.281395 & 0.281360 & -48.7 & -7.6 & 2.97 \\
\hline $11.1^{*}$ & 922 & 0.000988 & 0.281316 & 0.281299 & -51.5 & -31.8 & 3.72 \\
\hline $2.1 *$ & 945 & 0.000676 & 0.281372 & 0.281360 & -49.5 & -29.1 & 3.58 \\
\hline $20.1 *$ & 894 & 0.000710 & 0.281456 & 0.281444 & -46.6 & -27.3 & 3.43 \\
\hline $22.1 *$ & 968 & 0.001167 & 0.281426 & 0.281405 & -47.6 & -27.0 & 3.47 \\
\hline $24.1 *$ & 1269 & 0.001064 & 0.281416 & 0.281391 & -48.0 & -20.8 & 3.31 \\
\hline \multicolumn{8}{|c|}{ S.9 $(2145 \pm 7 \mathrm{Ma})$} \\
\hline 1.1 & 2139 & 0.000254 & 0.281496 & 0.281485 & -45.3 & 2.4 & 2.53 \\
\hline 2.1 & 2140 & 0.000490 & 0.281639 & 0.281619 & -40.1 & 7.1 & 2.22 \\
\hline 3.1 & 2151 & 0.000527 & 0.281436 & 0.281414 & -47.2 & 0.1 & 2.68 \\
\hline 5.1 & 2149 & 0.000336 & 0.281438 & 0.281424 & -47.2 & 0.4 & 2.66 \\
\hline 6.1 & 2136 & 0.000826 & 0.281491 & 0.281458 & -45.3 & 1.3 & 2.59 \\
\hline 7.1 & 2138 & 0.000366 & 0.281535 & 0.281520 & -43.7 & 3.6 & 2.45 \\
\hline 8.1 & 2091 & 0.000367 & 0.281501 & 0.281486 & -44.9 & 1.3 & 2.56 \\
\hline 9.1 & 2149 & 0.000530 & 0.281508 & 0.281486 & -44.7 & 2.6 & 2.52 \\
\hline 10.1 & 2136 & 0.000407 & 0.281581 & 0.281565 & -42.1 & 5.1 & 2.35 \\
\hline 11.1 & 2141 & 0.000408 & 0.281497 & 0.281481 & -45.1 & 2.2 & 2.54 \\
\hline 12.1 & 2136 & 0.000361 & 0.281490 & 0.281475 & -45.3 & 1.9 & 2.55 \\
\hline \multicolumn{8}{|c|}{$\mathrm{S} .10(2131 \pm 5 \mathrm{Ma})$} \\
\hline 20.1 & 2070 & 0.000369 & 0.281368 & 0.281354 & -49.6 & -3.9 & 2.87 \\
\hline 16.1 & 2078 & 0.000763 & 0.281396 & 0.281366 & -48.7 & -3.3 & 2.84 \\
\hline 9.1 & 2082 & 0.001302 & 0.281417 & 0.281365 & -47.9 & -3.2 & 2.84 \\
\hline 12.1 & 2105 & 0.000733 & 0.281366 & 0.281337 & -49.7 & -3.7 & 2.89 \\
\hline 18.1 & 2119 & 0.001126 & 0.281351 & 0.281306 & -50.2 & -4.5 & 2.95 \\
\hline 3.1 & 2120 & 0.000770 & 0.281541 & 0.281510 & -43.5 & 2.8 & 2.48 \\
\hline 7.1 & 2121 & 0.000774 & 0.281392 & 0.281361 & -48.8 & -2.5 & 2.82 \\
\hline 17.1 & 2126 & 0.000548 & 0.281315 & 0.281293 & -51.5 & -4.8 & 2.97 \\
\hline 21.1 & 2128 & 0.000744 & 0.281349 & 0.281319 & -50.3 & -3.8 & 2.91 \\
\hline 4.1 & 2131 & 0.000579 & 0.281438 & 0.281414 & -47.2 & -0.4 & 2.69 \\
\hline 8.1 & 2139 & 0.000802 & 0.281303 & 0.281270 & -51.9 & -5.3 & 3.01 \\
\hline \multicolumn{8}{|c|}{$\mathrm{S} .11(2125 \pm 21 \mathrm{Ma})$} \\
\hline 1.1 & 2090 & 0.001316 & 0.281401 & 0.281349 & -48.7 & -3.63 & 2.87 \\
\hline 3.1 & 2097 & 0.001278 & 0.281287 & 0.281236 & -52.5 & -7.50 & 3.12 \\
\hline 4.1 & 2105 & 0.001315 & 0.281302 & 0.281249 & -52.0 & -6.84 & 3.09 \\
\hline 6.1 & 2021 & 0.000940 & 0.281327 & 0.281290 & -51.1 & -7.27 & 3.05 \\
\hline 8.1 & 2074 & 0.000834 & 0.281321 & 0.281288 & -51.3 & -6.14 & 3.02 \\
\hline 10.1 & 2041 & 0.001124 & 0.281343 & 0.281299 & -50.5 & -6.52 & 3.02 \\
\hline 12.1 & 2068 & 0.001109 & 0.281415 & 0.281371 & -48.0 & -3.34 & 2.84 \\
\hline 13.1 & 2055 & 0.000840 & 0.281375 & 0.281342 & -49.4 & -4.65 & 2.91 \\
\hline 15.1 & 2023 & 0.000666 & 0.281424 & 0.281398 & -47.7 & -3.40 & 2.80 \\
\hline 16.1 & 2129 & 0.000996 & 0.281320 & 0.281280 & -51.3 & -5.20 & 3.00 \\
\hline 17.1 & 2045 & 0.001476 & 0.281342 & 0.281284 & -50.6 & -6.95 & 3.05 \\
\hline
\end{tabular}




\begin{tabular}{|c|c|c|c|c|c|c|c|}
\hline 9.1 & 1957 & 0.002726 & 0.281502 & 0.281400 & -44.9 & -4.8 & 2.85 \\
\hline 12.1 & 1975 & 0.002691 & 0.281433 & 0.281332 & -47.4 & -6.9 & 2.99 \\
\hline 13.1 & 1999 & 0.002451 & 0.281440 & 0.281346 & -47.1 & -5.8 & 2.94 \\
\hline 8.1 & 2040 & 0.002162 & 0.281332 & 0.281248 & -50.9 & -8.3 & 3.13 \\
\hline 3.1 & 2066 & 0.002261 & 0.281425 & 0.281336 & -47.6 & -4.6 & 2.92 \\
\hline 7.1 & 2069 & 0.000984 & 0.281307 & 0.281268 & -51.8 & -7.0 & 3.07 \\
\hline 10.1 & 2100 & 0.001261 & 0.281287 & 0.281236 & -52.5 & -7.4 & 3.12 \\
\hline 5.1 & 2107 & 0.001837 & 0.281348 & 0.281275 & -50.3 & -5.9 & 3.03 \\
\hline 11.1 & 2134 & 0.001138 & 0.281353 & 0.281306 & -50.2 & -4.1 & 2.94 \\
\hline 6.1 & 2164 & 0.001291 & 0.281396 & 0.281343 & -48.7 & -2.2 & 2.83 \\
\hline 1.1 & 2193 & 0.002735 & 0.281237 & 0.281123 & -54.3 & -9.3 & 3.31 \\
\hline \multicolumn{8}{|c|}{$\mathrm{S} .13(2114 \pm 6 \mathrm{Ma})$} \\
\hline 4.1 & 1939 & 0.001215 & 0.281211 & 0.281166 & -55.2 & -13.6 & 3.38 \\
\hline 2.1 & 1957 & 0.000284 & 0.281285 & 0.281274 & -52.6 & -9.3 & 3.13 \\
\hline 7.1 & 2070 & 0.001465 & 0.281419 & 0.281361 & -47.9 & -3.7 & 2.86 \\
\hline 8.1 & 2081 & 0.000936 & 0.281270 & 0.281233 & -53.1 & -7.9 & 3.14 \\
\hline 3.1 & 2108 & 0.000291 & 0.281318 & 0.281306 & -51.4 & -4.7 & 2.95 \\
\hline 1.1 & 2111 & 0.000438 & 0.281366 & 0.281349 & -49.7 & -3.2 & 2.86 \\
\hline 12.1 & 2121 & 0.000151 & 0.281302 & 0.281296 & -52.0 & -4.8 & 2.97 \\
\hline 6.1 & 2150 & 0.000203 & 0.281259 & 0.281250 & -53.5 & -5.8 & 3.05 \\
\hline \multicolumn{8}{|c|}{$\mathrm{S} .14(2111 \pm 4 \mathrm{Ma})$} \\
\hline 1.1 & 2122 & 0.000731 & 0.281195 & 0.281166 & -55.9 & -9.4 & 3.26 \\
\hline 1.2 & 2111 & 0.000499 & 0.281445 & 0.281425 & -46.9 & -0.4 & 2.68 \\
\hline 3.1 & 2125 & 0.000257 & 0.281459 & 0.281449 & -46.4 & 0.7 & 2.62 \\
\hline 5.1 & 2122 & 0.000786 & 0.281448 & 0.281416 & -46.8 & -0.5 & 2.70 \\
\hline 6.1 & 2102 & 0.000383 & 0.281443 & 0.281427 & -47.0 & -0.6 & 2.69 \\
\hline 7.1 & 2108 & 0.000424 & 0.281369 & 0.281352 & -49.6 & -3.1 & 2.85 \\
\hline 8.1 & 2120 & 0.000676 & 0.281446 & 0.281419 & -46.9 & -0.5 & 2.69 \\
\hline 9.1 & 2139 & 0.000247 & 0.281459 & 0.281449 & -46.4 & 1.1 & 2.61 \\
\hline 11.1 & 2081 & 0.000566 & 0.281279 & 0.281257 & -52.8 & -7.1 & 3.08 \\
\hline 13.1 & 2087 & 0.000722 & 0.281447 & 0.281418 & -46.9 & -1.2 & 2.72 \\
\hline 15.1 & 2110 & 0.000414 & 0.281382 & 0.281366 & -49.1 & -2.6 & 2.82 \\
\hline \multicolumn{8}{|c|}{$\mathrm{S} .15(2109 \pm 5 \mathrm{Ma})$} \\
\hline 14.1 & 1981 & 0.000986 & 0.281515 & 0.281477 & -44.5 & -1.6 & 2.66 \\
\hline 11.1 & 2052 & 0.000606 & 0.281430 & 0.281407 & -47.5 & -2.4 & 2.77 \\
\hline 13.1 & 2089 & 0.000871 & 0.281430 & 0.281396 & -47.4 & -2.0 & 2.76 \\
\hline 1.1 & 2102 & 0.000469 & 0.281469 & 0.281450 & -46.1 & 0.2 & 2.63 \\
\hline 9.2 & 2105 & 0.000390 & 0.281140 & 0.281125 & -57.7 & -11.3 & 3.36 \\
\hline 6.1 & 2114 & 0.000563 & 0.281466 & 0.281444 & -46.2 & 0.3 & 2.64 \\
\hline 1.2 & 2123 & 0.000912 & 0.281513 & 0.281476 & -44.5 & 1.6 & 2.56 \\
\hline 10.1 & 2128 & 0.000414 & 0.281442 & 0.281425 & -47.0 & 0.0 & 2.67 \\
\hline 3.1 & 2299 & 0.000852 & 0.281477 & 0.281439 & -45.8 & 4.4 & 2.52 \\
\hline 7.1 & 2316 & 0.001625 & 0.281465 & 0.281393 & -46.2 & 3.1 & 2.61 \\
\hline
\end{tabular}

\subsection{Geochemical data}

New and compiled geochemical data (35 samples; including 19 ones from Cherman, 2004) are discussed in the attempt to characterize the petrogenesis (in 
regional basis) and the geotectonic setting of the 2.17-2.09 Ga magmatic episodes determined here. The new analyses refer to three diorites that are ascribed to two separated bodies, thirteen metagranitoid and orthogneissic rocks (e.g., Macuco de Minas and Represa de Camargos), two from the Ritápolis granitoid. Much of these rocks show intrusive relationships given by distinct xenoliths. Data compiled from Cherman (2004) were referred as two types of orthogneisses that crop out nearby the towns of Itumirim and Nazareno. We considered these particular samples as the Macuco de Minas and Represa de Camargos plutons.

In the TAS $\left(\mathrm{K}_{2} \mathrm{O}+\mathrm{Na}_{2} \mathrm{O}\right.$ vs. $\left.\mathrm{SiO}_{2}\right)$ diagram all data plot within the sub-alkaline field (Fig. 7A) where three diorites show $\mathrm{SiO}_{2}$ contents between 57.8 to 58.1 wt. \%. The latter samples yield total alkalis $\left(\mathrm{Na}_{2} \mathrm{O}+\mathrm{K}_{2} \mathrm{O}\right)$ from 4.8 to 5.5 wt.\% which are consistent with gabbro to diorite compositions. However, we classify these samples as diorite due the presence of hornblende rather than pyroxene. The metaquartz-diorite sample (S.5) shows $\mathrm{SiO}_{2}$ contents of the 54.8 wt.\% and total alkalis $\left(\mathrm{Na}_{2} \mathrm{O}+\mathrm{K}_{2} \mathrm{O}\right)$ of the 3.82 wt.\%. The metagranitoid samples show $\mathrm{SiO}_{2}$ contents between 60.9-77.5 wt.\% and coupled total alkalis $\left(\mathrm{Na}_{2} \mathrm{O}+\mathrm{K}_{2} \mathrm{O}\right)$ ranging from 6.2 to 9.0 wt.\% (tonalitic to granitic composition).
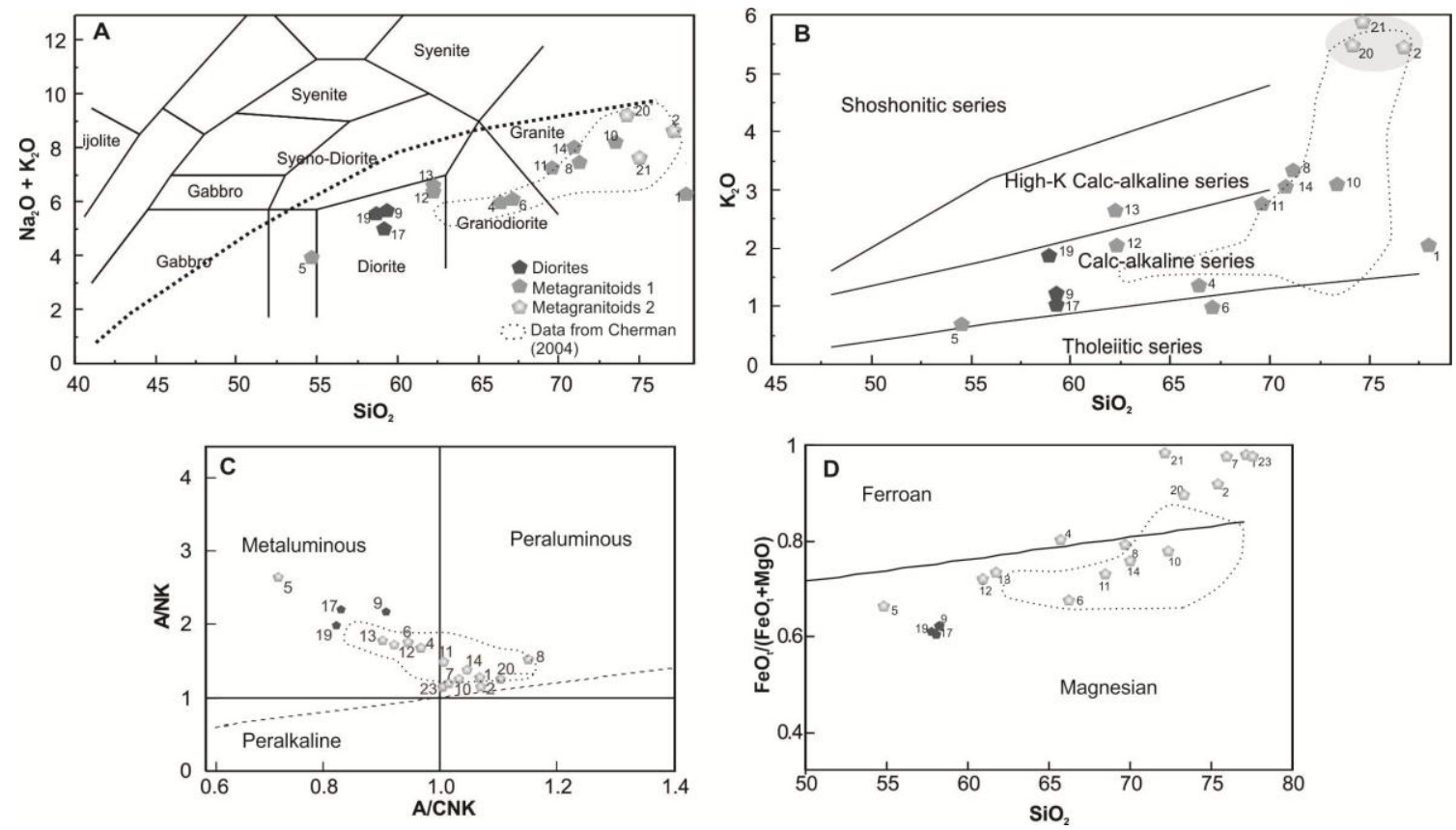

Fig. 7. (A) $\mathrm{SiO}_{2}$ vs. $\mathrm{Na}_{2} \mathrm{O}+\mathrm{K}_{2} \mathrm{O}$ (after Cox et al., 1979), (B) $\mathrm{SiO}_{2}$ vs. $\mathrm{K}_{2} \mathrm{O}$ (after Peccerillo and Taylor, 1976). (C) A/NK vs. A/CNK (after Shand, 1943), (D) $\mathrm{FeO}_{\mathrm{t}} /\left(\mathrm{FeO}_{\mathrm{t}}+\mathrm{MgO}\right)$ vs. $\mathrm{SiO}_{2}$ (Forst et al., 2001). The numbers represent the studied samples. Dashed field: selected data from Cherman (2004). 
In the $\mathrm{K}_{2} \mathrm{O}$ versus $\mathrm{SiO}_{2}$ plot (Fig. 7B) the samples delineate two different trends that are interpreted as two geochemical groups. Both fields include samples from the oldest and the youngest geochronological groups. The first group (Fig. 7B) shows calcalkaline affinity and defines a positive correlation between these oxides. It is named here metagranitoids 1 . The positive trend may be related to fractional crystallization, such as mirrored by dioritic magma (S.9) generating tonalites to granites (e.g., S.11, 12, 13, 14). These samples yielded U-Pb ages from 2145 to 2109 Ma (see section 4.2). Three samples $(\mathrm{S} .2,20,21)$ plot in the high-K calc-alkaline field, given by $\mathrm{SiO}_{2}$ contents higher than $72 \%$ and $\mathrm{K}_{2} \mathrm{O}$ higher than 5\% (gray field; named here metagranitoids 2). In a similar manner geochemical data from orthogneissic rocks in the Itumirim region (Cherman, 2004) show $\mathrm{SiO}_{2}$ contents between 70 and $75 \%$ and some yield $\mathrm{K}_{2} \mathrm{O}$ contents between 4.6 and $5.4 \%$. Hence they could be also ascribed to the metagranitoids 2 group. From the above we suggest that some sort of crustal assimilation/contamination has occurred in this particular group of rocks.

In Fig. 7C, both metagranitoids 1 and 2 groups can be distinguished as metaluminous and peraluminous types (Maniar and Picolli, 1989), given the $0.6<\mathrm{A} / \mathrm{CNK}<1.2$ and $1<\mathrm{A} / \mathrm{NK}<3$ values. The data from Cherman (2004) delineate again a similar feature. In the Frost et al. (2001) diagram (Fig. 7D) most of the data (metagranitoids 1 ) plot in the magnesian field including the diorites $\left(\mathrm{FeO}_{\mathrm{t}} / \mathrm{FeO}_{\mathrm{t}}+\mathrm{MgO}\right.$ variation from 0.63-0.98). This is in agreement with the composition of I-type rocks. Six samples plot in the ferroan field, including three metagranitoids 2 samples. However we interpret this behavior as due to crustal contamination (see below).

In Harker diagrams (Figs. 8A, B, C, D, E and F) the intermediate to acid samples (both metagranitoids 1 and 2) have negative correlation of $\mathrm{SiO}_{2}$ with $\mathrm{CaO}(0.17-8.66$ wt.\%), $\mathrm{TiO}_{2}\left(0.05-1.07\right.$ wt.\%), $\mathrm{P}_{2} \mathrm{O}_{5}$ (0.016-0.31 wt.\%), $\mathrm{Fe}_{2} \mathrm{O}_{3}$ (1.01-9.91 wt.\%), $\mathrm{MgO}$ (0.03 to 4.76 wt.\%), and $\mathrm{Al}_{2} \mathrm{O}_{3}$ (11.65 to 18.57 wt.\%). The diorites show positive correlation between $\mathrm{P}_{2} \mathrm{O}_{5}$ vs. $\mathrm{SiO}_{2}$ whereas the intermediate to acid samples show negative correlations of the same oxides against $\mathrm{SiO}_{2}$ (Fig. 8C). The inferred dashed arrows suggest the input of the new mineral phases such as apatite during the course of magmatic differentiation - see section 4.1. This may be the case for S.9 to S.10, 11, 13 and 14 samples. This inference agrees well with the petrographic diversity of the studied rocks that we tentatively attributed to the process of fractional crystallization. 

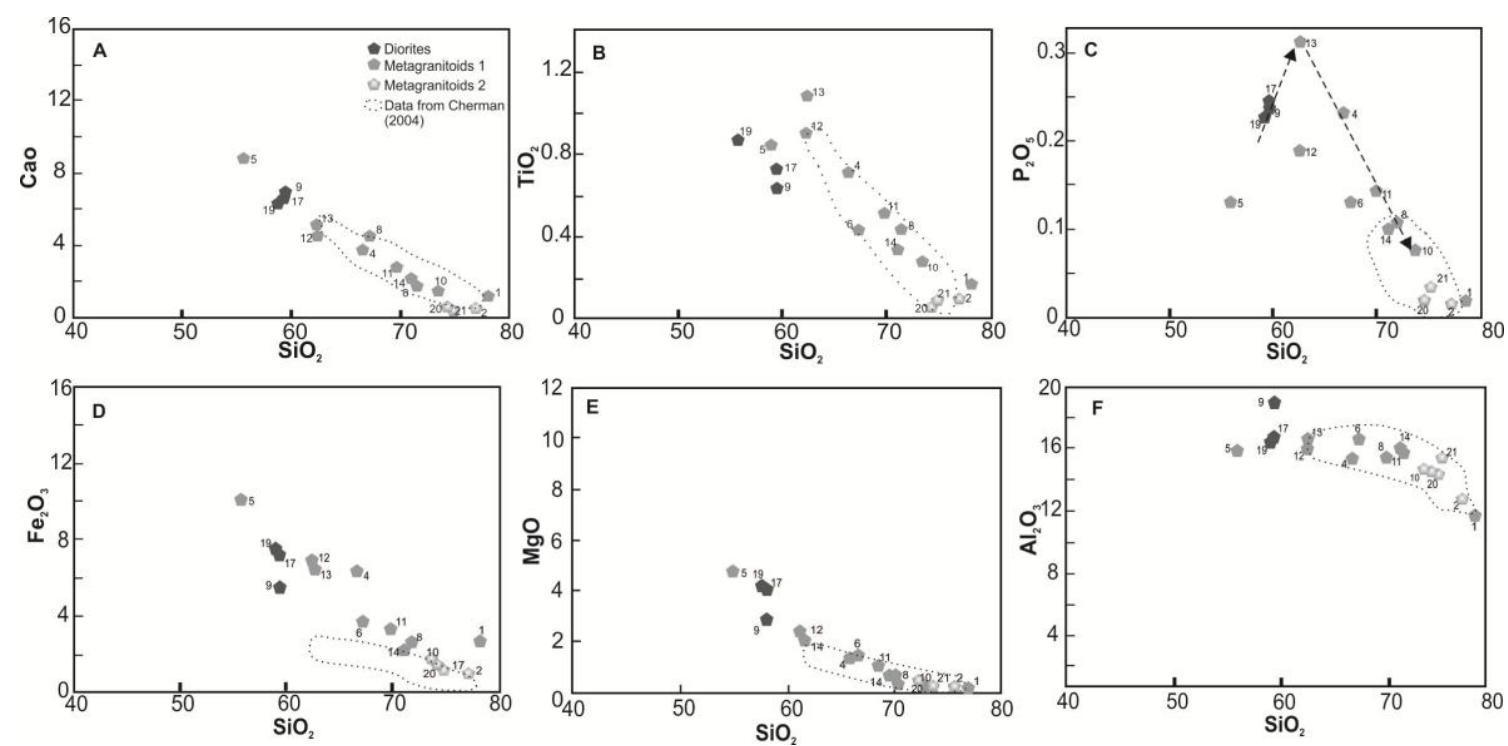

Fig. 8. Correlation diagrams of $\mathrm{SiO}_{2}$ vs. $\mathrm{CaO}, \mathrm{TiO}_{2}, \mathrm{P}_{2} \mathrm{O}_{5}, \mathrm{Fe}_{2} \mathrm{O}_{3}, \mathrm{MgO}, \mathrm{Al}_{2} \mathrm{O}_{3}$. Dashed field (Cherman, 2004). The numbers represent the studied samples.

The data from the intermediate to acid samples (metagranitoids 1 and 2) show strong variation and enrichment in LILE and LREE (large ion lithophile elements and light rare earth elements, respectively) such as Sr (19-707 ppm), Ba (25-1403 ppm), La (from 4.7 to $90.7 \mathrm{ppm}$ ), Ce (1.8-129 ppm), Nd (5.8-77.4 ppm) (samples S.11, 16, 13, 14, 20, 11, 9, 2, 8, 6, 4, 5; Table 6). This results again from the large compositional range for these samples (tonalites, granodiorites, granites). The diorites have a distinct LILE and LREE range compared to the metagranitoids, from 361-801 ppm (Sr), from 521 to $563 \mathrm{ppm}(\mathrm{Ba})$ and 28-30 ppm (La), and show variable fractionation of LREE values, given by $\mathrm{La} / \mathrm{Yb}_{\mathrm{N}}=9.60-13.82$. All samples have $\mathrm{Eu} / \mathrm{Eu}{ }^{*}$ values between 1.33 and 0.07 (see Table 6) where the diorites and some metatonalites yield the higher values (1.331.0), indicating the accumulation of plagioclase during the magmatic differentiation, whereas the lower $\mathrm{Eu} / \mathrm{Eu}^{*}$ values $(<1.0$; metatonalites and metagranites) may be related to fractionation crystallization (see above). Metagranitoids 1 , on the other hand, are depleted to strongly enriched in LREE $\left(\mathrm{La} / \mathrm{Yb}_{\mathrm{N}}=2.24-91.27\right.$; see Table 6), where the high $\mathrm{K}_{2} \mathrm{O}$ group (S.2, S.20 and S.21) shows relatively low $\mathrm{La} / \mathrm{Yb}_{\mathrm{N}}$ ratios between 8.32.2. The observed low Ni (5 to 56 including 71 and $146 \mathrm{ppm}$ ), Co (1.7 to $36 \mathrm{ppm}$ ), Sc (2 to 18 including 26 and $46 \mathrm{ppm})$ contents and the $\mathrm{MgO}\left(0.05-4.1 / 9.9\right.$ wt.\%) and $\mathrm{Cr}_{2} \mathrm{O}_{3}$ (0.002 to 0.079 wt.\%) values (see Table 6) are characteristic of rocks derived from basaltic source (e.g., Martin, 1994) like expected for I-type magmatism. However, our $\mathrm{Nd}-\mathrm{Sr}$ constraints suggest that a peridotitic source could be a minor component in magma genesis (see Fig. 5D). 
Table 6. Major and trace element data for whole rock samples (diorites, orthogneisses, granitoid and metagranitoid rocks).

\begin{tabular}{|c|c|c|c|c|c|c|c|c|c|c|c|c|c|c|c|c|c|c|}
\hline & S.17 & S.11 & $\begin{array}{l}\text { S.16 } \\
*\end{array}$ & S.18* & S.13 & S.14 & S. 20 & S.1 & S.9 & S. 2 & S.10 & S.12 & S.8 & S. 21 & S.6 & S. 4 & S.19 & S.5 \\
\hline $\mathrm{SiO}_{2}$ & $\begin{array}{l}57.8 \\
9\end{array}$ & $\begin{array}{l}68.4 \\
4\end{array}$ & $\begin{array}{l}73.8 \\
8\end{array}$ & 49.52 & $\begin{array}{l}61.6 \\
9\end{array}$ & $\begin{array}{l}69.9 \\
9\end{array}$ & $\begin{array}{l}73.3 \\
5\end{array}$ & $\begin{array}{l}77.0 \\
9\end{array}$ & $\begin{array}{l}58.1 \\
2\end{array}$ & $\begin{array}{l}75.4 \\
0\end{array}$ & $\begin{array}{l}72.3 \\
3\end{array}$ & $\begin{array}{l}60.8 \\
9\end{array}$ & $\begin{array}{l}69.7 \\
1\end{array}$ & $\begin{array}{l}72.1 \\
8\end{array}$ & 66.21 & 65.68 & $\begin{array}{l}57.8 \\
1\end{array}$ & $\begin{array}{r}54.8 \\
2\end{array}$ \\
\hline $\mathrm{TiO}_{2}$ & 0.71 & 0.5 & $\begin{array}{l}0 \\
0.12\end{array}$ & 0.29 & 1.07 & 0.33 & 0.05 & 0.16 & 0.62 & $\begin{array}{l}0.08 \\
8\end{array}$ & $\begin{array}{l}0.27 \\
6\end{array}$ & $\begin{array}{l}0.87 \\
7\end{array}$ & $\begin{array}{l}0.42 \\
6\end{array}$ & $\begin{array}{l}0 \\
0.07 \\
7\end{array}$ & 0.43 & 0.7 & $\begin{array}{l}1 \\
0.82 \\
8\end{array}$ & 0.86 \\
\hline $\mathrm{Al}_{2} \mathrm{O}_{3}$ & $\begin{array}{l}16.1 \\
1\end{array}$ & $\begin{array}{l}15.0 \\
6\end{array}$ & $\begin{array}{l}14.2 \\
6\end{array}$ & 15.27 & $\begin{array}{l}16.3 \\
5\end{array}$ & $\begin{array}{l}15.5 \\
6\end{array}$ & $\begin{array}{l}14.4 \\
4\end{array}$ & $\begin{array}{l}11.6 \\
5\end{array}$ & $\begin{array}{l}18.5 \\
7\end{array}$ & $\begin{array}{l}12.6 \\
2\end{array}$ & $\begin{array}{l}14.3 \\
6\end{array}$ & $\begin{array}{l}15.7 \\
7\end{array}$ & $\begin{array}{l}15.3 \\
1\end{array}$ & $\begin{array}{l}14.9 \\
9\end{array}$ & 16.25 & 14.99 & $\begin{array}{l}15.9 \\
4\end{array}$ & $\begin{array}{r}15.4 \\
0\end{array}$ \\
\hline $\mathrm{Fe}_{2} \mathrm{O}_{3}$ & 7.05 & 3.33 & 1.22 & 6.74 & 6.26 & 2.18 & 1.39 & 2.64 & 5.38 & 1.01 & 1.77 & 6.73 & 2.64 & 1.77 & 3.62 & 6.23 & 7.31 & 9.91 \\
\hline $\mathrm{MnO}$ & 0.12 & 0.07 & 0.05 & 0.15 & 0.09 & 0.03 & 0.01 & 0.06 & 0.08 & $\begin{array}{l}0.02 \\
7\end{array}$ & $\begin{array}{l}0.00 \\
2\end{array}$ & $\begin{array}{l}0.14 \\
2\end{array}$ & $\begin{array}{l}0.00 \\
2\end{array}$ & $\begin{array}{l}0.00 \\
2\end{array}$ & 0.07 & 0.11 & $\begin{array}{l}0.11 \\
5\end{array}$ & 0.15 \\
\hline $\mathrm{MgO}$ & 4.10 & 1.1 & 0.17 & 9.86 & 2.02 & 0.63 & 0.15 & 0.05 & 2.88 & 0.08 & 0.45 & 2.37 & 0.62 & 0.03 & 1.56 & 1.37 & 4.17 & 4.76 \\
\hline $\mathrm{CaO}$ & 6.67 & 2.65 & 0.85 & 14.99 & 4.96 & 1.99 & 0.43 & 0.98 & 6.58 & 0.45 & 1.37 & 4.41 & 1.77 & 0.17 & 4.37 & 3.63 & 6.27 & 8.66 \\
\hline $\mathrm{Na}_{2} \mathrm{O}$ & 3.67 & 4.39 & 3.94 & 1.11 & 4.24 & 4.87 & 3.67 & 4.25 & 4.52 & 3.17 & 4.93 & 3.84 & 4 & 1.58 & 5 & 4.55 & 3.66 & 3.17 \\
\hline $\mathrm{K}_{2} \mathrm{O}$ & 1.16 & 2.7 & 4.54 & 0.07 & 2 & 3 & 5.38 & 1.99 & 1.01 & 5.33 & 3.06 & 2.57 & 3.25 & 5.66 & 0.96 & 1.33 & 1.82 & 0.65 \\
\hline $\mathrm{P}_{2} \mathrm{O}_{5}$ & 0.24 & 0.14 & 0.03 & 0.02 & 0.31 & 0.1 & 0.02 & 0.02 & 0.23 & $\begin{array}{l}0.01 \\
6\end{array}$ & $\begin{array}{l}0.07 \\
6\end{array}$ & $\begin{array}{l}0.18 \\
6\end{array}$ & $\begin{array}{l}0.10 \\
3\end{array}$ & $\begin{array}{l}0.03 \\
4\end{array}$ & 0.13 & 0.23 & $\begin{array}{l}0.22 \\
3\end{array}$ & 0.13 \\
\hline $\begin{array}{l}\text { Total (- } \\
\text { LOI) }\end{array}$ & $\begin{array}{l}97.7 \\
2\end{array}$ & $\begin{array}{l}98.3 \\
8\end{array}$ & $\begin{array}{l}99.0 \\
6\end{array}$ & 98.02 & $\begin{array}{l}98.9 \\
9\end{array}$ & $\begin{array}{l}98.6 \\
8\end{array}$ & $\begin{array}{l}98.8 \\
9\end{array}$ & $\begin{array}{l}98.8 \\
9\end{array}$ & $\begin{array}{l}97.9 \\
9\end{array}$ & $\begin{array}{l}98.1 \\
9\end{array}$ & $\begin{array}{l}98.6 \\
2\end{array}$ & $\begin{array}{l}97.7 \\
9\end{array}$ & $\begin{array}{l}97.8 \\
3\end{array}$ & $\begin{array}{l}96.4 \\
9\end{array}$ & 98.60 & 98.82 & $\begin{array}{l}98.1 \\
5\end{array}$ & $\begin{array}{r}99.8 \\
2\end{array}$ \\
\hline LOI & 2.0 & 1.4 & 0.8 & 1.7 & 0.8 & 1.1 & 1.0 & 0.9 & 1.8 & 0.47 & 0.6 & 0.99 & 1.57 & 2.7 & 1.2 & 1.0 & 0.63 & 1.3 \\
\hline $\mathrm{Ba}$ & 559 & 9 & 455 & 25 & & & 92 & 635 & 563 & 4 & 783 & 7 & 3 & 223 & & & 1 & 161 \\
\hline $\mathrm{Co}$ & 20 & 7 & 1.7 & 36.1 & & 4 & 0.8 & 0 & 7 & 6 & 6 & 1 & 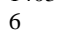 & 6 & 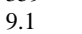 & & 7 & 29.7 \\
\hline Cs & 8 & 1. & 2. & 0 . & 1 & 2. & 6 & 0 & 2 & 0.84 & 0.88 & 6.36 & 9.06 & 13.4 & 4.7 & 9.5 & 7.2 & 2.8 \\
\hline $\mathrm{Ga}$ & $\begin{array}{l}.0 \\
19.2\end{array}$ & 19.6 & 20.1 & 11.9 & 20.3 & 21.3 & $\begin{array}{l}0.1 \\
17.9\end{array}$ & 21.4 & 16.9 & $\begin{array}{l}.04 \\
16\end{array}$ & 20 & 20 & 20 & 22 & 18.1 & 20 & 20 & 13.6 \\
\hline $\mathrm{Hf}$ & 3.6 & 5 & 3.7 & 0.4 & 7.3 & 4.6 & 5.9 & 9.3 & 2.6 & 4.16 & 3.63 & 3.41 & 5.52 & 4.72 & 3.5 & 5.8 & 3.48 & 2.7 \\
\hline $\mathrm{Nb}$ & 8.9 & 19.1 & 16 & 0.1 & 14 & 5.2 & 14.5 & 21 & 5.4 & 14.6 & 7.42 & 11.9 & 10.4 & 41.4 & 3.6 & 10 & 9.85 & 4.7 \\
\hline $\mathrm{Rb}$ & 40.9 & $\begin{array}{l}103 . \\
9\end{array}$ & 172 & 1.4 & 68.2 & 99.8 & $\begin{array}{l}194 . \\
9\end{array}$ & 47.4 & 26.6 & 227 & 106 & 262 & 213 & 437 & 26.2 & 60.8 & 146 & 18.2 \\
\hline Sn & 1 & 3 & 5 & 1 & 2 & 1 & 1 & 4 & 1 & 0 & 0 & 0 & 0 & 0 & 1 & 2 & 0 & 1 \\
\hline $\mathrm{Sr}$ & $\begin{array}{l}586 . \\
9\end{array}$ & 448 & 88.6 & 109.7 & $\begin{array}{l}526 . \\
5\end{array}$ & $\begin{array}{l}566 . \\
2\end{array}$ & 30.8 & 69 & $\begin{array}{l}801 . \\
3\end{array}$ & 63 & 320 & 362 & 346 & 19 & 706.9 & 202.9 & 361 & $\begin{array}{r}165 . \\
4\end{array}$ \\
\hline $\mathrm{Ta}$ & 0.7 & 0.9 & 0.7 & 0.1 & 0.8 & 0.4 & 0.4 & 1.3 & 0.3 & 0 & 0 & 0 & 0 & 0 & 0.4 & 0.7 & 0 & 0.7 \\
\hline Th & 12.9 & 20 & 29.9 & 0.2 & 11.6 & 21 & 34 & 7 & 7.2 & 36 & 9 & 10 & 24 & 45 & 3.2 & 3.2 & 12 & 2.4 \\
\hline $\mathrm{U}$ & 2.7 & 2.2 & 5 & 0.1 & 3.1 & 2.6 & 15.8 & 1.7 & 1.2 & 23.8 & 5.44 & 1.91 & 2 & 13.4 & 1.7 & 0.8 & 2.31 & 0.6 \\
\hline $\mathrm{V}$ & 129 & 42 & 8 & 170 & 100 & 22 & 8 & 8 & 107 & 9 & 9 & 109 & 33 & 9 & 44 & 36 & 100 & 188 \\
\hline W & 0.5 & 0.5 & 0.5 & 2.7 & 0.5 & 0.5 & 0.5 & 0.5 & 0.5 & 0 & 0 & 0 & 0 & 0 & 0.5 & 0.5 & 0 & $<0.5$ \\
\hline $\mathrm{Y}$ & 21.9 & 24.5 & 16.2 & 8.1 & 27.2 & 7.9 & 78.2 & $\begin{array}{l}125 . \\
8\end{array}$ & 13.2 & 63 & 5 & 20 & 7 & 40 & 7 & 32.1 & 20 & 17.3 \\
\hline $\mathrm{Zr}$ & $\begin{array}{l}123 . \\
3\end{array}$ & $\begin{array}{l}201 . \\
8\end{array}$ & 97.6 & 10.1 & $\begin{array}{l}308 . \\
2\end{array}$ & $\begin{array}{l}176 . \\
1\end{array}$ & $\begin{array}{l}129 . \\
5\end{array}$ & 307 & 91 & 101 & 135 & 151 & 218 & 107 & 137.3 & 229.4 & 133 & $\begin{array}{r}101 . \\
9\end{array}$ \\
\hline $\mathrm{Cd}$ & 0.1 & 0.1 & 0.1 & 0.1 & 0.1 & 0.1 & 0.1 & 0.1 & 0.1 & 0 & 0 & 0 & 0 & 0 & 0.1 & 0.1 & 0 & $<0.1$ \\
\hline $\mathrm{Cu}$ & 24.5 & 5.9 & 1.2 & 207.4 & 4.2 & 1.8 & 1.6 & 5.3 & 36.2 & 5 & 5 & 16 & 5 & 5 & 3.3 & 10.9 & 23 & 66.4 \\
\hline $\mathrm{Hg}$ & 0.01 & 0.01 & 0.01 & 0.01 & 0.01 & 0.01 & 0.01 & 0.01 & 0.01 & 0 & 0 & 0 & 0 & 0 & 0.01 & 0.01 & 0 & $<0.0$ \\
\hline Mo & 05 & 0.2 & 01 & 0.7 & 0.2 & 0. & 05 & 11 & 0.2 & 0 & 0 & 0 & 0 & 0 & 0.6 & 0.4 & 0 & 0.2 \\
\hline $\mathrm{Ni}$ & 56 & 20 & 20 & 146 & 20 & 20 & 20 & 20 & 35 & 5 & 5 & 23 & 5 & 5 & 20 & 20 & 71 & 46 \\
\hline $\mathrm{Pb}$ & 2.6 & 21.3 & 30 & 0.3 & 3.2 & 13.3 & 11.8 & 2.5 & 2.2 & 33 & 12 & 15 & 8 & 54 & 2.1 & 1.1 & 8 & 0.6 \\
\hline $\mathrm{Tl}$ & 0.2 & 0.5 & 0.4 & 0.1 & 0.4 & 0.5 & 0.1 & 0.1 & 0.1 & 0 & 0 & 0 & 0 & 0 & 0.1 & 0.4 & 0 & 0.1 \\
\hline $\mathrm{Zn}$ & 51 & 70 & 43 & 8 & 82 & 49 & 10 & 112 & 42 & 26 & 43 & 116 & 76 & 78 & 48 & 93 & 90 & 37 \\
\hline $\mathrm{Sc}$ & 17 & 8 & 3 & 46 & 13 & 3 & 3 & 2 & 12 & 14 & 14 & 15 & 14 & 14 & 6 & 10 & 18 & 26 \\
\hline $\mathrm{La}$ & 29.8 & 57.1 & 17 & 4.7 & 44.1 & 78.6 & 24.3 & 90.7 & 27.9 & 35.8 & 29.2 & 28.8 & 35.3 & 39.7 & 11.1 & 19.1 & 30.5 & 10.7 \\
\hline $\mathrm{Ce}$ & 61.1 & $\begin{array}{l}111 . \\
2\end{array}$ & 47.7 & 1.8 & 84.2 & $\begin{array}{l}101 . \\
3\end{array}$ & 62.5 & 64.7 & 52 & 97 & 58 & 37 & 129 & 75 & 19.2 & 48.7 & 36 & 21.8 \\
\hline $\operatorname{Pr}$ & 6.99 & $\begin{array}{l}10.1 \\
6\end{array}$ & 3.39 & 1.34 & $\begin{array}{l}10.5 \\
5\end{array}$ & $\begin{array}{l}12.2 \\
6\end{array}$ & 5.86 & $\begin{array}{l}22.0 \\
8\end{array}$ & 5.59 & 7.81 & 5.09 & 5.9 & 6.27 & 7.58 & 2.25 & 5.51 & 6.11 & 2.69 \\
\hline $\mathrm{Nd}$ & 29.5 & 33.8 & 9.8 & 5.8 & 44.3 & 41.4 & 20.9 & 77.4 & 21.9 & 25.4 & 16.4 & 22.5 & 20.1 & 24.5 & 9.1 & 23.2 & 22.8 & 10.9 \\
\hline $\mathrm{Sm}$ & 5.13 & 5.81 & 2.89 & 1.32 & 8.25 & 5.19 & 5.29 & $\begin{array}{l}18.4 \\
4\end{array}$ & 3.98 & 5.77 & 2.3 & 4.26 & 3.22 & 5.24 & 1.89 & 5.41 & 4.26 & 2.36 \\
\hline $\mathrm{Eu}$ & 1.33 & 1.25 & 0.36 & 0.54 & 2.15 & 0.95 & 0.14 & 3.08 & 1.16 & 0.45 & 0.66 & 1.33 & 0.95 & 0.24 & 0.77 & 1.37 & 1.28 & 0.86 \\
\hline $\mathrm{Gd}$ & 4.37 & 4.84 & 2.82 & 1.39 & 7.12 & 3.25 & 6.69 & $\begin{array}{l}19.3 \\
8\end{array}$ & 3.31 & 5.82 & 1.62 & 4.01 & 2.25 & 4.79 & 1.65 & 5.36 & 3.86 & 2.76 \\
\hline $\mathrm{Tb}$ & 0.7 & 0.98 & 0.51 & 0.25 & 1.05 & 0.36 & 1.54 & 3.44 & 0.45 & 1.32 & 0.16 & 0.6 & 0.28 & 0.85 & 0.24 & 0.95 & 0.56 & 0.47 \\
\hline Dy & 3.5 & 4.44 & 2.86 & 1.48 & 5.47 & 1.64 & $\begin{array}{l}11.7 \\
3\end{array}$ & 22.4 & 2.27 & 9.5 & 0.8 & 3.5 & 1.46 & 5.12 & 1.21 & 5.78 & 3.27 & 2.91 \\
\hline Ho & 0.71 & 0.84 & 0.56 & 0.3 & 1.01 & 0.24 & 2.88 & 4.39 & 0.48 & 2.32 & 0.14 & 0.73 & 0.25 & 1.07 & 0.21 & 1.18 & 0.68 & 0.65 \\
\hline $\mathrm{Er}$ & 2.12 & 2.48 & 1.35 & 0.87 & 2.73 & 0.66 & 8.66 & $\begin{array}{l}12.9 \\
5\end{array}$ & 1.28 & 6.94 & 0.35 & 1.97 & 0.62 & 3 & 0.59 & 3.39 & 1.81 & 1.90 \\
\hline $\mathrm{Tm}$ & 0.33 & 0.34 & 0.23 & 0.13 & 0.38 & 0.08 & 1.3 & 2.18 & 0.22 & 1.1 & 0.04 & 0.29 & 0.09 & 0.48 & 0.09 & 0.53 & 0.27 & 0.28 \\
\hline $\mathrm{Yb}$ & 2.09 & 1.9 & 1.47 & 0.65 & 2.39 & 0.58 & 7.29 & $\begin{array}{l}13.6 \\
5\end{array}$ & 1.36 & 6.54 & 0.27 & 1.92 & 0.53 & 3.19 & 0.63 & 3.16 & 1.75 & 1.95 \\
\hline $\mathrm{Lu}$ & 0.32 & 0.27 & 0.22 & 0.12 & 0.29 & 0.07 & 0.98 & 2.04 & 0.19 & 0.91 & 0.04 & 0.29 & 0.08 & 0.46 & 0.11 & 0.53 & 0.16 & 0.28 \\
\hline $\mathrm{La} / \mathrm{Yb}_{\mathrm{N}}$ & 9.60 & $\begin{array}{c}20.2 \\
4\end{array}$ & 7.79 & 4.87 & $\begin{array}{c}12.4 \\
3\end{array}$ & $\begin{array}{c}91.2 \\
7\end{array}$ & 2.24 & 4.47 & $\begin{array}{c}13.8 \\
2\end{array}$ & 3.69 & 13.8 & $\begin{array}{c}10.1 \\
0\end{array}$ & $\begin{array}{c}44.8 \\
6\end{array}$ & 8.38 & 11.87 & 4.07 & $\begin{array}{c}11.7 \\
4\end{array}$ & 3.70 \\
\hline Dy/Dy* & 0.54 & 0.60 & 0.67 & 0.91 & 0.68 & 0.46 & 0.82 & 0.67 & 0.48 & 0.63 & 0.51 & 0.58 & 0.56 & 0.54 & 0.58 & 0.77 & 0.57 & 0.65 \\
\hline $\mathrm{Dy} / \mathrm{Yb}_{\mathrm{N}}$ & 1.09 & 1.52 & 1.26 & 1.48 & 1.49 & 1.84 & 1.05 & 1.07 & 1.08 & 0.94 & 1.92 & 1.18 & 1.79 & 1.04 & 1.25 & 1.19 & 1.21 & 0.97 \\
\hline $\mathrm{Dy} / \mathrm{Yb}$ & 1.67 & 2.34 & 1.95 & 2.28 & 2.29 & 2.83 & 1.61 & 1.64 & 1.67 & 1.45 & 2.96 & 1.82 & 2.75 & 1.61 & 1.92 & 1.83 & 1.87 & 1.49 \\
\hline $\mathrm{Eu} / \mathrm{Eu}^{*}$ & 0.86 & 0.72 & 0.39 & 1.22 & 0.86 & 0.71 & 0.07 & 0.50 & 0.98 & 0.24 & 1.04 & 0.98 & 1.08 & 0.15 & 1.33 & 0.78 & 0.96 & 0.34 \\
\hline $\mathrm{Th} / \mathrm{Yb}$ & 6.17 & 10.5 & 20.3 & 0.31 & 4.85 & 36.2 & 4.66 & 0.51 & 5.29 & 5.55 & 34.0 & 5.16 & 44.9 & 13.9 & 5.08 & 1.01 & 6.80 & 1.23 \\
\hline
\end{tabular}




$\begin{array}{rrrrrrrrrrrrrrrrrrrrrr} & & 3 & 4 & & & 1 & & & & & 7 & & 1 & 8 & \\ \mathrm{La} / \mathrm{Nb} & 3.35 & 2.99 & 1.06 & 47.00 & 3.15 & 15.1 & 2 & 1.68 & 4.32 & 5.17 & 2.45 & 3.94 & 2.42 & 3.39 & 0.96 & 3.08 & 1.91 & 3.10 & 2.28 \\ \mathrm{Cs} / \mathrm{La} & 0.30 & 0.03 & 0.17 & 0.02 & 0.04 & 0.03 & 0.25 & 0.01 & 0.40 & 0.02 & 0.03 & 0.22 & 0.26 & 0.34 & 0.42 & 1.02 & 0.89 & 0.26 \\ \mathrm{Ba} / \mathrm{Th} & 43.3 & 47.3 & 15.2 & 125.0 & 64.4 & 59.2 & & 2.71 & 90.7 & 78.1 & 11.3 & 85.1 & 79.1 & 58.9 & 5.00 & 112.1 & 129.3 & 43.7 & 67.0 \\ & 3 & 5 & 2 & 0 & 8 & 9 & & 1 & 9 & 9 & 3 & 1 & 4 & & 9 & 8 & 7 & 8 \\ \mathrm{Ba} / \mathrm{La} & 18.7 & 16.5 & 26.7 & 5.32 & 16.9 & 15.8 & & 3.79 & 7.00 & 20.1 & 11.5 & 26.8 & 27.1 & 39.7 & 5.61 & 32.34 & 21.68 & 17.0 & 15.0 \\ & 6 & 8 & 6 & & 6 & 4 & & & 8 & 5 & 2 & 9 & 4 & & & \end{array}$

Fig. 9A (2174-2158 Ma metagranitoids 1 and 2) highlights the distinction between the high $\mathrm{K}_{2} \mathrm{O}$ sample (S.2) with a marked positive $\mathrm{Pb}$ anomaly and the low- to medium $\mathrm{K}_{2} \mathrm{O}$ samples $(\mathrm{S} .1,4,5)$. All samples show enriched $\mathrm{K}, \mathrm{Rb}$, Th and Cs contents, negative Nb-Ti anomalies. Two samples (S.1 and S.2) show quite similar negative P anomalies despite that belong to distinct granitoid groups. The diorites (2150 Ma; Fig 9B) show similar LILE, HFSE and LREE patterns with flat HREE depletion. They also show pronounced negative $\mathrm{Nb}$ anomalies and slightly negative Ti anomalies. In the Fig 9C our samples show variable enrichment in $\mathrm{Cs}, \mathrm{Rb}$, Th, U, K and La whereas samples S.6 and S.8 are HREE depleted (flat pattern). The Ba, Nb, P negative anomalies are also observed for all samples where the high $\mathrm{K}_{2} \mathrm{O}$ samples $(\mathrm{S} .20,21)$ yield negative $\mathrm{Sr}$ and $\mathrm{Ti}$ anomalies and the highest positive $\mathrm{Pb}$ anomalies. The younger rocks (<2130 Ma; Fig. 9D) present a similar pattern for the incompatible elements, with $\mathrm{Cs}, \mathrm{Rb}, \mathrm{Ba}, \mathrm{Th}, \mathrm{U}, \mathrm{La}$ and $\mathrm{Ce}$ enrichment, HREE depletion, $\mathrm{Nb}, \mathrm{P}$, and $\mathrm{Ti}$ negative $\mathrm{Pb}$ positive anomalies. Notably the diorites and the younger metagranitoids have similar pattern. From a tectonic point of view the observed $\mathrm{Nb}$-Ti negative anomalies, coupled with $\mathrm{K}, \mathrm{Rb}$, Th and Ce enrichment are characteristic of rocks derived in subduction zones (e.g., Rapp et al., 1991; Saunders et al., 1991). The positive $\mathrm{Pb}$ anomalies are characteristic of K-rich magmas in arc settings. Alternatively this chemistry may be a result from contamination/assimilation during magma ascent through the crust (e.g., Zhang et al., 2009). On the other hand, negative $\mathrm{Sr}$ and $\mathrm{P}$ anomalies might be associated with fractional crystallization of the plagioclase and apatite, respectively (Winchester et al., 2003). 

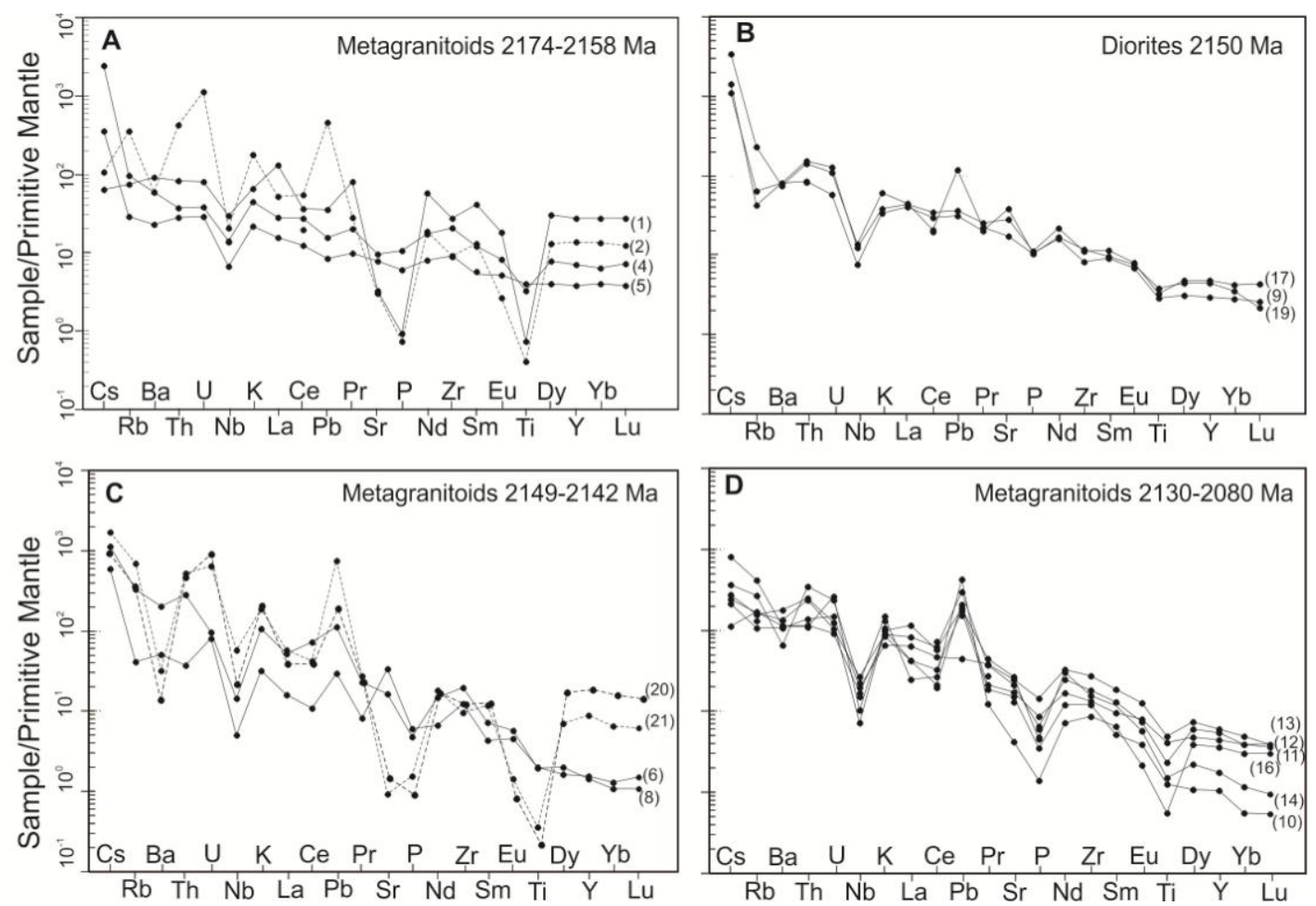

Fig. 9. Primitive mantle normalized spidergram for the orthogneisses, diorites and metagranitoids. Normalized values are from Sun and McDonough (1989). The numbers represent the studied samples. Dashed lines represent the high K samples of our study.

The Dy/Dy* vs. Dy/Yb diagram (Davidson et al., 2013) allows additional inferences about the petrogenetic processes of the studied samples (Fig. 10). The metagranitoids 1, 2 and diorites have Dy/Dy* variations from 0.5 to 0.8 and $\mathrm{Dy}_{\mathrm{N}} / \mathrm{Yb}_{\mathrm{N}}$ from 0.9 to 1.9 (see Table 6), and mainly plot below the MORB field. The data (metagranitoids 1 and 2) with the lowest $\mathrm{Dy}_{\mathrm{N}} / \mathrm{Yb}_{\mathrm{N}}$ values (0.94-1.25) and coupled decrease in Dy/Dy* values (0.48-0.82) could be a result of fractional crystallization of hornblende from a LREE enriched mantle $\left(\mathrm{La} / \mathrm{Yb}_{\mathrm{N}}<5\right.$ indicates depletion in Dy; e.g., $\mathrm{S} .2,5,1,20,21)$. Several samples from the metagranitoids 1 have high $\mathrm{Dy}_{\mathrm{N}} / \mathrm{Yb}_{\mathrm{N}}$ ratios (see Fig. 10), in agreement with some sort of crustal contamination (e.g., S.8, 10, 11, 13 and 14). This could be a response from involvement of old continental material in the origin of these particular rocks, as already pointed out (see previous section), such as the presence of inherited zircons. These samples show LREE enrichment $\left(\mathrm{La} / \mathrm{Yb}_{\mathrm{N}}>12 \mathrm{up}\right.$ to 91 ; see Table 6). 


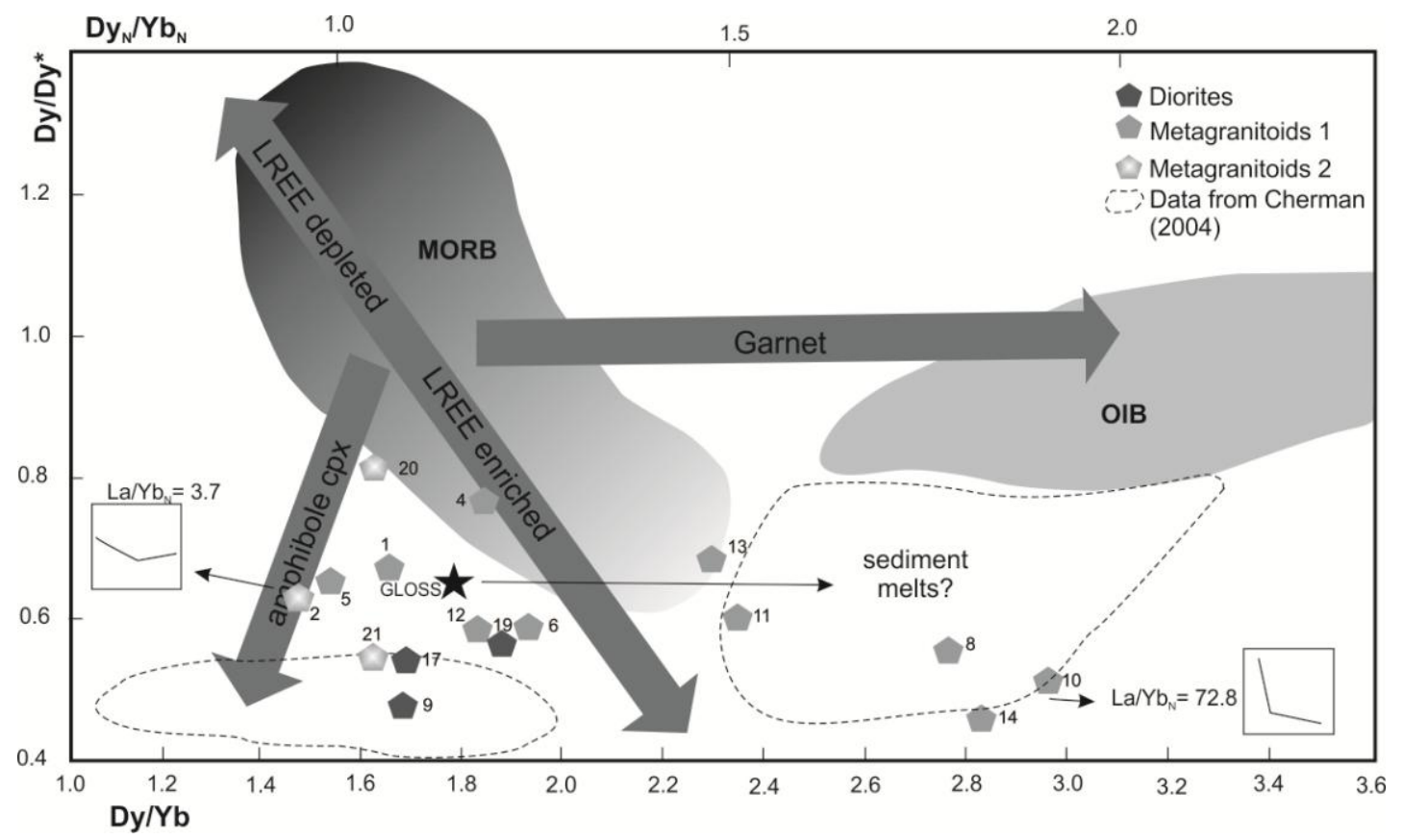

Fig. 10. Plot of Dy/Dy* vs. Dy $/ \mathrm{Yb}_{\mathrm{N}}$ vs. Dy/Yb extended diagram (after Davidson et al., 2013). $\mathrm{Dy} / \mathrm{Dy} *=\mathrm{Dy}_{\mathrm{N}} /\left(\mathrm{La}_{\mathrm{N}}{ }^{4 / 13} \times \mathrm{Yb}_{\mathrm{N}}{ }^{9 / 13}\right)$. The numbers represent the studied samples. Dashed field (Cherman, 2004). See text for details

\section{Petrogenesis and tectonic implications}

The studied rocks show compositions from diorites to granites, are metaluminous to peraluminous, and mostly magnesian. These chemical signatures in conjunction with the common presence of biotite, hornblende and titanite indicate that they can be classified as originally I-type (Fig. 7) rather than crustal derived rocks - as previously published interpretations. Our samples are variably enriched in $\mathrm{K}, \mathrm{Rb}, \mathrm{Th}$, $\mathrm{Ce}$ and $\mathrm{La}$ contents, show high $\mathrm{Th} / \mathrm{Yb}, \mathrm{La} / \mathrm{Yb}_{\mathrm{N}}, \mathrm{La} / \mathrm{Nb}, \mathrm{Cs} / \mathrm{La}, \mathrm{Ba} / \mathrm{Th}, \mathrm{Ba} / \mathrm{La}$ ratios and depleted in $\mathrm{Nb} / \mathrm{La}$ ones (Table 6). They also display negative $\mathrm{Nb}-\mathrm{Ti}$ and $\mathrm{P}$ anomalies (Fig. 9). The chemical characteristics are also consistent with the observed calc-alkaline to high-K calc-alkaline affinities, like arc derived rocks. Particularly, the observed LILE and LREE enrichment for some metagranitoids, such as Sr, Ba, K, La, Ce, Nd (Table 6), suggests some sort of arc maturity (Brown et al., 1984), whereas the high-K contents of particular samples (S.2, 20, 21), might be akin to evolved continental arcs (e.g., Hildreth and Moorbath, 1988). Nevertheless we interpret this particular chemistry as due to crustal assimilation/contamination during magma (I-type) ascent through the crust. In consequence, our data are consistent with a Paleoproterozoic evolved arc setting that has been subjected to old components in the magma genesis. Possible candidates for the crustal contaminants could be the Neoarchean/Early Paleoproterozoic crust of the SFC 
or sediments derived from the Minas Supergroup, given that their derived zircons also yielded Archean/Early Proterozoic ages (Hartmann et al., 2006; Romano et al., 2013).

The new $\mathrm{U}-\mathrm{Pb}$ data indicate that the studied rocks were formed during two separate episodes ranging in time from 2174-2158 Ma and 2149-2109 Ma where examples of fractional crystallization could be envisaged from the isotopic and geochemical constraints. These ages correspond to three coeval batholiths and associated bodies, according to field observations. The first episode involves the Morro do Resende orthogneissic pluton, the Represa de Camargos batholith (and associated pegmatites) and the Ribeirão do Amaral bodies that show crystallization ages between 2174 and $2158 \mathrm{Ma}$. The second episode includes the Macuco de Minas batholith and the Serrinha, Itumirim and Itutinga bodies that show ages between 2131 and $2109 \mathrm{Ma}$. This episode also includes the Ritápolis batholith that yields a LA-ICPMS age of $2149 \pm 10$ $\mathrm{Ma}$, although one slightly younger related pulse has been inferred on the basis of intrusive relationships with the Brumano diorite $(2128 \pm 2 \mathrm{Ma}$; C. Ávila - written communication) - see section 2.

It is worth mentioning that the Represa de Camargos batholith shows crystallization ages between 2173 and 2131 Ma while the Macuco de Minas batholith shows ages between 2174 and 2111 Ma. These differences in ages for both batholiths illustrate that multiple magmatic pulses occurred in the studied area. All batholiths were formed by interaction (different proportions) of pre-existent continental crust with DM and SLCM sources, as suggested by the Sm-Nd $\mathrm{T}_{\mathrm{DM}}$ ages (from 3.2 to $2.3 \mathrm{Ga}$ ) and $\mathrm{Hf}$ $\mathrm{T}_{\mathrm{DM}}$ ages $(3.2$ to $2.5 \mathrm{Ga}$ ), the $\mathrm{Hf}-\mathrm{Sr}-\mathrm{Nd}$ isotopic constraints (positive and negative parameters) and the geochemical inferences.

The youngest episode (2149-2109 Ma) has age match with a well-established plutonic episode $(2130 \mathrm{Ma})$ in the Mineiro belt, that formed the Alto Maranhão batholith (e.g., Seixas et al., 2013). According to these authors, the Alto Maranhão pluton was produced in an oceanic arc on the basis of the geochemical affinity and $\mathrm{Nd}$ isotopic constraints $\left(\varepsilon_{\mathrm{Nd}(\mathrm{t})}\right.$ values from -1.0 to +0.9$)$. In contrast, the Ritápolis batholith was formed in continental arc, given published high ${ }^{87} \mathrm{Sr}^{86} \mathrm{Sr}_{(\mathrm{t})}$ and negative $\varepsilon_{\mathrm{Nd}(\mathrm{t})}$ values (Noce et al., 2000; Teixeira et al., 2014). In this regard, our new data for the Ritápolis rocks (S.8 and S.21; Table 4) show $\varepsilon_{\mathrm{Nd}(\mathrm{t})}$ value of -3.2 and -4.5 , significantly low ${ }^{87} \mathrm{Sr} /{ }^{86} \mathrm{Sr}_{(\mathrm{t})}$ values of $0.7014-0.7032$ and positive $\varepsilon_{\mathrm{Hf}(\mathrm{t})}=+2.4$ and +1.0 . Therefore we conclude that the Ritápolis source is juvenile-derived but subjected to varied crustal 
assimilation/contamination during magma genesis or magma ascent (continental arc setting), such is envisaged here for other samples of the studied area.

We propose three petrogenetic processes for the evolution of the investigated granitoid and dioritic magmas (Figs. 5D, 6B, 10): (i) partial melting of LREE enrichedMORB, basaltic oceanic crust; (ii) partial melting/assimilation of the subcontinental lithospheric mantle and lower crust; (iii) crustal assimilation/contamination of Archean and Paleoproterozoic crust. As an example the variation in the obtained initial ${ }^{176} \mathrm{Hf} /{ }^{177} \mathrm{Hf}$ values $(+2.5$ to -6.6$)$ can be explained due to magma generation by mixing between mantle and continental crust melts. Granitoid rocks formed by differentiation of heterogeneous magmas (SLCM, LC, DM) with variable contamination have been reported elsewhere, based on interpretation of isotopic and chemical constraints (e.g., Nowel et al., 2004; Montecinos et al., 2008; Muñoz et al., 2012).

From a paleotectonic perspective the new $\mathrm{U}-\mathrm{Pb}$ ages support previous models that postulate the Mineiro belt is constituted by several Paleoproterozoic arcs that propagated outboard the Archean landmass of the proto-SFC. The bulk isotopic signature of the studied rocks points to an important role of slab subduction toward the Archean foreland in order to contaminate the I-type magmas. This assessment can be again demonstrated in regional scale by the contrasting isotopic signatures of the Ritápolis and Alto Maranhão batholiths. As a corollary a similar petrogenetic interpretation is hypothesized here for some of the samples located in the particular segment of the Mineiro belt studied here.

Much older Paleoproterozoic orogenic products have been identified inside the Mineiro belt, such as the juvenile suites of Resende Costa - Lagoa Dourada (2.36-2.32 $\mathrm{Ga}$ ) and the Serrinha -Tiradentes (2.23-2.21 Ga). Collectively these suites represent distinct tectonic units in time and space due to distinct orogenic phases, and illustrate the long-lived crustal growth of the main belt. From the above, the preceding arcs could also be possible crustal contaminants for our rocks. The youngest magmatic arc (2.17$2.09 \mathrm{Ga}$ ), first time identified here, eventually accreted to the Archean foreland at ca. $2.0 \mathrm{Ga}$ ago. This is in accordance with the published structural, metamorphic and geochronological evidence over the QF (Noce et al., 2000, 2007; Alkmim and Noce, 2006).

Finally, most of the new U-Pb diagrams yield lower intercepts with significantly younger ages between $436 \mathrm{Ma}$ and $825 \mathrm{Ma}$ though the large errors. This is probably due to $\mathrm{Pb}$-loss during Neoproterozoic-Eocambrian episodes, when a system of diachronic 
nappes was thrust over the southern border of the Mineiro belt (e.g., Campos Neto et al., 2011 and references therein).

Acknowledgements

N. S. Barbosa and W. Teixeira acknowledge the financial support of Fundação de Amparo à Pesquisa (FAPESP, grant 2004/15295-7) and Coordenação de Aperfeiçoamento de Pessoal de Nível Superior (CAPES; Doctoral grant). We thank M. A. S. Basei (CPGeo-USP) for assistance during the U-Pb analysis and the interpretation. C. A. Ávila and W. Teixeira are grateful to the Brazilian Research Council-CNPq for providing continued support for research (grants 2009/53818-5, 478805/2010-1 and 302917/2009-8).

\section{References}

Albarède, F., 1995. Introduction to Geochemical Modeling. Cambridge University Press, Great Britain, 543 pp.

Alkmim, F.F., Noce, C.M., 2006. Outline of the geology of Quadrilátero Ferrífero. In: Alkmim, F.F., Noce, C.M. (Eds.). The Paleoproterozoic Record of São Francisco Craton. IGCP-509 Field Workshop, Bahia and Minas Gerais. Field Guide and Abstracts, pp. 37-73.

Alkmim, F.F., Martins-Neto, M.A., 2012. Proterozoic first-order sedimentary sequences of the São Francisco craton, eastern Brazil. Marine and Petroleum Geology $33,127-139$.

Ávila, C.A., Teixeira, W., Bongiolo, E.M., Dussin, I.A., 2014. The Tiradentes suite and its role in the Rhyacian evolution of the Mineiro belt-São Francisco Craton: geochemical and U-Pb geochronological evidences. Precambrian Research 243, 221251.

Ávila, C.A., Teixeira, W., Cordani, U.G., Moura, C.A.V., Pereira, R.M., 2010. Rhyacian (2.23 2.20 Ga) juvenile accretion in the southern São Francisco craton, Brazil: Geochemical and isotopic evidence from the Serrinha magmatic suite, Mineiro belt. Journal of South American Earth Sciences 29, 464-482.

Ávila, C.A., 2000. Geologia, petrografia e geocronologia de corpos plutônicos Paleoproterozóicos da borda meridional do Cráton São Francisco, região de São João del Rei, Minas Gerais. Universidade Federal do Rio de Janeirio, 401 pp. 
Ávila, C.A., Teixeira, W., Cordani, U.G., Barrueto, H.R., Pereira, R.M., Martins, V.T.S., Dunyi, L., 2006. The Glória quartz-monzodiorite isotopic and chemical evidence of arc-related magmatism in the central part of the Paleoproterozoic Mineiro belt, Minas Gerais State, Brazil. Academia Brasileira de Ciências 78, 543-556.

Ávila, C.A., Cherman, A.F., Valença, J.G., 2008. Dioritos Brumado e Rio Grande: geologia e relação com o metamorfismo paleoproterozóico do Cinturão Mineiro, borda meridional do Cráton São Francisco, Minas Gerais. Arquivos do Museu Nacional 67, $248-277$.

Barbosa, N.S., Teixeira, W., Ávila, C.A., 2013. Rochas Siderianas na porção sul do Cráton do São Francisco (2468-2414 Ma) - Cinturão Mineiro. SGS - Simpósio de geologia do sudeste. Juiz de Fora/MG.

Beard, B.L., Johnson, C.M., 1997. Hafnium isotope evidence for the origin of Cenozoic basaltic lavas from the southwestern United States. Journal of Geophysical Research 102 (B9), 20, 149-20, 178.

Bizzi, L.A., Smith, B.C., De Witt, M.J., Macdonald, I., Armstrong, R.A., 1994. Isotope characteristics of the lithospheric mantle underlying the SW São Francisco craton margin, Brazil. International symposium on the Physics and Chemistry of the Upper Mantle, Invited lectures, pp. 227-256.

Black, L.P., Kamo, S.L., Allen, C.M., Aleinikoff, J.N., Davis, D.W., Korsch, R.J., Foudoulis, C., 2003. TEMORA 1: a new zircon standard for Phanerozoic U-Pb geochronology. Chemical Geology 200, 155-170.

Blichert-Toft, J., Albarede, F., 1997. The Lu-Hf isotope geochemistry of chondrites and the evolution of the mantle-crust system. Earth and Planetary Sciences Letters 148, 243-258.

Brown, G.C., Thorp R.S., Webb, P.C., 1984. The geochemical characteristic of granitoids in contrasting arcs and comments on magma source. Journal of the Geological Society of London 141, 413-26.

Campos, J.C.S., Carneiro, M.A., Basei, M.A.S., 2003. U-Pb evidence for Late Neoarchean crustal reworking in the southern São Francisco Craton (Minas Gerais, Brazil). Anais da Academia Brasileira de Ciências 75, 497-511.

Campos, J.C.S., Carneiro, M.A., 2008. Neoarchean and Paleoproterozoic granitoids marginal to the Jeceaba-Bom Sucesso lineament (SE border of the southern 
São Francisco craton): Genesis and tectonic evolution. Journal of South American Earth Sciences 26, 463-484.

Campos Neto, M.C., Basei, M.A.S., Janasi, V.A., Moraes, R., 2011. Orogen migration and tectonic setting of the Andrelândia Nappe system: An Ediacaran western Gondwana collage, south of São Francisco craton. Journal of South American Earth Sciences 32, 393-406.

Chappel, B.W., 1984. Source rocks of I- and S-type granites in the Lachlan Fold Belt, southeastern Australia. Philosophical Transactions of the Royal Society of London A $310,693-707$.

Cherman, A.F., 2004. Geologia, petrografia e geocronologia de ortognaisses paleoproterozoicos da borda meridional do Cráton do São Francisco, na região entre Itumirim e Nazareno, Minas Gerais. PhD Thesis, DG-UFRJ, Rio de Janeiro, 259p.

Cherman, A.F., Valença, J.G., 2005. Geologia e geocronologia dos ortognaisses paleoproterozóicos da borda meridional do Craton do São Francisco, entre as cidades de Nazareno e Lavras, sul de Minas Gerais. Anais do Simpósio sobre o craton São Francisco, Salvador. SBG 1, 147-150.

Corrêa Neto, A.V., Modesto, A.M. de, Caputo Neto, V., Guerrero, J.C., 2012. Alteração hidrotermal em zona de cisalhamento associada ao Lineamento Congonhas, sul do Quadrilátero Ferrífero, Minas Gerais. Anuário do Instituto de Geociências-UFRJ, $35(2), 55-64$.

Cox, K.G., Bell, J.D., Pankhurst, R.J., 1979. The interpretation of igneous rocks, George Allen and Unwin, London, 450p.

Davidson, J., Turner, S., Plank, T., 2013. Dy/Dy* variations arising from mantle sources and petrogenetic processes. Journal of Petrology 54 (3), 525-537.

DePaolo, D.J., 1981. Nd isotopic studies; some new perspectives on Earth structure and evolution. Transactions of American Geophysics Union 62, 137-140.

Dickin, A.P., 2005. Radiogenic isotope geology. 2ns edition. Cambridge University, 492p.

Duarte, B.P., Heilbron, M., Nogueira, J.R., Tupinambá, M., Silva, L.G.E., Almeida, J.C.H., Guia, C., Prado, J., Succena, M., Soares, A.C.P., Noce, C.M., 2003. Mapa geológico das Folhas Juiz de Fora: In: Pedrosa Soares, A.C., Noce, C.M., Trouw, R., Heilbron, M. (coordenadores) - Projeto Sul de Minas: map (1:100.000) and reports. Comig-Secretaria de Estado de Desenvolvimento Econômico de Minas Gerais. 822p. 
Elholou, S., Belousova, E., Griffin, W.L., Peasom, N.J., O’Reilly, S.Y., 2006. Trace element and isotopic composition of GJ red zircon standard by laser ablation. Geochemical Cosmochemical Acta 70, i18, p. A158.

Frost, B.R., Barnes, C.G., Collins, W.J., Arculus, R.J., Ellis, D.J., Frost, C.D., 2001. A geochemical classification for granitic rocks. Journal of Petrology 42, 20332048.

Gibson, S.A., Thomson, R.N., Leonardos, O.H., Dickin, A.P., Mitchell, J.G., 1995. The late Cretaceous impact of the Trindade mantle plume: evidence of largevolume, mafic, potassic magmatism in SE Brazil. Journal of Petrology 36(1), 189-229.

Goulart, L.M.A., Carneiro, M.A., 2013. New evidence of Neoarchean crustal growth in southern São Francisco Craton: the Carmópolis de Minas Layered Suite, Minas Gerais, Brazil. Brazilian Journal 66(4), 447-454.

Griffin, W.L., Belousova, E.A., Shee, S.R., Pearson, N.J., O’Reilly, S.Y., 2004. Archean crustal evolution in the northern Yilgarn Craton: U-Pb and Hf isotope evidence from detrital zircons. Precambrian Research 131, 231-282.

Hartmann, L.A., Endo, I., Suita, M.T.F., Santos, J.O.S., Frantz, J.A., Carneiro, M.A., MacNaughton, N.J., Barley, M.E., 2006. Provenience and age delimitation of Quadrilátero Ferrífero sandstone based on zircon U-Pb isotopes. Journal of South American Earth Sciences 20, 273-285.

Heilbron, M., Gonçalves, M.L., Teixeira, W., Trouw, R.A.J., Padilha, A.V., Kawashita, K., 1989. Geocronologia da região entre Lavras, São João del Rei, Lima Duarte e Caxambu (MG). Anais da Academia Brasileira de Ciências 61, 177-199.

Heilbron, M., Duarte, B.P., Valeriano, C.M., Simonetti, A., Machado, N., Nogueira, J.R., 2010. Evolution of reworked Paleoproterozoic basement rocks within the Ribeira belt (Neoproterozoic), SE-Brazil, based on U-Pb geochronology: Implications for paleogeographic reconstructions of the São Francisco-Congo paleocontinent. Precambrian Research 178, 136-148.

Hildreth, W., Moorbath, S., 1988. Crustal contributions to arc magmatism in the Andes of Central Chile. Contributions to Mineralogy and Petrology 98, 455-489.

Johnson, C.M., Shirey, S.B., Barovich, K.M., 1996. New approaches to crustal evolution and the origin of granitic rocks: What can the Lu-Hf and Re-Osi sotope systems tell us? Transactions of the Royal Society of Edinburgh Earth Sciences 87, 339352. 
Kösler, J., Fonneland, H., Sylvester, P., Tubrett, M., Pedersen, R.B., 2002. U-Pb dating of detrital zircons for sediment provenance studies, a comparison of laser ablation ICP14 MS and SIMS techniques. Chemical Geology 182, 605-618.

Lana, C., Alkmim. F.F., Armstrong, R., Scholz, R., Romano, R., Nalini, H.A., 2013. The ancestry and magmatic evolution of Archaean TTG rocks of the Quadrilátero Ferrífero province, southeast Brazil. Precambrian Research 230, 1-30.

Ludwig, K.R., 2000. Isoplot 3.0: A Geochronological Toolkit for Microsoft Excel, vol. 4. Berkeley Geochronology Center Special Publication, p. 71.

Ludwig, K.R., 2001. SQUID 1.03: a user's manual. Berkeley Geochronology Center Special Publication 2, 17p.

Ludwig, K.R., 2003. User's manual for ISOPLOT 3.00. A geochronological toolkit for Microsoft Excel. Berkeley Geochronological Center Special Publication 4, $70 \mathrm{p}$.

Machado, N., Carneiro, M.A., 1992. U-Pb evidence of late Archaean tectonothermal activity in southern São Francisco shield, Brazil. Canadian Journal of EarthSciences 29, 2341-2346.

Maniar, P.D., Picolli, P.M., 1989. Tectonic discrimination of granitoids. Geological Society of American Bulletin 101, 635-643.

Martin, H., 1994. The Archaean grey gneisses and the genesis of the continental crust. In: Condie, K.C. (Ed.) Archaean Crustal Evolution, Developments in Precambrian Geology. Elsevier, Amsterdam 11, 205-59.

Marshak, S., Alkmim, F.F., Jordt-Evangelista, H., 1992. Proterozoic crustal extension and the generation of dome-and-keel structure in an Archean granitegreenstone terrane. Nature 357, 491-493.

Montecinos, P., Schärer, U., Vergara, M., Aguirre, L., 2008. Lithospheric origin of Oligocene-Miocene magmatism in Central Chile: $\mathrm{U}-\mathrm{Pb}$ ages and $\mathrm{Sr}-\mathrm{Pb}-\mathrm{Hf}$ isotope composition of minerals. Journal of Petrology 49, 555-580.

Muñoz, M., Charrier, R., Fanning, C.M., Maksaev, V., Deckart, K., 2012. Zircon Trace Element and O-Hf Isotope Analyses of Mineralized Intrusions from El Teniente Ore Deposit, Chilean Andes: Constraints on the Source and Magmatic Evolution of Porphyry Cu-Mo Related Magmas. Journal of Petrology 17, 1-32.

Neri, M.E.N.V., Rosière, C.A., Lana, C.C., 2013. Supergrupo Minas na Serra de Bom Sucesso, extremo sudoeste do Quadrilátero Ferrífero - MG: Petrografia, 
geoquímica e isótopos de U-Pb. Revista Geologia USP, Série Científica 13 (2), 117 202.

Noce, C.M., Pedrosa-Soares, A.C., Silva, L.C., Armstrong, R., Piuzana, D., 2007. Evolution of polycyclic basement complexes in the Araçuaí Orogen, based on $\mathrm{U}-\mathrm{Pb}$ SHRIMP data: implication for Brazil-Africa links in Paleoproterozoic time. Precambrian Research 159, 60-78.

Noce, C.M., Teixeira, W., Quéméneur, J.J.G., Martins, V.T.S., Bolzachini, E., 2000. Isotopic signatures of Paleoproterozoic granitoids from southern São Francisco Craton, NE Brazil, and implications for the evolution of the Transamazonian Orogeny. Journal of South American Earth Sciences 13, 225-239.

Nowell, G.M., Pearson, D.G., Bell, D.R., Carlson, R.W., Smith, C.B., Kempton, P.D., Noble, S.R., 2004. Hf isotope systematics of kimberlites and their megacrysts: new constraints on their source regions. Journal of Petrology 45, 1583-1612.

Peccerillo, A., Taylor, S.R., 1976. Geochemistry of Eocene calkalkaline volcanic rocks from the Kastamonu area, northern Turkey. Contributions toMineralogy and Petrology 58, 61-83.

Petronilho, L.A., 2009. O método Sm-Nd no CPGeo-IGc-USP: procedimentos analíticos atualmente em rotina. Simpósio 45 anos de Geocronologia no Brasil, Instituto de Geociências, USP. Boletim de Resumos Expandidos, pp. 116-118.

Pinese, J.P.P., 1997. Geoquímica, Geologia Isotópica e Aspectos petrológicos dos Diques Máficos Pré-Cambrianos da Região de Lavras (MG), Porção Sul do Cráton do São Francisco. PhD Thesis, Instituto de Geociências da Universidade de São Paulo. 178 .

Quéméneur, J.J.G., Noce, C.M., 2000. Geochemistry and petrology of felsic and mafic suites related to the Paleoproterozoic Transamazonian orogeny in Minas Gerais, Brazil. Revista Brasileira de Geociências 30, 87-90.

Quéméneur, J.J.G, Ribeiro, A., Paciullo, F., Heilbron, M., Trouw, R., Valença, J., Noce, C.M. 2003. Mapa geológico da Folha Lavras. In: Pedrosa Soares, A.C., Noce, C.M., Trouw, R., Heilbron, M. (Eds.) Projeto Sul de Minas: map (1:100.000) and reports. Comig-Secretaria de Estado de Desenvolvimento Econômico de Minas Gerais. 822 p.

Rapp, R.P., Watson, E.B., Miller, C.F., 1991. Partial melting of amphibolite/eclogite and the origin of Archean trondhjemites and tonalites. Precambrian Research 51, 1-25. 
Ribeiro, A., Teixeira, W., Dussin, I.A., Ávila, C.A., Nascimento, D., 2013. U-Pb LA-ICP-MS detrital zircon ages of the São João del Rei and Carandaí basins: new evidence of intermittent Proterozoic rifting in the São Francisco paleocontinent. Gondwana Research 24, 713-726.

Romano, R., Lana, C., Alkmim, F.F., Stevens, G., Armstrong, R., 2013. Stabilization of the Southern São Francisco Craton, SE Brazil, through a long-lived and episodic period of potassic magmatism. Precambrian Research 224, 1-20.

Rudnick, R.L., Gao, S., Ling, W.L., Liu, Y.S., McDonough, W.F., 2004. Petrology and geochemistry of spinel peridotite xenoliths from Hannuoba and Qixia, North China Craton. Lithos 77, 609-637.

Sato, K., Tassinari, C.C.G., Kawashita, K., Petronilho, L., 1995. O Método Geocronológico Sm-Nd no IG/USP e suas aplicações. Anais da Academia Brasileira de Ciências 67, 313-336.

Sato, K., Basei, M.A.S., Siga Junior, O., Onoi, A.T., 2010. In situ U-Th-Pb isotopic analyses by excimer laser ablation/ICP-MS on Brazilian megacrystal xenotime: First results on U-Pb isoptes at CPGeo-IGC-USP. VII SSAGI-South American Simposium on Isotope Geology, Brasília, Abstracts, pp. 349-352.

Sato, K., Siga Jr., O., Silva, J.A., McReath, I., Liu, D., Iizuka, T., Rino, S., Hirata, T., Sproesser, W.M., Basei, M.A.S., 2009. In Situ Isotopic Analyses of U and Pb in Zircon by Remotely Operated SHRIMP II, and Hf by LA-ICP-MS: an Example of Dating and Genetic Evolution of Zircon by ${ }^{176} \mathrm{Hf} /{ }^{177} \mathrm{Hf}$ from the Ita Quarry in the Atuba Complex, SE Brazil. Geologia USP, Série Cientifica 9 (3), 61-69.

Sato, K., Tassinari, C.C.G., Basei, M.A.S., Siga Júnior, O., Onoe, A.T., Souza, M.D., 2014. Sensitive High Resolution Ion Microprobe (SHRIMP IIe/MC) of the Institute of Geosciences of the University of São Paulo, Brazil: analytical method and first results. Geologia USP, Série Científica 14 (3), 3-18.

Saunders, A.D., Norry, M. J., Tarney, J., 1991. Fluid influence on the traceelement compositions of subduction zone magmas. Philosophical Transactions of the Royal Society of London Series A - Mathematical Physical and Engineering Sciences $335,377-392$.

Seixas, L.A.R, David, J., Stevenson, R., 2012. Geochemistry, Nd isotopes and U$\mathrm{Pb}$ geochronology of a 2350 Ma TTG suite, Minas Gerais, Brazil: Implications for the crustal evolution of the southern São Francisco craton. Precambrian Research 196-197, 61-80. 
Seixas, L.A.R., Bardintzeff, J-M., Stevenson, R., Bonin, B., 2013. Petrology of the high-Mg tonalites and dioritic enclaves of the ca.2130 Ma Alto Maranhão suite: Evidence for a major juvenile crustal addition event during the Rhyacian orogenesis, Mineiro Belt, southeast Brazil. Precambrian Research 238, 18-41.

Shand, S.J. 1943. Eruptive rocks: their genesis, composition, classification, and their relation to ore-deposits, with a chapter on meteorites. New York.

Söderlund, U., Patchett, J.P., Vervoort J.D., Isachsen C.E., 2004. The ${ }^{176} \mathrm{Lu}$ decay constant determined by $\mathrm{Lu}-\mathrm{Hf}$ and $\mathrm{U}-\mathrm{Pb}$ isotope systematics of Precambrian mafic intrusions. Earth and Planetary Science Letters 219, 311-324.

Souza, A.N, 2009. Evolução petrográfica e geoquímica do granitóide Ritápolis, borda meridional do cráton São Francisco. Dissertação de mestrado. Instituto de Geociências, Universidade Federal do Rio de Janeiro. 120p.

Stacey, J. S., Kramers, J. D., 1975. Approximation of terrestrial lead isotope evolution by a two-stage model. Earth and Planetary Science Letters 26(2), 207-221

Steiger, R.H., Jäger, E., 1977. Subcommision on Geochronology convention on the use of decay constants in geo- and cosmochronology. Earth Planetary Science Letters 36, 359-362.

Sun, S.S., McDonough, W.F., 1989. Chemical and isotopic systematics of oceanic basalts: implication for mantle composition and processes. In: Condie, K.C. (Ed.), Magmatism in the Ocean Basins. Geological Society, London, Special Publications 42, London, pp. 313-345.

Teixeira, W., 1985. A evolução geotectônica da porção meridional do cráton do São Francisco, com base em interpretações geocronológicas. PhD Thesis, IGC-USP, São Paulo, 207p.

Teixeira, W., Sabaté, P., Barbosa, J., Noce, C.M., Carneiro, M. A. 2000. Archean and Paleoproterozoic evolution of the São Francisco Craton, Brazil. In: Cordani, U.G., Milani, E.J., Thomaz Filho, A., Campos, D.A. Tectonic evolution of South America. Rio de Janeiro: SBG, p. 101-137 (Special Publication).

Teixeira, W., Carneiro, M.A., Noce, C.M., Machado, N., Sato, K., Taylor, P.N., 1996. $\mathrm{Pb}, \mathrm{Sr}$ and $\mathrm{Nd}$ isotopic constraints on the Archean evolution of gneissic-granitoid complexes in the southern São Francisco Craton, Brazil. Precambrian Research 78, $151-164$.

Teixeira, W., Cordani, U.G., Nutman, A.P., Sato, K., 1998. Polyphase Archean evolution in the Campo Belo metamorphic complex, Southern São Francisco Craton, 
Brazil: SHRIMP U-Pb zircon evidence. Journal of South American Earth Sciences 11(3), 279-289.

Teixeira, W., Ávila. C.A., Bongiolo, E.M., Hollanda, M.H.B., Barbosa, N.S., 2014.

Age and tectonic significance of the Ritápolis batholith, Mineiro belt (Southern São Francisco

Craton): U-Pb LA-ICPMS, Nd isotopes and geochemical evidence. In: 9th South American Symposium on Isotope Geology, 2014.

Teixeira, W., Ávila, C.A., Dussin, I.A., Corrêa Neto, A.V., Bongiolo, E.M., Santos, J.O.S., Barbosa, N.S., 2015. Zircon U-Pb-Hf, Nd-Sr constraints and geochemistry of the Resende Costa Orthogneiss and coeval rocks: new clues for a juvenile accretion episode $(2.36-2.33 \mathrm{Ga})$ in the Mineiro belt and its role to the longlived Minas accretionary orogeny. Precambrian Research 256, 148-169.

Teixeira, W., Ávila, C.A., Nunes, L.C., 2008. Nd-Sr isotopic geochemistry and $\mathrm{U}-\mathrm{Pb}$ geochronology of Fé granitic gneiss and Lajedo granodiorite: implications for Paleoproterozoic evolution of the Mineiro belt, southern São Francisco Craton. Geologia USP Série Científica 8, 53-73.

Toledo, C.L.B., 2002. Evolução geológica das rochas máficas e ultramáficas no Greenstone Belt Barbacena, na região de Nazareno, MG. PhD Thesis, IG-UNICAMP, Campinas, 307 p.

Vervoort, J.D., Blichert-Toft, J., 1999. Evolution of the depleted mantle: Hf isotope evidence from juvenile rocks through time. Geochimica et Cosmochimica Acta 63, 533-556.

Vervoort, J.D., Patchett, P.J., Blichert-Toft, J., Albarède, F., 1999. Relationships between Lu-Hf and Sm-Nd isotopic systems in the global sedimentary system. Earth and Planetary Science Letters 168, 79-99.

Vollmer, R., 1976. Rb-Sr and U-Th-Pb systematics of alkaline rocks: The alkaline rocks of Italy, Geochimica and Cosmochimica Acta 40, 283 - 295.

Whitney, D.L., Evans, B.W., 2010. Abbreviations for names of rock-forming minerals. American Mineralogist 95, 185-187.

Winchester, J.A., Pharaoh, T.C., Verniers, J., 2003. Palaeozoic Amalgamation of Central Europe: London, Geological Society of London, Special publication 201, 19-36. 
Zhang, J.J., Zheng, Y.F., Zhao, Z.F., 2009. Geochemical evidence for interaction between oceanic crust and lithospheric mantle in the origin of Cenozoic continental basalts in east-central China. Lithos 110, 305-326. 


\section{CAPÍtULO 5}

\section{$5 \quad$ Súmula, conclusões e modelo evolutivo}

Este estudo definiu idades de cristalização de rochas plutônicas e respectivas inferências petrogenéticas e tectônicas ligadas à evolução do CM. Para tanto foram utilizados dados geocronológicos U-Pb (SHRIMP e LA-ICPMS), geoquímicos (rocha total - elementos maiores e traços) e isotópicos ( $\mathrm{Nd}, \mathrm{Sr}$ e $\mathrm{Hf})$.

O CM é o segmento crustal Paleoproterozoico situado no extremo sul do Cráton do São Francisco. Esta região é composta por uma variedade de metagranitoides e sequências metavulcanossedimentares (e.g., xistos, gonditos, quartzitos, filitos e BIF's), metamorfisados em baixo a médio grau. Neste contexto, as rochas mais antigas (batólito Cassiterita) são metatonalitos/trondhjemitos de composição TTG, enquanto que as mais jovens (batólito Macuco de Minas, Represa de Camargos e Ritápolis) representam uma variedade de tonalitos a granitos/leucogranitos com gabros e dioritos associados. Os limites do CM são aproximados às zonas de cisalhamentos regionais (Figura 18; Jaceaba Bom Sucesso e Congonhas-Itaverava). A extremidade sudoeste do lineamento Jaceaba Bom Sucesso (a porção mais a oeste) é limitada por rochas paleoproterozoicas aqui identificadas de 2,11 Ga, que contrapõem fisicamente ao embasamento arqueano do CSF.

Os dados isotópicos, geoquímicos e de campo de várias amostras sugerem misturas entre o material juvenil e a crosta continental pretérita. Àquelas localizadas mais próximas ao antepaís arqueano possuem valores de $\varepsilon_{\mathrm{Nd}(\mathrm{t})}$ mais negativos e maiores razões ${ }^{87} \mathrm{Sr} /{ }^{86} \mathrm{Sr}_{(\mathrm{t})}$, também é possível identificar uma maior quantidade de xenólitos félsicos nesta direção. Dessa forma verifica-se que existe um aumento gradativo no grau de contaminação crustal em direção as regiões meridionais do CM.

Em geral, as rochas plutônicas do CM localizadas na porção sudoeste são mais jovens (ca. 2,1 Ga) do que aquelas à nordeste (ca. 2,3 Ga). Em uma perspectiva cronológica, o CM apresenta três eventos tectono-magmático distintos: (i) 2,47-2,33 Ga, Ortognaisses Cassiterita e Resende Costa-Lagoa Dourada (e.g., Seixas et al., 2012; Teixeira et al., 2015); (ii) 2,23-2,20 Ga, suíte Serrinha-Tiradentes e ortognaisse Nazareno de derivação juvenil (e.g., Ávila et al., 2010; 2014); (iii) 2,17-2,09 Ga, os batólitos Alto Maranhão (Seixas et al., 2013), Macuco de Minas, Represa de Camargos e Ritápolis. 
A Figura 34 sumariza o modelo petrogenético que ilustra os 4 arcos propostos para a geração do CM. As rochas do batólito Cassiterita, do ortognaisse Resende Costa e da suíte Lagoa Dourada foram interpretadas aqui como pertencentes ao mesmo arco magmático (flecha 1), com gênese a partir da fusão do manto (Figura 34). O arco Serrinha-Tiradentes em conjunto com as rochas do ortognaisse Nazareno fazem parte do segundo arco magmático gerado por fusão do manto (flecha 2; Figura 34) em ambiente oceânico. O arco mais jovem é composto por rochas dos batólitos Macuco de Minas, Represa de Camargos e Ritápolis, a Figura 34 (flecha 3) indica que estas rochas apresentam uma gênese a partir da fusão do manto com contaminação da crosta continental, em ambiente de arco continental. Tentativamente este evento tectonotermal pode incluir o batólito Alto Maranhão, o qual estaria correlacionado ao evento mais tardio. Porém, dados obtidos por Seixas et al. (2013) interpretam estas rochas como derivadas da fusão do manto (flecha 4) em um arco oceânico. Dados detalhados dos arcos serão apresentados a seguir.

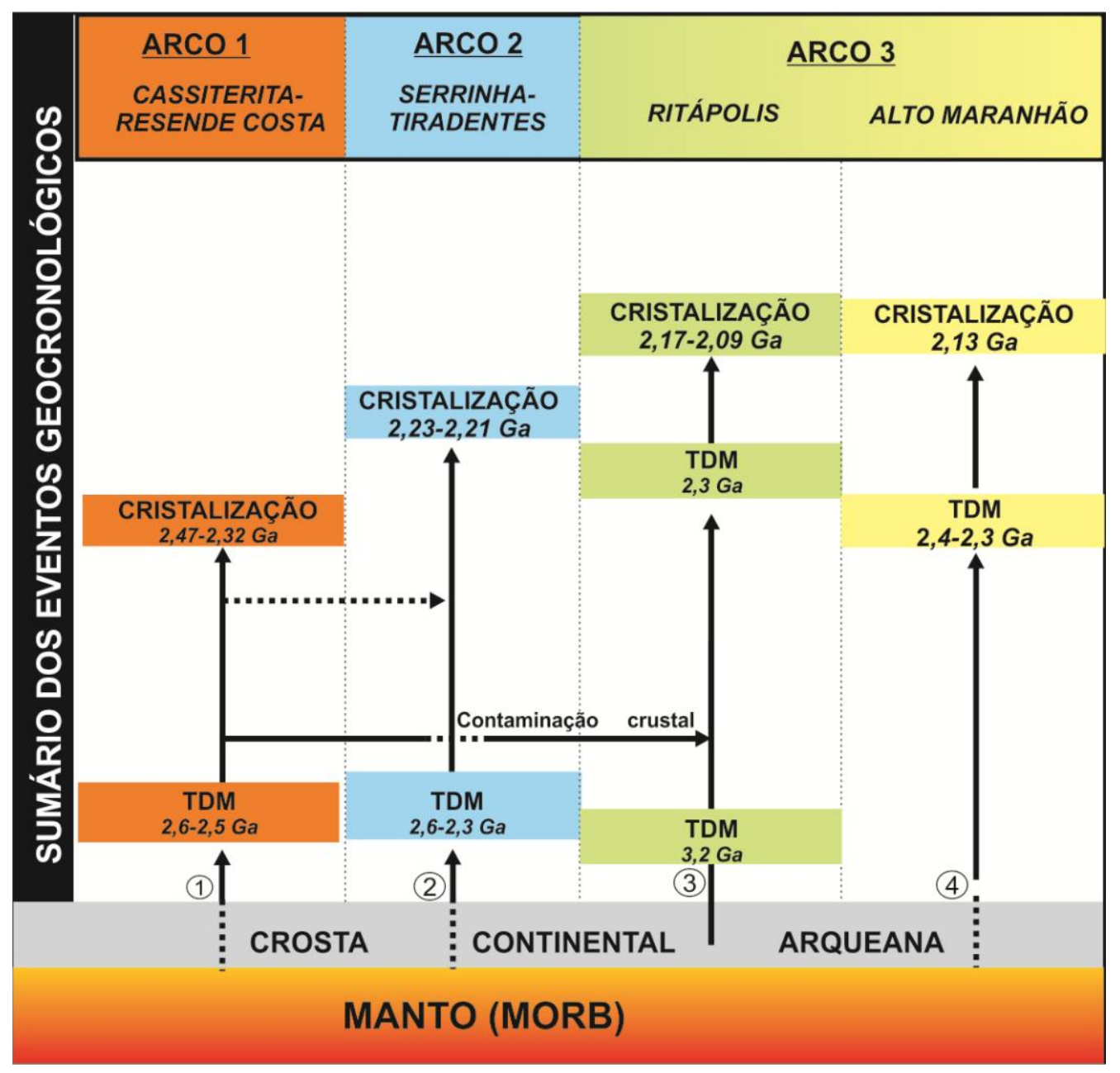

Figura 34. Modelo genético para os arcos do CM. 


\section{(i) Batólito Cassiterita}

O batólito Cassiterita (seção 4.2), o ortognaisse Resende Costa e a suíte Lagoa Dourada (seção 4.3), individualizam um segmento de derivação juvenil e de afinidade TTG em razão de suas similaridades petrográficas, químicas e isotópicas. Dessa forma, essas unidades perfazem a evolução subsequente de um mesmo arco ancestral do CM. Contudo, o plutonismo de 2,4-2,3 Ga é ainda discreto em relação àquelas de 2,1 Ga.

O batólito Cassiterita é composto por tonalitos e trondhjemitos com raros os granodioritos. Os dados químicos, em termos de elementos maiores e traços, são semelhantes. Correspondem a tonalitos magnesianos, levemente peraluminosos, do tipo I, com valores de $\mathrm{Sr} / \mathrm{Y}=24,1-75,3 ; \mathrm{La} / \mathrm{Yb}_{\mathrm{N}}=8,3-55,0$ e $\mathrm{Yb}=0,46-1,21$, sem anomalias de $\mathrm{Eu}$, anomalias positivas de $\mathrm{Pb}$ e negativas de $\mathrm{Nb}$ e Ti e valores crescentes de $\mathrm{Dy} / \mathrm{Yb}_{\mathrm{N}}$ $=0,96-2,06$. Já os valores isotópicos para $\varepsilon_{\text {Ndt }}$ são $(+5,2 \mathrm{a}+1,3),{ }^{87} \mathrm{Sr} /{ }^{86} \mathrm{Sr}_{\mathrm{i}}(0,700-0,702)$, $\varepsilon_{\mathrm{Hft}}(-2$ a -7$)$ e idades Sm-Nd $\mathrm{T}_{\mathrm{DM}}$ de 2,5 Ga. Alguns dados químicos (e.g., anomalias positiva de $\mathrm{Pb}$, crescente valores da razão $\left.\mathrm{Dy} / \mathrm{Yb}_{\mathrm{N}}\right)$ apontam que houve contaminação, em pequena escala, de materiais possivelmente derivados dos sedimentos do Supergrupo Minas. Neste contexto, os valores negativos de $\varepsilon_{\mathrm{Hf}(\mathrm{t})}$ e de $\mathrm{Sr} / \mathrm{Yb}$ e La/ $/ \mathrm{Yb}_{\mathrm{N}}$ sugerem que a fonte contém granada e reteve ERTP (e.g., Lu), já que o coeficiente de partição do Lu para granada é alto. A integração dos dados químicos e isotópicos sugere que as rochas são produto de um manto enriquecido como consequência da fusão parcial de uma crosta oceânica neoarqueana/eosideriana em subducção. Esse processo produziu um magma de composição tonalítica. Em síntese, corresponde a um arco intraoceânico distal ao embasamento arqueano.

De acordo com os dados geocronológicos regionais, este plutonismo estabelece o início da história evolutiva do CM. Em adição, os novos dados de U/Pb em zircão (SHRIMP) variam de 2472 e $2414 \mathrm{Ma}$. Uma análise ${ }^{207} \mathrm{~Pb} /{ }^{206} \mathrm{~Pb}$ no sobrecrescimento metamórfico do zircão (amostra NAT8- 9.1; seção 4.2) produziu idade de $2160 \pm 13$ Ma. Adicionalmente, uma rocha intrusiva no batólito Cassiterita apresenta uma idade $\mathrm{U} / \mathrm{Pb}$ (LA-ICPMS) em zircão de $2165 \mathrm{Ma}$, fato corroborado pela idade de um tonalito no batólito Cassiterita de 2162 Ma obtida em trabalhos desenvolvidos por Ávila et al. (2003). Essas últimas, possivelmente são representantes da evolução do arco continental entre 2,17-2,09 Ga. 


\section{(ii) Ortognaisse Resende Costa}

O ortognaisse Resende Costa e a suíte Lagoa Dourada estão associadas às sequências metavulcanossedimentares Congonhas-Itaverava e Restinga de Baixo, respectivamente (ver anexo 4). As idades U-Pb (SHRIMP e LA-ICPMS) variam entre 2356 e $2317 \mathrm{Ma}$. Os valores isotópicos $\varepsilon_{\mathrm{Nd}(\mathrm{t})}$ variam entre $+3,2$ e $-2,0$ e ${ }^{87} \mathrm{Sr} /{ }^{86} \mathrm{Sr}$ 0,7050,757 e as idades $\mathrm{T}_{\mathrm{DMs}}(\mathrm{Nd})$ entre 2,3 e 2,5 Ga, comprovando a origem a partir de protólitos de curta vivência crustal. Quimicamente, as rochas variam de metaluminosas a levemente peraluminosas, possuem altos valores de $\mathrm{Sr} / \mathrm{Y}\left(\geq 41\right.$ até 81 ) e de $\mathrm{La} / \mathrm{Yb}_{\mathrm{N}}$ ( $\geq 12$ até 46 ), além de baixos valores de LILE e ETRP e sem anomalia de Eu ou com anomalias positivas. Quanto aos elementos maiores e menores as rochas são classificadas como TTGs. Os dados químicos e isotópicos sugerem uma derivação de um manto levemente enriquecido (MORB) em ambiente de arco de ilha, onde a fusão da fonte toleítica foi sujeita a uma menor porcentagem de contaminação crustal. Os valores de $\varepsilon_{\mathrm{Hf}(\mathrm{t})}$ positivos a negativos indicam o envolvimento de componentes crustais. Os metabasaltos da sequência Congonhas-Itaverava (ver anexo 4) possuem valores de $\varepsilon_{\text {Ndt }}$ de $+3,1$ a $-5,8$ e valores de ${ }^{87} \mathrm{Sr}^{86}{ }^{8} r_{i}$ entre 0,703 e 0,708 , os quais em conjunto com as rochas máfica-ultramáficas da sequência Restinga de Baixo podem representar uma crosta oceânica ou o produto de derivação do arco oceânico (Teixeira et al., 2015). Consequentemente, os metabasaltos das duas sequências são as possíveis fontes dos TTGs. Similarmente ao batólito Cassiterita, correspondem ao produto da fusão de um manto enriquecido deixando um resíduo de composição granada anfibolito.

\section{(iii) Suítes Serrinha-Tiradentes e ortognaisse Nazareno}

As suítes Serrinha, Tiradentes e o ortognaisse Nazareno constroem a porção continental a sul da zona de cisalhamento regional Lenheiros. Estas suítes são as únicas que preservam rochas vulcânicas e sub-vulcânicas no CM e estabelecem uma variação de idade entre 2,26 a 2,21 Ga. As rochas são predominantemente granodioríticas, além de andesitos máficos e tonalitos. A composição varia de metaluminosa a peraluminosa, é enriquecidas em álcalis e são definidos como trondhjemitos de baixo $\mathrm{Al}_{2} \mathrm{O}_{3}$. Também apresenta anomalia negativa de Eu, alto conteúdo de ETRP. Os valores isotópicos de $\varepsilon_{\mathrm{Ndt}}$ variam entre $-0,8 \mathrm{a}+2.3$ e os valores de idade $\mathrm{T}_{\mathrm{DM}}$ entre 2,6 a 2,3 $\mathrm{Ga}$. As idades $\mathrm{T}_{\mathrm{DMs}}$ indicam um protólito de curta residência crustal. Os valores de ${ }^{87} \mathrm{Sr} /{ }^{86} \mathrm{Sr}_{\mathrm{i}}$ variam de 0,701 a 0,706 e confirma uma derivação juvenil. Estas rochas são interpretadas como geradas em ambiente de arco oceânico. 
(iv) Batólitos Represa de Camargos, Macuco de Minas e Ritápolis

A partir de 2,17 Ga, o plutonismo félsico foi mais dominante e contínuo no CM. Sua expressiva distribuição regional é destacada em batólitos denominados de Ritápolis, Macuco de Minas e Represa de Camargos. As rochas possuem uma variedade composicional desde tonalitos à granitos os quais documentam o último episódio magmático relacionado ao evento Paleoproterozoico no $\mathrm{CM}$. As idades U-Pb em zircão (SHRIMP e LA-ICPMS) variam de 2164-2109 Ma. Representam múltiplos estágios de intrusões, evidenciados por diferentes idades e composições em um mesmo batólito. A química destes metagranitoides reflete a composição cálcio-alcalina, magnesiana a ferrosa e predominantemente do tipo I. As rochas são levemente peraluminosas e algumas apresentam altos teores de $\mathrm{K}_{2} \mathrm{O}$. Os valores isotópicos de $\varepsilon_{\mathrm{Nd}(\mathrm{t})}$ variam de $-7,3 \mathrm{a}$ $+0,3 ; \varepsilon_{\mathrm{Hf}(\mathrm{t})}+2,5$ a $-6,6 ; \mathrm{Sr} / \mathrm{Sr}_{(\mathrm{i})} 0,700$ a 0,704 e idades $\mathrm{T}_{\mathrm{DM}}(\mathrm{Nd})$ entre 3,2 e 2,3 Ga. O conjunto de dados químicos, isotópicos associados a dados de campo (i.e., xenólitos, variedade composicional) indicam que estas rochas foram derivadas de um manto enriquecido em ambiente de arco continental, adjacente ao antepaís arqueano, com variável contaminação crustal. Esse evento possivelmente está associado ao batólito Alto Maranhão na porção nordeste do CM. Gabros, dioritos e granitoides representam, em conjunto, o intenso magmatismo consanguíneo na província Paleoproterozoica meridional do cráton do São Francisco.

Diferenças significantes (e.g., geológicas, petrográficas, químicas e geocronológicas) entre as rochas dos arcos Ritápolis (2,1 Ga); Serrinha-Tiradentes (2,2 Ga) e Resende Costa-Lagoa Dourada e Cassiterita (2,4-2,3 Ga) sinalizam que esses três segmentos tectônicos são entidades de natureza acrescionária que evoluíram de maneira independente no tempo e espaço (Figura 35). Este diacronismo caracteriza a expressão cronológica que edificou o CM, conforme idealizado no esboço tectônico da Figura 35, entre 2,47-2,09 Ga. A Figura 35 ilustra a evolução tectono-magmática idealizada para os arcos estudados. Como anteriormente mencionado as rochas são integrantes de arcos gerados da fusão da crosta oceânica em subducção em ambiente oceânico e continental (Figura 35). 


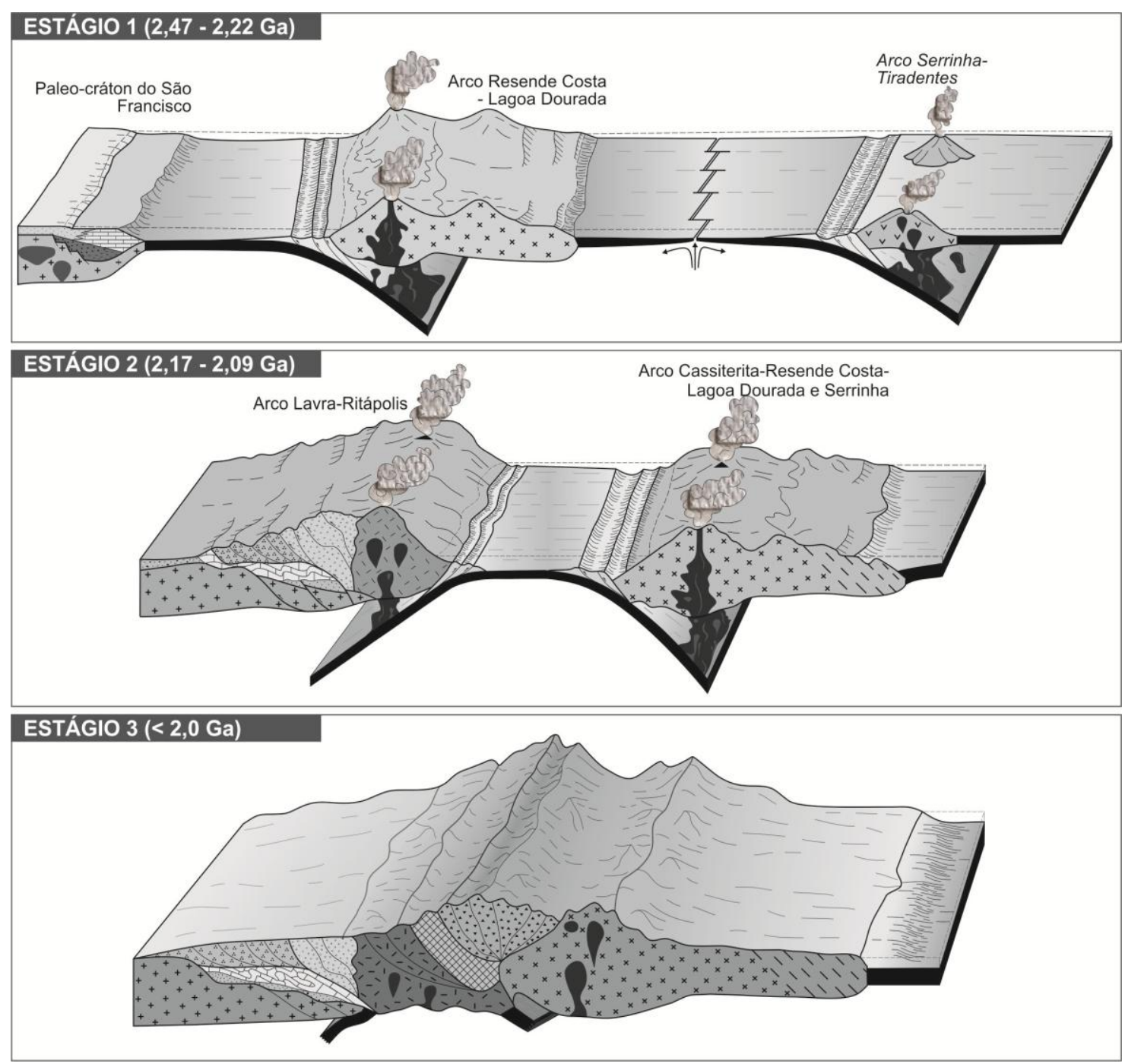

Figura 35. Modelo tectônico esquemático para rochas do $\mathrm{CM}$, durante o paleoproterozoico. Estágio 1: 2,4-2,3 Ga geração do arco 1, que compreende o batólito Cassiterita, o ortognaisse Resende Costa e a suíte Lagoa Dourada em ambiente oceânico, simultâneo a deposição dos carbonatos na margem passiva Minas; 2,2 Ga geração do arco Serrinha. Estágio 2: 2,1 Ga subducção contínua do oceano paleoproterozoico e geração do arco continental. Estágio 3: 2,1-2,0 Ga fechamento do oceano paleoproterozoico e deformação das rochas de arco e do paleo cráton do São Francisco.

Este sistema de arcos consequentes, juntamente com os complexos Mantiqueira e Juiz de Fora (2,35-2,00 Ga), pertenceriam ao denominado orógeno acrescionário Minas recentemente definido por Teixeira et al. (2015). O complexo Mantiqueira foi gerado em um ambiente de arco continental (2,20-2,01 Ga) derivado da fusão e posterior retrabalhamento da crosta continental (Noce et al., 2007). Já o CM envolveu arcos oceânicos e continentais. Contudo, em virtude da evolução polifásica e do overprint neoproterozoico, o limite E/NE entre o Mantiqueira e o CM ainda não é bem estabelecido (e.g., Teixeira et al., 2015). Por outro lado, Noce et al. (2007) indicam que a relação do Mantiqueira e Oeste Congo (e.g., Kimezian) estaria cotejada a orogenias 
diacrônicas como resultado da convergência das massas arqueanas (e.g., proto-cráton São Francisco e Oeste Congo).

O complexo Juiz de Fora (2,20-2,08 Ga) desenvolvido em um ambiente intraoceânico, apresenta a sua fase mais jovem coeva ao batólito Alto Maranhão. Este apresenta uma assinatura juvenil compatível com a geração de rochas do tipo I (Heilbron et al., 2010). Ambos (i.e., Juiz de Fora e Alto Maranhão) podem ter sido gerados em um amplo oceano que separou o cráton do São Francisco do Oeste Congo (Noce et al., 2007), cuja reciclagem iniciou-se em 2,47 Ga através de sucessos arcos magmáticos. Em resumo, os novos dados desta tese indicam uma maior extensão temporal para a orogenia Minas. $O$ arco inicial desta ocorreu afastado do paleocontinente São Francisco e sincronicamente a deposição de carbonatos e dolomitos na margem passiva Minas (i.e., Formação Gandarela, 2420 Ma). Já o arco mais jovem do CM (2,17-2,09 Ga) foi acrescionado à proto-margem do paleocontinente São Francisco, causando remobilizações sobre este. Em consequência o antepaís sofreu encurtamento, formando a arquitetura de domos e quilhas típicas de terrenos arqueanos (Marshak e Alkmim, 1989; Marshak et al., 1992; Chemale Jr. et al., 1994; Brueckner et al., 2000). O registro do soerguimento do Cinturão Mineiro reflete a troca da fonte dos sedimentos do Supergrupo Minas e o caráter da bacia, identificados por zircões detríticos do Grupo Sabará e Itacolomi (e.g., Alkmim e Noce, 2006; Alkmim et al., 2014)

Em escalas regionais e continentais a Orogenia acrescionária Minas pode ser correlacionada ao Orógeno Itabuna-Salvador-Curaçá e Urandi-Paratinga na porção norte do cráton do São Francisco marginal à uma pretérita margem passiva neoarqueana (e.g., Aklmim e Noce, 2006; Rosa, 1999) e ao complexo Kimezian (2085-2040 Ma) no cráton Oeste-Congo (e.g., Noce et al., 2007). Estes orógenos participaram da colagem dos blocos arqueanos na construção do Paleocontinente São Francisco-Oeste Congo (e.g., Ledru et al., 1994; Noce et al., 2007).

A evolução paleoproterozoica acrescionária do sul do cráton do São Francisco é bastante semelhante à evolução de outras regiões no mundo. Em especial, rochas de idade siderianas são encontradas na América do Sul (e.g., cráton Amazônico e província Borborema), Canadá (e.g., cráton Rae), Oeste da África (e.g., Dabakala area) e norte da China (e.g., Lüliang complex), e em outras províncias. Esse evento de dimensões globais representa o processo de consolidação das massas continentais, diretamente relacionado à formação do supercontinente Columbia (Rogers e Santosh, 2009). 


\section{REFERÊNCIAS}

Albarède, F., 1995. Introduction to Geochemical Modeling. Cambridge University Press, Great Britain, 543 pp.

Alkmim, F.F., 2004. O que faz um cráton um cráton? O Cráton São Francisco e as revelações Almedianas ao delimitá-lo. In: Mantesso-Neto, V., Bartorelli, A., Carneiro, C.D.R., Brito-Neves, B.B. (Eds.), Geologia do continente Sul-Americano: Evolução e obra de Fernando Flávio Marques de Almeida. São Paulo, Brazil. Beca Editora, pp. 1735 .

Alkmim, F.F., Marshak, S., 1998. Transamazonian Orogeny in the Southern São Francisco Craton, Minas Gerais, Brazil: Evidence for Paleoproterozoic collision and collapse in the Quadrilátero Ferrífero. Precambrian Research 90, 29-58.

Alkmim, F.F., Martins-Neto, M.A., 2012. Proterozoic first-order sedimentary sequences of the São Francisco craton, eastern Brazil. Marine and Petroleum Geology 33, 127-139.

Alkmim, F. F., Noce, C. M., 2006. Outline of the geology of Quadrilátero Ferrífero. In: Alkmim, F. F., Noce, C. M. (Eds.), The Paleoproterozoic Record of São Francisco Craton. IGCP Field Workshop, Bahia and Minas Gerais. Field Guide and Abstracts, pp. 37-73.

Alkmim, F. F., Brito Neves B. B. B, Alves J. A. C. 1993. Arcabouço tectônico do Cráton do São Francisco - Uma revisão. In: Dominguez, J. M. L. e Misi, A. (Ed.). O Cráton do São Francisco. Salvador, SBG-NBA/SE, SGM, CNPq. p.45-62.

Alkmim, F. F., 2004. O que faz um cráton um cráton? O Cráton São Francisco e as revelações Almedianas ao delimitá-lo. In: Mantesso-Neto, V., Bartorelli, A., Carneiro, C.D.R., Brito-Neves, B.B. (Eds.), Geologia do continente Sul-Americano: Evolução e obra de Fernando Flávio Marques de Almeida. São Paulo, Brazil. Beca Editora, pp. 1735.

Allégre, C. J., and Sutcliffe, C., 2008, Isotope Geology. Cambridge University Press, $512 \mathrm{pp}$.

Almeida, F. F. M. 1977. O Cráton do São Francisco. Revista Brasileira de Geociências 7, 349-364.

Almeida, F.F.M.; HASUI, Y. 1984. O embasamento da Plataforma Sul Americana. In: O Precambriano do Brasil, p. 1-5. Ed. Edgard Blucher, São Paulo, 378p.

Araujo, C.E.G., Cordani, U.G., Basei, M.A.S., Castro, N.A., Sato, K., Sproesser, W.M., 2012. U-Pb detrital zircon provenance of metasedimentary rocks from the Ceará Central and Médio Coreau Domains, Borborema province, NE Brazil: tectonic implication for a long-lived Neoproterozoic active continental margin. Precambrian Research 206- 207, 36-51.

Arndt, N.T., Goldstein, S.L. 1987. Use and abuse of crust-formation ages. Geology $15,893-895$.

Arth, J. G., 1979. Some trace elements in trondhjemites-their implications to magma genesis and paleotectonic setting. In: Barker, F. (Ed.) Trondhjemites, dacites, and related rocks. Amsterdam: Elsevier. p. 123-132.

Ávila, C.A., Teixeira, W., Bongiolo, E.M., Dussin, I.A., 2014. The Tiradentes suite and its role in the Rhyacian evolution of the Mineiro belt-São Francisco Craton: geochemical and UPb geochronological evidences. Precambrian Research 243, 221251.

Ávila, C. A., Teixeira, W., Cordani, U. G., Barrueto, H. R., Pereira, R. M., Martins, V. T. S., Dunyi, L., 2006. The Glória Quartz-Monzodiorite: Isotopic and Chemical 
Evidence of Arc-Related Magmatism in the central part of the Paleoproterozoic Mineiro Belt, Minas Gerais State, Brazil. Academia Brasileira de Ciências 78, 543-556.

Ávila, C. A., Teixeira, W., Cordani, U. G., Moura, C. A. V., Pereira, R. M., 2010. Rhyacian (2.23 2.20 Ga) juvenile accretion in the southern São Francisco craton, Brazil: Geochemical and isotopic evidence from the Serrinha magmatic suite, Mineiro belt. Journal of South American Earth Sciences 29, 464-482.

Ávila, C.A., 2000. Geologia, petrografia e geocronologia de corpos plutônicos Paleoproterozóicos da borda meridional do Cráton São Francisco, região de São João del Rei, Minas Gerais. Tese de Doutorado. Universidade Federal do Rio de Janeiro, 401 p.

Ávila, C. A., Teixeira, W., Vasques, F. S. G., Dussin, I. A., Mendes, J. C., 2012. Geoquímica e idade U-Pb (LA-ICPMS) da crosta oceânica Riaciana do Cinturão Mineiro, borda meridional do Cráton São Francisco. In: $46^{\circ}$ Congresso Brasileiro Geologia, Boletim Resumos. Sociedade Brasileira de Geologia, CD-ROM.

Ávila, C.A., Valenc, a, J.G., Moura, C.A.V., Klein, V.C., Pereira, R.M., 2003. Geoquímicae idade do Tonalito/trondhjemito Cassiterita, borda meridional do Cráton SãoFrancisco, Minas Gerais. Arquivos do Museu Nacional 61, 267-284.

Ávila, C.A., Cherman, A.F., Valença, J.G., 2008. Dioritos Brumado e Rio Grande: geologia e relação com o metamorfismo paleoproterozóico do Cinturão Mineiro, borda meridional do Craton São Francisco, Minas Gerais. Arquivos do Museu Nacional 67, 248-277.

Babinski, M., Chemale, F., William, R., Van Schmus, W.R., 1995. The Pb/Pb age of the Minas Supergroup carbonate rocks, Quadrilátero Ferrífero, Brazil. Precambrian Research 72, 235-245.

Barbosa, J.S.F., Sabaté, P., 2002. Geological features and the Paleoproterozoic collision of four Archaean crustal segments of the São Francisco Craton, Bahia, Brazil. A synthesis. Anais Academia Brasileira Ciências 74(2), 343-359.

Barbosa, J.S.F., Sabaté, P., 2004. Archean and Paleoproterozoic crust of the São Francisco craton, Bahia, Brazil: geodynamic features. Precambrian Research 133, 1-27.

Barbosa, J. S. F., Cruz, S. P., Souza, J. S. 2012. Terrenos Metamórficos do Embasamento. In: J. S. F. Barbosa, J. F. Mascarenhas, L. C. Corrêa-Gomes, J. M. L. Dominguez, J. S. de Souza (Eds.), Geologia da Bahia: Pesquisa e atualização. (1a ed., v.1. 101-199). Salvador-Bahia.

Barbosa, J. S. F, Dominguez, J. M. L. 1996. Texto Explicativo para o Mapa Geológico do estado da Bahia. Escala 1:1.000.000. Salvador: Secretaria da Indústria Comércio e Mineração do Estado da Bahia/SGM/PPPG/FAPEX/CPGG.

Barbosa, N.S., Teixeira, W., Ávila, C.A., Montecinos, P.M., Bongiolo, E.M., 2.17$2.09 \mathrm{Ga}$ crust forming episodes in the Mineiro belt, São Francisco craton, Brazil: U-Pb ages and geochemical constraints. Precambrian Research, submitted for publication.

Barher, F., Arth, J.G., 1976. Generation of trondhjemitic-tonalitic liquids and Archean bimodal trondhjemite-basalt suites. Geology, Boulder, 4,596-600.

Barley, M. E., Bekker, A., Krapez, B. 2005; Late Archean to Early Paleoproterozoic global tectonics, environmental change and the rise of atmospheric oxygen. Earth and Planetary Science Letters 238, 156- 171.

Beard, B.L., Johnson, C.M., 1997. Hafnium isotope evidence for the origin of Cenozoic basaltic lavas from the southwestern United States. Journal of Geophysical Research 102 (B9), 20, 149-20, 178.

Belousova, E.A., Griffin, W.L., O'Reilly, S.Y., 2006. Zircon crystal morphology, trace element signatures and $\mathrm{Hf}$ isotope composition as a tool for petrogenetic 
modelling: examples from eastern Australian granitoids. Journal of Petrology 47, 329353.

Brito Neves, B. B. 2011. The Paleoproterozoic in the South American Continent: Diversity in the Geological time. Journal of South American Earth Sciences 32, 1-20.

Brueckner, H.K., Cunningham, D., Alkmim, F.F., Marshak, S., 2000. Tectonic implications of Precambrian Sm-Nd dates from the southern São Francisco craton and adjacent Araçuaí and Ribeira belts, Brazil. Precambrian Research 99, 255-269.

Campos, J.C.S., 2004. O Lineamento Jeceaba-Bom Sucesso como Limite dos Terrenos Arqueanos e Paleoproterozóicos do Cráton São Francisco Meridional: Evidências Geológicas, Geoquímicas (Rocha Total) e Geocronológicas (U-Pb). Tese de Doutorado, Universidade Federal de Ouro Preto, 191 p.

Campos, J. C. S, Carneiro, M. A., 2008. Neoarchean and Paleoproterozoic granitoids marginal to the Jeceaba-BomSucesso lineament (SE border of the southern São Francisco craton): Genesis and tectonic evolution. Journal of South American Earth Sciences $26463-484$.

Campos, J. C. S., Carneiro, M., Basei, M. A. S., 2003. U-Pb evidence for late Neoarchean crustal reworking in the Southern São Francisco craton (Minas Gerais, Brazil). Anais da Academia Brasileira de Ciências 75 (4), 2-17.

Cawood, P. A., Kröner, A., Collins, W. J., Kusky, T. M., Mooney. W. D., Windley, B. F., 2009. Accretionary orogens through Earth history. Geological Society, London, Special Publications.

Chemale Jr., F., Rosière, C.A., Endo, I., 1994. The tectonic evolution of the Quadrilátero Ferífero, Minas Gerais, Brazil: Precambrian Research 65, 25-54.

Cherman, A.F. 1999. Geologia e Petrografia de áreas dos Greenstone Belts Rio Capivari - Rio das Mortes e Itumirim - Tiradentes e rochas granitóides associadas, entre Nazareno e Lavras (estado de Minas Gerais). Rio de Janeiro. Dissertação de Mestrado, Universidade Federal do Rio de Janeiro, 162p.

Cherman, A. F., 2004. Geologia, petrografia e geocronologia de ortognaisses paleoproterozoicos da borda meridional do Cráton do São Francisco, na região entre Itumirim e Nazareno, Minas Gerais. Tese de doutorado, Universidade Federal do Rio deJaneiro, 259p.

Campos Neto, M.C., Basei, M.A.S., Valdecir, A.J., Moraes, R. 2011. Orogen migration and tectonic setting of the Andrelandia Nappe system: An Ediacaran western Gondwana collage, south of Sãoo Francisco craton. Journal of South American Earth Sciences 32, 393-406.

Condie, K.C., Kröner, A. 2013. The building blocks of continental crust: Evidence for a major change in the tectonic setting of continental growth at the end of the Archean. Gondwana Research 23, 394-402.

Condie, K.C., 2007. Accetionary orogens in space and time. In: Hatcher, R. D. Jr., Carlson, M.P., McBride, J. H. and Martínez Catalan, J. R., eds., 4-D Framework of Continental Crust: Geological Society of America, Memoir 200, pp.145-158, http://dx.doi.org/10.1130/2007.1200(09).

Condie, K.C., O’Neil, C., Aster, R., 2009a. Evidence and implications for a widespread magmatic shutdown for $250 \mathrm{My}$ on Earth: Earth and Planetary Science Letters 28, 294-298.

Condie, K., 2005. Earth as an evolving planetary system. Amsterdam, Elsevier. $447 \mathrm{p}$.

Condie, K.C., 1994. Archean Crustal Evolution. Elsevier Scientific Publishers, Amsterdam (Ed.), 459p. 
Cordani, U.G., Sato, K., 1999. Crustal evolution of the South American Platform, based on $\mathrm{Nd}$ isotopic systematics on granitoids rocks. Episodes, 22 (3), 167-173. Cordani, U.G., Teixeira, W., 2007. Proterozoic accretionary belts in the Amazonian Craton. In: Hatcher, R.D. Jr., Carlson, M.P., McBride, J.H., Martínez-Catalán, J.R. (org.), 4-D Framework of Continental Crust, vol. 200. Geological Society of America, Denver, USA, pp. 297-320.

Cordani, U.G., Teixeira, W., D’Agrella, M.S., Trindade, R.I., 2009. The position of the Amazonian Craton in supercontinents. Gondwana Research 15, 396-407.

Corfu, F., Hanchar, J.M., Hoskin, P.O.W., Kinny, P., 2003. Atlas of zircon textures. In Zircon (eds Hanchar, J. M. \& Hoskin, P.W.O.). Reviews in mineralogy and geochemistry 53, 469-500.

Corrêa Neto, A.V., Modesto, A.M. de, Caputo Neto, V., Guerrero, J.C., 2012. Alteração hidrotermal em zona de cisalhamento associada ao Lineamento Congonhas, sul do Quadrilátero Ferrífero, Minas Gerais. Anuário do Instituto de Geociências-UFRJ, 35 (2), 55-64.

D"eAgrella-Filho. M.S., Trindade, R.I.F., Elming, S.-A., Teixeira, W., Yokoyama, E., Tohver, E., Geraldes, M.C., Pacca, I.I.G., Barros, M.A.S., Ruiz, A.S., 2012. The 1420 Ma Indiavai Mafic Intrusion (SW Amazonian Craton): Paleomagnetic results and implications for the Columbia/Nuna supercontinent. Gondwana Reseach 22, 956-973. http://dx.doi.org/10.1016/j.gr.2012.02.022.

Davidson, J., Turner, S., Plank, T., 2013. Dy/Dy* variations arising from mantle sources and petrogenetic processes. Journal of Petrology 54 (3), 525-537.

De Paolo, D. J. 1988. Neodymium Isotope Geochemistry: An Introduction (1a ed.). Springer: Verlag.

Dewey, J.F., 2007. The secular evolution of plate tectonics and the continental crust: Anoutline. In: Hatcher, R.D. Jr., Carlson, M.P., McBride, J.H., Martínez-Catalán, J.R. (org.), 4-D Framework of Continental Crust, vol. 200. Geological Society of America, Denver, USA, pp. 1-7.

Dickin, A.P., 2005. Radiogenic isotope geology. 2ns edition. Cambridge University, 492p.

Dilek, Y., 2003a. Ophiolite concept and its evolution. In: Dilek, Y., Newcomb, S. (eds.). Ophiolite Concept and the Evolution of Geological Thought. Geological Society of America, Special Paper, 373, 1-16.

Dorr, J. V. N. 1969. Physiographic, stratigraphic and structural development of the Quadrilátero Ferrífero, Minas Gerais, Brazil. U.S. Geological Survey Professional Paper, 641-748 A, 110pp.

Egal, E., Thie’blemont, D., Lahonde`re, D., Guerrot, C., Adi Costea, C., Iliescu, D., Delor, C., Goujou, JC., Lafon, J. M., Tegyey, M., Diaby, S., Kolie'e, P. 2002. Late Eburnean granitization and tectonics along the western and northwestern margin of the Archean Kénéma-Man domain (Guinea, West African Craton). Precambrian Research. $117,57-84$

Eriksson, P.G., Condie, K.C., 2014. Cratonic sedimentation regimes in the ca. 2450-2000 Ma period: Relationship to a possible widespread magmatic slowdown on Earth? Gondwana Res. 25, 30-47.

Evans, D.A.D., Mitchell, R 1765 .N., 2011. Assembly and breakup of the core of Paleoproterozoic-Mesoproterozoic supercontinent Nuna. Geology 39, 443-446, http://dx.doi.org/10.1130/G31654.1

Faure, G. 1986. Principles of isotope geology. John Wiley e Sons. 2 Eds. 589p. Gebauer, D., Schertl, H. P., Brix, M., Schreyer, W., 1997. 35 Ma old ultrahigh-pressure 
metamorphism and evidence for very rapid exhumation in the Dora Maira Massif, Western Alps. Lithos, 41, 5-24.

Gasquet, D., Barbey, P., Adou, M., Paquette, J., 2003. Structure, Sr-Nd isotope geochemistry and zircon $\mathrm{U}-\mathrm{Pb}$ geochronology of the granitoids of the Dabakala area (Côte d'Ivoire): evidence for a $2.3 \mathrm{Ga}$ crustal growth event in the Palaeoproterozoic of West Africa?. Precambrian Res. 127, 329-354.

Gebauer D, Schertl H-P, Brix M, Schreyer W, 1997. 35-Ma-old ultrahigh-pressure metamorphism and evidence for very rapid exhumation in the Dora Maira Massif, Western Alps. Lithos 41, 5-24.

Geraldes, M. C. 2010. Introdução à geocronologia. Sociedade Brasileira de Geolgia.

Griffin, W.L., Wang, X., Jackson, S.E., Pearson, N.J., O'Reilly, S.Y., Xu, X., Zhou, X., 2002. Zircon chemistry and magma genesis, SE China: in-situ analysis of Hf isotopes, Pingtan and Tonglu igneous complexes. Lithos 61, 237-269.

Griffin, W.L., Belousova, E.A., Shee, S.R., Pearson, N.J., O'Reilly, S.Y., 2004. Archean crustal evolution in the northern Yilgarn Craton: U-Pb and Hf-isotope evidence fromdetrital zircons. Precambrian Research 131, 231-282.

Harley, S. L., Kelly, N. M. 2007. Zircon Tiny but Timely. Elements, v.3 , 13-18.

Hartmann, L. A., Endo, I., Suita, M. T. F., Santos, J. O. S., Frantz, J. A., Carneiro, M. A., MacNaughton, N. J., Barley, M. E., 2006. Provenience and age delimitation of Quadrilátero Ferrífero sandstone based on zircon U-Pb isotopes. Journal of South American Earth Sciences 20, 273-285.

Hawkesworth, C. J., Kemp, A. I. S., 2006. Evolution of the continental crust. Nature 443, 811-817.

Hawkesworth, C., Cawood, P., Kemp, T., Storey, C., Dhuime, B., 2009. A Matter of Preservation Science 323 (5910), 49-50, http://dx.doi.org/10.1126/science.1168549.

Heilbron, M., Duarte, B. P., Valeriano, C. M., Simonetti, A., Machado, N., Nogueira, J. R., 2010. Evolution of reworked Paleoproterozoic basement rocks within the Ribeira belt (Neoproterozoic), SE-Brazil, based on U-Pb geochronology: Implications for paleogeographic reconstructions of the São Francisco-Congo paleocontinent. Precambrian Research 178, 136-148.

Heilbron, M., Valeriano, C.M., Tassinari, C.C.G., Almeida, J.C.H., Tupinambá, M., Siga Jr., O., Trouw, R.A.J., 2008. Correlation of Neoproterozoic terranes between the Ribeira Belt, SE Brazil and its African counterpart: comparative tectonic evolution and open questions. In: Pankhurst, R.J., Trouw, R.A.J., Brito-Neves, B.B., de Wit, M. (Eds.), West Gondwana pre-Cenozoic Correlations Across the South Atlantic Region. Geological Society of London, Special Publication 294, pp. 211-232.

Hofmann, A. W., 1988. Chemical differentiation of the Earth: The relationship between mantle, continental crust, and oceanic crust. Earth Planetery Science Letters, 90: 297-314.

Horodyskyj, U., Lee, C., Luffi, P., 2009. Geochemical evidence for exhumation of eclogite via serpentinite channels in oceancontinent subduction zones. Geosphere 5, 426-438.

Hoskin, P.W.O., Schaltegger, 2003. The composition of zircon and igneous andmetamorphicpetrogenesis. Reviews in Mineralogy and Geochemistry 53, 27-55.

Hou, G.T., Santosh, M., Qian, X.L., Lister, G.S., Li, J.H., 2008. Configuration of the Late Paleoproterozoic supercontinent Columbia: insights from radiating mafic dyke swarms. Gondwana Research 14 (3), 395-409.

Irvine, T. N., Baragar, W. R. A., 1971. A guide to the chemical classification of common volcanic rocks. Canadian Journal of Earth Sciences 8, 523-548. 
Isozaki, Y., Aoki, K., Takaaki Nakama, T., Yanai, S., 2010. New insight into a subduction-related orogen: A reappraisal of the geotectonic framework and evolution of the Japanese Islands. Gondwana Research 18, 82-105.

IUGS - International Stratigraphic Chart (2013).

Kinny, P. D., Maas, R. 2003. Lu-Hf and Sm-Nd isotope systems in zircon. In: J. M. Hanchar, P. W. O. Hoskin (Eds.) Reviews in Mineralogy \& Geochemistry - Zircon. v. 53. 327-341.

Kröner,A., Kovach, V., Belousova, E., Hegner, E., Armstrong, R., Dolgopolova, A., Seltmann, R., Alexeiev, D.V., Hoffmann, J.E., Wong, J., Sun, M., Cai, K., Wang, Tong, Y., Wilde, S.A., Degtyarev, K.E., Rytsk, E. 2014. Reassessment of continental growth during the accretionary history of the Central Asian Orogenic Belt. Gondwana Research 25, 103-125.

Lana, C., Alkmim, F. F., Armstrong, R., Scholz, R., Romano, R., Nalini Jr., H. A. The ancestry and magmatic evolution of Archaean TTG rocks of the Quadrilátero Ferrífero province, southeast Brazil. Precambrian Research. Submetido.

Ledru, P.; Johan, V.; Milési, J. P.; Tegyey, M., 1994. Markers of the last stages of the Palaeoproterozoic collision: evidence for a $2 \mathrm{Ga}$ continent involving circum-South Atlantic provinces. Precambrian Research 69, 169-191.

Leite, C. M. M., Barbosa, J. S. F., Nicollet, C., Sabaté, P. 2007. Evolução metamórfica/metassomática paleoproterozoica do Complexo Saúde, da Bacia Jacobina e de leucogranitos peraluminosos na parte norte do Cráton do São Francisco. Revista Brasileira de Geociências. 37(4): 777-797.

Liew, T.C., Hofmann, A.W. 1988. Precambrian crustal components, plutonic associations, plate environment of the Hercynian Fold Belt of Central Europe: indications from a $\mathrm{Nd}$ and $\mathrm{Sr}$ isotopic study. Contributions to Mineralogy and Petrology 98, 129-138.

Machado, N., Carneiro, M.A., 1992. U-Pb evidence of late Archean tectonothermal activity in the southern São Francisco shield, Brazil. Canadian Journal Earth Sciences 29, 2341-2346.

Machado, N., Schrank, A., Noce, C.M., Gauthier, G., 1996a. Ages of detrital zircon from Archean-Paleproterozoic sequences: Implications for greenstone belt setting and evolution of a Transamazonian foreland basin in Quadrilátero Ferrífero, southeast Brazil: evidence from zircon ages by laser ablation ICP-1895 MS. Earth and Planetary Science Letters, 141, 259-276. Geological Society of America Bulletin 104, 1221-1227.

Machado, N., Noce, C.M., Ladeira, E.A., Belo de Oliveira, O. A., 1992. U-Pb geochronology of Archean magmatism and Proterozoic metamorphism in the Quadrilátero Ferrífero, southern São Francisco craton, Brazil. Geological Society of America Bulletin 104 (9), 1221-1227.

Maniar, P.D., Picolli, P.M., 1989. Tectonic discrimination of granitoids. Geological Society of American Bulletin 101, 635-643.

Marshak, S., Alkmim, F.F., 1989. Proterozoic contraction/extension tectonics of the southern São Francisco region, Minas Gerais, Brazil. Tectonics 8, 555-571.

Marshak, S., Alkmim, F.F., Jordt-Evangelista, H., 1992. Proterozoic crustal extension and the generation of dome-and-keel structure in an Archean granite greenstone terrane. Nature 357, 491-493.

Marshak, S., Tinkham, D., Alkmim, F., Brueckner, H., 1997. Dome-and-keel provinces formed during Paleoproterozoic orogenic collapse-core complexes, diapirs, or either?: Examples from the Quadrilátero Ferrífero and the Penokean orogen. The Geological Society of American 25, 415-418. 
Mascarenhas, J. F., 1979. Evolução Geotectônica do Precambriano do Estado da Bahia. In: H. A. V. Inda (Ed.), Geologia e Recursos Minerais do Estado da Bahia (v. 2, 57-165, Textos Básicos). Salvador: SME/CPM.

Meert, J.G., 2012. What's in a name? The Columbia (Paleopangaea/Nuna) supercontinent. Gondwana Research 21, 987-993.

Nédélec, A., Bouchez, J-L., 2015. Granites Petrology, Structure, Geological Setting, and Metallogeny. 352p.

Neri, M. E. N. V., Rosière, C. A., Lana, C. C.2013. Supergrupo Minas na Serra de Bom Sucesso, extremo sudoeste do Quadrilátero Ferrífero - MG: petrografia, geoquímica e isótopos de U-Pb. Geologia USP, Série científica, v. 13, n. 2, p. 117-202.

Noce, C. M.; Teixeira, W.; Quéméneur, J. J. G.; Martins, V. T. S.; Bolzachini, E., 2000. Isotopic signatures of Paleoproterozoic granitoids from the southern São Francisco Craton and implications for the evolution of the Transamazonian orogeny. Journal of South American Earth Sciences 13, 225-239.

Noce, C. M.; Zucchetti, M; Baltazar, O. F.; Armstrong, R.; Dantas, E. L.; Renger, F. E.; Lobato, L. M., 2005. Age of felsic volcanism and the role of anciente continental crust in the evolution of the Neoarchean Rio das Velhas greenstone belt (Quadrilátero Ferrífero, Brazil): U-Pb zircon dating of volcaniclastic graywackes. Precambrian Research 141, 67-82.

Noce, C. M.; Pedrosa-Soares, A.C.; Silva, L. C.; Armstrong, R.; Piuzana, D., 2007. Evolution of polycyclic basement complexes in the Araçuaí orogen, based on $\mathrm{U}-\mathrm{Pb}$ SHRIMP data: Implication of Brazil-Africa links in Paleoproterozoic time. Precambrian Research 159, 60-78.

Nowell, G.M., Pearson, D.G., Bell, D.R., Carlson, R.W., Smith, C.B., Kempton, P.D., Noble, S.R., 2004. Hf isotope systematics of kimberlites and their megacrysts: new constraints on their source regions. Journal of Petrology 45, 1583-1612.

Oliveira, E.P., MCnaughton, N.J., Armstrong, R. 2010. Mesoarchaean to Palaeoproterozoic growth of the northern segment of the Itabuna Salvador Curaçá orogen, São Francisco craton, Brazil, 338: 263-286.

Partin, C.A., Bekker, A., Sylvester, P.J., Wodicka, N., Stern. R. A., Chacko, T., Heaman, L.M., 2014. Filling in the juvenile magmatic gap: Evidence for uninterrupted Paleoproterozoic plate tectonics. Earth and Planetary Science Letters 388, 123-133.

Patchett, P.J., Samson, S.D. 2005. Ages and growth of the continental crust from radiogenic isotopes pp. 321-348. In: The crust (ed. R.L. Rudnick) vol. 3,Treatise on geochemistry, Elsevier-Pergamon, Oxford.

Pearce, J.A., Harris, N.B.W., Tindle, A.G., 1984. Trace element discrimination diagrams for the tectonic interpretation of granitic rocks. Journal of Petrology 25, 956983.

Pimentel, M.M., Charnley, N., 1991. Intracrustal REE fractiontion and implications for SM-Nd model age calculations in late-stage granitic rocks: An example for central Brazil. Chemical Geol. (Isotope Geoscience Section), 86, 123-138

Pupin, J. P. 1980. Zircon and granite petrology. Contributions to Mineralogy and Petrology 73, 207-220.

Quéméneur, J.J.G.; Ribeiro, A.; Trouw, R. A.J.; Paciullo, F.V.P.; Heilbron, M. Geologia da folha Lavras 1: 100.000. In: Soares, A. C. P. (Org.). Projeto Sul de Minas. Belo Horizonte: CODEMIG, 2003. p. 259-316.

Queménéur, J.J., Garcia, D. 1993. Os maciços Tabuões e Ritápolis na região de São João Del Rei: granitóides transamazônicos com a associação granito-trondhjemitopegmatito. In: Simpósio de geologia minas gerais, 7, Belo Horizonte, 1993. Anais... Belo Horizonte, SBG. V. 1, P. 105 - 107. 
Ribeiro, A.; Paciullo, F.V.P.; Valença, J.G.; Ávila, C.A.; Andreis, R.R.; Trouw, R.A.J. 1998. Domínios do embasamento na região de São João del Rei, borda sul do Cráton de São Francisco, sul de Minas Gerais. In: Congresso Brasileiro de Geologia, 40, Belo Horizonte, Anais..., 2: 21.

Rios, D.C., Davis, D.W., Conceição, H., Rosa, M.L.S., Davis, W.J., Dickin, A.P., Marinho, M.M., Stern, R., 2008. 3.65-2.10 Ga history of crust formation from zircon geochronology and isotope geochemistry of the Quijingue and Euclides plutons, Serrinha nucleous, Brazil. Precambrian Research 167, 53-70.

Rogers, J.J.W., Santosh, M., 2009. Tectonics and surface effects of the supercontinent Columbia. Gondwana Research 15, 373-380. http://dx.doi.org/10.1016/j.gr.2008.06.008

Rollinson, H. 2007. Early earth system: A geochemical approach. Blachwell, Oxfrod, 285p.

Romano, R., Lama, C., Alkmim, F.F., Stevens, G., Armstrong, R., 2013. Stabilization of the Southern São Francisco Craton, SE Brazil, through a long-lived and episodic period of potassic magmatism. Precambrian Research 224, 1-20.

Rudnick, R.L., Gao, S. 2003. Composition of the continental crust. H.D. Holland, K.K. Turekian (Eds.), Treatise on Geochemistry, vol. 3Elsevier Ltd. (2003), pp. 1-64.

Sato, K., Tassinari, C. C. G., Kawashita, K., Petronilho, L. 1995. O método geocronológico Sm/Nd no IG/USP e suas aplicações. Anais da Academia Brasileira de Ciências, 7(3), 313-336.

Sato K., 1998. Evolução crustal da Plataforma Sul Americana com base na geoquímica Sm-Nd. Ph.D. thesis, Univ. São Paulo, Brazil, 301p.

Sato, K., Siga Jr., O., 2002. Rapid growth of continental crust between 2.2 to 1.8 $\mathrm{Ga}$ in the South American Platform: integrated Australian, European, North American and SW USA crustal evolution study. Gondwana Researc 5, 165-173.

Seixas, L. A. R, David, J., Stevenson, R., 2012. Geochemistry, Nd isotopes and U$\mathrm{Pb}$ geochronology of a $2350 \mathrm{Ma}$ TTG suite, Minas Gerais, Brazil: Implications for the crustal evolution of the southern São Francisco craton. Precambrian Research (196197): 61-80.

Seixas, L.A.R., Bardintzeff, J-M., Stevenson, R., Bonin, B., 2013. Petrology of the high-Mg tonalites and dioritic enclaves of the ca.2130 Ma Alto Maranhão suite: Evidence for a major juvenile crustal addition event during the Rhyacian orogenesis, Mineiro Belt, southeast Brazil. Precambrian Research 238, 18- 41.

Silva, A.M.; Chemale Jr, F.; Heaman, L. 1995. The Ibirité gabbro and the Borrachudos granite - the rift-related magmatism of Mesoproterozoic age in Quadrilátero Ferrífero (MG). In: Simpósio de geologia de Minas Gerais, 8., Belo Horizonte, 1995. Anais. Belo Horizonte, SBG/Núcleo Minas Gerais. p. 89-90.

Silva, L.C. da, Armstrong, R., Noce, C.M., Carneiro, M.A, Pimentel, M.M., Pedrosa-Soares, A.C., Leite, C.A., Vieira,V.S., Silva, M.A, Paes, V.J.C., Cardoso Filho. J.M. 2002c. Reavaliação da evolução geológica em terrenos pré-cambrianos brasileiros, com base em novos dados U-Pb SHRIMP, Parte II: Orógeno Araçuaí, Cinturão Mineiro e Cráton São Francisco Meridional. Revista Brasileira de Geociências 32(4), 513-528.

Silva, M.M., Ávila, C.A., Teixeira, W., Bongiolo, E.M., Dussin, I.A., Pinho, R.E., Rigueti,A.L.,2012. Interação entre magmas félsicos paleoproterozoicos associados ao Granito Gentio, Estado de Minas Gerais. In: Congresso Brasileiro Geologia, 46, 2012. Sociedade Brasileira de Geologia, Santos, Boletim Resumos.

Silva, L. C. 2006. Geocronologia aplicada ao mapeamento regional, com ênfase na técnica U-Pb SHRIMP e ilustrada com estudos de casos brasileiros. Brasília: CPRM. $146 p$. 
Silva, M.M. 2013. Mapeamento geológico, petrografia, geoquímica e idade do granito Gentio, região de Dores de Campos, Minas Gerais. Dissertação de mestrado. Universidade Federal do Rio de Janeiro, 160 p.

Teixeira, W., Ávila, C. A., Dussin, I. A., Corrêa Neto, A. V., Bongiolo, E. M., Santos, J., Barbosa, N.S., 2015. O. A juvenile accretion episode (2.35-2.32 Ga) in the Mineiro belt and its role to the Minas accretionary orogeny: zircon $\mathrm{U}-\mathrm{Pb}-\mathrm{Hf}$ and geochemical evidences. Precambrian Research 256, 148-169.

Teixeira, W., Ávila, C.A., Nunes, L.C., 2008. Nd-Sr isotopic geochemistry and U$\mathrm{Pb}$ geochronology of Fé granitic gneiss and Lajedo granodiorite: implications for Paleoproterozoic evolution of the Mineiro belt, southern São Francisco Craton. Geologia USP Série Científica 8, 53-73.

Teixeira, W.; Figueiredo, M. C. H., 1991. An outline of Early Proterozoic crustal evolution in the São Francisco craton, Brazil: a review. Precambrian Research 53, 1-22.

Teixeira, W.; Sabaté, P.; Barbosa, J. S. F.; Noce, C. M.; Carneiro, M. A., 2000. Archean and Paleoproterozoic tectonic evolution of the São Francisco Craton. In: Cordani, U. G., Milani, E.J., Thomaz-Filho, A, Campos, D. A. (Eds.), Tectonic Evolution of South America. 31st International Geological Congress, pp. 101-138.

Teixeira, W.; Carneiro, M. A.; Noce, C. M.; Machado, N.; Sato, K.; Taylor, P. N., 1996. $\mathrm{Pb}, \mathrm{Sr}$ and $\mathrm{Nd}$ isotopic constraints on the Archean evolution of gneissic-granitoid complexes in the southern São Francisco Craton, Brazil. Precambrian Research 78, 151-164.

Teixeira, W. 1985. Evolução Geotectônica da porção Meridional do Craton do São Francisco, com base em interpretações geocronológicas. Tese de Doutorado, Instituto de Geociências - Universidade de São Paulo, 207p.

Teixeira, W., Ávila. C.A., Bongiolo, E.M., Hollanda, M.H.B., Barbosa, N.S., 2014. Age and tectonic significance of the Ritápolis batholith, Mineiro belt (Southern São Francisco Craton): U-Pb LA-ICPMS, Nd isotopes and geochemical evidence. In: 9th South American Symposium on Isotope Geology, 2014.

Teixeira, W., Oliveira, E.P., Marques, L.S. Em preparação. Nature and evolution of the archean crust of the são francisco craton.

Toledo, C.L.B., 2002. Evolução geológica das rochas máficas e ultramáficas no Greenstone Belt Barbacena, na região de Nazareno, MG. PhD Thesis, IGUNICAMP, Campinas, 307 p.

Valeriano, C.M., Machado, N., Simonetti, A., Valladares, C.S., Seer, H.J., Simões, L.S.A.,2004. U-Pb geochronology of the southern Brasília belt (SE Brazil): sedimentary provenance, Neoproterozoic orogeny and assembly of West-Gondwana. Precambrian Research 130, 27-55.

Vervoort, J.D., Patchett, P.J., 1996. Behaviour of hafnium and neodymium isotopes in the crust: constraints from Precambrian crustally derived granites. Geochimica et Cosmochimica Acta 60, 3717-3733.

Vervoort, J.D., Blichert-Toft, J., 1999. Evolution of the depleted mantle: Hf isotope evidence from juvenile rocks through time. Geochimica et Cosmochimica Acta 63, 533556.

Vervoort, J.D., Patchett, P.J., Blichert-Toft, J., Albarède, F., 1999. Relationships between Lu-Hf and Sm-Nd isotopic systems in the global sedimentary system. Earth and Planetary Science Letters 168, 79-99.

Wetherill, G.W., 1956. Discordant uranium-lead ages. Transactions of the American Geophysical Union 37, 320-326.

Wilson, M., 1989, Igneous petrogenesis - a global tectonic approach, Unwin Hyman, London, 466p. 
Windley, B.F. 1995. The Evolving Continents, 3rd. edition, Wiley, Chichester, 526 pp.

Windley, B.F., 2003. Continental growth in the Proterozoic: a global perspective. In: Yoshida, M., Windley, B.F., Dasgupta, S. (Eds.), Proterozoic East Gondwana: Supercontinent Assembly and Breakup, Geological Society of London, Special Publication 206, 23-33.

Whitney, D.L., Evans, B.W., 2010. Abbreviations for names of rock-forming minerals. American Mineralogist 95, 185-187.

Zhang, S-L., Li, Z-X., Evans, D 2157 .A.D., Wu, H-C., Li, H-Y., Dong, J., 2012. Pre-Rodinia supercontinent Nuna shaping up: A global synthesis with new paleomagnetic results from North China. Earth and Planetary Science Letters 353-354, $145-155$.

Zhao, G. C., Cawood, P. A., Wilde, S. A., Sun, M., 2002a. Review of global 2,11,8 Ga orogens: implications for a pre-Rodinia supercontinent. Earth-Science Reviews $59,125-162$.

Zhao, G., Sun, M., Wilde S.A., Li, S., 2004. A Paleo-Mesoproterozoic supercontinent: assembly, growth, and breakup. Earth-Science Reviews 67, 91-123.

Zhao, G., Wilde, S.A., Sun, M., Li, S., Li, X., Zhang, J., 2008. SHRIMP U-Pb zircon ages of granitoid rocks in the Lüliang Complex: Implications for the accretion and evolution of the Trans-North China Orogen. Precambrian Res. 160, 213-226. 


\section{ANEXOS}

\section{Anexo I - Dados U-Pb pontuais em zircão (SHRIMP).}

Table 3.1 (supplementary material): Summary of the SHRIMP U-Pb zircon analytical data (seção 4.5).

\begin{tabular}{|c|c|c|c|c|c|c|c|c|c|c|c|c|c|c|c|c|}
\hline $\begin{array}{r}\text { Grain. } \\
\text { spot }\end{array}$ & $\begin{array}{r}\mathrm{U} \\
(\mathrm{ppm})\end{array}$ & $\begin{array}{r}\mathrm{Th} \\
(\mathrm{ppm})\end{array}$ & $\mathrm{Th} / \mathrm{U}$ & $\mathrm{f}^{206}$ & $\begin{array}{l}{ }^{208} \mathrm{~Pb} \\
{ }^{206} \mathrm{~Pb}\end{array}$ & $\begin{array}{l}{ }^{207} \mathrm{~Pb} \\
{ }^{235} \mathrm{U}\end{array}$ & error & $\begin{array}{l}{ }^{206} \mathrm{~Pb} \\
{ }^{238} \mathrm{U}\end{array}$ & error & $\begin{array}{l}{ }^{207} \mathrm{~Pb} \\
\rho^{206} \mathrm{~Pb}\end{array}$ & error & $\begin{array}{c}{ }^{206} \mathrm{~Pb} \\
{ }^{238} \mathrm{U} \\
\text { Age }\end{array}$ & $\begin{array}{r}\text { erro } \\
r\end{array}$ & $\begin{array}{r}{ }^{207} \mathrm{~Pb} \\
{ }^{206} \mathrm{~Pb} \\
\text { Age }\end{array}$ & $\begin{array}{r}\text { erro } \\
r\end{array}$ & Disc. \\
\hline \multicolumn{17}{|l|}{ S.1 } \\
\hline 1.1 & 199 & 86 & 0.45 & 0.05 & 0.1250 & 7.7217 & 3.7117 & 0.4114 & 3.6622 & 0.1361 & 0.6031 & 2221 & 68 & 2179 & 11 & -2 \\
\hline 2.1 & 94 & 37 & 0.40 & -0.04 & 0.1119 & 7.5569 & 3.7716 & 0.4055 & 3.6975 & 0.1352 & 0.7438 & 2194 & 68 & 2166 & 13 & -1 \\
\hline 3.1 & 99 & 43 & 0.45 & 0.14 & 0.1256 & 7.3151 & 3.8697 & 0.3890 & 3.7848 & 0.1364 & 0.8078 & 2118 & 68 & 2182 & 14 & 3 \\
\hline 4.1 & 116 & 51 & 0.46 & -0.02 & 0.1269 & 7.5716 & 3.7452 & 0.4007 & 3.6852 & 0.1370 & 0.6680 & 2172 & 68 & 2190 & 12 & 1 \\
\hline 5.1 & 135 & 51 & 0.39 & 0.17 & 0.1093 & 7.7966 & 3.7412 & 0.4176 & 3.6787 & 0.1354 & 0.6744 & 2249 & 69 & 2169 & 12 & -4 \\
\hline 6.1 & 115 & 51 & 0.46 & 0.12 & 0.1254 & 7.1295 & 3.7519 & 0.3809 & 3.6862 & 0.1358 & 0.6968 & 2080 & 65 & 2174 & 12 & 4 \\
\hline 7.1 & 98 & 44 & 0.46 & 0.15 & 0.1272 & 7.0561 & 3.8616 & 0.3791 & 3.7021 & 0.1350 & 1.0962 & 2072 & 65 & 2164 & 19 & 4 \\
\hline 8.1 & 147 & 72 & 0.51 & 0.41 & 0.1107 & 4.7143 & 3.8752 & 0.2595 & 3.6840 & 0.1317 & 1.1939 & 1487 & 49 & 2122 & 21 & 43 \\
\hline 9.1 & 159 & 75 & 0.49 & 0.05 & 0.1338 & 7.7030 & 3.7922 & 0.4131 & 3.7312 & 0.1353 & 0.6768 & 2228 & 70 & 2167 & 12 & -3 \\
\hline 10.1 & 125 & 56 & 0.46 & 0.73 & 0.1367 & 7.4374 & 3.9011 & 0.4028 & 3.6947 & 0.1339 & 1.1915 & 2181 & 68 & 2150 & 22 & -1 \\
\hline 11.1 & 158 & 85 & 0.56 & 0.10 & 0.1581 & 7.6319 & 3.9260 & 0.4064 & 3.875 & 0.1362 & 0.6439 & 2198 & 72 & 2179 & 11 & -1 \\
\hline 12.1 & 116 & 49 & 0.44 & 0.21 & 0.1184 & 6.9412 & 3.8241 & 0.3775 & 3.7023 & 0.1334 & 0.9515 & 2064 & 65 & 2143 & 17 & 4 \\
\hline 13.1 & 179 & 74 & 0.43 & 0.02 & 0.1189 & 7.5870 & 3.7086 & 0.4036 & 3.6669 & 0.1363 & 0.5543 & 2185 & 68 & 2181 & 10 & 0 \\
\hline 14.1 & 112 & 47 & 0.43 & 0.12 & 0.1192 & 7.6406 & 3.7759 & 0.4061 & 3.6914 & 0.1364 & 0.7913 & 2197 & 68 & 2183 & 14 & -1 \\
\hline 15.1 & 101 & 40 & 0.41 & 0.13 & 0.1141 & 7.5885 & 3.8834 & 0.4047 & 3.7945 & 0.1360 & 0.8231 & 2190 & 70 & 2177 & 14 & -1 \\
\hline 16.1 & 122 & 53 & 0.45 & 0.11 & 0.1238 & 7.6171 & 3.7497 & 0.4064 & 3.6836 & 0.1359 & 0.6982 & 2198 & 68 & 2176 & 12 & -1 \\
\hline \multicolumn{17}{|l|}{ S. 2} \\
\hline 1.1 & 382 & 166 & 0.45 & 0.36 & 0.1371 & 6.7468 & 2.2445 & 0.3660 & 2.1707 & 0.1337 & 0.5439 & 2011 & 39 & 2147 & 10 & 7 \\
\hline 2.1 & 229 & 141 & 0.64 & 0.11 & 0.1786 & 6.5725 & 2.2543 & 0.3645 & 2.1957 & 0.1308 & 0.5076 & 2008 & 40 & 2108 & 9 & 5 \\
\hline
\end{tabular}




\begin{tabular}{|c|c|c|c|c|c|c|c|c|c|c|c|c|c|c|c|}
\hline 3.1 & 635 & 216 & 0.35 & 0.56 & 0.1600 & 4.0519 & 2.4444 & 0.2433 & 2.2441 & 0.1207 & 0.9408 & 1378 & 30 & 1967 & 17 \\
\hline 4.1 & 332 & 181 & 0.56 & 0.11 & 0.1707 & 6.4965 & 2.2286 & 0.3543 & 2.1783 & 0.1330 & 0.4680 & 1950 & 39 & 2138 & 8 \\
\hline 5.1 & 528 & 252 & 0.49 & 0.18 & 0.1664 & 6.1205 & 2.2026 & 0.3369 & 2.1614 & 0.1318 & 0.4162 & 1856 & 37 & 2121 & 7 \\
\hline 6.1 & 703 & 151 & 0.22 & 3.51 & 0.1654 & 1.7840 & 5.2284 & 0.1358 & 2.1717 & 0.0952 & 4.5460 & 813 & 18 & 1534 & 90 \\
\hline 7.1 & 647 & 274 & 0.44 & 0.25 & 0.1606 & 3.6765 & 2.2158 & 0.2235 & 2.1551 & 0.1193 & 0.5067 & 1286 & 27 & 1946 & 9 \\
\hline 8.1 & 474 & 226 & 0.49 & 0.97 & 0.1881 & 5.5624 & 2.4582 & 0.3108 & 2.1762 & 0.1298 & 1.0551 & 1730 & 36 & 2095 & 20 \\
\hline 9.1 & 356 & 146 & 0.42 & 1.31 & 0.1860 & 5.4305 & 2.6372 & 0.2954 & 2.1817 & 0.1333 & 1.3711 & 1648 & 34 & 2142 & 26 \\
\hline 10.1 & 1213 & 83 & 0.07 & 9.08 & 0.2282 & 2.2513 & 13.033 & 0.1602 & 2.2722 & 0.1017 & 12.1547 & 959 & 24 & 1659 & 238 \\
\hline
\end{tabular}

S.5

\begin{tabular}{|c|c|c|c|c|c|c|c|c|c|c|c|c|c|c|c|c|}
\hline 1.1 & 214 & 116 & 0.56 & 0.14 & 0.1606 & 7.8099 & 2.8734 & 0.4176 & 2.717 & 0.1357 & 0.9309 & 2249 & 51 & 2172 & 16 & -3 \\
\hline 2.1 & 365 & 208 & 0.59 & 0.13 & 0.1616 & 7.4675 & 2.7752 & 0.4001 & 2.694 & 0.1354 & 0.6637 & 2169 & 49 & 2169 & 12 & 0 \\
\hline 3.1 & 366 & 275 & 0.77 & 0.03 & 0.2117 & 7.3688 & 2.7677 & 0.3992 & 2.696 & 0.1339 & 0.6259 & 2165 & 49 & 2150 & 11 & -1 \\
\hline 4.1 & 286 & 159 & 0.57 & 0.08 & 0.1600 & 7.7656 & 2.7859 & 0.4158 & 2.704 & 0.1355 & 0.6708 & 2241 & 51 & 2170 & 12 & -3 \\
\hline 5.1 & 237 & 106 & 0.46 & 0.19 & 0.1356 & 7.1463 & 2.8685 & 0.3894 & 2.735 & 0.1331 & 0.8594 & 2120 & 49 & 2139 & 15 & 1 \\
\hline 6.1 & 281 & 178 & 0.65 & 0.05 & 0.1837 & 7.5077 & 2.7906 & 0.3970 & 2.707 & 0.1371 & 0.6783 & 2155 & 49 & 2191 & 12 & 2 \\
\hline 7.1 & 280 & 190 & 0.70 & 0.11 & 0.1996 & 7.4798 & 2.7977 & 0.4007 & 2.717 & 0.1354 & 0.6650 & 2172 & 50 & 2169 & 12 & 0 \\
\hline 8.1 & 271 & 208 & 0.79 & 0.08 & 0.1874 & 7.4506 & 2.8131 & 0.3985 & 2.709 & 0.1356 & 0.7553 & 2162 & 49 & 2172 & 13 & 0 \\
\hline 9.1 & 274 & 187 & 0.71 & 0.11 & 0.2020 & 7.5356 & 2.8027 & 0.4080 & 2.707 & 0.1340 & 0.7235 & 2205 & 50 & 2150 & 13 & -3 \\
\hline 10 & 172 & 74 & 0.45 & -0.12 & 0.1275 & 8.2540 & 2.8734 & 0.4354 & 2.733 & 0.1375 & 0.8836 & 2330 & 53 & 2196 & 15 & -6 \\
\hline 11 & 541 & 363 & 0.69 & 0.11 & 0.1855 & 7.3067 & 2.7299 & 0.3946 & 2.678 & 0.1343 & 0.5258 & 2144 & 48 & 2155 & 9 & 1 \\
\hline 12 & 199 & 81 & 0.42 & 0.00 & 0.1172 & 7.9157 & 2.8522 & 0.4197 & 2.728 & 0.1368 & 0.8321 & 2259 & 52 & 2187 & 14 & -3 \\
\hline 13 & 311 & 135 & 0.45 & 0.00 & 0.1246 & 8.0107 & 2.7655 & 0.4262 & 2.699 & 0.1363 & 0.6012 & 2288 & 52 & 2181 & 10 & -5 \\
\hline 14 & 336 & 234 & 0.72 & 0.13 & 0.1957 & 8.0046 & 2.8624 & 0.4223 & 2.696 & 0.1375 & 0.9586 & 2271 & 51 & 2195 & 17 & -3 \\
\hline
\end{tabular}

S.4

$\begin{array}{rrrrrrrrrrrrrrrrr}1.1 & 265 & 127 & 0.49 & 1.49 & 0.1317 & 6.6462 & 3.2896 & 0.3648 & 3.1058 & 0.1321 & 1.0718 & 2004 & 53 & 2127 & 19 & 6 \\ 2.1 & 171 & 74 & 0.45 & -1.16 & 0.1233 & 8.1954 & 3.3215 & 0.4317 & 3.1566 & 0.1377 & 1.0292 & 2313 & 61 & 2198 & 18 & -5 \\ 3.1 & 163 & 53 & 0.33 & -1.73 & 0.0998 & 7.9724 & 3.5525 & 0.4334 & 3.3309 & 0.1334 & 1.2222 & 2320 & 65 & 2143 & 22 & -8\end{array}$




\begin{tabular}{|c|c|c|c|c|c|c|c|c|c|c|c|c|c|c|c|c|}
\hline 4.1 & 137 & 47 & 0.36 & 2.86 & 0.1290 & 5.4993 & 14.699 & 0.3488 & 7.5584 & 0.1144 & 12.3303 & 1929 & 125 & 1870 & 227 & -3 \\
\hline 5.1 & 218 & 83 & 0.39 & -0.06 & 0.1107 & 7.5516 & $3.272 \overline{4}$ & 0.4047 & 3.1112 & 0.1353 & 1.0096 & 2190 & 57 & 2168 & 18 & -1 \\
\hline 6.1 & 613 & 213 & 0.36 & 3.90 & 0.0910 & 4.4325 & 4.1730 & 0.2650 & 4.0243 & 0.1213 & 1.0831 & 1515 & 54 & 1976 & 20 & 30 \\
\hline 7.1 & 124 & 39 & 0.33 & -0.34 & 0.0922 & 7.6493 & 3.5181 & 0.4101 & 3.3061 & 0.1353 & 1.1983 & 2215 & 62 & 2168 & 21 & -2 \\
\hline 8.1 & 111 & 37 & 0.35 & -1.96 & 0.0973 & 7.9219 & 3.5345 & 0.4355 & 3.1766 & 0.1320 & 1.5292 & 2330 & 62 & 2124 & 27 & -9 \\
\hline 9.1 & 357 & 248 & 0.72 & -1.41 & 0.1956 & 8.2065 & 3.1636 & 0.4343 & 3.0807 & 0.1370 & 0.7143 & 2325 & 60 & 2190 & 13 & -6 \\
\hline 10 & 336 & 193 & 0.60 & 1.19 & 0.1523 & 6.9573 & 3.1811 & 0.3743 & 3.0856 & 0.1348 & 0.7727 & 2049 & 54 & 2162 & 13 & 5 \\
\hline 11 & 107 & 38 & 0.37 & 7.50 & 0.2652 & 7.4092 & 9.8772 & 0.3944 & 3.3536 & 0.1362 & 8.1693 & 2143 & 617 & 2180 & 162 & 2 \\
\hline 1.1 & 749 & 295 & 0.41 & 0.50 & 0.1149 & 5.8916 & 2.8061 & 0.3315 & 2.6807 & 0.1289 & 0.7959 & 1857 & 45 & 2083 & 15 & 13 \\
\hline 2.1 & 763 & 315 & 0.43 & 0.16 & 0.1090 & 4.6761 & 2.7446 & 0.2779 & 2.6791 & 0.1220 & 0.5924 & 1593 & 39 & 1986 & 11 & 26 \\
\hline 3.1 & 728 & 348 & 0.49 & 0.23 & 0.1184 & 5.2765 & 2.8045 & 0.3043 & 2.7259 & 0.1258 & 0.6511 & 1734 & 43 & 2040 & 12 & 19 \\
\hline 4.1 & 1172 & 670 & 0.59 & 4.01 & 0.1693 & 2.6351 & 24.523 & 0.2213 & 4.5393 & 0.0864 & 23.8574 & 1347 & 48 & 1346 & 465 & 4 \\
\hline 5.1 & 274 & 160 & 0.61 & 0.06 & 0.1689 & 7.6427 & $2.786 \overline{3}$ & 0.4095 & 2.7055 & 0.1354 & 0.6655 & 2216 & 54 & 2169 & 12 & -2 \\
\hline 6.1 & 280 & 244 & 0.90 & 6.70 & 0.3789 & 7.9886 & 6.9743 & 0.3466 & 3.2541 & 0.1664 & 5.4849 & 1957 & 65 & 2530 & 104 & 32 \\
\hline 6.1 & 693 & 968 & 1.44 & 21.15 & 0.6234 & 3.9566 & 23.756 & 0.1967 & 3.2434 & 0.1439 & 21.6126 & 1327 & 50 & 2298 & 404 & 98 \\
\hline 8.1 & 96 & 74 & 0.80 & 0.10 & 0.2221 & 10.8400 & $2.980 \overline{4}$ & 0.4768 & 2.7960 & 0.1649 & 1.0304 & 2516 & 63 & 2506 & 17 & 0 \\
\hline 9.1 & 733 & 410 & 0.58 & 0.07 & 0.1584 & 4.3993 & 2.8804 & 0.2638 & 2.7557 & 0.1210 & 0.8382 & 1517 & 40 & 1970 & 15 & 31 \\
\hline 10.1 & 271 & 83 & 0.32 & 0.33 & 0.0842 & 6.7161 & 2.8747 & 0.3668 & 2.7194 & 0.1328 & 0.9184 & 2026 & 48 & 2135 & 16 & 6 \\
\hline 11.1 & 665 & 270 & 0.42 & 3.27 & 0.1607 & 5.5640 & 4.8697 & 0.3164 & 2.7128 & 0.1274 & 3.7141 & 1805 & 45 & 2065 & 71 & 17 \\
\hline 12.1 & 574 & 439 & 0.79 & 1.72 & 0.1170 & 4.6481 & 3.5936 & 0.2652 & 2.7146 & 0.1270 & 2.2407 & 1622 & 41 & 2058 & 42 & 36 \\
\hline 1.1 & 206 & 152 & 0.76 & -0.72 & 0.2111 & 7.9464 & 3.2054 & 0.4204 & 3.0978 & 0.1371 & 0.8219 & 2262 & 59 & 2191 & 14 & -3 \\
\hline 2.1 & 72 & 22 & 0.31 & -0.65 & 0.0904 & 8.1733 & 3.8349 & 0.4275 & 3.4769 & 0.1387 & 1.6067 & 2294 & 67 & 2211 & 28 & -4 \\
\hline 3.1 & 112 & 48 & 0.44 & -1.61 & 0.1222 & 8.0596 & 3.4628 & 0.4355 & 3.1535 & 0.1342 & 1.4064 & 2330 & 61 & 2154 & 25 & -8 \\
\hline 4.1 & 660 & 251 & 0.39 & 3.60 & 0.1129 & 5.1148 & 3.3364 & 0.2978 & 3.1025 & 0.1245 & 1.1594 & 1680 & 46 & 2023 & 22 & 20 \\
\hline 5.1 & 657 & 220 & 0.35 & 2.85 & 0.0996 & 4.8389 & 3.1292 & 0.2889 & 3.0612 & 0.1215 & 0.6423 & 1636 & 44 & 1978 & 12 & 21 \\
\hline
\end{tabular}




\begin{tabular}{|c|c|c|c|c|c|c|c|c|c|c|c|c|c|c|c|c|}
\hline 6.1 & 518 & 146 & 0.29 & 0.54 & 0.0784 & 6.6420 & 3.1246 & 0.3732 & 3.0665 & 0.1291 & 0.5945 & 2044 & 53 & 2086 & 11 & 2 \\
\hline 7.1 & 598 & 191 & 0.33 & 1.71 & 0.0909 & 5.6607 & 3.3133 & 0.3302 & 3.2435 & 0.1243 & 0.6706 & 1839 & 51 & 2019 & 12 & 10 \\
\hline 8.1 & 58 & 26 & 0.47 & -2.06 & 0.1271 & 8.1497 & 3.8681 & 0.4421 & 3.4507 & 0.1337 & 1.7269 & 2360 & 68 & 2147 & 31 & -9 \\
\hline 9.1 & 92 & 40 & 0.45 & -1.97 & 0.1262 & 8.3837 & 3.3937 & 0.4434 & 3.1707 & 0.1371 & 1.2082 & 2365 & 62 & 2191 & 21 & -7 \\
\hline 10.1 & 375 & 315 & 0.87 & -0.50 & 0.2349 & 7.6061 & 3.4048 & 0.4097 & 3.3474 & 0.1347 & 0.6210 & 2213 & 62 & 2159 & 11 & -2 \\
\hline 11.1 & 51 & 14 & 0.29 & -0.43 & 0.1043 & 7.3054 & 5.3211 & 0.4212 & 3.3319 & 0.1259 & 3.9304 & 2265 & 63 & 2040 & 73 & -10 \\
\hline 12.1 & 149 & 80 & 0.55 & -0.28 & 0.1470 & 7.9178 & 3.3120 & 0.4163 & 3.1244 & 0.1379 & 1.0930 & 2243 & 59 & 2201 & 19 & -2 \\
\hline 13.1 & 343 & 185 & 0.56 & 0.23 & 0.1506 & 7.0638 & 3.1689 & 0.3879 & 3.0882 & 0.1321 & 0.7085 & 2113 & 55 & 2126 & 12 & 1 \\
\hline 14.1 & 129 & 61 & 0.49 & -1.23 & 0.1365 & 7.8157 & 3.4588 & 0.4253 & 3.1521 & 0.1333 & 1.4058 & 2284 & 60 & 2141 & 25 & -6 \\
\hline 15.1 & 136 & 75 & 0.57 & -1.50 & 0.1561 & 8.3013 & 3.3911 & 0.4390 & 3.1396 & 0.1371 & 1.2660 & 2346 & 61 & 2191 & 22 & -7 \\
\hline 16.1 & 58 & 24 & 0.43 & -0.47 & 0.1218 & 7.9081 & 4.0444 & 0.4199 & 3.6808 & 0.1366 & 1.6617 & 2260 & 70 & 2184 & 29 & -3 \\
\hline 17.1 & 158 & 96 & 0.63 & -0.87 & 0.1739 & 7.8379 & 3.2917 & 0.4197 & 3.1285 & 0.1355 & 1.0211 & 2259 & 59 & 2170 & 18 & -4 \\
\hline 18.1 & 337 & 138 & 0.42 & 1.13 & 0.1173 & 6.9041 & 3.2376 & 0.3761 & 3.0875 & 0.1331 & 0.9593 & 2058 & 54 & 2140 & 17 & 4 \\
\hline 1.1 & 74 & 39 & 0.55 & 0.0 & 0.1568 & 7.6380 & 5.4870 & 0.4163 & 5.4386 & 0.1331 & 0.7277 & 2243 & 103 & 2139 & 13 & -5 \\
\hline 2.1 & 97 & 53 & 0.57 & -0.06 & 0.1584 & 7.7291 & 5.4672 & 0.4211 & 5.4265 & 0.1331 & 0.6649 & 2265 & 103 & 2140 & 12 & -6 \\
\hline 3.1 & 92 & 70 & 0.79 & 0.13 & 0.2215 & 7.5275 & 5.5007 & 0.4075 & 5.4437 & 0.1340 & 0.7843 & 2203 & 101 & 2151 & 14 & -2 \\
\hline 4.1 & 127 & 99 & 0.81 & 0.06 & 0.2253 & 7.6504 & 5.4559 & 0.4177 & 5.4194 & 0.1328 & 0.6288 & 2250 & 102 & 2136 & 11 & -5 \\
\hline 5.1 & 150 & 84 & 0.57 & 0.02 & 0.1569 & 7.5805 & 5.4503 & 0.4108 & 5.4149 & 0.1338 & 0.6203 & 2218 & 101 & 2149 & 11 & -3 \\
\hline 6.1 & 99 & 101 & 1.06 & -0.05 & 0.2984 & 7.4974 & 5.4651 & 0.4094 & 5.4277 & 0.1328 & 0.6379 & 2212 & 101 & 2136 & 11 & -3 \\
\hline 7.1 & 124 & 85 & 0.71 & 0.02 & 0.1946 & 7.6136 & 5.4506 & 0.4152 & 5.4200 & 0.1330 & 0.5762 & 2238 & 102 & 2138 & 10 & -4 \\
\hline 8.1 & 60 & 27 & 0.47 & 0.33 & 0.1394 & 7.0400 & 5.6556 & 0.3943 & 5.4553 & 0.1295 & 1.4794 & 2142 & 99 & 2091 & 26 & -2 \\
\hline 9.1 & 105 & 82 & 0.81 & 0.13 & 0.2235 & 7.4465 & 5.4927 & 0.4034 & 5.4439 & 0.1339 & 0.7273 & 2184 & 100 & 2149 & 13 & -2 \\
\hline 10.1 & 57 & 30 & 0.55 & 0.12 & 0.1566 & 7.2368 & 5.5453 & 0.3951 & 5.4624 & 0.1328 & 0.9528 & 2146 & 99 & 2136 & 17 & -1 \\
\hline 11.1 & 58 & 52 & 0.93 & 0.00 & 0.2626 & 7.6563 & 5.5339 & 0.4168 & 5.4585 & 0.1332 & 0.9100 & 2246 & 103 & 2141 & 16 & -5 \\
\hline 12.1 & 149 & 83 & 0.57 & -0.05 & 0.1571 & 7.5012 & 5.4524 & 0.4096 & 5.4170 & 0.1328 & 0.6202 & 2213 & 101 & 2135 & 11 & -4 \\
\hline 13.1 & 116 & 120 & 1.07 & -0.07 & 0.2976 & 7.6972 & 5.4951 & 0.4207 & 5.4262 & 0.1327 & 0.8665 & 2263 & 103 & 2134 & 15 & -6 \\
\hline 14.1 & 72 & 51 & 0.72 & 0.00 & 0.2011 & 7.8780 & 5.5328 & 0.4247 & 5.4451 & 0.1345 & 0.9811 & 2282 & 104 & 2158 & 17 & -5 \\
\hline
\end{tabular}




\begin{tabular}{|c|c|c|c|c|c|c|c|c|c|c|c|c|c|c|c|c|}
\hline 15.1 & 80 & 59 & 0.77 & 0.00 & 0.2171 & 7.7779 & 5.5307 & 0.4233 & 5.4398 & 0.1333 & 0.9987 & 2275 & 104 & 2141 & 17 & -6 \\
\hline \multicolumn{17}{|l|}{ S.11 } \\
\hline 1.1 & 473 & 244 & 0.53 & 0.39 & 0.1670 & 6.2674 & 2.3797 & 0.3512 & 2.1921 & 0.1294 & 0.9070 & 1940 & 36 & 2090 & 16 & 8 \\
\hline 2.1 & 687 & 193 & 0.29 & 1.03 & 0.1117 & 3.7442 & 2.6924 & 0.2352 & 2.1719 & 0.1154 & 1.5292 & 1361 & 26 & 1887 & 29 & 39 \\
\hline 3.1 & 560 & 447 & 0.83 & 0.93 & 0.2430 & 6.6161 & 2.5682 & 0.3694 & 2.1733 & 0.1299 & 1.2836 & 2026 & 37 & 2097 & 24 & 3 \\
\hline 4.1 & 199 & 135 & 0.70 & 0.93 & 0.1909 & 6.3044 & 3.1505 & 0.3504 & 2.2541 & 0.1305 & 2.1523 & 1936 & 37 & 2105 & 39 & 9 \\
\hline 5.1 & 704 & 668 & 0.98 & 0.74 & 0.2678 & 4.5175 & 2.4718 & 0.2682 & 2.1670 & 0.1221 & 1.1453 & 1531 & 29 & 1988 & 21 & 30 \\
\hline 6.1 & 519 & 377 & 0.75 & 1.76 & 0.2365 & 5.4885 & 3.2216 & 0.3198 & 2.1967 & 0.1244 & 2.1931 & 1788 & 34 & 2021 & 42 & 13 \\
\hline 7.1 & 709 & 337 & 0.49 & 2.96 & 0.2076 & 3.1744 & 4.4450 & 0.2089 & 2.2032 & 0.1101 & 3.6392 & 1223 & 24 & 1802 & 70 & 47 \\
\hline 8.1 & 462 & 336 & 0.75 & 0.49 & 0.1999 & 6.2030 & 2.4664 & 0.3509 & 2.1863 & 0.1282 & 1.1155 & 1938 & 36 & 2074 & 20 & 7 \\
\hline 9.1 & 660 & 182 & 0.28 & 0.96 & 0.1063 & 3.0477 & 2.8731 & 0.2052 & 2.1905 & 0.1077 & 1.8155 & 1203 & 24 & 1761 & 34 & 46 \\
\hline 10.1 & 511 & 292 & 0.59 & 0.73 & 0.1666 & 5.3887 & 2.5118 & 0.3105 & 2.1819 & 0.1258 & 1.1977 & 1743 & 33 & 2041 & 22 & 17 \\
\hline 11.1 & 887 & 1643 & 1.92 & 9.64 & 0.5614 & 2.3940 & 12.046 & 0.1554 & 2.3118 & 0.1114 & 11.1548 & 931 & 20 & 1828 & 214 & 96 \\
\hline 12.1 & 615 & 267 & 0.45 & 1.36 & 0.1662 & 5.5656 & 2.8609 & 0.3158 & 2.2871 & 0.1278 & 1.5958 & 1769 & 35 & 2068 & 30 & 17 \\
\hline 13.1 & 494 & 367 & 0.77 & 0.19 & 0.2161 & 5.7736 & 2.3260 & 0.3300 & 2.2092 & 0.1269 & 0.7223 & 1838 & 35 & 2055 & 13 & 12 \\
\hline 14.1 & 768 & 299 & 0.40 & 2.76 & 0.1607 & 3.4562 & 6.4237 & 0.2187 & 2.2563 & 0.1145 & 5.8959 & 1275 & 26 & 1874 & 108 & 47 \\
\hline 15.1 & 474 & 122 & 0.27 & 1.38 & 0.1077 & 5.4346 & 2.9023 & 0.3164 & 2.1849 & 0.1246 & 1.7915 & 1771 & 33 & 2023 & 34 & 14 \\
\hline 16.1 & 520 & 587 & 1.17 & 0.31 & 0.3248 & 6.9396 & 2.3237 & 0.3805 & 2.1710 & 0.1323 & 0.8134 & 2078 & 38 & 2128 & 15 & 2 \\
\hline 17.1 & 501 & 322 & 0.67 & 2.02 & 0.2111 & 5.3592 & 3.3810 & 0.3081 & 2.2731 & 0.1261 & 2.3128 & 1731 & 34 & 2045 & 44 & 18 \\
\hline 18.1 & 702 & 327 & 0.48 & 0.31 & 0.1322 & 3.4555 & 2.3570 & 0.2200 & 2.1683 & 0.1139 & 0.9157 & 1282 & 25 & 1863 & 17 & 45 \\
\hline 19.1 & 745 & 607 & 0.84 & 1.76 & 0.2672 & 3.7224 & 3.6112 & 0.2398 & 2.1873 & 0.1125 & 2.7623 & 1385 & 27 & 1841 & 52 & 33 \\
\hline 20.1 & 627 & 383 & 0.63 & 0.40 & 0.1791 & 4.5320 & 2.3537 & 0.2720 & 2.1683 & 0.1208 & 0.8991 & 1550 & 29 & 1969 & 16 & 27 \\
\hline \multicolumn{17}{|l|}{ S.13 } \\
\hline 1.1 & 113 & 7 & 0.06 & 0.13 & 0.0180 & 6.8571 & 3.7942 & 0.3797 & 3.7017 & 0.1310 & 0.8305 & 2075 & 65 & 2111 & 15 & 2 \\
\hline 2.1 & 449 & 345 & 0.79 & 0.90 & 0.2048 & 4.3618 & 3.8408 & 0.2635 & 3.6492 & 0.1200 & 1.1314 & 1508 & 49 & 1957 & 21 & 30 \\
\hline 3.1 & 145 & 28 & 0.20 & 0.11 & 0.0534 & 7.3617 & 3.8324 & 0.4084 & 3.7746 & 0.1308 & 0.6603 & 2207 & 70 & 2108 & 12 & -5 \\
\hline 4.1 & 588 & 238 & 0.42 & 0.50 & 0.1414 & 4.3732 & 3.7660 & 0.2668 & 3.6544 & 0.1189 & 0.8821 & 1524 & 49 & 1939 & 16 & 27 \\
\hline
\end{tabular}




$\begin{array}{rrrrrrrrrrrrrrrrr}5.1 & 206 & 43 & 0.21 & 0.02 & 0.0595 & 7.2892 & 3.7099 & 0.4028 & 3.6680 & 0.1312 & 0.5560 & 2182 & 67 & 2115 & 10 & -3 \\ 6.1 & 131 & 10 & 0.08 & 0.15 & 0.0234 & 7.2523 & 3.8080 & 0.3982 & 3.6912 & 0.1321 & 0.9318 & 2160 & 67 & 2126 & 16 & -2 \\ 7.1 & 187 & 44 & 0.24 & 0.04 & 0.0583 & 6.5571 & 3.7355 & 0.3717 & 3.6845 & 0.1280 & 0.6143 & 2037 & 64 & 2070 & 11 & 2 \\ 8.1 & 365 & 279 & 0.79 & 0.34 & 0.2284 & 6.7071 & 4.2379 & 0.3777 & 4.1893 & 0.1288 & 0.6151 & 2065 & 74 & 2081 & 11 & 1 \\ 9.1 & 283 & 45 & 0.17 & 0.18 & 0.0485 & 5.9222 & 3.8422 & 0.3389 & 3.7838 & 0.1267 & 0.6623 & 1881 & 61 & 2053 & 12 & 9 \\ 10 & 546 & 538 & 1.02 & 0.86 & 0.2628 & 3.1239 & 4.1593 & 0.1951 & 3.6596 & 0.1161 & 1.9529 & 1148 & 38 & 1898 & 36 & 65 \\ 11 & 174 & 46 & 0.27 & 0.30 & 0.0773 & 7.0588 & 3.8610 & 0.3988 & 3.7739 & 0.1284 & 0.7990 & 2163 & 69 & 2076 & 14 & -4 \\ 12 & 339 & 252 & 0.77 & 0.03 & 0.2135 & 7.4765 & 3.6981 & 0.4116 & 3.6676 & 0.1318 & 0.4734 & 2222 & 68 & 2121 & 8 & -5 \\ 20 & 191 & 93 & 0.50 & 0.00 & 0.1340 & 14.4387 & 3.7039 & 0.5652 & 3.6770 & 0.1853 & 0.4451 & 2888 & 85 & 2701 & 7 & -6\end{array}$

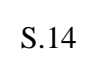

$\begin{array}{rrrrrrrrrrrrrrrrr}1.1 & 385 & 67 & 0.18 & 0.08 & 0.0512 & 7.6537 & 5.4098 & 0.4212 & 5.3989 & 0.1318 & 0.3392 & 2265 & 103 & 2122 & 6 & -6 \\ 1.2 & 261 & 165 & 0.65 & -0.03 & 0.1833 & 7.0426 & 5.4204 & 0.3901 & 5.4041 & 0.1309 & 0.4195 & 2123 & 97 & 2111 & 7 & -1 \\ 2.1 & 156 & 103 & 0.68 & -0.03 & 0.1951 & 7.3529 & 5.4381 & 0.4088 & 5.4125 & 0.1304 & 0.5273 & 2209 & 101 & 2104 & 9 & -5 \\ 3.1 & 128 & 68 & 0.55 & 0.02 & 0.1574 & 7.4085 & 5.4610 & 0.4071 & 5.4295 & 0.1320 & 0.5853 & 2201 & 101 & 2125 & 10 & -4 \\ 4.1 & 75 & 38 & 0.52 & 0.08 & 0.1447 & 7.2596 & 5.5157 & 0.4020 & 5.4422 & 0.1310 & 0.8956 & 2178 & 100 & 2111 & 16 & -3 \\ 5.1 & 165 & 72 & 0.45 & -0.02 & 0.1271 & 7.2710 & 5.4401 & 0.4002 & 5.4142 & 0.1318 & 0.5303 & 2169 & 99 & 2122 & 9 & -2 \\ 6.1 & 369 & 158 & 0.44 & 0.03 & 0.1215 & 7.1704 & 5.4081 & 0.3992 & 5.3986 & 0.1303 & 0.3192 & 2165 & 99 & 2101 & 6 & -3 \\ 7.1 & 172 & 94 & 0.57 & 0.03 & 0.1548 & 7.1793 & 5.4579 & 0.3983 & 5.4170 & 0.1307 & 0.6671 & 2161 & 99 & 2108 & 12 & -2 \\ 8.1 & 165 & 55 & 0.34 & 0.09 & 0.0952 & 7.3269 & 5.4392 & 0.4036 & 5.4106 & 0.1317 & 0.5550 & 2185 & 100 & 2120 & 10 & -3 \\ 9.1 & 90 & 49 & 0.56 & -0.03 & 0.1636 & 7.3621 & 5.4892 & 0.4012 & 5.4291 & 0.1331 & 0.8105 & 2174 & 100 & 2139 & 14 & -2 \\ 10.1 & 503 & 274 & 0.56 & -0.01 & 0.1533 & 7.2511 & 5.4218 & 0.4056 & 5.3987 & 0.1296 & 0.5000 & 2195 & 100 & 2093 & 9 & -5 \\ 11.1 & 145 & 67 & 0.48 & 0.89 & 0.1560 & 6.5794 & 5.7168 & 0.3705 & 5.4183 & 0.1288 & 1.7628 & 2031 & 94 & 2081 & 32 & 2 \\ 12.1 & 150 & 82 & 0.56 & -0.05 & 0.1554 & 7.2058 & 5.4425 & 0.4013 & 5.4140 & 0.1302 & 0.5559 & 2175 & 99 & 2101 & 10 & -3 \\ 13.1 & 255 & 83 & 0.34 & 0.26 & 0.0979 & 6.3489 & 5.4500 & 0.3564 & 5.4073 & 0.1292 & 0.6688 & 1965 & 91 & 2087 & 12 & 6 \\ 14.1 & 129 & 74 & 0.59 & -0.06 & 0.1629 & 7.4539 & 5.4490 & 0.4089 & 5.4175 & 0.1322 & 0.5842 & 2209 & 101 & 2128 & 10 & -4 \\ 15.1 & 248 & 104 & 0.43 & 0.01 & 0.1200 & 7.0615 & 5.4207 & 0.3913 & 5.4045 & 0.1309 & 0.4189 & 2128 & 98 & 2110 & 7 & -1\end{array}$




\begin{tabular}{|c|c|c|c|c|c|c|c|c|c|c|c|c|c|c|c|c|}
\hline 1.1 & 362 & 183 & 0.52 & 0.81 & 0.1505 & 6.6702 & 4.6814 & 0.3713 & 4.6476 & 0.1303 & 0.5540 & 2035 & 81 & 2102 & 10 & 3 \\
\hline 1.2 & 221 & 175 & 0.82 & 1.31 & 0.2325 & 6.6400 & 4.8499 & 0.3651 & 4.7907 & 0.1319 & 0.7490 & 2006 & 82 & 2123 & 13 & 6 \\
\hline 2.1 & 133 & 70 & 0.54 & 0.23 & 0.1575 & 8.8805 & 4.7536 & 0.4337 & 4.6636 & 0.1485 & 0.9167 & 2322 & 91 & 2329 & 16 & 0 \\
\hline 2.2 & 597 & 107 & 0.19 & 4.26 & 0.0530 & 2.0248 & 5.8446 & 0.1490 & 5.4286 & 0.0985 & 2.1544 & 895 & 45 & 1596 & 40 & 78 \\
\hline 3.1 & 101 & 29 & 0.30 & 0.17 & 0.0889 & 8.7867 & 4.8983 & 0.4366 & 4.7222 & 0.1460 & 1.2573 & 2335 & 92 & 2299 & 22 & -2 \\
\hline 4.1 & 516 & 311 & 0.62 & 4.90 & 0.1849 & 3.4752 & 4.8367 & 0.2161 & 4.7270 & 0.1166 & 0.9908 & 1261 & 54 & 1905 & 18 & 51 \\
\hline 5.1 & 982 & 573 & 0.60 & 5.39 & 0.2387 & 1.8254 & 5.6036 & 0.1374 & 4.6366 & 0.0964 & 3.0763 & 829 & 36 & 1555 & 59 & 87 \\
\hline 6.1 & 212 & 107 & 0.52 & -0.14 & 0.1474 & 7.1400 & 4.6888 & 0.3946 & 4.6425 & 0.1312 & 0.6508 & 2144 & 84 & 2114 & 12 & -1 \\
\hline 6.2 & 175 & 50 & 0.30 & 0.13 & 0.0943 & 7.1687 & 4.9538 & 0.3954 & 4.8599 & 0.1315 & 0.9285 & 2148 & 88 & 2118 & 17 & -1 \\
\hline 7.1 & 71 & 26 & 0.38 & 0.54 & 0.1155 & 8.8287 & 5.0231 & 0.4343 & 4.8018 & 0.1474 & 1.4314 & 2325 & 93 & 2316 & 25 & 0 \\
\hline 8.1 & 154 & 117 & 0.79 & 1.91 & 0.2279 & 8.5765 & 4.7806 & 0.4125 & 4.7009 & 0.1508 & 0.8427 & 2226 & 88 & 2355 & 15 & 6 \\
\hline 8.2 & 1219 & 730 & 0.62 & 7.40 & 0.2437 & 1.9939 & 12.487 & 0.1553 & 4.6598 & 0.0930 & 11.3736 & 930 & 40 & 1490 & 219 & 60 \\
\hline 9.1 & 77 & 55 & 0.74 & 4.39 & 0.2296 & 10.2287 & $5.425 \overline{4}$ & 0.4268 & 5.3337 & 0.1738 & 0.9743 & 2291 & 103 & 2595 & 17 & 13 \\
\hline 9.2 & 107 & 104 & 1.00 & -0.14 & 0.2819 & 7.1283 & 5.1139 & 0.3962 & 4.9217 & 0.1305 & 1.3751 & 2151 & 90 & 2105 & 24 & -2 \\
\hline 10.1 & 172 & 56 & 0.34 & -0.39 & 0.0969 & 7.3372 & 4.7202 & 0.4025 & 4.6646 & 0.1322 & 0.7172 & 2180 & 86 & 2128 & 13 & 2 \\
\hline 11.1 & 142 & 86 & 0.62 & 1.43 & 0.1677 & 6.1078 & 4.9129 & 0.3498 & 4.6649 & 0.1266 & 1.5303 & 1933 & 78 & 2052 & 27 & \\
\hline 12.1 & 327 & 160 & 0.50 & 1.74 & 0.1393 & 13.9248 & 4.6509 & 0.5179 & 4.6377 & 0.1950 & 0.3505 & 2690 & 102 & 2785 & 6 & 4 \\
\hline 13.1 & 260 & 227 & 0.90 & -0.38 & 0.2582 & 7.0225 & 4.6835 & 0.3938 & 4.6446 & 0.1293 & 0.5968 & 2140 & 84 & 2089 & 11 & -2 \\
\hline 14.1 & 358 & 249 & 0.72 & 3.38 & 0.1968 & 4.7146 & 4.7496 & 0.2810 & 4.6591 & 0.1217 & 0.9022 & 1596 & 65 & 1981 & 16 & 24 \\
\hline \multicolumn{17}{|l|}{ S.16 } \\
\hline 1.1 & 699 & 544 & 0.80 & 0.10 & 0.2113 & 6.7113 & 2.2844 & 0.3745 & 2.1583 & 0.1308 & 0.7165 & 2050 & 38 & 2098 & 13 & 2 \\
\hline 2.1 & 302 & 259 & 0.88 & 1.86 & 0.1946 & 6.4799 & 3.5811 & 0.3646 & 2.2222 & 0.1452 & 0.8396 & 2003 & 38 & 2083 & 49 & 4 \\
\hline 3.1 & 346 & 249 & 0.75 & 0.04 & 0.1926 & 6.8598 & 2.3044 & 0.3808 & 2.1988 & 0.1310 & 0.6709 & 2079 & 39 & 2107 & 12 & 1 \\
\hline 4.1 & 71 & 25 & 0.36 & 0.19 & 0.0970 & 7.4836 & 2.9492 & 0.4018 & 2.3988 & 0.1368 & 1.4276 & 2177 & 44 & 2165 & 30 & -1 \\
\hline 5.1 & 218 & 104 & 0.49 & 0.12 & 0.1309 & 6.7656 & 2.4161 & 0.3851 & 2.2232 & 0.1285 & 0.8738 & 2100 & 40 & 2063 & 17 & -2 \\
\hline 6.1 & 265 & 125 & 0.49 & 0.18 & 0.1311 & 6.6636 & 2.3850 & 0.3766 & 2.2049 & 0.1299 & 0.7768 & 2060 & 38 & 2075 & 16 & 1 \\
\hline 7.1 & 211 & 100 & 0.49 & 0.11 & 0.1307 & 6.5573 & 2.4929 & 0.3715 & 2.3162 & 0.1290 & 0.8822 & 2036 & 40 & 2071 & 16 & 2 \\
\hline 8.1 & 360 & 220 & 0.63 & 0.54 & 0.1703 & 6.0601 & 2.4860 & 0.3395 & 2.1902 & 0.1341 & 0.7692 & 1884 & 35 & 2091 & 21 & 11 \\
\hline 9.1 & 294 & 156 & 0.55 & 0.05 & 0.1462 & 6.7690 & 2.3541 & 0.3789 & 2.2046 & 0.1300 & 0.7859 & 2071 & 39 & 2092 & 15 & \\
\hline
\end{tabular}




\begin{tabular}{rrrrrrrrrrrrrrrrr}
10.1 & 452 & 216 & 0.49 & 0.36 & 0.1711 & 4.7528 & 2.4271 & 0.2621 & 2.1899 & 0.1345 & 0.7921 & 1500 & 29 & 2118 & 18 & 41 \\
11.1 & 349 & 793 & 2.35 & 0.49 & 0.2439 & 6.0725 & 2.4563 & 0.3384 & 2.1960 & 0.1343 & 0.7464 & 1879 & 39 & 2100 & 19 & 12 \\
12.1 & 530 & 371 & 0.72 & 0.04 & 0.1896 & 7.0412 & 2.2451 & 0.3927 & 2.1705 & 0.1304 & 0.5671 & 2135 & 39 & 2098 & 10 & -2 \\
13.1 & 212 & 151 & 0.74 & 0.13 & 0.1982 & 7.0169 & 2.4182 & 0.3939 & 2.2332 & 0.1303 & 0.9006 & 2141 & 40 & 2087 & 16 & -3 \\
14.1 & 565 & 454 & 0.83 & 0.19 & 0.1789 & 6.4730 & 2.2721 & 0.3647 & 2.1698 & 0.1304 & 0.5741 & 2004 & 37 & 2081 & 12 & 4 \\
15.1 & 876 & 233 & 0.28 & 0.29 & 0.0781 & 5.7715 & 2.2610 & 0.3337 & 2.1577 & 0.1279 & 0.4868 & 1856 & 34 & 2035 & 12 & 10 \\
16.1 & 291 & 149 & 0.53 & 0.97 & 0.1375 & 4.6813 & 2.9622 & 0.2588 & 2.3804 & 0.1391 & 0.9439 & 1483 & 31 & 2114 & 31 & 42 \\
17.1 & 657 & 679 & 1.07 & 0.14 & 0.2583 & 6.6959 & 2.3169 & 0.3739 & 2.2305 & 0.1311 & 0.5312 & 2047 & 39 & 2096 & 11 & 2 \\
\hline
\end{tabular}

Table 3 (supplementary material): Summary of the SHRIMP U-Pb zircon analytical data - Cassiterita ortogneiss (seção 4.2).

\begin{tabular}{|c|c|c|c|c|c|c|c|c|c|c|c|c|c|}
\hline Spot name & $\begin{array}{l}\mathrm{U} \\
(\mathrm{ppm})\end{array}$ & $\mathrm{Th} / \mathrm{U}$ & $\mathrm{Pb}_{\text {com }}$ & $\begin{array}{l}{ }^{207} \mathrm{~Pb} /{ }^{206} \\
\mathrm{~Pb}^{*}\end{array}$ & $1 \sigma$ & $\begin{array}{l}{ }^{207} \mathrm{~Pb} / \\
{ }^{235} \mathrm{U}\end{array}$ & $1 \sigma$ & $\begin{array}{l}{ }^{206} \mathrm{~Pb} / \\
{ }^{238} \mathrm{U}\end{array}$ & $1 \sigma$ & $\begin{array}{l}{ }^{207} \mathrm{~Pb} /{ }^{206} \\
\mathrm{~Pb}\end{array}$ & $1 \sigma$ & Disc. $\%$ & Error cor. \\
\hline \multicolumn{14}{|c|}{ NAT- 5} \\
\hline 1.1 & 205 & 0.62 & 0.19 & .1608 & 0.8 & 10.60 & 3.2 & .4778 & 3.1 & 2465 & 14 & -2 & .927 \\
\hline 2.1 & 175 & 0.41 & 0.34 & .1578 & 0.9 & 10.51 & 3.3 & .4829 & 3.1 & 2432 & 16 & -4 & .970 \\
\hline 3.1 & 197 & 0.70 & 0.19 & .1630 & 1.0 & 10.50 & 3.3 & .4671 & 3.2 & 2487 & 17 & 1 & .958 \\
\hline 4.1 & 180 & 0.63 & 0.28 & .1613 & 1.0 & 10.59 & 3.3 & .4761 & 3.1 & 2469 & 16 & -2 & .970 \\
\hline 5.1 & 382 & 0.80 & 0.16 & .1607 & 0.6 & 10.21 & 3.2 & .4609 & 3.1 & 2463 & 10 & 1 & .983 \\
\hline 6.1 & 1104 & 0.16 & 1.24 & .1181 & 1.6 & 3.28 & 3.5 & .2011 & 3.1 & 1928 & 29 & 63 & .906 \\
\hline 7.1 & 541 & 0.25 & 0.18 & .1276 & 0.7 & 5.80 & 3.1 & .3297 & 3.1 & 2065 & 12 & 12 & .983 \\
\hline 8.1 & 174 & 0.67 & 0.31 & .1572 & 0.9 & 10.49 & 3.3 & .4840 & 3.2 & 2426 & 15 & -5 & .972 \\
\hline 10.1 & 394 & 1.50 & 0.19 & .1563 & 0.7 & 8.07 & 3.2 & .3745 & 3.1 & 2416 & 11 & 18 & .805 \\
\hline 11.1 & 830 & 0.93 & 0.56 & .1217 & 0.9 & 3.23 & 3.4 & .1922 & 3.3 & 1982 & 17 & 75 & .982 \\
\hline 12.1 & 651 & 0.52 & 0.57 & .1324 & 0.9 & 4.77 & 3.5 & .2611 & 3.4 & 2130 & 16 & 42 & .962 \\
\hline 14.1 & 137 & 1.02 & 0.23 & .1623 & 1.0 & 10.80 & 3.3 & .4827 & 3.1 & 2480 & 17 & -2 & .962 \\
\hline 15.1 & 227 & 0.50 & 0.19 & .1583 & 0.8 & 9.57 & 3.2 & .4386 & 3.2 & 2437 & 13 & 4 & .976 \\
\hline 16.1 & 283 & 0.70 & 0.24 & .1597 & 0.7 & 10.99 & 3.2 & .4992 & 3.1 & 2453 & 11 & -6 & .982 \\
\hline 17.1 & 143 & 1.08 & 0.21 & .1641 & 0.9 & 11.11 & 3.2 & .4908 & 3.1 & 2498 & 15 & -3 & .959 \\
\hline
\end{tabular}




\begin{tabular}{|c|c|c|c|c|c|c|c|c|c|c|c|c|c|}
\hline 18.1 & 295 & 0.57 & 0.15 & .1622 & 0.6 & 10.99 & 3.2 & .4912 & 3.2 & 2479 & 10 & -4 & .945 \\
\hline $1.1^{*}$ & 349 & 0.42 & -0.26 & .1591 & 0.6 & 10.38 & 4.7 & .4732 & 4.7 & 2446 & 11 & -2 & .996 \\
\hline $1.2^{*}$ & 548 & 0.23 & 4.10 & .1428 & 0.4 & 6.45 & 4.8 & .3276 & 4.8 & 2261 & 7 & 24 & .996 \\
\hline $2.1 *$ & 621 & 0.30 & 4.41 & .1203 & 1.1 & 3.91 & 4.9 & .2357 & 4.8 & 1960 & 20 & 44 & .977 \\
\hline $2.2^{*}$ & 157 & 0.89 & 1.91 & .1284 & 1.1 & 6.13 & 4.8 & .3460 & 4.7 & 2076 & 21 & 8 & .984 \\
\hline $3.1^{*}$ & 564 & 0.32 & 4.79 & .1277 & 0.7 & 4.56 & 4.8 & .2590 & 4.8 & 2067 & 13 & 39 & .984 \\
\hline
\end{tabular}

\begin{tabular}{|c|c|c|c|c|c|c|c|c|c|c|c|c|}
\hline Spot name & $\mathrm{Th} / \mathrm{U}$ & Pbcom & $\begin{array}{c}{ }^{207} \mathrm{~Pb} / \\
{ }^{206} \mathrm{~Pb}^{*}\end{array}$ & $1 \sigma$ & $\begin{array}{l}{ }^{207} \mathrm{~Pb} / \\
{ }^{235} \mathrm{U} \\
\end{array}$ & $1 \sigma$ & $\begin{array}{r}{ }^{206} \mathrm{~Pb} / \\
{ }^{238} \mathrm{U}\end{array}$ & $1 \sigma$ & $\begin{array}{r}{ }^{207} \mathrm{~Pb} /{ }^{206} \mathrm{~Pb} \\
\text { age(Ma) }\end{array}$ & $1 \sigma$ & $\begin{array}{r}\% \\
\text { DISC } \\
\end{array}$ & $\begin{array}{r}\text { Error } \\
\text { cor. }\end{array}$ \\
\hline \multicolumn{13}{|l|}{ NAT-8 } \\
\hline 1.1 & 0.92 & -1.26 & .165 & 0.6 & 11.10 & 3.1 & .4929 & 3.1 & 2491 & 11 & -4 & .979 \\
\hline 2.1 & 0.93 & -2.67 & .164 & 0.5 & 11.53 & 3.1 & .5116 & 3.1 & 2491 & 8 & -6 & .989 \\
\hline 3.1 & 0.20 & 3.82 & .121 & 1.0 & 4.05 & 3.3 & .2504 & 3.1 & 1915 & 22 & 33 & .926 \\
\hline 4.1 & 1.26 & 4.22 & .150 & 1.0 & 7.05 & 3.5 & .3452 & 3.3 & 2325 & 19 & 22 & .949 \\
\hline 5.1 & 0.36 & 5.14 & .134 & 0.5 & 4.77 & 3.1 & .2600 & 3.1 & 2137 & 10 & 43 & .985 \\
\hline 6.1 & 0.98 & 1.51 & .157 & 0.6 & 9.14 & 3.2 & .4273 & 3.2 & 2404 & 13 & 5 & .973 \\
\hline 7.1 & 0.64 & 6.55 & .135 & 4.3 & 3.89 & 5.4 & .2141 & 3.1 & 2121 & 78 & 70 & .566 \\
\hline 8.1 & 0.67 & -2.34 & .187 & 0.9 & 14.20 & 4.3 & .5522 & 4.2 & 2712 & 15 & -4 & .976 \\
\hline 9.1 & 0.23 & 4.75 & .132 & 0.6 & 4.65 & 3.4 & .2651 & 3.1 & 2058 & 26 & 36 & .902 \\
\hline 10.1 & 0.42 & -2.81 & .156 & 0.7 & 10.50 & 3.2 & .4958 & 3.1 & 2386 & 14 & -8 & .965 \\
\hline 11.1 & 0.21 & 3.53 & .108 & 1.8 & 2.99 & 3.6 & .2034 & 3.1 & 1744 & 33 & 46 & .859 \\
\hline 12.1 & 0.37 & 4.72 & .139 & 1.5 & 5.57 & 3.6 & .2943 & 3.2 & 2192 & 27 & 32 & .898 \\
\hline 13.1 & 0.13 & 4.19 & .133 & 0.5 & 5.20 & 3.1 & .2863 & 3.1 & 2120 & 11 & 31 & .980 \\
\hline 15.1 & 0.41 & 5.56 & .153 & 0.8 & 6.76 & 3.2 & .3225 & 3.1 & 2369 & 14 & 31 & .966 \\
\hline 14.1 & 0.96 & -1.19 & .162 & 1.0 & 10.54 & 3.5 & .4842 & 3.3 & 2433 & 19 & -4 & .944 \\
\hline 16.1 & 0.23 & 2.84 & .144 & 0.5 & 7.08 & 3.1 & .3612 & 3.1 & 2253 & 12 & 13 & .974 \\
\hline 17.1 & 0.55 & 4.16 & .142 & 0.7 & 6.17 & 3.2 & .3196 & 3.1 & 2228 & 13 & 25 & .972 \\
\hline 18.1 & 0.85 & -0.94 & .162 & 0.9 & 10.75 & 3.4 & .4834 & 3.3 & 2470 & 15 & -3 & .964 \\
\hline 19.1 & 0.56 & -0.16 & .136 & 0.7 & 7.49 & 3.2 & .4036 & 3.1 & 2160 & 13 & -1 & .971 \\
\hline 20.1 & 0.75 & 1.80 & .153 & 1.0 & 8.59 & 3.4 & .4109 & 3.2 & 2363 & 19 & 7 & .944 \\
\hline 21.1 & 0.63 & 0.90 & .153 & 0.5 & 9.02 & 3.2 & .4296 & 3.1 & 2371 & 11 & 3 & .979 \\
\hline 1.1 & 0.29 & -3.73 & .169 & 1.5 & 12.40 & 5.1 & .5343 & 4.9 & 2541 & 25 & -8 & .955 \\
\hline 2.1 & 0.59 & -1.14 & .163 & 0.5 & 11.03 & 4.8 & .4896 & 4.8 & 2491 & 8 & -3 & .995 \\
\hline 3.1 & 0.74 & -1.57 & .162 & 0.4 & 11.05 & 4.7 & .4937 & 4.6 & 2481 & 7 & -4 & .995 \\
\hline 4.1 & 0.19 & 3.50 & .120 & 0.4 & 4.17 & 4.7 & .2557 & 4.7 & 1932 & 9 & 32 & .995 \\
\hline
\end{tabular}




\begin{tabular}{|c|c|c|c|c|c|c|c|c|c|c|c|c|}
\hline Spot name & $\mathrm{Th} / \mathrm{U}$ & $\mathrm{Pb}_{\text {com }}$ & $\begin{array}{l}{ }^{207} \mathrm{~Pb} / \\
{ }^{206} \mathrm{~Pb}^{*}\end{array}$ & $1 \sigma$ & $\begin{array}{l}{ }^{207} \mathrm{~Pb} / \\
{ }^{235} \mathrm{U}\end{array}$ & $1 \sigma$ & $\begin{array}{l}{ }^{206} \mathrm{~Pb} / \\
{ }^{238} \mathrm{U}\end{array}$ & $1 \sigma$ & $\begin{array}{l}{ }^{207} \mathrm{~Pb} /{ }^{206} \mathrm{~Pb} \\
\text { age }(\mathrm{Ma})\end{array}$ & $1 \sigma$ & $\begin{array}{l}\% \\
\text { DISC }\end{array}$ & Error cor. \\
\hline \multicolumn{13}{|c|}{ NAT-36 } \\
\hline 1.1 & 0.90 & 0.04 & .165 & 0.8 & 11.17 & 2.8 & .4909 & 2.7 & 2508 & 13 & -3 & .963 \\
\hline 2.1 & 1.15 & 0.40 & .160 & 0.9 & 9.67 & 3.0 & .4485 & 2.8 & 2416 & 21 & 1 & .916 \\
\hline 3.1 & 1.06 & 0.23 & .162 & 1.2 & 10.15 & 3.2 & .4618 & 2.9 & 2450 & 22 & 0 & .913 \\
\hline 4.1 & 0.46 & 0.48 & .149 & 0.6 & 7.52 & 2.9 & .3767 & 2.7 & 2286 & 16 & 11 & .944 \\
\hline 5.1 & 1.39 & 0.00 & .162 & 0.7 & 10.99 & 2.8 & .4907 & 2.7 & 2481 & 12 & -4 & .965 \\
\hline 6.1 & 0.84 & 0.81 & .135 & 1.3 & 4.33 & 3.3 & .2438 & 2.7 & 2082 & 33 & 48 & .827 \\
\hline 7.1 & 0.34 & 0.15 & .126 & 0.5 & 5.08 & 2.7 & .2967 & 2.7 & 2018 & 10 & 20 & .980 \\
\hline 8.1 & 0.70 & 2.73 & .162 & 1.6 & 4.79 & 4.4 & .2472 & 2.7 & 2233 & 59 & 57 & .621 \\
\hline 9.1 & 0.47 & 0.14 & .159 & 0.7 & 10.60 & 2.9 & .4882 & 2.8 & 2428 & 13 & -5 & .966 \\
\hline 10.1 & 0.27 & 0.28 & .130 & 0.6 & 6.67 & 2.8 & .3787 & 2.7 & 2066 & 15 & 0 & .955 \\
\hline 10.2 & 0.53 & 0.41 & .159 & 0.6 & 9.74 & 3.0 & .4554 & 2.8 & 2403 & 16 & -1 & .950 \\
\hline 6.2 & 0.63 & 0.24 & .141 & 0.4 & 5.83 & 2.8 & .3035 & 2.7 & 2220 & 10 & 30 & .979 \\
\hline 11.1 & 0.27 & 0.25 & .154 & 0.6 & 8.71 & 3.1 & .4165 & 3.0 & 2365 & 13 & 5 & .970 \\
\hline 12.1 & 0.51 & 1.34 & .142 & 0.6 & 5.61 & 3.3 & .3113 & 2.7 & 2109 & 33 & 21 & .821 \\
\hline 13.1 & 0.74 & 0.19 & .153 & 1.2 & 7.51 & 3.2 & .3608 & 2.9 & 2358 & 23 & 19 & .907 \\
\hline
\end{tabular}

\begin{tabular}{|c|c|c|c|c|c|c|c|c|c|c|c|c|c|c|c|c|c|}
\hline $\begin{array}{l}\text { Grain. } \\
\text { spot }\end{array}$ & $\begin{array}{l}\mathrm{U} \\
(\mathrm{ppm})\end{array}$ & $\begin{array}{l}\text { Th } \\
(\mathrm{ppm})\end{array}$ & $\mathrm{Th} / \mathrm{U}$ & $\begin{array}{l}{ }^{206} \mathrm{~Pb} \\
(\mathrm{ppm})\end{array}$ & ${ }^{204} \mathrm{~Pb} /{ }^{206} \mathrm{~Pb}$ & $\begin{array}{l}\mathrm{f}^{206} \\
\%\end{array}$ & ${ }^{207} \mathrm{~Pb} /{ }^{235} \mathrm{U}$ & $-1 \mathrm{~s}$ & ${ }^{206} \mathrm{~Pb} /{ }^{238} \mathrm{U}$ & $-1 \mathrm{~s}$ & ${ }^{207} \mathrm{~Pb} /{ }^{206} \mathrm{~Pb}$ & $-1 \mathrm{~s}$ & $\begin{array}{l}{ }^{206} \mathrm{~Pb}{ }^{238} \mathrm{U} \\
\text { Age (Ma) }\end{array}$ & $-1 \mathrm{~s}$ & $\begin{array}{l}{ }^{207} \mathrm{~Pb} /{ }^{206} \mathrm{~Pb} \\
\text { Age }(\mathrm{Ma}\end{array}$ & $1 \mathrm{~s}$ & Disc.\% \\
\hline \multicolumn{18}{|c|}{ NAT-38 } \\
\hline 1.1 & 363 & 132 & 0.38 & 0.52 & 0.0003 & 16 & 3.92 & 2.4 & .2367 & 2.2 & .1200 & $\overline{1.0}$ & 1369.5 & 26.9 & 1957 & 18 & 43 \\
\hline 2.1 & 536 & 476 & 0.92 & 1.22 & 0.0007 & 10 & 1.84 & 3.1 & .1402 & 2.3 & .0951 & 2.0 & 845.9 & 17.9 & 1530 & 39 & 81 \\
\hline 3.1 & 407 & 312 & 0.79 & 1.12 & 0.0007 & 10 & 3.18 & 2.8 & .2055 & 2.2 & .1123 & 1.7 & 1204.9 & 24.0 & 1837 & 31 & 53 \\
\hline 4.1 & 383 & 153 & 0.41 & 0.14 & 0.0001 & 32 & 6.13 & 2.3 & .3513 & 2.2 & .1266 & 0.6 & 1940.9 & 37.1 & 2051 & 11 & 6 \\
\hline 6.1 & 270 & 226 & 0.86 & 0.13 & 0.0001 & 29 & 5.01 & 2.3 & .2902 & 2.3 & .1253 & 0.6 & 1642.8 & 33.1 & 2033 & 10 & 24 \\
\hline 7.1 & 408 & 109 & 0.28 & 0.12 & 0.0001 & 33 & 4.67 & 2.2 & .2767 & 2.2 & .1223 & 0.5 & 1574.9 & 30.4 & 1990 & 10 & 26 \\
\hline 8.1 & 406 & 398 & 1.01 & 0.13 & 0.0001 & 24 & 4.90 & 2.3 & .2877 & 2.2 & .1237 & 0.6 & 1629.8 & 31.3 & 2010 & 10 & 23 \\
\hline
\end{tabular}




\begin{tabular}{|c|c|c|c|c|c|c|c|c|c|c|c|c|c|c|c|c|c|}
\hline 9.1 & 662 & 208 & 0.32 & 0.56 & 0.0003 & 12 & 1.90 & 2.4 & .1446 & 2.2 & .0952 & 1.0 & 870.4 & 17.5 & 1532 & 20 & 76 \\
\hline 10.1 & 509 & 247 & 0.50 & 1.37 & 0.0008 & 8 & 3.04 & 2.8 & .2000 & 2.2 & .1101 & 1.7 & 1175.3 & 23.3 & 1802 & 32 & 53 \\
\hline 11.1 & 400 & 243 & 0.63 & 0.06 & 0.0000 & 33 & 5.17 & 2.3 & .2994 & 2.2 & .1252 & 0.5 & 1688.1 & 32.8 & 2032 & 9 & 20 \\
\hline 12.1 & 529 & 413 & 0.81 & 0.36 & 0.0002 & 20 & 4.11 & 2.3 & .2476 & 2.2 & .1202 & 0.7 & 1426.2 & 28.3 & 1960 & 13 & 37 \\
\hline 13.1 & 473 & 57 & 0.12 & 0.75 & 0.0005 & 14 & 3.86 & 2.5 & .2390 & 2.2 & .1173 & 1.1 & 1381.2 & 27.0 & 1915 & 21 & 39 \\
\hline 14.1 & 398 & 295 & 0.77 & 0.47 & 0.0003 & 13 & 4.79 & 2.3 & .2821 & 2.2 & .1230 & 0.7 & 1601.7 & 30.9 & 2001 & 14 & 25 \\
\hline 15.1 & 383 & 215 & 0.58 & 1.17 & 0.0007 & 20 & 2.56 & 3.5 & .1766 & 2.3 & .1052 & 2.7 & 1048.1 & 21.9 & 1718 & 50 & 64 \\
\hline
\end{tabular}

\begin{tabular}{|c|c|c|c|c|c|c|c|c|c|c|c|c|c|c|c|c|c|}
\hline $\begin{array}{l}\text { Grain. } \\
\text { spot }\end{array}$ & $\begin{array}{l}\mathrm{U} \\
(\mathrm{ppm})\end{array}$ & $\begin{array}{l}\text { Th } \\
(\mathrm{ppm})\end{array}$ & $\mathrm{Th} / \mathrm{U}$ & $\begin{array}{l}{ }^{206} \mathrm{~Pb} \\
(\mathrm{ppm})\end{array}$ & ${ }^{7} \mathrm{~Pb} /{ }^{206} \mathrm{~Pb}$ & $\mathrm{f}^{206} \%$ & ${ }^{207} \mathrm{~Pb} /{ }^{235} \mathrm{U}$ & $-1 \mathrm{~s}$ & ${ }^{06} \mathrm{~Pb} /{ }^{238} \mathrm{U}$ & ${ }_{-1 \mathrm{~s}}$ & ${ }^{207} \mathrm{~Pb} /{ }^{206} \mathrm{~Pb}$ & $-1 \mathrm{~s}$ & $\begin{array}{l}{ }^{206} \mathrm{~Pb} /{ }^{238} \mathrm{U} \\
\mathrm{Age}(\mathrm{Ma})\end{array}$ & _1s & $\begin{array}{l}{ }^{207} \mathrm{~Pb} /{ }^{206} \mathrm{~Pb} \\
\mathrm{Age}(\mathrm{Ma}\end{array}$ & & Disc.\% \\
\hline \multicolumn{18}{|l|}{ NAT-39 } \\
\hline 1.1 & 440 & 85 & 0.20 & 0.37 & $2.4 \mathrm{E}-4$ & 13 & 5.98 & 2.3 & .3282 & 2.2 & .1322 & 0.6 & 1829.8 & 34.6 & 2127 & 10 & 16 \\
\hline 2.1 & 352 & 36 & 0.11 & 0.09 & $5.6 \mathrm{E}-5$ & 39 & 5.33 & 2.2 & .3036 & 2.2 & .1273 & 0.5 & 1709.0 & 32.7 & 2061 & 9 & 21 \\
\hline 3.1 & 405 & 86 & 0.22 & 0.17 & $1.1 \mathrm{E}-4$ & 21 & 5.74 & 2.2 & .3177 & 2.2 & .1310 & 0.5 & 1778.6 & 34.0 & 2111 & 9 & 19 \\
\hline 4.1 & 347 & 46 & 0.14 & 0.17 & $1.1 \mathrm{E}-4$ & 24 & 5.16 & 2.3 & .2810 & 2.2 & .1331 & 0.5 & 1596.3 & 30.9 & 2140 & 10 & 34 \\
\hline 5.1 & 412 & 69 & 0.17 & 0.03 & $1.9 \mathrm{E}-5$ & 27 & 7.54 & 2.2 & .4050 & 2.2 & .1351 & 0.3 & 2192.2 & 40.4 & 2165 & 6 & -1 \\
\hline 6.1 & 411 & 44 & 0.11 & 1.67 & $9.7 \mathrm{E}-4$ & 10 & 2.44 & 3.1 & .1543 & 2.2 & .1147 & 2.1 & 924.8 & 18.8 & 1877 & 39 & 103 \\
\hline 7.1 & 374 & 22 & 0.06 & 0.19 & $1.2 \mathrm{E}-4$ & 30 & 4.62 & 2.4 & .2730 & 2.3 & .1227 & 0.7 & 1556.2 & 31.2 & 1996 & 13 & 28 \\
\hline 8.1 & 434 & 91 & 0.22 & 1.27 & $7.6 \mathrm{E}-4$ & 8 & 3.21 & 2.9 & .1995 & 2.2 & .1166 & 1.9 & 1172.4 & 23.3 & 1905 & 36 & 63 \\
\hline 9.1 & 201 & 22 & 0.12 & 0.16 & $1.0 \mathrm{E}-4$ & 32 & 6.04 & 2.3 & .3318 & 2.2 & .1319 & 0.7 & 1847.1 & 35.7 & 2124 & 12 & 15 \\
\hline 10.1 & 489 & 135 & 0.28 & 0.16 & $9.7 \mathrm{E}-5$ & 22 & 4.31 & 2.2 & .2452 & 2.2 & .1276 & 0.5 & 1413.8 & 27.5 & 2065 & 9 & 46 \\
\hline 12.1 & 571 & 133 & 0.24 & 0.27 & $1.6 \mathrm{E}-4$ & 21 & 3.23 & 2.4 & .2060 & 2.3 & .1136 & 0.6 & 1207.2 & 25.1 & 1858 & 12 & 54 \\
\hline
\end{tabular}

Sample and standard are corrected after $\mathrm{Pb}$ and $\mathrm{Hg}$ blanks

Common $\mathrm{Pb}$ corrected using measured ${ }^{204} \mathrm{~Pb}$

Errors are 1-sigma. 


\section{Anexo II - Dados U-Pb pontuais em zircão (LA-ICPMS).}

Table 3.2 (supplementary material): Summary of the LA-ICPMS U-Pb zircon analytical data (seção 4.5).

\begin{tabular}{|c|c|c|c|c|c|c|c|c|c|c|c|c|c|c|c|c|c|}
\hline $\begin{array}{l}\text { Grain. } \\
\text { spot }\end{array}$ & $\begin{array}{l}\mathrm{U} \\
(\mathrm{ppm})\end{array}$ & $\begin{array}{l}\text { Th } \\
(\mathrm{ppm})\end{array}$ & $\mathrm{Th} / \mathrm{U}$ & ${ }^{204} \mathrm{~Pb}$ & $\begin{array}{l}{ }^{208} \mathrm{~Pb} \\
/^{206} \mathrm{~Pb}\end{array}$ & $\mathrm{~Pb} \mathrm{rad}$ & $\begin{array}{l}{ }^{207} \mathrm{~Pb} \\
\rho^{235} \mathrm{U}\end{array}$ & _1s & $\begin{array}{l}{ }^{206} \mathrm{~Pb} \\
{ }^{238} \mathrm{U}\end{array}$ & _1s & $\begin{array}{l}{ }^{207} \mathrm{~Pb} \\
{ }^{206} \mathrm{~Pb}\end{array}$ & _1s & $\begin{array}{r}{ }^{206} \mathrm{~Pb} \\
{ }^{238} \mathrm{U} \\
\text { Age }(\mathrm{Ma})\end{array}$ & ${ }_{-1 \mathrm{~s}}$ & $\begin{array}{r}{ }^{207} \mathrm{~Pb} \\
{ }^{206} \mathrm{~Pb} \\
\text { Age }(\mathrm{Ma})\end{array}$ & _1s & Conc. \\
\hline \multicolumn{18}{|l|}{ S. 3} \\
\hline 1.1 & 475 & 142 & 0.30 & 6.037 & 0.290 & 257 & 7.8373 & 0.1321 & 0.4143 & 0.0060 & 0.1407 & 0.0012 & 2234 & 27 & 2231 & 15 & 100 \\
\hline 2.1 & 60 & 31 & 0.52 & $<0.001$ & 0.345 & 42 & 10.3669 & 0.1490 & 0.4662 & 0.0058 & 0.1609 & 0.0013 & 2467 & 26 & 2462 & 14 & 100 \\
\hline 3.1 & 2053 & 587 & 0.29 & 38.26 & 0.230 & 405 & 1.7003 & 0.0371 & 0.1652 & 0.0032 & 0.0720 & 0.0007 & 985 & 18 & 987 & 21 & 100 \\
\hline 4.1 & 969 & 1103 & 1.14 & 18.10 & 0.673 & 282 & 3.6715 & 0.0583 & 0.2085 & 0.0029 & 0.1307 & 0.0011 & 1221 & 15 & 2104 & 15 & 58 \\
\hline 5.1 & 2026 & -266 & -0.13 & 82.31 & 0.013 & 371 & 1.6808 & 0.0259 & 0.1631 & 0.0023 & 0.0730 & 0.0007 & 974 & 13 & 1015 & 20 & 96 \\
\hline 6.1 & 2073 & 564 & 0.27 & 19.83 & 0.253 & 377 & 1.8774 & 0.0305 & 0.1478 & 0.0020 & 0.0912 & 0.0008 & 888 & 11 & 1456 & 16 & 61 \\
\hline 7.1 & 1229 & 88 & 0.07 & 7.914 & 0.136 & 304 & 3.2302 & 0.0498 & 0.2137 & 0.0029 & 0.1084 & 0.0009 & 1248 & 15 & 1776 & 15 & 70 \\
\hline 8.1 & 1494 & 454 & 0.30 & 32.23 & 0.455 & 326 & 2.2624 & 0.1074 & 0.1404 & 0.0029 & 0.1030 & 0.0013 & 847 & 16 & 1683 & 23 & 50 \\
\hline 9.1 & 476 & 229 & 0.48 & $<0.00$ & 0.359 & 240 & 7.5220 & 0.1306 & 0.4031 & 0.0051 & 0.1396 & 0.0019 & 2183 & 24 & 2219 & 23 & 98 \\
\hline 10.1 & 569 & 199 & 0.35 & 9.737 & 0.379 & 268 & 6.5987 & 0.2023 & 0.3803 & 0.0087 & 0.1287 & 0.0013 & 2077 & 40 & 2077 & 17 & 100 \\
\hline 10.2 & 317 & 206 & 0.65 & 0.431 & 0.459 & 165 & 7.2580 & 0.1116 & 0.3932 & 0.0051 & 0.1332 & 0.0011 & 2138 & 24 & 2137 & 14 & 100 \\
\hline 11.1 & 2844 & 2075 & 0.73 & 368.9 & 0.547 & 544 & 1.6320 & 0.0430 & 0.1545 & 0.0030 & 0.0736 & 0.0008 & 926 & 17 & 1030 & 23 & 90 \\
\hline 12.1 & 1932 & 2934 & 1.52 & 107.3 & 0.547 & 349 & 1.2482 & 0.0573 & 0.1318 & 0.0020 & 0.0659 & 0.0021 & 798 & 11 & 798 & 65 & 100 \\
\hline \multicolumn{18}{|l|}{ S.8 } \\
\hline 1.1 & 114 & 230 & 2.02 & 3.075 & 0.749 & 68 & 7.7911 & 0.1655 & 0.3877 & 0.0043 & 0.1310 & 0.0014 & 2112 & 20 & 2108 & 19 & 100 \\
\hline 2.1 & 901 & 339 & 0.38 & $<0.00$ & 0.016 & 183 & 1.0137 & 1.1350 & 0.1577 & 0.0145 & 0.0706 & 0.0185 & 944 & 81 & 945 & 468 & 100 \\
\hline 3.1 & 541 & 355 & 0.66 & $<0.00$ & 0.265 & 171 & 4.3583 & 0.1647 & 0.2737 & 0.0070 & 0.1170 & 0.0030 & 1559 & 35 & 1911 & 44 & 82 \\
\hline 4.1 & 729 & 485 & 0.67 & 4.474 & 0.252 & 148 & 1.8196 & 0.0697 & 0.1508 & 0.0017 & 0.0916 & 0.0028 & 905 & 10 & 1445 & 58 & 63 \\
\hline 5.1 & 1368 & 1302 & 0.95 & 22.584 & 0.520 & 255 & 1.9933 & 0.0467 & 0.1241 & 0.0013 & 0.1187 & 0.0021 & 754 & 8 & 1938 & 31 & 39 \\
\hline 6.1 & 107 & 70 & 0.65 & $<0.00$ & 0.292 & 59 & 7.2817 & 0.1337 & 0.3924 & 0.0045 & 0.1337 & 0.0013 & 2134 & 21 & 2143 & 17 & 100 \\
\hline
\end{tabular}




\begin{tabular}{|c|c|c|c|c|c|c|c|c|c|c|c|c|c|c|c|c|c|}
\hline 7.1 & 400 & 283 & 0.71 & 0.623 & 0.308 & 201 & 7.1420 & 0.2630 & 0.3957 & 0.0120 & 0.1336 & 0.0020 & 2149 & 55 & 2142 & 26 & 100 \\
\hline 8.1 & 293 & 147 & 0.50 & 0.553 & 0.198 & 145 & 7.8381 & 0.2436 & 0.4064 & 0.0077 & 0.1377 & 0.0018 & 2199 & 35 & 2194 & 22 & 100 \\
\hline 9.1 & 535 & 337 & 0.63 & 4.555 & 0.462 & 209 & 7.0882 & 0.1488 & 0.3248 & 0.0028 & 0.1788 & 0.0024 & 1813 & 14 & 2643 & 23 & 69 \\
\hline 10.1 & 713 & 534 & 0.75 & 15.687 & 0.416 & 199 & 3.7555 & 0.1041 & 0.2007 & 0.0022 & 0.1392 & 0.0037 & 1179 & 12 & 2213 & 45 & 53 \\
\hline 11.1 & 519 & 238 & 0.46 & 29.792 & 0.167 & 119 & 0.3624 & 0.5967 & 0.1518 & 0.0051 & 0.0698 & 0.0117 & 911 & 29 & 922 & 318 & 99 \\
\hline 12.1 & 1407 & 869 & 0.62 & 7.414 & 0.273 & 352 & 3.3319 & 0.0680 & 0.2239 & 0.0017 & 0.1102 & 0.0021 & 1302 & 9 & 1806 & 33 & 72 \\
\hline 13.1 & 988 & 512 & 0.52 & 156.151 & 0.275 & 175 & 1.9179 & 0.0674 & 0.1752 & 0.0012 & 0.0740 & 0.0037 & 1041 & 7 & 1041 & 100 & 100 \\
\hline 14.1 & 918 & 452 & 0.49 & $<0.00$ & 0.224 & 184 & 1.9789 & 0.0510 & 0.1659 & 0.0016 & 0.0906 & 0.0009 & 990 & 9 & 1444 & 18 & 69 \\
\hline 15.1 & 414 & 207 & 0.50 & 270.144 & 0.196 & 165 & 4.1193 & 0.1413 & 0.3443 & 0.0037 & 0.1162 & 0.0012 & 1907 & 18 & 1900 & 18 & 100 \\
\hline 16.1 & 1110 & 834 & 0.75 & 38.485 & 0.274 & 160 & 1.0955 & 0.0284 & 0.1069 & 0.0013 & 0.0748 & 0.0007 & 655 & 8 & 1063 & 19 & 62 \\
\hline 17.1 & 1388 & 487 & 0.35 & 13.076 & 0.198 & 198 & 1.2345 & 0.0321 & 0.1064 & 0.0014 & 0.0808 & 0.0010 & 652 & 8 & 1222 & 24 & 53 \\
\hline 18.1 & 607 & 311 & 0.51 & 27.698 & 0.295 & 127 & 1.8649 & 0.1274 & 0.1536 & 0.0018 & 0.0904 & 0.0048 & 921 & 10 & 1441 & 98 & 64 \\
\hline 19.1 & 1055 & 601 & 0.57 & 4.381 & 0.235 & 321 & 3.8738 & 0.1150 & 0.2423 & 0.0038 & 0.1152 & 0.0016 & 1398 & 20 & 1884 & 24 & 74 \\
\hline 20.1 & 1335 & 338 & 0.25 & 304.789 & 0.167 & 194 & 1.1023 & 0.0304 & 0.1157 & 0.0017 & 0.0689 & 0.0007 & 706 & 10 & 0894 & 21 & 79 \\
\hline 21.1 & 1038 & 475 & 0.46 & 15.420 & 0.175 & 183 & 1.8116 & 0.0405 & 0.1524 & 0.0016 & 0.0866 & 0.0007 & 914 & 9 & 1357 & 16 & 67 \\
\hline 22.1 & 1521 & 754 & 0.50 & 33.092 & 0.237 & 225 & 1.2293 & 0.0278 & 0.1261 & 0.0013 & 0.0714 & 0.0006 & 766 & 8 & 968 & 17 & 79 \\
\hline 23.1 & 317 & 47 & 0.15 & $<0.001$ & 0.099 & 157 & 7.1449 & $0.1643 f$ & 0.3966 & 0.0044 & 0.1426 & 0.0013 & 2153 & 20 & 2242 & 16 & 96 \\
\hline 24.1 & 1150 & 652 & 0.57 & 110.115 & 0.012 & 261 & 1.7054 & 0.1569 & 0.1882 & 0.0022 & 0.0828 & 0.0040 & 1112 & 12 & 1269 & 93 & 88 \\
\hline 25.1 & 1605 & 594 & 0.37 & 14.024 & 0.174 & 255 & 1.3914 & 0.0346 & 0.1252 & 0.0013 & 0.0801 & 0.0006 & 760 & 7 & 1204 & 16 & 63 \\
\hline 26.1 & 1211 & 939 & 0.78 & 9.424 & 0.272 & 210 & 1.5106 & 0.0373 & 0.1284 & 0.0016 & 0.0834 & 0.0008 & 779 & 9 & 1282 & 18 & 61 \\
\hline \multicolumn{18}{|l|}{ S.10 } \\
\hline 1.1 & 1593 & 881 & 0.55 & 3.067 & 0.214 & 353 & 2.2824 & 0.0374 & 0.1948 & 0.0025 & 0.0857 & 0.0006 & 1148 & 13 & 1337 & 13 & 95 \\
\hline 2.1 & 1354 & 161 & 0.12 & 1.088 & 0.062 & 318 & 3.1243 & 0.0585 & 0.2135 & 0.0027 & 0.1093 & 0.0007 & 1247 & 15 & 1790 & 12 & 87 \\
\hline 3.1 & 224 & 93 & 0.42 & 0.065 & 0.220 & 109 & 7.0538 & 0.1043 & 0.3891 & 0.0044 & 0.1319 & 0.0005 & 2118 & 20 & 2120 & 6.1 & 100 \\
\hline 3.2 & 778 & 85 & 0.11 & 106.1 & 0.045 & 185 & 3.3810 & 0.0720 & 0.2095 & 0.0026 & 0.1168 & 0.0017 & 1226 & 14 & 1909 & 25 & 82 \\
\hline 4.1 & 444 & 147 & 0.33 & $<0.00$ & 0.181 & 215 & 7.1331 & 0.1062 & 0.3912 & 0.0045 & 0.1328 & 0.0004 & 2128 & 21 & 2131 & 5.5 & 100 \\
\hline 4.2 & 1049 & 51 & 0.05 & 0.291 & 0.029 & 222 & 2.8733 & 0.0446 & 0.1919 & 0.0023 & 0.1059 & 0.0004 & 1131 & 12 & 1734 & 7.3 & 82 \\
\hline 5.1 & 1199 & 523 & 0.44 & 0.424 & 0.213 & 311 & 3.1273 & 0.0519 & 0.2028 & 0.0026 & 0.1134 & 0.0005 & 1190 & 14 & 1855 & 8.4 & 83 \\
\hline
\end{tabular}




\begin{tabular}{|c|c|c|c|c|c|c|c|c|c|c|c|c|c|c|c|c|c|}
\hline 6.1 & 341 & 207 & 0.61 & 1.086 & 0.322 & 160 & 6.5990 & 0.1272 & 0.3785 & 0.0052 & 0.1278 & 0.0007 & 2069 & 24 & 2065 & 10 & 100 \\
\hline 7.1 & 69 & 37 & 0.55 & $<0.00$ & 0.309 & 36 & 6.9828 & 0.1144 & 0.3879 & 0.0053 & 0.1320 & 0.0004 & 2113 & 25 & 2121 & 5.6 & 100 \\
\hline 7.2 & 939 & 248 & 0.27 & 5.952 & 0.075 & 232 & 2.8658 & 0.0488 & 0.2035 & 0.0025 & 0.1050 & 0.0005 & 1194 & 13 & 1718 & 7.8 & 87 \\
\hline 8.1 & 236 & 41 & 0.18 & $<0.00$ & 0.104 & 112 & 7.2842 & 0.1158 & 0.3955 & 0.0048 & 0.1333 & 0.0005 & 2148 & 22 & 2139 & 5.9 & 100 \\
\hline 9.1 & 440 & 149 & 0.34 & 0.033 & 0.182 & 198 & 6.6757 & 0.1036 & 0.3825 & 0.0044 & 0.1290 & 0.0004 & 2088 & 21 & 2082 & 5.8 & 101 \\
\hline 10.1 & 150 & 193 & 1.29 & 0.988 & 0.675 & 124 & 13.2708 & 0.1970 & 0.5203 & 0.0059 & 0.1847 & 0.0006 & 2700 & 25 & 2698 & 5.7 & 100 \\
\hline 10.2 & 1281 & 1200 & 0.94 & 13.96 & 0.287 & 258 & 2.2368 & 0.0265 & 0.1551 & 0.0014 & 0.1030 & 0.0004 & 929 & 8 & 1684 & 7.5 & 78 \\
\hline 11.1 & 239 & 94 & 0.39 & 0.061 & 0.189 & 166 & 13.5165 & 0.1482 & 0.5236 & 0.0043 & 0.1863 & 0.0007 & 2714 & 18 & 2712 & 6.2 & 100 \\
\hline 12.1 & 422 & 106 & 0.25 & 1.515 & 0.114 & 205 & 7.0570 & 0.0786 & 0.3851 & 0.0032 & 0.1307 & 0.0005 & 2100 & 15 & 2104 & 6.7 & 99 \\
\hline 13.1 & 361 & 153 & 0.42 & 6.008 & 0.249 & 204 & 8.7067 & 0.2115 & 0.4298 & 0.0077 & 0.1459 & 0.0010 & 2305 & 34 & 2293 & 12 & 100 \\
\hline 14.1 & 409 & 258 & 0.63 & $<0.00$ & 0.456 & 220 & 5.2398 & 0.1039 & 0.3326 & 0.0054 & 0.1163 & 0.0007 & 1851 & 26 & 1901 & 11 & 100 \\
\hline 15.1 & 730 & 196 & 0.27 & 29.88 & 0.200 & 204 & 2.4714 & 0.0509 & 0.1780 & 0.0025 & 0.1071 & 0.0006 & 1056 & 14 & 1753 & 11 & 84 \\
\hline 16.1 & 496 & 202 & 0.41 & 1.808 & 0.194 & 244 & 6.8976 & 0.0805 & 0.3804 & 0.0034 & 0.1287 & 0.0005 & 2078 & 16 & 2077 & 7.3 & 99 \\
\hline 17.1 & 127 & 45 & 0.38 & $<0.00$ & 0.170 & 64 & 7.1470 & 0.0820 & 0.3899 & 0.0036 & 0.1324 & 0.0005 & 2123 & 17 & 2126 & 6.3 & 100 \\
\hline 18.1 & 166 & 72 & 0.44 & 0.016 & 0.218 & 80 & 6.9295 & 0.0751 & 0.3829 & 0.0031 & 0.1318 & 0.0005 & 2090 & 14 & 2119 & 6.3 & 99 \\
\hline 19.1 & 815 & 380 & 0.47 & 1.193 & 0.215 & 294 & 4.8543 & 0.0623 & 0.2824 & 0.0027 & 0.1197 & 0.0005 & 1603 & 13 & 1950 & 7.1 & 89 \\
\hline 20.1 & 98 & 49 & 0.50 & $<0.00$ & 0.177 & 48 & 6.7482 & 0.0840 & 0.3788 & 0.0035 & 0.1281 & 0.0006 & 2071 & 16 & 2070 & 8.1 & 100 \\
\hline 20.2 & 697 & 383 & 0.55 & 277.8 & 0.574 & 219 & 1.5403 & 0.2362 & 0.1780 & 0.0075 & 0.0745 & 0.0053 & 1056 & 41 & 1057 & 138 & 112 \\
\hline 21.1 & 268 & 135 & 0.50 & $<0.00$ & 0.236 & 137 & 7.1525 & 0.0782 & 0.3916 & 0.0032 & 0.1325 & 0.0005 & 2130 & 15 & 2127 & 6.1 & 100 \\
\hline \multicolumn{18}{|l|}{ S.12 } \\
\hline 1.1 & 388 & 200 & 0.51 & 45.460 & 0.580 & 200 & 5.956 & 0.1970 & 0.3247 & 0.0068 & 0.1376 & 0.0020 & 1813 & 33 & 2193 & 25 & 83 \\
\hline 4.1 & 364 & 277 & 0.76 & 3.156 & 0.344 & 152 & 4.390 & 0.1390 & 0.2673 & 0.0038 & 0.1208 & 0.0018 & 1527 & 19 & 1967 & 25 & 78 \\
\hline 5.1 & -335 & -336 & 1.00 & 3.873 & 0.390 & -71 & 5.218 & 0.2421 & 0.2899 & 0.0095 & 0.1309 & 0.0020 & 1641 & 47 & 2107 & 26 & 78 \\
\hline 7.1 & 590 & 424 & 0.72 & 15.538 & 0.387 & 250 & 5.842 & 0.1735 & 0.3252 & 0.0049 & 0.1280 & 0.0017 & 1815 & 24 & 2069 & 22 & 88 \\
\hline 9.1 & 568 & 518 & 0.91 & 7.733 & 0.413 & 223 & 5.916 & 0.1862 & 0.3182 & 0.0049 & 0.1200 & 0.0020 & 1781 & 24 & 1957 & 29 & 91 \\
\hline 12.1 & 595 & 614 & 1.03 & $<0.001$ & 0.450 & 226 & 4.599 & 0.1356 & 0.2768 & 0.0038 & 0.1213 & 0.0017 & 1575 & 19 & 1975 & 24 & 80 \\
\hline 13.1 & 670 & 577 & 0.86 & 16.157 & 0.456 & 256 & 5.773 & 0.1659 & 0.3267 & 0.0044 & 0.1230 & 0.0016 & 1822 & 21 & 1999 & 23 & 91 \\
\hline 6.1 & 146 & 55 & 0.38 & $<0.001$ & 0.170 & 72 & 7.460 & 0.2422 & 0.3994 & 0.0078 & 0.1353 & 0.0018 & 2166 & 36 & 2164 & 23 & 100 \\
\hline
\end{tabular}




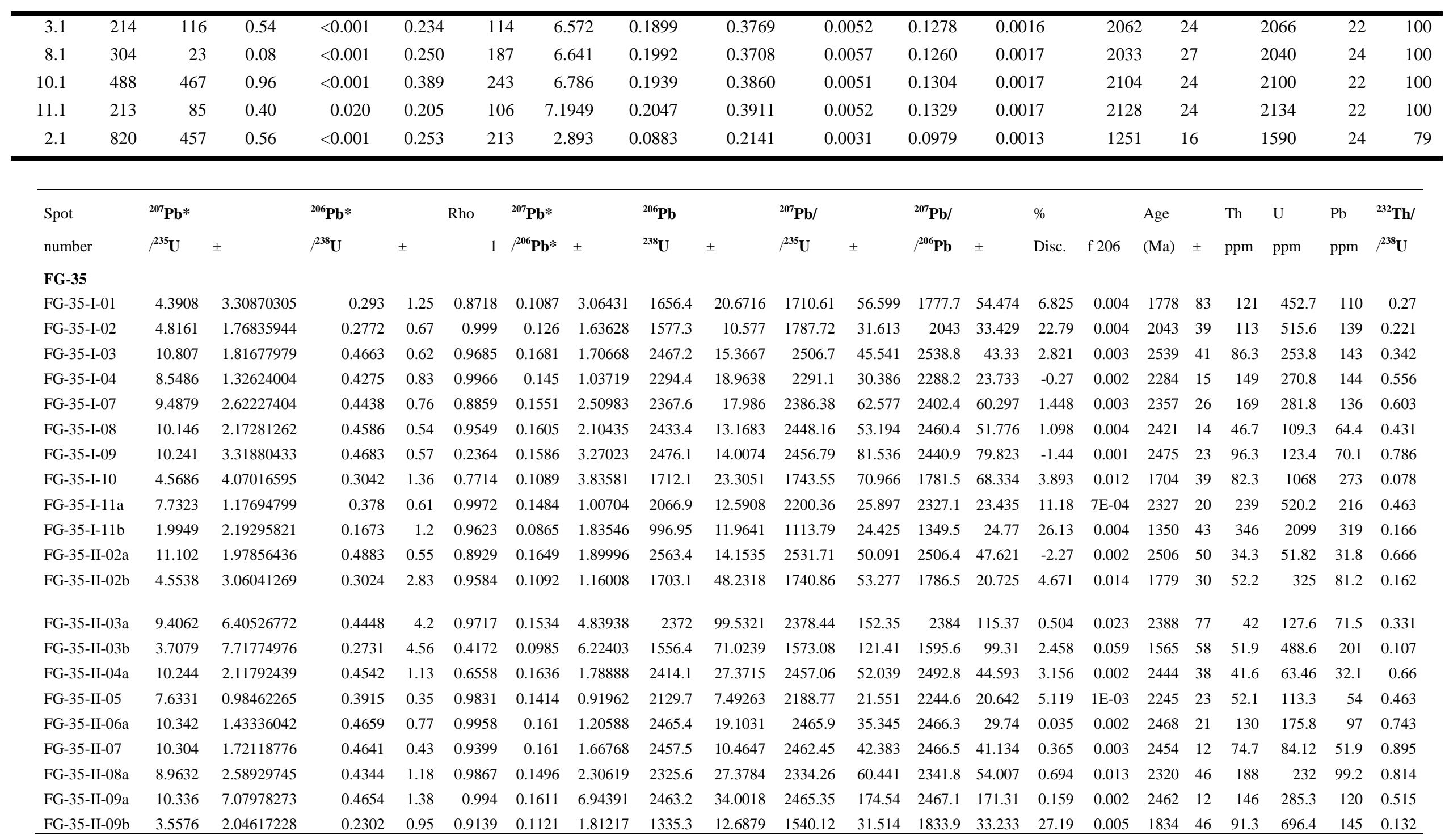




\begin{tabular}{|c|c|c|c|c|c|c|c|c|c|c|c|c|c|c|c|c|c|c|c|c|c|}
\hline FG-35 & 163 & 05384736 & 2385 & 14 & 7666 & 0948 & .90203 & 378.8 & 7.0477 & 36.71 & 2.609 & 523.6 & 4.215 & 505 & 0.006 & 1437 & 78 & 66.3 & 689.3 & 112 & 0.091 \\
\hline & & - & & & & & & & & & & & & & & & 75 & & & 0 & \\
\hline & & & & & & & & & & & & & & & & & 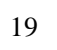 & 1 & & & \\
\hline $12-20-510-13$ & 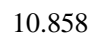 & & & & & & & & & & & & & & 07 & 73 & 59 & 9.6 & .1 & 5.5 & 522 \\
\hline FG-35-II-14 & 233 & 164408 r & 77 & 1.55 & 53 & & 591 & 85 & & .34 & 15 & & & 2.517 & 0.018 & 59 & 29 & 9.8 & 26 & .9 & 644 \\
\hline & & & & & & & & & & & & & & & & & & & & & \\
\hline $\mathrm{FC}$ & 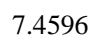 & 2. & & 1.64 & 21 & & 2.13826 & .7 & & 15 & 58.4 & & & -5.93 & 0.015 & 2108 & 47 & 94.1 & 605.2 & 166 & 0.157 \\
\hline & 78 & 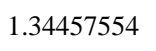 & & 0.39 & 878 & 316 & 1.28783 & 86.7 & & .27 & 5.403 & 9.8 & & 20.43 & 003 & 2120 & 34 & 350 & & - & 0.421 \\
\hline $\mathrm{FC}$ & 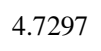 & 1.83621229 & & 1.23 & 13 & 5 & 1. & 5 & & 1 & & & & & 0.032 & 949 & 40 & 168 & 33.3 & 18 & 0.267 \\
\hline FG-3 & 10683 & 1077175 & 718 & 131 & 9762 & 1642 & 1.65286 & 191.4 & .5842 & 2495.91 & 52.607 & 2499.6 & 41.315 & 0.328 & 0.002 & 2503 & 27 & 56.1 & 115.6 & 68.1 & 0.489 \\
\hline & & & & & & & & & & & & & & & & & & & & & \\
\hline FG- & 771 & 1. & .085 & 96 & 44 & 7 & 1. & 2208 & 17 & 8.4 & 19 & .5 & 99 & -0.85 & 0.004 & 2195 & 31 & 155 & .1 & 55 & 0.451 \\
\hline & & & & & & & & & & & & & & & & 34 & 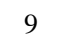 & 64 & & 35 & 24 \\
\hline FG-35-III-02a & & & & & & & & & & & & & & & & 592 & 13 & 189 & 272.5 & 184 & \\
\hline & & & & 1.2 & & & & 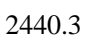 & 85 & 8 & 42.03 & .9 & 29.443 & 1.277 & $2 \mathrm{E}-04$ & 2484 & 13 & 39.5 & 04.4 & 11 & .294 \\
\hline FG-35-III-05 & 10.782 & 3.65160686 & & 0.88 & & & 3.54503 & & & 504.56 & & 2496.4 & 88.496 & -0.73 & 0.003 & 2518 & 33 & 53.2 & 28.92 & 22.8 & 1.854 \\
\hline FG-35-III-06 & 7.5367 & 1.87209495 & 3968 & 1.56 & 0.9938 & 0.1377 & 1.04155 & 2154.4 & 33.5136 & 2177.36 & 40.762 & 2199.1 & 22.905 & 2.034 & 0.001 & 2208 & 11 & 128 & 388.5 & 161 & 0.333 \\
\hline FG-35-III-07a & & & & 0.11 & & & & & & & & & & & & 2241 & 14 & 147 & 427.3 & 172 & 0.346 \\
\hline FG-35-III-09 & 9.9193 & 1.75987165 & .4585 & 0.63 & 0.8298 & 0.1569 & 1.64466 & 2432.8 & 15.2365 & 2427.31 & 42.717 & 2422.7 & 39.846 & -0.41 & 0.001 & 2433 & 25 & 366 & 225 & 158 & 1.638 \\
\hline
\end{tabular}

\begin{tabular}{|c|c|c|c|c|c|c|c|c|c|c|c|c|c|}
\hline Spot name & $\mathbf{U}(\mathbf{p p m})$ & $T \mathbf{T h} / \mathrm{U}$ & $\overline{\mathbf{P b}}$ com & $\begin{array}{l}{ }^{207} \mathrm{~Pb} / \\
{ }^{206} \mathrm{~Pb}^{*}\end{array}$ & $1 \sigma$ & $\begin{array}{l}{ }^{207} \mathbf{P b} / \\
{ }^{235} \mathbf{U}\end{array}$ & $1 \sigma$ & $\begin{array}{l}{ }^{206} \mathrm{~Pb} / \\
{ }^{238} \mathrm{U}\end{array}$ & $1 \sigma$ & $\begin{array}{l}{ }^{207} \mathrm{~Pb} /{ }^{206} \mathrm{~Pb} \\
\text { age }(\mathrm{Ma})\end{array}$ & $1 \sigma$ & $\begin{array}{l}\% \\
\text { DISC }\end{array}$ & Error cor. \\
\hline \multicolumn{14}{|l|}{ CS-03 } \\
\hline 1.1 & 419 & 0.39 & 1.90 & 0.1360 & 0.0027 & 6.7015 & 0.1355 & 0.3573 & 0.0031 & 2177 & 0.035 & 90 & 0.93 \\
\hline 2.1 & 276 & 0.40 & 0.13 & 0.1365 & 0.0029 & 7.4200 & 0.1624 & 0.3943 & 0.0037 & 2183 & 0.037 & 98 & 0.97 \\
\hline 3.1 & 400 & 0.32 & 1.81 & 0.1336 & 0.0027 & 7.3308 & 0.1481 & 0.3978 & 0.0034 & 2146 & 0.035 & 100 & 0.94 \\
\hline 4.1 & 429 & 0.46 & 0.08 & 0.1591 & 0.0031 & 10.0259 & 0.1969 & 0.4570 & 0.0039 & 2446 & 0.033 & 99 & 0.45 \\
\hline 5.1 & 203 & 0.60 & 0.11 & 0.1356 & 0.0028 & 7.2258 & 0.1591 & 0.3865 & 0.0036 & 2172 & 0.036 & 97 & 0.92 \\
\hline 6.1 & 849 & 0.35 & 0.21 & 0.1328 & 0.0023 & 6.7069 & 0.1177 & 0.3664 & 0.0027 & 2135 & 0.031 & 94 & 0.92 \\
\hline 7.1 & 722 & 0.28 & 0.63 & 0.1327 & 0.0023 & 6.8003 & 0.1219 & 0.3718 & 0.0028 & 2133 & 0.031 & 95 & 0.57 \\
\hline 8.1 & 244 & 0.26 & 8.80 & 0.1363 & 0.0028 & 7.8616 & 0.1634 & 0.4182 & 0.0038 & 2181 & 0.036 & 103 & 0.91 \\
\hline 9.1 & 291 & 0.33 & 0.24 & 0.1325 & 0.0030 & 7.2966 & 0.1615 & 0.3994 & 0.0037 & 2131 & 0.040 & 101 & 0.67 \\
\hline 10.1 & 981 & 0.31 & 0.18 & 0.1328 & 0.0024 & 7.2514 & 0.1329 & 0.3962 & 0.0031 & 2135 & 0.032 & 100 & 0.98 \\
\hline
\end{tabular}




\begin{tabular}{|c|c|c|c|c|c|c|c|c|c|c|c|c|c|}
\hline 11.1 & -180 & 0.58 & -0.63 & 0.1333 & 0.0023 & 6.6742 & 0.1127 & 0.3630 & 0.0026 & 2142 & 0.030 & 93 & 0.78 \\
\hline 12.1 & 300 & -0.33 & 0.14 & 0.1179 & 0.0021 & 3.7443 & 0.0683 & 0.2303 & 0.0017 & 1925 & 0.031 & 69 & 0.98 \\
\hline 13.1 & 24 & 0.22 & 2.77 & 0.1323 & 0.0023 & 6.7417 & 0.1166 & 0.3695 & 0.0027 & 2129 & 0.030 & 95 & 0.01 \\
\hline 14.1 & 639 & 0.37 & 0.21 & 0.1297 & 0.0024 & 5.9903 & 0.1288 & 0.3349 & 0.0029 & 2094 & 0.032 & 88 & 0.62 \\
\hline 15.1 & 853 & 0.27 & 0.46 & 0.1323 & 0.0025 & 6.9224 & 0.1420 & 0.3794 & 0.0033 & 2129 & 0.033 & 97 & 0.92 \\
\hline 16.1 & -115 & 0.67 & -0.33 & 0.1351 & 0.0025 & 7.2455 & 0.1518 & 0.3889 & 0.0034 & 2166 & 0.031 & 97 & 0.41 \\
\hline 17.1 & 1167 & 0.27 & 0.05 & 0.1343 & 0.0025 & 7.1954 & 0.1488 & 0.3886 & 0.0033 & 2155 & 0.032 & 98 & 0.01 \\
\hline 18.1 & 251 & 0.48 & 0.12 & 0.1382 & 0.0033 & 7.6686 & 0.1974 & 0.4023 & 0.0043 & 2205 & 0.041 & 98 & 0.84 \\
\hline 19.1 & 531 & 0.30 & 2.74 & 0.1340 & 0.0025 & 7.5535 & 0.1578 & 0.4090 & 0.0036 & 215 & 0.032 & 102 & 0.64 \\
\hline 20.1 & 636 & 0.25 & 2.02 & 0.1342 & 0.0025 & 7.3090 & 0.1412 & 0.3949 & 0.0032 & 2154 & 0.033 & 99 & 1.00 \\
\hline 21.1 & 885 & 0.24 & 0.32 & 0.1333 & 0.0025 & 7.2621 & 0.1492 & 0.3952 & 0.0034 & 2142 & 0.032 & 100 & 0.87 \\
\hline 22.1 & 788 & 0.23 & 0.13 & 0.1335 & 0.0025 & 6.5422 & 0.1318 & 0.3553 & 0.0030 & 2145 & 0.032 & 91 & 0.96 \\
\hline 23.1 & 1086 & 0.30 & 1.21 & 0.1293 & 0.0023 & 6.2946 & 0.1214 & 0.3530 & 0.0029 & 2089 & 0.032 & 93 & 1.00 \\
\hline 24.1 & -9 & -4.09 & -3.85 & 0.1302 & 0.0024 & 6.0116 & 0.1315 & 0.3349 & 0.0031 & 21 & 0.032 & 88 & 0.49 \\
\hline 25.1 & 1985 & 0.24 & 2.46 & 0.1290 & 0.0024 & 5.7112 & 0.1212 & 0.3211 & 0.0028 & 2084 & 0.033 & 86 & 0.96 \\
\hline 26.1 & 1243 & 0.22 & 2.37 & 0.1310 & 0.0024 & 7.1240 & 0.1385 & 0.3943 & 0.0032 & 2112 & 0.032 & 101 & 0.99 \\
\hline
\end{tabular}

Sample and standard are corrected after $\mathrm{Pb}$ and $\mathrm{Hg}$ blanks.

${ }^{207} \mathrm{~Pb} /{ }^{206} \mathrm{~Pb}$ and ${ }^{206} \mathrm{~Pb} /{ }^{238} \mathrm{U}$ are corrected after common $\mathrm{Pb}$ presence. Common $\mathrm{Pb}$ assuming ${ }^{206} \mathrm{~Pb} /{ }^{238} \mathrm{U}$ and ${ }^{207} \mathrm{~Pb} /{ }^{235} \mathrm{U}$ concordant age.

${ }^{235} \mathrm{U}=1 / 137.88 \times \mathrm{U}$ total.

Standard GJ-1.

$\mathrm{Th} / \mathrm{U}={ }^{232} \mathrm{Th} /{ }^{238} \mathrm{U} \times 0.992743$.

All errors in the table are calculated 1 sigma (\% for isotope ratios. absolute for ages). 
Anexo III - Imagens de catodoluminescência. Referente aos dados da seção 4.5.

S. 1

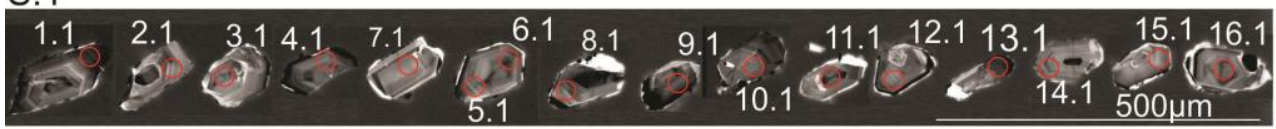

S.2

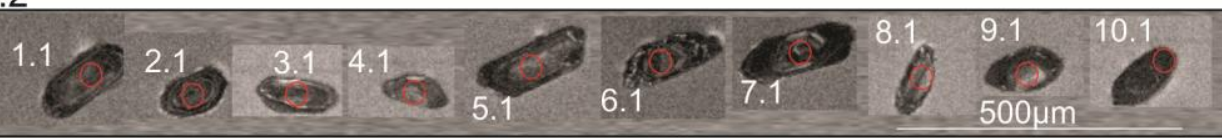
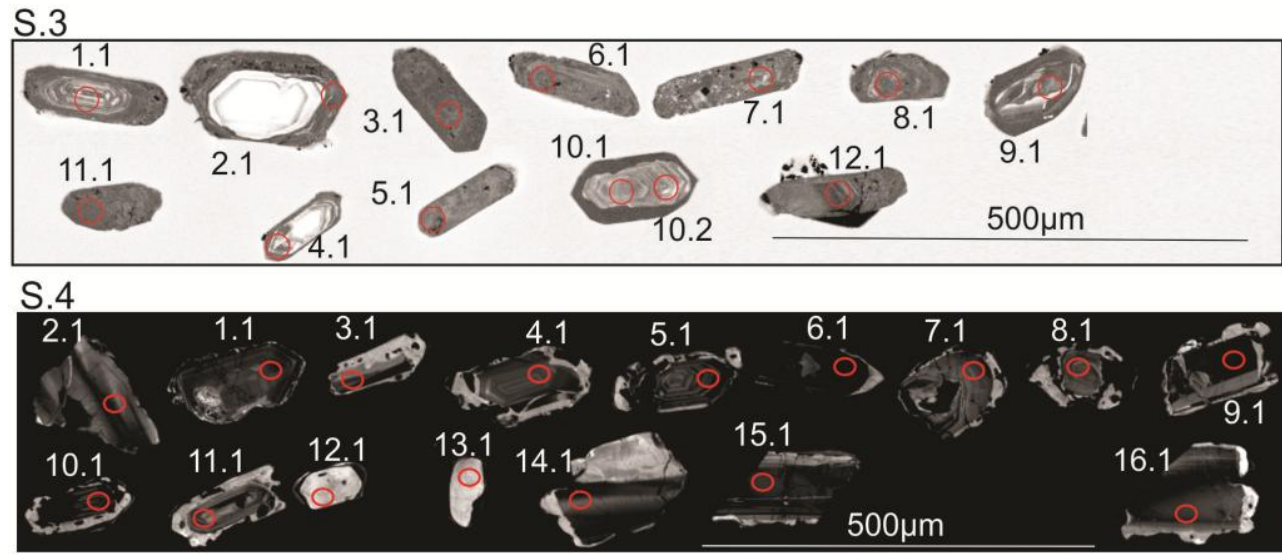

S. 5
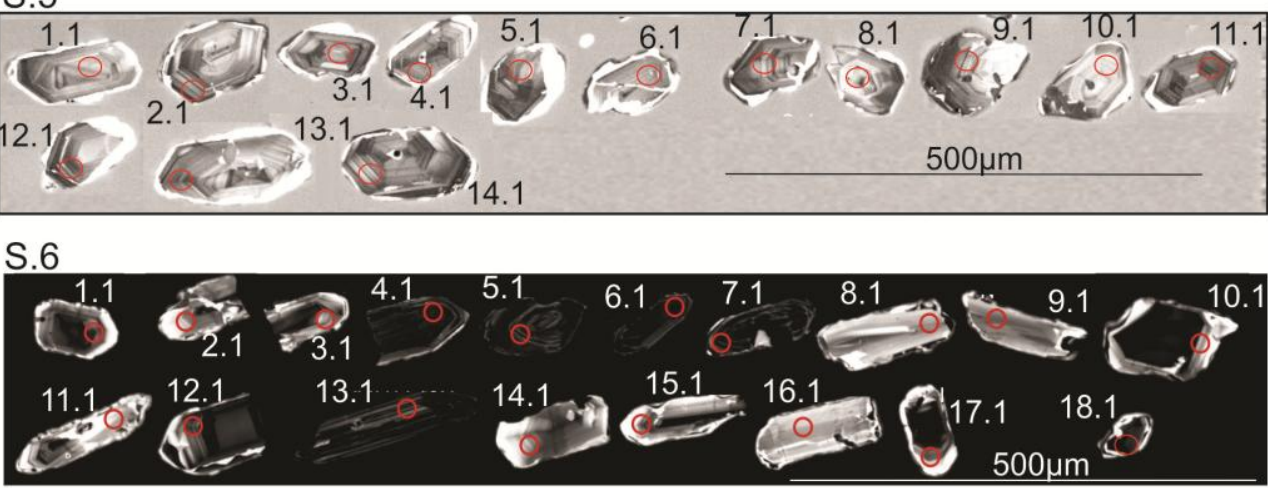

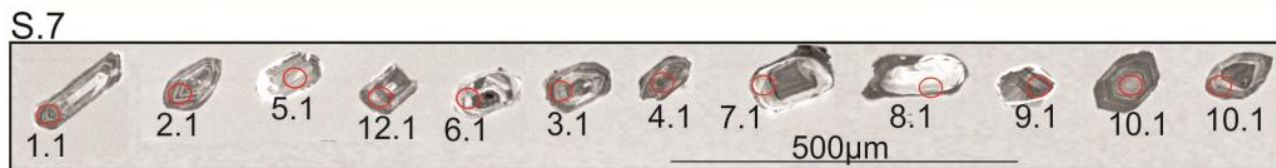

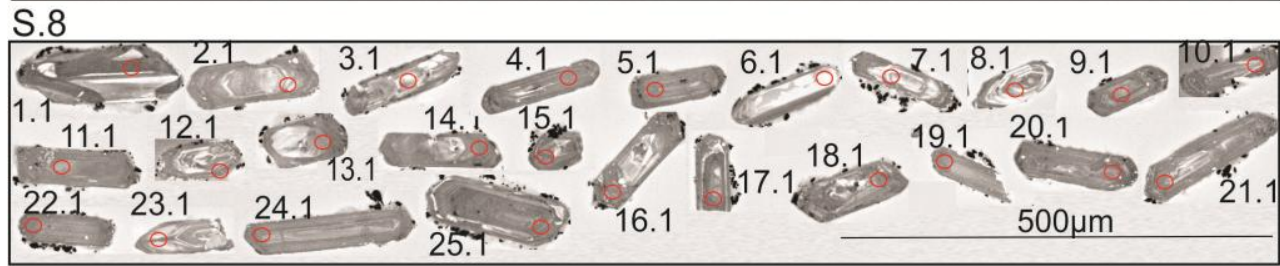
S.9

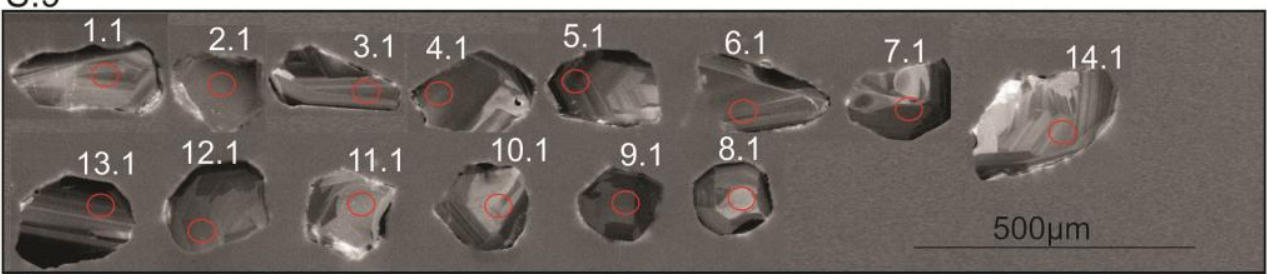


S.10
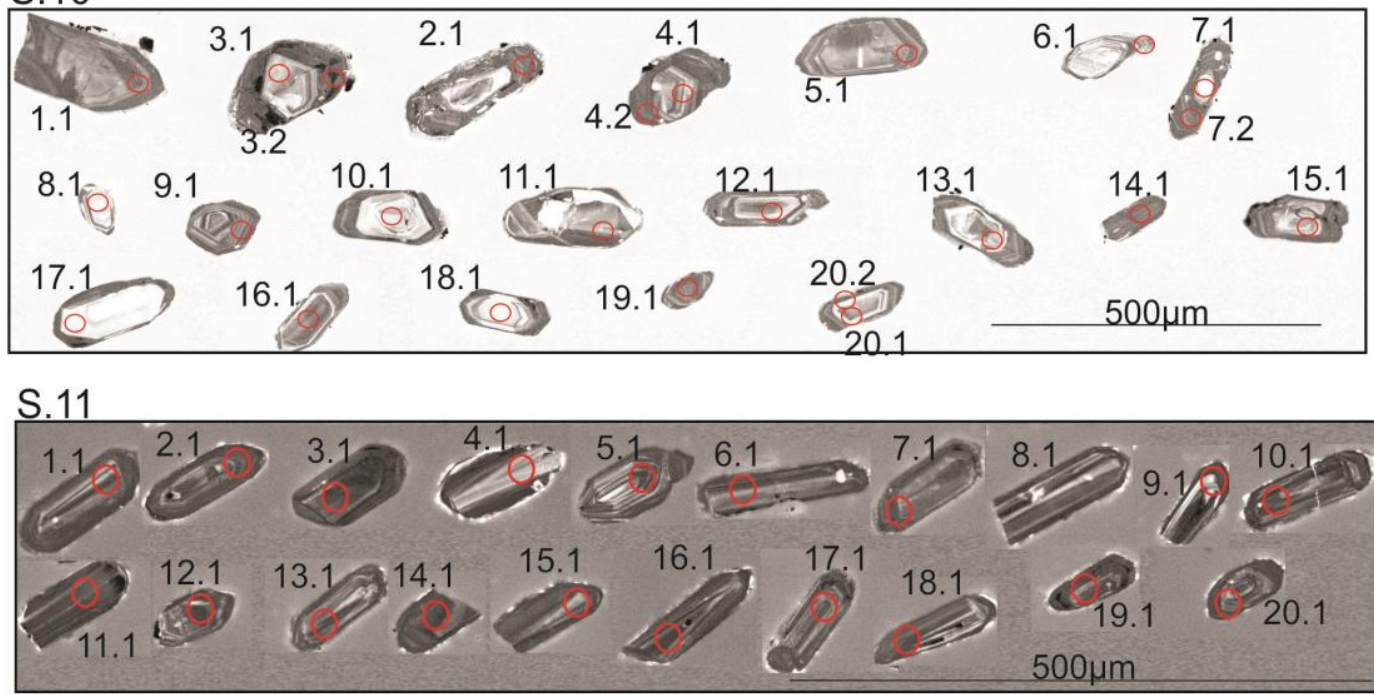

S.12

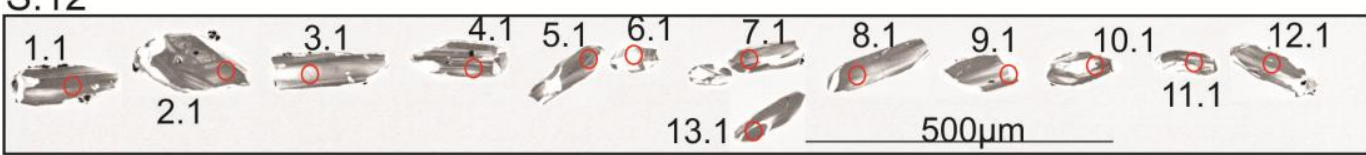

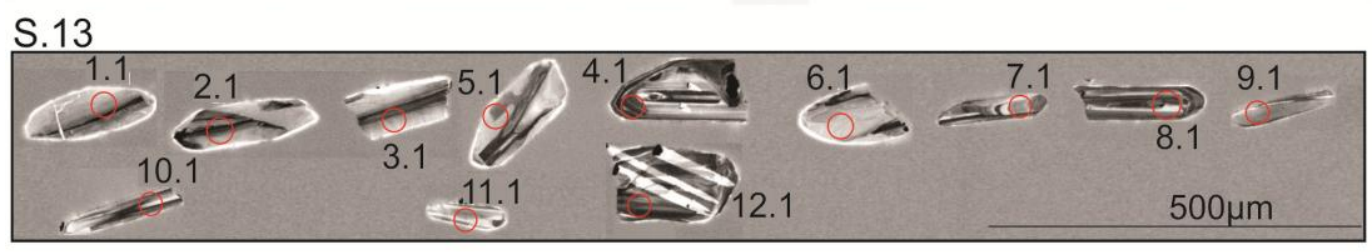

S. 14

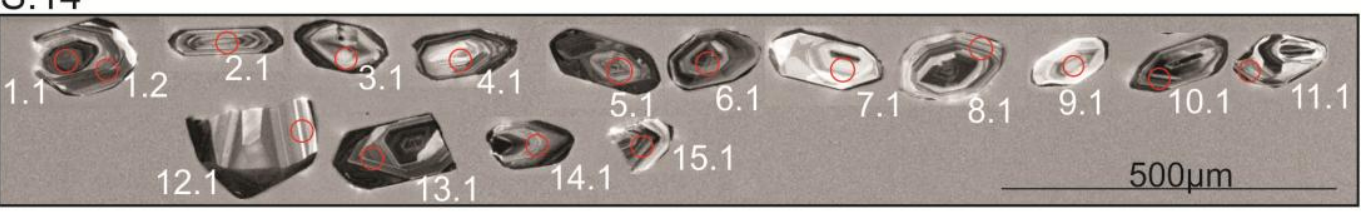

S.15
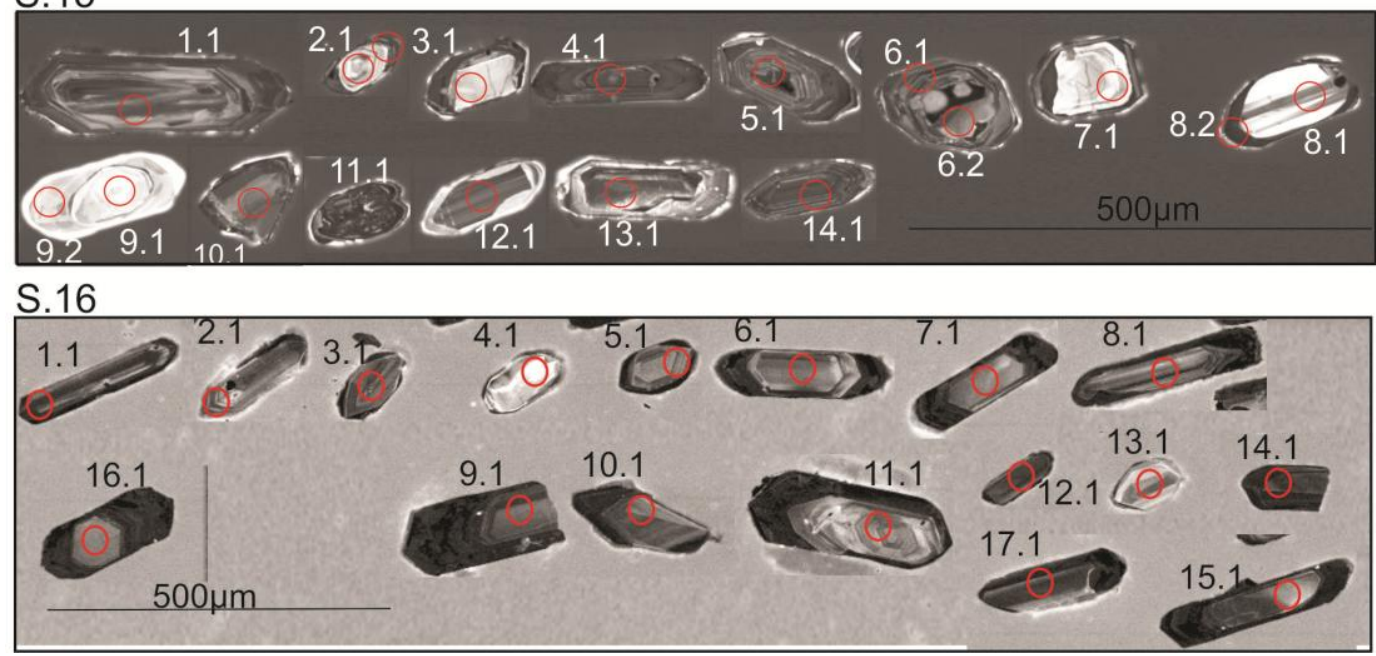


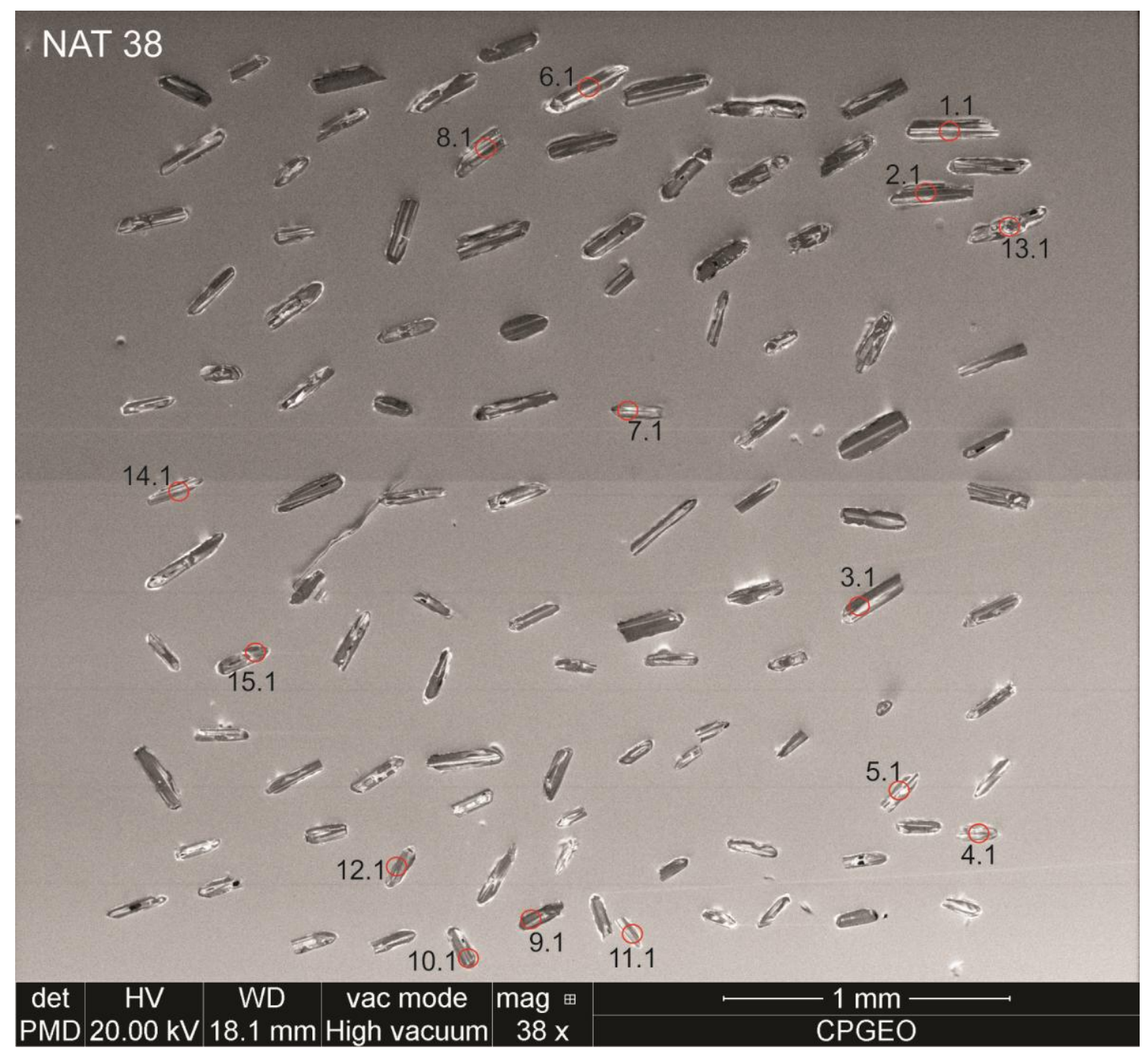

Imagem de Catodoluminescência (amostra NAT-38). 


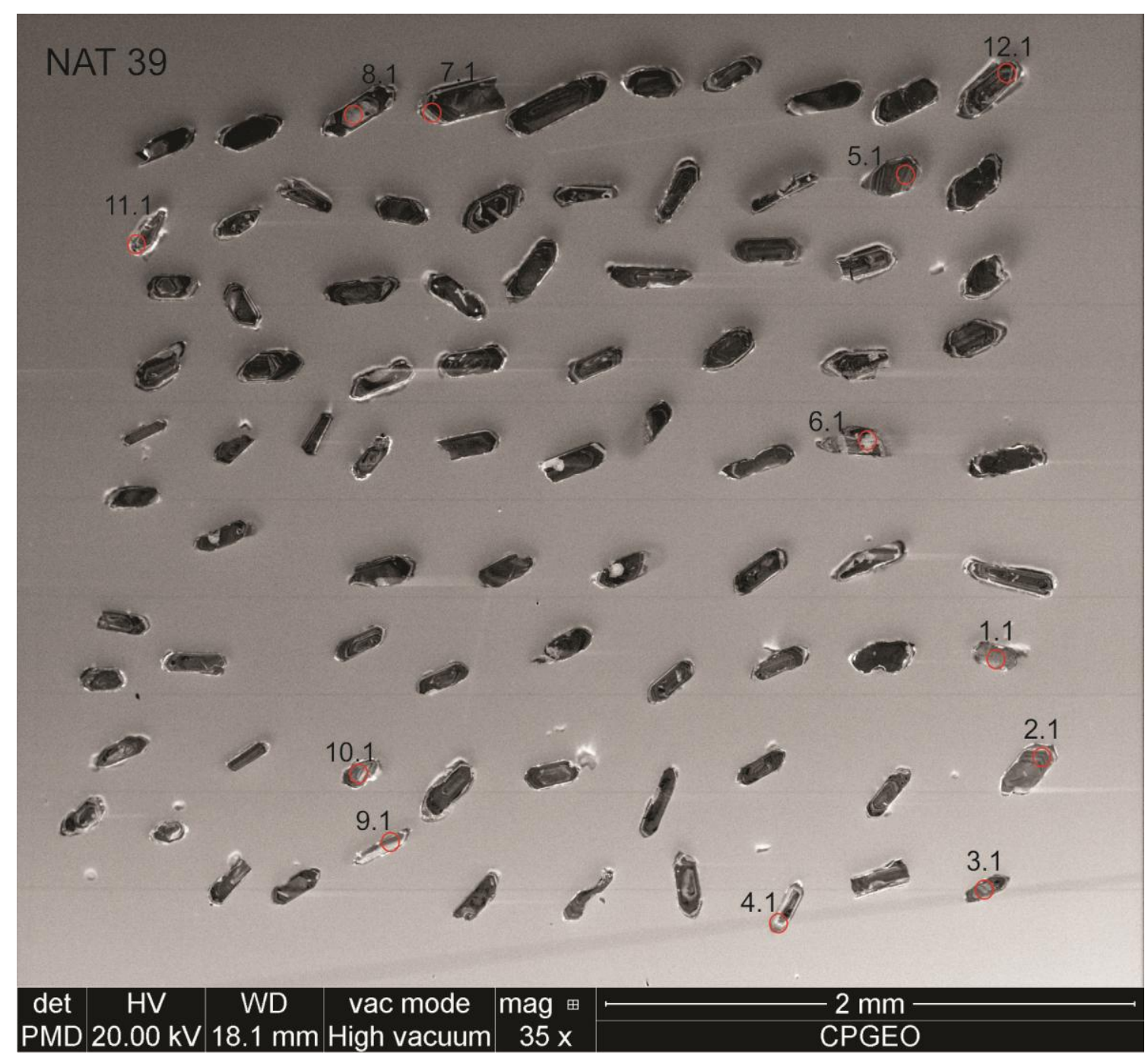

Imagem de Catodoluminescência (amostra NAT-39). 
Anexo IV - Evento tectono-termal de 2.36-2.31 Ga 